\title{
Die internationale Pionierphase der Windenergienutzung
}

\section{Dissertation}

zur Erlangung des Doktorgrades

der Sozialwissenschaftlichen Fakultät der Georg-August-Universität Göttingen.

vorgelegt von

Mario Neukirch

geboren in Cuxhaven

Göttingen, 2010 
1. Gutachter: Prof. Dr. Wolf-Sighart Rosenbaum

2. Gutachter: Prof. Dr. Matthias Heymann

Tag der mündlichen Prüfung: 28.10. 2009 


\section{Vorwort}

Auf der internationalen politischen Agenda gewinnt das Thema Energie immer größere Bedeutung. Zahlreiche Fragen stehen an: Wie verlässlich sind Gaslieferungen aus Russland und Ölimporte aus dem Nahen Osten? Wie großzügig dürfen die Werte Demokratie und Menschenrechte, denen sich die westliche Staatengemeinschaft verpflichtet fühlt, gehandhabt werden, wenn es um den Zugriff auf Ölreserven geht? Wie sicher sind Atomkraftwerke? Wie demokratisch wird über den Weiterbetrieb alter Reaktoren und den Neubau von Kohlekraftwerken entschieden? Inwieweit sollten indirekte Kosten, die bei der Produktion von Elektrizität aus nuklear-fossilen Energieträgern anfallen (bspw. Umwelt- und Klimaschäden) berücksichtigt werden?

Diese Schwierigkeiten, auf die hier verwiesen wird, treten bei regenerativen Energien gar nicht auf. Dafür sind sie teurer. Dass die oben genannten Fragen "anstehen" heißt noch lange nicht, dass ihnen in der öffentlichen Diskussion ein angemessener Stellenwert zukäme. Denn seit Jahrzehnten gilt das Primat der Kostenminimierung. Das habe Vorteile für die Konkurrenzfähigkeit der Wirtschaft und private Verbraucher, so argumentieren interessierte Kreise.

Eine ergebnisoffene gesellschaftliche Debatte darüber, wie gut die Priorität niedriger Erzeugungskosten gegenüber der Vermeidung negativer Begleiteffekte (Umwelt-, Klima- und Gesundheitsschäden, Importabhängigkeit, Stabilisierung von Öldiktaturen, Verursachung von Kriegen und geopolitisch motivierten Konflikten) eigentlich begründet ist, erscheint den Entscheidungsträgern aus Politik und Wirtschaft eher nicht wünschenswert. Geht es allgemein um die Zerstörung von Umwelt und Natur, um Proteste gegen Atomkraftwerke, oder Kriege um Öl: Stets sind Debatten von der Zivilgesellschaft initiiert worden. Dort, wo viele Menschen aufbegehrten und ihrem Unmut Geltung verschafften, musste etwas geschehen: Veränderungen der politischen Landschaft und eine partielle Neuausrichtung der Energiepolitik haben sich in einer Reihe westeuropäischer Länder eingestellt.

Anfangs ist den Kritikern vorgeworfen worden, sie hätten keine Alternative anzubieten als die "Rückkehr in die Steinzeit". Doch mittlerweile wäre die Energieversorgung etlicher Staaten ohne neue Technologien wie Solar- und Windkraft, kaum noch zu realisieren. In den Ländern Portugal, Spanien und Dänemark wird ein Anteil von mehr als zehn Prozent des Strombedarfs allein aus der Windenergie gewonnen. Vor diesem Hintergrund mussten die Kritiker eine vorsichtigere Haltung einnehmen. Mit zunehmender Tendenz sehen sich selbst die Hardliner bemüßigt, in der Öffentlichkeit die Notwendigkeit einer ökologischen Energiewende zu proklamieren.

Mein besonderer Dank gilt Wolf-Sighart Rosenbaum, meinem Doktorvater, der mich mit großer Geduld und Aufmerksamkeit betreut hat. Ebenfalls bedanke ich mich bei Matthias Heymann, dem Zweitgutachter. Wichtige Anstöße erhielt ich durch Gespräche mit Rüdiger Mautz und Andreas Byzio vom Soziologischen Forschungsinstitut in Göttingen, sowie meinen dänischen Interview-Partnern. Hervorheben möchte ich die Pioniere Erik GroveNielsen und Preben Maegaard. Ganz besonders bedanke ich mich bei Mette Mygind und ihrem Dänisch-Kurs am Skandinavischen Seminar für ehrenamtliche Übersetzungsarbeiten. Schließlich gilt mein Dank allen, die mich moralisch unterstützt haben, wenn ich einmal nicht weiter wusste. 


\section{Inhaltsverzeichnis}

Einleitung $\quad 7$

Analysekonzept $\quad 8$

Forschungsstand 12

1. Die internationale Pionierphase der Windenergienutzung:

$\begin{array}{ll}\text { Forschung an Großwindanlagen } & 15\end{array}$

1.1 Windenergieprogramme zur Technologieförderung in den Pionierländern 16

$\begin{array}{ll}\text { USA } & 17\end{array}$

Dänemark $\quad 20$

Niederlande $\quad 23$

Bundesrepublik Deutschland $\quad 26$

Großbritannien $\quad 31$

Schweden 33

Kanada $\quad 35$

$\begin{array}{lr}\text { Spanien } & 36\end{array}$

$\begin{array}{ll}\text { Italien } & 37\end{array}$

1.2 Vergleichende Analyse der Pionierländer 39

1.2.1 Energiepolitische und gesellschaftliche Rahmenbedingungen 39

1.2.2 Internationale Geltung des Large-Scale-Paradigma (LSP) 40

1.2.3 LSP-Programme versagen $\quad 42$

1.2.4 Fehleranalyse 44

1.2.5 Zeitlicher Rahmen des LSP 47

1.2.6 Einfluss zivilgesellschaftlicher Akteure auf die Forschungsphase 50

2. Die internationale Pionierphase der Windenergienutzung

Vom Nischenmarkt in Dänemark zur proven technology (1975-1991) 54

2.1 Periode 1: 1975-1978

Technische Innovation und Entstehung des Ursprungsmarktes (Dänemark) 57

2.1.1 Innovation und Akteure der ersten Stunde 58

2.1.2 Dänische Windanlagenindustrie in Periode 1 65

2.1.3 Windanlagenkäufer und -betreiber in Periode 1 72

2.2 Periode 2: 1979-1982

Industrialisierung und Stabilisierung des Ursprungsmarktes (Dänemark) 79

2.2.1 Das politisch-administrative System in Periode 2 79

2.2.2 Windanlagenindustrie in Periode $2 \quad 84$

2.2.3 Windanlagenkäufer und -betreiber in Periode 2 
Periode 3: 1983-1987

Beschleunigtes Wachstum und Erprobung in Kalifornien

(Dänemark, Kalifornien)

2.3.1 Kalifornien in Periode 3

2.3.1.1 Kalifornien: Das politisch-administrative System in Periode $3 \quad 107$

2.3.1.2 Kalifornien: US-Windanlagenindustrie in Periode 3 111

2.3.1.3 Kalifornien: Windturbinenkäufer und -betreiber in Periode $3 \quad 116$

2.3.2 Dänemark in Periode 3

2.3.2.1 Dänemark: Das politisch-administrative System in Periode $3 \quad 121$

2.3.2.2 Dänemark: Windanlagenindustrie in Periode 3 124

2.3.2.3 Dänemark: Windanlagenkäufer- und betreiber in Periode 3

$2.4 \quad$ Periode 4: 1988-1992

Verstetigung internationaler Diffusion

(Dänemark, Niederlande, Bundesrepublik Deutschland) 138

2.4.1 Dänemark in Periode 4

2.4.1.1 Dänemark: Das politisch-administrative System in Periode 4

2.4.1.2 Dänemark: Windanlagenindustrie in Periode $4 \quad 145$

2.4.1.3 Dänemark: Windanlagenkäufer und -betreiber in Periode $4 \quad 147$

2.4.2 Niederlande in Periode 4

2.4.2.1 Niederlande: Das politisch-administrative System Periode 4 154

2.4.2.2 Niederlande: Windanlagenindustrie in Periode 4 161

2.4.2.3 Niederlande: Windanlagenkäufer und -betreiber in Periode 4

2.4.3 Bundesrepublik Deutschland in Periode $4 \quad 175$

2.4.3.1 BRD: Das politisch-administrative System in Periode $4 \quad 175$

2.4.3.2 BRD: Windanlagenindustrie in Periode 4 181

2.4.3.3 BRD: Windanlagenkäufer und -betreiber in Periode 4

2.5 Pioniermärkte in vergleichender Perspektive 210

2.5.1 Quantitative Begründung: Erfolgreiche Pioniermärkte 211

2.5.2 Qualitative Indikatoren: Akteursstruktur und Fördersystem

2.5.3 Vergleichende Interpretation 215

2.5.4 Kleine oder große Akteure? Windkraft und Zivilgesellschaft 219

2.5.5 Das dänische Erfolgsmodell der Pionierphase 224

2.5.6 Zur Diffusionsfähigkeit des dänischen Modells 226

3. Phase internationaler Diffusion 236

Veränderte Akteurskonstellationen und ein neues Erfolgsmodell

$\begin{array}{lll}3.1 & \text { Griechenland } & 238\end{array}$

$\begin{array}{lll}3.1 .1 & \text { Pionierphase } & 238\end{array}$

$\begin{array}{ll}3.1 .2 & \text { Diffusionsphase }\end{array}$ 
3.2 Großbritannien 243

$\begin{array}{lll}3.2 .1 & \text { Pionierphase } & 244\end{array}$

$\begin{array}{lll}3.2 .2 & \text { Diffusionsphase } & 245\end{array}$

3.3 Spanien 250

$\begin{array}{ll}3.3 .1 & \text { Pionierphase } \\ 3.3 .2 & 250\end{array}$

3.3.2 Diffusionsphase 252

3.4 Ergebnisse: Vergleich der 92er Märkte und 259 Abgrenzung des dänischen Modells

3.5 Das dänische Modell in der Phase internationaler Diffusion

3.5.1 Das dänische Modell in der Diffusionsphase 265

3.5.2 Windenergie in Dänemark, Deutschland und den 92er Märkten 268

4. Windkraft als neue Komponente des Elektrizitätssystems -

Ein Beitrag zur Debatte um die Dynamik großer technischer Systeme

4.1 Darstellung des innovationssoziologischen Diskurses:

Ansätze und Kontroversen $\quad 272$

4.2 Darstellung des Forschungsstandes. Windenergie als neue

Systemkomponente: radikale oder inkrementelle Innovation? 276

4.3 Internationale Windenergienutzung:

Auf dem Weg zu einer Empirie hybridisierter Stromsysteme? 279

$\begin{array}{ll}\text { Ausblick } & 288\end{array}$

Literatur- und Quellenverzeichnis 289

Glossar $\quad 296$

$\begin{array}{ll}\text { Abkürzungsverzeichnis } & 313\end{array}$ 


\section{Einleitung}

Im Verlauf der letzten Jahrzehnte ist die Windenergie in diversen Ländern zu einer festen Komponente des Energiesektors geworden. Für die Pionierländer ${ }^{1}$ bilden die Faktoren, gesellschaftliche Kontroversen um Atomkraftnutzung, Importabhängigkeit von Energierohstoffen und die (latent) drohende Endlichkeit der Ressourcen, die wichtigsten Triebkräfte zur Einführung und Etablierung der Windkrafttechnologie.

Die Elektrizitätssysteme der 1970er Jahre waren i.a. zentralistisch organisiert. Zur Energieproduktion dienten fast ausschließlich fossil-nukleare Großkraftwerke, die vom Gebietsmonopolisten betrieben wurden. Diesen Systemen gegenüber handelt es sich bei der Windkraft, als dezentraler Energiequelle, um einen Fremdkörper. Die Möglichkeit, dass der neue Energieträger einmal den heutigen Status einnehmen könnte, war aus damaliger Perspektive nicht wahrscheinlich.

Mit dem Hinzutreten der Windkraft ist eine teilweise Marktöffnung der hier betrachteten Stromsektoren einhergegangen, wie insbesondere die Beispiele Kalifornien, Dänemark und die Bundesrepublik zeigen. Besonders das deutsche Beispiel zeigt, inwiefern dem neuen Energieträger die Funktion eines Toröffners für andere erneuerbare Energien wie Photovoltaik und Strom aus Biogas zugekommen ist. Aufgrund dieser Vorreiterrolle der Windkraft innerhalb der Gruppe der regenerativen Energien, ist der internationale Etablierungsprozess dieser Technologie von herausragendem Interesse und steht daher im Zentrum der folgenden Abhandlung.

In den 1970/80er Jahren lassen sich zwei Versuche beobachten, die neue Technologie einzuführen: Aus Sicht staatlicher Politik können sie unter den Begriffen Technologie-, bzw. Marktförderung zusammengefasst werden. Der erste Ansatz zielt darauf, Großwindanlagen zu kommerzialisieren. Forschungs- und Energieministerien vergaben Gelder an Technologiekonzerne und große Forschungszentren, um entsprechende Prototypen zu entwickeln. Zufriedenstellende Resultate wurden auf diesem Wege jedoch nicht erreicht. Die Versuche scheiterten, weil die Akteure von falschen Grundannahmen ausgingen und sich ungeeigneter Methoden bedienten. Zur Konstruktion von Großwindanlagen im Megawattsektor fehlte das Know-how. Nichtsdestoweniger zeigten sich die Ministerien kaum bereit, die Entwicklung kleinerer Modelle zu fördern. Man hatte die Vorstellung, dass sich Windenergie in das System zentraler Elektrizitätsversorgung einfügen sollte, was mit kleinen Windturbinen nicht möglich ist.

Gewissermaßen das Gegenteil, die aktive Förderung des Marktes durch Vergabe staatlicher Zuschüsse für den Erwerb kleiner Windanlagen, stellte während der 1980er Jahre eine Ausnahme dar. Dabei handelte es sich anscheinend großteils als Reaktion auf außerparlamentarische Widerstände gegen die Atomenergienutzung und die Zerstörung der Umwelt. Dieser zweite, bis heute dominierende, Förderansatz hat sich als erfolgreich erwiesen. Die daraus sich formierenden technisch-institutionellen Entwicklungspfade lassen sich mit dem Begriff bottom-up zusammenfassen, die Förderung der Konstruktion großer Prototyp-Windanlagen als top-down. Technische und wirtschaftliche Erfolge haben sich zuerst in Dänemark eingestellt, wo, angefangen bei $10-20 \mathrm{~kW}-G e n e r a t o r e n$, von den Herstellern sukzessive größere Modelle konstruiert wurden. Heutige große Modelle haben die Dimensionen damaliger Großwindanlagen mittlerweile überschritten. Der Versuch, den dafür erforderlichen etwa 20jährigen Lernprozess zu überspringen, konnte nicht gelingen.

Der der bottom-up Variante hingegen, war keineswegs voraussetzungsfrei. Nur in Dänemark und der Bundesrepublik, einem der späteren Pioniermärkte gelang die Einführung und langfristige Etablierung der Windenergie sowie der Aufbau einer international erfolgreichen

\footnotetext{
${ }^{1}$ Erläuterungen zu den kursiv gedruckten Begriffen finden sich im Glossar.
} 
Anlagenindustrie. In keinem der übrigen betrachteten Länder war jene besondere sozioökonomische Akteurskonstellation in Verbindung mit einer bestimmten Gestaltung institutioneller Förderbedingungen gegeben, das dänische Modell. Dessen wichtigste Eigenschaftt besteht in einer herausragenden Rolle zivilgesellschaftlicher Akteure als Betreiber von Windanlagen und in Dänemark zusätzlich als Pionierhersteller und Konstrukteure. In den weiteren Pioniermärkten Kalifornien und Niederlande, wo das Feld durch Privatinvestoren und Energiewirtschaft dominiert war, konnten sich weder stabile Märkte herausbilden, noch waren erfolgreiche inländische Anlagenhersteller vorhanden.

Generell ist die Bedeutung kleiner und mittelgroßer Akteure für die Pionierphase, dem Zeitraum 1975-1991 zu betonen, während Großakteure sich mitunter als kontraproduktiv erwiesen. Die technologische Weiterentwicklung und der breite Fundus gesammelter Erfahrungen auf institutioneller Ebene (Fördermaßnahmen, Anlagenbetrieb, Testprozeduren, Versicherung, Genehmigungsverfahren) haben Anfang der 90er Jahre eine beschleunigte internationale Diffusion der Windkraftnutzung unterstützt. In Ländern wie Spanien hat sich die zuvor insgesamt negative Wahrnehmung zugunsten der neuen Technologie gewandelt. Staatliche und, etwas später, auch private EVU begannen, ohne unmittelbare äußere Zwänge (bspw. Konkurrenz durch netzfremde Windanlagenbetreiber und Legitimationsprobleme wegen Umweltzerstörung etc.), größere Summen in den Kauf eigener Windparks zu investieren.

\section{Analysekonzept}

Diese Arbeit beschäftigt sich im Rahmen eines Ländervergleichs mit der Frage, unter welchen Bedingungen die Windenergie in den Pioniermärkten etabliert wurde. Diese Märkte haben sich nicht parallel, sondern in einem zeitlichen Nacheinander herausgebildet. Wer später eingestiegen ist, kann Pionierwissen aus anderen Ländern übernehmen. Um den Status quo zu interpretieren, genügt daher nicht, die Entwicklungen der Länder unabhängig voneinander zu betrachten. Vielmehr muss der Vergleich so gestaltet sein, dass die Möglichkeit internationaler Lernprozesse berücksichtigt wird. Aus diesem Grunde werden die sich in den Pioniermärkten vollziehenden Prozesse in zeitlich aufeinander folgenden Abschnitten betrachtet. Für internationale Diffusionsvorgänge, deren Ursprung deutlich einem einzigen Land - hier Dänemark - zugeordnet werden kann, existiert mit der industriellen Revolution eine historische Parallele. Hier kommt Großbritannien eine ähnliche Vorreiterrolle zu wie Dänemark für den Windenergiesektor. Auf die Industrialisierung Großbritanniens folgten zunächst die USA und Deutschland, später Frankreich und Italien. Wollte man eine Studie über die internationale Pionierphase der industriellen Revolution verfassen, so könnte man sich eines ähnlichen Konzeptes bedienen wie es hier für die Windenergie verwendet wird. Es gilt, die nationalen Besonderheiten als solche zu erkennen und demgegenüber abzugrenzen, bei welchen Elementen es sich um die Übernahme internationaler Erfahrungen handelt.

Die internationale Liberalisierung und Privatisierung des Telekommunikationssektors ist ein weiteres Beispiel für Innovationen, die in einem klar lokalisierbaren Zentrum entstanden sind und anschließend internationale Anwendung fanden. Pionier ist in diesem Fall die USA. Erste Nachzügler sind Japan und Großbritannien, einige Zeit später folgen Frankreich, Italien und Deutschland. Diese Vorgänge analysiert Schneider (2001) unter Einbeziehung nationaler Gründe und Voraussetzungen für den Import des US-amerikanischen Marktmodells. ${ }^{2}$ Einer

\footnotetext{
${ }^{2}$ Als wichtigen Grund für dessen Einführung bspw. nach Großbritannien bewertet Schneider (2008, 207ff.) den vorherrschenden neokonservativen Stil der Wirtschaftspolitik (Thatcherism). Die Privatisierung und Liberalisierung sämtlicher vormals staatlich kontrollierter Sektoren gehört zu den Primärzielen des Neokonservativismus.
} 
ähnlichen Linie folgt die hier verwendete Konzeption zur Analyse der internationalen Pionierphase der Windkraftnutzung.

Der wesentliche analytische Rahmen ist ein Phasenkonzept. Während der Energiekrise einsetzende Experimente im Bereich der Forschung an Großwindanlagen sowie eine, bis zum Beginn der 90er Jahre auf wenige Länder eingeschränkte Diffusion, rechtfertigen die Definition des Zeitraums 1973 bis 1991 als Pionierphase. Währenddessen hat sich die Windenergie zu einer international anerkannten Energietechnik, einer proven technology entwickelt.

Ein Ansatz zur Erschließung der Windenergieressourcen bestand in der staatlichen Forschungsförderung. Von den Regierungen diverser Staaten unter dem Einfluss der Ölkrise in Auftrag gegebene Studien kamen zu dem Ergebnis, dass Windenergie bis zu 20\% zur Stromversorgung beitragen könne. Zur Realisierung dieser Potenziale erklärte man jedoch die weitere Erforschung der Technologie für erforderlich. Daher wurden während der 70er und 80er Jahre teilweise dreistellige Millionenbeträge für entsprechende Zwecke bereitgestellt. Sämtliche Programme ähnelten sich in Methodik und Zielgebung. Die Leitung wurde jeweils vom zuständigen Ministerium, zentralen Forschungseinrichtungen und großen Energieversorgungsunternehmen (EVU) übernommen. Konzepte für Prototypen großer Windanlagen wurden entwickelt und deren Realisierung bei Technologiekonzernen der Luft-, Raumfahrt- und Maschinenbaubranche in Auftrag gegeben. Die Zielgebung sämtlicher Programme war die Kommerzialisierung solcher Großwindanlagen. Gekauft und betrieben werden sollten sie von Energieunternehmen, um einen Teil ihrer fossil-nuklearen Kraftwerke durch Windparks zu ersetzen. Zwar wurden etliche Prototypen hergestellt. Sofern sie nicht zuvor einen Totalschaden erlitten, wurden sie meist nach wenigen Betriebsjahren abgebaut, weil ein wirtschaftlicher Betrieb aufgrund zu hoher Reparatur- und Wartungskosten nicht möglich war. Daher gaben die meisten Staaten ihre Forschungen an Großwindanlagen bis zur zweiten Hälfte der 80er Jahre auf. Motivation, Inhalte und Ergebnisse der jeweiligen nationalen Forschungsprogramme werden im ersten Kapitel dargestellt. In einem analytischen Teil (Kap. 1.2) geht es anschließend darum, diese Programme, ihre Akteure und die Ergebnisse in vergleichender Perspektive zu betrachten. ${ }^{3}$

Mehrere Pionierländer hatten ihr Engagement im Windenergiesektor nach dem Scheitern dieses Large-Scale-Ansatzes gänzlich aufgegeben. Manche verfolgten stattdessen eine andere Strategie, welche sich als geeigneter erwies: die Marktförderung kleiner Windanlagen, bspw. Investitionszuschüsse und Steuererleichterungen (Förderregelungen). Märkte sind daraufhin in Dänemark, kurze Zeit später in Kalifornien, dann in den Niederlanden und der Bundesrepublik entstanden. Käufer waren zumeist neue Akteure auf dem Elektrizitätsmarkt, die zuvor weder am Netzbetrieb, noch als Betreiber großer Kraftwerke in irgendeiner Weise in Erscheinung getreten waren. Eine zweite Ähnlichkeit dieser Pioniermärkte besteht im Vorhandensein gesellschaftlicher Kontroversen um Atomkraft und der Präsenz aktiver sozialökologischer Bewegungen. Andererseits zeichnen sich die Akteursstrukturen der Pioniermärkte durch eine starke Heterogenität aus: Während in Kalifornien Investmentgesellschaften das Feld dominierten, handelte es sich bei den wichtigsten Akteuren auf dem niederländischen Markt um die traditionelle Energiewirtschaft. In Dänemark und Deutschland waren zivilgesellschaftliche Windradkooperativen bzw. Bürgerwindgesellschaften die wesentlichen Käufer von Windanlagen. Weil dieser andere bottom-up-Ansatz erfolgreich war, wird ihm hier die größte Aufmerksamkeit zuteil (Kapitel 2). Die Rede von einem ,Ansatz' sollte nicht dahingehend verstanden werden, als seien die sich in den Pioniermärkten vollziehenden Prozesse hauptsächlich das Produkt zielgerichteten staatlichen Handelns. Was für den Large-Scale-Ansatz noch halbwegs zutreffen mag, kann

\footnotetext{
${ }^{3}$ In diesem Kapitel werden sämtliche Staaten berücksichtigt, deren Forschungsprogramme zur Realisierung mindestens einer Prototyp-Großwindanlage mit mindestens einem Megawatt Generatorenkapazität während der 70er/80er Jahre geführt hat (Pionierländer).
} 
die Prozesse in den Pioniermärkten nicht plausibel erklären. Es genügt daher nicht, die Entwicklungen ausschließlich aus einer techno-politischen Perspektive zu analysieren. Neben dem politisch-administrativen System wird das Handeln der Windanlagenbetreiber sowie der Herstellerindustrie als Akteure betrachtet. Bei dieser Analyse von Akteurskonstellationen dominiert die Frage: "Wer handelt mit welchem Resultat?". Um das Handeln von Akteuren zu interpretieren, ist es zudem essentiell, danach zu fragen, in welche Strukuren die Akteure eingebettet sind. Agieren sie als Repräsentanten etablierter Akteure wie großen Stromkonzernen? Lässt sich ihre Handlungsweise dadurch erklären, dass sie bestimmte ökonomische Interessen verfolgen? Spiegeln sich in ihrem Handeln nationale Traditionen und Aspekte der nationalen Wirtschaftsweise wider? Hinsichtlich des Wirkens dieser Akteure, ihrer Interdependenzen und internationaler Lerneffekte, wird die Pionierphase in vier zeitlich aufeinanderfolgende Perioden zergliedert. ${ }^{4}$

Grundlage der zeitlichen und inhaltlichen Bestimmung dieser Abschnitte bilden sowohl wichtige landesspezifische Entwicklungsschritte, als auch internationale Diffusionsprozesse. Für die Lösung mancher Probleme, die mit der Windenergienutzung im weitesten Sinne verbunden sind, wird auf vorhandenes Know-how zurückgegriffen. Zur Überwindung anderer Barrieren mussten eigene Strategien erdacht werden, oder es wurden bewusst eigene Wege gewählt. Die Zergliederung der Pionierphase in vier aufeinander folgende Untersuchungsperioden dient nicht nur der präziseren zeitlichen Einordnung von Ereignissen und der Feststellung, in welche Richtungen das Pionierwissen geflossen ist. Zahlreiche hier dargestellte Entwicklungen haben sich entsprechend der in der jüngeren Techniksoziologie geltenden Annahme vollzogen, dass Innovationen nicht linear, sondern in Schüben entstehen. ${ }^{5}$ Demzufolge ist der eigentlichen Innovation ein inkrementeller, also Wandel vorangegangen. ${ }^{6}$ Die Übergänge der einzelnen Perioden sind dabei oft durch Brüche und kritische Hürden voneinander getrennt (Degele 2002, 62ff.).

Der erste Abschnitt über die Technikperiode (1975-1978) befasst sich mit den wichtigsten technischen Grundlagen der Kommerzialisierung des dänischen Anlagenkonzeptes (danish design). Diese wurden in Dänemark geschaffen und gehen wesentlich auf die Initiative nichtstaatlicher-staatlicher Akteure zurück.Auch in der folgenden Stabilisierungsperiode (19791982) werden ausschließlich Vorgänge auf dem dänischen Sektor untersucht. Staatliche Förderung geährleistet eine wachsende Nachfrage von Windanlagen. Ab diesem Zeitpunkt sind die meisten Anlagen nicht mehr in kleinen Werkstätten gefertig worden, sondern in der Serienfertigung durch mittelständische Unternehmen. Während der Erprobungsperiode (1983-1987) wird die Technologie in Kalifornien erstmals in großem Umfang angewendet. Dort entstand ein, für damalige Relationen, riesiger Markt für Windturbinen. Von herausragender Bedeutung ist das Agieren der vergleichsweise erfahrenen Anlagenhersteller aus Dänemark auf dem neuen Exportmarkt. Schließlich zeichnet sich die Verstetigungsperiode (1988-1991) durch die Einführung der neuen Technologie in zwei weiteren Ländern aus (BRD, Niederlande). In der Analyse dieser nationalen und internationalen Entwicklungen während des Zeitraums der Pionierphase liegt der wesentliche Fokus der Untersuchung.

\footnotetext{
${ }^{4}$ Die Rolle staatlicher Institutionen für Technologieförderung (top-down) wird ausschließlich in Kapitel 1 behandelt.

${ }^{5}$ Lange Zeit dominierte die Vorstellung, dass Innovationen prinzipiell steuerbar seien und linear verliefen. Ausgehend von der Grundlagenforschung, über angewandte Forschung, Entwicklungstätigkeit, hin zur Schaffung der Innovation als erster ökonomischer Anwendung und schließlich der Diffusion, der Phase der Verbreitung der Innovation über die gesamte Gesellschaft, sollten sich Innovationsprozesse geradlinig über diese fünf Stufen vollziehen (Degele 2002, 62f.).

${ }^{6}$ Ohne vielfältige Erfahrungen aus der Praxis wären Entdeckungen wie das elektrische Licht oder das Penicillin gar nicht möglich gewesen. Solche Innovationen werden daher als kumulative Ergebnisse von Lernprozessen begriffen.
} 
1992 manifestiert sich erstmals ein Prozess beschleunigter internationaler Diffusion der Technologie Dieser Zeitpunkt markiert daher den Eintritt in die Diffusionsphase, einen neuen Entwicklungsabschnitt der Windenergienutzung.

Nicht nur quantitativ, bezogen auf die Zahl der Länder, in denen Windanlagen betrieben werden, sondern auch qualitativ, stellt das Jahr 1992 eine Zäsur dar. Kennzeichnend ist das aufkommende Interesse von Energiekonzernen wie der spanischen Endesa an der neuen Technologie. Charakteristisch für die 92er Märkte (Spanien, Großbritannien und Griechenland) ist darüber hinaus, dass in ihnen, anders als in den Pioniermärkten keine AntiAKW-Bewegungen präsent waren, auf deren Proteste die Förderung erneuerbarer Energien eine Antwort hätten sein können. Das ,aufrichtige 'Verhältnis der EVU zur Windkraft, die von ihnen i.a. mit großer Skepsis betrachtet wurde, deutet darauf hin, dass Anfang der 90er Jahre entscheidende technische und institutionelle Durchbrüche erreicht wurden.

Die 92er Märkte werden nicht in derselben Intensität behandelt wie die Pioniermärkte. In diesem dritten Kapitel geht es in erster Linie darum, den Begriff und die zeitliche Eingrenzung der Pionierphase, noch präziser zu fassen. Diesem Zweck dient auch ein Vergleich zwischen den 92er und den Pioniermärkten. Wie haben sich die Strukturen der Pioniermärkte im Verlauf der 90er Jahre entwickelt? Haben sich diese an die 92er Märkte angenähert?

Die Methode des internationalen Vergleichs und die Einbettung nationaler wie internationaler Entwicklungen in zeitlich aufeinander folgende Perioden bilden den wesentlichen konzeptionellen Rahmen der Untersuchung. Darüber hinaus wird im empirischen Teil (Kapitel 1-3) Bezug auf einige der Technikforschung entliehene Ansätze und Begriffe genommen. Bestimmte Neuerungen werden als radikale Innovationen bezeichnet, um sie als Besonderheiten hervorzuheben (bspw. gezielter Aufbau einer Zuliefererindustrie in Dänemark, Bildung von Windanlagenkooperativen). Mit Bezügen auf das Konzept des ,technological shaping' geht es darum aufzuzeigen wie sehr die Gestaltung einer Technologie von bestehenden Akteurskonstellationen und nationalen Rahmenbedingungen abhängig ist. Die Unterschiede in der Windanlagentechnologie Dänemarks, Kaliforniens und der Niederlande lassen sich auf diese Weise sehr gut verstehen. Ein drittes Beispiel ist die Netzwerkanalyse: Bestimmte Gegebenheiten werden als Produkte des Zusammenwirkens mehrerer Akteure interpretiert, bspw. die frühzeitigen Erfolge der dänischen Windanlagenindustrie. Dasselbe gilt für die Tatsache, dass zivilgesellschaftliche Akteure auf die forschungspolitische Ausrichtung - Entwicklung von Großwindanlagen - keinen Einfluss zu nehmen vermochten.

Auf diese Weise werden zahlreiche Ergebnisse, denen allerdings eher eine regionale als globale Bedeutung für die Gesamtstudie zukommt, hinsichtlich ihrer techniksoziologischen Relevanz beleuchtet. Der Schwerpunkt des empirischen Teils besteht in der Analyse technischer, ökonomischer, sozialer wie administrativer Aspekte der Windkraftnutzung, um die Frage zu klären wie sich die neue Technologie in den Pioniermärkten etabliert hat.

Die gesamte Pionierphase hindurch zeigt sich die Energiewirtschaft weitestgehend als erbitterter Gegner der Windkraft. Dieses gilt verstärkt, wenn es darum geht, externen Windstromproduzenten den Zugang zum Netz zu gewähren. Welche Veränderungen der Stromsysteme werden durch das Eintreten der Windenergie ausgelöst oder katalysiert? Inwieweit lassen sich diese Entwicklungen in einen globaleren Kontext der Innovationssoziologie einordnen? Mit diesen Fragen beschäftigt ein abschließendes Kapitel. Hier geht zudem, die Rolle der Windenergie für das Gesamtsystem der Energieversorgung zu betrachten. Einschlägige Modelle und Konzepte werden auf ihre Erklärungsfähigkeit dieses Anwendungsfalls geprüft. Wie sehr verhalten sich die Elektrizitätssysteme als große technische Systeme? Wie hoch ist der Erklärungswert der Pfadabhängigkeitsthese? Inwieweit handelt es sich bei der Windenergie um eine radikale Innovation im des Elektrizitätssektors? 


\section{Forschungsstand}

Eine international vergleichende Studie zur Pionierphase der Windkraft kann insbesondere für die Pioniere Dänemark und Kalifornien auf einen sehr ausführlichen Literaturstand zurückgreifen (van Est 1999, Garud/Karnoe 2003, Gipe 1995, Hantsch 1998, Heymann 1995, Kamp 2002, Righter 1994 und Vestergaard 2004). Die meisten dieser Studien behandeln die beiden Pioniermärkte in vergleichender Perspektive. Auch für die beiden Nachzügler Deutschland und Niederlande existiert ein ausreichender Fundus an Literatur (BRD: Byzio et al. 2002, Heymann 1995, Oelker et al. 2005, Pulczynski 1991, Tacke 2004, Bruns et al. 2008; NL: Kamp 2002, Verbong 1999, Wolsink 1996).

Die weiteren hier betrachteten Pionierländer Griechenland, Schweden, Kanada, Großbritannien, Spanien und Italien werden nur spärlich behandelt. Diese Auslassungen gilt es, insbesondere auch was die 92er Märkte betrifft, aufzuarbeiten. Die übrigen Staaten werden ausschließlich im ersten Kapitel berücksichtigt, hinsichtlich ihrer Large-Scale-Politik. Bei der hilfreichsten Quelle handelt es sich um das internationale Fachmagazin Windpower Monthly (WPM), das vom dänischen Verband der Windanlagenbetreiber herausgegeben wird. Dort finden sich zahlreiche Artikel zu den betreffenden Ländern. Auch weitere einschlägige Zeitschriften wie Neue Energie, Wind Directions und Erneuerbare Energie werden berücktsichtigt.

Schneider (2001) hat für die Analyse des Telekommunikationssektors einen ähnlich konzeptionalisierten internationalen Vergleich gewählt, wie er hier verwendet wird. Unterschiedliche Studien (Byzio et al. 2002, Kamp 2002, Karnoe 1991) haben die Windenergieentwicklung anhand von Phasenmodellen dargelegt. Dabei sind diese Arbeiten jeweils unterschiedlichen Ländern gewidmet und behandeln verschiedene Zeiträume und Gegenstände (s.u.). Solche Phasenkonzepte haben einen hohen Stellenwert in der Technikforschung. Im Ansatz, vernetzter Innovationen ' geht Weyer (1997) etwa davon aus, dass sich die soziale Dynamik einer Innovation über drei Phasen erstreckt: Entsehung, Stabilisierung und Durchsetzung. Für den Einstieg in die nächste Phase müssen jeweils spezifische Barrieren überwunden werden. ${ }^{7}$

Über das Scheitern des Large-Scale-Ansatzes (Kap. 1) besteht in der Literatur weitgehende Einigkeit. Insbesondere Gipe (1995, 90f.) extrapoliert seine Ergebnisse, die er in erster Linie aus seinen Forschungen zum US-amerikanischen Mod-Programm der NASA gewonnen hat, recht großzügig auf die Forschungsprogramme der übrigen Staaten. Die Produktionsstatistiken (Verfügbarkeit, Energieoutput) der dort hergestellten Prototypen dienen ihm als wesentliche Beweise. Ausführlich beschäftigt mit dem Mod-Programm hat sich auch Righter (1996). Pulczynski (1991) und Heymann (1995) setzen sich kritisch mit dem deutschen Growian-Projekt auseinander.

Die hier berücksichtigten Studien analysieren die Forschungsförderung maximal dreier Staaten. Um zu einer differenzierten und verallgemeinerbaren Gesamteinschätzung der Forschungsprogramme, der Gründe ihrer Durchführung, ihres Scheiterns und dessen Folgen

\footnotetext{
${ }^{7}$ Die Entstehungsphase ist von Kreativität und der Abweichung vom Bestehenden gekennzeichnet. ,Die entscheidende Leistung der Entstehungsphase besteht in der Ausbildung technischer und sozialer Konstruktionsprinzipien, die über die Innovation hinaus stabil bleiben.' (Degele 2002, 70). In der Stabilisierungsphase ,geht es darum, Handlungsstrategien durchweg heterogener Akteure so miteinander zu verkoppeln, dass eine technische Entwicklung die Chance hat, sich auf dem Markt zu bewähren....Netzwerke bilden sich (oder werden von Erfinder-Unternehmen gebildet), um visionäre Projekte auch über Durststrecken hinweg am Leben und in der Diskussion zu halten.' (ebd., 71). Amateure und Bastler müssen sich zu Konstrukteuren und Organisatoren funktionierender Netzwerke entwickeln. Es kommt darauf an, mit der Innovation Geld zu verdienen. ,In der Durchsetzungs- oder Diffusionsphase nimmt der Markt die Innovation an.' Die Technik ist häufig noch nicht so ausgereift, dass für neue Nutzer kein Risiko mehr bestände. Es bedarf neuer Netzwerke und Pioniere, durch deren Nachfrage die erforderliche Verbreitung in Gang gebracht wird. In der Einbindung neuer Akteure in den Kreis der bisherigen Nutzer besteht die wesentliche Leistung dieser Netzwerke. Dadurch werden die Voraussetzungen für weitere Standardisierung und damit erhöhte Verlässlichkeit der Technologie geschaffen (ebd., 73).
} 
$\mathrm{zu}$ gelangen, ist es erforderlich, auch die Aktivitäten bislang von der Literatur vernachlässigter Staaten detailliert zu betrachten. Ein umfassenderer internationaler Vergleich soll zur Klärung nachfolgender Fragen beitragen: War es in jedem Fall so, dass sowohl an den Entscheidungen über die Verwendung der Gelder, als auch an den Planungs- und Durchführungsprozessen ausschließlich große Akteure beteiligt waren? Lässt sich in manchen Fällen nachweisen, dass die Entscheidungen zur Erforschung erneuerbarer Energietechnologien als Reaktion auf außerparlamentarische Proteste zu interpretieren sind? Muss davon gesprochen werden, dass immer wieder dieselben Fehler gemacht wurden, oder sind Lernfortschritte erkennbar? ${ }^{8}$

Sämtliche hier genannte Studien analysieren mindestens einen der Pioniermärkte, deren Entstehung und Entwicklung in Kapitel 2 behandelt wird. Prinzipiell ist hier dasselbe ,regionale Ungleichgewicht' des Literaturstandes zu beobachten wie es bereits für die Studien zur internationalen Technologieförderung konstatiert wurde: Im Rampenlicht stehen Dänemark und Kalifornien, den Nachzüglern Niederlande und Deutschland kommt eine deutlich geringere Aufmerksamkeit zu. Das wesentliche Defizit besteht allerdings darin, dass bislang keine Studie die Pioniermärkte zueinander in Beziehung gebracht hat. Daher herrscht bislang ein Mangel an vergleichenden und zugleich empirisch hinreichend fundierten Aussagen über die Pionierphase der Windenergienutzung. Ein weiteres Defizit besteht darin, dass die, für die spätere internationale Diffusion so wichtige, frühe Periode der Entwicklungen in Dänemark (1975-1978), zumindest im deutsch-angelsächsischen Sprachraum kaum Niederschlag gefunden hat. Das fehlende Material ist durch drei Quellen ergänzt worden: Beuse et al. (2000), ${ }^{9}$ drei Experten-Interviews mit dänischen Pionieren ${ }^{10}$ und

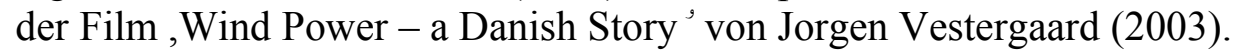

Die meisten hier berücksichtigten Untersuchungen gehen offenbar davon aus, dass sich die Verfasstheit der Pioniermärkte nicht begreifen lässt, wenn man deren Entstehung einzig als Reaktion auf das Handeln staatlicher Akteure (Förderregelungen etc.) interpretiert - und der Einfluss weiterer Akteure daher in der gleichen Weise untersucht werden muss (Beuse et al. 2000, Bruns et al. 2008, Byzio et al. 2002, van Est 1999, Heymann 1995, Kamp 2002, Garud/ Karnoe 2001 und 2003, Suck 2004, Verbong 1999 und Wolsink 1999). Byzio et al. (2002) beschäftigen sich mit den deutschen Bürgerwindgesellschaften, also den Organisations- und Akteursstrukturen auf Seiten der Windanlagenbetreiber, deren Wirken ein maßgeblicher Einfluss auf den Erfolg der Windkraft in Deutschland zugesprochen wird. Konzeptionell bedienen sich die Autoren eines zweistufigen Phasenmodells, mit einer Modell- und Diffusionsphase. Ein Phasenkonzept wird auch von Bruns et al. (2008) in ihrer ,Innovationsbiographie der Windenergie' (in Deutschland) verwendet, wobei sie den Focus auf die Aktivitäten des politisch-administrativen Systems legen. Karnoe (1991, 248) zergliedert die Entwicklung der dänischen Windindustrie im Zeitraum 1974-1990 in fünf Phasen. ${ }^{11}$ Auch Kamp (2002) verwendet ein Phasenkonzept, um den Innovationsprozess der Windenergienutzung in den Pioniermärkten Dänemark und Niederlande, während der Zeit 1975-2000, zu analysieren. Bei der Definition der Phasen geht es Kamp weniger um eine inhaltlich-analytische Einteilung, als vielmehr die Festlegung jeweils fünfjähriger Zeitabschnitte. Darüber hinaus wird für die beiden Länder unterschieden, ob es sich um

\footnotetext{
${ }^{8}$ Die Breite des zu diesem Zweck mit einbezogenen empirischen Materials wirkt sich auf den Lesefluss des betreffenden Kapitels 1.1 leider nicht immer positiv aus.

${ }^{9}$ Ausgewählte Passagen des dänischen Sammelbandes, Vedvarende energi i Danmark ' hat freundlicherweise ein Dänisch-Kurs des Seminars für Skandinavistik der Universität Göttingen ins Deutsche übersetzt.

${ }^{10}$ Dabei handelt es sich um: Erik Grove-Nielsen, der 1977 das weltweit erste unabhängige Unternehmen zur Hersteller von Rotoren gründete (Oekaer Vind Energi); Preben Maegaard, dem in der Mitte der 70er Jahre eine leitende Rolle innerhalb der OVE zukam und der später das Folkecenter eröffnete; Joergen Krogsgaard, einer der ersten Mitarbeiter der Teststation für kleine Windanlagen in Risoe.

${ }^{11}$ 1974-1979 (Graswurzel-Periode); 1980-1983 (Frühe Industrialisierung); 1984-1985 (Beschleunigte Industrialisierung); 1986-1988 (Krisenzeit); 1989-1990 (Stabiles Wachstum), (vg. van Est 1999, 327).
} 
Entwicklungen im großen oder kleinen Innovationssystem handelt, die jeweils getrennt voneinander betrachtet werden. Garud/Karnoe (2001) beobachten Pfadentwicklungen im dänischen Windenergiesektor und bedienen sich dabei eines ,technological frame'-Konzeptes. Die ,frames ', welche von den Autoren definiert werden, entsprechen im wesentlichen den drei Akteuren (Politisch-administratives System, Industrie und Käufer/Betreiber), deren Einfluss auf die Pioniermärkten in dieser Studie untersucht wird (Kapitel 2): ,frames regarding production, frames regarding use, frames regarding regulation of technology".

Der Sammelband von Oelker et al. (2005) bietet eine detaillierte Aufarbeitung des deutschen Windenergiesektors. Besonders hilfreich sind die Abschnitte über den Reifungsprozess und die Schwierigkeiten der deutschen Windanlagenindustrie sowie die Entwicklungen im Dreieck EVU, Betreiber und Administration. Die wirtschaftliche und kulturelle Tradition der Kooperativen und des kooperativen Arbeitens in ihrer Bedeutung für die dänische Windenergienutzung hebt van Est $(1999,253)$ hervor: ,Joint innovation learning seemed a natural thing within this subpolitical network, and represents one of its key success factors.'

Anhand der Vergleiche zwischen Kalifornien und Dänemark zeigen van Est 1999, Gipe 1995, Heymann 1995, Karnoe 2003 und Vestergaard 2004, dass dem Zusammenwirken staatlicher Förderinitiativen, in Kombination mit der Akteurstruktur der Industrie sowie der Käufer und Betreiber von Windanlagen, für die erfolgreiche und langfristige Etablierung der Windenergie nicht beliebig ist. Darüber, dass die Windradkooperativen Dänemarks zum Betrieb von Windanlagen besser geeignet waren als Investmentgesellschaften besteht unter den genannten Autoren weitgehende Einigkeit. Das gleiche gilt für die Struktur der Industrie: erfolgreich waren dänische Handwerksbetriebe und mittelständische Maschinenbauunternehmen. Den meisten US-amerikanischen Herstellern, darunter viele Entrepreneurs, die auf das ,schnelle Geld ' aus waren, gelang es dagegen nicht, international konkurrenzfähige Produkte auf den Markt zu bringen. Zur Erklärung administratives Versagen angeführt. Darüber hinaus geht Heymann (1995) von einer prinzipiellen Inkompatibilität der US-amerikanischen und insbesondere auch der kalifornischen Techniktradition ${ }^{12}$ mit den spezifischen Erfordernissen der Windtechnologie aus. Andererseits wird die traditionsreiche Maschinen- und Schiffbauindustrie Dänemarks, mit einer für dänische Windanlagenhersteller typischen robusten Bauweise in Verbindung gebracht. Aufgrund einer gewissen Schwerfälligkeit traten zwar Effizienzverluste auf. Dafür waren dänische Modelle zuverlässiger und langlebiger als internationale Konkurrenzprodukte. Heymann (1995) betont die Einflussnahme der dänischen Zivilgesellschaft auf die Energiepolitik, während die kalifornische Umweltbewegung kaum Anteil an Entscheidungsprozessen nehmen konnte. Wolsink (1996) hat sich mit der Frage des stagnierenden Windenergiemarktes der Niederlande auseinandergesetzt. Als eines der wichtigsten Hemmnisse wird eine unzweckmäßige Windparkplanungspolitik, hinsichtlich mangelnder Einbindung anliegender Kommunen, ausgemacht. Verbong (1999) zufolge ist die niederländische Windenergiepolitik daran gescheitert, dass es nicht gelungen war, technoökonomische Netzwerke zu etablieren.

Jenseits diverser zeitgenössischer Artikel der Windpower Monthly werden für die Untersuchung der 92er Märkte (Kap. 3) folgende Quellen verwendet: Spanien: Arocena et al. 1999, Faulin et al. 2006; Großbritannien: Elliott (1997), Rothgang 1990, Suck 2004, Toke (1999, 2004, 2005); Griechenland: Dede 1993, Hadjilambrinos 1996.

Stromerzeugung durch Windkraft ist eine potenzielle Komponente grundlegender Transformationen des Elektrizitätssystems. Dieses wird anhand der Beispiele Spaniens, Dänemarks und der Bundesrepublik dargelegt. $\mathrm{Zu}$ diesem Zweck wird auf auf vorhandene Materialien zurückgegriffen (Kap. 4).

Für die Diskussion der Anwendbarkeit techniksoziologischer Konzepte werden darüber hinaus folgende Quellen verwendet: Baedeker 2002; Beyer 2005; Byzio et al. 2002; Dolata

\footnotetext{
${ }^{12}$ Gemeint sind etwa positive Erfahrungen mit Hightech- und Large-Scale-Methoden. Man denke etwa an Silicon Valley und die Mondlandung.
} 
2008; Dolata/Werle 2007; Geels 2005; Heymann (1999); Hughes 1983; Markard/Truffer 2006; Mautz 2006, 2007; Mayntz/Hughes 1988. Die Frage, ob sich Stromsysteme infolge des Hinzutretens der Windenergie als große technische Systeme verhalten, wird auf der Grundlage von Hughes (1983) gleichnamigem Konzept untersucht. Beyer (2005) attestiert der Pfadabhängigkeitsthese einen ,impliziten Konservativismus'. Demzufolge werden radikale Pfadwechsel und -abweichungen von Anfang an als Ausnahmefälle konzipiert. Eine entsprechende Annahme vertreten Dolata (2008) und Dolata/Werle (2007) in ihrer Theorie des ,institutionellen/sektoralen Wandels '. Das Problem dauerhafter ,lock-ins s' ${ }^{\prime 13}$ wird trotz der Annahme starker Pfadabhängigkeiten nicht gesehen. Vielmehr gehen die Autoren von einem permanenten inkrementellen Wandel aus, der über Jahre, bzw. Jahrzehnte zu grundlegenden Änderungen führte. Markard/Truffer (2006) kritisieren die unscharfe Verwendung des Begriffs ,radikale Innovation 'und schlagen für Energietechnologien ein alternatives Konzept vor: Der Begriff ist demnach auf neue Technologien anzuwenden, wenn sich diese in technischer Hinsicht, oder bzgl. der Wertschöpfungskette stark von bisherigen Standards unterscheiden. Byzio et al. (2002) und Mautz (2006) schlagen ein Konzept vor, dass speziell auf die Rolle (dezentraler) erneuerbarer Energien im Stromsystem zugeschnitten ist. Demzufolge handelt es sich bei diesen um radikale Innovationen, weil sie die wichtigsten Paradigmen der Stromsysteme infrage stellen (Kraftwerksbetrieb durch ein oder wenige Unternehmen; Ökonomie als Leitlinie bei der Auswahl der Energieträger; zentrale Energieproduktion in Großkraftwerken). Heymann (1999) sieht die Windenergie als wichtige Triebkraft partieller Veränderungen der Energieversorgungssysteme, im Sinne einer Hybridisierung, d.h. einer Koexistenz großer und kleiner Kraftwerke, privat und von EVU betriebener Kraftwerke, zentraler und dezentraler Technologien.

\section{Die internationale Pionierphase der Windenergienutzung: Forschung an Großwindanlagen}

Neben der Nachfrageförderung (Kap. 2) ist die Forschungsarbeit an Großwindanlagen ein zweiter Versuch, Windkraft als neue Energiequelle zu etablieren. Die Anfänge beider Förderstrategien liegen innerhalb der Pionierphase, deren Beginn durch den Start des USamerikanischen Mod-Programms definiert ist. National wie international bestehen zeitliche Überlappungen zwischen Technologie- und Marktförderung. Während die Technologiepolitik mangels Erfolgen seit Mitte der 80er Jahre international stark an Bedeutung verloren hat, dominiert die andere Strategie bis heute.

Insgesamt neun westliche Industriestaaten führten in den 70er und 80er Jahren Programme zur Erforschung der Windenergie in großtechnischer Anwendung durch. Auffällig sind große Ähnlichkeiten in der Vorgehensweise, den Zielsetzungen und der Akteursstruktur. Grundsätzliches Ziel war die Herstellung großer Prototyp-Anlagen, die später kommerzialisiert werden sollten. Die verantwortlichen Ministerien vergaben Aufträge über Konstruktion und Bau solcher Prototypen an große Forschungsinstitute und Technologiekonzerne. Als Betreiber waren die Energieversorgungsunternehmen vorgesehen,

\footnotetext{
${ }^{13}$ Dabei handelt es sich um dauerhafte und offensichtlich nachteilige Zustände (bspw. Neubau klimaschädlicher Braunkohlekraftwerke, andauernde Entwicklung von Kraftfahrzeugen mit hohem Benzinverbrauch), die sich als Produkte starker Pfadabhängigkeiten interpretieren lassen.
} 
deren Interesse an der Windkraft nicht immer selbstverständlich war. Aus ihrer Sicht stellt Windkraft eine unzuverlässige Energiequelle dar, die zudem nicht wirtschaftlich ist, insbesondere damals nicht. Hinzu kommt, dass Windanlagen ausschließlich dezentral eingesetzt wurden und nicht in das zentralisierte, auf Großkraftwerken basierende Versorgungssystem, einzufügen waren. Windkraft ist daher als eine Bedrohung etablierter Versorgungsstrukturen wahrgenommen worden. Um ihr Image zu verbessern und weil der größte Teil der Kosten ohnehin vom Staat getragen wurde, erklärten sich zahlreiche EVU dennoch bereit, die großen Prototyp-Windanlagen zu kaufen und an ihr Netz zu schließen.

Manche Regierungen hatten für die Windenergietechnik Summen in dreistelliger Millionenhöhe bereit gestellt. Ausgelöst wurden diese Aktivitäten durch die Ölkrise, welche in der westlichen Welt ein Nachdenken über die Gefahren der Energieabhängigkeit ausgelöst hat. Die Windkraft sollte dazu beitragen, diese Abhängigkeit zu verringern, eigene Ressourcen zu schon und die Versorgung auf eine breitere Basis zu stellen. Man ließ daher neben der Windkraft auch andere regenerative Energietechniken wie Solarenergie erforschen. Einige Untersuchungen kamen in den 70er Jahren zu dem Ergebnis, dass die Windenergie mindestens zehn Prozent zur Versorgung mit Elektrizität beitragen könne. Daher war die Technologie besonders für Flächenstaaten mit guten Windressourcen wie die USA, Kanada, Spanien und Großbritannien attraktiv.

In den meisten westlichen Staaten betrachteten die Energiepolitiker nicht nur erneuerbare Energien, sondern vor allem auch die verstärkte Nutzung der Kernkraft als Alternative zu konventionellen Energien. Entsprechend hoch waren die Forschungsetats für diesen Sektor. Aus Sicht der politischen Befürworter und wirtschaftlichen Nutznießer der Atomenergie bestand das Hauptproblem in der niedrigen Akzeptanz. Teilweise war die Förderung regenerativer Energien eine Reaktion auf massive Proteste, die sich in manchen Ländern gegen den Bau von Atomkraftwerken entwickelten. ${ }^{14}$ Das Ziel konnte ganz allgemein darin bestehen, die Protestbewegungen zu besänftigen, indem man behauptete, ihren Forderungen nachzukommen. Einige Programme setzten sich bewusst zu anspruchsvolle Ziele. Riesige Windanlagen wurden finanziert und nach Konzepten realisiert, die zuvor entweder gar nicht im kleinen Maßstab getestet wurden, oder bereits im Modell nicht überzeugen konnten. In einigen Ländern dienten die ausbleibenden Erfolge offenbar dazu, Beweise für die Nutzlosigkeit der Windtechnologie insgesamt zu liefern und die Öffentlichkeit indirekt von der Notwendigkeit der Atomkraft zu überzeugen. Kennzeichnend für die Programme ist darüber hinaus, dass umweltpolitisch motivierte Technikergruppen und Wissenschaftler, die nicht dem System Staat-Großforschung-Konzerne angehörten, hinsichtlich der Verwendungszwecke der Forschungsgelder keinerlei Mitspracherecht erhielten. Deren häufig artikulierte Forderung, verstärkt auch kleinere Prototypen zu entwickeln, blieb zumeist ohne Resonanz.

\subsection{Windenergieprogramme zur Technologieförderung in den Pionierländern}

Als Pionierländer gelten alle Staaten, welche in den 70er und 80er Jahren Großwindanlagen entwickeln ließen. Im folgenden werden die Forschungsprogramme zur Windenergie in der zeitlichen Reihenfolge betrachtet. ${ }^{15}$

\footnotetext{
${ }^{14}$ Heymann $(1995,344)$ zufolge hat die kritische Öffentlichkeit der Durchführung von Programmen zur Erforschung neuer Energien in den Niederlanden, Deutschland und den skandinavischen Ländern Vorschub geleistet.

${ }^{15}$ Dieses geschieht je nach Umfang und Relevanz der Programme mehr oder weniger ausführlich.
} 
In den Länderanalysen geht es zunächst darum, denkbare Hintergründe für das Interesse an der Windkraft zu erkennen. Nachfolgend werden Ziele, repräsentative Inhalte und Ergebnisse der wichtigsten Projekte dargestellt. Abschließend erfolgt eine Gesamteinschätzung. Wurden die Ziele des Forschungsprogramms erreicht? Lässt sich ein bestimmter Zeitraum erkennen, in dem die Projekte geplant und realisiert wurden? Waren ausschließlich Großakteure beteiligt? Inwieweit ist zivilgesellschaftlichen Kräften ein Mitspracherecht zugekommen?

\section{USA}

Energiepolitik war in den USA bereits vor der Ölkrise ${ }^{16}$ von 1973 ein wichtiges Thema. Die National Science Foundation (NSF) prognostizierte zu Beginn der 70er Jahre ein deutliches Wachstum des Energiebedarfs. Zudem begannen die Öl- und Gasreserven von Texas knapp zu werden (Heymann 1995, 346). Vor diesem Hintergrund gab die Nixon-Administration bereits im Juni 1973 eine Studie über die zukünftige Energieversorgung bei der Atomic Energy Commission (AEC) in Auftrag. Nach deren Veröffentlichung (Dezember 1973) sprach sich der Präsident für den Bau weiterer Atomkraftwerke aus. ${ }^{17}$ Darüber hinaus plädierten die Autoren der Studie für systematische Energiesparmaßnahmen und die Nutzung erneuerbarer Energien. Sie gingen davon aus, dass eine vollständige Unabhängigkeit von Energieimporten bis 1985 auf Basis ihrer Vorschläge erreichbar sei (Heymann 1995, 367).

Die Unsicherheit der zukünftigen Energieversorgung und steigende Energiekosten erregten den Unmut vieler Konsumenten, welche sich an die Niedrigpreise der 50er/60er Jahre gewöhnt hatten. Bis dahin hatte man die unbegrenzte Verfügbarkeit von Ressourcen als selbstverständlich wahrgenommen. Auf dieser Einstellung basierte die sogenannte, grow-and-build'-Strategie der EVU. Vor der Ölkrise war es unkompliziert, Genehmigungen für den Bau neuer Kraftwerke zu erlangen. Man hielt die Tarife auf niedrigem Niveau, steigerte die Gewinne jedoch trotzdem, weil die ohnehin niedrigen Einkaufspreise noch weiter gefallen waren (van Est 1999, 27f.).

Anfang der 70er Jahre begannen Teile der Öffentlichkeit das ungebremste Wachstum zu hinterfragen und problematisierten wachsende Umweltschäden. Eine Anti-AKW-Bewegung war entstanden und hatte besonders in Kalifornien beachtliche Stärke erlangt. Anfangs scheiterten die AKW-Gegner daran, den rasant vonstatten gehenden Bau neuer Reaktoren zu verhindern. Die Zahl der pro Jahr geplanten AKW-Neubauten ist zwischen 1965 und 1974 von sieben auf 231 angestiegen. Schließlich gelang es der Protestbewegung, die Risiken der Atomtechnik und die Problematik des radioaktiven Abfalls kontinuierlich in der öffentlichen Diskussion zu halten. Die Behörden reagierten mit der Einführung strikterer Genehmigungskriterien, wodurch den Planern Zeitverluste und zusätzliche Kosten entstanden waren. Daher kam es $1975 \mathrm{zu}$ einem Stopp der Antragsflut. Jetzt wurden nur noch Genehmigungen für 15 Reaktoren beantragt, zahlreiche Vorhaben sind unter den neuen Bedingungen aufgegeben worden. Dutzende Projekte wurden trotz Baubeginn abgebrochen (Righter 1996, 151). Auf diese Weise haben die Proteste wesentlich dazu beigetragen, die Realisierbarkeit der föderalen Atomstrategie infrage zu stellen. Zur selben Zeit hatte die Zentraladministration Programme zur Erforschung der Windkraft und anderer erneuerbarer Energien beschlossen, was mit den Vorschlägen der AEC im Einklang zu stehen schien. Erstmalig wird der Schritt von bloßen Sympathiebekundungen für erneuerbare Energien, hin zu tatsächlichen Investitionen vollzogen.

In der Forschung an großen Windanlagen kommt den USA die Rolle des internationalen Vorreiters zu. Das Energieministerium stellte hohe Erwartungen: Künftig sollte die Windkraft nicht nur in ,utility-scale' verfügbar sein und in das Stromsystem integriert werden, sondern auch Energie zu konkurrenzfähigen Preisen liefern.

\footnotetext{
${ }^{16}$ Das Ölembargo gegen die USA dauerte vom 19.10. 1973 bis 18.3. 1974 an (Righter 1996, 155, zur Ölkrise vg. auch: Hohensee 1996).

${ }^{17}$ Kernkraft hat in den USA eine lange Tradition. Allein zwischen Juni 1955 und Juni 1964 wurden \$27 Milliarden in die Nuklearforschung investiert. Leiter der Programme war die AEC (Righter 1996, 150).
} 


\section{$\underline{\text { Repräsentative Projekte, Ergebnisse und Bewertung }}$}

1972 untersuchte das von der NSF und der National Aeronautics and Space Administration (NASA) ins Leben gerufene ,Solar Energy Panel' die Potenziale von Sonnen- und Windenergie. Den Ergebnissen zufolge konnten bis zu 19\% des für 2000 erwarteten Stromaufkommens aus Windenergie produziert werden. Um dieses Potenzial zu erschließen, sollten weitere Forschungen durchgeführt werden. Der Start des auf fünf Jahre angelegten Wind Energy Program (FWEP) markiert 1973 den Beginn der Pionierphase. Dazu sollten große Prototyp-Windanlagen gebaut werden. Die Entwicklungsarbeiten wurden am Lewis Research Center (Cleveland), einem Forschungszentrum der NASA, durchgeführt (Heymann 1995, 347). Hauptziel des FWEP bestand in der Kommerzialisierung der Großwindanlagen (ebd.). In den folgenden Jahren wurden High-Tech Konzerne der Luft- und Raumfahrt wie Boeing, Westinghouse, General Electric, Grumman Aerospace und McDonnell Douglas mit der Herstellung entsprechender Prototypen beauftragt (Vestergaard 2004, 36).

Unter der Schirmherrschaft der NASA werden zwischen 1973 und 1978 drei Prototypen (Mod-0, Mod-0A, Mod-1) der 1. Generation der Mod (Modification) Programms entwickelt. Mod-0 (100kW Generator) wurde vom Lewis Research Center entworfen, von Westinghouse gebaut und im Herbst 1975 auf dem Gebiet des NASA-Stützpunktes in Sandusky/ Ohio installiert. Nach kurzer Zeit erlitt der Prototyp aufgrund mangelnder Stabilität einen Totalschaden (Righter 1996, 159).

Eine vergrößerte Version der Mod-0, die Mod-0A (200kW-Generator), wurde in einer Viererserie hergestellt und an verschiedenen Orten getestet. ${ }^{18}$ Zwar wiesen die Testanlagen eine bessere Zuverlässigkeit als das Vorgängermodell auf. Aufgrund zu hoher Wartungskosten wurden sie dennoch nach einiger Zeit von den beteiligten EVU abgebaut und verschrottet (Gipe 1995, 103). In den folgenden Jahren bemühte sich Westinghouse um eine Kommerzialisierung von Mod-0A. Trotz einiger Verbesserungen blieben die Ergebnisse hinter den Standards marktgängiger Turbinen zurück. Daraufhin gab der Konzern seine Arbeiten im Windenergiesektor gegen Ende der 80er Jahre auf (ebd., 106).

Mit dem Bau der deutlich größeren Mod-1 (2000kW, 61m Rotordurchmesser) wurde General Electric betraut. Diese erste Großwindanlage wird 1978 in Boone, North Carolina, installiert und von Blue Ridge Electric betrieben. Nachdem Mod-1 zu keiner Zeit gemäß der Erwartungen funktionierte, nahm man sie 1983 außer Betrieb. Während der Betriebszeit hatten sich allein die laufenden Kosten, aufgrund andauernder Reparaturen, auf \$30 Mio. addiert. Ein große Schwäche des Mod-1-Projektes besteht darin, dass mit dem Bau des Prototyps so früh begonnen wurde, dass Lerneffekte aus den Konstruktionsschwächen der Vorgängermodelle ausgeschlossen waren (Gipe 1995, 104; Vestergaard 2004, 34).

Trotz ausbleibender Erfolge des FWEP weitete man die Windenergieetats in den folgenden Jahren stark aus: 1974: \$1,5 Mio., 1975: \$8 Mio., 1977: \$25 Mio. (van Est 1999, 36). Im August 1977 wurde von der Regierung Carter, unter Leitung des neu gegründeten Energieministeriums, ein weiteres Forschungsprogramm gestartet. Die negativen Erfahrungen mit dem kostspieligen Mod-1-Prototyp schienen vergessen, denn man bediente sich derselben Strategie. Zur Herstellung einer noch größeren Mod-2-Windanlage $(2000 \mathrm{~kW}, 91 \mathrm{~m}$ Rotordurchmesser) beauftragte man Flugzeughersteller Boeing. Nachdem der Konzern eine Fünferserie produziert hatte, wurden die Prototypen zu Probezwecken an das Netz eines kalifornischen Energieversorgers geschlossen. Sollte sich die Versuchsanlage bewähren, kündigte PG \& E den Aufbau eines großen Windparks mit 40 Mod-2-Maschinen an (Righter 1996, 179). Letztendlich brachte Mod-2 ähnlich mangelhafte Resultate wie die Vorgängermodelle. Auch diese Prototypen wurden daher bis 1988 stillgelegt und abgerissen

\footnotetext{
${ }^{18}$ Dabei handelte es sich um Standorte in New Mexico, Puerto Rico, Hawaii und Rhode Island.
} 
(Gipe 1995, 104). ${ }^{19}$ Daraufhin hatte das Energieministerium eine weitere Fehlinvestition in Höhe von $\$ 60$ Mio. zu verbuchen.

Die letzte der großen Versuchsanlagen im Rahmen des Mod-Programms ist Mod 5B (3200kW und 98m Rotordurchmesser). Ein von Boeing gelieferter Prototyp begann im Januar 1988 Strom in das Netz des Versorgers von Hawaii einzuspeisen. Obgleich die Mod-5B gegenüber den bisherigen Versuchen ein Fortschritt war, eignete sie sich nicht für eine Kommerzialisierung. Infolgedessen stellte Boeing keine weiteren Prototypen der Anlage her und die einzige Mod-5B wird 1993 stillgelegt. Weitere \$55 Mio. sind damit ins Leere gelaufen (Gipe 1995, 104). ${ }^{20}$

Test- Forschungseinrichtung für kleine Windanlagen

Seit 1976 wurde auch die Entwicklung kleiner und mittlerer Windturbinen vom Energieministerium mit \$120 Mio. gefördert. Diesem Zweck diente das National Research Energy Laboratory (NREL) in Rocky Flats, Colorado (Gipe 1995, 72). Zudem erhielten Konzerne wie Rockwell International und McDonnell Aircraft Zuschüsse für die Herstellung von Kleinwindanlagen, welche vom NREL geprüft wurden (ebd., 77). Derivate dieser Maschinen sind später zu Hunderten in kalifornischen Windparks errichtet worden. Dabei zeigten sich bei vielen der Windturbinen gravierende Mängel. Aufgrund schwerwiegender konzeptioneller Fehler sind gegen Ende der 80er Jahre sämtliche der im NREL geprüften Designs verworfen worden (ebd., 72). Allein das 44/40 Design von Enertech erzielte begrenzte technische und kommerzielle Erfolge (ebd., 89).

Von den zwischen 1974 und 1992 für Windenergieforschungen insgesamt zur Verfügung gestellten Mitteln in Höhe von \$486 Mio. wurden \$350 Mio. (72\%) für Konstruktion und Betrieb der Großanlagen aufgewendet (ebd., 106). Keiner der Prototypen erreichte das Stadium der Serienreife. Die Maschinen waren insgesamt unzuverlässig, instabil und arbeiteten ineffizient. Das Hauptziel des FWEP, die Kommerzialisierung der großen ModAnlagen wurde verfehlt. Neben dem Versagen des Mod-Programms waren die seit Mitte der 80er Jahre gesunkenen Energiepreise ein weiterer Grund, weshalb die Windtechnologie an Attraktivität eingebüßt hatte. Daraufhin schrumpfte der Etat zwischen 1980 und 1988 von $\$ 60$ auf \$10 Mio. (vg. Gipe 1995, 72 Abb. 3.1 und Vestergaard 2004, 35). Darüber hinaus hatten sich bis zum Ende der 80er Jahre sämtliche beteiligte Unternehmen aus dem Sektor zurückgezogen und das Know-how ging verloren (Heymann 1995, 354). Bis 1994 werden alle Großwindanlagen entweder abgerissen oder stillgelegt. Auch das Programm für Kleinwindanlagen zeitigte keine besseren Ergebnisse. Gipe (1995) bewertet die Förderung der Großwindanlagen als kontraproduktiv. Sie lenkten das öffentliche Interesse von den Erfolgen bei der Kommerzialisierung kleiner Modelle ab und diffamierten die Technologie insgesamt. ${ }^{21}$ Am Programm beteiligt sind ausschließlich Großakteure: Das Energieministerium, Konzerne aus der Luft- und Raumfahrtbranche (Hamilton Standard, Grummon, Boeing, Rockwell International, McDonnell Aircraft, Alcoa, Kaman und United Technologies), NREL und Lewis Research Center/NASA. Zivilgesellschaftliche Akteure wie kleinere kommerzielle Hersteller und NGOs sind in keiner Weise integriert, insbesondere auch nicht am Programm für kleine Windturbinen.

\footnotetext{
${ }^{19}$ vg. auch : Tacke 2004, 134 und Righter 1996, 177

${ }^{20}$ Zum Bau einer weiteren Großanlage erhielt der Raumfahrtkonzern Hamilton Standard mit Sitz in Connecticut einen Auftrag aus Schweden. Zudem entwarf der Konzern das Design der Rotoren. Von der Anlage wurden zwei Prototypen hergestellt (drei, bzw. vier Megawatt Generatoren): Installiert worden sind WTS-3 in Schweden und WTS-4 in Wyoming. Energieoutput und Zuverlässigkeit waren mit den Mod-Anlagen vergleichbar. WTS-4 ist bis 1994 am Netz geblieben, bevor ein Sturm zum Totalschaden führte (Gipe 1995, 106 und Righter 1996, 178). Daraufhin gab Hamilton Standard seine Arbeiten im Windenergiesektor auf (van Est 1999, 46).

${ }^{21}$ Ähnlich argumentiert Righter $(1996,159)$ : ,It did not help the reputation of wind energy when the experimental unit at Sandusky, Ohio (Mod-0) failed in less than two days, prompting the New York Times to headline its story, \$1Million for only 30 Hour of Work' ' (ebd.).
} 


\section{Dänemark}

Aufgrund niedriger Preise gewann das Öl seit der Nachkriegszeit für die dänische Energieversorgung an Bedeutung. Der Anteil am Primärenergieverbrauch ist 1972 auf 94\% gewachsen. Da Dänemark über keine eigenen Ölressourcen verfügt, musste der gesamte Bedarf importiert werden. Entsprechend groß war der Schock der Ölkrise (Heymann 1995, 355). Noch im selben Jahr kam es zur Verdreifachung der Preise. Innerhalb von nur zwei Jahren wurde der Ölkonsum im Stromsektor um $40 \%$ gesenkt und durch Kohleverstromung ersetzt.

Aus Sicht der Danske Elvarkers Forening (DEF), der Vereinigung dänischer Stromversorger, bildet Atomkraft die einzig realistische Alternative zu fossiler Energie. Nachdem der DEF 1974 bekannt gab, künftig alle zwei Jahre ein neues Atomkraftwerk bauen zu lassen, kam es sofort zu heftigen Protesten. Das dänische Parlament, der Folketing, bot der Atomstrategie des DEF vorläufig Einhalt (Heymann 1995, 355). Angesichts wachsender umweltpolitischer Sensibilisierung seit Anfang der 70er Jahre hatte die sozialdemokratische Regierung bereits 1971 ein Ministerium für Umwelt eingerichtet. Die neu entstandene Umweltbewegung, die zuerst gegen Verschmutzungen durch Strom- und Chemieindustrie protestierte, nahm die Veröffentlichung der Atomstrategie als besondere Provokation wahr. Es entstand ein neuer Fokus des Widerstands (van Est 1999, 70). Kritische Öffentlichkeitsarbeit leistete die pragmatisch ausgerichtete Organisation zur Information über Nuklearenergie (OOA, Organizationen til Oplysning om Atomkraft). ${ }^{22}$ Sie konzentrierte sich auf eine Informationskampagne gegen Atomkraft, ohne sich darüber hinaus politisch festzulegen. Erfolgreich ist die OOA nicht nur in der Durchsetzung eines Moratoriums über die Einführung der Atomkraft. ${ }^{23}$ Das konservative Handelsministerium schlug sich auf die Seite des DEF und plädierte 1976 dafür, bis 1995 zwei Drittel der Elektrizität aus Atomenergie zu gewinnen. Innerhalb und außerhalb des Folketings kam es daraufhin $\mathrm{zu}$ erneuten Kontroversen. ${ }^{24}$ Kritisiert wurde u. a., dass nur ein einziges Energieszenario vorgelegt worden ist. Eine kleine Gruppe engagierter Forscher aus dem Umfeld der OOA erarbeitete einen alternativen Energieplan, in dem der Bau von AKWs ausgeschlossen war, sowie KraftWärme-Kopplung und erneuerbare Energien (v.a. Windkraft) besonders gefördert werden sollten. Die Diskussionen um Atomkraft kamen nicht zur Ruhe und das Moratorium wurde immer wieder verlängert, bevor die Atomoption im Jahr 1985 per Gesetz ausgeschlossen wurde. ${ }^{25}$

\footnotetext{
${ }^{22}$ Die NOAH war eine weitere einflussreiche Protestgruppe, die im Jahr 1969 im Kontext der Studentenrevolte gegründet wurde und eine radikalere Gesellschaftskritik vertrat. (vg. van Est 1999, 70ff.). Einen anderen Ansatz verfolgte die Organisation für erneuerbare Energie (OVE). In ihr waren zahlreiche Ingenieure und Technikstudenten vereinigt, denen es darum ging, alternative Energietechniken zu entwickeln, anstatt Forderungen an die Politik zu richten. Bei der Entstehung des dänischen Windanlagenmarktes kommt der OVE eine Schlüsselrolle zu (vg. Kap. 2).

${ }^{23}$ Während der Zeit des Moratoriums sollte eine öffentliche Debatte über die Atomkraft stattfinden. Das Handelsministerium bildete 1974 ein ,Energy Information Committee' (Energioplysningsudvalg), durch das die Öffentlichkeit über energiepolitische Probleme des Landes wie etwa die Ölabhängigkeit in Kenntnis gesetzt werden sollte (van Est 1999, 73). 1981 erlangte die OOA zudem eine wesentliche Einflussnahme auf die Gestaltung des Energieplans (Energiplan 81).

${ }^{24}$ Der schwere Zwischenfall eines Atomreaktors in Pennsylvania (30. März 1976), der mitten in den Zeitraum der Debatte fiel, verschaffte den Argumenten der Kritiker mehr Gewicht und ließ die Anti-AKW-Bewegung weiter erstarken (van Est 1999, 311 Fußnote 41).

${ }^{25}$ Nielsen, H; Nielsen, K.; Petersen; Siggaard $(1999,87)$ analysieren das endgültige Aus der Kernenergie als Ergebnis politischer und sozialer Kräfteverhältnisse: ,Just as the utilities, Risoe, and the politicians finally joined forces, the press and the public managed to pesent their view of nuclear power as an unsafe and inresponsible technology in a way massive enough to win a majority of politicians over. Thus one could say that in Denmark nuclear technology was socially deconstructed.' (ebd., 89)
} 
Wind hatte als Energieträger in der dänischen Gesellschaft eine beachtliche Popularität. 1975 gelingt es Christian Riisager, einem ambitionierten Tischler, eine eigenständig gefertigte Windanlage an das Stromnetz $\mathrm{zu}$ schließen. Damit hatte er eine regelrechte Bewegung ausgelöst und viele waren seinem Beispiel gefolgt. Mitte der 70er Jahre gelingt es Hobbyisten und Aktivisten der Anti-AKW-Bewegung an der Volkshochschule von Tvind, eine großes Windturbine im Selbstbau herzustellen und $\mathrm{zu}$ betreiben. Die erste Großwindanlage Dänemarks ist damit ohne staatliche Hilfe und die Mitarbeit großer Akteure entstanden und verschaffte der Windkraft neuen Zuspruch. Windmühlen sind zum Symbol der Atomkraftgegner geworden.

\section{Repräsentative Projekte, Ergebnisse und Bewertung}

Auch im Parlament erhielt die Windkraft über Parteigrenzen hinweg breite Zustimmung. Unter den erneuerbaren Energien wurde sie als die vielversprechendste Option angesehen. ${ }^{26}$ Man war sich darüber einig, dass zunächst eine technische Verbesserung nötig sei (van Est 1999, 74f.). Auf Initiative der dänischen Akademie für technische Wissenschaften wurde 1977 ein Forschungsprogramm aufgenommen, dass vom Handelsministerium und DEF geleitet wurde (van Est 1999, 75). ${ }^{27}$ Forschungspolitische Linie des Programms ist die Kommerzialisierung von WEA, der größten Größe, die heute mit ausreichend guter Aussicht auf Erfolg konstruiert werden könnten. ${ }^{128}$ Eine anvisierte Generatorenstärke von 400-600kW zeugte von einer gewissen Zurückhaltung, verglichen mit dem US-amerikanischen Federal Wind Energy Program (Tacke 2004, 138 und van Est 1999, 85). Im Zeitraum 1977-1980 sind $82 \%$ des Etats (38 Mio. DKK) für Planung und Bau von Großwindanlagen aufgewendet worden. Insofern entspricht das Programm der Schwerpunktlegung des FWEP. ${ }^{29}$ In den 80er Jahren ließ das Interesse an Großanlagen deutlich nach. ${ }^{30}$

Für die erste Phase des Forschungsprogramms (1977-79) wurden 14,3 Mio. DKK (5,2 Mio. DM) bereitgestellt. Darin wurde die alte Gedser-Mühle, die nach einem Design des Ingenieurs Johannes Juul gefertigt und im Jahr 1957 in Betrieb genommen wurde, instandgesetzt und durch Installation zahlreicher Messinstrumente auf ihre Eignung untersucht. ${ }^{31}$ Dabei wurden ,u.a. Leistungskurven, Belastungen, Schwingungen, Leistungsschwankungen und Störungen von Radio- und Fernsehempfang' (Heymann 1995, 358) gemessen. Diese im März 1979 abgeschlossenen Untersuchungen führten zu positiven Ergebnissen (ebd.).

Unter Leitung des für Jütland zuständigen Energieversorgers Elsam startet parallel die zweite Phase des Programms (1978-1980), für die 19,1 Mio. DKK zur Verfügung standen. Ausgehend von den Erfahrungen mit der Gedser-Mühle wurden in Nibe zwei ähnliche Großanlagen (jeweils 630kW Generatorenkapazität), die ,Nibe-Zwillinge' gebaut, Nibe A (fertiggestellt September 1979) und Nibe B (August 1980) und mit 14,36 Mio. DKK

\footnotetext{
${ }^{26}$ Eine Ausnahme bildete die 1974 vom DEFU (Forschungsinstitut der DEF) herausgegebene Studie über die Möglichkeiten der Windkraft, welche negativ bewertet werden (Heymann 1995, 355).

${ }^{27}$ Reiche $(2002 b, 68)$ betont die Rolle der Universitäten bei der Förderung erneuerbarer Energien. Die relative Unabhängigkeit der Universitäten vom dänischen Staat bewertet Reiche als wichtige Voraussetzung. Nicht nur waren sie unabhängig von Drittmitteln. Auch durften Professoren und Dozenten über $40 \%$ der Mittel frei verfügen.

${ }^{28}$ Aus dem Programm des Handelsministerium zur Energieforschung - erste Phase, Kopenhagen, November 1976), zitiert nach: Tacke 2004, 137.

${ }^{29}$,The terminology, planning schemes, and R\&D strategy of the Danish program were also copied. Just like their American colleagues, the Danes talked about so-called ,o-series' turbines, whose design would be based on ,well-known calculation methods and familar technology'.' (van Est 1999, 76)

${ }^{30}$ Betrachtet man die Schwerpunktlegung über den Zeitraum 1977-1986, so zeichnet sich ein deutlicher Trend zur Abkehr von Großwindturbinen ab. Für großtechnisch ausgerichtete Vorhaben werden im Gesamtzeitraum nur etwa 50\% aufgewendet (Hantsch 1998, 36).

${ }^{31}$ Die 200kW-Anlage zeichnet sich u.a. durch hohe Robustheit aus. Seit 1957 war sie elf Jahre ohne Reparatur gelaufen (Vestergaard 2004, 11).
} 
gefördert. Die in den meisten Eigenschaften baugleichen Anlagen wurden zum Zweck optimaler Vergleichbarkeit nebeneinander errichtet. ${ }^{32}$ Das Design der Prototypen wurde am Forschungszentrum von Risoe und der technischen Universität entwickelt. Da sich kein dänisches Unternehmen für die Produktion bereit fand, sind die Nibe-Zwillinge auf ,multicontract-Basis' entstanden (Kamp 2002, 134). ${ }^{33}$ Obgleich die schadensresistente GedserMühle als Vorbild diente, stellten sich insbesondere an den Rotorblättern der neuen Prototypen gravierende Probleme ein. Aufgrund ihres höheren Energieoutputs diente insbesondere Nibe B als Basis weiterer Forschungen. ${ }^{34}$

Im Jahr 1985 nimmt Elsam die Planungsarbeiten für eine weitere Großwindanlage (Leistung: 2MW, Rotordurchmesser: 61m) auf. Finanziert wurde das Projekt - die Kosten betrugen insgesamt 65 Mio. DKK - gemeinsam durch das Energieministerium, Elsam und EU-Mittel (IEA LS WECS Annual Report 1988, 17). Ebenso wie die Nibe-Maschinen wurde auch der Esbjerg-Prototyp auf Zulieferer-Basis hergestellt (Kamp 2002, 140). Das Design orientierte sich an Nibe B. Im Juni 1988 ging die Großwindanlage in Betrieb. Abgesehen von kleineren Störungen wies sie eine hohe Zuverlässigkeit auf. An den Flügeln waren auch nach 1000 Betriebsstunden keinerlei Schäden festzustellen. Ernüchternd waren die Ergebnisse insofern, als ein wirtschaftlicher Betrieb ausgeschlossen war (Heymann 1995, 361). Nachdem im August 1989 schwere Schäden im Getriebe auftreten, wird die Esbjerg-Maschine 1990 außer Betrieb genommen (Kamp 2002, 141), bevor man sie im 2001 sprengt (Oelker et al. 2005, 367).

Einen ersten Kommerzialisierungsversuch auf Basis des Nibe-Konzepts wagte das Energieministerium 1984 in Kooperation mit Elkraft, neben Elsam dem anderen großen Energieversorger Dänemarks. Elkraft bestellte beim Staatsunternehmen DWT ${ }^{35}$ fünf Prototypen einer auf $750 \mathrm{~kW}$ vergrößerten Version von Nibe B, die Windane 40. Die Gesamtkosten in Höhe von 50 Mio. DKK wurden von Elkraft, der dänischen Regierung und der EU getragen (Kamp 2002, 139f.). Im Januar 1987 gingen die Windane 40 auf der Insel Masnedoe in Betrieb. Aufgrund einer vergleichsweise leichten, zu wenig widerstandsfähigen Bauweise kam es wiederholt zu Betriebsausfällen und die maximale Leistung musste daher im Jahr 1990 auf 450kW reduziert werden (Heymann 1995, 360f.). Weitere Exemplare der Windane 40 wurden nicht produziert. 1989 ist DWT von Vestas übernommen (www.windsofchange.dk, Abruf vom 3.9.2007) worden, wo zu damaliger Zeit niemand an der Entwicklung von Großwindanlagen interessiert war.

Teststation für Kleinwindanlagen in Risoe

Der übrige Teil der in Phase 2 des Programms zur Verfügung stehenden Mittel wurde für den Bau und Betrieb einer Teststation für Kleinwindanlagen genutzt. Die notwendige Erweiterung des Etats um 5 Mio. DKK musste gegen den Willen des Handelsministeriums durchgesetzt werden (Heymann 1995, 357). ${ }^{36}$ Ein Sprecher des Ministeriums bewertete die Förderung von

\footnotetext{
${ }^{32}$ Wesentlicher Unterschied der Prototypen besteht im aerodynamischen Bremssystem. Wie auch die GedserMühle ist Nibe A mit einer Stall-Regulation, Nibe B dagegen mit dem neueren Pitch-Konzept ausgestattet worden (Heymann 1995, 358-359).

${ }^{33}$ F.L. Smith (Kopenhagen) lieferte das Getriebe der Nibe B; Thrige Titan (Odense) baute den Generator und das elektrische Kontrollsystem; Frichs (Arhus) lieferte die meisten Maschinenteile (van Est 1999, 239).

${ }^{34}$ Bis zum 1.April 1988 hatte Nibe A eine Laufzeit 6146 und Nibe B 18175 Stunden. Der Energieoutput von Nibe A beträgt bis zu diesem Zeitpunkt 1313MWh, der von Nibe B 4825MWh (National Energy Administration (Hrsg.): IEA Large-Scale Wind Energy - Annual Report 1988. Statens Energiverk, Schweden 1989). Weiteres zu den Mängeln der Nibe-Zwillinge, vg. Heymann 1995, 360-361.

${ }^{35} \mathrm{Da}$ im privaten Sektor kein Interesse an der Fertigung von Großwindanlagen vorhanden war, gründete der Staat das Unternehmen Danish Wind Technology (DWT) im Jahr 1983 (van Est 1999, 239).

${ }^{36}$ In diesem Zusammenhang spielt der Ingenieur und erste Leiter der Teststation, Helge Petersen, eine wichtige Rolle (vg. Heymann 1995, 357 FN 43). Seit dem Beschluss der Regierung vom August 1976, als die Einführung der Atomenergie verschoben wurde, waren in der Forschungsanlage in Risoe Kapazitäten zur Förderung erneuerbarer Energien frei geworden (Jensen et al. 1998, 390).
} 
Kleinanlagen als Fehler: ,Selbst wenn ein Teil der Energieproduktion mit kleinen Windkraftanlagen direkt an angeschlossenen Gebäude geliefert werden kann, würde ein größerer Ausbau mit kleinen Anlagen doch in wesentlichem Ausmaß den potenziellen Markt für größere Anlagen beeinflussen.' (zitiert nach: Heymann 1995, 412)

1978 entstand die Teststation auf dem Gelände des Forschungszentrums für Nukleartechnologie in der Nähe von Risoe. Dort erhielten die Anlagenbauer Unterstützung von Ingenieuren, die bei der Optimierung der Konzepte halfen. Seit 1979 mussten kommerzielle Anbieter ihre Produkte in Risoe zertifizieren lassen. Denn ein Markteinführungsprogramm förderte ausschließlich den Kauf geprüfter Windturbinen (vg. Kap. 2).

Die angestrebte Kommerzialisierung von Großwindanlagen ist während der Pionierphase nicht gelungen. Eine erfolgreiche dänische Windturbinenindustrie entstand vollkommen unabhängig vom Forschungsprogramm (vg. Kap. 2). Keines der drei Großprojekte, Nibe, Esbjerg und Masnedoe ist erfolgreich. Bereits Anfang der 80er Jahre, als die technischen Schwächen der Nibe-Zwillinge offenkundig geworden sind und sich parallel erste kommerzielle Erfolge im Kleinwindsektor einstellten, gab man die Arbeit an Großwindanlagen weitgehend auf. Ende des Jahrzehnts waren sich dänische Fachleute darüber einig, dass die wirtschaftlichste Anlagengröße zwischen 300 und $700 \mathrm{~kW}$ gelegen hätte (Heymann 1995, 361). ${ }^{37}$

Einzig die Teststation für kleine Windturbinen hatte über die Pionierphase hinaus Bestand und leistete wichtige Beiträge zur Industrieförderung. Sie war insofern eine Kuriosität des Programms, als Finanzierung und Aufbau der Teststation ohne die aktive Einflussnahme zivilgesellschaftlicher Akteure nicht denkbar gewesen wäre (vg. Kap. 2.2).

Ansonsten waren ausschließlich Großakteure an dem Programm des Energieministeriums beteiligt: Elsam, Elkraft, EVU-Organisation DEF, große Zulieferer und Staatsunternehmen DWT.

\section{Niederlande}

Neben den USA waren die Niederlande vom Ölboykott der arabischen Staaten aufgrund ihrer Israel-freundlichen Politik am stärksten betroffen. Darüber hinaus nahm die Veröffentlichung der Studie des Club of Rome, ,Die Grenzen des Wachstums' (1972), die Kritik am Wachstumsparadigma der Industriegesellschaften geübt hat, beachtlichen Einfluss auf die Entstehung aktiver Energiepolitik. Eine entsprechende Neuorientierung kündigte das Wirtschaftsministerium im September 1974 an (Energienota). Energiesparen, Verbesserung der Energieeffizienz, Verringerung der Importabhängigkeit und Diversifizierung der Energiequellen sind wesentliche Ziele (Verbong 1999, 141). Für die Zeit bis 1990 bewertete man die Atomenergie als einzige realistische Alternative zu fossilen Energieträgern (Reiche 2002a, 36). ${ }^{38}$ Andererseits waren Forschungsprogramme für Wind- und Solarenergie geplant, weil man davon ausging, dass sie für den zukünftigen Weltenergiebedarf eine wichtige Rolle spielen würden (ebd.). Das 1957 ausgegebene Ziel des Atomprogramms, dass von 1957 an alle neuen Kraftwerke Atomreaktoren sein sollten, wurde damit relativiert. Tatsächlich sind bis 1973 nur zwei AKWs installiert worden (Lagaaij/ Verbong 1999, 39). Die Umsetzung der Atomstrategie scheiterte zum einen daran, dass der Aufbau einer nationalen Nuklearindustrie misslungen war (ebd., 38f.). Der schwerwiegendere Grund besteht jedoch in der mangelnden Konsensfähigkeit dieser Technologie.

Traditionell hat die Umweltpolitik in der niederländischen Öffentlichkeit einen sehr hohen Stellenwert. Dieses äußert sich bspw. in den hohen Mitgliederzahlen der Umwelt- und

\footnotetext{
${ }^{37}$ Diese Größe lag nur geringfügig oberhalb des zu dieser Zeit marktgängigen Standards.

${ }^{38}$ Von 1955-71 werden 1,3 Mrd. Gulden (etwa zehn Prozent des niederländischen Forschungsetats) für Nuklearforschungen ausgegeben (Reiche 2002a, 37).
} 
Naturschutzverbände. ${ }^{39}$ Öffentliche Proteste von Atomkraftgegnern schürten unter den Parteien starke Polarisierungen. Während unterschiedliche Regierungen aus Christdemokraten, Sozialdemokraten und wirtschaftsliberalen Parteien die Atomkraft als einzige Alternative $\mathrm{zu}$ konventionellen Energien ansahen, forderten Linksparteien, Antiatombewegung und Kirchenkreise eine nationale Debatte über die Energiepolitik (Verbong 1999, 147). Zu einer solchen Debatte kam es zwischen 1981 und 1984. Sie brachte das Ergebnis, dass die Mehrheit der Niederländer den Bau neuer AKW ablehnte. ${ }^{40}$ Als Mitte der 70er Jahre die Strompreise gestiegen waren, weil sich die Regierung am kostspieligen Bau des schnellen Brüters in Kalkar beteiligte und von den Bürgern eine Sondersteuer forderte (Kalkar Heffing), kam es zu einer erneuten Protestwelle. Daraufhin schaffte die Regierung die Option, die Steuer in einen Fonds für regenerative Energien einzuzahlen (Reiche 2002a, 37). Der Windkraft galt das Hauptinteresse unter den alternativen Energien (Verbong 1999, 148).

\section{Repräsentative Projekte, Ergebnisse und Bewertung}

Neben der Ölkrise sind Probleme bei der Etablierung der Atomtechnik eine wichtige Triebfeder zur Erforschung erneuerbarer Energien. Mit LSEO und NEOM schaffte die Regierung zwei Institutionen zur Leitung der Forschungen im Energiesektor. Der 1974 gegründete LSEO (Landelijke Stuurgroep Energie Onderzoek) war ein Zusammenschluss diverser Forschungsinstitutionen, Energieunternehmen und (technischer) Universitäten. Auch die Antiatombewegung war repräsentiert. Die LSEO entschied darüber, welche Projekte gefördert werden sollten. ${ }^{41}$ Im Januar 1975 kommt ein Zwischenbericht des LSEO zum Ergebnis, dass neben Geothermie und Solarenergie, insbesondere auch die Windkraft zu den vielversprechendsten Optionen zu zählen sei. ${ }^{42}$

Auf Initiative des LSEO wird 1976 das erste ,National Research Program on Wind Energy' (NOW) gestartet. Das NOW sollte Aufschlüsse darüber bieten, in welchem Umfang die Windkraft zur Energieversorgung beitragen könne. ${ }^{43}$ Die erste Phase des NOW, NOW1, war auf fünf Jahre (1976-1980) angelegt. Für diesen Zeitraum stellte das Wirtschaftsministerium 20 Mio. Gulden zur Verfügung (Kamp 2002, 44ff.). Wesentliches Ziel war die Entwicklung einer Großwindanlage. Dem LSEO zufolge sollten die Windpotenziale, aufgrund der hohen Besiedelungsdichte, durch zentrale Anwendungen bestmöglich ausgeschöpft werden

\footnotetext{
${ }^{39}$ In den Niederlanden gibt es drei große Natur- und Umweltschutzverbände: Natuurmonumenten $(850.000$ Mitglieder), Wereld Natuur Fonds ( 700.000) und Greenpeace Niederlande (610.000), wobei die Mitgliederzahlen erst seit 1980 deutlich zunahmen (Reiche 2002a, 70-71)

${ }^{40}$ Die Regierung hielt dennoch an ihrer Atomstrategie fest, bis alle Pläne durch die Katastrophe von Tschernobyl im Jahr 1987 blockiert wurden (Verbong 1999, 148).

${ }^{41}$ Eine weitere Komponente im forschungspolitischen Gefüge ist BEOP (Bureau Energie Onderzoeks Projecten). Im BEOP waren mit RCN (Reactor Centre of the Netherlands) und TNO (Netherlands Organisation for Applied Scientific Research) zwei der wichtigsten Forschungsinstitute der Landes organisiert. Das BEOP koordinierte die niederländische Wind- und Solarforschung. Zuständig für die Kommerzialisierung der Forschungsergebnisse war NEOM (Nederlandse Energie Ontwikkelings Maatschappij), deren erstes Ziel darin bestand, das Interesse von Unternehmen zu wecken (Kamp 2002, 42f.).

${ }^{42}$ Verbong $(1999,139 f$.) führt das besondere Interesse an der Windenergie auch auf kulturhistorische Gründe zurück. Über Jahrhunderte ist Windkraft die Hauptenergiequelle des Landes. Insbesondere seitdem die Windmühlen im 20. Jahrhundert zunehmend durch Dampfmaschinen verdrängt wurden, gilt sie vielen als integraler Bestandteil der Landschaft. 1923 wurde die Gesellschaft zum Erhalt der Windmühlen, ,The Dutch Wind Mill' gegründet. In den 50er Jahren gab die Organisation Impulse zur Erzeugung von Strom aus Windenergie. Sogenannte, Windmotoren' wurden zwar vereinzelt betrieben, hatten jedoch aufgrund der in den 60er Jahren gesunkenen Energiepreise keine Diffusionschancen.

${ }^{43}$ Bzgl. dieser Frage gingen die Meinungen weit auseinander. Erwartungsgemäß gelangte KEMA, Forschungsinstitut der EVU, zu einer sehr pessimistischen Einschätzung. KEMA zufolge wären nur 650MW Windkraftleistung problemlos integrierbar. Auch der LSEO ging von geringen nutzbaren Potenzialen der Windenergie aus. Optimistischere Schätzungen prognostizierten 2500-5000MW (Kamp 2002, 47ff.).
} 
(Verbong 1999, 141). ${ }^{44}$ Im Dezember 1981 startet das Nachfolgeprogramm NOW2 (19811990). Unter den NOW-Akteuren bestand Einigkeit darüber, dass die Windkraft auch ohne anspruchsvolle Speichertechnologien, etwa zehn Prozent des Strombedarfs liefern könne. Dazu hielt man allerdings weitere Forschungen für unerlässlich (Verbong 1999, 146f.). Für die erste NOW-2-Phase (1981-85) wurden 37 Millionen Gulden bewilligt (ebd., 149-150). Wichtige Schwerpunkte waren der Bau einer Großwindanlage und eines 10MW-Windparks, der von EVU-Verband SEP betrieben werden sollte (ebd., 150).

Eine erste kleine Windanlage (5m-Rotordurchmesser, vertikale Achse) ist von Flugzeugbauer Fokker Aircraft entworfen und hergestellt worden. Das Design war als Vorlage für eine anschließend herzustellende Großwindanlage konzipiert. Das RCN/ECN nahm Messungen an der kleinen Anlage vor. Die an ihn gestellten Erwartungen vermochte der 1976 in Betrieb genommene Prototyp nicht zu erfüllen (vg. Kamp 2002, 50). ${ }^{45}$ Noch während Fokker und Rijn-Schelde-Verome an Planungen für größere Versionen des Konzeptes arbeiteten, erlitt der kleine Prototyp einen Totalschaden, nachdem er ein halbes Jahr auf dem Gelände des ECN getestet wurde (Kamp 2002, 51). Aufgrund mangelnder Erfolge mit der 5m-VAT verzichtete Fokker auf die Realisierung des bereits erstellten Konzepts für eine größere 15m-VAT. 1985 brach der Flugzeughersteller die Aktivitäten im Windkraftsektor ab (Kamp 2002, 62). Die Herstellung des 15m-VAT übernahm stattdessen Polymarin. Danach wurden VAT-Turbinen im Rahmen des NOW aus Kostengründen nicht weiter gefördert (Verbong 1999, 150). Maschinenbauunternehmen Stork entwickelte in Kooperation mit dem ECN den 25m-HAT, eine größere Prototyp-Windturbine mit horizontaler Achse (300kW Generator, 25m-Rotordurchmesser). Die unterschiedlichen Hauptkomponenten des Stork/ECN-Projektes wurden von Fokker (Rotoren), Holec (elektrische Kontrolle) und Rademakers (Getriebe) fabriziert. Später sollte aus dem 25m-HAT ein ,80m-HAT' (drei Megawatt Generator) entwickelt werden, was nicht geschehen ist (Kamp 2002, 51). Im Juni $1981 \mathrm{nahm}$ der 25m-HAT auf dem Gelände des ECN in Petten - wie zuvor der 5m-VAT - seinen Betrieb auf. Der 25m-HAT, vollständig aus NOW-Mitteln finanziert, kostete insgesamt 8,6 Mio. Gulden (ebd., 54). Nach der Testphase bemühte sich Stork um die Kommerzialisierung des Prototyps. Doch die Erfolge des Newecs-25 hielten sich in Grenzen. ${ }^{46}$

An die Erfahrungen mit dem 25m-HAT anschließend, arbeitete Stork seit 1983 an einem größeren Design, der Newecs-45 (45m-Rotordurchmeser, 1MW-Generator). Die Herstellung der Rotoren übernahm Polymarin. Die Newecs-45 war als Zwischenschritt für eine später zu entwickelnde 3MW-Anlage konzipiert. Die Entwicklungskosten des 1985 fertiggestellten Prototyps beliefen sich auf 14 Mio. Gulden, die vom niederländischen Staat, der EU, Stork und PEN getragen wurden (ebd., 72). Im Dezember 1985 ist Newecs-45 von PEN (EVU Nord Hollands) in Betrieb genommen worden. Ökonomisch arbeitete sie nicht, denn die Stromproduktionskosten lagen mit $\$ 0,17$ etwa doppelt so hoch wie bei (damals) marktüblichen Kleinanlagen (Gipe 1995, 41). 1987 wurden erstmals Risse an den Rotorblättern festgestellt, die auf Konstruktionsfehler zurückgeführt wurden. Ein neues Rotorendesign hätte erstellt werden müssen, was aus Kostengründen nicht geschah. Newecs45 wies zahlreiche Stillstandzeiten auf, bevor sie 1995 vom Netz genommen wurde (Kamp 2002, 81f.). Wegen finanzieller Risiken entschied sich Stork im Jahr 1987, von der ursprünglichen Planung, weitere 18 Anlagen dieses Typs zu produzieren, zurückzutreten. Im selben Jahr gab das Unternehmen seine Arbeiten im Windenergiesektor auf. Daher sind drei Prototyp-Projekte Storks trotz fortgeschrittener Planungsstadien nicht mehr umgesetzt worden (ebd., 82). ${ }^{47}$

\footnotetext{
${ }^{44}$ Selbst kleine Windparks sollten aus mindestens 20-30 großen Windanlagen bestehen. Größere Windparks sollten nur auf dem Meer errichtet werden (Verbong 1999, 141f.).

${ }^{45}$ Den Konstrukteuren war es trotz der geringen Rotorlänge nicht gelungen, einen vibrationsfreien Lauf zu erreichen. Daher kam es zu massiven Schallemissionen.

${ }^{46}$ Stork hatte eine Dreierserie des Newecs-25 produziert. Aufgrund deutlicher Abweichungen vom 25m-HATDesign handelte es sich auch hier faktisch um Prototypen. Gekauft und betrieben wurden die Newecs-25 von drei EVU (PZEM, Schiedam und Kodela). Nach einigen Betriebsjahren mussten zwei der Anlagen vom Netz genommen werden. Stork verzichtete daraufhin auf die Herstellung weiterer Newecs-25 (Kamp 2002, 80f.).

${ }^{47}$ Dabei handelt es sich um GROHAT (3MW). Die Großwindanlage war bereits seit 1983 geplant. Neue Hersteller fanden sich nicht. Für zwei weitere Projekte lagen bereits Machbarkeitsstudien vor: Newecs-40
} 
Im Jahr 1982 beauftragte das Wirtschaftsministerium EVU-Organisation SEP mit der Realisierung des ersten niederländischen Windparks (18 WEA á 300kW). ${ }^{48}$ Die Kosten von etwa 50 Mio. Gulden wurden je zur Hälfte vom Ministerium und SEP getragen. Hersteller war der Elektronikkonzern Holec, der im Windanlagenbau nur über geringe Erfahrung verfügte (ebd., 68ff.). 1987 wurde der Windpark, bestehend aus 18 300kW-Prototypen in Sexbierum aufgebaut und von PEB (EVU von Friesland) in Betrieb genommen. Wegen technischer Mängel (vg. Kamp 2002, 85) musste der Windpark bereits Anfang der 90er Jahre vom Netz genommen werden. Teilweise verkaufte man die Windanlagen nach Indien und ersetzte sie durch neuere Produkte des dänischen Herstellers Nordtank. Daraufhin gaben sowohl SEP, als auch Holec ihr Windkraft-Engagement auf (Verbong 1999, 154; Kamp 2002, 87).

Sämtliche NOW-Prototypen mussten aufgrund von Fehlkonstruktion zumeist nach wenigen Jahren außer Betrieb genommen werden. Nur in einem Fall ist ein Prototyp (Holec-300kW) in größerer Stückzahl hergestellt worden. Impulse zur Kommerzialisierung gingen vom NOW nicht aus. Vielmehr zogen sich die wichtigsten beteiligten Firmen wegen ausbleibender Erfolge aus dem Sektor zurück: Fokker Aircraft bereits im Jahr 1985, Stork und Holec 1987. Bei den Herstellern handelte es sich ausschließlich um Großunternehmen aus der Flugzeugund Technologiebranche. Staatliche Institute wie ECN, TNO und die technische Universität Eindhoven leisteten die Forschungsarbeiten im Rahmen des NOW. Betrieben wurden die Forschungswindanlagen zumeist von den regionalen EVU.

Ausschließlich im LSEO, wo über Projektvorschläge entschieden wurde, waren u.a. kleinere Akteure wie die Anti-AKW-Bewegung repräsentiert. Nennenswerten Einfluss hatten Fürsprecher dezentraler Nutzung der Windkraft offenbar nicht. Bei den wesentlichen Projekten handelte es sich um Großanlagen, welche am ehesten mit dem zentralisierten Stromsystem vereinbar schienen. Nur ein geringer Teil der Mittel wurde für dezentrale Projekte aufgewendet. ${ }^{49}$ Die Errichtung des Sexbierum-Windparks, ein wichtiges Projekt des NOW-2, bedeutete eine Kurskorrektur gegenüber einer zuvor ausschließlich auf Großwindanlagen zielenden Forschungspolitik.

Erst das im Jahr 1986 startende IPW (Integraal Windprogramma Windenergie) kam einem grundlegenden Wandel der Windenergiepolitik gleich. Von nun stand die Förderung kleiner und mittlerer Windanlagen kommerzieller Hersteller im Zentrum (vg. Kapitel 2).

\section{Bundesrepublik Deutschland}

Die Ölkrise hat die Bundesrepublik zu einem Zeitpunkt wachsender Importabhängigkeit des Energiekonsums getroffen. Der Anteil der Einfuhren am Gesamtverbrauch war zwischen 1962 und 1972 von 31,0\% auf 60,6\% gestiegen. Ursachen waren der zunehmende Energieverbrauch und die wachsende Nachfrage nach Öl und Gas (vg. Jägeler 1975, 80f.). ${ }^{50}$ Der Ölverbrauch war 1972 zu 87,7\% von Importen aus den OPEC-, bzw. zu 65,1\% aus den OAPEC-Staaten abhängig (Jägeler 1975, 88 Tab.35). Diese Zahlen verdeutlichen die Verwundbarkeit der deutschen Wirtschaft durch den Ölboykott. Steigende Benzinpreise und der Ausruf autofreier Sonntage führten die Energieproblematik auch der Gesamtbevölkerung

(1MW-Generator) für küstennahe Standorte und Newecs-55 (Kamp 2002, 82).

${ }^{48}$ Verbong $(1999,154)$ kritisiert die Entscheidung für SEP als Projektleiter. SEP war der größte Fürsprecher der Atomkraft und bewertete die Windkraft zudem negativ. Auch wird SEP ein mangelhafter Erfahrungsfundus bzgl. der Windenergie attestiert.

${ }^{49}$ Während P. Sens, Leiter des NOW behauptete, 15\% der Mittel für NOW 1 seien in dezentrale Projekte geflossen, gingen Kritiker dagegen von maximal drei Prozent aus (Verbong 1999, 147).

${ }^{50}$,Bei Zunahme des gesamten Verbrauchs um durchschnittlich 4,8\% im Jahr stieg der Anteil des Erdöls von 21,0\% im Jahre 1960 auf 55,4\% im Jahre 1972 an.' (Jägeler 1975, 80); Näheres zur allmählich sinkenden Kohleförderung (ebd., 82-87). 
vor Augen. Die Ölkrise war der Ausgangspunkt aktiver Energiepolitik. Seit 1956 bezogen sich Energieforschungen ausschließlich auf die kommerzielle Nutzung der Atomkraft. 1973 kündigte die Bundesregierung an, neben der Kernenergie künftig auch die Nutzung erneuerbarer Energien zu untersuchen (Pulczynski 1991, 36) ${ }^{51}$ Im Juli 1974 erklärte das Forschungsministerium, dass Windenergie in der Forschung nur geringe Priorität habe, da man von einer ausschließlich ,lokalen Bedeutung ${ }^{152}$ der Windenergie ausging. An dieser Sichtweise änderte sich auch zwei Jahre später nichts, nachdem eine vom Ministerium in Auftrag gegebene Studie zu dem Ergebnis kam, dass der Energieträger theoretisch $75 \%$ zur Stromversorgung Deutschlands beitragen könnte (Heymann 1995, 363). Nichtsdestotrotz sollten die Möglichkeiten der Windkraft erforscht werden. Im Sommer 1977 gab Regierungsdirektor Alois Ziegler auf der Tagung, Energie vom Wind' bekannt, dass bis 1980 ca. fünf Mio. DM pro Jahr für die Windenergieforschung bereitgestellt werden sollten (Heymann 1995, 363). ${ }^{53}$

Neben der Ölkrise sind Proteste der Umwelt- und Antiatombewegungen die zweite Rahmenbedingung dieser - wenngleich minimalen - energiepolitischen Neuausrichtung. Durch den ,Druck, von unten', der sich in den großen Anti-AKW-Demonstrationen am deutlichsten artikulierte, aber auch in mannigfaltigen Protesten gegen industriebedingte Umweltverschmutzungen oder in den zahlreichen Bürgerinitiativen zum Ausdruck kam', wurde der Umweltschutz zum politischen Topthema (Byzio et al. 2002, 15). Müller-Brandeck spricht in diesem Zusammenhang von einer technologiepolitischen Legitimationskrise:

,Drohende bzw. faktische Akzeptanzverweigerung in breiten Bevölkerungskreisen wirkte in der Bundesrepublik Deutschland als auslösendes Moment für einen langwierigen, im Ergebnis beachtlichen Umdenkprozess auf Seiten der atompolitischen Handlungsträger; denn angesichts unzähliger Einsprüche bei Verwaltungsgerichten, massenhafter Demonstrationen, Bauplatzbesetzungen, ja gar gewalttätiger Aktionen engagierter Kernenergiegegner, konnte die Bundesregierung etwa ab 1974/75 ihren atompolitischen Kurs nicht mehr allein mit massivem Polizeieinsatz, durchdrücken', sondern musste ihn auch argumentativ rechtfertigen' (Müller-Brandeck 1986, 166).

Über das reine Forschungsinteresse hinaus, ging es der Bundesregierung mit ihren Aufwendungen für erneuerbare Energien auch darum, das Vertrauen der Bürger zurückzugewinnen. Dieses Unterfangen war jedoch von vorn herein mit schweren Hypotheken belastet. Denn das BMFT hatte ausgerechnet die Energiewirtschaft zum Hauptakteur der Forschungen berufen, obgleich deren Anti-Windkraft-Position hinlänglich bekannt gewesen ist. ${ }^{54}$ Die öffentliche Kontroverse zur Atomkraft nötigte die EVU jedoch zur Vorsicht. Um offene Konflikte zu vermeiden, stimmten sie ihr Auftreten untereinander ab und stellten Argumente wie den Landschaftsschutz in den Vordergrund, um ihre Ablehnung zu begründen (Heymann 1995, 364). ${ }^{55}$ Die Antiatom- und Umweltbewegung, der es um Mitte

\footnotetext{
${ }^{51}$ Von den 6,532 Mrd. DM des Budgets für Energieforschungen (1977-1980) wurden 4,532 Mrd. DM, d.h. 69,4\% für Kernenergie aufgewendet. 540 Mio. DM, also 8,3\% waren es für erneuerbare Energien (vg. Keiser 1979, 80 Tabelle 11c).

${ }^{52}$ Antwort des Forschungsministeriums auf eine kleine Anfrage; vg. Heymann 1995, 362

${ }^{53}$ An derselben Stelle kommentierte Ziegler die Geringfügigkeit der Aufwendungen: ,Zeitrahmen und Mitteleinsatz machen deutlich, dass die Bundesregierung kurzfristig keine größeren Beiträge der Windenergie zur Deckung des Energiebedarfs erwartet.' Zitiert nach: Heymann 1995, 363.

${ }^{54}$ Die EVU stellten die Netzintegration von Strom aus Windenergie grundsätzlich in Frage. Die Unstetigkeit des Windes führe zu Destabilisierungen des Netzes. Energie aus Wind bedeute aufgrund der zur Einspeisung ,notwendigen Spannungstransformation' einen reinen Zusatzaufwand (Pulczynski 1991, 43 FN 1) .

${ }^{55}$,Die Haltung der Elektrizitätswirtschaft in der Öffentlichkeit blieb aber verkrampft, da sie eine umfassende und offene Auseinandersetzung scheute und alles zu vermeiden versuchte, was zu größeren Diskussionen und Erwartungen in einer, emotionalisierten' Öffentlichkeit beitragen könnte.' (Heymann 1995, 364). VDEWExperte Mackenthun hatte 1975 vorgeschlagen, den Schutz der Nordseeküste als Argument gegen den Aufbau von WEA ins Feld zu führen (ebd., 121). 1975 hatte die Nordwestdeutsche Kraftwerke AG die Beteiligung an einem privaten Windforschungsprojekt mit Verweis auf negative Forschungsergebnisse der Studiengesellschaft Windkraft aus den 50er und 60er Jahren abgelehnt. Aufgrund der geringen Energiedichte des Windes, dem damit
} 
der 70er Jahre gelungen war, weite Teile der Öffentlichkeit für umweltpolitische Themen zu sensibilisieren, hat indirekten Einfluss auf die Durchführung von Programmen zur Förderung erneuerbarer Energien - sowie die Beteiligung der Energiewirtschaft an diesen - genommen. ${ }^{56}$

\section{Repräsentative Projekte, Ergebnisse und Bewertung}

Für die Jahre 1974-1977 hatte die Bundesregierung ein ,Rahmenprogramm Energieforschung' verabschiedet. Neben anderen Zielen wie der Kohlevergasung und -Verflüssigung, Energieumwandlung, -transport und -speicherung war auch die ,Erschließung neuer Energiequellen für den großtechnischen Einsatz' im Programm verankert. Signifikante Schritte zur Erforschung der Windkraft wurden erst im Nachfolgeprogramm, ,Energieforschung und Energietechnologien 1977-1980' beschossen (Pulczynski 1991, 37). Im Zentrum stand der Aufbau von Multimegawattanlagen wie Growian (s.u.). Forschungen an Kleinwindanlagen waren zweitrangig. An dieser Schwerpunktsetzung orientierte sich die Windenergiepolitik bis 1986, als die Forschungsmittel stark reduziert wurden. Technisch waren die Versuchswindanlagen an der ,W34' orientiert, die in den 50er Jahren nach dem Konzept des deutschen Ingenieurs Ulrich Hütter konstruiert worden war. ${ }^{57}$

Seit 1975 arbeitete die Firma Voith Getriebe GmbH an der Realisierung eines technisch anspruchsvollen, am Design der W34 orientierten Konzeptes (Oelker 2005 et al., 25; Rotorendurchmesser 52m, 316kW Generatorenleistung, zwei Rotorblätter, horizontale Achse, hohe Schnellläufigkeit). Für die Herstellung dieser WEC 520 erhielt Voith 1976 insgesamt 8,3 Mio. DM vom BMFT. 1981 nahm die Versuchsanlage ihren Betrieb auf dem Testfeld des Deutschen Zentrum für Luft- und Raumfahrt in Schnittlingen auf. Durch ständige Reparaturarbeiten sind Voith Kosten von 4,3 Mio. DM entstanden (34\% der Gesamtkosten). Nach Abschluss des Projekts brach das Unternehmen sämtliche Entwicklungsarbeiten im Windsektor ab (vg. Heymann 1995, 383ff.). ${ }^{58}$

Das wichtigste und teuerste Projekt ist Großwindanlage Growian (3MW-Generator, 100mRotordurchmesser). Mit den Gesamtkosten von 90Mio. DM (BMFT-Anteil: 95\%) wurden von den insgesamt für die Windenergieforschung bis 1988 zur Verfügung gestellten Mitteln (218 Mio. DM), 40\% für das Growian-Projekt aufgewendet (ebd., 382). Ebenso wie WEC 520 ist auch das Growian-Design an der Leichtbauweise von Hütters W34 orientiert. Auch Hütter selbst war an den Forschungsarbeiten beteiligt. ${ }^{59}$ Er äußerte sich optimistisch über die aktuellen Möglichkeiten großtechnischer Nutzung der Windenergie und war der Meinung, dass eine 3MW-Anlage sofort gebaut werden konnte: ,Die Technologie ist sehr weit entwickelt, und in Zukunft ist kaum mit epochemachenden neuen Prinzipien zu rechnen.' (zitiert nach: Heymann $(1995,367)$ ).

Auf einem Expertentreffen am 11. Juni 1976 in Jülich haben sich Vertreter aus Forschung und Energiewirtschaft im Konsens mit dem BMFT für die Entwicklung einer großen WEA der Rotorlänge von 113-120m ausgesprochen (vg. Pulczynski 1991, 49). ${ }^{60}$ Nicht durchsetzen konnten sich potenzielle Hersteller, die für eine schrittweise Vergrößerung plädierten

\footnotetext{
verbundenen Raumbedarf und hohen Investitionskosten, sei Windkraft für den ,großtechnischen Einsatz völlig ungeeignet' (ebd., 363f.).

${ }^{56}$ Verstärkt wurde der Einfluss durch die Gründung der Partei Die Grünen, die aus den Protesten

hervorgegangen war. Als Oppositionskraft gelang es ihr, parlamentarische Debatten aktiv und im Sinne der Atomkraftgegner mitzugestalten.

${ }^{57}$ Gefertigt wurde die ,W34' durch Segelflugzeugbauer Allgaier im Jahr 1958. Aufgrund niedriger Ölpreise zog sich Allgaier kurze Zeit später aus dem Windenergiesektor zurück (Oelker et al. 2005, 23).

${ }_{58}$ Besonders am Rotor, der sich durch extreme Leichtbauweise (Schlankheit, Material aus einem GlasfaserKohlenfaser-Verbundstoff) auszeichnet, traten schon bald schwerwiegende Probleme auf (bspw. Flatter- und Knickbewegungen der Flügel). Daraufhin wurden beide Flügel kurzerhand um je 5,5m gekürzt. Aufgrund weiterer Mängel (vg. Heymann 1995, 386) musste der Betrieb eingestellt werden.

${ }^{59}$ Hütter ist Mitautor der 1976 vom BMFT veröffentlichten Studie ,Energiequellen für morgen? Nichtfossile Nichtnukleare Primärenergietechnologien', welche die Grundlage des Forschungsprogramms für 1977-1980 bildete; vg. Pulczynski 1991, 37.
} 
(Pulczynski 1991, 51). 1978 hatte das BMFT den Bau Growians endgültig beschlossen. Den Bauauftrag erhielt der Maschinenbaukonzern MAN. Wegen ihrer Erfahrungen beim Kraftwerksbau und -betrieb sollte das Projekt von Energieunternehmen geleitet werden. Von dieser Seite zeigt sich zunächst keinerlei Interesse. Erst nach zähen Verhandlungen fanden sich die Hamburger Elektrizitätswerke AG (HEW), Schleswag und die RheinischWestfälischen Elektrizitätswerke AG (RWE) zur Teilnahme an dem Projekt bereit. ${ }^{61}$ Die ,Große Windenergieanlage Bau- und Betriebsgesellschaft mbH' wird schließlich am 8. Januar 1980 gegründet. Der Vorstand der GmbH bestand aus je einem Vertreter der HEW, Schleswag und RWE. Seitens der EVU wurde nur ein geringer Anteil der kalkulierten Projektkosten in Höhe von 4,7\% (2,07 Mio. DM) beigesteuert (Heymann 1995, 370f.). Nach andauernden Diskussionen um die Bauweise und Schwierigkeiten beim Aufbau, nahm Growian am 5. Juli 1983 den Betrieb auf. ${ }^{62}$ Aufgrund permanenter Störungen der Versuchsanlage, vermochte Growian, bis zur Stilllegung im Sommer 1987, letztendlich nicht mehr als 420 Betriebsstunden zu absolvieren. Das entspricht 99\% Stillstandszeiten. ${ }^{63} \mathrm{Im}$ Sommer 1997 erfolgte der Abriss Growians (ebd., 377ff.). Die Growian-GmbH beurteilt die Ergebnisse dennoch als Erfolg. Projektleiter Witt zufolge wurden 90\% der Forschungsziele erreicht. ${ }^{64} \mathrm{Im}$ Abschlussbericht heißt es unter der Rubrik ,Problemfälle': ,Während der Erprobungs- und Betriebsphase der Windenergieanlage sind nur wenige nennenswerte Probleme aufgetreten. Die beim Bau von Prototypanlagen dieser Größenordnung unvermeidbaren Schwachstellen an Komponenten und Subsystemen sind schon im Laufe der Inbetriebnahme erkannt und beseitigt worden. ${ }^{165}$

Vor dem Hintergrund kompromittierender Äußerungen aus dem BMFT ${ }^{66}$ und der GrowianGmbH über den eigentlichen Zweck des Projekts erscheint die Darstellung Witts als ein recht unbeholfener Versuch, das Engagement der EVU ins rechte Licht zu rücken. Glaubhaft war die Growian-GmbH zu diesem Zeitpunkt nicht mehr. Bereits 1981 stellte Günther Klätte, Vorstandsmitglied der RWE, auf einer Hauptversammlung klar: ,Wir brauchen Growian (...), um zu beweisen, dass es nicht geht.' Seiner Meinung nach war ,Growian so etwas wie ein pädagogisches Modell..., um Kernkraftgegner zum wahren Glauben zu bekehren. ${ }^{67}$ Oelker et al. $(2005,60)$ verweisen auf einen längerfristigen Erfolg des Growian-Projektes: Ein Großteil der etwa 200 beteiligten Ingenieure, die sich spezifisches Know-how angeeignet hatten, arbeitete später in der Windanlagenindustrie und leistete der neuen Branche dadurch wichtige Starthilfe.

1978 erhielt Messerschmidt-Bölkow-Blohm (MBB) vom BMFT den Auftrag zur Herstellung einer einflügeligen Großwindanlage (mit 5MW-Generator), Growian II. Zusätzlich zu den 40,6 Mio. DM (Heymann 1995, 383) des BMFT wurde das Projekt durch Mittel vom Land Niedersachsen und der EU gefördert. Aufgrund der schwer $\mathrm{zu}$ beherrschenden Einflügeltechnik hat MBB jedoch bald vom Growian-II-Projekt Abstand genommen. Stattdessen entwickelte der Konzern drei kleinere Prototypen mit 1-Flügel-Rotoren: Monopetrus-15 (Rotordurchmesser 15m, 30kW-Generator), Monopetrus-30 (33m, 200kW) und Monopetrus-50 (56m, 700kW). Der erste Monopetrus-50 wird 1988 errichtet und zur Hälfte vom BMFT finanziert (8,7 Mio. DM). Drei Exemplare werden 1989 im Jadewindpark

\footnotetext{
${ }^{60}$ An derselben Stelle merkt Pulczynski an, dass die Einbindung wissenschaftlicher Kräfte davon abhängig war, ob es sich bei ihnen um, Verfechter einer extrem großen Windkraftanlage' handelte.

${ }^{61}$ Ein nicht unwesentlicher Konflikt verzögerte das Projekt. Während das BMFT forderte, dass die von ihm finanzierte Testanlage nach Projektende von den EVU übernommen wird, planten diese, nach Erschöpfung der Mittel, den Abriss Growians (Heymann 1995, 371).

${ }^{62} \mathrm{Zu}$ den Gründen der Verzögerungen beim Bau Growians vg. Heymann (1995, 374ff.)

${ }^{63}$ Näheres zu den Betriebsstörungen vg. Heymann 1995, $378 f$.

${ }^{64}$ Herbert Witt: ,Experiment gelungen' in: Energiewirtschaftliche Tagesfragen (September 1985). Zitiert nach: Heymann 1995, 381

${ }^{65}$ Reinhold et al., Betrieb der großen Windenergieanlage Growian, 29f. Zitiert nach: Heymann 1995, 381

${ }^{66}$ Bereits 1982 äußerte sich der Forschungsminister zum Growian-Projekt: ,Wir wissen, dass es uns nichts bringt. Aber wir machen es, um den Befürwortern der Windkraft zu beweisen, dass es nicht geht.' (Die Welt, 13.12. 1982), zitiert nach: Heymann 1995, 373

${ }^{67}$ Die Welt, 28.2.1981. Zitiert nach: Heymann 1995, 373
} 
bei Wilhelmshaven installiert. Hauptkostenträger waren das Land Niedersachsen $(60 \%)$ und das BMFT (30\%) (WPM 12/89, 10). Sonderlich erfolgreich war MBB mit seiner MonopetrusSerie nicht. Anstatt der erhofften Skaleneffekte, nahmen die spezifischen Kosten (DM/ kW) mit der Anlagengröße zu. ${ }^{68}$ Anfang der 90er Jahre gab MBB das Monopetrus-Design auf (Heymann 1995, 386ff.).

Weitere 15 Mio. DM und damit 100\% der Kosten, stellt das BMFT für die Realisierung einer Aufwindanlage (100kW-Generator) im spanischen Manzanares zur Verfügung (Projektstart 1979). Geplant und errichtet worden ist die Aufwindanlage vom Stuttgarter Ingenieurbüro Schlaich \& Partner. Wegen mangelnder Effizienz und entsprechend geringer Kommerzialisierungschancen wurde nicht weiter an dem Konzept gearbeitet (Heymann 1995, 389). ${ }^{69}$

Im Jahr 1984 startet MAN die Konstruktionsarbeiten für den Bau einer neuen Großwindanlage, die WKA-60 (1200kW-Generator). Beim Anlagendesign sind einige Lehren aus dem Growian-Fiasko gezogen worden (verringerte Anlagengröße, Nutzung von drei statt zwei Rotoren, robustere Bauart). Die erste WKA-60 ist 1990 auf Helgoland, eine zweite, 1992 im Windpark Westküste (Kaiser-Wilhelm-Koog) installiert worden (Heymann 1995, 426). ${ }^{70}$

Beim letzten der geförderten Großprojekte handelte es sich um eine Kooperation zwischen PreussenElektra und der schwedischen Vattenfall. Je eine zweiflügelige 3MW-Testanlage sollte in Deutschland (Aeolus II) und in Schweden (Näsudden II) installiert werden. Der Auftrag für Aeolus II wurde erneut an MBB vergeben. Ein Großteil der Kosten von insgesamt \$34 Mio. trugen die beiden Energiekonzerne selbst (Gipe 1995, 109). Je 20,5\% der Kosten steuerten das BMFT, bzw. das Land Niedersachsen bei (IEA 1988, 41). ${ }^{71} 1993$ ist die Großwindanlage in der Nähe von Wilhelmshaven in Betrieb genommen worden (Heymann 1995, 426f.). Auch hier stand eine Serienfertigung nicht zur Disposition.

Innerhalb des BMFT-Programms stellt die Einrichtung eines Testfeldes für Kleinwindanlagen (Pellworm) eine Ausnahme dar. Dort werden zwischen 1981 und 1984, unter Leitung des Forschungsinstitutes GKSS, Modelle kommerzieller Hersteller getestet, wobei sich herausstellte, dass die meisten für eine Serienfertigung nicht geeignet waren. Daraufhin ist die Testeinrichtung nach wenigen Jahren geschlossen worden (vg. Kapitel 2.4).

Das BMFT-Programm, insbesondere Growian, ist großteils als Reflex auf öffentliche Kritik und Proteste gegen Kernenergienutzung einzuordnen. Am Forschungsprogramm beteiligt waren fast ausschließlich Großakteure: Konzerne aus der Maschinen- und Flugzeugbaubranche wie MAN, MBB, Dornier und Krupp als Hersteller, sowie EVU als Projektleiter und Anlagenbetreiber.

Bis 1988 werden etwa $75 \%$ des Windkraftetats für Großtechnologie investiert (Heymann 1995, 392). Die Ergebnisse blieben insgesamt weit hinter den Erwartungen zurück. Nachdem sich das vollständige technische Versagen von Hauptprojekt Growian abzeichnete, mindert sich das Interesse des BMFT an der Windenergie. Zwischen 1981 und 1984 verringern sich die Aufwendungen des Ministeriums: 1981: 24 Mio., 1982: 23 Mio., 1983: 6,4 Mio. und 1984: 1,5 Mio. DM. In den nachfolgenden Jahren schwankte der Posten zwischen fünf und

\footnotetext{
${ }^{68}$,Nach einer Marktübersicht des Interessenverbandes Windkraft Binnenland (IWB) kosteten 1989 Monopetrus 15 etwa 80.000 DM, Monopetrus 30 etwa 650.000 DM und Monopetrus 50 etwa 6 Mio. DM ab Werk....Diese Preise (entsprachen) spezifischen Kosten von 2670, 3250 und 9375 DM/ kW, zeigen also einen inversen Skaleneffekt' (Heymann 1995, 389).

${ }^{69}$ Darüber hinaus förderte das BMFT auch WEA mit senkrechter Achse und sogenannte Windkonzentratoren. Technische und ökonomische Erfolge sind auch hier ausgeblieben. Beteiligt waren u.a. Dornier, Krupp und einige universitäre Forschungsinstitute (Heymann 1995, 390). Dornier erhält für seine Arbeiten mit DarrieusKonzepten etwa acht Mio. DM (Tacke 2004, 149).

${ }^{70}$ Im Rahmen des deutsch-spanischen Joint Ventures wird AWEC-60, die sehr hohe Ähnlichkeit mit WKA-60 aufwies, im Nordwesten Spaniens aufgestellt. Das BMFT trat als Förderer in den Hintergrund. Maßgeblich unterstützt wurden beide Projekte durch die EU (Heymann 1995, 426f.).

${ }^{71}$ Verglichen mit den vorherigen Projekten ist die BMFT-Förderquote sehr niedrig.
} 
sechs Mio. DM (ebd., 426). Die bedeutendsten Projekte lassen sich grob in zwei Generationen aufteilen. Zur ersten Generation zählen: WEC 520 (Voith), Growian (MAN), Aufwindkraftwerk (Schlaich \& Partner) und Monopetrus (MBB). Der zweiten Generation gehören WKA 60 (MAN), AWEC 60 (MAN) und Aeolus II (MBB) an. Alle Projekte der ersten Generation sind spätestens 1978 gestartet worden, diejenigen der zweiten nicht vor 1984. Der wesentliche Unterschied beider Generationen besteht in der Förderquote. Die frühen Projekte erhielten annähernd 100\%, während Aeolus II nur noch mit 20,5\% bezuschusst wurde. Unmittelbare Impulse zur Kommerzialisierung sind sowohl hier als auch dort ausgeblieben. Im Fall Growians, des teuersten Projektes, dass sich aus zugleich als die größte Fehlinvestition manifestiert hatte, offenbarte sich der tatsächliche Hintergrund des Interesses, seitens BMFT und Energiewirtschaft in einzigartiger Deutlichkeit. Beiden Akteuren ging es um Imagepflege und darum, das Versagen der Windkraft für die Legitimation der Atomkraftnutzung in Wert zu setzen. Entsprechendes Feedback gab es von Teilen der Medienlandschaft. Von der ,Zeit' sind die BMFT-Projekte 1985 als ,Windspielereien' bezeichnet worden, die ,dem Ansehen der Windenergie schwer geschadet' hätten (,Die Zeit', 14.6.1985, zititiert nach: Tacke 2004, 161).

\section{Großbritannien}

Aus drei Gründen war in Großbritannien der Ölschock von 1973 weniger gravierend ausgefallen als in einigen anderen Ländern: Erhöhung der Kohleproduktion (seit 1973), Investitionen in Nuklearforschung (seit 1956) und Erschließung eigener Ölressourcen in der Nordsee (seit 1973).

Der Kohle-Anteil am Stromverbrauch ist zwischen 1972 und 1980 von 36\% auf 79\% gewachsen. Aufgrund reichhaltiger Vorkommen stellte sich bald heraus, dass Großbritannien neben Norwegen das einzige westeuropäische Land sein würde, das nicht auf Ölimporte angewiesen war (Keiser 1979, 125). Nuklearenergie ist die dritte Säule der britischen Energiepolitik. Anders als Deutschland und Frankreich etwa, war Großbritannien nicht darauf angewiesen, zur Erhaltung der Versorgungssicherheit unmittelbar nach der Ölkrise, mit dem Bau zusätzlicher Atomkraftwerke zu beginnen. Die Nutzung eigener Kohle- und Ölvorkommen entspannte die Situation (Rothgang 1990, 36). Erst 1990 erreicht der Stromanteil an Nuklearenergie 19\% (Reiche 2002b, 242).

In den 70er und 80er Jahren lag dennoch ein wichtiger Schwerpunkt der Forschungen im Energiesektor bei der Kernkraft, während erneuerbare Energien kaum gefördert wurden Von insgesamt 500 Mio. Pfund wurden in den Haushaltsjahren 1984/85 und 1985/86 je 200 Millionen Pfund (40\%) für Nuklearforschungen aufgewendet. Der Anteil erneuerbarer Energien betrug dagegen nur 2,8\%, davon 0,96\% für Windenergie (WPM 12/85, 8).

Der staatliche Strommonopolist Central Electricity Generating Board (CEGB) hatte kein Interesse an der Windtechnologie und anderen dezentralen Energien. Im Konsens mit der Regierung hatte CEGB während der 70er/80er Jahre seinen Kraftwerkspark mit fossilnuklearen Großkraftwerken aufgerüstet (Suck 2004, 10).

Umweltproteste und Kontroversen um Atomenergienutzung waren zwar präsent, entwickelten jedoch keine Wirksamkeit wie in einigen westeuropäischen Ländern. Zur Erklärung dieser Schwäche führt Rothgang (1990) einige Gründe an. Aufgrund eigener Kohle- und Ölreserven konnte es sich die Regierung leisten, den Ausbau der Atomkraft flexibel zu gestalten. Angesichts größerer lokaler Proteste konnte auf die geplanten Standorte vergleichsweise leicht verzichtet werden (z.B. Portskewett). Diese Strategie trug dazu bei, dass Konflikte zumeist unterhalb einer bestimmten Eskalationsstufe verblieben sind. Militante Auseinandersetzungen zwischen Polizei und Demonstranten wie in Grohnde, Whyl und Brokdorf blieben aus. Stattdessen dominierte seitens der Umweltverbände die Tradition 
des ,working within the system', bspw. die Durchführung öffentlicher Umfragen (Rothgang 1990, 36). ${ }^{72}$ Das Nuklearprogramm wurde $\mathrm{zu}$ einem Zeitpunkt aufgenommen, als der Energieträger auch unter kritischen Bevölkerungsteilen eine gewisse Popularität besaß (ebd., $32) .^{73}$

\section{Repräsentative Projekte, Ergebnisse und Bewertung}

Trotz dieser schwierigen Ausgangsbedingungen für die Nutzung erneuerbarer Energien wurde bereits 1977 ein erstes Windkraftprogramm gestartet. Es sollte untersucht werden, ob Windenergie zu konkurrenzfähigen Preisen einen nennenswerten Teil zur Stromversorgung Großbritanniens beitragen könne. ${ }^{74}$ Angestrebt wird zunächst die Demonstration und später die Kommerzialisierung von WEA zur großtechnischen Stromproduktion (IEA 1989 LSWind Energy, 109).

Durchgeführt wurde das Programm in Schottland, unter Leitung des regionalen Stromversorgers, North Scottland Hydro Electric Board (NSHEB). Neben den Windverhältnissen ${ }^{75}$ und der geringen Bevölkerungsdichte gab es für die Wahl des Standorts weitere Gründe wie die Fragmentierung des schottischen Versorgungssystems und Beschäftigungsförderung. ${ }^{76}$ Seit 1977 werden sowohl Testanlagen entwickelt, als auch Grundlagenforschung betrieben. Bis 1985 nimmt die Bedeutung letzterer zugunsten der Arbeiten an Prototypen stark ab (WPM 12/85, 8).

Wichtigstes Projekt ist die Entwicklung der Großwindanlage LS-1 (3MW-Generator, 60m Rotordurchmesser, horizontale Achse). Bei der Entwicklung LS-1 handelte es sich um ein Joint Venture zwischen der General Electric Company, British Aerospace und Taylor Woodrow Construction (WPM 12/87, 11). Den Bauauftrag vergab das Energieministerium 1982 an die britische Wind Energy Group (WEG). Die Projektkosten in Höhe von 12 Mio. Pfund hatte zu einem Großteil das Ministerium getragen (WPM 6/88, 30). Die LS-1 war über einige Jahre der größte Posten des Windenergieetats. Im November 1987 nahm NSHEB die Großanlage auf Orkney in Betrieb (WPM12/85, 8 und WPM 12/87, 11). Zwei Jahre später zieht der Versorger eine enttäuschende Bilanz (Gipe 1995, 110). ${ }^{77}$ Weitere LS-1 wurden nicht produziert. Eine ursprünglich geplante, noch größere Prototyp-Windanlage LS-2 wurde nicht realisiert. Erfolgreicher ist WEG mit ihrer kleineren MS-3 mit 300kW-Generator (vg. WPM 12/85, 9; WPM 12/90, 6).

Der Bauauftrag eines kleineren 130kW-Prototypen mit vertikaler Achse erging an die Vertical Axes Wind Turbines Ltd. (VAWT). Seit dem Planungsbeginn vergingen drei Jahre, bevor die vom Ministerium mit 3,5 Mio. Pfund subventionierte Anlage im November 1986 vom CEGB gekauft und in Betrieb genommen wurde (WPM 1/87, 13). Im Fall positiver Ergebnisse wollte der Stromkonzern auf Basis der 130kW-Maschine eine Großwindanlage mit 4MW-Generator für den Einsatz auf See entwickeln lassen (WPM 12/85, 8). Im Juli 1990 hatte VAWT eine letzte Prototyp-Windanlage (VAWT 850/ 500kW-Generator) hergestellt, die Unterstützung vom Energieministerium erhielt. Als Konsequenz ernüchternder Resultate der VAWT 850 wurden die Arbeiten an Windanlagen mit vertikaler Achse aufgegeben.

Neben der WEG war James Howden Ltd. der andere Produzent größerer HAT-Modelle, die vom Energieministerium, CEGB und von der EU Zuzahlungen erhielten (Bericht der Europäischen

\footnotetext{
${ }^{72}$ vg. auch: Weingart 2007, 119 und $182 \mathrm{ff}$.

${ }^{73}$ Bei Friedensdemonstrationen der 50er/60er Jahre ist häufig die Parole ,Atoms for Peace' anzutreffen (ebd.).

${ }^{74}$ Bedford/Page: The United Kingdoms Department of Energy's Wind Energy Programme - A Progress Report. (Bericht über die Windenergie Konferenz der EU vom 6.-10. Juni 1988 in Herning, Dänemark, 646).

${ }^{75}$ Der schottische Windkraftexperte John Twidell geht für Schottland von $9 \mathrm{~m} / \mathrm{s}$ als durchschnittlicher Windgeschwindigkeit in zehn Meter Höhe aus (WPM 10/86, 22).

${ }^{76}$ Aufgrund der hohen Zahl von Inseln und netzfernen Regionen ist das schottische Stromsystem stark dezentralisiert. In weiten Landesteilen muss der Strom kostspielig, mittels Dieselgeneratoren erzeugt werden. Günstiger war die Installation von WEA, bzw. Wind-Diesel-Systemen, bei denen Diesel nur ergänzend verwendet wird. Daraus erklärt sich das Engagement des NSHEB für die Windkraft (WPM 12/85, 9). Schließlich hatte sich die Scottish Development Agency für die Auswahl eines Standorts in Schottland stark gemacht. Durch die Ansiedlung von Unternehmen der Branche sollte die hohe Arbeitslosigkeit reduziert werden.

${ }^{77}$ vg. auch: WPM 7/88
} 
Windenergiekonferenz 1990, 462). Angesichts der internationalen Misserfolge der MegawattPrototypen, entschied der CEGB im Jahr 1986, die Fertigung einer vergleichsweise kleinen 1MWMaschine bei Howden in Auftrag zu geben (WPM 3/86, 12; WPM 5/86, 30). Zuvor hatte das Unternehmen bereits kleinere Windanlagen $(300 \mathrm{~kW}$ - bis $750 \mathrm{~kW}-$ Generatoren) hergestellt und begrenzte Kommerzialisierungserfolge erlangt. Für die neue 1-MW-Prototyp-Windanlage, die 1990 ans Netz von CEGB-Nachfolger PowerGen geschlossen wurde, gab es dagegen keine Nachfrage. ${ }^{78}$

Mit dem Start des Windkraftprogramms von 1977 ist Großbritannien in die Pionierphase eingetreten. Verglichen mit anderen Ländern wie den USA waren die Mittel in Höhe von \$60 Mio., die bis 1992 vom Energieministerium aufgewendet wurden, eher gering (Gipe 1995, 73) Der größte Teil der Gelder ist für den Bau von Prototypen wie der großen LS-1 (3MW-Generator) und der Howden-1000 (1MW) eingesetzt worden. Erfolge blieben begrenzt, beide Konzepte wurden verworfen. Im Unterschied zu anderen Staaten erhielten in Großbritannien WEA mittlerer Größe relativ große Aufmerksamkeit. Insbesondere die Wind Energy Group erzielte mit einer 300kW-Turbine, deren Prototyp ebenfalls Fördermittel erhalten hatte, beachtliche kommerzielle Erfolge. In der zweiten Hälfte der 80er Jahre zog sich der Staat immer mehr aus der Windenergieforschung zurück und wendete sich Anfang der 90er Jahre der Nachfrageförderung zu (vg. Kap. 3).

An dem Programm beteiligt waren insbesondere Großakteure wie British Aerospace, Taylor Woodrow, General Electric Company, Howden, WEG, VAWT Ltd. und EVU wie NSHEB und CEGB. Zivilgesellschaftliche Akteure aus Forschung und NGOs hatten keine Möglichkeit, auf die Mittelvergabe und die Ausrichtung des Programms Einfluss zu üben.

\section{Schweden}

Aufgrund der in den 70er Jahren wachsenden Relevanz der Kernenergie, beachtlicher Ressourcen an Wasserkraft und Biomasse war Schweden von der Ölkrise weniger stark betroffen als andere Länder. Dennoch hatte das Embargo die Verwundbarkeit der zu 70\% auf Öl basierenden Energieversorgung Schwedens offengelegt (Löfstedt 1993, 54).

Die in der damaligen Regierung dominierende Sozialdemokratische Partei wollte Mitte der 70er Jahre umfangreiche Forschungen zur Atomkraft beschließen, wobei sie jedoch auf unerwartete Opposition gestoßen war. Jetzt war die Kernenergienutzung auch in Schweden zu einem hochbrisanten Thema geworden. ${ }^{79}$ Denn aufgrund ihrer Befürwortung der Nukleartechnologie haben die Sozialdemokraten im Jahr 1976, das erste Mal seit 1932, eine Regierungsbeteiligung verfehlt. ${ }^{80}$ Stattdessen übernahm die Zentrumspartei mit Thorbjörn Fälldin an der Spitze, bei dem es sich um einen dezidierten AKW-Gegner handelte, die Regierung.

\footnotetext{
${ }^{78}$ Als sich der Verkauf eines 32MW-Windparks zu einem großen Minusgeschäft entpuppte, zog sich Howden 1989 aus dem Sektor zurück (WPM 10/91, 18).

${ }^{79}$ Auch das Parlament war in dieser Frage gespalten. Sozialdemokraten, Konservativen und Liberalen waren Befürworter, Zentrumspartei und Kommunisten Gegner der Atomenergie.

${ }^{80} 1979$ kam es in Harrisburgh (USA) zu einem Reaktorunfall. Um Eskalationen und damit weiteren Stimmenverlusten vorzubeugen, fühlten sich die Sozialdemokraten zur Befürwortung eines 1980 durchgeführten Referendums zur Kernenergienutzung genötigt. Die Entscheidung fiel zugunsten des Atomausstiegs. Bis 2010 sollten alle zwölf schwedischen Atomkraftwerke stillgelegt und ihre Kapazitäten durch erneuerbare Energieträger ersetzt werden (WPM 2/87, 12). Zur Bedeutung des Ausstiegsbeschlusses ist anzumerken, das dieser zu einem Zeitpunkt kam, als die sechs größten Nuklearmeiler bereits seit Jahren im Bau waren (Löfstedt 1993, 52; Näheres zum Referendum vg. Jasper 1990, 225ff.) So ist zu erklären, dass sich der Stromanteil der Atomenergie trotz Ausstiegsbeschluss zwischen 1980 und 1986 verdoppelt hat (vg. Löfstedt 1993, 15 Figur 1.5). Dieser beträgt seitdem etwa 50\%. Angesichts dessen gewann die Antiatombewegung weiter an Stärke. 1981 wurde die Grüne Partei gegründet und zieht 1988 mit 5,6\% in das Parlament ein (Müller-Rommel 1993, 68f.). Neben Sozialdemokraten, Konservativen und Liberalen drängten auch die EVU, Wirtschaftsverbände und Gewerkschaften auf die Verschiebung des Atomausstiegs. Ausschließlich die regierende Zentrumspartei, die seit 1976 mit Thorbjörn Fälldin den Premierminister stellte, vertrat eine konsequente Ausstiegsposition, die nicht politisch-taktischen Erwägungen geschuldet war (Carlman 1990, 282f.).
} 


\section{Repräsentative Projekte, Ergebnisse und Bewertung}

Der Atomausstieg erforderte energiepolitische Korrekturen, bspw. die Förderung erneuerbarer Energien. Für die Jahre 1977-1985 gelang es der Zentrumspartei, beachtliche Forschungsmittel für Windkrafttechnik zu akquirieren (Carlman 1990, 283). Carlman zufolge $(1990,289)$ herrschte in der schwedischen Gesellschaft eine positive Einstellung gegenüber Windenergie. ${ }^{81}$ Zwischen 1977 und 1992 werden \$71 Mio. für F\&E zur Verfügung gestellt (Gipe 1995, 73 Tab.3.1). 63\% der Mittel werden für Herstellung und Betrieb zweier Großwindanlagen ausgegeben (ebd., 109). Die Leitung des Programms übernahm die schwedische National Energy Administration (NEA) (Bericht der ECWEC 1990, 36).

1979 vergab die NEA den Auftrag zur Herstellung der WTS-3, einer Großwindanlage (3MWGenerator). WTS-3 ist Teil einer internationalen Kooperation zwischen dem USLuftfahrtkonzern Hamilton Standard (s.o.) und der schwedischen Karlskronavarvet. EVU Sydkraft hat WTS-3 1982 auf Insel der Malmoe in Betrieb genommen. Das Projekt erhielt eine Förderung von 400 Mio. schwedischer Kronen, ca. 90 Mio. DM (Neue Energie 6/98, 41). Trotz technischer Mängel ${ }^{82}$ wie sie bei den MW-Prototypen beinahe selbstverständlich waren, erreichte die WTS-3 bis 1988 eine beachtliche Verfügbarkeit von 51\% (Gipe 1995, 109) und einen Ertrag von insgesamt 36 Mio. Kilowattstunden. Nach Abschluss der Forschungsarbeiten an WTS-3 kaufte Sydkraft die Windturbine zum symbolischen Preis einer Krone. Trotz der Proteste einer lokalen Bürgerinitiative, die sich für den Weiterbetrieb der WTS-3 aussprach, wurde der Prototyp 1993 durch Sydkraft gesprengt (Neue Energie 6/98, 41).

Ebenfalls 1979 vergab die NEA einen Auftrag zur Konstruktion einer weiteren Großwindanlage. Hersteller Kvaerner entschied sich, verglichen mit der WTS-3, für ein etwas kleineres Design (2MW-Generator, Rotorendurchmesser 75m), dass der Bremer Flugzeugbaukonzern ERNO (Entwicklungsring Nord $\mathrm{GmbH}$ ) beisteuerte. 1983 ging der Prototyp in Näsudden auf Gotland ans Netz des damaligen Swedish State Power Board. ${ }^{83}$ Mit einer Verfügbarkeit von 58\% erzielt die Näsudden-Maschine nur leicht bessere Resultate als WTS-3. Aufgrund schwerer Rotorschäden, die hohe Reparaturkosten verursacht hätten, wurde sie 1991 deinstalliert (Neue Energie 7/2001, 89).

1986 startet eine EU-Kooperation zwischen Schweden und Deutschland. Je eine Großwindanlage sollte in Näsudden (Näsudden II) und Wilhelmshaven (Aeolus II) hergestellt werden (s.o.). Finanziert wurde Näsudden II durch das State Power Board, NEA, EU und ein EVU-Konsortium (Swedish Energy Development Organization), welches 25\% beisteuerte (EWEC Konferenzbericht 1990, 37). Ebenso wie Aeolus II war auch Näsudden II mit einem 3MW-Generator und 80m-Rotor ausgestattet. Hergestellt wurde der schwedische Prototyp durch Kvaerner Turbin, dem Fabrikanten von Näsudden I. Im Jahr 1993 ist die neue Großwindanlage auf das Fundament ihres Vorgängers montiert und durch Vattenfall ans Netz geschlossen worden.

Kleinere Projekte

Die Förderung kleinerer Projekte ist die Ausnahme. 1988 wird ein 750kW-Modell der britischen Howden in Risholmen zu Forschungszwecken installiert. Im selben Jahr errichtet Vattenfall auf Gotland vier kommerzielle WEA (Danwind, je 180kW). Bereits 1987 setzt in Schweden die Erforschung der Offshore-Windtechnologie ein. 1987 wird die erste Windanlage auf See in Betrieb genommen worden (Küstenentfernung 250m, Wassertiefe: 5m

\footnotetext{
${ }^{81}$ Dabei bezieht sich Carlman auf entsprechende Äußerungen von Greenpeace und der Naturschutzorganisation Swedish Association for the Conservation of Nature. Aufgrund ihrer positiven Umweltaspekte wurde die Windenergienutzung den Ergebnissen einer Umfrage zufolge, auch von denen befürwortet, die in der Umgebung zweier großer Versuchsanlagen leben (WPM 2/87, 13).

${ }^{82}$ vg. Gipe 1995, 109; IEA 1998, 101

${ }^{83}$ Aus dem Swedish State Power Board geht 1992 Vattenfall hervor.
} 
(vg. EWEC 1990 Konferenzbericht, 38). Aufgrund zu hoher Kosten arbeitete man in dieser Richtung zunächst nicht weiter.

Ausgangspunkt des Windenergieprogramms sind Debatten um die zukünftige Rolle der Atomenergie für die Energieversorgung. Wichtigste Akteure sind der staatliche Energieversorger und die National Energy Administration. Den Schwerpunkt bildete die Herstellung dreier MW-Prototyp-Windanlagen durch zwei schwedische Firmen aus dem Boots- und Maschinenbau, Karlskronavarvet und Kvaerner. Zwei dieser Prototypen werden nach einigen Betriebsjahren aufgrund zu hoher Kosten deinstalliert. Wegen ausbleibender Erfolge sind anschließend keine weiteren Prototypen mehr gefördert worden. Hinzu kommt, dass die Mittel für Windkraftforschungen nach der Wiederwahl der Sozialdemokraten im Jahr 1985 stark gekürzt worden sind (Carlman 1990, 284).

\section{Kanada}

Enorme Energievorräte und eine stark diversifizierte Energieproduktion sind die Gründe, weshalb die kanadische Versorgungssicherheit durch die Ölkrise kaum bedroht war. ${ }^{84}$ Als Nebenprodukt der während des 2. Weltkrieges gestarteten Atomwaffenforschung, bot sich der Bau von Reaktoren zur Stromproduktion an. Entsprechende Forschungsarbeiten wurden in den 50er Jahren begonnen (Buckley 2000, 103). ${ }^{85}$

Nichtsdestoweniger hat die Ölkrise angesichts des starken Föderalismus und der geographischen Ungleichverteilung der Ressourcen zu Schwierigkeiten geführt. Während die Ölkrise für einige Provinzen zur ökonomischen Katastrophe geworden war, konnten andere wie bspw. Alberta, die mit reichhaltigen Vorräten ausgestattet waren, aus den erhöhten Ölpreisen Vorteile ziehen. Zwischen den energiereichen und importabhängigen Provinzen kam es daher zu massiven Konflikten bzgl. der Frage des Zugriffs auf die Ressourcen. Vor diesem Hintergrund gab die Bundesregierung ihre Passivität auf und nahm verstärkt Einfluss auf die gesamtkanadische Energiepolitik (vg. Schiller et al. 1991, 161). ${ }^{86}$ Die liberale Zentralregierung verfolgte seit 1980 eine interventionalistische Politik und verabschiedete für 1980-84 das NEP, ein nationales Energieprogramm (ebd., 170f.). Seitdem sind erstmals erneuerbare Energietechnologien unterstützt worden, wobei der größte Anteil der Windkraft zukam. Mit etwa 50GW nutzbarer Windressourcen zählt Kanada zu den Ländern mit den größten Windpotenzialen (Renewable Energy World 9-10/2005). Nichtsdestotrotz kam das Hauptinteresse der Forschungspolitik nach wie vor konventionellen Energien und der Atomtechnologie zu.

Unter Leitung des National Research Council (NRC) ${ }^{87}$ wurde bereits 1974 mit dem WERD (Wind Energy Research and Development) ein erstes Programm zur Windkraft gestartet. 1984 übernahm das Department of Energy, Mines and Ressources (EMR) diese Aufgabe. Sämtliche

\footnotetext{
${ }^{84}$ Ende 2004 verfügt das Land mit 16,8 Mrd. Barrel Öl über ebenso große Vorräte wie Brasilien und Indien zusammen. Die Gasressourcen der beiden Länder sind mit 1,25 Bio. Kubikmeter geringer als diejenigen Kanadas (1,6 Bio. Kubikmeter). Die mit Abstand größten Vorräte Europas befinden sich in Norwegen (9,7 Mrd. Barrel Öl; 9,7 Bio. Kubikmeter Gas). Zum Vergleich, die jeweils größten Vorräte: Saudi-Arabien besitzt 262,7 Mrd. Barrel Öl, Russland 48,0 Bio. Kubikmeter Gas (Quelle:BP, vg. Neue Energie 2/06). Auch die Kohlevorräte Kanadas reichen bei gleichbleibender Produktion (inklusive Exporte) noch für 120 Jahre (eigene Berechnungen auf der Grundlage von Daten aus www.worldenergy.org, abgerufen am 9.1.2006).

${ }^{85}$ Bis 2002 ist der Anteil der Atomenergie am Primärenergieverbrauch auf acht Prozent gewachsen. Herausragende Bedeutung kommt auch der Wasserkraft zu, die im selben Jahr zwölf Prozent zur Energieversorgung beigetragen hat (Neue Energie 5/2005, 76).

${ }^{86}$ Diese Bestrebungen führten zu Unstimmigkeiten zwischen der Bundesregierung und der Ölprovinz Alberta. Der Petroleum Act von 1975 ermächtigte die Bundesregierung dazu, die Öl- und Gaspreise selbst festzulegen, was zu einem Bedeutungsverlust der Ölindustrie Albertas führte (vg. Schiller et. al 1991, 169f.).

${ }^{87}$ Der NRC ist das kanadische Pendant zur NASA (WPM 12/86, 18).
} 
Forschungsarbeiten wurden von Universitäten und Forschungsinstituten sowie der Industrie geleistet. Der Fokus lag auf Darrieus-Anlagen. In der zweiten Hälfte der 80er Jahre ebbte das Interesse an der Windkraft deutlich ab. Über die Jahre 1986 bis 1990 pendelte der Forschungsetat für Windkraft zwischen Cdn. \$4 bis Cdn. \$5,75 Mio. (WPM 1/87, 8).

Das wichtigste Programmelement ist die Konstruktion der international größten Windanlage mit vertikaler Achse. Shawinigan Inc. hat 1984 das genaue Anlagendesign abgeschlossen. Unter Leitung des NRC und dem Stromkonzern Hydro Québec ist der 4MW-DarrieusPrototyp 1987 in Cap Chat/ Québec errichtet und im Januar 1988 an das Netz von Hydro Québec geschlossen worden (IEA 1988 LS, 11f). Für Projekt Éole stellte das EMR circa Cdn. \$ 40 Mio. zur Verfügung (Gipe 1995, 114). Zwischen 1987 und 1993 hat die Turbine bei 19.000 Betriebsstunden etwa zwölf Gigawattstunden Energie produziert (ebd., 104 Tab. 4.1). Die kanadischen Hersteller DAF-Indal, Adecon und Dornier sahen nach Projektschluss davon $\mathrm{ab}$, weitere Maschinen des Typs zu produzieren.

Die Forschungsförderung erneuerbarer Energien hatte in Kanada primär keine umwelt-, sondern in erster Linie energiepolitische Gründe. Eine gesellschaftliche Kontroverse um Atomenergie war entweder nicht vorhanden, oder hatte zumindest keinen Einfluss auf politische Entscheidungen.

Bei den wesentlichen Akteuren des Projekt Éole handelte es sich mit dem Department for Energy, Mines and Ressources, dem National Research Council, Shawinigan und Hydro Québec ausschließlich um Großakteure. Der 4-MW-Prototyp bildete das Hauptelement des kanadischen Windkraftprogramms. Nach dem sich herausstellte, dass Éole nicht für kommerzielle Zwecke, also auch nicht zur Serienfertigung geeignet war, wurden keine Großwindanlagen mehr gefördert. Dennoch hielt man weiterhin an der Windtechnik fest. Im Jahr 1988 zeichnet sich insofern eine Schwerpunktverschiebung ab, als $45 \%$ des Windenergieetats für Wind/Diesel-Systeme und Kleinanlagen ohne Netzanbindung, bspw. für landwirtschaftlichen Gebrauch, aufgewendet wurden.

\section{Spanien}

Spanien gehört zu den Ländern Europas mit der höchsten Importabhängigkeit der Energieversorgung. 1973 stammen nur 28\% des Bedarfs aus eigenen Ressourcen. Angesichts des stark wachsenden Verbrauchs, kündigte die Regierung an, erneuerbare Energien zu fördern (Reiche 2002b, 211). ${ }^{88}$ Tatsächlich war es zunächst bei den Ankündigungen geblieben. Stattdessen galt das Hauptinteresse der Atomtechnologie. Bereits in den 60er Jahren hatte das Franco-Regime ein umfangreiches Programm zur Atomkraft eingeleitet. Franco plante den Bau von bis zu 43 Nuklearmeilern sowie den Ausbau der Plutoniumwirtschaft zur Herstellung von Atomwaffen. Bereits vor der Ölkrise, im Jahr 1972, waren die ersten drei Reaktoren fertiggestellt und trugen mit insgesamt 1079MW zur Stromproduktion bei. Trotz eines Moratoriums zur Kernenergienutzung im Jahr 1983 gingen weitere Reaktoren ans Netz. Noch heute sind in Spanien neun Atomkraftwerke in Betrieb, die mit 23\% zur Stromversorgung beitragen. (www.global2000.at/pages/tatomspanien.htm; Abruf vom 14.9.2007). ${ }^{89}$ Die letzten Pläne für den Neubau eines AKW werden erst 1994 aufgegeben. Umweltakteure und Atomkraft-Gegner waren in Spanien kaum aktiv. Jegliche Proteste wurden im Franco-Regime brutal unterdrückt. Die Atomstrategie bildete ein strukturelles Hindernis der Förderung erneuerbarer Energien. Vorsichtige Aktivitäten im Windenergiesektor entfaltete der spanische Staat dennoch bereits seit 1979. In diesem Rahmen testete der staatliche Energieversorger Endesa kleine WEA auf Mallorca. Bis 1982 wird u.a. eine Windkarte des Landes erstellt und eine 100kW-Turbine zu Testzwecken

\footnotetext{
${ }^{88}$ Zwischen 1985 und 1998 nimmt der jährliche Energieverbrauch um 61\% zu (ebd.).

${ }^{89} 2004$ hat die sozialistische Regierung den Ausstieg aus der Kernenergienutzung bis spätestens 2024 (www.global2000.at/pages/tatomspanien.htm; Abruf vom 14.9.2007) beschlossen.
} 
konstruiert. Mit der AWEC-60, dem zentralen Projekt der Forschungen, geht auch aus dem spanischen Windenergieprogramm eine große Prototyp-Windturbine hervor.

AWEC-60, ein spanisch-deutsches Kooperationsprojekt, startete im Frühjahr 1985. Beteiligt waren auf spanischer Seite die Forschungsinstitute IER-CIEMAT und ASINEL, sowie Unión Eléctrica Fenosa als Betreiber. Mit der Herstellung der AWEC-60 wurde die deutsche MAN beauftragt. Bereits seit 1984 arbeitete MAN an der WKA-60 (s.o.), dessen Design AWEC-60 stark ähnelte. Im Oktober 1989 wurde der 1,2MW-Prototyp in Carbo Villano (Galicien) ans Netz der Unión Eléctrica Fenosa geschlossen. Wichtigster Geldgeber ist die EU, welche das Projekt im Rahmen des WEGAProgramms $\mathrm{zu} \quad 50 \%$ förderte. Zusätzliche Unterstützung erhielt es vom spanischen Industrieministerium und dem BMFT (EWEC 1990, 467; WPM 10/90, 13).

Bei den wichtigsten Akteuren des Programms, Forschungseinrichtungen, Energiekonzern Endesa und Unión Eléctrica Fenosa sowie MAN, handelt es sich ausschließlich um Großakteure. Ähnlich wie die WKA-60, erweist sich auch AWEC-60 für eine als Serienfertigung ungeeignet. Forschung an großen Windenergieanlagen wurde anschließend nicht weiter gefördert. Stattdessen orientierte sich die staatliche Windenergiepolitik seit Ende der 80er Jahre auf den kommerziellen Sektor. Dort begann sich zu dieser Zeit eine Windanlagenindustrie herauszubilden (vg. Kap. 3).

\section{Italien}

Aufgrund der starken Ölabhängigkeit Italiens (Reiche 2002b, 161) hat das Land als Reaktion auf die Ölkrise eine aktive Energiepolitik betrieben. Ein erster nationaler Energieplan wird 1975 beschlossen. Zur Lösung des Energieproblems favorisierte man die Atomkraft und richtete die Forschungspolitik entsprechend aus. Ein deutlicher Kurswechsel erfolgt 1979, nachdem es im AKW Three Mile Island in Harrisburg zu einer Kernschmelze gekommen war und die geplante Einführung der Atomenergie zu politischen Spannungen geführt hatte. Gemeinsam mit der zweiten Ölkrise von 1978/79 bildete Harrisburg den Ausgangspunkt der Förderung erneuerbarer Energien..$^{90}$ Deutlichstes Merkmal dieser Neuausrichtung ist die im Jahr 1982 erfolgte Umbenennung des Nationalen Komitees für Atomkraft (CHEN) in Nationale Agentur für neue Technologien, Energie und Umwelt (ENEA) ${ }^{91}$ Im selben Jahr wird das erste Windkraftprogramm ${ }^{92}$ gestartet (http://en.wikipedia.org/wiki/ENEA_(Italy), Abruf: 12.9.2007). Nach der Katastrophe von Tschernobyl sammelte die Anti-AKWBewegung über 500.000 Unterschriften und setzte ein Referendum über die Kernenergienutzung durch. Am 8. November 1987 haben sich knapp $80 \%$ der Abstimmenden, bei einer Wahlbeteiligung von 65,5\% für den Atomausstieg entschieden. ${ }^{93}$ Daraufhin wird 1990 das letzte der vier Atomkraftwerke Italiens stillgelegt. ${ }^{94}$ Die Antiatombewegung ist ein wahrnehmbarer Faktor gewesen, welcher die italienische Energiepolitik aktiv mitgestaltet hat.

Im Vele, dem italienischen Windenergieprogramm, sollten möglichst große Windenergieanlagen entwickelt und getestet werden. Begründet wurde die Präferenz für diese, bekanntermaßen kostenintensive Ausrichtung damit, dass aufgrund der hohen Bevölkerungsdichte und einer Vielzahl von Naturschutzgebieten, nur wenige Flächen für die

\footnotetext{
${ }^{90}$ http://www.gses.it/pub/1939-PirazziSilvi.pdf (abgerufen am 11.9.07): Luciano Pirazzi/ Cesare Silvi: WIND POWER IN ITALY FROM THE LATE 1970s TO THE PRESENT (Abstract)

${ }^{91} \mathrm{ENEA}=$ Ente per le Nuove tecnologie, l'Energia e l'Ambiente (http://en.wikipedia.org/wiki/ENEA_(Italy), Abruf: 12.9.2007)

${ }^{92}$ Bereits 1979 erhielten der italienische Forschungsrat (CNR) und ENEL im Rahmen des VELE (Windenergie zur Stromproduktion) erste Mittel zur Windkraftforschung (Pirazzi)

${ }^{93} \mathrm{http}$ ://www.icanw.org/italy (Abruf: 11.9.2007)

${ }^{94} \mathrm{http}: / /$ de.wikipedia.org/wiki/Italien (Abruf: 12.9.2007)
} 
Windenergienutzung zur Verfügung standen. Den Einsatz von Großwindanlagen betrachtete man als einzig sinnvolle Option (EWEC 1988, 657). Darüber hinaus ist der Aufbau einer international konkurrenzfähigen Windindustrie als wichtiges Ziel definiert worden. Für das Programm verantwortlich war das Ministerium für Industrie und Kommerz. Die nationale Behörde für Elektrizität (ENEL) testete bereits seit 1980 kleine WEA im Leistungsbereich 3$68 \mathrm{~kW}$. In einem neuen Programm wollte die ENEL nun auch mittlere und große Modelle untersuchen (ebd., 656f.).

1986 startet das Projekt ,Gamma-60', die einzige große Prototyp-Windanlage, welche aus dem italienischen Windenergieprogramm hervorgegangen ist. Das von ENEL und ENEA erstellte Design war an der WTS-4 von Hamilton Standard (s.o.) orientiert. Mit der Realisierung der Gamma-60 (Rotordurchmesser 60m, 1,5MW-Generator, zwei Rotorblätter) wurde ein privatwirtschaftliches Konsortium beauftragt, dessen wichtigster Akteur Aeritalia ist, der größte Flugzeughersteller Italiens (WPM 12/86, 26; EWEC 1988, 657). Träger des Projekts sind ENEL, ENEA und die EU. Im Jahr 1992 ist der Prototyp fertiggestellt und auf dem Testgelände des ENEL in Alta Nurra (Sardinien) installiert worden. Nach einer kurzen Versuchsphase entsteht in der Anlage ein Brand. Daraufhin brach ENEL die Arbeiten an der Gamma $60 \mathrm{ab}$, ohne dass praktische Ergebnisse erlangt worden wären. Weitere Maschinen des Typs wurden nicht produziert (Pirazzi/ Silvi). ${ }^{95}$

Neben Gamma-60 förderte das Programm auch zwei mittelgroße Prototyp-Windanlagen. Bereits im Mai 1986 hat ENEL die ebenfalls von Aeritalia produzierte MEDIT (zwei Rotorblätter, 225kW-Generator) in Alta Nurra installiert. Finanziert wurde dieses ,MEDITProjekt' durch ENEA, die EU und Aeritalia (IEA 1988, 57). Der italienische Hersteller West entwickelte ein Derivat von MEDIT, MEDIT-320 (320kW). Mit dieser Turbine erzielte West begrenzte kommerzielle Erfolge. ${ }^{96}$ Der zweite Prototyp M30 (einflügeliger Rotor, 200kWGenerator) wurde im Rahmen einer 1985 gestarteten Kooperation zwischen Riva Calzoni und MBB hergestellt. ${ }^{97}$ Fast 100 WEA dieses Typs sind in unterschiedlichen Teilen des Landes errichtet worden. Dennoch hielten sich die Erfolge der M30 offenbar in Grenzen. Nach einigen Jahren ersetzte man die meisten durch effizientere Anlagen (vg. Pirazzi/ Silvi).Keines der drei großen Projekte des Forschungsprogramms (Gamma-60, MEDIT und M30) erzielte nachhaltige technische oder kommerzielle Erfolge. Weder sind aus dem Programm serienreife Großwindanlagen, noch konkurrenzfähige mittelgroße Turbinen hervorgegangen. Ähnliche Projekte werden seit Anfang der 90er Jahre nicht mehr gefördert. Zivilgesellschaftliche Akteure wie die Anti-Atombewegung hatten zwar Einfluss auf die Energiepolitik (Atomausstieg, Förderung der Windkraft). Die Entscheidung für die einzelnen Projekte sowie deren Durchführung blieb Großakteuren wie dem Flugzeugkonzern Aeritalia, MBB, sowie staatlichen Akteuren ENEL und ENEA vorbehalten.

\footnotetext{
${ }^{95}$ An der selben Stelle merkt Pirazzi an, dass einige innovative Elemente der Gamma 60 für die MK3, eine kleinere $600 \mathrm{~kW}-$ Maschine genutzt werden konnten.

${ }^{96} \mathrm{vg}$. http://www.wind-tschechien.de/site/portal/default.aspx?pid=45 (Abruf vom 12.9.2007)

${ }^{97}$ Riva Calzoni ist ein bekannter Hersteller von Wasserkraftwerken (EWEC 1988, 657). Aufgrund der Arbeiten mit der Monopetrus-Serie verfügte MBB bereits über reichhaltige Erfahrungen mit einflügeligen WEA.
} 


\subsection{Vergleichende Analyse der Pionierländer}

\subsubsection{Energiepolitische und gesellschaftliche Rahmenbedingungen}

Unabhängig davon, wie die Programme zur Windenergieforschung seitens der Entscheidungsträger letztlich begründet wurden, bestehen in jedem Land spezifische Bedingungen, durch die solche Entscheidungen positiv beeinflusst worden sein konnten. Hier sollen drei Faktoren berücksichtigt werden. Energieabhängigkeit/ Ressourcenmangel (1): Ein Staat möchte seine Energieabhängigkeit minimieren und strebt daher eine Versorgung auf der Basis eigener Vorkommen an. Erschließbare Windressourcen (2): Windenergie bietet sich insbesondere dort an, wo überdurchschnittliche Vorkommen an zugänglichen Standorten verfügbar sind. Anti-AKW-Bewegung (3): Um stabile Verhältnisse zu erhalten, gehen viele demokratische Staaten den Weg der Vermittlung sozialer Konflikte. Die Förderung erneuerbarer Energien kann möglicherweise als ein Zugeständnis an die Proteste gegen Atomkraftnutzung interpretiert werden. Im Fall eines Atomausstiegs (oder der NichtEinführung wie in Dänemark) ist die Suche nach neuen Energietechnologien unausweichlich. Welche Aussagen lassen sich aus einer vergleichenden Betrachtung der Faktoren gewinnen? In Tabelle 1.2.a sind die Faktorenkombinationen für alle Pionierländer dargestellt. Diese Kombinationen werden einer zweiten Ländergruppe gegenübergestellt, in denen Windenergieforschung in der Pionierphase nicht in größerem Umfang betrieben worden ist.

Tab. 1.2a Ausgangsbedingungen der Forschungsprogramme

\begin{tabular}{|c|c|c|c|c|}
\hline Land & $\begin{array}{l}\text { Relevante } \\
\text { erschließbare } \\
\text { Vorkommen? }\end{array}$ & $\begin{array}{l}\text { Energieabhängigkeit/ } \\
\text { Ressourcenmangel }\end{array}$ & $\begin{array}{l}\text { Starke } \quad \text { Proteste } \\
\text { gegen Atomenergie? }\end{array}$ & $\begin{array}{l}\text { Forschungsprogramm } \\
\text { für Windenergie? }\end{array}$ \\
\hline \multicolumn{5}{|c|}{$\begin{array}{l}\text { Länder mit } \\
\text { Forschungsprogramm* } \\
\text { (Gruppe A) }\end{array}$} \\
\hline USA & ja & ja & ja & ja \\
\hline Dänemark & ja & ja & ja & ja \\
\hline Deutschland & ja & ja & ja & ja \\
\hline Niederlande & ja & ja & ja & ja \\
\hline Großbritannien & ja & nein & nein & ja \\
\hline Schweden & ja & nein & ja & ja \\
\hline Kanada & ja & nein & nein & ja \\
\hline Italien & ja & ja & ja & ja \\
\hline Spanien & ja & ja & nein & ja \\
\hline \multicolumn{5}{|c|}{$\begin{array}{l}\text { Vergleichsgruppe } \\
\text { ohne } \\
\text { Forschungsprogramm } \\
\text { (Gruppe B) } \\
\end{array}$} \\
\hline Schweiz & nein & ja & ja & nein \\
\hline Österreich & nein & ja & ja & nein \\
\hline Luxemburg & nein & ja & ja & nein \\
\hline Frankreich & ja & ja & nein & nein \\
\hline Finnland & ja & nein & nein & nein \\
\hline Japan & ja & ja & nein & nein \\
\hline
\end{tabular}

Quellen: EWEA/Greenpeace 2001/2002 (Tab. 3-1); Müller-Rommel (1993); Radkau (ohne Jahresangabe)

* Gemeint sind ausschließlich umfangreiche, während der Pionierphase implementierte Forschungsprogramme, die zur Entwicklung mindestens einer Großwindanlage geführt hatten.

Der Tabelle 1.2a lassen sich folgende Ergebnisse entnehmen: Grundsätzlich lässt sich kein einzelner Faktor identifizieren, dessen Vorhandensein für die Durchführung eines Forschungsprogramms hinreichend gewesen wäre. Faktor (1), ,relevante erschließbare Windressourcen' ist offenbar eine notwendige Voraussetzung, die von allen Gruppe-A-Staaten erfüllt wird. Windenergie war in den Binnenländern der Gruppe B (Schweiz, Österreich, 
Luxemburg) - trotz Energieknappheit und Protesten gegen AKWs - nicht als mögliche Energiequelle ernsthaft erwogen worden.

In Gruppe A treten diverse Kombinationen auf. Einige sind offenbar nicht hinreichend, weil einige B-Staaten dieselben Kombinationen aufweisen (Beispiele: Kanada, Finnland; Spanien, Japan). Zwei Drittel der Gruppe-A-Staaten waren von der Ölkrise stark betroffen, bzw. leiden unter Energiemangel. Dennoch: Windenergie wurde nicht in allen windreichen Ländern mit Energieknappheit als zukünftige Option betrachtet (vg. Frankreich und Japan). Ausnahmen bilden auch die energiereichen Staaten Kanada und Großbritannien, welche zu den Ländern gehören, welche über die weltweit größten Windenergieressourcen verfügen.

Schließlich lässt sich der Tabelle entnehmen, dass sämtliche windreiche, energiearme Länder, mit starken Protesten gegen die Kernenergienutzung, also Länder, in denen alle drei Faktoren gegeben waren, Gelder für Windkraftforschungen aufwendeten.

\subsubsection{Internationale Geltung des Large-Scale-Paradigma (LSP)}

Alle Forschungsprogramme wurden staatlich initiiert und von Energiekonzernen und großen Forschungseinrichtungen geleitet. Als Anlagenhersteller sind ausschließlich große Unternehmen aus dem Flugzug- und Maschinenbau tätig. Nicht nur in der Akteursstruktur, sondern auch in Zielsetzung und Durchführung existieren Parallelen zwischen den Programmen. Sie alle sind darüber hinaus durch ähnliche Grundannahmen, Denkmuster und Ziele gekennzeichnet. Diese Gesamtheit, welche im folgenden als Large-Scale-Paradigma (LSP) bezeichnet wird, ist durch folgende Eigenschaften gekennzeichnet:

1. Das Hauptziel der Technologiepolitik ist die Kommerzialisierung großer Windanlagen. Zu diesem Zweck hat man die Entwicklung entsprechender Prototypen gefördert.

2. Die Leitung und Durchführung der Projekte ist stets Großakteuren aus Politik, Forschung und (Energie-)wirtschaft zugedacht worden.

3. Nachdem sie die Serienreife erlangt hatten, sollten die großen WEA von den EVU gekauft und betrieben werden. Auf diese Weise sollte die Windenergie, eine bis dahin ausschließlich dezentral nutzbare Energiequelle, in das Stromsystem integriert werden, ohne dessen Struktur zu verändern. Dezentrale Energien waren für die Energiewirtschaft uninteressant.

4. Es galt die Überzeugung, dass man die Windtechnologie weitgehend beherrschte. Mit den verfügbaren Mitteln der Spitzentechnologie sei die Konstruktion von Großwindanlagen problemlos zu realisieren.

5. Man ging davon aus, dass die Flugzeugindustrie, aufgrund ihrer Erfahrungen aus der Praxis der Aerodynamik, für die Herstellung großer WEA optimal geeignet wäre. Dieselben Materialien, Rechenansätze und Werkzeuge, die sich im Flugzeugbau bewährt hatten, sollten auf die Windenergie übertragbar sein.

6. Die Integration zivilgesellschaftlicher Akteure wie Umweltgruppen, die sich für erneuerbare Energien und eine dezentralisierte Versorgung aussprachen, betrachtete man als kontraproduktiv - und wurde daher so weit wie möglich vermieden. Sie wäre dem LSP insgesamt zu wider gelaufen.

\section{Zum Nachweis der LSP-Eigenschaften}

Die Eigenschaften, bzw. die Grundsätze 1, 3 und 4 werden teilweise von den Initiatoren der Programme explizit formuliert (s.o.). Zu einem anderen Teil lässt sich ihre Geltung anhand der Akteursstrukturen der wichtigsten Projekte indirekt nachweisen. Letzteres gilt auch für die Eigenschaften/Grundsätze 2, 5 und 6. Wer ist an den Projekten beteiligt? Wie groß sind die Wachstumssprünge bzgl. Rotorenlänge und Generatorkapazität? Aus Tabelle 1.2.b geht hervor, inwieweit die LSP-Elemente bei den repräsentativen Projekten (vg. Kapitel 1.1) gegeben sind. 
Tab. 1.2.b Internationale LSP-Projekte

\begin{tabular}{|c|c|c|c|c|c|c|c|c|}
\hline Land & \begin{tabular}{|l|} 
Projekt \\
(Generatoren- \\
kapazität in \\
kW) \\
\end{tabular} & $\begin{array}{l}\text { Großwindanlage/ } \\
\text { als Modell für } \\
\text { Großanlage } \\
\text { konzipiert? (1) }\end{array}$ & $\begin{array}{l}\text { Leitung durch } \\
\text { Großakteur? } \\
\text { (2) }\end{array}$ & $\begin{array}{l}\text { Herstellung durch } \\
\text { Konzerne? (2) }\end{array}$ & $\begin{array}{l}\text { Flurgzeug- } \\
\text { industrie } \\
\text { beteiligt? } \\
\text { (5) } \\
\end{array}$ & \begin{tabular}{|l|} 
Große \\
technische \\
Sprünge? \\
$(4)$ \\
\end{tabular} & $\begin{array}{l}\text { Zivilgesellschaft- } \\
\text { liche Akteure } \\
\text { beteiligt? (6) }\end{array}$ & $\begin{array}{l}\text { Geltung } \\
\text { der LSP } \\
\text { Grundsätze }\end{array}$ \\
\hline USA & \begin{tabular}{|l|} 
Mod-0: \\
100kW; Mod- \\
0A: 200kW \\
\end{tabular} & ja & ja (NASA) & ja (Westinghouse) & ja & nein & nein & $1,2,3,5,6$ \\
\hline USA & \begin{tabular}{|l} 
Mod-1: \\
2000kW
\end{tabular} & ja & ja (NASA) & \begin{tabular}{|ll} 
ja & (General \\
Electric) & \\
\end{tabular} & ja & ja & nein & alle erfüllt \\
\hline USA & \begin{tabular}{|l} 
Mod-2: \\
2500kW
\end{tabular} & ja & ja (NASA) & ja (Boenig) & ja & ja & nein & alle erfüllt \\
\hline USA & $\begin{array}{l}\text { Mod-5B: } \\
\text { 3200kW }\end{array}$ & ja & ja (NASA) & ja (Boeing) & ja & nein & nein & $1,2,3,5,6$ \\
\hline DK & $\begin{array}{|lr|}\begin{array}{l}\text { Nibe } \\
630 \mathrm{~kW}\end{array} & \text { A/B: } \\
\end{array}$ & nein & ja (DEF/ Risoe) & \begin{tabular}{|l} 
nein \\
(Multivertragsbasis)
\end{tabular} & nein & nein & nein & $2,3,6$ \\
\hline $\mathrm{DK}$ & \begin{tabular}{|l|} 
Esbjerg: \\
$2000 \mathrm{~kW}$ \\
\end{tabular} & ja & ja (Elsam) & $\begin{array}{l}\text { nein } \\
\text { (Multivertragsbasis) }\end{array}$ & nein & ja & nein & $1,2,3,4,6$ \\
\hline$\overline{\mathrm{DK}}$ & $\begin{array}{l}\text { Masnedoe: } 4 \mathrm{x} \\
750 \mathrm{~kW}\end{array}$ & nein & ja (Elkraft) & $\begin{array}{l}\text { ja (Danish Wind } \\
\text { Technology) }\end{array}$ & nein & nein & nein & $2,3,6$ \\
\hline$\overline{\mathrm{DK}}$ & \begin{tabular}{|l} 
Risoe \\
Teststation \\
\end{tabular} & nein & nein & nein & nein & nein & ja & - \\
\hline $\mathrm{NL}$ & $\begin{array}{|lr|}5 \mathrm{~m} \text { VAT, } & 15 \mathrm{~m} \\
\text { VAT, } & 25 \mathrm{~m} \\
\text { HAT } & \\
\end{array}$ & ja & ja (LSEO, ECN) & $\begin{array}{l}\text { ja (Fokker, Stork, } \\
\text { Polymarin) }\end{array}$ & ja & nein & nein & $1,2,3,5,6$ \\
\hline $\mathrm{NL}$ & \begin{tabular}{|l|} 
Newecs-45: \\
1000kW \\
\end{tabular} & ja & ja (LSEO, ECN) & ja (Stork) & ja & nein & nein & $1,2,3,5,6$ \\
\hline $\mathrm{NL}$ & $18 \times 300 \mathrm{~kW}$ & nein & ja (LSEO, SEP) & ja (Holec) & nein & nein & nein & $2,3,6$ \\
\hline BRD & \begin{tabular}{|l|} 
Growian \\
3000kW \\
\end{tabular} & ja & \begin{tabular}{|l|}
$\mathrm{ja} \quad$ (Growian \\
$\mathrm{GmbH})$
\end{tabular} & ja (MAN) & nein & ja & nein & $1,2,3,4,6$ \\
\hline BRD & \begin{tabular}{|l|} 
Monopetrus \\
$700 \mathrm{~kW}$ \\
\end{tabular} & ja & ja (MBB) & ja (MBB) & ja & nein & nein & $1,2,3,5,6$ \\
\hline BRD & \begin{tabular}{|l|} 
WKA-60: \\
1200kW \\
\end{tabular} & ja & $\begin{array}{|lr|}\text { ja } & \text { (BMFT, } \\
\text { MAN) } & \\
\end{array}$ & ja (MAN) & nein & nein & nein & $1,2,3,6$ \\
\hline BRD & $\begin{array}{|ll|}\text { Aeolus } & \text { II: } \\
3000 \mathrm{~kW} & \\
\end{array}$ & ja & $\begin{array}{l}\text { ja } \\
\text { (PreußenElektra, } \\
\text { MBB) }\end{array}$ & ja (MBB) & ja & nein & nein & $1,2,3,6$ \\
\hline GB & LS-1: 3000kW & ja & ja (NSHEB) & ja (WEG) & ja & ja & nein & alle erfüllt \\
\hline$\overline{G B}$ & \begin{tabular}{|l} 
VAWT \\
$130 / 500 \mathrm{~kW}$ \\
\end{tabular} & ja & ja (CGEB) & ja (VAWT Ltd.) & nein & nein & nein & $1,2,3,6$ \\
\hline$\overline{G B}$ & \begin{tabular}{|l|} 
Howden: \\
1000kW \\
\end{tabular} & ja & ja (CGEB) & ja (Howden) & nein & nein & nein & $1,2,3,6$ \\
\hline $\mathrm{S}$ & $\begin{array}{l}\text { WTS-3: } \\
\text { 3000kW }\end{array}$ & ja & ja (NEA) & $\begin{array}{l}\text { ja (Hamilton } \\
\text { Standard, } \\
\text { Karlskronavarvet) }\end{array}$ & ja & ja & nein & alle erfüllt \\
\hline $\mathrm{S}$ & $\begin{array}{|ll|}\begin{array}{l}\text { Näsudden } \\
2000 \mathrm{~kW}\end{array} \\
\end{array}$ & ja & ja (NEA) & ja (Kvaerner) & nein & ja & nein & $1,2,3,4,6$ \\
\hline$S$ & $\begin{array}{|ll|}\begin{array}{l}\text { Näsudden } \\
\text { 3000kW }\end{array} \\
\end{array}$ & ja & \begin{tabular}{|l|}
$\mathrm{ja}(\mathrm{NEA}$, \\
Vattenfall) \\
\end{tabular} & ja (Kvaerner) & nein & nein & nein & $1,2,3,6$ \\
\hline KAN & Eole: $4000 \mathrm{~kW}$ & ja & \begin{tabular}{|l|} 
ja (NRC, Hydro \\
Quebec)
\end{tabular} & ja (Shawinigan) & ja & nein & nein & $1,2,3,4,6$ \\
\hline $\mathrm{I}$ & \begin{tabular}{|l|} 
Gamma-60 \\
$1500 \mathrm{~kW}$ \\
\end{tabular} & ja & $\begin{array}{|ll|}\text { ja } & \text { (ENEL, } \\
\text { ENEA) }\end{array}$ & ja (Airitalia) & ja & nein & nein & $1,2,3,5,6$ \\
\hline$\overline{\mathrm{SP}}$ & $\begin{array}{l}\text { AWEC-60: } \\
1200 \mathrm{~kW}\end{array}$ & ja & \begin{tabular}{|l|} 
ja (Ierciemat, \\
Asinel, Endesa)
\end{tabular} & ja (MAN) & nein & nein & nein & $1,2,3,6$ \\
\hline
\end{tabular}

Quellen: vg. Kapitel 1.1

20 der insgesamt 24 hier berücksichtigten Projekte erfüllen mindestens vier LSPEigenschaften/-Grundsätze. Bei 75\% der übrigen Projekte handelt es sich um Elemente des dänischen Windenergieprogramms. Dort ist das LSP weniger stark ausgeprägt. Die Teststation für kleine Windanlagen (Risoe) hat 1978 einen wichtigen internationalen Sonderfall dargestellt: die Förderung kleiner Akteure. Insbesondere in den USA, der BRD und den Niederlanden war die Luft- und Raumfahrtindustrie federführend an den 
Programmen beteiligt. Die größten und teuersten Prototypen wurden in den USA, Deutschland und Schweden hergestellt. Vorsichtiger war man in Dänemark und den Niederlanden, wo ein beachtlicher Teil der Mittel in kleinere und mittelgroße Prototypen geflossen war. Zusammenfassend lässt sich sagen, dass alle Forschungsprogramme auf dem LSP basieren. Dabei stellt der Grad der Geltung des LSP ein Kontinuum dar, an dessen unterem Ende das dänische Programm liegt, am oberem Ende, das US-amerikanische.

\subsubsection{LSP-Programme versagen}

Im Verlauf der Pionierphase erreichten die Programme international nur geringfügige Kostensenkungen des Windstroms. Dieses gilt insbesondere für die großen Versuchsanlagen im Multi-MW-Bereich. Erwartungen bzgl. der Zuverlässigkeit, Energieoutput und Serienreife/ Beiträgen zur Kommerzialisierung wurden nicht erfüllt (vg. Tab.1c und Tab. 1d).

Tab. 1.2c Verfügbarkeit der Großwindanlagen (Arbeitsstunden pro Jahr)

\begin{tabular}{|l|l|l|l|l|l|}
\hline Prototyp & $\begin{array}{l}\text { Inst. von- } \\
\text { bis }\end{array}$ & $\begin{array}{l}\text { Arbeits- } \\
\text { stunden }\end{array}$ & $\begin{array}{l}\text { Installationsdauer } \\
\text { in Jahren* }\end{array}$ & $\begin{array}{l}\text { Zuverlässigkeit in } \\
\text { Arbeitsstunden pro Jahr }\end{array}$ & Prozent ${ }^{{ }^{8}}$ \\
\hline Mod-1 & $1979-1983$ & - & 5 & - & 0 \\
\hline Growian, D & $1981-1987$ & 420 & 7 & 60 & 0,7 \\
\hline WTS-4, USA & $1982-1994$ & 7200 & 13 & 554 & 6,3 \\
\hline Nibe A, DK & $1979-1993$ & 8414 & 15 & 561 & 6,4 \\
\hline Mod-2, USA & $1982-1988$ & 8658 & 7 & 1237 & 14,1 \\
\hline WEG LS-1, GB & $1987-1992$ & 8441 & 6 & 1407 & 16,1 \\
\hline Näsudden I, Schweden & $1983-1988$ & 11400 & 6 & 1900 & 21,7 \\
\hline Esbjerg, DK & $1988-1993$ & 14175 & 6 & 2363 & 27,0 \\
\hline Nibe B, DK & $1980-1993$ & 29400 & 14 & 2100 & 24,0 \\
\hline WTS-3, Schweden & $1982-1992$ & 26159 & 11 & 2378 & 27,1 \\
\hline Éole, Kan & $1987-1993$ & 19000 & 7 & 2714 & 30,1 \\
\hline Mod-5B, USA & $1987-1992$ & 20561 & 6 & 3427 & 39,1 \\
\hline
\end{tabular}

Quelle: Gipe 1995, 104 Tab. 4.1 und eigene Berechnungen

Tab. 1.2d Energieoutput (produzierte GWh)

\begin{tabular}{|l|l|l|l|l|l|l|}
\hline & $\begin{array}{l}\text { Inst. von - } \\
\text { bis }\end{array}$ & $\begin{array}{l}\text { produzierte GWh } \\
\text { absolut }\end{array}$ & $\begin{array}{l}\text { Installationsdauer } \\
\text { in Jahren* }\end{array}$ & $\begin{array}{l}\text { prod. GWh } \\
\text { pro Jahr }\end{array}$ & $\begin{array}{l}\text { Kapazität } \\
\text { (MW) }\end{array}$ & $\begin{array}{l}\text { prod. GWh pro } \\
\text { Jahr und MW }\end{array}$ \\
\hline Mod-1, USA & $1979-1983$ & - & 5 & 0 & 2,00 & 0 \\
\hline Growian, D & $1981-1987$ & - & 7 & 0 & 3,00 & 0 \\
\hline Nibe A, DK & $1979-1993$ & 2 & 15 & 0,1 & 0,63 & 0,2 \\
\hline WTS-4, USA & $1982-1994$ & 16 & 13 & 1,2 & 4,00 & 0,3 \\
\hline WEG LS-1, GB & $1987-1992$ & 6 & 6 & 1,0 & 3,00 & 0,3 \\
\hline Éole, Kan & $1987-1993$ & 12 & 7 & 1,7 & 3,60 & 0,5 \\
\hline Esbjerg, DK & $1988-1993$ & 10 & 6 & 1,7 & 2,00 & 0,9 \\
\hline Mod-2, USA & $1982-1988$ & 15 & 6 & 2,5 & 2,50 & 1,0 \\
\hline WTS-3, S & $1982-1992$ & 34 & 11 & 3.1 & 3,00 & 1,0 \\
\hline Nibe B, DK & $1980-1993$ & 8 & 14 & 0,6 & 0,63 & 1,0 \\
\hline Näsudden, S & $1983-1988$ & 13 & 6 & 2,2 & 2,00 & 1,1 \\
\hline Mod-5B, USA & $1987-1992$ & 27 & 6 & 4,5 & 3,20 & 1,4 \\
\hline
\end{tabular}

Quelle: Gipe 1995, 104 Tab. 4.1 und eigene Berechnungen

* bezieht sich auf die Zeit bis 1993, manche WEA wurden ersten später deinstalliert

Davon abgesehen, dass auch Mod-5B, der Prototyp mit den besten Ergebnissen, weit hinter mittelgroße Windturbinen zurückfällt, ${ }^{99}$ die zu dieser Zeit auf dem Markt erhältlich waren, weisen die LSP-Windanlagen untereinander große Differenzen auf. Das Hauptproblem lag in

\footnotetext{
${ }^{98}$ Diese Werte sind nicht zu verwechseln mit dem Anteil der Volllaststunden im Jahr. Hier geht es ausschließlich um die Verfügbarkeit.

${ }^{99}$ Gipe $(1995,114)$ zufolge erreichte eine damalige mittelgroße WEA etwa 6000 Arbeitsstunden pro Jahr. Alle Großanlagen - inklusive Mod-5B - sind von diesem Wert sehr weit entfernt.
} 
der mangelnden Verfügbarkeit. Häufige Pannen machten langwierige Reparaturarbeiten erforderlich. Wegen der dadurch entstehenden Kosten war ein wirtschaftlicher Betrieb ohne staatliche Zuschüsse ausgeschlossen. Daher wurden die meisten Prototypen i.a. nach wenigen Jahren deinstalliert.

Bewertung der Programmergebnisse

Anhand von Tab. 1.2c und 1.2d lassen sich keine wesentlichen Unterschiede im Erfolg der Programme feststellen. ${ }^{100}$ Zwar erlangte keine einzige der Versuchsanlagen je die Serienreife. Dennoch sind einige, wenngleich teuer erkaufte, Beiträge zur technischen Innovation zu vermerken. Der größte internationale Erfolg ist die dänische Teststation für kleine WEA bei Risoe, wobei dieses Programmelement vollständig aus dem LSP-Rahmen fällt und insofern keinen Maßstab bilden kann. Die Restaurierung der Gedser-Mühle und die Realisierung von Nibe B stehen weitgehend in Einklang mit dem LSP. Das Nibe-B-Design war nicht nur Grundlage der großen Esbjerg-WEA (s.o.), sondern auch der WinDane 40. Fünf dieser 750kW-Maschinen wurden 1986 installiert. Die britische Howden setzte von Anfang an auf kleinere Prototypen bis maximal 1MW. Mit einer verkleinerten $300 \mathrm{~kW}$-Version erzielte Howden zumindest vorübergehend Erfolge. Auch der Wind Energy Group gelang die Kommerzialisierung einer mittelgroßen WEA. Die italienischen Unternehmen West und Riva Calzoni kommerzialisierten je einen kleineren Prototyp (ca. 200kW-Generatoren). Westinghouse bemühte sich einige Jahre um die Vermarktung der kleinen MOD-0A, jedoch ohne Erfolg. Obgleich Mod-5B für den Markt unwichtig war, ist sie dennoch als relativer Erfolg gegenüber den anderen LSP-Windanlagen zu bewerten. Dasselbe gilt für die deutsche Aeolus II. Die von MBB hergestellte und 1993 ans Netz geschlossene 3MW-WEA, produzierte innerhalb eines Jahres 7,7GWh (Neue Energie 7/01, 90), also noch einmal doppelt so viel wie der durchschnittliche Output von Mod-5B.

Um den Erfolg der Programme zu bewerten, ist die Effizienz als zweiter Indikator hinzuziehen. Welche Mittel sind aufgewendet worden und was wurde demgegenüber erreicht? Ohne den Versuch zu unternehmen, ein exaktes Ranking zu erstellen, lassen sich doch einige Aussagen leicht begründen. So handelt es sich bei Dänemark (\$53 Mio. für F\&E, 1974-1992), Großbritannien ( $\$ 60$ Mio.) und Italien um Staaten, die relativ geringe Gelder für F\&EZwecke investiert hatten, während USA (\$486 Mio.) und BRD (\$178 Mio.) deutlich höhere Ausgaben tätigten (Gipe 1995, 73 Tab. 3.1). Aufgrund ihrer niedrigen Ausgaben und begrenzten Erfolge bei der Kommerzialisierung mittelgroßer WEA sind die Programme von Dänemark (Teststation Risoe), Italien und Großbritannien, noch als relativ erfolgreich zu bewerten. Gipe $(1995,73)$ zufolge schneidet das schwedische Programm am schlechtesten ab. Trotz der Investition von \$71 Mio. (ebd.,Tab. 3.1) gingen von diesem Programm gar keine Impulse zur Kommerzialisierung aus. Dasselbe gilt für Aelus II und Mod-5B, die jeweils erfolgreichsten Projekte des deutschen, bzw. des US-amerikanischen Programms. Beide waren sehr kostenintensiv, sodass diesen Programmen eine hohe Ineffizienz zugesprochen werden muss. Auch die kanadischen F\&E-Gelder schufen nichts anderes als die teure Eole-Maschine, ein Millionengrab. Die Niederlande und Spanien bewegen sich im Mittelfeld (vg. Tab. 1.2e).

\footnotetext{
${ }^{100}$ Das gilt auch für die Bundesrepublik, wo außer Growian, noch weitere, vergleichsweise gut arbeitende Prototypen hergestellt worden sind.
} 
Tab. 1.2e Effizienz der LSP-Programme

\begin{tabular}{|l|l|}
\hline $\begin{array}{l}\text { Programm-Bewertung (bzgl. } \\
\text { technischer Erfolge im Verhältnis } \\
\text { zur Höhe aufgewendeter Mittel) }\end{array}$ & Länder \\
\hline relativ gut & Dänemark, Großbritannien, Italien \\
\hline mäßig & Spanien, Niederlande \\
\hline ineffizient & Schweden, USA, BRD, Kanada \\
\hline
\end{tabular}

Quellen: vg. Kap. 1.1

\subsubsection{Fehleranalyse}

Das LSP hat nicht zu den erhofften Fortschritten geführt. Im folgenden geht es um die Klärung der Frage, worin eigentlich die Hauptfehler gelegen haben. In den USA sind mehr große WEA gebaut und dafür mehr Gelder aufgewendet worden als in allen anderen Ländern. Daher steht das Mod-Programm im Zentrum der folgenden Betrachtungen. Die meisten Aussagen treffen jedoch auf die übrigen Forschungsprogramme in derselben Weise zu.

Fehleinschätzung: Technologie ausgereift

Der vielleicht größte Fehler des LSP besteht in der Annahme der Verfügbarkeit des Knowhows zur Realisierung großer WEA, die bspw. von Ingenieuren wie Ulrich Hütter (s.o.) vertreten wird (Grundsatz 4). Technische Probleme an sämtlichen Prototypen und mangelhafter Energieoutput haben diese Annahme in der Praxis widerlegt. Anstatt kleine WEA schrittweise zu vergrößern, werden häufig unmittelbar Großwindanlagen konstruiert. Falls man überhaupt Zeit und Mittel für den Bau kleinerer Modellanlagen aufzuwenden bereit war, so fielen die nachfolgenden Technologiesprünge i.a. viel zu groß aus. Dieses galt insbesondere, weil nicht einmal die Modelle zufriedenstellende Ergebnisse lieferten. Besonders drastisch offenbarte sich das mangelnde Know-how bei dem Versuch der Herstellung einflügeliger Anlagen. So benötigte etwa MBB mehrere Jahre, um den stabilen Lauf des kleinen Monopetrus zu erreichen (s.o.). Ähnliche Erfahrungen machte Fokker mit der Darrieus-Technologie (s.o.). Die US-amerikanische Mod-Serie begann bei $100 \mathrm{~kW}$ Generatorenleistung (Mod-0). Sie wurde mit der Mod-0A $(200 \mathrm{~kW})$ fortgesetzt. Unmittelbar anschließend folgte Großwindanlage Mod-1 (2MW-Generator). Techniker, die am Planungsprozess Growians beteiligt waren, gingen vom 1,3-fachen der vorherigen Anlagengröße als allgemeiner Wachstumsgrenze für technische Neuentwicklungen aus (Pulczynski 1991, 51). ${ }^{101}$ Growian, den schwedischen WTS-3 und Näsudden I sowie der kanadischen Éole gingen offenbar keine Modellanlagen voraus. Mit der Größe eines Prototypen wächst zudem der zeitliche und finanzielle Aufwand, etwaige Fehler zu korrigieren und Reparaturen durchzuführen. Der Versuch, eine unausgereifte Technologie großtechnisch zu nutzen, war zum Scheitern verurteilt. ${ }^{102}$ Für die LSP-Akteure gab es keine

\footnotetext{
${ }^{101}$ Bereits in einer Denkschrift von 1980 übte die DGW eine international verallgemeinerbare Kritik am BMFTProgramm: ,So begrüßenswert die Förderung des Growian durch das BMFT ist, so muss doch festgestellt werden, dass ein Bau solcher Großmodelle ohne Erfahrungshintergrund aus dem Bau mittlerer und kleinerer Anlagen riskant erscheint. Niemand würde es für vernünftig halten, sich an den Bau von Großraumjets zu machen, ohne auf einen gesicherten Erfahrungsschatz aus dem Bau von Kleinflugzeugen zurückgreifen zu können' (zitiert nach: Tacke 2004, 161).

102 Gipe $(1995,99 f$.) erläutert ausführlich, weshalb insbesondere die Vergrößerung von WEA mit größeren Schwierigkeiten und höheren Kosten verbunden ist, als dieses bspw. für thermische Kraftwerke der Fall ist.
} 
Alternative zu Großwindanlagen. Entweder Windenergie ließ sich in das bestehende System integrieren, oder sie schied als zukünftige Energiequelle aus. Man war nicht bereit, der Windkrafttechnologie die Chance einer sukzessiven Entwicklung zu gewähren.

Fehleinschätzung: Luft- und Raumfahrtindustrie als optimale Hersteller Flugzeugbaukonzerne wie Boeing, Westinghouse, MBB und Fokker wurden mit der Herstellung der Prototypen beauftragt. Aufgrund ihrer praktischen Erfahrungen in der Aerodynamik und der Verwendung von Leichtbaustoffen, wurde ihnen die erforderliche Kompetenz zugesprochen. Ihre Methoden und Entwicklungswerkzeuge wie Simulationsprogramme, Konstruktionsverfahren und Verfahren zur Lastberechnung sollten sich auf die Windanlagentechnik übertragen lassen. Unberücksichtigt blieb dabei, dass Windkraftanlagen anderen Kräften und Lasten ausgesetzt waren und sich nicht wie Flugzeuge verhielten' (Heymann 1995, 463).

Andererseits ist bemerkenswert, dass dänische Versuchsanlagen, die mit wesentlich geringerem Einsatz an Hightechmaterialien und finanziellen Mitteln, ${ }^{103}$ mindestens ebenso gute Ergebnisse brachten wie die Produkte aus dem Mod-Programm. Die Gedser-Mühle des Elektroinstallateurs Juul, deren Design den Nibe-Anlagen Pate gestanden hat, war einfach und robust gehalten. Demgegenüber steht die mit technisch anspruchsvollen Mitteln gestaltete W34 von Hütter, an deren Leichtbauweise sich insbesondere die Ingenieure der Mod- und Growian-Projekte orientiert hatten. Heymann $(1995,463)$ zufolge sind die Unterschiede in den Baustilen Ausdruck unterschiedlicher Technologiepfade. Während die Dänen üblicherweise auf handwerkliche Verfahren zurückgreifen, dominiert in den USA und Deutschland eine ingenieurwissenschaftliche Herangehensweise. ${ }^{104}$ Hier verlässt man sich auf Rechnungsverfahren und theoretisch begründete Neuentwicklungen, dort beruft man sich auf Faustregeln, die aus langjähriger Erfahrung gewonnen wurden. Wie sich insbesondere auch bei der Fertigung kommerzieller mittelgroßer WEA zeigt, hat sich die dänische Methode für den Windanlagenbau als geeignet herausgestellt (s.u.).

Hemmnis: Lernresistenz

Mit der kanadischen Eole (3,6MW), der britischen LS-1 (3MW) und der dänischen EsbjergTurbine (2MW) sind 1987, bzw. 1988 drei Großwindanlagen in Betrieb genommen worden. Sie gehörten damit einer späten Generation der LSP-Prototypen an. Bis spätestens 1983 waren diverse ältere Modelle wie Mod-2, WTS-3 und Näsudden I bereits am Netz. Vergleicht man den durchschnittlichen Energieoutput und jährliche Arbeitsstunden beider PrototypGenerationen miteinander (Tab. 1.2c und 1.2d), so stellt man fest, dass zwischen beiden Generationen offenbar überhaupt keine Lernfortschritte erreicht wurden. Es kann nicht generell davon gesprochen werden, dass später in Betrieb genommene WEA effizienter gearbeitet hätten. Lerneffekte lassen sich ausschließlich innerhalb der Mod-Serie und für die 1993 in Betrieb genommene Aeolus II nachweisen (s.o.). Das LSP ist für die Windenergienutzung als grundlegender Fehler erkannt worden. Dennoch ist damit nicht erklärt, weshalb innerhalb des gesetzten Rahmens keine Fortschritte erzielt wurden. Die Ursachen dieser ,Lernresistenz' sollen im folgenden erörtert werden. Sie besteht sowohl bei den aufeinander folgenden Prototypen eines Herstellers (bspw. Westinghouse: Mod-0 und Mod-0A; Boeing: Mod-2 und Mod-5B; MAN: Growian und WKA-60; MBB: Monopetrus

\footnotetext{
${ }^{103}$ Die Arbeitskraft von Handwerkern und den von ihnen verwendeten Baustoffe sind weniger kostenintensiv als der Einsatz von Wissenschaftlern und Ingenieren.

${ }^{104}$ Als weiteren Grund für die Unterschiede in der Bauart (robust, etwas schwerfällig vs. so leicht und effizient wie möglich) führt Heymann $(1995,462)$ die unterschiedlichen Windverhältnisse an. Die Gedser-Mühle musste widerstandsfähiger sein und lief aufgrund ihrer Schwerfälligkeit erst bei wesentlich höheren Geschwindigkeiten an als bspw. W34.
} 
und Aeolus II; Kvaerner: Näsudden I und Näsudden II) als auch, was die Diffusion internationaler Erfahrungen betrifft.

Die folgenden Ausführungen beziehen sich insbesondere auf das Mod-Programm. Mit Abstrichen gelten sie auch für die übrigen Pionierländer. Eine besondere Schwierigkeit lag in der Gleichzeitigkeit der Auftragsvergabe. Durch die bewusste Orientierung auf ökonomische Konkurrenz wurden Spielräume für Nachbesserungen eingeengt und der Präsentation technisch unausgereifter Modelle Vorschub geleistet. Häufig wurden neue Aufträge vergeben, obwohl die Ergebnisse laufender Projekte noch gar nicht verfügbar waren. (Heymann 1995, 355). Boeing startete die Arbeiten an Mod-2 bereits kurz nachdem General Electric mit der Fertigung des Mod-1 begonnen hatte. Problematisch war die Diskontinuität zahlreicher Hersteller. Viele zogen sich nach offenkundigen Misserfolgen aus der Branche zurück (s.u.). Mit ihnen ging das Know-how verloren.

Windenergie war für die NASA und beteiligte Konzerne aus dem Flugzeugbau nicht unbedingt die erste Wahl. Gipe $(1995,103)$ hat das besondere Interesse der NASA am ModProgramm mit der Suche nach neuen Aufgabenfeldern erklärt, nachdem die Mittel für Raumfahrt gekürzt worden waren. Ähnlich war die Interessenlage der Flugzeugbauer. Über die eigentlichen Konstruktionsaufträge hinaus fielen Reparaturen und Aufträge zur Abänderung der Bauweise an, um technische Mängel zu beheben. Je größer und technisch anspruchsvoller die Prototypen gestaltet waren, desto zeit- und kostenaufwendiger waren solche Korrekturen. Um weitere Aufträge und Fördermittel zu erhalten, mussten solche Modifikationen als erfolgverheißend und die Prototypen insgesamt immer wieder als Erfolge dargestellt werden (ebd., 99). Als das Versagen dieser renommierten High-Tech-Akteure offenkundig geworden war und die Subventionen großer WEA ausliefen, zogen sich die Konzerne aus dem Sektor zurück (ebd., 114).

Die Tatsache, dass das wiederholte Scheitern der kostspieligen Mod-Prototypen über so viele Jahre von der US-amerikanischen Öffentlichkeit geduldet worden war, lässt sich kaum rational erklären. Besonders in Kalifornien ist der Glaube an die technologische Omnipotenz weit verbreitet. Man wollte es nicht wahrhaben, dass die NASA zum Mond fliegen, aber keine Windanlagen konstruieren konnte (vg. Heymann 1995, 455ff.). ${ }^{105}$

Hemmnis: Integration der Energiewirtschaft

In fast allen Ländern sind EVU und Verbände der Energiewirtschaft an der Leitung der LSPProjekte (bspw. Growian, Nibe, Éole, LS-1 und Näsudden II) beteiligt. Aufgrund der Erfahrungen mit dem Kraftwerksbetrieb wurde ihnen die erforderliche Kompetenz zugesprochen. Die bekannten grundsätzlichen Vorbehalte der Energiewirtschaft gegen die Windkraft änderten daran nichts.

Von den meisten EVU ist die neue Technik überhaupt nicht ernst genommen worden. In erster Linie diente ihr Engagement dazu, sich ein sauberes Image zu verleihen. Für die EVU war es zweitrangig, ob WEA eine Verfügbarkeit von 15 oder $50 \%$ erreichten, oder man einen Windpark mit 20- oder 2000kW-WEA ausstatten konnte. Bei gleichzeitiger Erhaltung des Status quo versuchten sie, den Protesten gegen ihre Kraftwerkspolitik, die Grundlage zu nehmen. In einigen Pionierländern mussten die EVU aktiv werden, um ökologische Betroffenheit zu suggerieren und gleichzeitig die Machbarkeit der Windkraft zu widerlegen. ${ }^{106}$ Für sie galt das Credo: ,Der Weg ist das Ziel.'

Grundsätzlich entschieden sich die EVU für Testanlagen im Megawattsektor. Design, Bauphase und Reparaturen waren entsprechend kostspielig und zeitintensiv. Sind die Mittel

\footnotetext{
${ }^{105}$ Zur Popularität F\&E-basierter Lösungsstrategien und einem entsprechenden Selbstvertrauen USamerikanischer Wissenschaftler und Ingenieure vg. van Est 1999, 299 FN 14).

${ }^{106}$ Bei den Intentionen der Growian-GmbH (s.o.) handelte es sich nicht um eine Ausnahme, sondern nur um einen besonders eklatanten Fall.
} 
einmal aufgebraucht, wurde von weiterer Initiative abgesehen. Dasselbe galt für den Betrieb der Prototypen, die nach Auslaufen der Förderung deinstalliert wurden, weil die Reparaturund Wartungskosten höher waren als die Einnahmen aus dem Stromverkauf. Trotz gegenteiliger Ankündigungen fand sich kein einziger Versorger, der auf eigene Rechnung weitere Großanlagen bestellt und damit die Kommerzialisierung der Prototypen unterstützt hätte. Solange nur an Prototypen geforscht wurde, galt für die EVU ,business as usual'. Der Erfolg des kommerziellen Sektors wurde bestmöglich negiert. Dennoch: Im Verlauf der 80er Jahre mussten die EVU anerkennen, dass der Siegeszug mittelgroßer WEA nicht mehr zu stoppen war und in manchen Pionierländern startete eine vorsichtige Neuorientierung.

\subsubsection{Zeitlicher Rahmen des LSP}

Die Forschungsprogramme enthalten eine Reihe von Gemeinsamkeiten. Sämtliche Bestrebungen sind am LSP orientiert und weisen daher dieselben Fehler auf: Diskontinuität der Projekte, Anwendung der Luft- und Raumfahrttechnologie, Lernresistenzen der Akteure, Entscheidung für energiewirtschaftliche Akteure als Projektleiter, Ignoranz der Erfolge kommerzieller Hersteller kleiner Windanlagen. Seit Mitte der 80er Jahre breitete sich eine Skepsis gegenüber der Großwindtechnologie aus. Die Entwicklung neuer Großanlagen wurde kaum noch gefördert. Die LSP-Hersteller erhielten keine Aufträge mehr und mussten akzeptieren, dass ihre Erzeugnisse keine Marktfähigkeit erreichen würden. Die meisten Konzerne zogen sich daraufhin vollständig aus dem Sektor zurück (vg. Tab. 1.2f).

Tab. 1.2f Rückzug der LSP-Hersteller

\begin{tabular}{|l|l|l|l|}
\hline Hersteller & Land & Prototyp & $\begin{array}{l}\text { Jahr des Ausstiegs } \\
\text { aus dem } \\
\text { Windsektor }\end{array}$ \\
\hline General Electric & USA & Mod-1 & 1983 \\
\hline Westinghouse & USA & Mod-0; Mod-0A & $1988^{*}$ \\
\hline Boeing & USA & Mod-2 & $1988^{*}$ \\
\hline Grumman Aerospace & USA & Mod-Programm & $1988^{*}$ \\
\hline McDonnell Douglas & USA & Mod-Programm & $1988^{*}$ \\
\hline Lockheed & USA & Mod-Programm & $1988^{*}$ \\
\hline Hamilton Standard & USA & WTS-4 & $1986^{*}$ \\
\hline Fokker Aircraft & Niederlande & 5m-VAT & 1985 \\
\hline Storck & Niederlande & $\begin{array}{l}\text { Newecs-45; 25m- } \\
\text { HAT }\end{array}$ & 1987 \\
\hline Holec & Niederlande & Sexbierum-WP & $1991^{*}$ \\
\hline Voith & Deutschland & WEC 520 & $1985^{*}$ \\
\hline MAN & Deutschland & $\begin{array}{l}\text { Growian; WKA-60; } \\
\text { AWEC-60 }\end{array}$ & $1994^{*}$ \\
\hline MBB & Deutschland & $\begin{array}{l}\text { Monopetrus; Aeolus } \\
\text { II }\end{array}$ & $1994^{*}$ \\
\hline Howden & Großbritannien & WEA bis 1MW & 1989 \\
\hline Quellen: & & \\
\hline
\end{tabular}

Quellen: vg. Kapitel 1.1

* Unsicherheit von bis zu zwei Jahren

Eine weitere Entwicklung, in der sich eine internationale Distanzierung vom LSP äußert, besteht in der Tendenz, Prototypen vorsichtiger zu dimensionieren. Nachdem sich die erhofften Skaleneffekte nicht eingestellt hatten, überwogen die Zweifel am Nutzen des größtmöglichen Designs. Dieses gilt insbesondere auch seit 1983, dem Jahr der Inbetriebnahme Growians. Konkrete Planungen zum Bau weiterer, noch größerer Versuchsanlagen, bspw. Grohat (NL), Howden (GB) und Growian II (BRD), wurden zugunsten vorsichtiger dimensionierter Konzepte mit Generatoren von 1-1,2MW modifiziert (Downscaling). Da die Größe kommerzieller WEA immer mehr zugenommen hatte, lässt sich von einer Verringerung der Kluft zwischen marktgängigen Produkten und LSP-Prototypen sprechen. Denn der technische Standard des kommerziellen Sektors hatte sich zwischen 1980 
und 1990 von $50 \mathrm{~kW}$ auf 200kW-Generatorenkapazität vervierfacht. Im Jahr 1990, auf der Windenergiekonferenz der EU in Madrid, musste selbst Wolfgang Palz, einer der konsequentesten Vertreter der Multimegawattmaschinen, eingestehen, dass die wirtschaftlichste Anlagengröße maximal ein Megawatt betrage (Gipe 1995, 101).

In diesen Entwicklungen äußert sich die Abkehr vom LSP: nachlassende Forschungsförderung, Rückzug der LSP-Hersteller und Downscaling. Diese Phänomene können seit Mitte der 80er Jahre in allen Pionierländern beobachtet werden:

USA (1973-1988) $)^{107}$

Seit 1973 stieg der Forschungshaushalt für LSP-Projekte kontinuierlich an und erreichte 1980 sein Maximum bei \$64 Mio. Bis 1988 schrumpft er auf \$9 Mio. Großanlagen wurden nach Inbetriebnahme von Mod-5B (1988) nicht mehr gefördert. Sämtliche Hersteller des ModProgramms haben sich bis Ende der 80er Jahre aus der Windenergiebranche verabschiedet.

Dänemark (1977-1988)

Das LSP war in Dänemark vergleichsweise schwach ausgeprägt. Dennoch wurden auch hier zwischen 1976 und 1988 mit den Nibe-Zwillingen, der Esbjerg-Turbine und dem MasnedoeWindpark einige LSP-Projekte gefördert. Im Masnedoe-Projekt (5x WinDane $750 \mathrm{~kW}$, seit 1987 in Betrieb) zeigt sich eine Tendenz zum Downscaling.

Niederlande (1976-1985)

Zwischen 1976 und 1981 werden mindestens 85\% des Etat für LSP-Projekte genutzt. ${ }^{108}$ Das NOW zeichnet sich durch eine gewisse Vorsicht gegenüber kostenintensiven Großanlagen aus. Die in der Zeit 1983-1985 hergestellte Newecs-45 (1MW-Generator) bildete insofern eine Ausnahme. Mit Einführung des IPW lässt sich eine deutliche Abkehr vom LSP auf das Jahr 1986 datieren. Seitdem beträgt der maximale LSP-Anteil 36\%. Von jetzt gewinnt die Forschungsarbeit an kommerziellen WEA an Bedeutung. Die LSP-Hersteller Fokker, Storck und Holec zogen sich zwischen 1985 und 1991 aus dem Sektor zurück.

Deutschland (1977-1993)

Zwischen 1977 und 1988 hat das BMFT mindestens 75\% der Mittel für LSP-Projekte aufgewendet. Mit \$25 Mio. erreicht die Förderung 1981 ein Maximum, ging anschließend bis 1984 auf \$5 Mio. zurück. Wichtigste Hersteller waren die Technologiekonzerne MAN und MBB. Beide gaben ihre Aktivitäten in der Windenergiebranche bis Mitte der 90er Jahre auf. ${ }^{109}$

Großbritannien (1977-1990)

Das wesentliche LSP-Projekt war LS-1 (3MW-Generator), das bis Mitte der 80er Jahre den größten Teil der Ressourcen gebunden hatte. In der zweiten Hälfte des Jahrzehnts förderte das Energieministerium ausschließlich Designs, deren Generatorenkapazitäten weniger als ein Megawatt betragen hatten. Wichtigster Hersteller Howden stellt 1989 die Windanlagenproduktion ein.

\footnotetext{
${ }^{107}$ Die angegebenen Jahreszahlen begründen sich folgendermaßen: Das Anfangsjahr ist das Jahr, in dem das erste LSP-Programm gestartet wurde. Das Endjahr bezieht sich auf die Installation der letzten Großwindanlage, die im LSP-Rahmen staatliche Förderung erhielt.

${ }^{108}$ Die Kritik, von den Mitteln des NOW-1 seien nur maximal drei Prozent in dezentrale Projekte geflossen, wurde von P. Sens (Direktor des NOW) zurückgewiesen. Seiner Darstellung zufolge waren es 15\% (Verbong 1999, 147). Nimmt man diesen Wert als Obergrenze, verbleiben 85\% für LSP-Zwecke.

109 Bemerkenswert ist, dass zwischen 1984 und 1986 nach den Growian-Erfahrungen, noch eine zweite Großanlagen-Generation auf den Weg gebracht wurde (WKA-60, Aeolus II).
} 
Schweden (1975-1993)

Insgesamt sind zwischen 1974 und 1992 \$71 Mio. für die Forschung an WEA, d.h. insbesondere die Realisierung von drei LSP-Prototypen, aufgewendet worden. Während die ersten beiden, Näsudden I und WTS-3, 1982, bzw. 1983 in Betrieb gegangen waren, startete das letzte schwedische LSP-Projekt, Näsudden II, Teil einer deutsch-schwedischen Kooperation, erst 1986.

Kanada (1974-1987)

1982 startete das einzige LSP-Projekt Éole (3,6MW-Generator). Dafür wurden bis zur Fertigstellung im Jahr 1987, Cnd. \$37 Mio. zur Verfügung gestellt. Bereits seit 1984 hat Kanada die Fördermittel deutlich reduziert. Nach 1987 ging das Interesse an der Windenergie verloren.

Spanien (1979-1989)

1985 erhielt MAN den Auftrag zur Herstellung der AWEC-60 (1,2MW). Im internationalen Vergleich handelt es sich bei dem 1989 installierten Prototyp um eine kleine Prototyp-WEA. Weitere LSP-Projekte wurden nicht gefördert.

Italien (1980-1992)

Aeritalia, größter Flugzeugbauer Italiens, hat im Jahr 1986 die Planungsarbeiten zur Herstellung, von Gamma-60 (1,5MW), der einzigen Großwindanlage aufgenommen. Nach Errichtung des Prototyps im Jahr 1992, förderte Italien keine weiteren LSP-Projekte.

Tab. 1.2g Geltungszeiträume der LSP-Programme

\begin{tabular}{|l|l|l|l|l|l|l|l|l|l|l|l|l|l|l|l|l|l|l|l|l|l|l|l|}
\hline Land/ Jahr 19.. & 72 & 73 & 74 & 75 & 76 & 77 & 78 & 79 & $\mathbf{8 0}$ & $\mathbf{8 1}$ & $\mathbf{8 2}$ & $\mathbf{8 3}$ & $\mathbf{8 4}$ & $\mathbf{8 5}$ & 86 & 87 & 88 & 89 & 90 & 91 & 92 & 93 & 94 \\
\hline USA & & + & + & + & + & + & + & + & + & + & + & + & + & + & + & + & + & + & & & & & \\
\hline Kanada & & & + & + & + & + & + & + & + & + & + & + & + & + & + & + & & & & & & & \\
\hline Schweden & & & & + & + & + & + & + & + & + & + & + & + & + & + & + & + & + & + & + & + & + & \\
\hline Deutschland & & & & & + & + & + & + & + & + & + & + & + & + & + & + & + & + & + & + & + & + & \\
\hline Niederlande & & & & & + & + & + & + & + & + & + & + & + & + & & & & & & & & & \\
\hline Dänemark & & & & & & + & + & + & + & + & + & + & + & + & + & + & + & & & & & & \\
\hline Großbritannien & & & & & & + & + & + & + & + & + & + & + & + & + & + & + & + & + & & & & \\
\hline Spanien & & & & & & & & + & + & + & + & + & + & + & + & + & + & + & & & & & \\
\hline Italien & & & & & & & & & + & + & + & + & + & + & + & + & + & + & + & + & + & & \\
\hline insgesamt & 0 & 1 & 2 & 3 & 5 & 7 & 7 & 8 & $\mathbf{9}$ & $\mathbf{9}$ & $\mathbf{9}$ & $\mathbf{9}$ & $\mathbf{9}$ & $\mathbf{9}$ & 8 & 8 & 7 & 6 & 4 & 3 & 3 & 2 & 0 \\
\hline
\end{tabular}

Quellen: vg. Kap. 1.1

Aus Tab. 1.2g geht hervor, dass zwischen 1980 und 1985 alle Pionierländer LSP-Programme finanzierten. Man kann diese erste Hälfte der 80er Jahre daher als die Blütezeit des LSP ansehen. Davor und danach hat sich die Zahl aktiver Programme verkleinert. Sowohl im Start, als auch im Auslaufen der Forschungsförderung lassen sich beachtliche internationale Ungleichzeitigkeiten erkennen. Spätestens für das Jahr 1990 ist ein Auslaufen der LSPdominierten Technologiepolitik zu konstatieren: Neue Großprojekte werden nicht mehr gestartet, die meisten sind abgeschlossen. Von den ursprünglich 14 wichtigsten Herstellern der Prototypen sind jetzt nur noch einzelne in der Branche tätig (vg. Tab. 1.2f). Ein retardierendes Moment war die Förderung durch EU-Mittel. Während auf Staatenebene die Forschungsetats in der zweiten Hälfte der 80er Jahre i.a. verkleinert wurden, erhielten LSPProjekte (Aeolus II/Näsudden II; Gamma-60) zu diesem Zeitpunkt noch großzügige Unterstützung durch die EU. Mit Wolfgang Palz, dem Leiter der F\&E-Abteilung der EU für Windkraft und dem renommierten Ingenieur Erich Hau vom ISET, hatten LSP-Akteure eine starke Lobby, welche erst auf der EU-Windenergiekonferenz von 1990 in Madrid in die Defensive geraten ist (Gipe 1995, 97ff.). 


\subsubsection{Einfluss zivilgesellschaftlicher Akteure auf die Forschungspolitik}

Eigenschaft (6) des LSP zufolge hatten zivilgesellschaftliche Akteure keine Möglichkeiten, Einfluss auf die Mittelvergabe zu nehmen oder an den Projekten aktiv mitzuwirken. Kleine Unternehmen verfügen weder über die erforderliche Finanzkraft, noch das technische Knowhow. Dasselbe gilt für Akteure aus dem Umfeld der Umwelt- und Anti-AKW-Bewegung, welche darüber hinaus dem LSP kritisch gegenüber stehen. ${ }^{110}$ Mit anderen Worten: Ein LSPProjekt unter Beteiligung zivilgesellschaftlicher Akteure wäre kein LSP-Projekt.

Im folgenden sollen zwei Aspekte zivilgesellschaftlicher Einflussnahme - hier geht es ausschließlich um Umwelt-/Anti-AKW-Akteure - auf die Forschungsprogramme betrachtet werden: erstens, indirekte Einflussnahme auf die Durchführung der Programme insgesamt und zweitens, direkte (Mit)Entscheidung über die Mittelvergabe sowie aktive Beteiligung an den Projekten.

Indirekte Einflussnahme

Nach der Ölkrise bemühten sich alle Pionierländer, die Energiesicherheit durch den Bau von Atomkraftwerken zu erhöhen. Oft lag die Hauptbarriere darin, derartige Planungen gegen öffentliche Proteste durchzusetzen. In manchen Pionierländern sind erneuerbare Energien offenbar, neben tatsächlich erwarteter energiepolitischer Vorteile, als Mittel betrachtet worden, um die Gesellschaft mit der staatlichen Energiepolitik zu auszusöhnen.

\section{USA}

Insbesondere in Kalifornien entstand Anfang der 70er Jahren eine Anti-AKW-Bewegung (,Green California'). Ihr gelang es, die Öffentlichkeit für eine kritische Wahrnehmung der Atomenergie $\mathrm{zu}$ sensibilisieren. Beschwerden und Klagen gegen den Neubau von Kernreaktoren seitens der Anrainer häuften sich. Als Reaktion führten die Behörden strengere Genehmigungsverfahren ein. Seit 1975 gaben die EVU viele AKW-Planungen auf, Anträge für Neubauten wurden kaum mehr gestellt (s.o.). Insofern steht eine indirekte Einflussnahme zivilgesellschaftlicher Akteure auf die Energiepolitik außer Frage. Ob ein Zusammenhang zwischen den Durchsetzungsproblemen der Atomtechnologie und der Forschungspolitik für Großwindanlagen existiert, lässt sich an dieser Stelle nicht einwandfrei nachweisen.

\section{Dänemark}

Nachdem der DEF 1974 ankündigte, alle zwei Jahre ein neues AKW in Betrieb zu nehmen, kam es zu massiven Protesten. Als Folge schob das Parlament die Entscheidung über die Kernenergienutzung immer wieder auf, bis die Atomkraft 1985 entgültig als energiepolitische Option ausgeschlossen wurde. Atomenergie war in Dänemark, bereits vor dem GAU von Tschernobyl (1986), politisch nicht durchsetzbar. Die in 70er den Jahren aufgenommenen Forschungen im Windenergiesektor dienten nicht nur dem Zweck der Versorgungssicherheit, sondern waren auch eine Antwort auf die Proteste. Dasselbe gilt für die Beteiligung des DEF am Forschungsprogramm, dessen großtechnische Orientierung den Interessen des DEF entsprach. Ove Dietrich, Leiter des Versorgers SEAS hatte die Installation der Nibe-Zwillinge später als, no more than a political show' bezeichnet (zitiert nach: Heymann 1999, 135 FN 16). DEF-Sprecher Jakob L. Hansen zufolge hätten die Erfahrungen mit den

\footnotetext{
${ }^{110}$ Diese Seite favorisiert eine dezentrale Energieversorgung. Sie kritisiert die LSP-Orientierung der Technologiepolitik ebenso wie die Beteiligung der EVU. Auf diese Weise werde der Status quo zentraler und monopolisierter Energieversorgung aufrechterhalten, was von Fürsprechern des ,sanften Energiepfades' abgelehnt wird. ,The small wind system element was encouraged by the soft energy advocates because of their theoretical interest in small-scale, decentralized energy production. Small machines would increase social choices and their use would improve energy consciousness...Nevertheless, as a result of the soft versus hard energy controversy, the budgeting of the federal program received explicit political meaning. The soft energy set criticized the FWEP's emphasis on the development of large turbines and argued that the program supported the present electricity power structur and hegemonic technologogical culture.' (van Est 1999, 39f.)
} 
Nibe-Anlagen bewiesen, dass Windkraft zur Stromproduktion ungeeignet sei (WPM 9/86, 6). Wichtigstes Ziel war offenbar die Immunisierung gegen öffentliche Kritik. Auch ging es dem DEF darum zu verhindern, dass die EVU ,infolge des erheblichen öffentlichen Drucks durch Gesetze des Folketing in ihrem Gestaltungsspielraum noch weiter eingeengt' (Tacke 2004, 137) wurden. Für Dänemark steht die indirekte Einflussnahme der AKW-Gegner damit außer Frage.

Niederlande

Generell lässt sich sagen, das die Naturschutzverbände ebenso wie Atomkraftgegner und Fürsprecher erneuerbarer Energien, allein aufgrund der hohen Mitgliederzahlen der wichtigsten Verbände, einen wichtigen politischen Faktor darstellen. Reiche zufolge (2002a, 70f.), beeinflusst die aktionsorientierte Organisation Greenpeace (650.000 Mitglieder) die öffentliche Meinung noch stärker als die beiden großen Naturschutzgruppen Natuurmonumenten (850.000 Mitglieder) und World Nature Fonds (700.000 Mitglieder).

Als Reaktion auf die Proteste gegen den Bau des schnellen Brüters von Kalkar, erhielten die Bürger die Möglichkeit, eine Steuer zur Finanzierung der kostspieligen Nuklearanlage (,Kalkar-Heffing') stattdessen in einen Fonds zur Förderung erneuerbarer Energien einzuzahlen. Die Proteste hatten zudem großen Anteil an der Durchsetzung eines Stopps des Atomprogramms im Jahr 1987. Ebenso wie für Dänemark erscheint auch für die Niederlande die Annahme indirekter Einflussnahme auf die Windenergiepolitik evident.

Deutschland

Trotz starker öffentlicher Proteste, gelang es den AKW-Gegnern nicht, das Atomprogramm zu stoppen. Dennoch gerieten die Verantwortlichen einer auf Atomkraft festgelegten Energiepolitik in deutliche Legitimationsschwierigkeiten. Wie am Beispiel des GrowianProjekts gezeigt, diente das Windenergieprogramm großteils dazu, Windkraft als energiepolitische Alternative zu diskreditieren. Für die BRD ist damit ein indirekter Einfluss auf die Forschungsförderung der Windkraft nachgewiesen.

Schweden

In der zweiten Hälfte der 70er Jahre herrschte in der schwedischen Gesellschaft eine deutlich ablehnende Haltung gegen Atomkraft, die sich in der Abwahl der Sozialdemokraten manifestierte. Diese Stimmungslage äußerte sich auch 1980, als ein Referendum zu Gunsten des Atomausstiegs ausgefallen war. Die Einflussnahme der Zivilgesellschaft auf die Energiepolitik äußert sich in der Tatsache der Durchführung dieses Referendums an sich und in dessen Ausgang. Ähnlich wie bei den USA lässt sich ein Zusammenhang zwischen dem Schwinden der Atomenergieoption und dem Start der Windenergieförderung auch für Schweden nicht einwandfrei nachweisen.

Italien

Auch in Italien ist der Atomausstieg per Referendum entschieden worden. In dessen Folge sind alle vier Atomreaktoren zwischen 1987 und 1990 stillgelegt worden. Das vorherige Komitee für Atomkraft ist in eine Agentur für erneuerbare Energien umgewandelt worden. Hier ist der Fall ähnlich gelagert wie in Schweden und den USA: indirekte Einflussnahme auf die Energiepolitik: ja; Einfluss auf die Windenergiepolitik: möglich, aber hier nicht nachzuweisen.

Prinzipiell ist es schwieriger, die Wirksamkeit von Demonstrationen und Kampagnen hinsichtlich ihre Einflussnahme auf Entscheidungen zentraler Politik nachzuweisen als im Falle direkter Partizipation. Nur für die BRD, Dänemark und Niederlande kann mit hoher Wahrscheinlichkeit von einem wesentlichen Einfluss außerparlamentarischer Politikakteure auf die Durchführung der Windenergieforschungen ausgegangen werden. Ebenfalls nachgewiesen werden konnte die Annahme energiepolitischer Einflussnahme bzgl. der Atomenergienutzung in den Pionierländern USA, Schweden und Italien. Dem 
Forschungsstand zufolge war der direkte und indirekte Einfluss von Umwelt- und AntiatomAkteuren auf Energiepolitik und Windenergieförderung in Großbritannien, Kanada und Spanien eher gering.

Direkte Einflussnahme

Nennenswerte Anteile der Forschungsmittel für Projekte ohne LSP-Charakter wurden ausschließlich in Dänemark und den Niederlanden aufgewendet. In anderen Staaten wie Großbritannien konnten sich die Fürsprecher kleiner Windanlagen, mit ihrer Kritik an der LSP-Ausrichtung der Programme, nicht durchsetzen. ${ }^{111}$

\section{Dänemark}

Der Aufbau und die Arbeiten an der Teststation für kleine WEA auf dem Gelände des damaligen Nuklearforschungszentrums von Risoe waren für die Entwicklung der kommerziellen Windanlagenindustrie von sehr hoher Bedeutung. Der in dem Forschungszentrum tätige Ingenieur Helge Petersen gab wichtige Impulse zur Realisierung der Teststation und machte seinen Einfluss gegenüber dem Handelsministerium geltend. Von Petersen, dem ersten Leiter der Teststation abgesehen, zählten die ersten Ingenieure zu Mitgliedern der Organisation für erneuerbare Energien. Das Projekt stellt insofern eine Besonderheit dar, weil dessen Zweck, die Optimierung und Prüfung von Kleinwindanlagen, dem LSP zuwider lief (s.o.).

Die Weichenstellung für das Ende des LSP erfolgt in Dänemark bereits 1981 (Energiplan 81), um Jahre früher als in allen übrigen Ländern. Dabei wurden mehrere Vorschläge des alternativen Energieplans der OAA (Organisation zur Information über Atomkraft) in den Status offizieller Politik erhoben (Hantsch 1998). Im Energiplan 81 ist die Förderung dezentraler Windenergienutzung festgeschrieben.

\section{Niederlande}

Die in das NOW integrierten Umweltakteure opponierten gegen den LSP-Mainstream des Programms. Ihr Einfluss auf die Wahl der Projekte war gering. ${ }^{112}$ Dennoch war es ihr in begrenztem Umfang gelungen, neben den Hauptlinien, Großtechnikförderung und Grundlagenforschung, einen neue Forschungszweig mit dem Ziel dezentraler Anwendungen der Windkraft zu etablieren. In diesem Zusammenhang ist besonders die Windenergie Gruppe an der Universität von Eindhoven zu nennen, die Konzepte zur Energieversorgung der Dritten Welt erarbeitete (Verbong 1999, 146).

Tabelle 1.2h fasst die Ergebnisse zur Einflussnahme zivilgesellschaftlicher Akteure auf die Windenergieförderung zusammen. Dabei wurde berücksichtigt, dass Atomausstiegsbeschlüsse bei allen hier untersuchten Fällen nur unter Beteiligung,von unten' möglich waren; seien es die Wähler eines Referendums (Schweden, Spanien, Italien), oder Reaktionen auf Proteste (Dänemark, Niederlande). Je stärker die Partizipation zivilgesellschaftlicher Akteure insgesamt einzuschätzen ist, desto weiter links sind die entsprechenden Länder in der Tabelle aufgeführt.

\footnotetext{
${ }^{111}$ Die ,Appropriate Technology Group' von der offenen Universität Großbritanniens sprach von einer ,simplistic attitude toward economies of scale'. Der Zusammenschluss kritisiert das Fehlen eines ,accurate assessment of the savings obtainable through quantity production of medium scale wind programmes' (zitiert nach: WPM 5/86, $11)$.

${ }^{112}$ Der Direktor des Zentrums für Energieeinsparung in Delft kritisiert das Netzwerk aus Wirtschaftsministerium, Forschungsinstituten und großer Industrie. Dieses Netzwerk würde sich grundsätzlich gegen jede neue Idee sperren, sofern sie von außerhalb käme (Verbong 1999, 151).
} 
Zivilgesellschaftliche Einflussnahme auf Energiepolitik und Windenergieförderung

\begin{tabular}{|l|l|l|l|l|l|l|l|l|l|}
\hline & DK & NL & BRD & S & I & USA & SP & GB & KAN \\
\hline Ausstiegsbeschluss? ${ }^{113}$ & ja & ja & nein & ja & ja & nein & ja & nein & nein \\
\hline $\begin{array}{l}\text { Aktive } \\
\text { wahrnehmbare Anti- } \\
\text { AKW-Bewegung }\end{array}$ & ja & ja & ja & ja & ja & nein & nein & nein \\
\hline $\begin{array}{l}\text { Indirekter Einfluss auf } \\
\text { die Durchführung der } \\
\text { LSP-Programme } \\
\text { nachweisbar? }\end{array}$ & ja & ja & nein & nein & nein & nein & nein & nein \\
\hline $\begin{array}{l}\text { ZG-Einfluss } \\
\text { direkt? }\end{array}$ & ja & ja & nein & nein & nein & nein & nein & nein & nein \\
\hline
\end{tabular}

Quellen: vg. Kap. 1.1

Insgesamt lassen sich die Partizipationsgrade in drei grobe Kategorien einteilen: Dänemark, Niederlande (stark), BRD, Schweden, USA, Italien (durchschnittlich), Großbritannien, Spanien und Kanada (schwach). Direkte Partizipation war nur in der ersten Gruppe möglich. Für die zweite Gruppe konnte nachgewiesen werden, dass zivilgesellschaftliche Akteure teilweise sehr gute Erfolge gegen Atomenergienutzung errungen hatten. Weniger aktiv waren Zivilgesellschafter in Spanien, Großbritannien und Kanada, wo die Höhe erschließbarer Windkraftpotenziale für sich genommen ein starkes Argument für den regenerativen Energieträger bedeutete.

\section{Fazit}

Das LSP, als ein erster Ansatz zur Etablierung der Windkraft, ist in allen Pionierländern gescheitert. Größere Innovationen gingen aus keinem einzigen Projekt hervor. Die Annahme, vorhandene Technologien aus der Luftfahrt 1:1 auf die Windkraft übertragen zu können, hat sich als falsch herausgestellt. Es fehlte am spezifischen Know-how. Die Produktion der Megawattanlagen wäre ohne Millionensubventionen ein Wagnis gewesen, auf das sich die beteiligten Unternehmen niemals eingelassen hätten. Für sie war die Windkraft nicht längerfristig als Technologie interessant, sondern zuvorderst als Quelle neuer Aufträge.

Die EVU hatten kein Interesse an dezentralen Energieträgern wie der Windkraft, weil ein Abrücken von dem auf fossilen und nuklearen Großkraftwerken basierenden Energiepfad zu erheblichen Transaktionskosten geführt hätte. Den Regierungen ging es mit ihrer Finanzierung der Windenergieprogramme häufig darum, diesen Status quo der Stromsysteme $\mathrm{zu}$ erhalten und Proteste ins Abseits zu stellen. Durch mangelhafte Ergebnisse der Großwindanlagen konnte Windenenergie als alternative Energiequelle in Misskredit gebracht werden.

\footnotetext{
${ }^{113} \mathrm{Ob}$ ein Ausstieg aus der Kernenergienutzung beschlossen wurde, ist nicht in allen Fällen auf die Stärke der Proteste zurückzuführen. In Spanien bspw. ist der Ausstieg auch ohne international wahrnehmbare Anti-AKWBewegung beschlossen worden. Andererseits war den sehr aktiven Kernkraftgegnern in Deutschland zunächst kein Erfolg beschieden. ,Forschungspolitik und Wirtschaft hatten sich auf beträchtliche Aufwendungen und Verpflichtungen eingelassen und industrielle und wissenschaftliche Kapazitäten geschaffen. Es existierte ein einflussreiches, auf die Atomkraft eingeschworenes Establishment aus Politik, Versorgungsunternehmen und Industrie' (Heymann 1995, 362). Deshalb wollte man unbedingt an der Nuklearenergie festhalten. Zudem ging das BMFT davon aus, dass Windenergie aufgrund der zentralen Struktur des deutschen Stromnetzes schwerer zu integrieren gewesen wäre als bspw. in Dänemark. Heymann $(1995,464)$ verweist auf eine ,relativ abgeschirmte Elite energiepolitischer Entscheidungsträger,...die anderen politischen Strömungen nur geringe Partizipationsmöglichkeiten und einen geringen Einfluss auf die Energiepolitik' ermöglichte. Ein langfristiger Ausstieg wurde erst unter der Rot-Grünen Regierung beschlossen. Weniger schwer fiel der Ausstieg in den Niederlanden und Dänemark. Hier zeichneten sich bereits in der zweiten Hälfte der 70er Jahre massive ökonomische Probleme bei der Umsetzung ihrer Atomprogramme ab, so dass durch eine Beendigung keine allzu großen Verluste entstanden (Lagaaij/Verbong $(1999,39)$ und Siggaard et.al.(1999, 89)).
} 
Die LSP-Politik geriet zunehmend in die Kritik und hat seit Mitte der 80er Jahre an Bedeutung verloren. Paradigmatisch und international generalisierbar sind Gipes Äußerungen $(1995,90)$ über das Mod-Programm: ,For Congress, R\&D is often politically preferable to market incentives because it gives the semblance of action without creating programs that could threaten the status quo and stir heated dabate'. Gipe (ebd., 93) zitiert einen Repräsentanten der amerikanischen Naturschutzorganisation Sierra Club: ,...R\&D serves only to keep renewables in a ,green ghetto'.'

Neben dem LSP existierte in der Pionierphase eine zweite Entwicklungslinie der Windenergiepolitik, die sich als erfolgreicher erwiesen hat: Nachfrageförderung kleiner Windanlagen von kommerziellern Herstellern.

\section{Die internationale Pionierphase der Windenergienutzung}

Vom Nischenmarkt in Dänemark zur proven technology (1975 - 1991)

Vollständig getrennt vom LSP-Sektor haben sich während der späten 70er Jahre in einzelnen Ländern rudimentäre Märkte für kleine WEA herausgebildet. Seit 1979/80 in Dänemark und Kalifornien, ab Mitte der 80er Jahre auch in der Bundesrepublik und den Niederlanden, sind kommerzielle WEA von staatlicher Seite gefördert worden. Gegenüber dem LSP stellt diese Förderpolitik einen Paradigmenwechsel dar: Während es im LSP um die Entwicklung kommerzieller WEA ging, werden nun Produkte gefördert, die bereits über eine mehr oder weniger ausgeprägte Serienreife verfügen.

Nicht nur in den Pioniermärkten, sondern auch bspw. in Großbritannien, Spanien, Griechenland und Schweden waren bereits in den 80er Jahren winzige Märkte für kleine WEA entstanden. Diese stagnierten jedoch aufgrund ausbleibender Fördermaßnahmen die gesamte Pionierphase hindurch. Windenergie und noch dazu kleine Windanlagen, durch deren Anwendung der Status quo der Stromversorgungssysteme herausgefordert werden könnte, bedeuteten für die politischen Entscheidungsträger ein wirtschaftliches Risiko mit offenem Ausgang. Es bedurfte daher mindestens eines weiteren Motivationsfaktors, der in allen Pioniermärkten gegeben war: die Erhaltung des sozialen Friedens. Dort, wo gegen den Bau von Atomkraftwerken buchstäblich gekämpft wurde und eine breite Öffentlichkeit der Atomenergienutzung kritisch gegenübersteht, mussten demokratische Regierungen in irgendeiner Weise auf die Proteste reagieren. Insofern lässt sich die neue Windenergiepolitik der Pioniermärkte - zumindest in der Anfangszeit - als ein Zugeständnis an die Protestakteure interpretieren. Zudem handelt es sich bei den Pioniermärkten um die einzigen Länder, in denen sämtliche, eine Windenergiepolitik begünstigende Faktoren gegeben sind: Windenergieressourcen, Importabhängigkeit von konventionellen Energierohstoffen und Proteste gegen Atomenergienutzung (vg. Tab. 1.2a). Die Vorreiterrolle der Pioniermärkte wird aus Tab. 2a ersichtlich. 
Tab. 2a Internationale Markteinführung

\begin{tabular}{|l|l|l|l|l|l|l|l|l|l|}
\hline & DK & KAL & NL & BRD & IND & GB & GR & SCH & SP \\
\hline 1980 & 7 & & & & & & & & \\
\hline 1981 & 12 & 10 & & & & & & & \\
\hline 1982 & 17 & 70 & & & & & & & \\
\hline 1983 & 20 & 240 & & & & & & & \\
\hline 1984 & 27 & 617 & & & & & & & \\
\hline 1985 & 49 & 911 & 9 & & & & & & \\
\hline 1986 & 82 & 1235 & 9 & 1 & & & & & \\
\hline 1987 & 114 & 1304 & 22 & 3 & & & & & \\
\hline 1988 & 196 & 1202 & $25 ?$ & 9 & & & & & \\
\hline 1989 & 263 & 1275 & 40 & 21 & 32 & & & & \\
\hline 1990 & 343 & 1454 & 57 & 61 & 37 & & & 7 & 5 \\
\hline 1991 & 413 & 1679 & 92 & 111 & 39 & 4 & 5 & 14 & 12 \\
\hline 1992 & 458 & 1655 & 109 & 179 & 51 & 29 & 26 & 20 & 46 \\
\hline
\end{tabular}

Quellen: Heymann 1995, WPM, div. Ausgaben, vg. Kap. 2-3

Aus der Sicht politisch-staatlicher Akteure lassen sich die Entwicklungen in den Pioniermärkten vor allem auf die Fördermaßnahmen zurückführen. Um die komplexen Prozesse zu verstehen, die sich während der Pionierphase in diesen Ländern ergaben, reicht es nicht hin, die Vorgänge einzig als Reaktionen auf staatliches Handeln zu analysieren. Vielmehr ist die gesamte Akteurkonstellation in den politisch garantierten Märkten, d.h. neben dem Wirken politisch-administrativer Systeme (PAS), auch die Rolle der Windanlagenhersteller und -käufer in die Analyse mit einzubeziehen.

Tab. 2a verdeutlicht, dass eine Abhandlung über die Pionierphase der Windkraft nicht ohne Dänemark und Kalifornien geschrieben werden kann. Die zusätzliche Auswahl der Niederlande und Deutschland erscheint nicht unmittelbar evident. Die Bestimmung dieser Vergleichsfälle geht aus dem Setting der Pionierphase hervor, die in vier zeitlich aufeinander folgende Abschnitte zergliedert wird. Überwunden wird die Pionierphase erst am Ende der letzten Untersuchungsperiode (1988-1991). Jeweils treten neue Probleme auf, denen sich die Pioniere stellen müssen. Dabei kann es sich einerseits um landesspezifische Barrieren handeln. Andererseits können Märkte wie die Niederlande und Deutschland in der vierten Periode bereits auf internationale Erfahrungen zurückgreifen. Die Untersuchung zeigt, welche Lösungswege von den Akteuren eingeschlagen werden und wie erfolgreich sie sind. In jeder der vier Untersuchungsperioden werden diejenigen Märkte betrachtet, in denen zur fraglichen Zeit wichtige Prozesse beobachtbar sind.

Die Pionierphase setzt 1975 in Dänemark ein. Während der Periode technischer Innovation (Periode 1: 1975-78) werden erstmals serienreife Windanlagenkonzepte entwickelt. Christian Riisager kommerzialisiert das Design der Gedser-Mühle von Johannes Juul. Das Monopol der Stromversorger wird gebrochen. Eine kleine Zulieferindustrie (bspw. Rotorenproduzenten) entsteht.

Auch für die nachfolgende Periode der Marktstabilisierung (Periode 2: 1979-82) sind ausschließlich Vorgänge in Dänemark zu beobachten. Seit 1979, als der Kauf von Windanlagen mit 30\% bezuschusst wurde, wuchs die Nachfrage deutlich an. Zu diesem Zeitpunkt handelte es sich bei den meisten Produzenten um kleine Handwerksbetriebe, die der steigenden Nachfrage nicht länger gerecht wurden. Daraufhin kam es unter den Herstellern zu einem Generationenwechsel. Auch bei den Betreibern fand ein Wechsel statt. Waren es zuerst Selbstbauer, dann Einzelkäufer, zumeist Handwerker und Landwirte, übernahmen nun ortsansässige Kooperativen das Feld. Diese Windanlagenkooperativen (Vindmoellelaugen) waren als Betreiber von WEA ideal. Sie waren innovationsfördernd, weil Einzelpersonen nicht mehr als 135 Prozent des Eigenverbrauchs aus Windkraft herstellen durften, die Anlagengröße also sehr bald an Grenzen gestoßen wäre. Sie förderten die lokale Akzeptanz, d.h. sie erleichterten die Standortsuche. Die Windkraft führte in Dänemark zu einem partiellen Wideraufleben der kooperativen Tradition. Seit 1979 stellt sich ein kontinuierliches Wachstum des Windenergiesektors ein. 
Damit quantitative Sprünge nicht Jahrzehnte dauerten, war eine Internationalisierung erforderlich. Bis 1981 werden kommerzielle Windanlagen ausschließlich in Dänemark hergestellt und dort auch größtenteils betrieben. Anders als die ersten Pioniere waren mittelständische Maschinenbauunternehmen wie Vestas durchaus dazu in der Lage, ihre Kapazitäten mit der steigenden Nachfrage zu erweitern. Zumal sich Anfang der 80er Jahre auf dem Inlandmarkt eine leichte Krise abzuzeichnen begann, war der Schritt in den Export eine logische Konsequenz. Hier half der Zufall: Als in Kalifornien lohnende Steuerabschreibungen (Tax Credits) eingeführt und dadurch eine enorme Nachfrage geschaffen wurde, eröffneten sich gigantische Absatzmöglichkeiten für dänische Hersteller.

In dieser Erprobungsperiode (Periode 3: 1983-1987) wird analysiert, unter welchen Bedingungen sich dänische Technologie in großem Stil auf einem neuen Markt bewähren konnte. Betrachtet wird ebenfalls, von welchen Akteuren der kalifornische Markt getragen wurde. Unter Berücksichtigung der Gestaltung der Fördergesetze wird untersucht, weshalb die WEA kalifornischer Produzenten hinter den technischen Stand der Konkurrenz aus Dänemark zurückblieben. Obgleich auf dem kalifornischen Markt erprobt, ließe sich kaum davon sprechen, dass die Windkraft 1987 international als proven Technology anerkannt gewesen wäre. Das Problem begann, als der Exportmarkt nach dem Auslaufen der Tax Credits zusammenbrach und dänische Hersteller, die ihre Produktion massiv ausgeweitet hatten, nun in eine schwere Krise stürzten. Es drohte die Gefahr des Zusammenbruchs der gesamten Branche und der Verlust wichtigen Know-hows.

Die Frage, unter welchen Bedingungen sich die dänische Windanlagenindustrie aus der Krise erholt hatte, wird im Abschnitt über die vierte Periode internationaler Verstetigung (Periode 4: 1988-1991) behandelt. Dabei spielen neue Absatzmärkte wie die Niederlande, die Bundesrepublik und Indien ${ }^{114}$ eine wichtige Rolle. Die beiden mitteleuropäischen Länder steigen zu einem Zeitpunkt ein, als nicht nur die Technologie bereits einen guten Zuverlässigkeitsgrad erlangt hatte, sondern auch grundlegende Probleme legislativer und administrativer Art in Dänemark schon bewältigt waren. Es stellt sich die Frage der Übertragbarkeit dieser Lösungen auf andere Industrieländer. War eine Adaption nicht möglich oder nicht gewollt, mussten neue Wege gesucht werden, welche nicht immer zu den besten Ergebnissen geführt haben. Die Investitionskosten stiegen, weil immer größere WEA mit technisch anspruchsvolleren Designs hergestellt wurden. Dazu musste der Käuferkreis erweitert werden. Insbesondere in den dicht besiedelten Niederlanden trat das Problem der Standortsuche auf. Das problematische Verhältnis zwischen EVU und externen Windmüllern ist in allen Pioniermärkten aufgetreten. Dabei weist dieser Konflikt jeweils unterschiedliche Ausprägungen und Entwicklungslinien auf. Manche EVU kaufen selbst Windparks, andere setzen auf Konfrontation. Beide Seiten zufriedenstellende Lösungen werden in keinem Land gefunden.

Insgesamt sind die meisten Pionierleistungen in Dänemark erbracht worden, von denen die wichtigsten in Periode 4 durch die Bundesrepublik übernommen worden sind. Nur in Dänemark haben zivilgesellschaftliche Akteure wie atomenergiekritisch motivierte Ingenieure, technisch versierte Handwerker und Windradkooperativen an den vielfältigen Prozessen der Marktentwicklung aktiv mitgewirkt. Nicht nur in Dänemark, sondern auch in Deutschland haben PAS-Akteure, oft unter Vermittlung der Windenergie-Interessenverbände, zweckmäßige Regelungen getroffen, wodurch zentrale Barrieren überwunden werden konnten.

\footnotetext{
${ }^{114}$ Die Bedingungen der indischen Marktentwicklung unterscheiden sich stark von denen der Industrieländer. Ohne die Förderung durch Entwicklungshilfeorganisationen wie der dänischen DANIDA wäre eine Markteinführung der Windtechnik, insbesondere zu einem so frühen Zeitpunkt, in dem Schwellenland kaum möglich gewesen. Aus einem Markt, dessen Existenz so stark vom Ausland abhängig war, können kaum Pionierleistungen erwachsen, die in den Industrieländern von Bedeutung hätten sein können. Daher wird der indische Markt nur am Rande und in erster Linie in seiner Funktion als Absatzmarkt für dänische Hersteller betrachtet.
} 


\subsection{Periode 1: 1975 - 1978 Technische Innovation und Entstehung des Ursprungsmarktes} (Dänemark)

Mit der Kommerzialisierung des Danish Design wurde in der zweiten Hälfte der 70er Jahre in Dänemark die technische Grundlage der internationalen Windkraftnutzung geschaffen. Bis heute sind dänische Unternehmen führend im Export von Windturbinen. Über mehr als zwei Jahrzehnte hinweg erfuhr der dänische Windenergiesektor ein kontinuierliches Wachstum. Im Jahr 1992 sind über 250.000 Dänen, d.h. etwa fünf Prozent der dänischen Bevölkerung, Anteilseigner einer Windanlage (Gipe 1995, 59). Mittlerweile werden etwa 20 Prozent des dänischen Stromkonsums aus Windkraft gewonnen.

Diese besondere Rolle Dänemarks für die moderne Windenergienutzung lässt sich nicht allein durch einen Verweis auf allgemeine, der Windenergieförderung zuträgliche Faktoren, die in Dänemark gegeben sind, erklären: windige Küstengebiete und landwirtschaftlich genutzte Flächen, die sich für Windanlagenstandorte eignen, Energiemangel und -importabhängigkeit, erfolgreiche Proteste gegen die Einführung der Atomenergie, indirekte und direkte Einflussnahme zivilgesellschaftlicher Akteure auf Inhalt und Durchführungsweise des Forschungsprogramms. Um den Erfolg der Windenergie in Dänemark zu begreifen, sind nicht nur diese allgemeinen, sondern auch landesspezifische Voraussetzungen zu betrachten.

Über Jahrhunderte hinweg ist die Windenergie der wichtigste Energieträger des Landes. Ohne die Segelschifffahrt wären die berüchtigten Wikingerfeldzüge nicht denkbar gewesen. Besonders für die Landwirtschaft ist Windkraft auch in jüngerer Vergangenheit ein bedeutender Faktor gewesen. 1920 trägt sie 120-150MW zur Versorgung bei. Dabei handelte es sich allerdings kaum um Elektrizität, sondern überwiegend um mechanische Energie. Darüber hinaus spiegelt sich die Bedeutung der Windkraft auch im kulturellen Leben wider: Überall ist die rotweiße Nationalflagge auf den historischen Windmühlen zu sehen (Gipe 1995, 53). Für die dänische Gesellschaft ist Windenergie etwas Normales. Die Struktur der Wirtschaft ist für ihre Nutzung prädestiniert. Drei Viertel des Landes wurden zu agrarischen Zwecken genutzt. Das sich daraus ergebende Reservoir an Standorten ist anfangs weniger bedeutsam. Wichtiger ist, dass die landwirtschaftliche Prägung, die Entwicklung einer metallverarbeitenden Industrie, vor allem im Agrarmaschinensektor und Schiffsbau ${ }^{115}$, entscheidend begünstigte. Aus dieser Branche rekrutierten sich Hersteller von Windturbinen wie Vestas, Bonus und Nordtank, welche die Produktion um 1980 aufnahmen. Auch existiert zwischen der Nutzung der Windkraft und der sozio-ökonomischen Tradition der Kooperativen sowie des kooperativen Arbeitens ein hoher Grad an Kompatibilität. Zur Erklärung des Erfolgs der Windkraft ist auch die handwerkliche Prägung des dänischen Technikpfades zu berücksichtigen (vg. Kap. 1.2). Windanlagen wurden als etwas einfaches wahrgenommen; als etwas, das ohne formalisierte Berechnungen, Spezialwerkzeuge und aufwendige Materialien gefertigt werden konnte. Diese Selbstverständlichkeiten und die Wertschätzung handwerklicher Methoden motivierte Tischler, Schmiede, Automechaniker und Elektriker, sich der Windmühlen-Konstruktion zu widmen. Seit der Ölkrise sind solche Aktivitäten verstärkt zu beobachten. Es wird von einer regelrechten ,Selbstbaubewegung' gesprochen (s.u.). Diesen Bastlern ging es in erster Linie darum, für sich selbst Wege aus der Energiekrise zu finden und sich von der Abhängigkeit der Stromkonzerne zu befreien.

Der erfolgreichste unter ihnen ist der Tischler Christian Riisager. Intensiv beschäftigt er sich mit den Konstruktionszeichnungen des Ingenieurs Johannes Juul, der in den späten 50er Jahren eine zuverlässige Windanlage von beachtlicher Größe (200kW-Generator) entwickelt. Nach jahrelanger Arbeit gelingt es Riisager, wesentliche Elemente des Juul-Konzepts erfolgreich auf eine 22kW-Mühle zu übertragen. 1975 schließt er die Windmühle an das allgemeine Stromnetz und löst damit die Entstehung einer landesweiten Bewegung gegen die

\footnotetext{
${ }^{115}$ Im Schiffbau zählte Dänemark weltweit zu den fünf wichtigsten Exporteuren (Gipe 1995, 51).
} 
Monopolmacht der EVU aus. Dieses Ereignis markiert den Beginn der Periode ,Technischer Innovation und Entstehung des Ursprungsmarktes' (im folgenden: Technikperiode/Periode 1). Zahlreiche Eigenbauer folgten dem Beispiel Riisagers. Zwischen den EVU und den Windmüllern entwickelte sich ein Gefecht, das den letzteren viel Geduld abverlangte, bevor eine WEA ans Netz geschlossen werden durfte. 1976 wurde Riisager zum ersten kommerziellen Windmühlenhersteller.

$\mathrm{Zu}$ den wichtigsten Pionierleistungen der Technikperiode zählen die Konstruktion und der Aufbau einer Großwindanlage, der sogenannten Tvind-Mühle, im Eigenbau. Auf dem Gelände der Volkshochschulen von Tvind trafen sich zahlreiche Antiatom-Aktivisten und Windenergiebegeisterte. Sie bauten eine für damalige Verhältnisse gigantische Windanlage. Die Erbauer haben die Tvind-Mühle als Symbol für Selbstorganisation und als reale Alternative zu den geplanten Atomkraftwerken verstanden.

Weniger symbolträchtig, aber ebenso einflussreich, waren die Windtreffen (Vindtraefs), auf denen die Bastler sich halbjährlich trafen und ihr Wissen austauschten. Organisiert wurden die Zusammenkünfte von den ökologischen Praktikern der Organisation für erneuerbare Energien. Anders als viele Eigenbauer übten sie eine grundsätzliche Gesellschaftskritik: Ihnen ging es darum, die Einführung der Atomkraft zu verhindern und die Macht der Konzerne zu bekämpfen. Die OVE zielte auf die Förderung einer kooperativen wirtschaftlichen und technischen Entwicklung des Windenergiesektors. Die in der kapitalistischen Wirtschaft übliche Konkurrenz wurde abgelehnt. Konzentrationsprozesse sollten verhindert werden. Man strebte die lokale Produktion von Windanlagen durch viele kleine Betriebe an.

Die OVE erkannte das Problem, dass viele Selbstbauer große Schwierigkeiten mit der Fertigung der Rotoren und anderer Komponenten wie der elektrischen Steuerung und dem Getriebe hatten. Ihre Idee war die Schaffung einer unabhängigen Zulieferindustrie. Ein wichtiger Schritt war die Gründung eines Rotorenherstellers im Jahr 1977. Produzenten anderer Komponenten (bspw. Getriebe, Elektrik) folgten. Sämtliche erfolgreiche Hersteller, die seit 1977/78 den Markt betreten hatten, griffen auf die Zulieferindustrie zurück. Bei den meisten Windmühlen handelte es sich daher um Komponentenmühlen. Das größte Problem der neuen Windturbinenhersteller, bei denen es sich praktisch ausschließlich um kleine Handwerksbetriebe handelte, bestand in chronischer Unterfinanzierung. Einige waren permanent mit der drohenden Pleite konfrontiert und konnten sich nur durch ausgeprägtes Improvisationstalent über Wasser halten.

Anfangs war es für die Käufer, häufig Techniklehrer und Landwirte, sehr schwierig, sich für ein Produkt zu entscheiden. Der Interessenverband der Windturbinenbesitzer gab ihnen durch Veröffentlichung von Produktionsstatistiken eine gute Entscheidungshilfe. ${ }^{116}$

\subsubsection{Innovation und Akteure der ersten Stunde}

\section{Christian Riisager: Innovation und Revolte}

Unter den Windmühlen-Bastlern nimmt Christian Riisager aus Skaerbaek in Jütland eine Sonderrolle ein. Nach jahrelangen Versuchen gelang es ihm erstmals, eine vergleichsweise gut arbeitende Windmühle nach dem Konzept der Gedser-Mühle von Juul zu konstruieren. Es war eine robuste Maschine mit $12 \mathrm{~m}$ hohem Turm, 22kW-Asynchron-Generator, horizontaler Achse und drei Flügeln à fünf Meter mit Luv (Aufwind)-Orientierung. In den folgenden Jahren verkaufte Riisager circa 50 WEA, welche dem Prototyp entsprachen. Viele Selbstbauer

\footnotetext{
${ }^{116}$ Der folgende Abschnitt zur ersten Periode ist nicht in die Reihenfolge ,PAS, Industrie, Käufer' zergliedert, wie die übrigen Perioden der Pionierphase. Eine strikte Unterscheidung zwischen Industrie, Käufer und Anwender ist noch nicht möglich. Anfangs gab es nur Selbstbauer, ein Markt bildete sich erst im Verlauf von Periode 1 heraus. Das PAS hat zu dieser Zeit kaum Einfluss genommen.
} 
und spätere Hersteller ${ }^{117}$ orientierten sich an diesem Design. Riisager ist während der Periode 1 zum erfolgreichsten Windanlagenhersteller avanciert. Er war zweifelsohne ein begabter Bastler. ${ }^{118}$ Nichtsdestotrotz hat Riisager ,sein' Konzept, dass später als Danish Design bezeichnet wird, nicht selbst entwickelt. Stattdessen hat er sich der öffentlich zugänglichen Konstruktionszeichnung der Gedser-Mühle bedient. Torgny Moeller, der 1976 eine der ersten Riisager-WEA gekauft hatte, sagt über die Bedeutung der Gedser-Mühle: ,Juul was the father of any wind turbine in the world. ${ }^{119}$ Angesichts fallender Energiepreise geriet das Know-how während der 60er Jahre in Vergessenheit. Riisagers Beitrag zur Innovation liegt also in der Wiederentdeckung des Juul-Designs und dessen Kommerzialisierung. 1975 gelingt Riisager eine dritte Pioniertat: der Anschluss seiner Prototyp-Windmühle an das Stromnetz. Er beschreibt seine Erfahrungen:

,We tried turning on the lights - that went well. That went on for three days. I asked the neighbours if connecting the turbine to the grid had any effect - but they hadn't noticed anything. But I lost my nerves - because if anything went wrong - I might have to compensate people. So I disconnected it. I asked the electricity company if I could connect it to the grid. They laughed and said I had to submit an application. So I wrote an application and sent it to them. But Lund didn't dare to say yes, because he was in charge there. Then one day we started the turbine. A journalist from the local paper saw that it was running. He thought that we had been granted permission. He knew it had been on the city council's agenda. So he wrote in the paper that we had been given permission. We got calls from newspapers - in Copenhagen. And they spoke to the mayor in Herning. He figured we had been given permission, but we never had. Everyone just assumed it. So it's been running ever since - without permission on the grid.' (zitiert nach: Vestergaard 2003)

Riisager hatte den Mut aufgebracht, das Monopol des ansässigen Stromversorgers zu brechen. Dass die Angelegenheit auf diese Weise in die Öffentlichkeit getreten ist, war ein glücklicher Zufall. Windenergie zur Einspeisung ins Stromnetz war damals zweifelsohne eine kleine Sensation. Ein absolutes Novum war sie hingegen nicht. Tatsächlich hatte auch die GedserMühle bereits Strom für das Netz produziert. Also kommt Riisager erneut die Rolle des Wieder-Entdeckers zu.

Interessanter ist die Frage, warum der zuständige Versorger sich dagegen entschied, Riisager mit Verweis auf die fehlende Genehmigung zu zwingen, die WEA zu deinstallieren. Der Hauptgrund lag im gesellschaftspolitischen Klima. Insbesondere aufgrund ihrer Pläne, in den nächsten Jahre Atomkraftwerke in Betrieb zu nehmen, mussten die Energiekonzerne sehr vorsichtig auftreten, um sich in der Öffentlichkeit nicht zu diskreditieren. ${ }^{120}$ Vor diesem Hintergrund akzeptierten sie, dass sie Riisagers kleine Revolte gegen ihr Monopol nicht niederschlagen durften. Der Tischler erlangte große Popularität. Sein Handeln galt vielen als Auftakt einer demokratischen und am Willen gesellschaftlicher Mehrheiten orientierten Energieversorgung. ,Hunted by the press' (van Est 1999, 78) und durch das wachsende private Interesse an der Windkraft gezwungen, erließ DEF, die Organisation der Stromversorger, im August 1976 provisorische Richtlinien zur Einspeisung von Strom aus Windkraft. Darin forderte der Verband seine Mitglieder auf, die privaten Initiativen zu unterstützen, um

\footnotetext{
${ }^{117}$ Die Gruppe der ersten Hersteller ist bis zum Jahr 1978 durch kleine Handwerksunternehmen dominiert, von denen Riisager Moellen die meisten Turbinen verkauft hatte. Zusätzlich zu dieser Gruppe waren etwa 50 Selbstbauer aktiv, die nur eine WEA für sich und möglicherweise ein oder zwei weitere, für ihre Nachbarn bauten. Sie verfolgten keine kommerziellen Ziele. Dazwischen existierte ein Kontinuum von Herstellern und ambitionierteren Bastlern, die zumeist weniger als zehn Windmühlen verkauft hatten (s.u.).

${ }^{118}$ Auf Grundlage seiner Ausbildung zum Tischler in den 40er Jahren, konnte Riisager auf langjährige

Erfahrungen mit der Konstruktion von WEA und Mühlen i.a. zurückblicken. Anfang der 70er Jahre baute er auf seinem Grundstück eine Wassermühle (van Est 1999, 76). Seitdem der Pegel des Bachs gesunken war, beschäftigte er sich wieder mit Windanlagen.

${ }^{119}$ Torgny Moeller in: Wind Power - A danish Story (Dänischer Film von Joergen Vestergaard aus dem Jahr 2003 (im folgenden: ,Vestergaard 2003', zitiert wird nach englischen Untertiteln) Moeller gründete später das Windenergie-Magazin ,Naturlig Energi', bekannter ist die englisch-sprachige Ausgabe ,Windpower monthly'. ${ }^{120}$ vg. bspw. van Est 1999. Im folgenden wird die grüne Mehrheit im Folketing ebenso noch des öfteren eine Rolle spielen wie Akteure der Ökologie- und Antiatombewegung.
} 
Windkraft zu fördern und die überschüssige Elektrizitätsproduktion zum Preis vermiedener Kosten abzunehmen (ebd.). ${ }^{121}$

\section{Windtreffen als kooperative Innovationszentren}

In der zweiten Hälfte der 70er Jahre ist der technische Erfolg der Windkraft untrennbar mit dem Einsatz zahlreicher Aktivisten der Anti-AKW-Bewegung verbunden. Der Organisation für erneuerbare Energie (OVE), in der etwa 2000 Mitglieder aktiv waren, kam dabei eine Schlüsselrolle zu. Gründet wurde die OVE im Jahr 1975 als Abspaltung der Organisation zur Information über Atomkraft (OOA). Während die letztere in erster Linie das Ziel verfolgte, über Gefahren der Atomenergie aufzuklären, ging es der OVE darum, alternative Energietechniken selbst zu entwickeln. Erik Grove-Nielsen, der die Abspaltung miterlebt hat und zu den Gründungsmitgliedern der OVE zählt, beschreibt den Konflikt: ,It was not enough to say that we don't want nuclear power. We must say: ,What else can we have then?'. That was the birth of the OVE, the organization for renewable energy.' (Interview vom 27. Juni 2007).

Seit ihrer Gründung richtete die OVE halbjährliche Windtreffen aus. Dort trafen sich Selbstbauer, OVE-Mitglieder, darunter viele Ingenieure und Technikstudenten sowie Hersteller, um sich über technische Probleme und Neuerungen auszutauschen. Auf diese Weise haben sich neue Erkenntnisse und Ideen zügig verbreitet. ,As soon as we had in 1975 the first Vindtraef, interested people gathered there. They hear from other selfbuilders: ,How did you solve it?' That's where a lot of exchange of information took place in those days.' (Grove-Nielsen, Interview vom 27. Juni 2007). Nicht zufällig fanden sämtliche Windtreffen an einer der zahlreichen Volkshochschulen Dänemarks statt. Pionier Preben Maegaard charakterisiert deren Bedeutung (Interview vom 2. Juli 2007): ,At Folk High Schools you always find the breaktrough of new ideas. People who look for changes and transitions in society - they go to Folk High Schools. Several Folk High Schools built their own wind turbines or bought one. ${ }^{122}$

Die Gründung der Volkshochschulen geht auf die politischen Ideen der kooperativen Bewegung zurück, die im 19. Jahrhundert vor dem Hintergrund wirtschaftlicher Krisen und sozialer Ungleichheit entstanden war. Unabhängigkeit und Achtung vor dem gemeinschaftlichen Besitz sind wichtige Prinzipien, die an den Volkshochschulen gelehrt werden. Das Selbstvertrauen der ländlichen Bevölkerung sollte gestärkt werden. Steven M. Borrish fasst die Weltanschauung von Nikolaj F. S. Grundtvig, dem wichtigsten Verfechter dieser Denkweise, zusammen:

,Grundtvig was opposed to domination in a way that stands outside the European emancipation tradition, with its emphasis on liberal individualism...He wanted to substitute for violent revolution a peaceful transformation of all elements in society based on a mutual recognition that all had the right to exist...He was really insisting upon a mutual recognition that each institution, each power center, and indeed each individual, could both teach and learn in dialogue predicated on mutual respect.' ${ }^{123}$

Neben der Offenheit für neue Ideen und der Förderung gemeinsamer Lernprozesse finden sich weitere Aspekte dieser Tradition auf den Windtreffen wieder. Die Teilnehmer waren durch gemeinsame Ziele verbunden. Sie sahen die Windkraft als ein Mittel, die Einführung der Atomenergie zu verhindern und die Macht der Konzerne anzugreifen. Die Idee alternativer Versorgung durch den Eigenbau von Windturbinen korrespondiert mit der von Grundtvig propagierten Subversion (,peaceful transformation'). Von den meisten sozialen Bewegungen in der Bundesrepublik wie der Antiatombewegung ist zudem bekannt, dass sie überwiegend von Mitgliedern der Bildungselite getragen werden. Die Sozialstruktur der Windtreffen ist dagegen sehr heterogen. Diese Heterogenität ist wesentlich gekennzeichnet durch die

\footnotetext{
${ }^{121}$ In der Praxis spielte diese Richtlinie kaum eine Rolle. Anfangs musste um jede Anschlussgenehmigung gekämpft werden. Die meisten EVU weigerten sich, den in ihr Netz eingespeisten Strom zu vergüten (ebd.).

${ }^{122}$ Maegaard, der die ersten Windtreffen moderierte, führt einen Grund an, weshalb die Treffen in der Literatur bis heute nur schwach repräsentiert sind: ,During the first years there was no one to write articles to report of these meetings. So the reports are very few, because there were no journalists or others reporting from them.' (Interview vom 2. Juli 2007).
}

${ }^{123}$ Borish 1991, 169. Zitiert nach: van Est 1999, 132 
Kooperation zwischen Personen mit akademischem Hintergrund (Ingenieure, Techniklehrer und -studenten) einerseits, sowie Handwerkern andererseits, die als Hersteller und Bastler tätig waren. Grove-Nielsen stellt den Zusammenhang zwischen dem übergreifenden Charakter der Windtreffen und dem Ort ihrer Austragung her:

,Vindtraefs did not take place in universities or places like that. The Folk High school is not a High school, but it's a place very different from universities. Because ordinary people can go there. In early times there were peasants and farmers who were invited to come there and to learn more.' (Interview vom 27.6.2007).

Es wäre verfehlt, den späteren Erfolg dänischer Windanlagenhersteller als Ergebnis einer linearen Entwicklung zu betrachten, deren Anfang der Staat durch Markt- und Forschungsförderung erst ermöglicht hätte. Der eigentliche Impuls ging von einer basisdemokratischen Strömung aus, die angesichts eines progressiven gesellschaftlichen Klimas und kooperativer Tradition des Landes, erstarkt war.

Wenn es um Fragen des konkreten Verlaufs von Innovationsprozessen geht, verhält sich die Sozialwissenschaft manchmal etwas zurückhaltend. In zahlreichen Fällen mag dieses daran liegen, dass es an spezifischen Kenntnissen fehlt. Um die technische Dimension der Anfangsphase moderner Windenergienutzung zu verstehen, sind derartige Kenntnisse nur in begrenztem Umfang erforderlich. Es ist daher eine dankbare und lohnende Angelegenheit, bestimmte Innovationsvorgänge im Detail nachzuvollziehen. Anhand der Darstellung des zentralen Beispiels der Komponentenwindmühle, lässt sich der Einfluss der OVE und der Pioniere aus dem Umfeld der Volkshochschulen einschätzen.

Die größte technische Barriere sämtlicher Windmühlenhersteller war das Rotorendesign. Es fehlte an Fachwissen, bspw. aus der Aerodynamik. Preben Maegaard hat die Bedeutung der Rotoren wie folgt eingeschätzt: ,The blades are the core of it. It has no use for you to be able to build a windmill, if you don't have blades.' (Interview vom 2. Juli 2007).

Dieses Problem hatte zuerst Amdi Petersen (Vestjysk Energikontor) an der Volkshochschule von Tvind im März 1976 erkannt. Seine Idee war es, eine Schablone zu entwickeln, mit deren Hilfe das Design der Rotoren leicht kopiert werden konnte. ${ }^{124}$ Auf dem Windtreffen vom 20. November 1976 wurde der Gedanke Petersens weiterentwickelt. Die Idee der Komponentenmühle war geboren. Ihr Prinzip ist es, die Windturbine in vier Hauptkomponenten (Rotoren, Gondel (u.a. Getriebe, Achse und mechanische Bremse), Turm und elektrische Kontrolle) aufzuteilen, die jeweils von verschiedenen Unternehmen produziert werden sollten. Für die Turbinenhersteller vereinfachte sich die Entwicklung, weil sie nicht mehr jede Komponente selbst konstruieren mussten, sondern auf Zulieferfirmen zurückgreifen konnten. Die Hauptaufgabe der Anlagenproduzenten sollte künftig darin bestehen, standardisierte Komponenten aufeinander abzustimmen. ${ }^{125}$ Die Gründung von Arbeitsgruppen wurde beschlossen, von denen jeweils eine der vier Komponenten entwickelt werden sollte. $\mathrm{Zu}$ der Gruppe, die für die Rotoren zuständig war, gehörte Jens Gjerding, ein junger Ingenieur, der ebenso wie Amdi Petersen sowohl am Tvind-Projekt, als auch im Energiebüro der Volkshochschule von Tvind arbeitete (OVE-Netzwerk). Die Rotoren-Gruppe, an der u.a. Erik Grove-Nielsen beteiligt war, entschied sich für das Rotorenkonzept der großen Tvind-Mühle. Man konstruierte eine auf 4,5m verkleinerte Version der $27 \mathrm{~m}$ langen Rotorblätter, ebenfalls aus Fiberglas. Die Komponenten ${ }^{126}$ wurden zusammengesetzt und es entstand die erste Komponentenmühle ,Praktisk Teoretisk Grundkursus' (PTG), die mit einem $18 \mathrm{~kW}-$ Generator ausgerüstet wurde und ansonsten dem danish design entsprach. Interessierte

\footnotetext{
124 ,Just come...all our experiences are there for the benefit of everyone... We will avoid that the utilization of wind power becomes monopolized.' (Amdi Petersen am 22.März 1976; Zitiert nach: Preben Maegaard, Interview vom 2. Juli 2007)

${ }^{125}$ Für die meisten Komponenten gab es etablierte Unternehmen, welche Türme, Getriebekästen, Generatoren und elektrische Kontrollsysteme problemlos herstellen konnten. Andere Bestandstandteile wie die mechanische Bremse waren sehr speziell, d.h. man konnte auf keinerlei Erfahrungen anderer Branchen zurückgreifen. Dieses gilt insbesondere auch für die Rotoren.

${ }^{126}$ Die Arbeitsgruppen der PTG verfügten über beachtliches Improvisationstalent. Bspw. wählte man für den Getriebekasten das Hinterachsensystem eines LKW (www.windsofchange.dk, Abruf vom 5.6.2008).
} 
sollten hier das erforderliche Know-how zur Herstellung von Windturbinen erlernen. Wie es bereits Amdi Petersen vorgeschlagen hatte, erstellte die Rotoren-Gruppe nicht nur die Flügel, sondern auch eine Schablone, mit deren Hilfe das Design auch von denjenigen reproduziert werden konnte, die mit dem Lesen technischer Zeichnungen nicht vertraut waren. Bereits wenige Monate später wurde der Rotor von Pionieren aus Kolding im Süden Jütlands nachgebaut. Auch der Elektriker Leif Nielsen aus Gredstedbro verwendete den PTG-Rotor. Nachdem sich bereits im Sommer 1977 einer der Flügel gelöst hatte, erlitt das Ansehen selbstgebauter Fiberglasrotoren schweren Schaden. Zudem führte die hohe Drehfrequenz zu starker Geräuschentwicklung. Als niemand mehr die Schablone verwenden wollte, kaufte sie Grove-Nielsen und gründete auf der Basis des PTG-Konzepts, das erste unabhängige Unternehmen zur Herstellung von Rotoren, Oekaer Vind Energi. Jedoch war auch GroveNielsen nicht erfolgreich bei dem Versuch, das PTG-Design zu kommerzialisieren und verkaufte nur vier Exemplare.

Die OVE hielt an der Komponentenmühle fest und entwickelte sie am Nordwestjütländischen Institut für erneuerbare Energie (NIVE), einer Vereinigung aus Ingenieuren, Schmieden, Techniklehrern und interessierten Benutzern, weiter. Der NIVE-Gruppe ging es nicht nur um technische Verbesserungen, sondern auch darum, eine bestimmte Produktionsweise zu etablieren. Sie wollte ihre Konstruktionszeichnungen nicht monopolisieren, sondern die Ergebnisse vor allem an kleine und mittlere Betriebe weitergeben (Beuse et al. 2000, 206f.). Die Gruppe konstruierte eine neue Windmühle mit $22 \mathrm{~kW}$-Generator, bei der fast alle Komponenten - Getriebe, elektrische Windnachführung, Turm, Kontrollsystem und Rotor von unabhängigen Firmen geliefert wurden. ${ }^{127}$ Auch die NIVE-Gruppe wollte nicht die in Misskredit geratenen PTG-Rotoren von Oekaer kaufen. Stattdessen entwickelte sie einen neuen dreiflügeligen Rotor, der am Design des Juul'schen Gedser-Rotors orientiert war. Nach Verhandlungen erhielt Grove-Nielsen den Auftrag zur Produktion des neuen Rotors. Die Rotorblätter sollten fünf Meter lang sein und mit niedriger Drehzahl laufen, um die Geräuschbildung zu reduzieren (Kapitler af Vindkraftens Historie i Danmark, Oeko-tryk, Videbaek 2005, 22ff.). Das erste Rotoren-Set lieferte Oekaer im Mai 1978. Der NIVE-Rotor erbrachte deutlich bessere Ergebnisse als das vorherige PTG-Modell. Mit diesem Produkt etablierte sich Oekaer als erster unabhängiger Rotorenhersteller. Von nun produzierte kaum mehr ein Hersteller die Rotoren selbst. Preben Maegaard, Koordinator der NIVEVereinigung, bilanziert: ,Suddenly it was much simpler to bring a wind turbine to the market.' (Interview vom 2. Juli 2007).

Als Urheberin der Konzepte der PTG- und NIVE-Windturbinen, kommt der OVE nicht nur bzgl. der Stabilisierung von Oekaer eine Schlüsselrolle zu. Damals existierten viele unterschiedliche Windanlagenkonzepte. Es war unklar, welche groben Eigenschaften ein optimales Design haben sollte: vertikale oder horizontale Achse der Rotoren, Zahl der Flügel, synchroner oder asynchroner Generator, Luv- oder Leeorientierung des Rotors, robuste oder leichte Bauweise, hohe oder niedrige Drehfrequenz, Strom- oder Wärmeproduktion. Viele Kombinationsmöglichkeiten wurden getestet, von denen sich die meisten nicht bewährt haben. Obgleich sich das Danish Design der Gedser-Mühle bereits in den 50er Jahren als zuverlässig erwiesen hatte, war dessen Einsatz für viele Selbstbauer und Hersteller zwei Jahrzehnte später alles andere als selbstverständlich. Ähnlich wie Riisager, entschieden sich OVE und PTG-, NIVE- und Tvindmühlen-Akteure für das Juul-Design und entwickelten die Prototypen entsprechend (Horizontale Rotorenachse, drei Flügel, asynchroner Generator zur Produktion von Wechselstrom, robuste Bauweise, niedrige Drehzahl). Indem man diese Präferenz auf den Windtreffen propagiert hatte, wurde Einfluss auf die Planungen vieler Selbstbauer und Hersteller genommen. Einen entscheidenden Schritt vollzog die NIVE-Gruppe, indem sie Oekaer mit der Anfertigung von Danish-Design-Rotoren beauftragte. Denn 1978 waren einzig diese Rotoren auf dem Markt erhältlich.

\footnotetext{
${ }^{127}$ Das elektrische Kontrollsystem kam von HM Automatic. Seitdem stellte das Unternehmen diese Komponente her und lieferte das erste System an Herborg Vindkraft, später an Vestas. Fenner lieferte das Getriebe, dass wegen zu hoher Geräuschproduktion später nicht mehr verwendet wurde.(Beuse et al. 2000, 206f).
} 
Ein Problem der Rotoren von Oekaer bestand darin, dass sie keine aerodynamische Bremse enthielten. Wurden sie bei Sturm nicht außer Betrieb gesetzt, bestand die Gefahr, dass die Flügel außer Kontrolle gerieten und sich aus der Verankerung lösten. Eine entsprechende Erfahrung hatte der junge Bastler Henrik Stiesdal machen müssen. Nach seinem Bericht auf dem Windtreffen vom 18. Februar 1978 beschloss die Versammlung, einen von der OVE geleiteten Sicherheitsausschuss einzurichten. Dieser entwickelte Richtlinien für den Windanlagenbau. $\mathrm{Zu}$ seinen wichtigsten Forderungen zählte die Installation eines aerodynamischen Bremssystems an den Rotorblättern. Dadurch konnte ein Überdrehen des Rotors verhindert werden, falls die mechanische Bremse bei Starkwind versagen sollte. Diese Forderung war deshalb notwendig, weil viele Hersteller der Meinung waren, sichere mechanische Bremsen herzustellen. Die erforderliche Investition für ein zweites Bremssystem wollten sie nach Möglichkeit umgehen. Die Richtlinien des Sicherheitsausschusses bildeten die Grundlage späterer Prüfverfahren der Teststation für Windturbinen in Risoe (vg. Kap. 2.2.). Ebenfalls auf diesem Windtreffen kündigte Torgny Moeller die Schaffung der Danske Vindmoellerfoerening (DV), eines Interessenverbandes der Windturbinenkäufer an, der im Mai 1978 gegründet wurde (Beuse et al. 2000, 168f.). ${ }^{128}$

Vor dem Hintergrund der Erfolge Riisagers und den ambitionierten Tvind-Leuten, bildeten die Windtreffen seit 1975 die wichtigste organisatorische Arena, in der sich bis 1978 die entscheidenden Innovationsprozesse vollzogen. $\mathrm{Zu}$ diesen Innovationen zählen die Realisierung der Komponentenmühle, die Etablierung eines unabhängigen Rotorenherstellers, die Gründung des Verbands der Anlagenkäufer sowie die Erkenntnis der Notwendigkeit eines doppelten Bremssystems, also dem Zubau einer aerodynamischen Bremse. Darüber hinaus ist mit der Gestaltung der Riisager-WEA und der Komponentenmühle (sowie der großen TvindAnlage), eine wichtige Vorentscheidung für das erfolgreiche Dänische Windanlagendesign getroffen worden. ${ }^{129}$

\section{Tvind-Mühle}

Lehrer und Schüler der Volkshochschule von Tvind, Ingenieure von außerhalb und viele Windenergiebegeisterte aus ganz Dänemark entwickelten in der zweiten Hälfte der 70er Jahre die einzige Großwindanlage außerhalb des LSP-Rahmens. Symbolisch für den Charakter des Projekts war der gleichzeitige erste Spatenstich durch 300 Personen am 28. Mai 1975 (van Est 1999, 242). Diese Idee des ,gemeinsam-etwas-Großes-schaffen' entspricht der kooperativen Tradition, so wie sie an den Volkshochschulen gelebt und gelehrt worden ist. Vom Beginn der Konstruktion bis zur Inbetriebnahme am 26. März 1978 vergingen etwa drei Jahre. Währenddessen ist Tvind $\mathrm{zu}$ einem Brennpunkt der Proteste gegen Atomkraft und Monopolisierung der Energiewirtschaft geworden. Mehr als das: Die Tvind-Leute bewiesen die Machbarkeit der Windenergie als Alternative. Deshalb war es ihnen wichtig, nicht nur eine kleine Windmühle, sondern quasi ein ,Windkraftwerk' zu realisieren. Während der Bauphase brachte Initiator Amdi Petersen dieses Ziel auf den Punkt: ,With 600 turbines we won't need a nuclear power plant.' (Vestergaard 2003).

Iben Oestergaard betrachtete ihre Arbeit in Tvind als Wettlauf gegen die Zeit: ,The government and Risoe - They were waiting for nuclear power and the only question was the site. We were aware of this and this kept us going. ${ }^{130}$

\footnotetext{
${ }^{128}$ Für diese Quelle wird auf die Übersetzung des Dänisch Kurses von Mette Mygind am Skandinavischen Seminar der Göttinger Universität zurückgegriffen.

${ }^{129}$ Die endgültige Entscheidung fiel Anfang der 80er Jahre durch den Markt, als sich die wesentlichen Hersteller der Nachfrage gemäß, an diesem Konzept orientierten (vg. Kap. 2.2).

${ }^{130}$ Iben Oestergaard war nach ihrer Schulzeit als freiwillige Helferin tätig. Sie erhielt eine Quasi-Ausbildung als Metallarbeiterin und lernte bspw. das Schweißen. Nachdem die Arbeiten abgeschlossen waren, ging sie an die Technische Universität und wurde Ingenieurin (Vestergaard 2003).
} 
Viele wurden durch die gemeinsame Arbeit, ${ }^{131}$ durch das Erlebnis der Unabhängigkeit von staatlichen Institutionen und der Perspektive, sich aus der Abhängigkeit von den EVU zu lösen, inspiriert und motiviert. Pionier Henrik Stiesdal beschreibt seinen Besuch auf der Baustelle: ,Boys and girls were welding, laying bricks and making fiberglass etc. It was something only professionals normally do. But these were ordinary young people like me. It was very inspiring. So the visit to Tvind was a very motivating factor for me.' (Vestergaard 2003).

Man konnte zur Baustelle kommen und dort wenige Tage helfen, bspw. bei der Herstellung der Flügel. Viele Schulabgänger kamen nach Tvind und absolvierten dort ein freiwilliges soziales Jahr. Die Koordination übernahmen der charismatische Amdi Petersen sowie die ,Turbine Crew', die alle wichtigen Entscheidungen zum Bauprozess getroffen hatte. Die Tvind-Leute gehörten ebenso wie das Umfeld der Windtreffen und Selbstbauer, einem basisdemokratisch orientierten Milieu an. Zwischen der OVE und dem Tvind-Projekt bestehen sowohl personelle, als auch institutionelle Überschneidungen. Die Ingenieure, die im Energiebüro von Tvind arbeiteten, waren zugleich Mitglieder der ,Turbine Crew', die ihre Treffen in den Räumlichkeiten des Energiebüros abhielt (Interview mit Erik Grove-Nielsen vom 20. August 2007). Andere Mitglieder kamen von außerhalb und wurden durch Annoncen angeworben. Ein Kuriosum stellt die Unterstützung des Projekts durch Helge Petersen dar. Dieser war leitender Ingenieur der Nuklearforschungsanlage in Risoe. Gleichzeitig zählte er zu den Protagonisten des LSP-Windkraftprogramms. Petersen entwickelte das Design der 27 Meter langen Flügel der Tvindmühle, ${ }^{132}$ die Lastenberechnungen hat OVE-Ingenieur Jens Gjerding vorgenommen (Interview mit Grove-Nielsen vom 27.6.07).

Zur Realisierung des Projekts musste viel improvisiert werden. Es begann mit dem Zeitplan. Aus den ursprünglich geplanten drei Monaten wurden schließlich drei Jahre. Neben dem Zusammengehörigkeitsgefühl und der Überzeugung, ein wichtiges Symbol gegen das Establishment $\mathrm{zu}$ schaffen, hat nicht zuletzt die Person Amdi Petersen zum Erfolg beigetragen: ,Amdi was a good business man. We would never have built the turbine without him.' (Iben Oestergaard, zitiert nach: Vestergaard 2003). ${ }^{133}$

Als Beispiel führt sie die Entstehung des Innenlebens der Gondel an. Petersen fuhr zur Rotterdamer Schiffswerft, wo er die $70 \mathrm{~cm}$ starke Achse günstig erwarb. Die übrigen Teile der Gondel wurden an die Achse angepasst. Auf diese Weise wurden später Kleinanlagen gebaut (Vestergaard 2003). Angesichts der großen an den Rotorblättern auftretenden Kräfte, war der Aspekt der Stabilität von zentraler Bedeutung. Amdi Petersen bestand darauf, die Flügel mit Glasfiberkabeln zu verstärken. Die Kabel wurden an den Flanschbolzen, welche den Flügelansatz mit der Turbinenachse verbinden, befestigt. Dieses entsprach dem Rotorendesign von Ulrich Hütter (Kapitler af Vindkraftens Historie i Danmark, Oeko-tryk, Videbaek 2005, 23). Anders als bspw. die Leichtbauweise des US-amerikanischen Mod-Programms, hat sich das Hütter-Design bewährt. Während die Tvind-Flügel bis heute intakt sind, erlitten die ModPrototypen entweder Totalschäden, oder wurden aufgrund mangelnder Wirtschaftlichkeit vor mehr als 15 Jahren deinstalliert. Zu den weiteren Innovationen des Tvind-Projektes zählt die erstmalige Anwendung von Glasfiber als Rotorenwerkstoff. Zunächst ist Glasfiber beim kleinen PTG-Rotor eingesetzt worden, später von Oekaer und LM Glasfiber. Ebenso wie

\footnotetext{
${ }^{131}$ Iben Oestergaard (Beuse et al. 2000, 132) hat von einer ,kollektiv kraftanstrengelse' gesprochen.

${ }^{132}$ Helge Petersen (Brief vom 2. Juli 2007). Seine Arbeit am Tvind-Projekt betrachtete er als ,just an interesting thing like a hobby.' (ebd.). In erster Linie war Helge Petersen ein zentraler Repräsentant staatlicher

Energiepolitik, die von den Tvind-Leuten abgelehnt wurde. In einem Telefonat vom 26.6.2007 hat Petersen die Bedeutung gesellschaftlicher Konflikte als Triebfeder zur Entstehung und Förderung der Windkraft in Dänemark zurückgewiesen. Stattdessen betont er die Einigkeit und den Willen zur Kooperation als wichtige Charakteristika der dänischen Gesellschaft. Zumindest für seine Person trifft diese Wahrnehmung zu. Denn seine Motivation für die Unterstützung des Tvind-Projekts war ,die Freude an der Zusammenarbeit.' Sowohl von der Regierung, als auch den Energiekonzernen wurden die Tvind-Leute als ,a bunch of freaks' wahrgenommen (van Est 1999, 78).

${ }^{133}$ Die Konstrukteure waren die mündliche Übereinkunft eingegangen, solange an der Turbine zu arbeiten, bis sie fertiggestellt war (Vestergaard 2003).
} 
Juuls Gedser-Mühle verfügte die Tvind-Anlage über drehbare Blattspitzen als aerodynamisches Bremssystem.

Während der Bauphase kamen viele Bastler nach Tvind. Dort hatten sie Gelegenheit, ihr Know-how zu erweitern. ,Like they went to the Vindtraefs, they also went to Tvind.' (Grove-Nielsen, Interview vom 27. Juni 2007).

$\mathrm{Zu}$ den wichtigsten Erfolgsbedingungen des Projekts zählte die Verfügbarkeit handwerklicher und ingenieurwissenschaftlicher Qualifikationen (ebd.). Im Unterschied $\mathrm{zu}$ den LSPPrototypen läuft die Tvind-Anlage auch 30 Jahre nach Inbetriebnahme weiter. Aus technischer Sicht richtungsweisend war die Tvind-Mühle vor allem während der Bauphase. 1977/78 betraten nach Riisager die ersten professionellen Turbinenhersteller den Markt, welche die wichtigsten in Tvind gewonnenen Kenntnisse bereits in ihre Produkte integriert hatten. Die Großwindanlage war dem Anspruch, Kapazitäten der Großkraftwerke zu ersetzen, nur bedingt gerecht geworden. Zuerst musste die Generatorenleistung von zwei Megawatt auf die Hälfte reduziert werden. Anders als die Modelle von Juul und Riisager, die Wechselstrom produzierten, hatten die Tvind-Leute ihre Maschine mit einem Gleichstromgenerator ausgestattet. Zur Netzeinspeisung reichte die Qualität des Stroms daher nicht aus (Kamp 2002, 144). In erster Linie dient die Tvind-Mühle zur Versorgung des Schulkomplexes von Tvind. ${ }^{134}$

Die gesellschaftspolitische Bedeutung des Projekts reichte weit über das Jahr 1978 hinaus. Die bloße Existenz einer von Amateuren im Selbstbau gefertigten Großwindanlage stellt eine grundsätzliche Kritik des LSP dar. Die Tvind-Mühle arbeitete nicht nur zuverlässiger als die übrigen Prototypen, sondern war mit Gesamtkosten von sechs Millionen Kronen, die aus Eigenmitteln und Spenden aufgebracht wurden, auch deutlich kostengünstiger. Die NibeZwillinge und Growian waren zehnmal, bzw. 50 mal teurer als die Tvind-Mühle (Maegaard, Interview vom 2.7.07). Mit einfachen technischen Mitteln, improvisierten Komponenten und Baustoffen erreichten die Tvind-Leute mehr als die Akteure der LSP-Programme.

\subsubsection{Dänische Windanlagenindustrie in Periode 1}

Im folgenden Abschnitt geht es um die frühe Kommerzialisierung der Windanlagentechnik. Welches sind die ersten Akteure der aufkommenden Industrie? Wie ist die Anlagenproduktion aufgebaut? Welche Verbindungslinien existieren zu Grassroots-Organisationen wie der OVE? Mit welchen Schwierigkeiten sind die ersten Hersteller konfrontiert und wie werden sie ggf. überwunden?

Bei den meisten Herstellern handelte es sich nicht um kommerziell agierende Unternehmen, sondern um Selbstbauer (s.o.). Insgesamt wurden zwischen 1976 und 1978 etwa 170 WEA verkauft. ${ }^{135}$ Neben Riisager, der ca. 50 Windturbinen verkauft hatte, waren einige weitere Firmen auf dem Markt, deren Verkaufszahlen auf einen Status jenseits des Selbstbauers und einen gewissen Professionalisierungsgrad schließen lassen. Aus Gründen der Übersichtlichkeit werden ausschließlich diese Unternehmen betrachtet. Darüber hinaus sind in dieser Gruppe die innovativsten Hersteller zu finden.

\section{Riisager Moellen}

Riisagers Beiträge zur Innovation liegen in der Wiederentdeckung und Kommerzialisierung des Juul-Designs sowie im Netzanschluss seiner Windmühle. Im folgenden geht es um

\footnotetext{
${ }^{134}$ Demgegenüber ist es eine Ironie der Geschichte, dass das Monopol der EVU gerade von einem typischen Selbstversorger wie Riisager durchbrochen worden ist.

${ }^{135}$ Die meisten dieser WEA speisten nicht in Elektrizitätsnetze, sondern dienten der Wärmeproduktion (van Est 1999, 87).
} 
Riisagers Rolle als Unternehmer im engeren Sinne und sein Verhältnis zu den übrigen Akteuren der frühen Windkraftindustrie.

Innerhalb der Gruppe der Eigenbauer nimmt Riisager insofern eine Sonderrolle ein, als er die Vermarktung seiner WEA anstrebte. ,He was the first one who wanted to make business and sell turbines. Many of the other selfbuilders didn't want to. They only want to make a turbine for themselves.' (Grove-Nielsen, Interview vom 27.6.07).

Riisager Moellen ist 1976 das erste Unternehmen, das WEA zum Kauf anbot. Anders als die meisten zeitgenössischen Hersteller arbeitete Riisager vollständig außerhalb der OVE-Strukturen. Zur AntiAKW-Bewegung und der Organisation für erneuerbare Energien hatte er keinerlei Bezug (GroveNielsen, Interview vom 26.7.07).

$\mathrm{Zu}$ den wichtigsten Eigenschaften der Riisager-Turbine zählen: Dreiflügelrotor, robuste Bauweise, horizontale Achse, Aufwindorientierung, Stall-Regulierung, niedrige Drehzahl, Asynchrongenerator (Danish Design). Mit der Produktion der von Riisager entworfenen Flügel beauftragte er LM, ein Bootsbauunternehmen, das aufgrund von Umsatzverlusten Interesse an der neuen Branche zeigte. Die Tatsache, dass die Riisager-Flügel aufgrund der schweren Bauweise und des ,etwas klobigen Designs' aus Stahl, ,nur mäßige Ergebnisse brachten' (Krogsgaard, Interview 19.9.07), tat den Verkaufszahlen keinen Abbruch. Der improvisierte Charakter der Windmühle wird offenkundig, wenn man einen Blick auf die Einzelteile wirft. So diente der Hinterradantrieb eines alten englischen Panzers als Achse, das Getriebe stammte aus einem LKW.

Anfangs baute Riisager die Maschinen gemeinsam mit dem Schmied Erik Nielsen. Nachdem die beiden ersten Exemplare 1976 verkauft wurden und sich bald als ,antriebssichere Leistungskühe' (driftsikre Hoejtydende) herausstellten (Beuse et al. 2000, 128), weitete Riisager die Produktion aus. Seit 1977 arbeitete er mit Sonebjerg, einer etablierten Maschinenfabrik zusammen, die in Riisagers Auftrag bis 1978 die meisten seiner Windanlagen produzierte (Krogsgaard, Interview vom 19.9.07). Mit diesem Schritt war der Tischler ein großes Risiko eingegangen. Denn ein Antrag auf Forschungsförderung wurde abgelehnt (Kamp 2002, 144). Er übernahm sich und fand 1978 in der Genossenschaft Windmatic einen neuen, finanzkräftigeren Partner.

Kongsted Moellen/ Erini

1978 gründeten der Automechaniker Ole Hansen und seine Frau die Firma Kongsted Moellen. Hansen war ein früherer Kunde Riisagers und verwendete ein der Riisager-Maschine ähnliches Design, wobei er sich für Holz- anstatt Stahlflügel entschied. Als Achse nutzte er einen Getriebekasten von Enthegritte. In der Werkstatt des Automechanikers wurden etwa 25 WEA gefertigt. Zusätzliche Arbeitskräfte stellte Hansen nur bei Aufträgen ein. 1982 stoppte er die Produktion (Krogsgaard, Interview vom 19.9.07).

Auch Erik Nielsen, der vorherige Partner Riisagers, war kurzzeitig als Windmühlenhersteller tätig (1978-79). In seiner Schmiederei wurden jedoch nur wenige Mühlen gefertigt. Das Erini-Design entsprach dem Konzept von Riisager (www.windsofchange.dk, Abruf vom 28.1.08).

Riisager und die Hersteller Sonebjerg, Kongsted und Erini, welche Riisagers Zeichnung übernahmen, oder in dessen Auftrag produziert hatten, sowie Svend Jensen (s.u.), hatten ihre Turbinen unabhängig von den im Kontext der OVE gewonnenen Erfahrungen konstruiert, bzw. gefertigt. Wie oben dargestellt wurde, hatte die Realisierung der Komponentenmühle eine Entwicklung weitreichender Tragweite in Gang gesetzt. Um 1977/1978 bildete sich eine neue Zulieferindustrie heraus, so dass die Turbinenfertigung wesentlich erleichtert wurde. $\mathrm{Zu}$ den wichtigsten Pionieren der Komponentenherstellung zählte Oekaer Vind Energi, der erste unabhängige Rotorenproduzent. Daraufhin traten mit Adolfsen Moellen und Herborg Vindkraft die innovativsten Hersteller dieser Periode hinzu. Beide wiesen einige Gemeinsamkeiten auf: Sie kooperierten mit dem OVE-Umfeld, verwendeten Oekaer-Rotoren, ein dänisches Windanlagenkonzept und sind Handwerker. Gemeinsam mit Oekaer kommt Adolfsen und Herborg eine herausragende Position im Innovationsprozess während dieser Periode zu. 
Oekaer Vind Energi

Anfang 1977 wurde die Herstellung der 4,5m langen PTG-Flügel mittels der Form von Energiekontor bei der Glasfiber-Werkstatt TV-Glasfiber in Auftrag gegeben. Doch es unterliefen schwere Produktionsfehler. Bereits wenige Tage nachdem der Rotor auf die selbstgebaute Windmühle des Elektrikers Leif Nielsen gesetzt wurde, löste sich bei schwachem Wind einer der Flügel. TV Glasfiber gab die Rotorenproduktion auf und Erik Grove-Nielsen kaufte die Form für 2.500 DKr. Daraufhin eröffnete er am 8. August 1977 Oekaer Vind Energi. Gemeinsam mit Christian Soerensen, dem einzigen Angestellten GroveNielsens, errichtete er in einer alten Scheune die erste Produktionsstätte für Glasfiberrotoren. Aufgrund mangelnden Eigenkapitals nahm er anfangs Kredite in Höhe von $70.000 \mathrm{DKr}$ (ca. \$10.500) auf. Ende November 1977 lieferte er den ersten Rotor an Adolfsen Moellen. Auch die Oekaer-Variante der PTG-Flügel, von denen Grove-Nielsen bis Januar 1978 nur vier Sets verkauft hatte, wurde den Erwartungen nicht gerecht. Als sich diese Unzulänglichkeit der Flügel herumgesprochen hatte, kaufte niemand mehr bei ihm. Schließlich rettete ihn der NIVE-Auftrag (s.o.) vor dem Bankrott. Durch die Anforderung neuer und technisch verbesserter 5m-Rotoren, die im Mai 1978 erstmals geliefert wurden, überstand Oekaer die Krise. (www.windsofchange.dk Abruf vom 29.1.2008). Während der Sommermonate verkaufte das Unternehmen zehn Sätze à drei Flügel. Zu diesem Zeitpunkt ist die Rotorentechnologie bei weitem nicht ausgereift. Bis dahin hatten die Flügel keine aerodynamische Bremsvorrichtung. In den ersten Herbststürmen gerieten daher zwei Rotoren außer Kontrolle und die Flügel verselbständigten sich. ,After that it was difficult to sleep at night during a storm. We closed down our production and decided to develop air brakes.' (Grove-Nielsen in: Vestergaard 2003).

Unter anderen Umständen hätte darin kein größeres Problem bestanden. Denn die StallTechnik $^{136}$ war bereits an der Gedser-Mühle erprobt worden. Doch angesichts mangelnder Kapitalreserven, bahnte sich Oekaers nächste Krise an. Schadenersatzforderungen wurden erhoben. Zudem versagte der VW-Bus, der als Transportfahrzeug integraler Bestandteil der Unternehmens gewesen war, seiner Dienste. Die Bank gewährte ihm weitere Kredite. ${ }^{137}$ Grove-Nielsen erhielt Kontakt zur privaten Otto Johannes Bruuns Stiftung, wo er sich um Fördermittel bewarb und erhielt 50.000DKr.(ca. \$7.000). Diese Zahlung verhinderte den Bankrott Oekaers. Die Mittel genügten, um die dringendsten Rechnungen zu begleichen, die Luftbremse zu entwickeln und den VW-Bus zu reparieren (Beuse et al. 2000, 143f.).

Bei der Konstruktion des aerodynamischen Sicherungssystems erhielt Grove-Nielsen Unterstützung durch die neuen Hersteller Svend Adolfsen und Karl Erik Joergensen (Herborg Vindkraft). Letzterer war Betreiber einer derjenigen Windmühlen, die aufgrund der fehlenden Luftbremse schwere Schäden davon getragen hatten. Im November 1978 wurde der erste Satz der neuen Oekaer-Flügel hergestellt und an der Herborg-WEA getestet. (ebd., 144). Die Luftbremse bewährte sich und Oekaer Vind Energi erhielt weitere Aufträge.

\footnotetext{
${ }^{136}$ Das Prinzip der Stall-Bremse nutzt den aerodynamischen Effekt des Strömungsabrisses aus. Der Effekt tritt bspw. auf, wenn sich die Blattspitzen verdrehen. Diese Technik basiert auf einem einfachen Prinzip. Die Blattspitze ist durch gefederte Bolzen mit dem Flügel verbunden. Bei einer bestimmten Drehfrequenz werden die Federn durch die Zentrifugalkraft so stark komprimiert, das diese Verbindung unterbrochen wird. Anschließend klappt die Blattspitze um und rastet im rechten Winkel zum Flügel ein. Grove-Nielsen verwendete stattdessen ausfahrbare Drehspitzen, die ebenfalls zum Strömungsabriss und damit zum Einsetzen der Bremswirkung führten. Dabei handelte es sich um ein Patent von Johannes Juul aus dem Jahre 1949 (Beuse et al. 2000, 144).

${ }^{137}$ Die niedrigen Verkaufspreise waren nach Ansicht des Firmengründers ein weiterer Grund zur Erklärung, weshalb das Unternehmen während der ersten Jahre kaum aus den Schulden herauskam: ,We didn't make much money. In the early years I was a long-haired guy from the left wing. We thought that's a bad thing to make profit. The price of the blades should be the price of the materials and the wages.' (Grove-Nielsen, Interview vom 27.6.07)
} 
Adolfsen Moellen

Svend Adolfen betrieb in Knudstrup bei Viborg eine kleinere Autowerkstatt mit etwa fünf bis zehn Beschäftigten. Der Automechaniker und Elektriker interessierte sich sehr für Windräder. Teilweise unter Verwendung des PTG-Konzeptes entwickelte Adolfsen 1977 eine kleine Windmühle mit $11 \mathrm{~kW}-G e n e r a t o r$. Dabei arbeitete er eng mit dem Energiebüro von Tvind zusammen. Das Design der elektrischen Systeme hatte er vollständig selbst entworfen (Grove-Nielsen, E-Mail vom 21.8.07). Als Achse und Getriebekasten diente ihm die Hinterwelle eines LKW. Die Rotoren kaufte Adolfsen bei Oekaer.

Auch Riisager stellte seine Rotoren nicht selbst her, sondern beauftragte LM. Anders als bei Adolfsen, stammte die Zeichnung der Rotoren von Riisager selbst. Adolfsens Windmühle war daher die erste für den Markt produzierte Komponentenmühle. Als Adolfsen mit seiner Turbine im Frühjahr 1978 eine kleine Serienfabrikation startete, wurde er zum ersten Konkurrenten Riisagers (Beuse et al. 2000, 142). Die erste Maschine verkaufte Adolfsen an einen Nachbarn. Sie wurde ca. 100 Meter von seiner Werkstatt entfernt in Betrieb genommen. Beim Aufbau waren ihm die Käufer behilflich (Grove-Nielsen, Interview vom 27.6.07). 1979 verkaufte Adolfsen sein Patent an Kuriant, wo das Adolfsen-Design in größeren Serien produzierte wurde (vg. Kap. 2.2).

\section{Herborg Vindkraft}

Der Schmied Karl-Erik Joergensen besaß eine kleine Reparaturwerkstatt, in der er diverse Zulieferarbeiten für ansässige Unternehmen tätigte. In seiner Freizeit beschäftigte sich der Handwerker mit energietechnischen Problemen. Für seine Werkstatt produzierte er Strom mit einem alten Dieselgenerator, dessen Abwärme in das Heizungssystem gespeist wurde. Joergensen entwickelte damit einen Vorläufer heutiger Blockheizkraftwerke. Inspiriert von zwei in der Nähe gelegenen Riisager-Mühlen, begann er mit dem Aufbau einer ,SuperWindrose' (Beuse et al. 2000, 169). Das Ergebnis entsprach nicht seinen Erwartungen.

Damals beschäftigte sich auch der 18jährige Henrik Stiesdal mit Windturbinen. Stiesdal nutzte die Werkstatt des erfinderischen Handwerkers ${ }^{138}$ und erhielt von diesem praktische Unterstützung bei der Realisierung seiner eigenen Prototyp-Windmühle. Im Umkehrzug bat Joergensen den angehenden Technikstudenten, ihn bei der Erstellung einer Zeichnung für eine neue, größere Windanlage zu unterstützen. Stiesdal zeigte sich interessiert. Beiden fehlte es jedoch an der erforderlichen Liquidität. Zu dieser Zeit, im Frühjahr 1978, gründete das Technologische Institut (Teknologiske Institut) ein Erfinderbüro, das Innovationen im Energiesektor unterstützte. Stiesdal fertigte die Zeichnung eines einfachen dreiflügeligen Windrades an. Gemeinsam mit einer kurzen Projektbeschreibung bildete diese Zeichnung die Grundlage eines Förderantrages, den sie beim Erfinderbüro einreichten. Wenige Wochen später erhielten sie einen Check über 50.000DKr.

Die Bauphase wurde von Joergensen und Stiesdal arbeitsteilig bewältigt. Ersterer übernahm die praktischen Arbeiten: Viele Elemente, bspw. den Turm, hat er selbst hergestellt. Bei den Aufbauarbeiten wurde Joergensen zusätzlich von seinem Sohn unterstützt. Stiesdal führte die Berechnungen durch und erledigte den Einkauf der Komponenten. Er entschied sich für ein Getriebe und eine Achse von Hansen. Ebenso wie Adolfsen wählten auch Joergensen/Stiesdal die Oekaer-Flügel (Beuse 2000 et al., 171). Die elektrische Kontrolle lieferte HM Automatik. Damit war die Herborg-Turbine in ähnlicher Weise eine Komponentenmühle wie diejenige Adolfsens. Bereits im Frühsommer des Jahres war der Prototyp betriebsbereit. Ebenso wie bei den WEA von Riisager und Adolfsen handelte es sich auch hier um ein dänisches Konzept. Die Entscheidung für diese Bauweise wurde von Adolfsen ebenso wenig wie von Joergensen/

\footnotetext{
${ }^{138}$ Stiesdal hat Joergensen als ,Inbegriff eines Jungunternehmers' charakterisiert, der schon in jungen Jahren eine Maschinenwerkstatt aufgebaut hatte. Für ihn gab es nichts wichtigeres als seine Arbeit. Joergensen arbeitete in Vollzeit, obgleich er aufgrund eines Krebsleidens eine 100\%ige Invalidenrente erhielt (Beuse et al. 2000, 169). Noch in den letzten Monaten vor seinem Tod kletterte er auf seine Windmühlen, bevor er 1982 verstarb (Näheres zur Person Karl Erik Joergensen, vg. Beuse et al. 2000, 169f.)
} 
Stiesdal zufällig getroffen. Der erste Grund sind die Erfolge Riisagers. ${ }^{139}$ Der zweite und wichtigere Grund besteht in Stiesdals Verbindungen zum OVE-Netzwerk (Grove-Nielsen, per E-Mail vom 20.8.07). Auch dort hatte man sich früh für das dänische Design entschieden und das Konzept des späteren Oekaer-Rotoren entwickelt. Nachdem die Rotoren mit der aerodynamischen Bremse ausgestattet worden sind und sich Joergensens WEA im Testlauf bewährt hatte, stellte der Handwerker einige Maschinen für den Verkauf her. Die ersten vier gingen ausschließlich an seine Nachbarn. Dabei fühlte sich Joergensen persönlich verantwortlich dafür, dass die Turbinen funktionstüchtig waren (Grove-Nielsen, Interview vom 27.6.07).

Wichtiger ist weniger der kommerzielle Erfolg der Herborg-Turbine, sondern ihre Beiträge zur technischen Entwicklung der Windkraft insgesamt: ,Die Mühle ragte als eine Art Archetyp hervor für das, was für lange Zeit der Inbegriff einer modernen dänischen Windmühle sein sollte - ein dreiblättriger Rotor mit Luftbremsen, motorgesteuerter Windnachführung und Zwei-Geschwindigkeitsantrieb mit direkten, netzgekoppelten Generatoren' (Henrik Stiesdal, zitiert nach: Beuse et al. 2000, 172). Ende 1979 hatte Joergensen die Lizenz zur Fertigung dieser Windanlage an den Maschinenhersteller Vestas verkauft (vg. Kap. 2.2). Mit dem Herborg-Design erlangte Vestas bereits frühzeitig eine führende Rolle in der neuen Branche. Die Bedeutung der Kombination akademischer und handwerklicher Fähigkeiten für den Erfolg des Tvind-Projekts ist bereits aufgezeigt worden. Diese Kombination bildete auch für Herborg Vindkraft eine entscheidende Erfolgsvoraussetzung. Denn ohne Stiesdals Fähigkeit, Berechnungen anzustellen und ohne seinen Bezug zum Grassroots-Milieu, hätten die handwerkliche Begabung und Erfahrung Joergensens nicht ausgereicht, um so frühzeitig und so weit über den technischen Stand der ,Super-Windrose' hinaus zu gelangen.

\section{S.J. Wind Power}

Ebenfalls 1978 gründete der Elektriker Svend Jensen eine kleine Windmühlenproduktion. Er konstruierte eine Windrose. Der Rotor unterschied sich stark von den Dreiflüglern. Jensen hatte ein gutes Dutzend kleiner, aus Poly Urethane Schaum bestehender Flügel, konzentrisch um die horizontale Achse angeordnet. Mit einem 10kW-Generator und 6m-Rotordurchmesser ausgestattet, war Jensens Modell selbst für damalige Verhältnisse klein dimensioniert. Die meisten Windrosen speisten keinen Strom ins allgemeine Netz, sondern dienten der Wärmeproduktion (www.windsofchange.de, Abruf vom 29.1.08). Die größte Schwäche der Windrose war eine mangelnde Stabilität. Insbesondere im Sturm von 1981 trugen 50 der insgesamt etwa 200 verkauften Windrosen einen Totalschaden davon (Krogsgaard, Interview vom 19.9.07). Daraufhin musste Jensen Konkurs anmelden. Das Design der Windrose ,stammt weitgehend von ihm' (Krogsgaard ebd.). Ebenso wie Riisager arbeitete auch Jensen unabhängig von den OVE-Strukturen. Im Unterschied zu diesem betrat Jensen etwa zwei Jahre später den Sektor, zu einem Zeitpunkt also, als er das Rad nicht mehr neu hätte erfinden müssen.

\section{Die neue Windanlagenindustrie}

In ihrer Arbeitsweise lassen sich die Hersteller in zwei Gruppen teilen: diejenigen, die allein gearbeitet haben und solche, die direkt oder indirekt mit dem OVE-Netzwerk (Windtreffen, Energiebüros, Tvind-Leute) kooperierten. Unter den Firmen der ersten Gruppe waren ausschließlich Riisager und seine Lizenznehmer erfolgreich. Adolfsen Moellen und Herborg Vindkraft zählten zur zweiten Gruppe. Beide fertigten Komponentenmühlen und verwendeten

\footnotetext{
${ }^{139}$ Dennoch haben in den späten 70er Jahren nicht nur viele Selbstbauer, sondern auch Unternehmer wie Svend Jensen auf andere Konzepte gesetzt.
} 
Rotoren von Oekaer. Anders als Riisager waren sie, gemeinsam mit Oekaer, zwar nur bedingt kommerziell erfolgreich, dafür nichtsdestoweniger innovativ. ${ }^{140}$

Außer den hier genannten Firmen und S.J. Wind Power gab es keine weiteren, die sich vor 1979 gründeten und über den Selbstbauer-Status - ob mit oder ohne Teilnahme an den Windtreffen - wesentlich hinaus gelangten (vg. www.windsofchange.dk, Abruf vom 2.2.08). Alle Hersteller, deren Produkte besonders innovativ und technisch richtungsweisend waren, d.h. Herborg, Adolphsen und Oekaer, kooperierten sowohl untereinander, als auch mit dem OVE-Netzwerk. Dort waren u.a. Ingenieure beteiligt. Sie konstruierten die PTG- und NIVEAnlagen, stellten die Zeichnungen allen interessierten $\mathrm{zu}$ Verfügung und berieten die Hersteller in den Energiebüros. Die formalisierten Methoden, wie sie üblicherweise von Ingenieuren angewendet werden, waren den Herstellern, die über keinerlei akademische Ausbildung verfügten, fremd. ${ }^{141}$ Probleme wurden in der Praxis gelöst, die Fehler von Anlage zu Anlage verringert (,trail-and-error'-Prinzip).

Diejenigen, die sich mit der Windkraft selbständig machten, gingen ein wirtschaftliches Risiko ein. $\mathrm{Ob}$ sie ein erfolgreiches Modell produzieren würden, war völlig unklar. Große Profite hatten die ersten Hersteller weder erzielt, noch unbedingt angestrebt. Während sich Grove-Nielsen in der Anfangsphase Oekaers sogar explizit vom Gewinnstreben distanzierte, war das Geldverdienen für den ,Einzelkämpfer' Riisager, der zunächst wirtschaftlich erfolgreicher war, als alle anderen Hersteller, durchaus nicht unwichtig.

Doch schon bald begannen andere, gegenüber Riisager Boden gut zu machen. Während jene kooperativ arbeiteten und Entwicklungsschritte daher gemeinsam vollzogen, gingen grundlegende Neuerungen an Riisager vorbei. Letzterer hielt etwa, auch nach dem Vertragsschluss mit Windmatic von 1979 (vg. Kap. 2.2), noch an Rotorblättern aus Stahl fest, anstatt auf Glasfiber umzusteigen. Zu den wichtigen Eigenschaften der Technikperiode zählt die Dominanz des kooperativen über den komparativen, also konkurrenzorientierten Entwicklungspfad technischer Innovation.

In anderen Punkten bildeten die Hersteller eine deutlich homogenere Gruppe (vg. Tab. 2.1a und Tab. 2.1b). Sämtliche Turbinenproduzenten sind Handwerker, die zwischen 1976 und 1978 in den Markt eingestiegen waren. Fertigungsorte waren die Werkstätten von Elektrikern, Tischlern, Schmieden und Automechanikern. Sie arbeiteten mit jenen einfachen und robusten Baustoffen, an die sie vielfach aus ihrer Berufspraxis gewöhnt waren und nutzten die ihnen vertrauten Faustregeln, um ihre Konzepte zu verbessern.

Die üblicherweise gewählten Anlagengrößen ähnelten einander: Rotordurchmesser von 8$10 \mathrm{~m}$, Generatorenkapazitäten lagen bei 10-30kW. Zwischen Herstellern und Käufern bestand eine enge regionale Beziehung. Häufig wurden Turbinen an die Nachbarschaft verkauft, so dass ein kontinuierliches Feedback gegeben werden konnte und die Turbinenbauer Anregungen zur technischen Verbesserung erhielten. ${ }^{142}$

\footnotetext{
${ }^{140}$ Die Kooperationsbereitschaft einiger Hersteller beschränkte sich nicht nur auf ihren Bezug zum OVENetzwerk, sondern bestand auch untereinander. Ein Beispiel ist die Zusammenarbeit zwischen Karl-Erik Joergensen und Henrik Stiesdal. Die Grundlage dafür war kein Lohnarbeitsverhältnis, sondern bestand im wechselseitigen Lernen. Ein anderes Beispiel ist die Entwicklung der ersten Luftbremse für Oekaers Rotoren. Die Entscheidung fiel auf eine Stall-regulierte Luftbremse mit Drehspitzen aus Stahl an den Flügelenden. Den ersten Satz dieser Drehspitzen produzierte Joergensen in seiner Werkstatt (Beuse et al. 2000, 144). GroveNielsen erinnert sich an die Kooperation mit den neuen Herstellern, die seine Rotoren, noch ohne aerodynamische Bremsen gekauft hatten : ,Viele Diskussionen und Entwicklungen technischer Lösungen fanden in der Werkstatt oder am Küchentisch von Karl Erik Joergensen oder Sven Adolfsen statt. Selbstgebackenes Weißbrot mit Rhabarbermarmelade und Kaffee teilten den Platz mit Skizzen auf Kladdenpapier.' (ebd.)

${ }^{141}$ Eine Ausnahme bildeten die etablierten Unternehmen Sonebjerg und LM, die allerdings nicht selbständig agierten, sondern im Auftrag Riisagers tätig wurden. Henrik Stiesdal und Erik Grove-Nielsen hatten ihr Technikstudium noch nicht begonnen, bzw. abgebrochen.

${ }^{142}$,When something is put into production the relationsship to the customer was a fruitful thing. It helped development because the customer told you: ,This could be better.' You could learn from his experiences. That
} 
Alle Pioniere waren permanent unterfinanziert. Sie arbeiteten mit einfachsten Materialen und bauten Schrottteile (bspw. LKW-Hinterachsen) in ihre WEA ein, was eine ausgeprägte Improvisationsgabe erforderte. In Ausnahmefällen erhielten die Unternehmen staatliche Fördermittel und günstige Kredite, wodurch ein Bankrott verhindert werden konnte. Tab. 2.1a fasst die wesentlichen Charakteristika der Pioniere zusammen.

Tabelle 2.1a Akteursstruktur der frühen Windindustrie

\begin{tabular}{|c|c|c|c|c|}
\hline & Gründungsjahr & $\begin{array}{l}\text { Zahl der } \\
\text { Beschäftigten }\end{array}$ & $\begin{array}{l}\text { Herkunft des } \\
\text { Designs? }\end{array}$ & Ort der Produktion \\
\hline Riisager Moellen & 1976 & 2 & Juul/ Riisager & Schreinerwerkstatt \\
\hline Erini & 1978 & $\max .10$ & Juul/ Riisager & Schmiederei \\
\hline $\begin{array}{l}\text { Sonebjerg } \\
\text { (Auftragnehmer) }\end{array}$ & etabliert & ca. 50 & Juul/ Riisager & Maschinenfabrik \\
\hline Kongsted Moellen & 1978 & $\begin{array}{lr}2, \quad \text { nur } & \text { bei } \\
\text { Aufträgen } & \text { zus. } \\
\text { Kräfte } & \\
\end{array}$ & Riisager & Autowerkstatt \\
\hline $\begin{array}{l}\text { LM } \\
\text { (Auftragnehmer) }\end{array}$ & etabliert & mind. 50 & Riisager & Bootsbaufabrik \\
\hline Adolfsen Moellen & 1977 & $5-10$ & $\begin{array}{l}\text { Energiekontor/ } \\
\text { Adolfsen/ } \\
\text { Oekaer }\end{array}$ & Autowerkstatt \\
\hline Herborg Vindkraft & 1978 & $2-3$ & $\begin{array}{l}\text { Energiekontor/ } \\
\text { H. Stiesdal/ } \\
\text { Joergensen/ } \\
\text { Oekaer } \\
\end{array}$ & Reparaturwerkstatt \\
\hline S.J. Wind Power & \begin{tabular}{|l|}
1978 \\
\end{tabular} & $\max .10$ & S.J. Windpower & Werkstatt \\
\hline $\begin{array}{ll}\text { Oekaer } & \text { Vind } \\
\text { Energi } & \\
\end{array}$ & 1977 & $2-3$ & $\begin{array}{l}\text { Energiekontor } \\
\text { (PTG/ NIVE) }\end{array}$ & Werkstatt \\
\hline
\end{tabular}

Quellen: Beuse et al. 2000; Interviews mit Erik Grove-Nielsen und Joergen Kroogsgaard

Stellt man diese Produktionsbedingungen dem LSP-Umfeld gegenüber, so weisen die Pionierhersteller eine starke Homogenität auf. Gearbeitet wurde nicht in Forschungslaboren und Fabriken, sondern zumeist in Werkstätten. Während die LSP-Prototypen von Energieund Forschungsministerien in Auftrag gegeben und mit Millionenbeträgen subventioniert wurden, hatten staatliche Akteure auf den Windmühlenbau in Dänemark zunächst gar keinen Einfluss. Hier waren Ingenieure eher als Ideengebern und Ansprechpartnern tätig, während die Baumeister nach handwerklichen Standards arbeiteten. Die Konstruktion der Großwindanlagen fand dagegen von der Planung bis zum letzten Fertigungsschritt unter der Obhut von Ingenieuren und Wissenschaftlern statt. Die Anlagenkonzepte genau zu berechnen war bei den Megawatt-Prototypen eine zwingende Notwendigkeit. Die Möglichkeit grundlegender Fehlannahmen konnte dennoch nicht ausgeschlossen werden. Aufgrund scheinbar unbegrenzt verfügbarer Mittel konnten sich die LSP-Akteure solche Fehler leisten. Bei dänischen Pionieren hätten entsprechende Vorgehensweisen zu einer sofortigen Pleite geführt. Hier nutzte man konventionelle Materialien (bspw. Holz und Stahl) und entschied sich für robuste Bauweisen, wodurch eine hohe Stabilität der WEA angestrebt wurde. Dort bediente man sich spezieller Baustoffe aus der Luft- und Raumfahrt und wollte die Prototypen so leicht wie möglich konstruieren, um eine maximale Effizienz zu erreichen. Man kann in diesem Zusammenhang von umgekehrter Prioritätensetzung sprechen. Die Tatsache, dass der robuste Baustil der Windmühlenpioniere aus der Not geboren war, tat dessen Erfolg keinen Abbruch. 
Tabelle 2.1b Windmühlenpioniere und LSP-Akteure

\begin{tabular}{|c|c|c|}
\hline & Dänische Kleinanlagen & LSP-Prototypen \\
\hline Hersteller & Handwerksbetriebe & Hightech-Konzerne \\
\hline Anlagendesigner & $\begin{array}{l}\text { OVE-Ingenieure/ Handwerker/ } \\
\text { J. Juul }\end{array}$ & Forschungszentren/ Hightech-Konzerne \\
\hline Produktionsort & Werkstätten & Forschungszentren/ Fabriken \\
\hline Grundlage von Design/ Herstellung & trail-and-error, Erfahrungsregeln & Berechnungen, formalisiertes Wissen \\
\hline $\begin{array}{l}\text { Entwicklungsarbeiten } \\
\text { finanziert? }\end{array}$ & nein & ja \\
\hline Kapitalmangel? & ja & nein \\
\hline Bauweise & robust, einfache Baustoffe & \begin{tabular}{|lrcr}
$\begin{array}{l}\text { Leichtbauweise } \\
\text { Materialen, unter }\end{array}$ häufig & $\begin{array}{c}\text { Einsatz } \\
\text { aus }\end{array}$ & $\begin{array}{r}\text { spez. } \\
\text { dem }\end{array}$ \\
Flugzeugbau & & & \\
\end{tabular} \\
\hline $\begin{array}{l}\text { Windturbinengröße (Rotordurchmesser } \\
\text { in Meter, Generatorenleistung in } \\
\text { Kilowatt) }\end{array}$ & $8-10 \mathrm{~m}, 10-30 \mathrm{~kW}$ & $50-100 \mathrm{~m} ; 1000-4000 \mathrm{~kW}$ \\
\hline Motivation & $\begin{array}{l}\text { Alternative Energienutzung, } \\
\text { gegen Atomkraft, Energie } \\
\text { produzieren, Faszination für } \\
\text { Technik, Profitinteresse steht i.a. nicht } \\
\text { an oberster Stelle }\end{array}$ & $\begin{array}{l}\text { Public Relations, Erschließung neuer } \\
\text { Energiequellen, Reaktion auf Proteste } \\
\text { gegen Atomkraft, Profite erzielen }\end{array}$ \\
\hline Serienreifes Produkt hervorgebracht? & ja & nein \\
\hline
\end{tabular}

Quellen: vg. Kap. 1 und Kap. 2.1

\subsubsection{Windanlagenkäufer und -betreiber in Periode 1}

In den 70er und frühen 80er Jahren ist die Windtechnologie aus privatwirtschaftlicher Perspektive gesehen nicht rentabel. Vielmehr konnten die ersten Windmüller von Glück reden, wenn sie keine Verluste schrieben.

Angesichts dessen kann von einer generell idealistischen Motivlage der Käufer und Betreiber ausgegangen werden. Ähnlich wie der Selbstbau-Bewegung ging es auch ihnen um Energieunabhängigkeit und Proteste gegen die Energiekonzerne. Preben Maegaard (Interview vom 2.7.07) beschreibt inwiefern die Ölkrise einen wichtigen psychologischen Hintergrund bildete, wodurch nicht nur eine abstrakte Sympathie für die Windkraft gefördert wurde, sondern auch der Wille, selbst aktiv zu werden:

,In the winter of 1974 there was a critic shortage of oil. Our minister of trade who was responsible for energy was every Saturday on televison and said: ,Turn off heat in all your rooms, only have one small room where you sit. No driving on Sundays for private people.' People said: ,We want to be independent. These arabian Scheichs should not decide whether we have energy in our family. We will not use oil. We will not use coal. We will be self-suppliers. We will not buy a new car. We will spend the money for a wind turbine."

Von Anfang an ist der Protest gegen die von der Regierung geplante Einführung der Atomkraft nicht nur für die Tvind-Leute und das OVE-Umfeld ein wichtiges Motiv, sondern auch für einen Großteil der ersten Windmüller (Beuse et al. 2000, 145). Ein weiterer Bezugspunkt ist die Kritik am staatlichen Windprogramm, dass unter Integration der EVU durchgeführt wurde. Denn in Dänemark herrscht eine ,eingefleischte Skepsis gegenüber allem, was mit Expertentum und Großkapital zu tun.' (Beuse et al. 2000, 129).

Der Erwerb und Betrieb von Windmühlen war mit einer Reihe von Problemen verbunden. Zuerst stellte sich die Frage der Baugenehmigung. Da Windkraft erst seit der Ölkrise auf neues Interesse stieß, kam die Errichtung von WEA im Planungsrecht noch gar nicht vor. Erst 1978 gab das Innenministerium vorläufige Richtlinien für Antragsteller und Beamte in den Genehmigungsbehörden heraus. Darin wurde vor allem festgelegt, dass die Anlagen mindestens ,100m Meter von jeglicher Wohnbebauung' entfernt aufgestellt werden müssen und in der Umgebung des Standorts ,Flächen mit nur geringem Verkehr' gelegen sind (Vogt 1983, 6f.). Auf eine die Windkraft befürwortende Administration verweisend, war es dem OVE-Pionier Maegaard zufolge in der Anfangszeit sehr unbürokratisch, eine Baugenehmigung zu erhalten (Interview vom 2.7.07). 
Eine weitere Barriere war der Zugang zum öffentlichen Stromnetz. Auch Jahre nachdem Riisager im Jahr 1975 seine WEA installiert hatte, produzierten die meisten Windmüller ausschließlich für den Eigenbedarf. Im Juli 1979 hat Naturlig Energi nicht mehr als 23 netzgekoppelte Windanlagen registriert (Naturlig Energi 9/79, 9). ${ }^{143}$ Aber die Gruppe derjenigen, die ihre Windmühle ans Netz schließen wollten, vergrößerte sich stetig. Die Betreiber mussten in Verhandlungen mit dem Netzbetreiber treten und eine Einspeisegenehmigung erwirken. Zunächst gab es keine verbindlichen Regelungen. Die Betreiber waren der Willkür der EVU ausgesetzt und mussten langwierige Verhandlungen und niedrige Tarife akzeptieren, oder erhielten gar kein Geld für ihre Stromlieferungen (Hantsch 1998, 40). Zwar vereinfachte sich die Situation seit 1976 etwas. Als Reaktion auf den Druck der Öffentlichkeit und des Parlamentes gab der DEF erstmals vorläufige Richtlinien zum Umgang der lokalen und regionalen EVU mit den Windanlagenbetreibern herausgab. Darin empfahl der Verband seinen Mitgliedern, die Turbinen ans Netz zu nehmen. ${ }^{144}$

Bis etwa 1977 hat der Markt für WEA eine untergeordnete Rolle gespielt. Noch 1979 stellten die Fertigungen ,Marke Eigenbau' einen deutlichen Anteil der neu errichteten Windmühlen dar. Für diejenigen, die ihre Anlage selbst gebaut haben, war der Betrieb vergleichsweise unproblematisch. Sie vermochten, Defekte früh zu erkennen und zu beheben. Sie wussten, worauf bei der Wartung zu achten war. Jedoch wuchs die Zahl derer, die ihre Windturbine tatsächlich auf dem Markt erwarben, stetig an. Die meisten dieser Käufer waren technisch versierte Windenergiebegeisterte, die möglicherweise selbst am Windmühlenbau interessiert waren. ${ }^{145}$ Grove-Nielsen (Interview vom 27.6.07) hat die (Technik-)Lehrer als wesentliche ,Problemgruppe' angesehen. Sie kannten sich häufig nicht gut genug mit der Windanlagentechnik aus und waren auf Hilfe des Herstellers angewiesen. Hier war es oft sehr nützlich, dass der Verkäufer nicht weit entfernt lebte und im Problemfall schnell Abhilfe leisten konnte.

Die meisten Selbstbauer waren quasi ihre eigene Lobby. Versagte die Windmühle, konnten sie niemand anders als sich selbst belangen. Ein Käufer dagegen würde gern seine Schadensansprüche geltend machen. ${ }^{146}$ Doch 1978 existierte kein Versicherungsschutz. Auch brauchte sich ein Selbstbauer nicht lange nach dem besten Modell umzuschauen. Wer aber half einem potenziellen Käufer, der sich auf dem Markt für ein bestimmtes Fabrikat und einen Produzenten entscheiden sollte? Dieses Problem der Interessenwahrung der Windmühleneigentümer gegenüber den Herstellern verband alle Windturbinenkäufer. Die logische Konsequenz war die Bildung einer Interessenorganisation. Mit der Danske Vindmoellefoerening (DV) ist eine solche im Mai 1978 durch circa 40 Mitglieder auf Initiative von Torgny Moeller gegründet worden (s.o.). Ihre Hauptforderung an die Hersteller bestand in der Einführung zweier unabhängig voneinander arbeitender Bremssysteme, d.h. der Ausstattung der Rotorblätter mit einer aerodynamischen Bremse. Damit stand der DV in Einklang mit den Zielen des Sicherheitsausschusses der OVE (s.o.). Die Havariequote lag damals bei $50 \%$ und betraf insbesondere WEA ohne Luftbremse. Der DV empfahl daher seinen Mitgliedern, sich ausschließlich für Hersteller zu entscheiden, die doppelt gesicherte WEA anboten. Faktisch kam diese Empfehlung einem Boykottaufruf gegen die übrigen Produzenten gleich. Der Aufruf verfehlte seine Wirkung nicht. Denn innerhalb eines halben

\footnotetext{
${ }^{143}$ Von diesen wurden gut 15 auf dem Markt erworben (Schätzung des Autors). Zu diesem Zeitpunkt waren in Dänemark bereits deutlich mehr Windmühlen in Betrieb, die nicht ans Netz geschlossen waren, sondern Strom und Wärme für den Haushalt lieferten. Dabei handelte es sich häufig um selbstgebaute Mühlen.

${ }^{144}$, The grid connection was quite easy, because utilities were under pressure of politicians and they had to allow people to connect the wind turbines.' (Maegaard, Interview vom 26.7.07). Darüber hinaus sollte der überschüssige Strom zum Preis vermiedener Kosten vergütet werden. Mit dieser Richtlinie wollte der DEF angeblich ,private Initiativen unterstützen, um Windkraftnutzung zu fördern'. (zitiert nach: van Est 1999, 78, Übersetzung aus dem englischen: Autor). In der Praxis jedoch zahlten die meisten Versorger weiterhin gar nichts für den Strom, der in ihr Netz gespeist wurde (ebd.).

${ }^{145}$ Ole Hansen von Kongsted Moellen bspw. hatte vor Beginn seiner Mühlenproduktion selbst eine RiisagerTurbine erworben (s.o.).

146 ,Bying turbines was a risky thing because many of the early turbines collapsed and the customers lost money. So they were real pioneers, these early buyers of turbines.' (Grove-Nielsen, Interview vom 27.6.07).
} 
Jahres hatten alle Anbieter ihre Windmühlen entsprechend nachgerüstet (Beuse et al. 2000, 195). ${ }^{147}$ Gipe $(1995,59)$ bewertet diese Intervention als wichtigsten Beitrag des Verbands überhaupt. Mit dieser Auswahlhilfe vertrat der DV nicht nur die Interessen seiner Mitglieder, sondern beschleunigte die technische Innovation. Eine zweite Auswahlhilfe geht auf eine Initiative Torgny Moellers zurück, der seit 1976 eine Riisager-Mühle betrieben hatte. Seitdem veröffentlichte der Journalist jeden Monat Statistiken, welche Auskünfte über produzierte Kilowattstunden und Zuverlässigkeit seiner Windanlage boten. Zu diesem Zeitpunkt bestand darin vor allem Werbung für das Unternehmen Riisagers, dem zu dieser Zeit einzigen Hersteller. ${ }^{148}$ Diese Situation veränderte sich, als der DV kurze Zeit nach seiner Entstehung das Magazin ,Naturlig Energi' herausgab. Darin wurden monatlich die Produktions- und Schadensstatistiken jeder einzelnen WEA veröffentlicht. Oft wurde auch analysiert, weshalb manche Anlagen bessere Ergebnisse brachten als andere. So erhielten die Fabrikanten Anreize, ihren Service- und Garantieverpflichtungen nachzukommen (Beuse et al. 2000, 196). Auch förderte die Lektüre des Magazins ein Zusammengehörigkeitsgefühl unter den Windmüllern sowie den Erfahrungsaustausch und ein wechselseitiges Interesse. ${ }^{149}$

In den ersten Jahren bestand kein hinreichender Versicherungsschutz. Dies wurde bereits kurz nach Gründung des Verbands offenkundig, als der bis dahin größte Schadenfalls auftrat. Etwa 20 Kunden eines Herstellers waren betroffen. Daraufhin ging die Firma Bankrott. Über den Produzenten waren die Windmüller bei einer der größten Gesellschaften des Landes versichert. Doch die Versicherung weigerte sich einzutreten, weil die Schäden innerhalb der Garantiefrist auftraten - und deshalb der Produzent haftbar sei. Doch einem bereits aufgelösten Unternehmen gegenüber, konnten keine Garantieansprüche geltend gemacht werden (Traenes 1997, 11). ${ }^{150}$ Dadurch, dass das Verband die Hersteller zu einer kurzfristigen Ergänzung der Rotoren mit aerodynamischen Bremsen zwang und sie durch Veröffentlichung der Produktionsstatistiken in eine transparente Konkurrenz zueinander brachte, wurde der DV 1978 zu einem wichtigen Motor der Innovation.

Die Interessenvertretung gegenüber den Produzenten war in der Anfangsphase die wichtigste Aufgabe des DV. Verhandlungen mit der Regierung und den Energieversorgern waren zwei weitere Arbeitsfelder des Verbands, die in der Folgezeit zunehmend an Bedeutung gewannen. Seit 1978 bestand ein deutlicher Trend, neu aufgestellte Windanlagen an das allgemeine Stromnetz zu schließen. Zwar war der Netzanschluss seit 1976 einfacher geworden. An die Richtlinie des DEF, der zufolge der eingespeiste Strom in Höhe vermiedenen Kosten hätte vergütet werden sollen, hielten sich die meisten EVU nicht.

In dieser Periode ist das Ungleichgewicht zwischen dem kleinen DV einerseits sowie den Stromkonzernen und Ministerien andererseits so stark, dass der Verband kaum eine Chance hatte, die Dinge im Sinne der Windmüller zu beeinflussen. Die Erfolge des DV bzgl. der Windturbinenentwicklung beruhen auch darauf, dass der Verband mit den Herstellern, bzw. dem FDV, deren ebenfalls 1978 gegründeter Organisation, auf Augenhöhe verhandeln konnte.

\footnotetext{
${ }^{147}$ Nur ein Windanlagentyp wurde nicht mit neuen Flügeln ausgestattet. Der Hersteller verschwand innerhalb eines Jahres vom Markt (Beuse et al. 2000, 195).

${ }^{148}$ Der Journalist warb auch für die Windtechnologie insgesamt. Die WEA Moellers befindet sich heute auf dem Gelände des Folkecenter und ist noch immer intakt. Vorsitztender des Folkecenters Maegaard (Interview vom 2.7.07) bewertet die Rolle des Journalisten: ,Torgny Moeller is a very important person in this whole development. He could proove that his small $20 \mathrm{~kW}$ windmill was very reliable and worked well. Month after month, year after year.'

149 ,In the families they were sitting on Sunday morning, discussing, getting the new issue of the ,Naturlig Energi' and saw: How much energy was produced this month? How much did our wind mill produce? How much did the neighbours' produce?' (Maegaard, Interview vom 2.7.07)

${ }^{150}$ Daraufhin ging der DV vor Gericht. Es folgten langwierige und kostenintensive Prozesse. Bis zur endgültigen Urteilsverkündung dauerte es fünf Jahre. Der DV verlor den Prozess. Grundlage des Urteils war, dass der Vertrag zwischen der Versicherung und dem Hersteller abgeschlossen worden war (Traenes 1997, 11).
} 
Zur Motivlage der Akteure

Der Enthusiasmus und Idealismus, den alle Windkraft-Akteure bewiesen, die in der Technikperiode aktiv waren, stellt keine Selbstverständlichkeit dar. Die kognitive und emotionale Lücke zwischen vorhandenen Ideen und der Entscheidung, wirklich arbeits- und zeitintensive Schritte zu gehen, musste erst überwunden werden. Dazu bedurfte es bestimmter motivierender Faktoren. Dabei konnte es sich allgemein um äußere Entwicklungen handeln (bspw. drohender Aufbau von Atomkraftwerken, wachsende Energieknappheit). Eine ähnlich aktivierende Funktion hatten Teilerfolge wie die Realisierung der Tvind-Mühle und Riisagers Netzanschluss, die alternative Wege aufzeigten. Eine heterogene Akteurskonstellation aus Selbstbauern und ökologischen Praktikern der OVE erhielt dadurch enormen Aufwind. Die Idee der Unabhängigkeit von den Stromkonzernen war zumindest im kleinen Maßstab Realität geworden. Zusätzlich unterstützt wurde die ,Windszene' durch Antiatom-Aktivisten, die ihren Protest wahrnehmbar in die Öffentlichkeit trugen. Wichtigster Schnittpunkt beider Akteure ist die Arbeit an der Tvind-Mühle (s.o.). Auf diese Weise lässt sich der soziale Kontext der Marktentstehung beschreiben. Die Einflussgrößen auf die Handlungsmotive der Akteure des Systems, kleiner Windkraft' sind in Schaubild 2.1a dargestellt. 


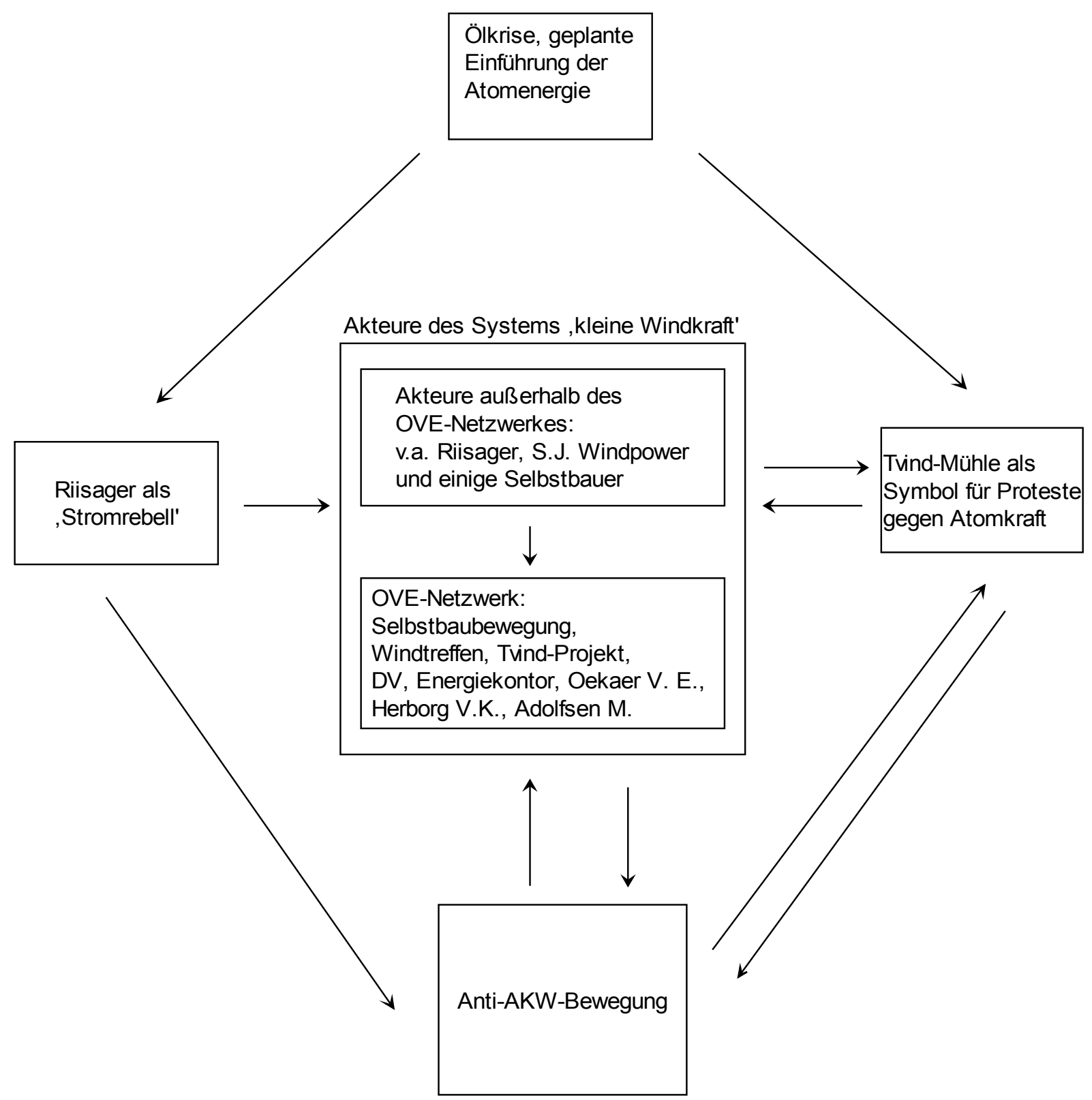

Eigenschaften und Bedingungen des Innovationsvorgangs

Die Windanlagen mussten den Anforderungen serienreifer Produkte gerecht werden. Diesem Ziel kamen die erfolgreichen Hersteller der Technikperiode zumindest relativ nahe. Riisager war der prominenteste Vertreter des individualisierten, auf Konkurrenz basierenden wirtschaftlichen Entwicklungspfades. Anfangs profitierte er von seinem Erfahrungsvorsprung. Problematisch für Riisager, der alle Komponenten selbst entwarf, war, dass er die 1977/78 aus dem OVE-Netzwerk hervorgegangenen Innovationen nicht 
aufgegriffen hatte und entsprechend nur geringe Lernfortschritte erzielte. Nichtsdestotrotz blieb Riisager der erfolgreichste ökonomische Akteur dieser Periode. Für die Innovation bedeutsamer ist der kooperative Entwicklungsstil. Dieser ist sowohl gekennzeichnet durch die Zusammenarbeit mancher Hersteller untereinander, als auch diejenige zwischen OVEIngenieuren und den eigentlichen Baumeistern, begabten Handwerkern wie Karl-Erik Joergensen. Der Windmühlenbau erforderte gleichermaßen handwerkliche Qualifikationen und die Fähigkeit, Konzepte zu entwerfen, d.h. etwa technische Zeichnungen zu erstellen und Lastenberechnungen durchzuführen. Die OVE erkannte frühzeitig, dass einzelne Hersteller mit der Fertigung sämtlicher Mühlenteile überfordert waren. Daher förderte sie gezielt die Entstehung einer unabhängigen Zulieferindustrie zur separaten Produktion einzelner Komponenten. 1977 hat die OVE erstmals eine Komponentenwindmühle hergestellt. Im selben Jahr gründete sich eine Rotorenfirma. Dadurch vereinfachte sich die Windanlagenfertigung und der Kreis potenzieller Hersteller erweiterte sich. Deren Hauptaufgabe sollte künftig darin bestehen, die verschiedenen Komponenten optimal zu kombinieren.

1977/78 betrat eine kleine Reihe professioneller Turbinenhersteller, die zuvor bereits als Handwerker tätig waren, den Markt. Deren erste Produkte waren von der Serienreife noch weit entfernt. Der Mangel an Ingenieurwissen war insofern unproblematisch, als die verwendeten Zeichnungen und Baustoffe gut mit den Kenntnissen und dem Erfahrungswissen der Baumeister korrespondierten. Technische Fehler wurden nach der ,trail-and-error'Methode sukzessive korrigiert. Möglich war eine solche Vorgehensweise, weil die Turbinen nicht als Serien, sondern als Einzelstücke produziert wurden. Auch waren die Mühlen so klein, dass sich der Korrekturaufwand in Grenzen hielt. Schließlich ermöglichte die regionale Beziehung zwischen Käufer und Verkäufer ein schnelles Feedback zum Hersteller. Die Wege waren so kurz, dass die Fehler kurzfristig in Augenschein genommen und behoben werden, bzw. beim Bau der nächsten Maschine vermieden werden konnten (Gipe 1995, 56).

Der DV flankierte den Innovationsprozess erfolgreich, indem er die Hersteller frühzeitig zur Verwendung einer Luftbremse genötigt hatte. Dadurch verringerte sich die Schadensanfälligkeit deutlich. Die wichtigsten Entwicklungsschritte sind in Tabelle 2.1c zusammengefasst.

Tab. 2.1c Zentrale Ereignisse und Entwicklungen in Periode 1 (1975-1978)

\begin{tabular}{|c|c|}
\hline Akteur & Entwicklung/ Ereignis \\
\hline Hersteller/ OVE & 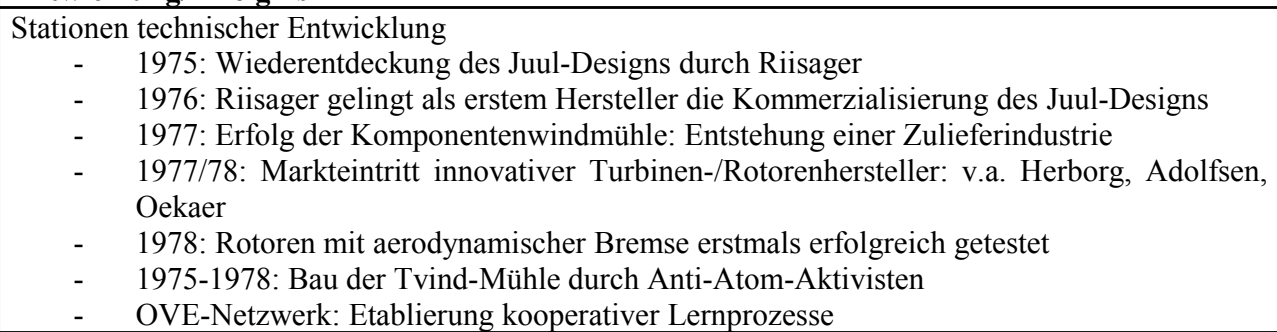 \\
\hline Käufer/ Betreiber & 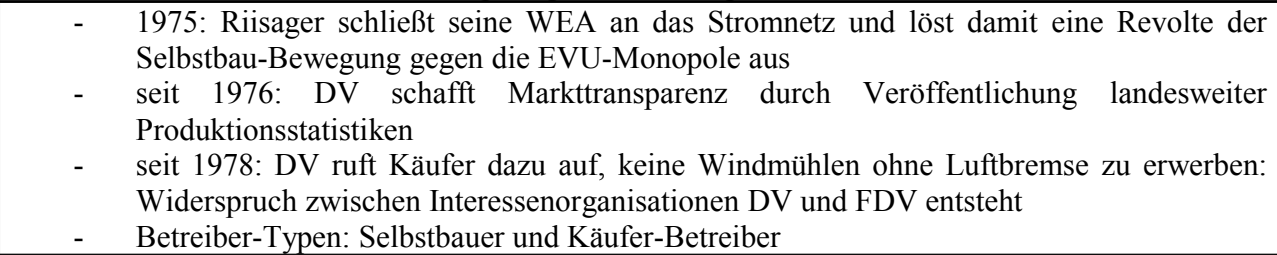 \\
\hline
\end{tabular}

Quellen: vg. Kap. 2.1

Diese Periode ist gekennzeichnet durch den Übergang von Selbstbau-Windmühlen zu solchen Modellen, die ausschließlich für den Markt hergestellt wurden. Das größte Problem der Betreiber bestand darin, von den EVU eine Einspeiseerlaubnis zu erhalten sowie über die Vergütung eingespeister Energie zu verhandeln. In dieser ungleichen Auseinandersetzung erhielten die Windmüller Unterstützung durch eine den EVU kritisch gesonnene 
Öffentlichkeit und dem DV. Letzterer scheiterte zunächst daran, eine Verbesserung der Situation der Windmüller durchzusetzen. Erfolgreich ist der Verband in der Interessenvertretung seiner Mitglieder gegenüber den Herstellern. Der Anlagenbetrieb selbst erforderte gewisse technische Qualifikationen, bspw. was die Wartung und kleine Reparaturen betrifft. Die meisten Betreiber verfügten über entsprechende Kenntnisse, bzw. hatten die WEA selbst gebaut. Andernfalls konnte ein Besuch des Herstellers, der i.a. in derselben Region ansässig war, Abhilfe schaffen. Eine Übersicht über Schwierigkeiten, Lösungsversuche und Akteure bietet die folgende Tabelle 2.1d.

Tab. 2.1d

Zentrale Barrieren: Technikperiode

\begin{tabular}{|c|c|c|c|}
\hline Problem & \begin{tabular}{|l|} 
Lösungsansatz/ \\
Lösungsvoraussetzungen
\end{tabular} & Beteiligte Akteure & \begin{tabular}{|l|}
$\begin{array}{l}\text { Lösungsansatz } \\
\text { erfolgreich? }\end{array}$ \\
\end{tabular} \\
\hline $\begin{array}{l}\text { Selbstbau-Bewegung fehlt ein geeignetes } \\
\text { Anlagenkonzept }\end{array}$ & $\begin{array}{l}\text { Riisager verwendet Juul-Design und } \\
\text { ist damit erfolgreich }\end{array}$ & Riisager & ja \\
\hline $\begin{array}{l}\text { Selbstbauer stoßen an Grenzen, weil } \\
\text { ihnen spezifisches Know-how fehlt }\end{array}$ & $\begin{array}{|lc|}\text { Austausch auf Windtreffen, } \\
\text { Kooperation mit OVE-Ingenieuren }\end{array}$ & $\begin{array}{l}\text { OVE, Handewerker, } \\
\text { Volkshochschulen }\end{array}$ & ja \\
\hline $\begin{array}{l}\text { keine Gewinnerwartung, Erfolg setzt } \\
\text { Idealismus voraus }\end{array}$ & \begin{tabular}{|l|} 
Komplexes Systems motivierender \\
Faktoren (vg. Schaubild 2.1a)
\end{tabular} & $\begin{array}{|lr|}\text { Anti-AKW- } & \\
\text { bewegung } \quad \text { OVE- } \\
\text { Netzwerk, Ölkrise, } \\
\text { Selbstbauer, Riisager } \\
\end{array}$ & ja \\
\hline $\begin{array}{l}\text { EVU weigert sich, Riisagers Windturbine } \\
\text { ans Netz zu schließen }\end{array}$ & $\begin{array}{l}\text { Riisager schafft Politikum, indem er } \\
\text { seine WEA ohne Erlaubnis anschließt }\end{array}$ & $\begin{array}{l}\text { Riisager, kritische } \\
\text { Öffentlichkeit, } \\
\text {,grüne Mehrheit' } \\
\end{array}$ & ja \\
\hline $\begin{array}{l}\text { Trotz vorläufiger DEF-Regelung von } \\
1976 \text { sind Verhandlungen um } \\
\text { Netzanschluss nach wie vor kompliziert; } \\
\text { Viele EVU weigern sich, eingespeiste } \\
\text { Energie zu vergüten }\end{array}$ & $\begin{array}{l}\text { Beharrlichkeit der Käufer, Druck } \\
\text { seitens Öffentlichkeit und Regierung, } \\
\text { Öffentlichkeitsarbeit des DV }\end{array}$ & \begin{tabular}{|l|} 
Käufer, Regierung, \\
DV
\end{tabular} & kaum \\
\hline $\begin{array}{l}\text { Selbstbauer arbeiten alleine. } \\
\text { Weiterentwicklung ihrer Konzepte droht, } \\
\text { aufgrund mangelnder Kenntnisse und } \\
\text { Austausch mit anderen zu stagnieren }\end{array}$ & $\begin{array}{l}\text { OVE-Windtreffen: Austausch } \\
\text { zwischen Selbstbauern, OVE- } \\
\text { Ingenieure geben Know-how weiter }\end{array}$ & OVE & ja \\
\hline $\begin{array}{lcr}\text { Selbstbauer/ } & \text { Hersteller } & \text { haben } \\
\text { Schwierigkeiten mit der Fertigung } \\
\text { bestimmter Komponenten, insb. Rotoren }\end{array}$ & $\begin{array}{l}\text { OVE-Ansatz: Komponentenmühle, } \\
\text { Aufbau einer Zulieferindustrie }\end{array}$ & $\begin{array}{l}\text { OVE, neue } \\
\text { Zulieferbetriebe wie } \\
\text { Oekaer V.E. }\end{array}$ & ja \\
\hline $\begin{array}{l}\text { Kapitalmangel der Hersteller bedroht } \\
\text { technische Weiterentwicklung }\end{array}$ & \begin{tabular}{|l|} 
Kredite, Improvisierung, \\
Verwendung günstigster Materialien; \\
vereinzelt: Förderung \\
\end{tabular} & \begin{tabular}{ll|} 
Hersteller, & PAS, \\
Stiftungen &
\end{tabular} & zeitweise \\
\hline $\begin{array}{l}\text { Der Betrieb einer WEA muss technisch } \\
\text { bewerkstelligt werden: Wartung, } \\
\text { Kontrolle, Reparaturen }\end{array}$ & \begin{tabular}{|l|} 
für \\
unproblematisch; andere erhielten \\
schnelle Hilfe durch Hersteller, der \\
häufig in der Nähe lebte
\end{tabular} & $\begin{array}{l}\text { Hersteller, } \\
\text { Selbstbauer }\end{array}$ & ja \\
\hline mangelnde Transparenz des Marktes & $\begin{array}{|ll|}\begin{array}{l}\text { Veröffentlichung von } \\
\text { jeder einzelnen WEA }\end{array} & \text { Statistiken } \\
\end{array}$ & DV & ja \\
\hline Havariequote von $50 \%$ & \begin{tabular}{|l|} 
Boykottaufruf gegen Hersteller von \\
WEA ohne Luftbremse
\end{tabular} & DV & ja \\
\hline $\begin{array}{l}\text { mangelnder Versicherungsschutz im } \\
\text { Bankrottfall des Verkäufers }\end{array}$ & \begin{tabular}{|l|l|} 
DV will Schadensansprüche vor \\
Gericht geltend machen
\end{tabular} & DV & nein \\
\hline
\end{tabular}

Quellen: vg. Kap. 2.1

,Zivilgesellschaftler' sind der bestimmende Akteurstyp in Periode 1: OVE, Selbstbauer, Riisager, Tvind-Leute, DV, Volkshochschulen und Hersteller. In der Lösung der meisten Probleme waren sie erfolgreich. Regierung und Großunternehmen sind nicht präsent, bzw. nicht an prominenter Stelle. 


\subsection{Periode 2: 1979-1982 Industrialisierung und Stabilisierung des Ursprungsmarktes (Dänemark)}

Zwischen 1975 und 1978 entwickeln die Pioniere ein weitgehend zuverlässiges und marktfähiges Produkt. Dennoch: Windenergie ist noch immer eine absolute Nischentechnik, die nur für Bastler und Windenergiebegeisterte interessant war. Es bedurfte einer Legitimation der neuen Technologie durch den Staat, der bis dahin an der Entwicklung nicht beteiligt war. Erst vor dem Hintergrund des Eintritts der Regierung in das System ,kleine Windkraft' kommt es seit 1979 zu einer deutlichen Markterweiterung (vg. Tab. 2a). In diesem Jahr wurde eine Investitionsförderung in Höhe von 30\% auf Erwerb und Installation geprüfter WEA eingeführt. Entsprechende Zertifizierungsverfahren sind in der Teststation für kleine Windturbinen in Risoe durchgeführt worden. Mit dem Energiplan 81 garantierte die Regierung, einen Windenergiemarkt langfristig zu erhalten. Schließlich maßregelte sie die Energiewirtschaft in ihrem, den Windmüllern gegenüber, restriktiven Verhalten.

Mit der wachsenden Nachfrage konnten die handwerklichen Betriebe nicht Schritt halten. Zur Einführung industrieller Produktion (Serienfertigung) mangelte es an Kapital und Know-how. Ein Reformierungsprozess, in dessen Zuge die meisten der kleinen Hersteller vom Markt verschwanden, stellte sich ein. Größere Unternehmen, insbesondere der Agrarmaschinenindustrie betraten den Sektor und übernahmen die Branche innerhalb weniger Jahre.

Mit dem Größenwachstum der WEA begannen diese, den Bedarf und die finanziellen Möglichkeiten des einzelnen privaten Betreibers zu übersteigen. Nach der Restrukturierung auf Herstellerseite hatte sich auch auf Betreiberseite eine grundlegende Transformation eingestellt. Wurde der erste Nachfrageschub durch Landwirte ausgelöst, so traten bald genossenschaftliche Betreiber hinzu. Für mehrere Käufer reduzierte sich sowohl die Investition, als auch das damit verbundene Risiko. Jedes Mitglied produzierte nur so viel Strom wie von ihm verbraucht wurde. Kooperativen sind aus historischen Gründen eine beliebte Unternehmensform. Schon bald waren Hunderte Haushalte im Besitz von Windmühlenanteil.

Tab. 2.2a: $\quad$ Entwicklung der Installation netzgekoppelter WEA

\begin{tabular}{|l|l|l|l|l|}
\hline Jahr & $\begin{array}{l}\text { Neu WEA pro Jahr } \\
(\mathbf{M W})\end{array}$ & $\begin{array}{l}\text { Gesamtkapazität } \\
\text { (MW) }\end{array}$ & WEA-Zahl pro Jahr & WEA-Zahl gesamt \\
\hline $1976-78$ & 2 & 2 & 50 & 50 \\
\hline 1979 & 2 & 4 & 55 & 105 \\
\hline 1980 & 3 & 7 & 120 & 225 \\
\hline 1981 & 5 & 12 & 135 & 360 \\
\hline 1982 & 5 & 17 & 90 & 450 \\
\hline
\end{tabular}

Quelle: Heymann 1998

\subsubsection{Das Politisch-administrative System in Periode 2}

Eine günstige Rahmenbedingung ist die Regierungsübernahme durch die sozialdemokratische Partei, die seit Oktober 1979 allein regieren konnte. Anders als die zuvor regierende konservative Partei waren die Sozialdemokraten nicht unbedingt auf die Einführung der Atomenergie festgelegt. Als Reaktion auf die zweite Ölkrise von 1979 startete sie die Förderung erneuerbarer Energien. Zudem nahm sie Abstand von der Annahme, dass ein Wirtschaftswachstum notwendig mit wachsendem Energieverbrauch einher gehen müsse.

Die wichtigsten Instrumente zur Förderung kleiner WEA waren der besagte 30\%ige Investitionszuschuss und die Installation einer Teststation am Nuklearforschungsinstitut von Risoe (van Est 1999, 80f.). Darüber hinaus hat die Regierung zwei energiepolitische 
Richtungsentscheidungen getroffen, wodurch der kleine Windanlagenmarkt stabilisiert worden ist. Erstens zwingt sie den EVU-Verband DEF zur Einführung von Richtlinien zum Windanlagenbetrieb durch unabhängige Akteure. Zweitens beschließt sie bereits 1981 die weitgehende Abkehr vom LSP-Programm. Der Ausbau kleiner Windkraft wird festgeschrieben. In keinem anderen Pionierland liegen das Versagen der großen Prototypen einerseits sowie der kommerzielle und technische Erfolg kleiner Windanlagen andererseits, so eng beieinander wie in Dänemark.

Investitionsförderung erneuerbarer Energien

Seit August 1979 wird erstmals der Kauf geprüfter WEA - ausschließlich von Nicht-EVUKäufern - mit 30\% der Gesamtkosten gefördert. Das Gesetz wurde zunächst vom Wohnungsbauministerium ausgearbeitet und anschließend durch das Handelsministerium zur Abstimmung eingebracht und von den meisten Parteien befürwortet. ${ }^{151}$ Der Wohnungsbauminister betonte, dass mit dem Gesetz weder die Förderung der Grundlagenforschung, noch der Pioniere beabsichtigt sei, sondern der Industrie die Gelegenheit zur Einrichtung von Serienproduktionen geboten werden sollte. Die konservative Partei, nicht unbedingt eine Befürworterin der Windenergie, begründete ihre Zustimmung zum Gesetz damit, dass aufgrund der hohen Ölpreise derzeit jede Energiequelle genutzt werden müsse (van Est 1999, 79f.).

Die Förderhöhe war so gewählt, dass eine deutliche Risikominderung gegeben war, hohe Gewinne jedoch ausgeschlossen wurden. Infolge von Effizienzsteigerungen wurde die Förderquote 1982 erstmals auf 20\% abgesenkt (van Est 1999, 244f.; Hantsch 1998, 49).

Regelung des DEF von 1979 (79er Richtlinien)

Angesichts des wachsenden Marktes gewannen die Windenergieverbände DV/FDV an Einfluss und setzten sich beim Handelsministerium dafür ein, gesetzliche Regelungen gegen die EVU zu beschließen, da diese sich bzgl. der Vergabe von Anschlusserlaubnissen und der Zahlung von Einspeisevergütungen, nicht an ihre eigenen Richtlinien gehalten hätten (van Est 1999, 80). Nach entsprechenden Drohungen der Regierung konkretisierte der DEF seine bisherigen Regelungen und gab ihnen einen verbindlicheren Status. ${ }^{152}$ Die Regelung garantierte einzelnen und gemeinschaftlichen Betreibern von WEA seit 1979, in das Netz des ansässigen Versorgers einzuspeisen und den Strom zum Preis vermiedener Kosten vergütet zu bekommen. Die Betreiber durften maximal drei Kilometer vom Standort entfernt leben $(3 \mathrm{~km}-$ Kriterium) und nicht mehr als 135 Prozent des Eigenverbrauchs produzieren (135\%Kriterium).

\section{Energiplan 81}

Den Planungen zufolge sollten bis zum Jahr 2000, 60.000 kleine WEA errichtet werden und 8,5\% des Strombedarfs liefern. Der Ende 1981 verabschiedete Energiplan 81 kam damit einer Aufgabe des LSP gleich. Darüber hinaus eröffnete er die Möglichkeit eines Paradigmenwechsels im gesamten Stromsystem. Der Energieplan enthielt zwei Szenarien, eines mit und eines ohne Kernenergienutzung. Die Option einer atomenergiefreien Energiepolitik war ein Novum. Zur Erklärung, weshalb sich der dänische Staat relativ leicht bereit zeigte, eine Aufgabe der Atomkraft zu akzeptieren, sind drei Gründe zu berücksichtigen. Zunächst gab es seit Mitte der 70er Jahre in Dänemark keine politischen Mehrheiten für die Einführung der Atomenergie. Abgesehen von dem Forschungsreaktor in

\footnotetext{
${ }^{151}$ Eine Ausnahme bildete die rechte ,Fortschrittspartei'.

${ }^{152}$ An dieser Stelle zeigt sich die Moderatorenrolle, welche staatliche Institutionen angesichts sozialer Konflikte gern einnehmen. Die eigenständige Suche der Konfliktparteien nach einer Kompromisslösung, ohne auf Hilfe dritter (Staat, Justiz) zurückzugreifen, ist charakteristisch für die dänische Konfliktkultur.
} 
Risoe wurden 1981 noch keine sehr großen Investitionen getätigt, insbesondere ist noch kein AKW gebaut worden. Ein weiterer Grund der Verzögerungen waren techno-ökonomischer Art: Der dänischen Wirtschaft fehlte es an Know-how und entsprechenden HightechUnternehmen, wodurch sich der Aufbau einer Nuklearindustrie als kompliziert erwies.

Erstmals fordert ein Energieplan die Entkopplung des Wirtschaftswachstums von einer Zunahme des Energieverbrauchs. Schließlich wurde der massive Ausbau dezentraler KraftWärme-Kopplung und erneuerbarer Energien festgelegt. Damit enthielt der Energieplan alle wichtigen Punkte des Alternativen Energieplans von 1976 (,Macht Pläne ohne Atomkraft!'), der damals von der OAA als Antwort auf den geplanten Bau von AKWs herausgegeben wurde. Am Entstehungsprozess des Energiplan 81 waren die Verfasser des Alternativen Energieplans insofern beteiligt, als sie gebeten wurden, einen Rohentwurf des Plans zu kommentieren (van Est 1999, 80f.).

Für den mangelnden Erfolg des US-amerikanischen Mod-Programms gab es zu dieser Zeit bereits erste Anzeichen. Auch die Nibe-Zwillinge blieben hinter den Erwartungen zurück (vg. Kap. 1.1). Diese Erfahrungen stellten für die Regierungen aller übrigen Pionierländer keinen hinreichenden Grund dar, von der LSP-Strategie Abstand zu nehmen. Im Unterschied zu diesen, existierte 1981 in Dänemark ein Markt für kommerziell erfolgreiche kleine Windanlagen.

Teststation für kleine WEA: Schnittstelle zwischen PAS und Windindustrie ${ }^{153}$

Auf dem Gelände des Nuklearforschungsinstituts in Risoe wurde 1978 eine Teststation für kleine WEA eingerichtet. ${ }^{154}$ Im Rahmen des Forschungsprogramms wurde sie mit 5,5 Mio. DKr über einen Zeitraum von drei Jahren gefördert (Kamp 2002, 147). Bis dahin sollte entschieden werden, ob Windkraft ökonomisch nutzbar und damit weiter förderungswürdig sei (Beuse et al. 2000, 183). Der Aufbau der Teststation (im folgenden kurz: Risoe) war umstritten. Das Handelsministerium zweifelte daran, dass Kleinwindanlagen einen nennenswerten Teil der Stromnachfrage decken konnten. Es monierte die Gefahr, dass ein potenzieller Markt für größere Windturbinen beeinträchtigt werden konnte (Heymann 1995, 412). Als Element des Forschungsprogramms war Risoe weitgehend unabhängig von den LSP-Projekten (vg. Kamp 2002, 147).

Mit der Testanlage betritt im April 1978 erstmals ein staatlicher Akteur das System ,kleine Windkraft'. Die neue Industrie tritt jetzt mit dem PAS in Kontakt. Dadurch, dass sich die Teststation auf dem selben Gelände wie die Nuklearforschungsanlage befand, war in Risoe beinahe so etwas wie eine, interkulturelle Begegnungsstätte' entstanden. Seitens der Basisbewegung wurde das Engagement Risoes mitunter kritisch wahrgenommen. Die Windleute waren gegen Atomkraftnutzung und lehnten es daher ab, mit Risoe zu kooperieren. Der spätere DV-Vorsitzende Asbjoern Bjerre, dessen Riisager-WEA nach Risoe gebracht wurde, um sie dort genauen Messungen zu unterziehen, äußerte sich beschwichtigend. In einem TV-Interview stellte er heraus, dass die Teststation nicht Teil der Nuklearforschungsanlage sei, sondern sich lediglich auf deren Gelände befunden hätte (Beuse et al. 2000, 185). Die Polarisierung wurde dadurch verringert, dass sich die Mehrheit der ersten Mitarbeiter stärker mit der Teststation identifizierte, als mit dem Nuklearforschungsinstitut. Sie alle waren vom Nutzen kleiner Windanlagen überzeugt. Ihre erklärten Ziele waren der Aufbau einer Windkraftindustrie und die Optimierung der Windtechnik, um die Atomenergienutzung überflüssig zu machen. Drei der ersten fünf Mitarbeiter waren Mitglieder der OVE. Die jungen Ingenieure zählten zur Windprojektgruppe der Umweltorganisation (ebd. 183f.). Die allgemeine Harmonie auf dem Gelände der

\footnotetext{
${ }^{153}$ Aufgrund der Komplexität der für den weiteren Verlauf sehr wichtigen Interaktion zwischen Risoe und Windanlagenindustrie wird der Abschnitt zur Teststation an dieser Stelle ausführlich behandelt.

${ }^{154}$ Wichtige Impulse gab Helge Petersen, ein Ingenieur der dortigen Forschungsanlage. Petersen interessierte sich für WEA und hatte bereits das Tvind-Projekt unterstützt (s.o.). Er wurde auch der erste Direktor der Testanlage (van Est 1999, 311).
} 
Forschungsanlage wurde dadurch nicht gefördert. Viele Atomforscher nahmen die Teststation als eine Art ,Gegenkultur' wahr (van Est 1999, 81f.). Einige betrachteten das Engagement für Windkraft sogar als peinlich. Sie glaubten nicht an deren Erfolg und hielten die Testanlage daher für nutzlos. ${ }^{155}$

Anfangs diente Risoe zur technischen Unterstützung der unerfahrenen Branche. Den Mitarbeitern fehlte es spezifischem Know-how. Erst in der Zusammenarbeit mit den Herstellern gewannen sie an Erfahrung. Eine Schwierigkeit bestand darin, dass manche Unternehmen den Kontakt zu Risoe scheuten, weil sie fürchteten, dass Firmengeheimnisse weitergegeben würden. ${ }^{156}$ Bei der Suche nach geeigneten Komponenten wurden die RisoeAngestellten auch selbst aktiv. 1978 zählte es zu ihren Aufgaben, bei Schrotthändlern nach LKW-Hinterachsen Ausschau $\mathrm{zu}$ halten, die als Turbinenachsen geeignet sein konnten (Garud/ Karnoe 2003, 289).

Bis zum Beginn der Investitionsförderung für WEA existierte die Kooperation zwischen Risoe und Herstellern auf freiwilliger Basis. Dieses änderte sich 1979 mit der Einführung der Zertifizierungsverfahren. Gefördert wurde ausschließlich der Kauf von Windanlagen mit Risoe-Zertifikat. Die Regierung wollte verhindern, dass Gelder in mangelhafte Konzepte investiert würden. Seitdem bestand Risoes Hauptaufgabe in der Windturbinenprüfung (van Est 1999, 82). ${ }^{157}$ Bis 1980 vergab sie etwa 40 Zertifikate.

Anfangs waren die Prüfkriterien bewusst niedrig angesetzt. Man hatte absolutes Neuland betreten und musste entsprechende Verfahren erst entwickeln. Zuerst wurden vor allem zwei Anforderungen gestellt. Die Windanlagen mussten von nun an sowohl über ein mechanisches, als auch ein aerodynamisches Bremssystem verfügen. Damit übernahm Risoe die wichtigste Forderung des DV und des OVE-Sicherheitsrats und knüpfte an einen weitgehenden Konsens der Branche an. Bei der zweiten Anforderung ging es vor allem darum, dass statische und dynamische Belastungen an Turm, Fundament und Flügeln berechnet und gemessen werden mussten. Anfangs bestand das Hauptziel der Prüfungsverfahren nicht darin, die Entwicklung möglichst effizienter Windturbinen zu fördern, als vielmehr Stabilität und Zuverlässigkeit zu verbessern (ebd.). ${ }^{158}$ Erst allmählich, mit der wachsenden Erfahrung der Risoe-Mitarbeiter und der Industrie, ist das Prüfungsverfahren anspruchsvoller geworden.

Die von den Firmen eingereichten Zeichnungen und Berechnungen waren oft unbefriedigend. Häufig besuchten Risoe-Mitarbeiter die Werkstätten, um technische Details zu klären und ggf. Unterstützung zu bieten. Die dabei entstehenden informellen Kontakte erhöhten das Vertrauen der Hersteller zur Teststation und waren für den Austausch von Know-how sehr wichtig (Kamp 2002, 148f.). Die Ingenieure aus Risoe erweiterten ihre Kenntnisse über die unterschiedlichen Anlagenkonzepte und erkannten deren Stärken und Schwächen. Davon ausgehend, ,versuchten sie die Windkraftanlagenhersteller auf das Juulsche Design einzuschwören, das sich als das einfachste und zuverlässigste erwiesen hatte und die schnellste Realisierung wirtschaftlicher Anlagen versprach' (Heymann 1995, 413). Von verschiedener Seite wird betont, ${ }^{159}$ dass die letztendliche Entscheidung für das dänische Anlagenkonzept weder von den Herstellern selbst, noch von Risoe, sondern auf dem Markt getroffen wurde. Risoe hatte auf den Selektionsprozess nur eine katalytische Wirkung

\footnotetext{
${ }^{155}$ Dieses Verhältnis zwischen Zentrum und Peripherie der dänischen Energie- und Forschungspolitik spiegelt sich auch in der räumlichen Aufteilung des Forschungscenters wider. Die Teststation für WEA befand sich in einem abgelegenen Teil des Geländes und war in einem Holzschuppen untergebracht (Kamp 2002, 147).

${ }^{156}$ Aus diesem Grunde war bspw. Riisager anfangs gar nicht bereit, mit der Teststation zu kooperieren. (Beurse et al. 2000, 189).

${ }^{157}$ Das erste Zertifikat erhielt die Windturbine von Adolfsen mit 5m-Flügeln von Oekaer (s.o.).

${ }^{158}$ „It is not a matter of building the best turbine technology, instead it is more important to develop an industry.“ (Helge Petersen 1988, zitiert nach: van Est 1999, 81)

${ }^{159}$ vg. van Est 1999, 82; Gipe 1995, 81; Maegaard (Interview vom 2.7.07)
} 
ausgeübt. Denn mit Windmatic, Vestas, Danregn und Kuriant hatten sich die meisten wichtigen Hersteller bereits 1979 für dieses Konzept entschieden (s.u.). ${ }^{160}$

1979 waren praktisch alle Hersteller mit der Aufgabe überfordert, ihre Zeichnungen durch systematische Berechnungen zu optimieren. Die dänische Windmühlenindustrie arbeitete praktisch ohne Ingenieure. Erst allmählich gelang es den Risoe-Angestellten, die Hersteller von der Notwendigkeit zu überzeugen, Ingenieure einzustellen und ihnen diese Aufgaben zu übertragen. Der erste Ingenieur wurde 1980 von Vestas eingestellt. Seitdem war es in der neuen Industrie schnell üblich geworden, die Berechnungsarbeiten durch Ingenieure verrichten zu lassen (Heymann 1995, 413).

Prinzipiell war man in Risoe darauf bedacht, die technische Entwicklung möglichst wenig zu steuern. Aufgrund ihrer Erfahrungen erschien es den Angestellten in manchen Fällen dennoch sinnvoll, aktiv einzugreifen. Dadurch wollten sie verhindern, dass sich Hersteller auf technische Irrwege begaben, die langfristige Schäden zufolge haben würden. Ein Beispiel für eine solche Intervention bildete die Evaluation der Riisager-Mühle. Es stellte sich heraus, dass Getriebeschäden auf eine zu hohe Drehzahl zurückzuführen waren. Das Bremssystem reagierte erst bei einer Leistung von $45 \mathrm{~kW}$, anstatt der Nennleistung von 30kW (Beuse et al. 2000, 189). Nachdem die Getriebeübersetzung verändert wurde, lief die Anlage einwandfrei und das Stall-System reagierte zum richtigen Zeitpunkt (Heymann 1995, 413). Niedrige Drehfrequenzen haben sich bis heute durchgesetzt. ${ }^{161}$

\section{Zusammenfassung}

Durch den Eintritt in das System ,kleine Windkraft' hat das PAS die Voraussetzungen zur Lösung eines großen Problems dieser Periode geschaffen. Handelte es sich bei den Windanlagenkäufern und -betreibern ausschließlich um Selbstbauer und Windenergiebegeisterte, so wäre der Markt sehr schnell an Grenzen getreten. Es war daher notwendig, neue Käuferkreise zu schaffen. Windkraft musste für Personen attraktiv werden, von denen die Windmühlen nicht ausschließlich als Symbole gegen Atomkraft und die Macht der Großkonzerne betrachtetet wurden. Zwar mussten die neuen Käufer bereit sein, ein begrenztes finanzielles Risiko einzugehen. Die 30\%ige Förderung bot ihnen allerdings eine gute Chance, ihre Stromkosten $\mathrm{zu}$ reduzieren. In der vorherigen Periode mussten die Windmüller um jeden Netzanschluss kämpfen. Seit Einführung der 79er Regelung entspannte sich diese Situation.

Die Regierung hatte bewiesen, dass sie bereit war, die Windmüller gegen die Interessen der Stromwirtschaft zu verteidigen. Mit dem 30\%igen Investitionszuschuss schaffte der Staat geeignete ökonomische Rahmenbedingungen zur Nachfrageförderung. Einer Beispielrechnung Maegaards zufolge war der Kauf, bzw. die Beteiligung an einer Windanlage eine begrenzte, wenngleich lohnende Investition. ${ }^{162}$ Die Aufstellung des Energiplan 81 erhöhte

\footnotetext{
${ }^{160}$ Auch Mitte der 80er Jahre gab es noch einige kleine Hersteller, die andere Konzepte verwendeten. Sie produzierten jedoch nur in geringer Stückzahl und waren kaum erfolgreich (vg. www.windsofchange.dk).

${ }^{161}$ Ein weiteres Beispiel eines aktiven Eingriffs durch Risoe: Ende der 70er Jahre wollten einige Produzenten vom Stall-Regulationssystem zugunsten des ,Aus-dem-Wind-drehen' (Pitch-System) abrücken. Aufgrund ihrer praktischen Erfahrungen und ihrer Ingenieurkenntnisse waren die Mitarbeiter der Teststation in der Lage, die Hersteller davon zu überzeugen, ihr bisheriges Design beizubehalten. Die Experten argumentierten erfolgreich, dass die Anwendung des neuen Regulierungssystems zu einer deutlich größeren Materialbelastung geführt und die Lebensdauer der Turbinen verkürzt hätte (Hantsch 1998, 42). Mit dem widerstandsfähigen Stall-System waren die Hersteller in den nächsten Jahren sehr erfolgreich.

${ }^{162}$ Eine 200kW Windturbine produziert ca. 400.000kWh im Jahr. Ein Anteil entspricht 1000kWh, d.h. insgesamt 400 Anteile. Ein durchschnittlicher Haushalt verbraucht maximal 9000kWh (inklusive Toleranz von zusätzlich 35\%). Die Zahl der Haushalte berechnet sich damit zu 400 Anteile insgesamt, geteilt durch neun, dem Bedarf eines Haushalts, d.h. 44,4 Haushalte erwerben diese Windanlage. Bei Investitionskosten von einer Million DKr, entspricht ein Anteil 2.500 DKr. Jeder Haushalt hätte demnach - bei neun Anteilen - durchschnittlich 22.500DKr. zu investieren. Beim Preis einer $\mathrm{kWh}$ von $0,6 \mathrm{DKr}$ ergibt sich bei $9000 \mathrm{kWh}$ ein Bruttogewinn von 5.400DKr pro Jahr. 20\% entfallen auf Wartung und Versicherung, so dass 4.500DKr verbleiben. Nach Maegaards Rechnung amortisierte sich die Investition nach fünf Jahren (Interview vom 2.7.07).
} 
das Vertrauen in die Kontinuität des Windenergiesektors. Darin wurde von staatlicher Seite erstmals die Absicht erklärt, Windkraft langfristig in das Energiesystem zu integrieren. Die Einführung von Zertifizierungsverfahren stellte sicher, dass staatliche Mittel nicht für den Kauf unzuverlässiger WEA aufgewendet würden.

\subsubsection{Windanlagenindustrie in Periode 2}

Die beginnende Unterstützung der Windkraft durch das PAS, die erfolgreiche Öffentlichkeitsarbeit des DV und eine deutliche Verbesserung der Anlagentechnik sind die wichtigsten Rahmenbedingungen des Nachfragewachstums von 1979. Wurden zwischen 1976 und 1978 etwa 50 WEA an die Stromnetze geschlossen, so sind es 1979 bereits 120 . Eine so hohen Nachfrage konnten die Handwerksbetriebe nicht bedienen - und schon gar nicht in so kurzer Zeit. Viele hatten sich ohnehin schon finanziell übernommen. Sie gingen bankrott oder zogen sich aus der Branche zurück. Für sie wäre es undenkbar gewesen, die Produktion auf industrielle Serienfertigung umzustellen (Heymann 1995, 411). Mangelndes Kapital war zwar die größte, jedoch nicht einzige Barriere, welche die Kleinstunternehmen darin hinderte, ihre Innovationsträgerschaft fortzuführen. Die Handwerker waren es gewohnt, mit Faustregeln umzugehen und nach dem Prinzip ,trail-and-error' vorzugehen. Solche Methoden erwiesen sich als praktikabel für die Erstellung kleiner Prototyp-WEA. Von Modell zu Modell konnten Fehler entdeckt und behoben, bzw. die Auswirkungen der Fehler reduziert werden. Ein Fehler, der in eine Serienproduktion eingeht multipliziert sich und verursacht, je nach Anlagengröße, entsprechend hohe Kosten. Jetzt kommt es darauf an, genaue Lastenberechnungen vorzunehmen, um die Konzepte nicht wiederholt überarbeiten zu müssen. Die Einführung der Serienproduktion machte den Einsatz von Ingenieurwissen unerlässlich, über das Männer wie Karl-Erik Joergensen und Svend Adolfsen nicht verfügten. Hinzu kommt, dass viele Selbstbauer und Kleinsthersteller einen Hang zum Individualismus und Eigenbrötlertum aufwiesen. ${ }^{163}$ Sie hätten es nicht ohne weiteres akzeptiert, sich von einem Ingenieur sagen zu lassen, wie sie ihre Anlagen bauen sollten. Nun kam es darauf an, mit anderen zu kooperieren und sich nicht länger auf die eigenen Fähigkeiten zu verlassen und andere nur bei Bedarf zu konsultieren. Zusammenfassend lässt sich sagen: Die bisherige Produktionsweise ist wirtschaftlich und organisatorisch an ihre Grenze gestoßen.

Von jetzt an muss der Innovationsprozess von neuen ökonomischen Akteuren getragen werden, die den veränderten Anforderungen gewachsen sind. Ein solcher Wandlungsprozess setzt 1979 ein und ist 1981/82 zu großen Teilen abgeschlossen. Das Umfeld, in dem die Windanlagen produziert wurden, hatte sich grundlegend verändert. Mittelständische Unternehmen wie Vestas, Nordtank und Bonus, die in ihren Fabrikhallen problemlos eine Serienfertigung zu installieren vermochten, übernahmen nicht nur die Konzepte der Pioniere, sondern die Branche insgesamt. ${ }^{164}$ Diese Firmen entstammen alle dem metallverarbeitenden Gewerbe. Für die dänische und damit die internationale Windkraftnutzung ist es ein günstiger Zufall, dass die Metallindustrie gerade zu jenem Zeitpunkt neue Aufgabenfelder suchte, als der Windenergiesektor den Eintritt kapitalstärkerer Unternehmen erforderte. Diese Umbrüche werden im folgenden anhand der Zerfalls- und Formierungsprozesse der wichtigsten alten und neuen Akteure untersucht.

\footnotetext{
${ }^{163}$ Mit Bezug auf Riisager und Adolfsen äußerte sich Grove-Nielsen über die ersten Turbinenhersteller: ,Once they dared to go in front that early days. But when it came to cooperate with others they had problems. They wanted to do things on their own.' (Interview vom 27.6.07)

164 Der dänische Innovationsforscher Peter Karnoe hat diese Entwicklung als ,frühe Industrialisierung' bezeichnet. (vg. Heymann 1995, 411).
} 
Von Riisager Moellen zu Windmatic

Bereits 1978 hatte sich Riisager Moellen in eine schwierige Situation gebracht. Anders als Herborg und Adolfsen, war Riisager nicht daran interessiert, die Vorteile der neuen Zulieferindustrie zu nutzen. Die negativen Folgen dieser Haltung wuchsen in der folgenden Zeit. Riisager hatte sich finanziell übernommen und musste 1979 Konkurs anmelden (Heymann 1995, 411). Im selben Jahr verkaufte er die Lizenz zur Produktion seiner Windmühle an Flemming Panduro. Gemeinsam mit Panduro und dem Schmied Poul Lützhoeft gründete Riisager 1979 die Firma Windmatic. So erfolgreich Riisager in der Anfangsphase mit seiner 22/30kW-WEA gewesen war, so sehr repräsentiert er den Typ des überkommenen Selbstbauers. Riisager kooperierte nicht mit dem OVE-Netzwerk. Er weigerte sich so lang wie möglich gegen jede Zusammenarbeit mit Risoe, angeblich aus Angst um seine Betriebsgeheimnisse. Grove-Nielsen (Interview vom 27.6.07) beschreibt, weshalb mangelndes Kapital nicht als alleiniger Grund herangezogen werden sollte, um Riisagers Scheitern zu erklären:

,He was a craftman and a developer, but that time it was necessary that you were able to see things from an industrial perspective. If you wanted to do anything yourself, this was like Riisager. This means, he could not take advantage of the specialization. For instance, he never adopted fibreglass blades. He didn't buy blades from independent manufacturers. When I made the turnable tips, the airbrakes in 1978: He didn't realize that people wanted safety-systems. He didn't do it, before Risoe wanted it, before they claimed that every machine should have a safety-system.'

Wind-Matic ist eher ein Ausnahmefall unter den, seit 1979 neu entstehenden Turbinenproduzenten. Bei dem Unternehmen handelte es sich um eine Genossenschaft mit nur drei Mitarbeitern, Riisager inklusive (Beuse et al. 2000, 129). Seit Mai 1979 produziert Windmatic ein modifiziertes Konzept der Riisager Maschine. Die Produktionsweise blieb dieselbe: Riisager entwickelte sämtliche Komponenten, inklusive der Rotoren, alleine. Die Rotorenfertigung gab Riisager nach wie vor bei LM Glasfiber in Auftrag (www.windsofchange.dk, Abruf vom 22.3.2008). Erfolgreich war Windmatic mit diesem Modell jedoch weniger. Mit Unterstützung eines Ingenieurs gelang es Windmatic, an alte Erfolge anzuknüpfen (Joergen Krogsgaard, Interview vom 19.9.07). Mit der neuen 55kWLeistungsklasse, die Windmatic 1981/82 herausbrachte, bediente sich Riisager erstmals der Zulieferindustrie. In der Zwischenzeit hatte sich LM Glasfiber als Rotorenhersteller selbständig gemacht und eigene Konzepte entwickelt. Für die neue Anlagenserie erhielt Windmatic nicht nur die Rotoren, sondern auch den Turm von LM Glasfiber (www.windsofchange.dk; Beuse et al. 2000, 131).

Von Adolfsen Moellen zu Kuriant

Svend Adolfsen ist einer der innovativen Pioniere, die frühzeitig eine Komponentenwindmühle auf dem Markt angeboten hatten. Für die Fertigung größerer Serien war seine Autowerkstatt ungeeignet. Daher verkaufte er im November 1979 sein Patent an den Agrarmaschinenhersteller Kuriant.

Obgleich Adolfsen gewiss nicht in der gleichen Weise eigenbrötlerisch wie Riisager gewesen ist, hatte auch er offenbar die Tendenz, anderen Fachleuten die Kompetenz abzusprechen. Dieses verdeutlicht eine Begegnung Grove-Nielsens mit Adolfsen:

,I remember when I delivered the first set of blades to Svend Adolfsen: When we put it into his shop, on the floor, he looked at the blades and said: ,No, they are wrong. They twist the wrong way.' So he was trying to convince me that I had made the blades wrongly. Although he had not much knowledge, he wanted to know it best. It was typical of many early selfbuilders.' (Grove-Nielsen, Interview vom 27.6.07).

Eigentümer von Kuriant war der Schmied Alfred Christiansen, der sich vom einfachen Handwerker zum Firmenchef hochgearbeitet hatte. Kuriant hatte 1979 die erste Serienfertigung für Windkraftanlagen eingerichtet. Bis 1985 produzierte das Unternehmen etwa 100 WEA. Dabei handelte sich stets um verhältnismäßig kleine Maschinen der Leistungsklasse 10-20kW. Die Turbinen wurden für die Netzeinspeisung ebenso hergestellt wie zur Wärmeproduktion. Sie alle arbeiteten mit $5 \mathrm{~m}$-Rotoren, die anfangs von Oekaer 
geliefert und seit 1980 von KJ Flügel geliefert wurden. Später verwendeten auch Bosted und Genvind das Adolfsen-Konzept (Joergen Krogsgaard, Interview vom 19.9.07); www.windsofchange.dk, Abruf vom 23.3.2008).

Von Herborg Vindkraft zu Vestas

Ebenso wie Adolfsen, zählte auch der Schmied Karl Erik Joergensen zu den innovativen Herstellern der Technikperiode. Joergensen teilte das Schicksal Riisagers. Auch ihm mangelte es an Kapital. Mit den Einnahmen aus dem Verkauf der einen Windanlage, finanzierte er die Herstellung der nächsten. Die Rechnungen der Zulieferer konnte Joergensen kaum bezahlen. Die Bank gab ihm keinen Kredit, obwohl er bereits zehn Maschinen produziert und verkauft hatte. Daher war er gezwungen, sein Patent zu verkaufen. Für diesen Zweck bot sich Vestas, eine etablierte Schmiedefabrik mit circa 120 Mitarbeitern aus der näheren Umgebung, an. Dort wurden bspw. Kräne und LKWs produziert. Anscheinend betrachtete Vestas die Windenergie als neues Geschäftsfeld. Zu dieser Zeit arbeitet Vestas am Prototyp einer Darrieus-Windanlage. 1979 war noch nicht abzusehen, dass sich das dänische Konzept durchsetzen würde. Die Vestas-Maschine jedenfalls lief geräuschvoll und ineffizient. Für eine Kommerzialisierung erschien sie nicht geeignet. Vestas verfügte über hinreichende Mittel, um sich die Lizenz des erfolgreichen Joergensen-Designs zu sichern. Im Herbst 1979 kam es zu einer Einigung zwischen Vestas und Herborg Vindkraft. Aus dem Erlös des veräußerten Patents konnte Joergensen die Schulden begleichen (Vestergaard 2003).

Ähnlich wie Riisager und Adolfsen, fehlte auch Joergensen das notwendige Kapital, um die Produktion auszubauen, so wie es der Markt seit 1979 erforderlich machte. Auch war er nicht der Typ eines Großunternehmers. ,Joergensen knew: ,I will never become an industrialist.' He was an ordinary blacksmith.' (Maegaard, Interview vom 2.7.07).

Sein Sohn Per sagte über ihn, dass er zwar ein genialer Handwerker sei, jedoch kein guter Geschäftsmann. (Vestergaard 2003). Aufgrund seiner Ungeduld tendierte er dazu, Risiken einzugehen, die ein Unternehmen leicht in den Ruin treiben konnten. ${ }^{165}$ Insbesondere passte die Arbeitsweise Joergensens nicht zum rationalen, berechnenden Vorgehen eines Großunternehmens.

Vestas war ein solches Unternehmen. Die Übernahme des Patents von Herborg Vindkraft stellte kaum ein Wagnis dar. Die Herborg-Maschine wurde vom Markt gut angenommen, nachdem die Luftbremse im November 1978 den Test erfolgreich absolviert hatte. Darüber hinaus betrat Vestas den Windenergiesektor ohnehin. Daher bedeutete der Kauf des HerborgPatentes im Fall eines Zusammenbruchs des neuen Marktes kein zusätzliches Risiko. Die ersten Anlagen von Vestas wurden in der Kranfabrik hergestellt. Bereits im März 1980 baute die Firma eine eigene Produktionseinheit zur Serienfertigung für Windturbinen auf. Dort waren zunächst acht Mitarbeiter tätig (Vestergaard 2003). Ein Ingenieur wurde kurze Zeit später eingestellt. Vestas war mit der Herborg-Anlage sehr erfolgreich und entwickelte sich

\footnotetext{
${ }^{165}$ Karl Erik Joergensen war ein sehr ungeduldiger Mensch. Nachdem es, aufgrund der fehlenden Luftbremse zur Havarie der Flügel seines ersten erfolgreichen Modells kam, wollte er das Stall-System, die ausfahrbaren Flügelspitzen (s.o.), unbedingt sofort testen. Dazu musste die mechanische Bremse deaktiviert werden. Angesichts des Sturms wäre es zu einem erneuten Totalschaden der Rotoren gekommen, sofern die aerodynamische Bremse nicht korrekt funktioniert hätte. Grove-Nielsen wollte den geplanten Test aufgrund des Starkwindes von 15-16m/s absagen. Seiner Ansicht nach hätte man warten müssen, bis sich der Wind auf ca. 8$10 \mathrm{~m} / \mathrm{s}$ reduzierte. Doch Joergensen sagte darauf hin: „Ja så gjør a, et sgu sjal.' (,Dann mach ich’s allein.'). GroveNielsen blieb keine andere Wahl. Wohl oder übel unterstützte er Joergensen bei dem Test und war sehr erleichtert, als die Luftbremse, die hier das erste Mal in Praxis getestet wurde, korrekt funktionierte (Beuse 2000 et al., 144).
} 
zum marktführenden Anbieter. Joergensens ${ }^{166}$ (und Stiesdals) Design hatte auch Einfluss auf die Arbeiten von Danregn und Nordtank (s.u.).

Noch im Jahr 1980 stellte Vestas eine 55kW-Turbine her und brachte die neue Standardgröße als erster auf den Markt. Da die neuen 7,5m Flügel von Oekaer nicht hinreichend erprobt waren, kam es anfangs zu einigen Havarien. Das Rotorendesign erwies sich als fehlerhaft und etwa 20 Sets mussten ausgetauscht werden. Dadurch geriet Vestas in eine schwierige Situation. Als einzigem Hersteller, der bereits 1980 mit der neuen Rotoren-Generation arbeitete, führte der erforderliche Austausch der Rotoren zu einem deutlichen Tempoverlust des Unternehmens.

\section{Nordtank-Moellen}

Nordtank gründete sich 1962 zur Herstellung von LKW-Tanks für die Ölindustrie. Die Ölkrise von 1973 hatte dem Unternehmen bereits schwere Verluste eingebracht. Als sich gegen Ende der 70er Jahre eine erneute Krise abzeichnete, entschied sich Nordtank für einen Wechsel des Betätigungsfeldes, um erneute Umsatzeinbußen vermeiden. Im Dezember 1979 startete das Unternehmen die Produktion von Windmühlen. Nordtanks Wahl fiel auf die Windenergiesektor, weil die Branche zu dieser Zeit noch überwiegend durch Pioniere bestimmt war, die nur in geringer Stückzahl produzierten.

In ähnlicher Weise wie sich die industrielle Produktion Nordtanks von der zuvor üblichen handwerklichen Arbeitsweise unterschied, so bedeutete auch der Umgang mit einer neuen Kundschaft, eine deutliche Umstellung für das Unternehmen. Als Öltankhersteller hatte Nordtank vor allem mit Ölgesellschaften und Transportfirmen zu tun. Bei den Windmüllern handelte es sich demgegenüber um einen völlig neuen Kundenkreis, auf den sich Nordtank erst einstellen musste. ${ }^{167}$ Thorkild Roerbaek, Sprecher von Nordtank, hat die Firmenstrategie auf den Punkt gebracht: ,Unser Ziel war es, eine komplett von Ingenieuren berechnete Mühle herzustellen, die perfekt für die Serienproduktion geeignet war' (Beuse et al. 2000, 174).

Dieser Aufgabe widmete sich seit Januar 1980 Erik Oerum Nielsen, der einzige Ingenieur des Unternehmens. Bereits im Mai des Jahres konnte die erste 30kW-Prototypmaschine den Testbetrieb aufnehmen. Abgesehen davon, dass die Turmhöhe von 24 auf $22 \mathrm{~m}$ verringert werden musste, lief die Anlage zuverlässig. ${ }^{168}$ Das neue an dem Nordtank-Modell war in erster Linie der geschlossene Röhrenturm. Insbesondere für den vorherigen Tank-Produzenten bot sich diese Konstruktion an, da man beim Walzen von Metallplatten auf Erfahrungen zurückgreifen konnte (ebd.). Zu den Vorteilen des Röhrenturms zählte, dass die Mechaniker nicht mehr bei jedem Wetter am Gitterturm klettern mussten. Von jetzt an stand ihnen der geschützte Weg, über eine Leiter im Turminneren zur Verfügung. In den folgenden Jahren wurde der Röhrenturm von den meisten anderen Produzenten übernommen. Anders als Vestas, brachte Nordtank die 55kW-Leistungsklasse, unter Verwendung der 7,5m-Flügel, erst 1981 auf den Markt. Zu diesem Zeitpunkt war die neue Rotorenklasse bereits ausgiebig getestet. Im Unterschied zu Windmatic, Kuriant und Vestas, übernahm das Unternehmen kein bereits existierendes Patent. Nichtsdestotrotz hat auch der Nordtank-Ingenieur kein völlig neues Anlagendesign entwickelt. Vielmehr orientierte er sich am Konzept der HerborgAnlage (Heymann 1995, 411).

\footnotetext{
${ }^{166}$ Joergensen führt seine Arbeit an Windturbinen auch nach dem Verkauf an Vestas fort und perfektionierte sein Konzept. Weiterhin verkauft er WEA in geringer Stückzahl. Im Frühjahr 1982 erkrankt er erneut an Krebs. Aufgrund seiner Bewegungsunfähigkeit installiert er einen Fahrstuhl im Turm der letzten Maschine. Joergensen verstarb im Oktober des Jahres (Beuse et al. 2000, 144).

${ }^{167}$ Gekauft wurden die Windanlagen vor allem von ,Landwirten, Pädagogen und anderen fanatischen, energiebewussten Menschen, die ,eine ganze Menge über das Ganze wussten” (Beuse et al. 2004, 174).

${ }^{168}$ Der Turm einer Höhe von 24m hatte dieselbe Eigenfrequenz wie der Rotor (Beuse et al. 2000, 174). Diese Korrektur war notwendig, um Resonanzeffekte - und damit Energieverluste - zu verhindern.
} 


\section{Danregn Vindkraft}

Danregn ist ein Familienunternehmen zur Herstellung von Agrarmaschinen, insbesondere Bewässerungsanlagen. Ende der 70er Jahre litt die Firma unter der Krise der Landwirtschaft. Daher konnten die Produktionskapazitäten nur teilweise ausgeschöpft werden. Die Unternehmensstruktur erforderte den Einsatz zahlreicher Arbeitskräfte in den Monaten April bis Juli. Den Rest des Jahres wurden deutlich weniger Mitarbeiter beschäftigt. Der Firmengründer Soeren Soerensen verfügte über bedeutendes Eigenkapital. Sein Sohn Peter Stubjaer Soerensen dachte gemeinsam mit Egon Kristensen, einem Berater Danregns, darüber nach, wie das Unternehmen in den ruhigeren Zeiten des Jahres aktiver werden könnte. Auf der jährlichen Industriemesse in Herning besuchten sie 1980 den Stand von Nordtank. Sie hielten die Produktion von Windturbinen für eine gute Idee und bemühten sich vergeblich darum, Nordtank das Patent abzukaufen.

Soerensens Vater hielt die Geschäftsidee des Sohnes zwar für sehr fragwürdig, stellte dem Sohn dennoch ein Startkapital von einer Millionen Kronen bereit. Nun, wo sich herausgestellt hatte, dass geeignete Patente nicht mehr ohne weiteres auf dem Markt zu haben waren, ergab sich die Frage nach der Wahl und der Herkunft des Anlagenkonzepts. Kristensen, Soerensen und seine Frau Alice Soerensen, die als technische Zeichnerin arbeitete, entschieden sich dafür, ein eigenes Design zu entwerfen (Beuse et al. 2000, 176). Dieses war am Konzept der Nordtank-, bzw. Herborg-Anlage, orientiert (Heymann 1995, 411). Sie baten den Pionier und späteren Gründer des Folkecenters, Preben Maegaard, um technische Unterstützung. Mit der Begründung, ausschließlich, nicht-kommerzielle Hersteller zu fördern, lehnte Maegaard zunächst ab. Auf Nachfrage erklärte er sich dennoch bereit, den Neulingen einige Grundsätze näher zu bringen, die sich im Turbinenbau bewährt hätten. ${ }^{169}$ Nun konstruierten sie eine erste Prototyp-Windanlage mit 22kW-Generator. Ebenso wie Vestas, Kuriant und Nordtank nutzte auch Danregn anfangs (seit Dezember 1980) die 5m-Flügel von Oekaer. Seitens der RisoeMitarbeiter erhielt der neue Hersteller einige Korrekturvorschläge, die umgesetzt wurden, bevor man die neue Anlage in Betrieb nahm. Bald darauf wurde sie mit einem größeren 30kW-Generator ausgestattet und auf den Markt gebracht. 1981 gründete sich Danregn Vindkraft A/S als eigenständige Firma. Zu diesem Zeitpunkt begannen Vestas und Nordtank mit ihren 55kW-Anlagen die Marktführerschaft zu erringen. Nach Aussage Kristensens war der technische Rückstand Danregns - denn zu diesem Zeitpunkt konnten sie nur eine 30kWTurbine anbieten - unproblematisch. Denn durch diesen Rückstand ,verschlief' Danregn die Krise, welche mit der Einführung der 7,5m Flügel von Oekaer einhergegangen war. Vestas, als erster Nutzer des neuen Rotors, erlitt dadurch gewisse Imageschäden (s.u.). Als Danregn 1982 die 55kW-Anlage herausgab, war die neue Rotorenklasse bereits gut erprobt und betriebssicher. Ähnlich wie Vestas, Nordtank und Windmatic, erkannte auch Danregn die Notwendigkeit der Mitarbeit eines Ingenieurs zur Weiterentwicklung des Anlagendesigns. Eine entsprechende Arbeitskraft wurde im August 1982 eingestellt (Beuse et al. 2000, 177).

\section{Von Oekaer Vind Energi zu Alternegy}

Insbesondere seit 1980 erfährt der Rotorenhersteller ein enormes Wachstum. Zwischen 1977 und 1981 wächst der Umsatz um 400\% pro Jahr. Im November 1979 beschäftigte GroveNielsen vier Arbeitskräfte; Zwei Jahre später waren es bereits 13. Seit der Gründung 1979/80 zählen mit Vestas (seit Februar 1980), Nordtank (seit März 1980) und Danregn (seit Dezember 1980), die drei wichtigsten Hersteller zum Kundenkreis Oekaers. Hinzu trat auch eine gewachsene Nachfrage durch Selbstbauer und Kleinstunternehmen, die zwischen 197779 gegründet wurden. Sie alle nutzten anfangs die 5m-Flügel von Oekaer. Seit 1979 lieferte Grove-Nielsen einzelne Rotoren auch in die Nachbarländer Schweden und Deutschland.

\footnotetext{
${ }^{169}$ Für seine Beratertätigkeit lehnte Maegaard die Zahlung eines Honorars ab (Beuse et al. 2000, 177).
} 
Unter Einflussnahme von Joergensen, der an der Entwicklung einer 55kW-Turbine arbeitete und dafür längere Flügel benötigte, beginnt Grove-Nielsen Ende 1979 mit der Produktion eines neuen Rotoren (Flügellänge von $7,5 \mathrm{~m}$ ). Diese wurden unter problematischen Bedingungen hergestellt: in einem großen Zelt mit Holzfußboden. Im Winter musste das Zelt kostspielig beheizt werden, da die Temperatur immer circa 20 Grad Celsius betragen musste. Im Sommer war daher eine permanente Kühlung des Zeltdachs durch eine Sprinkleranlage erforderlich. Um Energiekosten zu sparen, baute Grove-Nielsen in Sparkaer eine neue Produktionshalle auf. Dazu hatte er sich bei der Regierung um ein günstiges Darlehen beworben. Nach einem Jahr Wartezeit erhielt er eine Ablehnung. Begründet wurde sie damit, dass man für die Windkraftnutzung keine vielversprechende Zukunft sähe. Im September 1980 kauft Grove-Nielsen ein Industriegebäude in der Nähe von Moensted, dass für die serienmäßige Herstellung der Fiberglasrotoren ausgestattet wurde (www.windsofchange.dk, Abruf vom 3.4. 2008).

Oekaer Vind Energi ist das einzige Unternehmen der Branche, dem sowohl der Sprung aus der Technikperiode, als auch die Umstellung auf industrielle Produktionsweise gelungen war. Der Rotorenhersteller ist mit der steigenden Turbinenproduktion gewachsen, deren Industrialisierung den Umbau der Rotorenfertigung nach sich gezogen hatte. Mit diesem Prozess gehen zwei weitere Transformationen innerhalb des Unternehmens einher. Bestand die Kundschaft Oekaers in der vergangenen Periode noch aus Pionieren und Selbstbauern, dominierten seit 1980 Industriebetriebe. Mit dem Umzug nach Moensted wuchs nicht nur die Zahl der Beschäftigten, sondern es veränderte sich auch ihre Sozialstruktur. Die ursprüngliche Belegschaft bestand aus ,langhaarigen Basisdemokraten' (ebd., 146), die aus idealistischen Gründen bereit waren, zu schlechteren Konditionen als üblich zu arbeiten. Mit dem Einzug in die neue Fabrikhalle stellte Grove-Nielsen auch klassische Industriearbeiter ein, die gewerkschaftlich organisiert waren und bessere Arbeits- und Umweltbedingungen forderten. Im März 1980 lieferte Oekaer den neuen 7,5m-Rotor erstmals an Vestas. Allein im Dezember des Jahres kaufte die Vestas 20 Rotoren. Noch im selben Monat bewies ein schwerer Sturm, dass die neue Flügelklasse offenbar nicht hinreichend erprobt war. Es kam zu einem Flügelbruch. Nun trat der Garantiefall für sämtliche an Vestas verkauften Rotoren ein, was bei Oekaer eine weitere Krise auslöste. Die Serienfertigung brachte für die Hersteller größere Risiken mit sich, was die Fehlertoleranz betrifft. Bei der Lieferung einzelner Rotoren wäre eine schrittweise Optimierung relativ unproblematisch gewesen. Nun hatte Oekaer zum Zeitpunkt der Feststellung des Fehlers bereits mindestens 20 Rotoren geliefert. Bis dahin existierte kein Prüfstand für Flügel der 7,5m-Klasse. Um die Fehlerursache zu klären blieb dem Unternehmen keine Alternative als eine solche Anlage zu installieren und sich dadurch weiter zu verschulden. Weitere Verluste ergaben sich dadurch, dass die Fertigung des 7,5mRotors zwischen Januar und März 1981 ausgesetzt werden musste. Es zeigte sich, dass die Rotoren ein grundsätzliches Stabilitätsproblem aufwiesen. ${ }^{170}$ Mit Unterstützung der Mellurgieabteilung der Forschungsanlage in Risoe und Joergen Tirstrup von Vestas, wurde der Fehler erfolgreich behoben. Risoe nutzte die Erfahrungen dazu, die Zertifizierungsanforderungen zu präzisieren (www.windsofchange.dk, Abruf vom 3.4. 2008). Nicht behoben wurden die finanziellen Probleme Oekaers. Nur dadurch, dass Vestas seine Garantierechte nicht vollständig ausschöpfte, konnte der Konkurs zunächst verhindert werden. Nichtsdestotrotz wurde dem Unternehmen der Strom abgestellt. Grove-Nielsen nahm daraufhin einen alten Dieselgenerator in Betrieb, den er günstig vom Schrotthändler erwarb (Beuse et al. 2000, 146). Obgleich auf diese Weise Produktionsausfälle verhindert wurden und die Auslieferung der 7,5m-Rotoren bald fortgesetzt werden konnte, gelang es Oekaer nicht, die Krise zu überwinden. Noch immer verfügte das Unternehmen über keinerlei Rücklagen. Wie unter den Pionieren der vorherigen Periode üblich, musste Oekaer die Herstellung eines neuen Flügelsatzes aus dem Verkauf des letzten finanzieren.

\footnotetext{
${ }^{170}$ Näheres dazu vg. www.windsofchange.dk.
} 
Am 21. April 1981 entschied Grove-Nielsen daher, mit dem renommierten Yacht- und Motorboothersteller Coronet einen Lizenzvertrag einzugehen. Letzterer war von nun an zuständig für Produktion und Verkauf der Rotoren, während sich Grove-Nielsen der Entwicklung neuer Konzepte widmete. Aufgrund einer Absatzkrise war Coronet auf der Suche nach neuen Aufgabenfeldern. Die Erfahrung mit Glasfiberarbeiten machte die Rotorenproduktion für Coronet zu einer naheliegenden Option. Im Juni 1981 wurde die Rotorenproduktion unter dem Namen Alternegy fortgeführt und der Standort von Moensted nach Slagelse verlegt. Alternegy übernahm sämtliche Kunden von Oekaer und weitete die Fabrikation der Rotoren, welche nun den Namen Aerostar trugen, deutlich aus (Beuse et al. 2000, 147). ${ }^{171}$

Kurze Zeit, nachdem Grove-Nielsen den Lizenzvertrag mit Coronet geschossen hatte, ging Oekaer bankrott. Coronet/Alternegy dagegen wurde mit der Rotorenherstellung in den folgenden Jahre so erfolgreich, dass Coronet den Schiffbau gänzlich aufgab.

\section{Von LM zu LM Glasfiber}

Ebenso wie Coronet ist auch LM ein etabliertes Unternehmen, dass u.a. Boote produzierte. Im Unterschied zu Oekaer entwickelte LM die Rotorenkonzepte nicht selbst, sondern fertigte diese, nach Zeichnungen der Anlagenhersteller - insbesondere Riisager/Windmatic - an. Für die Betrachtung der Pionierphase der Windenergie ist LM daher weniger von Interesse als Oekaer. Erst vor dem Hintergrund des sich stabilisierenden Marktes und unter Betrachtung der Erfolge Oekaers, bzw. Coronets, hatte sich LM Anfang der 80er Jahre dazu entschlossen, ein eigenes Glasfiber-Rotorendesign zu entwickeln, dass technisch ausgereifter war, als der Stahlrotor Riisagers. Mit dem neuen Werkstoff war LM aufgrund seiner Arbeiten im Bootsbau ebenso vertraut wie Coronet. Die Entscheidung für Glasfiber war für LM auch deshalb kaum mit Risiken verbunden, weil sich Anfang der 80er Jahre bereits herausgestellt hatte, dass dieser Werkstoff zur Rotorenfertigung besser geeignet war als Holz oder Metall. Von nun an produzierte LM die Flügel unter dem Namen LM Glasfiber.

NIVE-Gruppe

In der vergangenen Periode hatte die NIVE-Gruppe, die in enger Kooperation mit der OVE die erste zuverlässig funktionierende Komponentenmühle entwickelte, eine Initialzündung der Zulieferindustrie bewirkt. Die Rotoren kamen von Oekaer. Ohne diesen Auftrag hätte GroveNielsen seine Produktion nicht über 1977 hinaus fortsetzen können (s.o.). Ebenfalls eine wichtige Rolle kam HM Automatic zu. Das Unternehmen lieferte die elektrische Steuerung der NIVE-Turbine. Anschließend richtete HM Automatic eine Produktion für Steuerungssysteme ein und versorgte Turbinenhersteller mit dieser Komponente (Beuse et al. 2000, 206f.). Von der NIVE-Maschine selbst wurden nur wenige Exemplare gebaut.

Auf dem Windtreffen vom 30. September 1978 war die Schmiedemeistervereinigung präsent, welche erstmals ihr Interesse an der Produktion von Windturbinen bekundete. Bei der Schmiedemeistervereinigung handelte es sich um eine einflussreiche Industrieorganisation, die etwa 2.200 kleine und mittelständische Betriebe repräsentierte. Angesichts der Krise der Metallbranche sollte mit dem Einstieg in die Windmühlenfertigung ein neues Arbeitsfeld erschlossen werden. Konstruktionszeichnungen sollten von NIVE entworfen und den

\footnotetext{
${ }^{171}$ In Slagelse wurde die Produktion auch qualitativ verbessert. Bereits im Jahr der Übernahme wurden die alten Oekaer-Formen durch höherwertige ersetzt. Dennoch kam es bei einem Sturm im Herbst 1981 zu weiteren Havarien. Die Rotoren enthielten noch die Hütter-Flanschen (Verstärkung der Flügel durch Glasfiberkabel). Dieses Konzept wurde von Amdi Petersen nach Dänemark importiert und sowohl in der Tvind-Mühle, als auch der PTG-Komponentenmühle und allen Nachfolgerotoren von Oekaer verwendet (s.o.). Die Experten in Risoe kamen zu dem Schluss, dass Rotoren künftig ohne Hütter-Flanschen gefertigt werden sollten, um deren Lebensdauer zu erhöhen. Mit Unterstützung der Teststation wurde ein neues System entwickelt, um eine feste Verbindung zwischen Flügel und Achse zu ermöglichen. Dadurch erhöhte sich der Anlagenpreis um 10-15\%. Trotz besserer Stabilitätsergebnisse des neuen Systems, setzte es sich nicht uneingeschränkt durch. Risoe hatte das alte Hütter-Konzept offenbar recht negativ beurteilt. Viele der Rotoren mit Hütter-Flanschen sind noch heute, d.h. seit 20 Jahren und länger, intakt (vg. Beuse et al. 2000, 147; www.windsofchange.dk).
} 
Schmieden zugänglich gemacht werden. Dieser Vorschlag entsprach der La Cour Tradition, auf die sich NIVE bezogen hat. Gute Erfahrungen mit der Nutzung von Standardkonstruktionen hatten die Schmiede bereits im Sektor landwirtschaftlicher Fahrzeuge und Stahlsparrendächer erworben (Beuse et al. 2000, 207).

Mit technischer Unterstützung des Ingenieurs Knud Buhl Nielsen von der NIVE-Gruppe fertigte der talentierten Schmied Bendy Poulsen einen 22kW-Prototyp an, den er im September 1979 in Risoe testen ließ. Ebenso wie beim NIVE-Vorgängermodell verwendete man erneut das dänische Konzept. Nun wurde die Zeichnung der ,Smedemester'-Windanlage innerhalb der Schmiedemeistervereinigung öffentlich gemacht. Anschließend folgten etwa zehn Schmiede dem Beispiel Poulsens und begannen, die 22kW-Maschine zu produzieren (ebd., 208). Jedoch hielten sich die Erfolge in Grenzen. Anders als neue Hersteller wie Vestas und Nordtank, verfügten die Schmiede weder über das Know-how zur Verbesserung des Konzepts, noch über Möglichkeiten zur Produktion größerer Serien. Bis auf eine Ausnahme gaben die meisten Schmiede ihre Produktion nach wenigen Jahren auf.

1982 entwickelte Knut Buhl Nielsen gemeinsam mit einem NIVE-Team und dem Schmied Anders Davidsen auf Lolland, eine verbesserte Version des Smedemester-Designs. Ungefähr 75 Exemplare unterschiedlicher Größe werden später nach Kalifornien exportiert. Diese Lolland-Anlagen waren die einzigen kommerziell erfolgreichen Windturbinen, die auf Basis des Smedemester-Konzepts entstanden waren. Die Mehrzahl der 175 bis zum Jahr 1992 produzierten Smedemester-Maschinen (ebd., 211), entstammten der Produktionsstätte Davidsens. Das Lolland-Design mündete 1985 in die Gründung von Nordex (www.windsofchange.dk, Abruf vom 7.4. 2008).

\section{Windanlagenindustrie: Vergleichende Analyse}

Die Pionierunternehmen stießen 1979 an ihre Grenzen. Eine Weiterentwicklung der Branche hing vom Zufluss neuen Kapitals und der Einführung von Serienproduktionen ab. Generell lässt sich für diese Zeit von einer Krise der dänischen Industrie insgesamt sprechen. Dieses galt insbesondere für die Landwirtschafts-, Öl- und Schiffsbauindustrie. Einige der betroffenen Unternehmen entschlossen sich, frei gewordene Kapazitäten mit der Herstellung von Windkraftanlagen aufzustocken. Dazu zählten fünf der sechs größten und produktionsstärksten Unternehmen, die zwischen 1979 und 1981 in die Windbrache eingestiegen waren: Vestas, Danregn und Kuriant als Agrarmaschinenhersteller, Nordtank als Produzent von Öltankwagen und Coronet als Bootsfabrikant. Die Unternehmen agrarindustrieller Herkunft hatten einen strukturellen Vorteil gegenüber der Konkurrenz. Viele Anlagenkäufer kamen aus der Landwirtschaft und zählten daher möglicherweise bereits vorher zum Kundenkreis von Vestas, Danregn oder Kuriant. Für sie war daher die Suche neuer Kunden erleichtert.

Etwas aus dem Rahmen fällt das Unternehmen Windmatic, dass sich als kleine Genossenschaft formiert hatte, allerdings über beachtliche finanzielle Mittel verfügte. ${ }^{172}$ Auch Oekaer ist ein Sonderfall: Als einziger der Pioniere verteidigte das Kleinunternehmen seine marktführende Rolle, trotz finanzieller Schwäche, über das Jahr 1979 hinaus. Mit dem Umzug nach Moensted gelang Oekaer der Einstieg in die industrielle Produktion. Bald forderte der Markt die Herausgabe einer neuen Rotorenklasse. Indem Oekaer voreilig ein unreifes Produkt herausbrachte, hatte sich das Unternehmen in eine Krise manövriert. Hohe Kosten durch entstandene Schäden und die Anschaffung notwendiger Testeinrichtungen zwangen Oekaer im Jahre 1981, eine Kooperation mit Coronet einzugehen.

Gemeinsam ist den neuen Herstellern, dass sie entweder von Anfang an Ingenieure mit der Entwicklungsarbeit betrauten, oder kurze Zeit nach ihrer Gründung einen Ingenieur

\footnotetext{
${ }^{172}$ Ebenso wie Windmatic startete auch Danregn mit nur drei Beschäftigten. Anders als Windmatic konnte Danregn von Anfang an auf eine maschinenbau-gerechte Infrastruktur zugreifen.
} 
einstellten. Der Impuls zur Abkehr von der handwerklichen Konstruktionsweise kam sowohl von der Teststation, als auch den Firmen selbst. Letztere hatten erkannt, dass sie ihre Produktionsreihen nicht länger auf Basis der bis dahin üblichen ,trail-and-error'-Methode aufbauen konnten, weil die entstehenden Kosten durch wiederholte nachträgliche Korrekturen zu hoch zu werden drohten. ${ }^{173}$

Die Rotoren, als technisch anspruchsvollste Komponente, hatten im Innovationsprozess von Anfang an eine zentrale Rolle gespielt. Mit der Gründung eines unabhängigen Rotorenlieferanten vereinfachte sich die Windanlagenproduktion für die Hersteller wesentlich. Der erste deutliche Wachstumssprung von fünf auf siebeneinhalb Meter Flügellänge veranschaulicht darüber hinaus den bestimmenden Charakter der Rotorengröße hinsichtlich der Anlagengröße. Parallel war die Kapazität der Standardturbine von 30 kW (bei $5 \mathrm{~m}$-Flügeln) auf $55 \mathrm{~kW}$ (bei 7,5m-Flügeln) gewachsen. Ein Hersteller konnte sich nicht beliebig aussuchen, welche Generatorengröße er verwendet. Maegaard (Interview vom 2.7.07) betont die Funktion der Rotorenproduzenten als Taktgeber der Industrie, die in der Stabilisierungsperiode erstmals offenkundig geworden ist: ,If Intel developes a new computership, many companies will start developing new computers. When Rolls Royce developes a new jet engine, manufacturers start building. I am saying that the driving force in development and innovation is not the wind turbine manufacturers, but the blade manufacturers.'

Der Leistungssprung von 30 auf 55kW ist eine Folge des Markteintritts des 7,5m-Flügels. Mit Ausnahme Kuriants ${ }^{174}$ hatten alle wichtigen Hersteller, Windmatic, Danregn, Vestas und Nordtank diesen Schritt vollzogen, so bald es ihnen möglich war.

Bereits am Ende von Periode 1 ist eine Vorentscheidung für das dänische Windturbinendesign als dem siegreichen Konzept gefallen. Aber: Neben den Mühlen von Riisager, Herborg, Adolfsen, NIVE u.a., gab es noch immer viele Selbstbauer mit anderen Ideen. Seit 1979/80 entschieden sich alle großen Hersteller und die Schmiedemeister für die Verwendung des dänischen Konzepts. ${ }^{175}$ Dessen kommerzieller Erfolg vor 1979 und die damit verbundene Übernahme der entsprechenden Patente Riisagers, Herborgs und Adolfsens, ist dafür ein wichtiger Grund. Auch Risoe hat diese Entwicklung gefördert. Nicht zuletzt hat der DV durch Veröffentlichung von Statistiken die Überlegenheit des Danish Designs transparent gemacht und damit die Produktion solcher Anlagen unterstützt. Spätestens seit 1981/82 hatte sich die dänische Bauweise komplett durchgesetzt. ${ }^{176}$

Aufgrund verbesserter Sicherheit und Zuverlässigkeit der Windturbinen, infolge der Einführung aerodynamischer Bremssysteme, ist die Polarisierung zwischen DV und Windanlagenindustrie weitgehend verschwunden. Hieran hatten sowohl die geläuterten Hersteller, als auch Risoe, indem sie den Markteintritt unsicherer Modelle verhinderte, einen Anteil. Der Windindustrieverband FDV, der zwischenzeitlich Bankrott gegangen war, wird 1981 wiedergegründet. Er wirkte seitdem als Mittler zwischen Betreibern, Energieunternehmen, Behörden und Energieministerium (WPM 5/85, 11). In den meisten Fällen agierten DV und FDV gemeinsam und bildeten eine zunehmend einflussreiche Interessenvertretung (van Est 1999, 242).

\footnotetext{
${ }^{173}$ Beispiel Oekaer: Das Unternehmen nahm die Serienproduktion der 7,5m-Flügel auf, bevor die Prototypen ausgiebig in einer speziellen Testanlage geprüft wurden. Zu entsprechenden Investitionen fehlten Oekaer die Mittel. Zu dem Zeitpunkt, als ein Konstruktionsfehler entdeckt wird, waren bereits mindestens 20 Rotoren verkauft worden. Der Austausch der Rotoren zog so hohe Kosten nach sich, dass der Konkurs Oekaers unausweichlich geworden war.

${ }^{174}$ Kuriant hatte sich auf den Bau kleinerer WEA bis 18,5kW konzentriert. Langfristig erfolgreich ist Kuriant nicht. 1985 wird das Unternehmen geschlossen (www.windsofchange.dk, Abruf vom 25.4. 2008).

${ }^{175}$ Eine Ausnahme bildete S.J. Windpower. Das Unternehmen hielt bis zum Konkurs im Jahr 1981 an der ,Windrose' fest (WPM 2/85, 6).

${ }^{176}$ Anderen Designs kam seitdem nur noch rudimentäre Bedeutung zu: ,After 1981/82 Production of Darrieus, VAT (Winberg) and Poulsen Turbine stopped. The wind rose (Fredrikshavn - small company - GSS Powermills) was produced for a few years. An electricity company (Søndjyllands Højspændingsværk) tried to start a Darrieus project, but never succeeded. Only theoretically working people of Risoe cared about Darrieus etc. after 1980.' (Grove-Nielsen, E-Mail vom 20.8.07).
} 
In den folgenden Tabellen 2.2b und 2.2c werden die hier beschriebenen Eigenschaften der führenden Unternehmen dieser und der vergangenen Periode zusammengefasst und einander gegenübergestellt.

Tab. 2.2b Führende Akteure der Windanlagenindustrie (Periode 1)

\begin{tabular}{|c|c|c|c|c|c|c|}
\hline & Riisager M. & Adolfsen M. & Herborg V.K. & S. Jensen M. & \begin{tabular}{|l|} 
Oekaer V.K. \\
\end{tabular} & Kongsted \\
\hline $\begin{array}{l}\text { in der Windbranche } \\
\text { seit }\end{array}$ & 1976 & 1977 & 1978 & 1978 & 1977 & 1978 \\
\hline $\begin{array}{l}\text { etabliertes } \\
\text { Unternehmen? }\end{array}$ & nein & nein & nein & nein & nein & nein \\
\hline Kapitalmangel? & ja & ja & ja & ja & ja & ja \\
\hline bish. Branche & Handwerk & Handwerk & Handwerk & Handwerk & - & Handwerk \\
\hline $\begin{array}{ll}\text { Verwendung des } \\
\text { dän. Konzepts? }\end{array}$ & ja & $\mathrm{ja}$ & ja & nein & - & ja \\
\hline \begin{tabular}{lll|} 
Größte & WEA & in \\
Periode $1(\mathrm{~kW})$
\end{tabular} & 30 & 11 & 30 & 10 & 5m-Flügel & 22 \\
\hline $\begin{array}{l}\text { kommerziell } \\
\text { erfolgreich? }\end{array}$ & ja & $\mathrm{ja}$ & ja & anfangs & ja & bedingt \\
\hline $\begin{array}{l}\text { Kooperativer } \\
\text { Entwicklungspfad? }\end{array}$ & nein & ja & ja & nein & ja & nein \\
\hline $\begin{array}{l}\text { Konstruktionszeich- } \\
\text { nung }\end{array}$ & $\begin{array}{l}\text { Juul/ Gedser- } \\
\text { Mühle }\end{array}$ & $\begin{array}{l}\text { Unterst. durch } \\
\text { OVE-Netzwerk }\end{array}$ & $\begin{array}{l}\text { Unterst. durch } \\
\text { OVE-Netzwerk }\end{array}$ & S. Jensen & $\begin{array}{l}\text { Unterst. durch } \\
\text { OVE- } \\
\text { Netzwerk }\end{array}$ & $\begin{array}{l}\text { Riisager/ } \\
\text { Juul }\end{array}$ \\
\hline
\end{tabular}

Quellen: vg. Kap. 2.1 und 2.2

Tab. 2.2c Führende Akteure der Windanlagenindustrie (Periode 2)

\begin{tabular}{|c|c|c|c|c|c|c|c|c|}
\hline & Vestas & Kuriant & Windmatic & Nordtank & Danregn & Oekaer & Coronet & Smedemester \\
\hline $\begin{array}{l}\text { in der } \\
\text { Windbranche seit }\end{array}$ & 1979 & 1979 & 1979 & 1980 & 1980 & 1977 & 1981 & 1979 \\
\hline $\begin{array}{l}\text { etabliertes } \\
\text { Unternehmen? }\end{array}$ & ja & $\overline{j a}$ & nein & ja & $\overline{j a}$ & nein & ja & nein \\
\hline Kapitalmangel? & nein & nein & nein & nein & nein & $\mathrm{ja}$ & nein & $\mathrm{ja}$ \\
\hline bisherige Branche & $\begin{array}{l}\text { Agrarmaschinen- } \\
\text { bau }\end{array}$ & $\begin{array}{l}\text { Agrarmschinen- } \\
\text { bau }\end{array}$ & - & Ölindustrie & $\begin{array}{l}\text { Agrarmaschinen- } \\
\text { bau }\end{array}$ & - & Bootsbau & Metall \\
\hline $\begin{array}{l}\text { Verwendung des } \\
\text { dän. Konzepts? }\end{array}$ & ja & ja & ja & ja & ja & - & - & ja \\
\hline $\begin{array}{l}\text { Größte WEA in } \\
\text { Periode } 2(\mathrm{~kW}) \text { ? }\end{array}$ & 55 & 18,5 & 55 & 55 & 55 & \begin{tabular}{|l|}
$7,5 \mathrm{~m}-$ \\
Flügel \\
\end{tabular} & $\begin{array}{l}7,5 \mathrm{~m}- \\
\text { Flügel } \\
\end{array}$ & 22 \\
\hline $\begin{array}{l}\text { kommerziell } \\
\text { erfolgreich? }\end{array}$ & ja & ja & $\mathrm{ja}$ & ja & ja & $\begin{array}{l}\text { anfangs, } \\
\text { 1981: } \\
\text { Konkurs }\end{array}$ & ja & $\begin{array}{l}\text { nein, } \\
\text { ausgenommen } \\
\text { Lolland-WEA }\end{array}$ \\
\hline $\begin{array}{l}\text { Kooperativer } \\
\text { Entwicklungspfad? }\end{array}$ & nein & nein & nein & nein & nein & nein & nein & ja \\
\hline $\begin{array}{l}\text { Konstruktions- } \\
\text { zeichnung }\end{array}$ & Herborg V.K. & Adolfsen M. & $\begin{array}{l}\text { Riisager } \\
\text { M. }\end{array}$ & $\begin{array}{l}\text { eigenes, an } \\
\text { Herborg- } \\
\text { Design } \\
\text { orientiert } \\
\end{array}$ & $\begin{array}{ll}\text { eigenes, an } \\
\text { Herborg- } \\
\text { Design } \\
\text { orientiert }\end{array}$ & $\begin{array}{l}\text { eigenst. } \\
\text { Weiter- } \\
\text { entwickl. }\end{array}$ & $\begin{array}{l}\text { Oekaer } \\
\text { Vind } \\
\text { Energi }\end{array}$ & NIVE \\
\hline
\end{tabular}

Quellen: vg. Kap. 2.1 und 2.2 


\section{Ökonomischer Entwicklungspfad}

$\mathrm{Zu}$ den Hauptschwierigkeiten der Umstellung auf industrielle Produktion zählt die Überwindung des unter den Pionieren üblichen Kapitalmangels. Wie dargestellt, vollzieht sich der Zufluss neuer Kapitalien entlang des in der marktwirtschaftlichen Ökonomie gängigen Entwicklungspfades. Die Pioniere gaben auf, oder wurden vom Markt gedrängt. Größere Unternehmen traten hinzu, machten sich das Wissen der Pioniere zu Nutze und dominierten den Markt: ,Already from 1981 Vestas, Danregn, Nordtank and Windmatic became dominant.' (Grove-Nielsen, Interview vom 27.6.07).

Daneben sind zu diesem Zeitpunkt noch circa 10-15 kleine Unternehmen aktiv, die in ihrer Arbeitsweise eher dem Typ des Selbstbauers entsprachen. $\mathrm{Zu}$ diesen sind übrigens auch die Schmiedemeister zu zählen, welche erst in dieser Periode den Sektor betreten. Sie alle verlieren auf dem Markt immer mehr an Bedeutung. ${ }^{177}$

Konkurrenzorientiertes Handeln beginnt jetzt, unter Windkraftfirmen Raum zu greifen. Dafür ist der veränderte Charakter der Windtreffen ein wichtiger Indikator. In Periode 1 waren die Windtreffen vor allem ein Ort, wo sich die Akteure über technische Neuerungen und Ideen austauschten. Besonders die OVE war bemüht, Selbstbauer bei der Anlagenentwicklung zu unterstützen. Zahlreiche Selbstbauer und Pionierunternehmen arbeiteten kooperativ und waren bereit, ihr Know-how weiterzugeben. Das änderte sich gegen Ende der 70er Jahre. Die zuvor von der OVE geleiteten Zusammenkünfte werden jetzt vom DV ausgerichtet. Dieser Wechsel repräsentiert sowohl die Bedeutungszunahme der Windanlageneigentümer, als auch eine paradigmatische Neuorientierung. Diskussionen um technische Probleme und Neuerungen nehmen seitdem einen immer geringeren Stellenwert ein, bis sie 1982 eingestellt werden. Stattdessen rückt die Interessenvertretung gegenüber Politik, Energiewirtschaft und Verwaltung ins Zentrum (Grove-Nielsen, Interview vom 27.6.07).

Die Schmiedemeistervereinigung hatte auf dem Windtreffen vom September 1978 vorgeschlagen, eine Standardkonstruktion entwerfen zu lassen und die Zeichnungen allen Schmieden zugänglich zu machen. Mit der Veröffentlichung des Smedemester-Konzepts versuchte die NIVE-Gruppe, einen kooperativen Entwicklungspfad zu etablieren. Der notwendige Kapitalzufluss sollte nicht von einzelnen, das Know-how monopolisierender Unternehmen ausgehen, sondern von der Breite zahlreicher kleinerer Schmiedeunternehmen bewerkstelligt werden. ${ }^{178}$ Zur Erklärung, weshalb sich die Vorstellungen der NIVE-Gruppe nicht realisieren ließen, sind insbesondere drei Gründe heranzuziehen.

Erstens nehmen die meisten Schmiede erst 1980/81 die Produktion auf, als die Marktaufteilungsprozesse schon weit fortgeschritten sind. Beteiligte Unternehmen wie Vestas, Windmatic und Kuriant repräsentieren den auf Konkurrenz beruhenden Entwicklungspfad. Eine Vorentscheidung zu dessen Gunsten ist damit bereits gefallen. Zudem verfügen diese Unternehmen, zweitens, nicht nur über einen technologischen Vorsprung, sondern sind auch mit besseren Ressourcen ausgestattet. Drittens wird die Konkurrenz-basierte Entwicklung durch die Interaktion zwischen Risoe und Hersteller gefördert. Know-how wird nicht vermittelt. ${ }^{179}$ Diese Vorgehensweise ist Resultat des Handelns jener Pioniere, die von Beginn an nur zur Kooperation mit Risoe bereit waren, falls die Teststation garantierte, keine Details weiterzugeben.

\footnotetext{
${ }^{177}$ Pioniere wie Riisager, Joergensen und Grove-Nielsen, die zwar als Hersteller nicht mehr relevant waren, spielten im Entwicklungssektor weiterhin eine wichtige Rolle.

${ }^{178}$ Die Idee kooperativer, statt auf Konkurrenz beruhender wirtschaftlicher Entwicklung, erscheint für die meisten westlichen Länder eher abwegig. Anders in Dänemark: Dort ist die Weitergabe von Konstruktionszeichnungen bspw. in der Agrarmaschinenindustrie durchaus üblich.

${ }^{179}$ Smedemester-Pionier Bendy Poulsen hatte gehofft, in Risoe Details zur Verbesserung des SmedemesterKonzepts zu erfahren. Doch anstatt ihre technische Ausstattung für diesen Zweck zu nutzen und ihre Erfahrungen weiterzugeben, interessierten sich die Mitarbeiter der Teststation ausschließlich dafür, dass seine WEA die Stabilitäts- und Sicherheitskriterien erfüllte (Beuse et al. 2000, 208).
} 
Es dauerte bis 1982, ganze drei Jahre nach Veröffentlichung der ersten SmedemesterZeichnung, bis unter Mitarbeit der NIVE-Gruppe, auf Lolland ein verbessertes Modell entwickelt wird. Kommerzielle Erfolge der Lolland-Turbine ändern nichts daran, dass ein ökonomischer Pfadwechsel im Jahr 1982 praktisch ausgeschlossen war.

\subsubsection{Windanlagenbetreiber in Periode 2}

Der Einfluss des PAS hat nicht nur bei der Industrie, sondern auch den Windturbinenkäufern Transformations- und Wachstumsprozesse ausgelöst. Nach den Pionieren betreten in erster Linie einzelne Landwirte den Sektor. Politische Motivation wie Protest gegen Atomenergienutzung nahm bei diesem Akteur einen geringeren Stellenwert ein. Vor allem ging es ihnen darum, die Stromkosten zu senken. Gänzlich neu ist der gemeinschaftliche Anlagenkauf: Seit 1980 tritt die in der dänischen Kultur- und Wirtschaftsgeschichte verankerte Kooperative hinzu. Die lokal ansässige Windkooperative, bestehend aus mehreren Haushalten, die eine Windmühle gemeinschaftlich erwerben, wird zum vorwiegenden Käufertyp. Ihre Nachfrage bildet eine der wichtigsten Erfolgsvoraussetzungen der Windtechnologie in Dänemark. Eine Reihe von Schwierigkeiten, die sich den Betreibern während der Stabilisierungsperiode gestellt haben, können mit dieser Organisationsform überwunden werden. Mit den EVU, von denen die Windmüller anfangs bekämpft wurden, musste in irgendeiner Weise ein Kompromiss getroffen werden. Vor dem Hintergrund, dass die Windkooperativen viel Zuspruch aus Parlament und Gesellschaft erhielten, fiel der Kompromiss zu Gunsten der Windmüller aus.

Feedback an das PAS

Den Einstieg in die Windkraftförderung hat die Regierung damit begründet, einen neuen Industriezweig $\mathrm{zu}$ fördern. Darüber hinaus ist sie als Zugeständnis an eine die Atomtechnologie ablehnende Öffentlichkeit zu interpretieren. Auch der Einfluss der sogenannten ,grünen Mehrheit' im Parlament ist hier zu nennen.

1978/79 ist die Förderung kleiner WEA nicht nur für Dänemark, sondern auch auf internationaler Ebene etwas völlig Neues. Mit der Investitionszulage werden lediglich allgemeine Bedingungen geschaffen, um ein Marktwachstum zu beschleunigen. Es bedurfte der Nachjustierungen und Ergänzungen, um ein geeignetes Fördersystem zu etablieren. Solche Justierungen vereinfachten sich durch die wachsende Präsens einer Windenergielobby, insbesondere des DV. Politische Entscheidungsträger werden über Schwierigkeiten in Kenntnis gesetzt, Lösungsansätze werden vorgeschlagen. Von der Renitenz der EVU (Netzanschluss, mangelnde Vergütungen) wusste die Regierung entweder nichts, oder sah zunächst keine Notwendigkeit etwas an der für die Windmüller unbefriedigenden Situation zu ändern. Erst nachdem der DV an die Parteien des Folketing herantrat, um sich über die Restriktionen des DEF zu beschweren, wurde das Parlament aktiv. Insbesondere offen für die Sache der Windmüller zeigten sich die kleineren Parteien ER, RV, SF und VS. Diese setzten sich beim Handelsministerium für einen Gesetzesbeschluss ein, durch den die Einhaltung der DEF-Richtlinien von 1976 hätte gewährleistet werden sollen (van Est 1999, 80). Erst als die Regierung mit einem entsprechenden Schritt drohte, gab der DEF nach und verlieh 1979 den provisorischen Richtlinien einen verbindlichen Charakter.

Die Errichtung einer Teststation war im offiziellen Programm anfangs gar nicht vorgesehen. Sie wurde erst nachträglich und nur unter Vorbehalten aufgenommen. Erfolgreich war die Prüfanlage nicht zuletzt deshalb, weil es sich bei den Beschäftigten großteils um Fürsprecher erneuerbarer Energien handelte, die teilweise als OVE-Mitglieder den technischen 
Entwicklungsprozess der vergangenen Periode aktiv mitgestalteten. Sie trugen maßgeblich zur Entstehung konstruktiver Interaktion zwischen Windindustrie und Teststation bei.

Für die Regierung war es zunächst nicht absehbar, dass sich Kooperativen zur üblichen Organisationsform des Betriebs von Windmühlen entwickeln würden. Die erste Kooperative, die sich 1980 gründete, musste feststellen, dass im Subventionsgesetz die Förderung einer Gruppe von Käufern gar nicht vorgesehen war. Zunächst wurde der Investitionszuschuss verweigert. Einige Artikel, in denen der DV-Vorsitzende und Naturlig Energi Redakteur Torgny Moeller diesen Missstand problematisierte, mochten dazu beigetragen haben, dass die Regierung das Gesetz zu Gunsten der Kooperativen modifizierte (Beuse et al. 2000, 191).

\section{Kooperativen in Dänemark}

Die kooperative Tradition des Landes geht auf die 1870er Jahre zurück und ist mit dem Namen Nikolas F. S. Grundtvigs - dem Begründer der Volkshochschulbewegung - untrennbar verbunden. Kernelemente seines Denkens sind Autonomie, Freiheit, gegenseitigen Respekt und Achtung vor dem gemeinschaftlichen Besitz. Die Liberalisierung in England und die preußische Annexion Schleswig-Holsteins durch Bismarck von 1864 sind wichtige Bezugspunkte. Der Verlust Schleswig-Holsteins war für die Volkshochschulbewegung von großer symbolischer Bedeutung. In der folgenden Zeit wurden zahlreiche Volkshochschulen neu gegründet. Die Grundtvig-Ideen verbreiteten sich rasch insbesondere unter der ländlichen Bevölkerung.

In den 1870er Jahren ist die dänische Landwirtschaft in eine strukturelle Krise geraten. Seit Einführung der Dampfschifffahrt und der Eisenbahn als neuen Transportmitteln, ist es für Amerika und Russland möglich geworden, große Getreidemengen nach Westeuropa zu exportieren. Dort sind riesige Plantagen entstanden, auf denen billiger produziert werden konnte, als auf denen kleinen Feldern der europäischen Landwirte. Die Preise fielen daraufhin so stark, dass dänische Agrarprodukte nicht mehr konkurrenzfähig waren. Die damalige Popularität Grundtvigs war ein glücklicher Zufall für die Landbevölkerung. Seine Vision wirtschaftlicher Organisation war demokratischer Art: Kooperativ-Unternehmen, in denen jeder, unabhängig von Kapital und Besitz, über dieselben Stimmrechte verfügen sollte (Traenes 1997, 4). Diese Idee, die einen Weg zur Überwindung der Krise aufzuzeigen schien, stieß auf große Resonanz. Wenn die Ursache des Problems darin bestand, dass dänische Landwirtschaftsbetriebe zu klein waren, warum sollte man sich dann nicht zusammenschließen? Plötzlich erschien dieser Gedanke vielen naheliegend. Die landwirtschaftliche Kooperativbewegung war entstanden: Molkereien, Tierfutterproduzenten, Fleischereien - alle organisierten sich als kleine Kooperativen mit lokaler Verankerung. Der Vorteil für die Mitglieder bestand darin, dass sie einerseits alle Vorzüge eines größeren Unternehmens genossen: Preissenkungen und Investitionen in neue Produktionsmittel. Andererseits behielten sie ihre Unabhängigkeit (van Est 1999, 161ff.).

Auf diese Weise konnte die Krise überwunden werden, und die ländliche Bevölkerung verbesserte ihre wirtschaftliche Situation deutlich. Noch bis ins 20.Jahrhundert hinein waren die meisten landwirtschaftlichen Betriebe in Kooperativen organisiert. Doch ihre ökonomische Bedeutung ging zurück. In den 1970er Jahren hatten sich viele Kooperativen entweder aufgelöst, oder waren so stark gewachsen, dass der ursprüngliche lokale Charakter und der persönliche Bezug unter den Mitgliedern verlorengegangen sind.

Die Vindmoellelaugen - eine neue kooperative Bewegung?

Für die dänische Wirtschaft der 1970/80er Jahre spielen die ökonomischen Vorstellungen Grundtvigs nur mehr eine marginale Rolle. In der dänischen Kultur, insbesondere in ländlichen Gebieten dagegen, ist die Sympathie für kooperatives Handeln ungebrochen. 
Scheinbar idealisierend beschreibt Traenes (1997, 4f.) die Entstehung von Windradkooperativen als ein Wiederaufleben dieser Tradition:

,In many villages people missed the popular sense of community, which had existed in many small cooperatives - they missed something meaningful like being together with a common purpose. Here wind power filled the vacuum. The subject was positiv: To strive for renewable energy, to strive for a better environment and to revive the joint problem solving community spirit.'

Seit 1981 entstehen in Dänemark zahlreiche Windanlagenkooperativen. Eine der ersten bildete sich im April 1981 in Bruunshab, nahe Viborg. ${ }^{180}$ An der Kooperative waren 34 Haushalte beteiligt, von denen sich jeder mit einem bis maximal vier Anteilen beteiligte. Die Mitglieder erwarben eine 55kW-Maschine von Nordtank, die sie im Oktober des Jahres in Betrieb setzten (Beuse et al. 2000, 191f.). In den folgenden Jahren werden die Kooperativen zur dominierenden Käufer- und Betreibergruppe. Bis Mitte der 90er Jahre sind etwa 250.000 Personen (100.000 Haushalte) direkt oder indirekt, Miteigentümer von Windturbinen, was etwa fünf Prozent der Bevölkerung entspricht (Gipe 1995, 60). Angesichts dessen erscheint es keineswegs abwegig, in Bezug auf die dänische Windkraftnutzung durch Kooperativen von einer sozial-ökologischen Bewegung, bzw. sogar einem Wiederaufleben der kooperativen Bewegung des 19. Jahrhunderts zu sprechen.

Festzuhalten ist, dass es sich bei der Kooperative in Dänemark nach wie vor um eine diffusionsfähige wirtschaftliche Organisationsstruktur handelt. Jenseits kulturhistorischer Motivation, existierten für den Erfolg des Kooperativmodells zwei pragmatische Gründe. Erstens verfügten die meisten Interessenten, vorwiegend Landwirte, kaum über die zum Kauf erforderlichen Mittel, insbesondere nicht, was den Erwerb einer neuen 55kW-Maschine betrifft. Zweitens produzierten Modelle dieser Größe so viel Energie, dass die maximale Stromeinspeisung von $135 \%$ des Eigenverbrauchs von den meisten Betreibern überschritten worden wäre. Ohne die Möglichkeit, Käufergruppen $\mathrm{zu}$ bilden, hätten die Interessenten ausschließlich auf kleinere Windmühlen mit geringerer Effizienz zurückgreifen müssen. Der gemeinschaftliche Kauf und Betrieb war daher nicht allein eine finanzielle Notwendigkeit, sondern auch aus betriebswirtschaftlichen Gründen geboten (van Est 1999, 327).

Windanlagenkooperativen: eine soziale Innovation

Die Regierung schuf die legislativen und administrativen Grundlagen, um die notwendige Erweiterung des Käufer- und Betreiberkreises über Bastler und Idealisten hinaus zu fördern. Zur Überwindung dieser Barriere trug die Möglichkeit zur Mitgliedschaft in einer Windanlagenkooperative und damit dem Erwerb, eventuell auch geringer Mühlenanteile, wesentlich bei. Die 55kW-Maschine ist in dieser Periode nicht nur die effizienteste, sondern auch leistungsstärkste Windmühle. Aufgrund der Kopplung der Stromproduktion an den Eigenbedarf, ist es ausgeschlossen, dass einzelne Investoren, durch den Kauf mehrerer Anlagen, die technische Entwicklung hätten steuern können. Ohne die Kooperativen hätte der dänische Markt kaum wesentlich über das Niveau von 1980/81 hinaus wachsen können. Windkraft ist eine dezentrale Energiequelle. Während der Stabilisierungsperiode sind einige Hundert WEA installiert worden. Deren Präsenz brachte für die ansässige Bevölkerung mehr oder weniger eine Minderung der Lebensqualität mit sich. Windturbinen produzieren nicht nur Strom, sondern verursachen Lärmbelastungen und stellen optische Beeinträchtigungen dar. Auf der anderen Seite verdienen nur die Windmüller an deren Betrieb, während negative Begleiterscheinungen von sämtlichen Anrainern erduldet werden müssen. Je nach Einzelfall

\footnotetext{
${ }^{180}$ Traenes $(1997,3)$ verweist auf eine andere Kooperative in Ny Solbjerg, die bereits 1980 gegründet wurde. Genau genommen handelte es sich bei dieser Käufergruppe nicht um klassische Kooperativen, bzw. genossenschaftliche Vereine, sondern um formale Partnerschaften. Dieses hatte seinen Grund in der Gestaltung des Subventionsgesetzes. Denn nur aufgrund dessen hatten die Beteiligten die Möglichkeit, Zinsen ihrer Kredite, die sie für den Windanlagenerwerb aufgenommen haben, von der Steuer abzuschreiben. In der täglichen Praxis funktionierten die Partnerschaften als Kooperativen (Traenes 1997, 4).
} 
ist hier objektiv von einer Gerechtigkeitslücke $\mathrm{zu}$ sprechen. Erstmals tritt das Akzeptanzproblem auf. Die meisten Fälle mochten eher unproblematisch gelagert sein: Man denke etwa an einen Landwirt, der eine Windturbine auf seinem Grundstück errichtet, das einen Kilometer von der Siedlungsgrenze entfernt gelegen ist. Die Tatsache, dass die Anlage von der Siedlung aus gesehen werden kann, mag als eine geringfügige Einschränkung toleriert werden. Ein anderer Fall ist das Beispiel eines Windmüllers, der eine Anlage nahe der Siedlungsgrenze installieren möchte, während seine Wohnstätte vom eigentlichen Standort mehrere Hundert Meter entfernt gelegen ist. Ein einzelner entsprechender Fall könnte genügen, um länger andauernde Aversionen gegen die Windenergie zu schüren.

Dafür, dass der Aufbau von WEA während dieser Periode nicht durch mangelnde Akzeptanz verzögert worden ist, gibt es einige Gründe. Die Existenz der besagten Gerechtigkeitslücke ist nicht von der Hand zu weisen. Sie wächst mit der Lukrativität des Windanlagenbetriebs. Für die Erhaltung der Akzeptanz war es daher sehr wichtig, dass die Förderregelung so gestaltet war, dass sie zwar wirtschaftliche Anreize bot, gleichzeitig jedoch ausschloss, dass größere Gewinne erzielt werden konnten. Durch die Einschränkungen der DEF-Regelung $(135 \%$ des Eigenverbrauchs $=$ Einspeisemaximum, $3 \mathrm{~km}=$ maximaler Abstand zwischen Wohnstätte des Betreibers und Standort) wurde verhindert, dass sich wohlhabende Stadtbewohner auf Kosten der ländlichen Bevölkerung bereicherten (van Est 1999, 245). ${ }^{181}$ Von den Initiatoren eines Projekts wurde zudem versucht, weitere Personen aus der näheren Umgebung und der angrenzenden Gemeinde, als Kooperativenmitglieder zu gewinnen. Einzelne Anteile konnten erworben werden, was nur geringfügige Investitionen erforderte und daher für die meisten Haushalte möglich war. Auf diese Weise kamen die Einnahmen aus dem Stromverkauf ${ }^{182}$ nicht nur Einzelpersonen, sondern immer mehreren Windmüllern aus der Umgebung zugute, die auch in die Planungen miteinbezogen waren. Auf diese Weise gewann die neue Technologie immer mehr gut informierte Fürsprecher, die vor Ort als Multiplikatoren wirkten.

\section{EVU und Windkraft}

Wie in anderen Ländern hatte auch die dänische Energiewirtschaft kein Interesse an der Windenergie. Besonders unliebsam war ihr die Tatsache staatlicher Förderung privater Windanlagenbetreiber. ${ }^{183}$ Um das Verhältnis der EVU zu Windenergie und Windmüllern zu interpretieren sind bestimmte, das Konfliktpotenzial mindernde Ausgangsvoraussetzungen des dänischen Strommarktes zu berücksichtigen. Erstens wurden neue Energietechniken gebraucht, weil konventionelle Energierohstoffe großteils importiert werden mussten und auch Atomenergie für Dänemark keine Alternative darzustellen schien. Zweitens eignete sich Windkraft für den dänischen Markt aufgrund einer relativ dezentralen Struktur des Stromnetzes und einer geeigneten Topographie (Küstenlinien, landwirtschaftlich genutzte

\footnotetext{
$181, \ldots$ the state restricted the profit margin of wind turbine owners by carefully adjusting the amount of investment subsidy...In short, the utility rules and subsidy law created a small market that forced the producers and consumers involved not to expect too high profits.' (van Est 1999, 244). In Kalifornien war es sehr wohl möglich, mit der Windkraft Profite zu erzielen. Darin lag der wichtigste Grund des dortigen Akzeptanzverlustes, obwohl die Standorte buchstäblich in der Wüste lagen (vg. Kap. 2.3).

${ }^{182}$ Hier ist zu berücksichtigen, dass der Kauf einer Windmühle auch in der Stabilisierungsperiode noch immer kein sicheres Plusgeschäft gewesen ist. So konnten die erwarteten Einnahmen etwa durch Reparaturkosten, Produktionsausfälle, Totalschäden und mangelnde Bereitschaft der EVU, die vereinbarten Tarife zu zahlen, geschmälert werden.

${ }^{183}$ Nach einer 1983 veröffentlichten Positionierung des DEF sollte Windkraft keine Subventionen erhalten. Stattdessen sollten WEA von den EVU besessen und betrieben werden. Der private Betrieb von WEA sei mit den Zielen der Versorgungssicherheit und niedrigen Strompreisen unvereinbar, weil Privatakteure eine Abschaltung ihrer Anlagen im Falle der Verfügbarkeit günstigen Stroms aus Wasserkraft aus Norwegen und Schweden nicht akzeptieren würden. Ferner problematisiert der DEF die Inkompatibilität von Kleinkraftwerken mit der Netzstruktur sowie die Gefahr der Netzzusammenbrüche aufgrund von Leistungsschwankungen (vg. van Est 1999, 86).
} 
ebene Flächen), vergleichsweise gut. Drittens war die neue Technologie Anfang der 80er Jahre keine aktuelle, sondern eher eine mögliche zukünftige Energieoption. Großwindanlagen wie die Nibe-Zwillinge waren zur kommerziellen Nutzung ungeeignet. Die Installation von Windparks, bestehend aus zahllosen 55kW-WEA, über deren Reifegrad und Lebensdauer mangelhafte Kenntnisse vorlagen, stellten ebenfalls keine Alternative dar.

Zwar lief die Tatsache, dass der Ausbau der Windkraft ohne die EVU vonstatten gehen sollte, ihren Interessen zuwider. Dennoch war auf diese Weise sichergestellt, dass eine mögliche zukünftige energiepolitische Chance nicht vergeben wurde. Ohnehin blieb dem DEF keine Alternative als mit den Windmüllern zu kooperieren. Öffentlicher Druck und Furcht vor staatlichen Restriktionen zwangen ihn dazu. Mit der Vorgabe seiner Richtlinien von 1979 (3km- und 135\%-Kriterien) war es dem Verband nichtsdestotrotz gelungen, den Ausbau zu verlangsamen.

Der DEF zielte darauf, die Windmüller auf den Status der Selbstversorger festzulegen (Hantsch 1998, 46). Er gestand ihnen quasi eine Randexistenz auf dem Stromsektor zu. Keinesfalls sollte der Eindruck erweckt werden, dass die Windkraft wesentlich zur Energieversorgung beitragen könne. Weite Teile der Stadtbevölkerung blieben vom Markt ausgeschlossen, weil in einem $3 \mathrm{~km}$-Radius keine Standorte verfügbar waren. Auch war die Möglichkeit durch das 135\%-Kriterium prinzipiell ausgeschlossen, dass wohlhabende ökologisch gesonnene Personen mehrere Windräder kauften und große Windparks eröffneten. Man kann also sagen: Der DEF war erfolgreich darin, den potenziellen Kapitalzufluss in den Windenergiemarkt zu reduzieren.

Ob das Regelwerk des DEF letztendlich die von ihm erhofften Wirkungen erzielt hat, bleibt fraglich. Denn interessanterweise sind es gerade auch diese Restriktionen, die zum langfristigen Erfolg der Windenergie beigetragen haben. Indem die Bildung von Kooperativen quasi zur Notwendigkeit geworden war, löste die Regelung indirekt das Akzeptanzproblem, dass in dieser Periode erstmals aufzutreten drohte. Die Regelung förderte die lokale Verankerung der Windkraft ${ }^{184}$ und verunmöglichte den Aufbau von Windparks durch Investoren.

Für die Energiewirtschaft hatte keine Möglichkeit bestanden, die Installation privater WEA zu verhindern. Zudem ist aufgezeigt worden, inwiefern die Richtlinien des DEF in Einklang mit den Interessen der Windbranche gestanden haben. Diese Sichtweise des Konflikts könnte den Eindruck erwecken als ließe sich die Einigung auf der obersten Ebene der Interessenorganisationen, unmittelbar auf die Beziehungen zwischen den einzelnen Windmüllern und EVU vor Ort übertragen. Die Regelung verpflichtete die EVU, Windanlagen an ihre Netz zu schließen und jede Kilowattstunde auf dem Niveau ihrer eingesparten Kosten zu vergüten. Jenseits dieser Richtlinie verfügten die EVU über zahlreiche Möglichkeiten, die Situation der Windmüller zu erschweren. Ein Versorger führte bspw. ein Bußgeld für die Einspeisung überschüssigen Stroms ein. Andere erhoben einen Abschlag von zehn Prozent des vereinbarten Tarifs, oder forderten ungerechtfertigt hohe Zahlungen für die Installation der Anlage. In einigen dieser Fälle klagte der DV und erhielt Recht (Traenes 1997, 8). Obgleich dem DEF daran gelegen war, nach außen hin das Bestehen einer harmonischen Beziehung zwischen ihnen und den Windmüllern zu suggerieren, blieb der fundamentale Widerspruch zwischen beiden Akteuren erhalten.

\footnotetext{
${ }^{184}$ Das Abstandskriterium des DEF stand so sehr im Einklang mit den Interessen des DV, dass es zu einem, von den Windmüllern gewollten Prinzip umgedeutet wurde: ,The idea was...that it was right that if anyone in the local area suffered any inconvenience, they should also be the ones having the advantages.' (Traenes 1997, 6). Später wurde das Abstandskriterium trotz gewisser Modifikationen zur Marktbarriere, weil sich in der näheren Umgebung der Anlagen nicht mehr genug Käufer fanden (vg. Kap. 2.4).
} 
Von der Technik- zur Stabilisierungsperiode

Die Stabilisierungsperiode zeichnet sich durch grundlegende Veränderungen der Akteurskonstellation des Windenergiesektors aus. Erstmals tritt das PAS in Erscheinung. Gesetzliche Förderregelungen führen zu (relativer) Kostensenkung. Windenergie als Energiequelle erhält jetzt einen legitimen Status. Die Energiewirtschaft wird zur Kooperation mit den Windmüllern gezwungen.

Auf der Angebotsseite vollziehen sich wichtige Neustrukturierungen. Die Windanlagen werden nicht länger in kleinen Werkstätten produziert, sondern in den Fabrikhallen etablierter Maschinenbaufirmen. Die Fertigung einzelner WEA wird durch Serienproduktion abgelöst. Mit dem Eintritt der neuen Herstellerklasse gewinnt ein konkurrenzorientierter Entwicklungspfad zunehmend die Oberhand. Kooperative Ansätze wie sie vom OVENetzwerk in der vorherigen Periode mit Erfolg praktiziert wurden, verlieren an Einfluss. Wesentliche technische Innovationen wurden in der Technikperiode hervorgebracht. Innovationen ähnlicher Tragweite wie die Wiederentdeckung des Juul-Designs, der Netzeinspeisung durch Riisager und dem Aufbau einer Zulieferindustrie bedurfte es nach 1978 nicht mehr. Die technische Weiterentwicklung zeichnet sich in dieser Periode durch inkrementelle Verbesserungen aus: Schrittweise wird die Rotoren- und Anlagengröße ausgebaut, Zuverlässigkeit, Effizienz und Anlagensicherheit erhöht. Die Vorentscheidung für das dänische Konzept wird bestätigt.

Die Zahl der Selbstbauer und Windenergieenthusiasten war begrenzt. Vor dem Hintergrund verbesserter Rahmenbedingungen, insbesondere politischer Förderung und erhöhter Anlagenzuverlässigkeit, erweitert sich der Käuferkreis. Den Pionieren treten nun zahlreiche Landwirte und Personen aus ländlichen Gebieten hinzu, die zwar Sympathie für die Windkraft empfanden, also idealistisch motiviert waren, zugleich aber das Interesse verfolgten, ihre Stromkosten zu verringern. Keinem der Windmüller ging es darum, größere Gewinne zu erzielen. Flankiert durch die Regelungen des DEF wird die Kooperative seit 1981/82 zur dominierenden Struktur des Anlagenbetriebs. Die Popularität der kooperativen Unternehmensform und die Möglichkeit, auf einfache Weise selbst Windmüller zu werden, verschafften der Windkraft eine gute Akzeptanz.

Die folgende Tabelle $2.2 \mathrm{~d}$ bietet eine Übersicht der wichtigsten Transformationsvorgänge zwischen Technik- und Stabilisierungsperiode auf Ebene des PAS, der Windanlagenindustrie und der Käufer. 


\begin{tabular}{|c|c|c|}
\hline & Technikperiode & Stabilisierungsperiode \\
\hline PAS & - $\quad$ Entwicklung unabhängig vom PAS & $\begin{array}{l}\text { - } 1978 / 79 \text { : PAS betritt Windenergiesektor } \\
\text { - } 1978 \text { : Einrichtung der Teststation für } \\
\text { kleine WEA } \\
\text { - } \\
\text { 1979: Einführung 30\%iger Subvention } \\
\text { für Windanlagenkauf } \\
\text { 1979: PAS zwingt DEF zur Kooperation } \\
\text { mit Windmüllern } \\
\text { - 1981: Energiplan 81: Langfristige } \\
\text { Förderung kleiner Windkraft }\end{array}$ \\
\hline \multirow{11}{*}{ Hersteller } & Produktionsort: Werkstätten & - $\quad$ Seit 1980/81: Produktion verlagert sich \\
\hline & - Kleinstunternehmen dominieren Markt & $\begin{array}{l}\text { 1979: Patente werden von } \\
\text { Mittelständlern gekauft; Größere Firmen } \\
\text { beherrschen den Markt seit 1980/81 }\end{array}$ \\
\hline & $\begin{array}{l}\text { - Produktionsweise: Herstellung einzelner } \\
\text { WEA }\end{array}$ & $\begin{array}{lll}\text { - } & \text { seit 1980/81: Produktionsweise: } \\
& \text { Serienfertigung } & \end{array}$ \\
\hline & $\begin{array}{l}\text { - Entwicklungsmethode: Handwerker } \\
\text { verbessern ihre Konzepte nach dem } \\
\text { Prinzip ,trail-and-error' }\end{array}$ & $\begin{array}{l}\text { - Entwicklungsmethode: Ingenieure } \\
\text { verwenden präzise Verfahren auf der } \\
\text { Basis formalisierter Kenntnisse }\end{array}$ \\
\hline & $\begin{array}{l}\text { - zahlreiche unterschiedliche Konzepte } \\
\text { werden verwendet }\end{array}$ & - $\quad$ Dänisches Konzept setzt sich durch \\
\hline & $\begin{array}{l}\text { - } \quad \text { Anlagensicherheit gering, Havariequote: } \\
50 \%\end{array}$ & $\begin{array}{l}\text { - Nach 1981: Deutliche Erhöhung der } \\
\text { Anlagensicherheit/ Zuverlässigkeit }\end{array}$ \\
\hline & $\begin{array}{ll}\text { - } & \text { Standardgröße der Rotorblätter/ } \\
\text { Kapazität der Generatoren: } 5 \mathrm{~m} / 30 \mathrm{~kW}\end{array}$ & $\begin{array}{l}\text { - 1981: Standardgröße der Rotorblätter/ } \\
\text { Kapazität der Generatoren: } 7,5 \mathrm{~m} / 55 \mathrm{~kW}\end{array}$ \\
\hline & $\begin{array}{l}\text { - technische Entwicklung: Innovation geht } \\
\text { vom OVE-Netzwerk und } \\
\text { handwerklichen Betrieben aus }\end{array}$ & $\begin{array}{llr}\text { - } & \text { technische Entwicklung: vor allem } \\
\text { quantitatives } \quad \text { Wachstum } & \text { und } \\
\text { Detailverbesserungen; } & \text { Akteure: } \\
\text { etablierte Maschinenhersteller } & \end{array}$ \\
\hline & Hersteller ohne Kontakt zum PAS & $\begin{array}{l}\text { - Hersteller treten durch Teststation/ } \\
\text { Zertifikationspflicht erstmals in Kontakt } \\
\text { mit PAS }\end{array}$ \\
\hline & $\begin{array}{ll}\text { - } & \text { dominierender } \\
& \text { Entwicklungspfad: kooperativ }\end{array}$ & 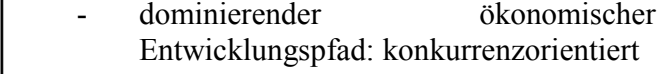 \\
\hline & $\begin{array}{l}\text { - Windtreffen organisiert durch: OVE } \\
\text { - } \quad \text { hauptsächliche Themen: Austausch über } \\
\text { technische Neuerungen und Probleme }\end{array}$ & $\begin{array}{ll}\text { - } & \text { Vindtraefs organisiert durch: DV } \\
\text { - } & \text { hauptsächliche } \\
\text { Interessenvertretung der Windbranche }\end{array}$ \\
\hline \multirow{4}{*}{ Käufer/ Betreiber } & \multirow{4}{*}{ 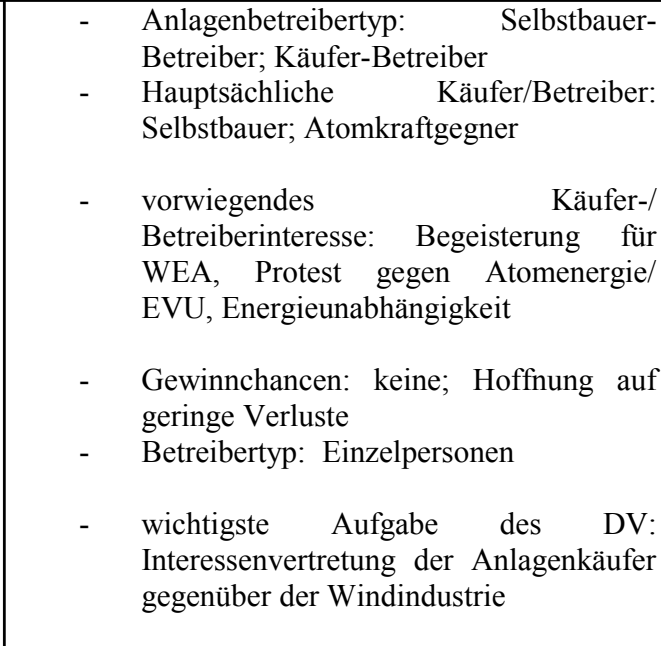 } & $\begin{array}{ll}\text { - } & \text { Anlagenbetreibertyp: Käufer-Betreiber } \\
\text { - } & \text { Hauptsächliche Käufer: Landwirte, } \\
\text { ländliche Bevölkerung }\end{array}$ \\
\hline & & $\begin{array}{lll}\text { - } & \text { vorwiegendes } & \text { Käuferinteresse: } \\
\text { Stromkosten sparen, Sympathie für } \\
\text { Windkraft }\end{array}$ \\
\hline & & $\begin{array}{ll}\text { - } & \text { Gewinnchancen: Hoffnung auf } \\
\text { Minderung der Stromkosten } \\
\text { - } \\
\text { Betreibertyp: zunehmend Kooperativen }\end{array}$ \\
\hline & & $\begin{array}{l}\text { - wichtigste Aufgabe des DV: } \\
\text { Interessenvertretung der Anlagenkäufer } \\
\text { gegenüber Parlament, Behörden und } \\
\text { EVU (seit 1981 unterstützt durch FDV) }\end{array}$ \\
\hline
\end{tabular}


Zusammenfassend lässt über die Stabilisierungsperiode sagen, dass die Windkraft während dieser Zeit eine beachtliche Annäherung an das Zentrum der dänischen Gesellschaft durchlaufen hat. Diese Entwicklung ist in Schaubild 2.2a dargestellt.

Schaubild 2.2a Windenergie-Akteure an der Peripherie und im Zentrum der dänischen Gesellschaft

Technikperiode:

Windenergie-Akteure an der Peripherie der dänischen Gesellschaft

\begin{tabular}{llr|}
\hline \multicolumn{1}{|c|}{ Selbstbauer } & Handwerksbetriebe \\
Windenergieverbände \\
DV und FDV
\end{tabular}

Stabilisierungsperiode:

Windenergie-Akteure rücken in das politische, wirtschaftliche und soziale Zentrum vor

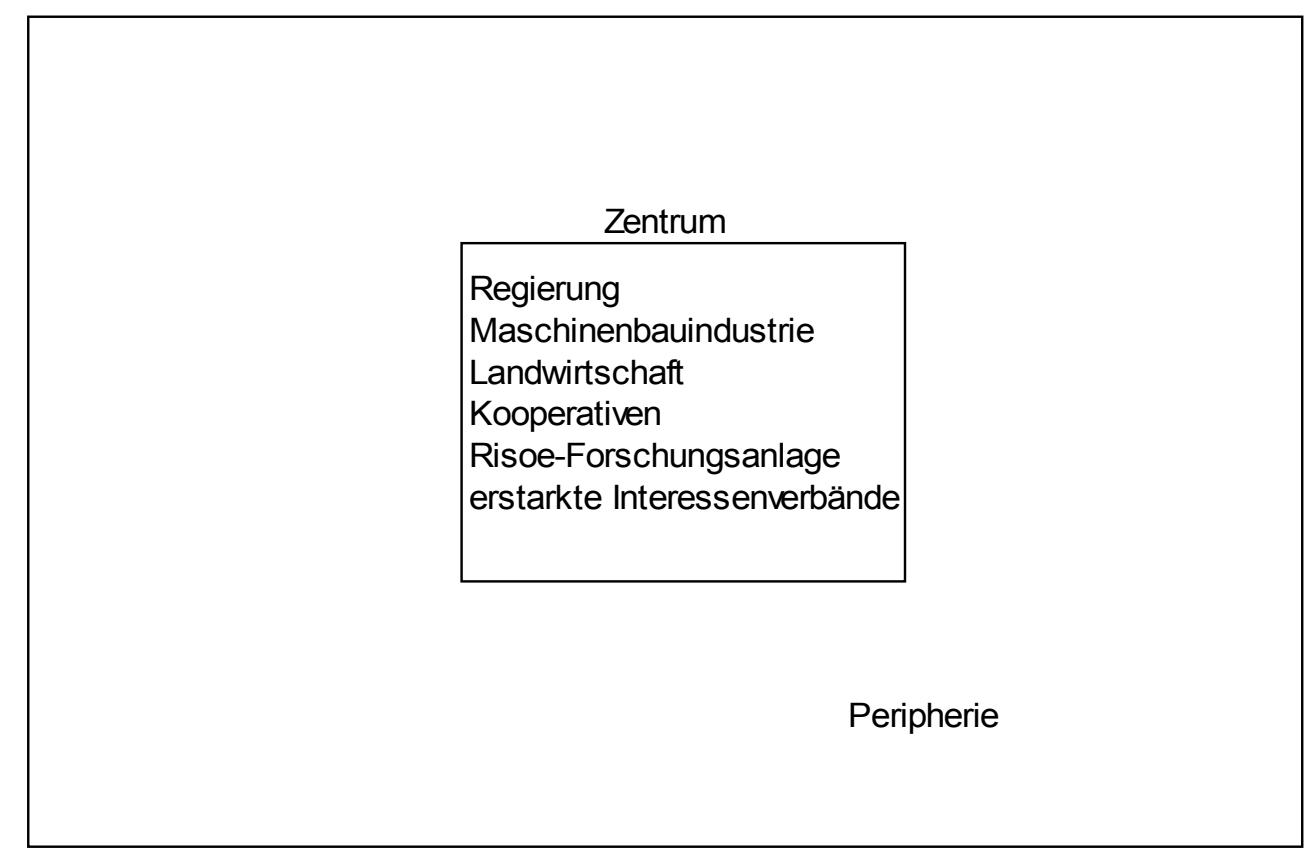


Die Stabilisierungsperiode ist für die Branche erfolgreich verlaufen. Die wichtigsten Barrieren überwindet sie eigenständig, oder staatliche Akteuren sind dabei behilflich. Manche Schwierigkeiten haben sich im Zuge urwüchsig und ohne Steuerung sich vollziehender Transformationen gelöst (bspw. Kapitalmangel, durch Veränderung der Herstellerstruktur), andere durch gezieltes Handeln (bspw. Interventionen der Risoe-Ingenieure). Die Umgehensweise mit diesen Barrieren wird in Tabelle 2.2e zusammengefasst. Als Betreiber dominieren zivilgesellschaftliche Akteure, ähnliche wie in Periode 1. Während auf Herstellerseite zuvor ebenfalls Kleinakteure aktiv waren, haben jetzt Mittelständler das Feld übernommen. Mit dem PAS tritt erstmals ein Großakteur in Erscheinung.

Tab. 2.2e Zentrale Barrieren in der Stabilisierungsperiode

\begin{tabular}{|c|c|c|c|}
\hline Problem & Lösungsansätze & Akteur/e & \begin{tabular}{|l|}
$\begin{array}{l}\text { Lösungsansatz } \\
\text { erfolgreich? }\end{array}$ \\
\end{tabular} \\
\hline $\begin{array}{lr}\text { Begrenzter } & \text { Käuferkreis bedroht } \\
\text { Kontinuität } & \text { technischer } \\
\text { Entwicklung } & \end{array}$ & $\begin{array}{l}\text { Intervention durch PAS; } \\
\text { Verbesserung der Anlagentechnologie; } \\
\text { Wiederentdeckung der Kooperative; } \\
\text { DEF-Regelung; Energiplan } 81 \text { erhöht } \\
\text { Wahrscheinlichkeit kontinuierlicher } \\
\text { Förderung }\end{array}$ & $\begin{array}{l}\text { PAS, Hersteller, Käufer, } \\
\text { EVU (ungewollt), OOA }\end{array}$ & ja \\
\hline Kapitalmangel der Hersteller & \begin{tabular}{|lcr} 
Kapitalzufluss & durch & größere \\
$\begin{array}{l}\text { Unternehmen, } \\
\text { übernehmen }\end{array}$ & welche den & Markt \\
\end{tabular} & \begin{tabular}{|l} 
mittelständische \\
Unternehmen, Ölkrise
\end{tabular} & ja \\
\hline $\begin{array}{l}\text { Technische Entwicklung wird } \\
\text { durch Kontinuität des ,trail-and- } \\
\text { error'-Ansatzes bedroht }\end{array}$ & \begin{tabular}{|lll} 
Einsatz von Ingenieuren, welche \\
präzisere Methoden anwenden
\end{tabular} & $\begin{array}{l}\text { Mitarbeiter der Teststation, } \\
\text { mittelständische Hersteller }\end{array}$ & ja \\
\hline $\begin{array}{l}\text { Anlagenproduktion der Pioniere } \\
\text { hält nicht mit der Nachfrage Schritt }\end{array}$ & $\begin{array}{l}\text { Einführung der Serienproduktion durch } \\
\text { etablierte Maschinenbauunternehmen }\end{array}$ & Maschinenfabriken & ja \\
\hline $\begin{array}{l}\text { Zunehmende } \quad \text { Windanlagen- } \\
\text { Installation: } \\
\text { droht }\end{array}$ & $\begin{array}{l}\text { Profitmöglichkeiten stark reduziert } \\
\text { aufgrund moderater Förderung; DEF- } \\
\text { Regelung schließt Großinvestoren aus } \\
\text { und fördert die Bildung lokaler } \\
\text { Kooperativen; Käufer organisieren sich } \\
\text { in Kooperativen }\end{array}$ & $\begin{array}{l}\text { PAS, EVU (ungewollt), } \\
\text { Käufer }\end{array}$ & ja \\
\hline $\begin{array}{l}\text { Energiewirtschaft versucht die } \\
\text { Installation privater Kleinanlagen } \\
\text { zu verringern }\end{array}$ & $\begin{array}{l}\text { PAS zwingt EVU zur Kooperation mit } \\
\text { Windmüllern; Interessenverbände der } \\
\text { Windkraft bilden wirksame Lobby, } \\
\text { gesellschaftliches Klima zu Ungunsten } \\
\text { der EVU }\end{array}$ & $\begin{array}{l}\text { PAS, DV, FDV, Anti- } \\
\text { AKW-Bewegung, ,grüne } \\
\text { Mehrheit' im Parlament }\end{array}$ & ja \\
\hline $\begin{array}{l}\text { Technische Fehlentwicklungen } \\
\text { führen zu Stagnation }\end{array}$ & $\begin{array}{l}\text { Entscheidung für das dänische } \\
\text { Anlagenkonzept; } \\
\text { Beratung durch Risoe-Beschäftigte }\end{array}$ & $\begin{array}{l}\text { Käufer, Pioniere, } \\
\text { mittelständische Hersteller, } \\
\text { Mitarbeiter der Testanlage, } \\
\text { DV }\end{array}$ & ja \\
\hline $\begin{array}{l}\text { Distanz zwischen Windindustrie } \\
\text { und PAS erschwert Gestaltung } \\
\text { legislativer Rahmenbedingungen } \\
\text { und die Integration kleiner } \\
\text { Windkraft in die energiepolitische } \\
\text { Planung }\end{array}$ & $\begin{array}{l}\text { Teststation fördert Dialog zwischen } \\
\text { PAS und Windindustrie, Stärkung des } \\
\text { DV, positives Feedback vom Parlament; } \\
\text { Feedback durch DV und OVE, neue } \\
\text { mittelständische Hersteller stehen dem } \\
\text { PAS näher als die Pioniere }\end{array}$ & $\begin{array}{l}\text { Angestellte der Teststation } \\
\text { mit OVE-Hintergrund, } \\
\text {,grüne Mehrheit', DV, } \\
\text { mittelständische Hersteller }\end{array}$ & ja \\
\hline $\begin{array}{l}\text { Polarisierung } \text { zwischen DV und } \\
\text { FDV spaltet die Branche und } \\
\text { erschwert die Interessenvertretung } \\
\text { gegenüber EVU und Parlament }\end{array}$ & $\begin{array}{l}\text { DV erhält Unterstützung durch OVE/ } \\
\text { Risoe; Notwendigkeit der Luftbremse } \\
\text { wird zum Konsens unter den } \\
\text { Herstellern, nach } 1981 \text { sind die } \\
\begin{array}{l}\text { wesentlichen } \\
\text { behoben }\end{array} \\
\text { Kinderkrankheiten }\end{array}$ & Hersteller, OVE, Risoe & ja \\
\hline
\end{tabular}

Quellen: vg. Kap. 2.1 und 2.2 


\subsection{Periode 3: 1983-1987}

Beschleunigtes Wachstum und Erprobung in Kalifornien

(Dänemark, Kalifornien)

Innerhalb der vorherigen Perioden wurden in Dänemark sämtliche technischen, ökonomischen und administrativen Grundlagen geschaffen, um das moderate Wachstum eines Marktes für Windanlagen zu ermöglichen. Windkraft hat sich als dezentral nutzbare Energietechnik bewährt. Sie diente in erster Linie der Selbstversorgung und trug nur in geringem Umfang zur Stromversorgung bei. Es wurde dargestellt wie viele zufällige und landesspezifische Faktoren in Dänemark gegeben waren, ohne die ein solcher Erfolg undenkbar gewesen wäre.

Heute ist die Nutzung der Windenergie in vielen Industrie- und Schwellenländern eine Selbstverständlichkeit. Anfang der 80er Jahre ist diese Entwicklung nicht vorhersehbar, und Dänemark als ein internationaler Sonderfall einzustufen. Bis dahin ist die Nutzung moderner Windanlagen im wesentlichen, ein auf dieses Land begrenztes Phänomen. Die Zukunft der neuen Technologie war offen, und viele internationale Entscheidungsträger zeigten sich skeptisch. Wenn man überhaupt über Windkraft nachdachte, dann setzte man auf Großwindanlagen, anstatt auf die Ideen von Atomkraftgegnern und Handwerkern, die ihre Prototypen aus alten LKW-Teilen zusammenschusterten. Wie konnte einem dänischen Handwerker das gelingen, was internationale Forschungslaboratorien nicht $\mathrm{zu}$ Stande brachten? Wie lange hätte es dauern können, bis sich auch andere Länder für die Windkraft zu interessieren begannen? Fünf oder zwanzig Jahre? Eine Initialzündung fehlte. Der Markt musste deutlich erweitert werden. Es war zu beweisen, dass Windkraft keine Nischentechnik bleiben würde, sondern in großem Umfang eingesetzt werden konnte.

Eine solche Initialzündung bringt die Eröffnung des kalifornischen Marktes Anfang der 80er Jahre. Dort leitet die Einführung der tax credits (Förderregelungen) einen regelrechten Nachfrage-Boom ein (vg. Tab. 2.3a). Für die dänische Windindustrie war es ein glücklicher Zufall, dass die Förderung zu einem Zeitpunkt einsetzte, als die WEA bereits einen recht hohen Zuverlässigkeitsgrad erreicht hatten. Jetzt verfügten die Hersteller aus Dänemark über einen Exportmarkt mit enormen Absatzmöglichkeiten. Diese Neuerung markiert den Start der dritten Periode. Ein großes Testfeld entseht in Kalifornien, wo die neue Technologie erstmals in großem Stil erprobt wird (Erprobungsperiode).

Tab. 2.3a Windkraft in Kalifornien: Anzahl der WEA und Kapazität (MW)

\begin{tabular}{|l|l|l|l|l|}
\hline Jahr & Anzahl der WEA /Jahr & WEA-Zahl (kumuliert) & $\begin{array}{l}\text { Neue Kapazität/Jahr } \\
(\mathbf{M W})\end{array}$ & $\begin{array}{l}\text { Gesamtkapazität } \\
(\mathbf{M W})\end{array}$ \\
\hline 1981 & 150 & 150 & 10 & 10 \\
\hline 1982 & 1200 & 1350 & 60 & 70 \\
\hline 1983 & 2550 & 3900 & 170 & 240 \\
\hline 1984 & 4750 & 8650 & 377 & 617 \\
\hline 1985 & 3900 & 12550 & 398 & 911 \\
\hline 1986 & 2900 & 14600 & 275 & 1235 \\
\hline 1987 & 1350 & 15000 & 154 & 1304 \\
\hline 1988 & 560 & 13450 & 59 & 1202 \\
\hline 1989 & 490 & 13950 & 73 & 1275 \\
\hline 1990 & 1000 & 14900 & 161 & 1454 \\
\hline 1991 & 740 & 16400 & 165 & 1679 \\
\hline 1992 & 80 & 15850 & 17 & 1655 \\
\hline 1993 & 60 & 15300 & 9 & 1608 \\
\hline 1994 & 50 & 15350 & 14 & 1622 \\
\hline
\end{tabular}

Quelle: Heymann 1995, 397 Tab.5 
Hauptsächlich aktiv auf dem neuen Markt sind Hersteller aus den USA und Dänemark (neun der zehn absatzstärksten Firmen; Heymann 1995, 400). Außerhalb der beiden Länder existieren bis Mitte der 80er Jahre keine Windanlagenmärkte. Daher werden im Abschnitt zur dritten Periode ausschließlich Prozesse in Dänemark und Kalifornien beobachtet. Die Kernfrage ist dabei: Inwieweit gelingt es den Akteuren zu beweisen, dass sich Windkraft zur Stromproduktion in größerem Umfang eignet? Dabei handelt es sich offenbar um eine notwendige Vorraussetzung internationaler Diffusion einer neuen Technologie, welche im Fall der Windkraft, noch nicht erfüllt worden ist. Zwar können aufgrund der Förderung durch Staat und Föderation in Kalifornien Tausende WEA abgesetzt werden. Technisch erfolgreich sind die großen Windparks nicht, es profitierten allein die Investoren.

Wie lässt sich dieses Scheitern erklären? Ein wichtiges Charakteristikum des kalifornischen Marktes ist seine Kurzlebigkeit. Das Aufsteigen und Fallen der Nachfrage zwischen 1982 und 1987 ist ebenso untrennbar mit der Einführung, bzw. der Beendigung der tax credits verbunden wie die Exporterfolge dänischer Hersteller (vg. Tab. 2.3b). Innerhalb dieses Zeitfensters bietet sich die Chance, Windkraft als proven technology zu etablieren. Die Periode beginnt 1983 mit dem Einstieg dänischer Firmen in den kalifornischen Markt. Dieses Jahr markiert einen Quantensprung für den Export. Plötzlich übersteigt der Export den Inlandmarkt um das Sechsfache. Die Periode endet 1987 als die dänische Windindustrie, nach dem Wegfall ihres wichtigsten Marktes, in eine schwere Krise gerät.

Tab.2.3b Dänischer Export- und Inlandmarkt

\begin{tabular}{|l|l|l|l|l|l|}
\hline Jahr & $\begin{array}{l}\text { Zahl der pro Jahr } \\
\text { exportierten } \\
\text { WEA }\end{array}$ & $\begin{array}{l}\text { Zahl der pro } \begin{array}{l}\text { Jahr in DK } \\
\text { errichteten } \\
\text { WEA }\end{array} \\
\text { Dänemark in } \\
\text { (kumuliert) }\end{array}$ & $\begin{array}{l}\text { Pro Jahr in } \\
\text { DK } \\
\text { installierte } \\
\text { WE-Kapazität } \\
(\text { MW) }\end{array}$ & $\begin{array}{l}\text { Gesamtkapazität } \\
\text { (MW) }\end{array}$ \\
\hline 1980 & & 120 & 225 & 5 & 9 \\
\hline 1981 & 30 & 135 & 360 & 7 & 16 \\
\hline 1982 & 50 & 90 & 450 & 7 & 23 \\
\hline 1983 & 360 & 60 & 510 & 4 & 27 \\
\hline 1984 & 1.600 & 126 & 636 & 8 & 35 \\
\hline 1985 & 3.000 & 326 & 962 & 25 & 60 \\
\hline 1986 & 2.000 & 358 & 1.320 & 30 & 90 \\
\hline 1987 & 753 & 311 & 1.631 & 25 & 115 \\
\hline 1988 & 55 & 557 & 2.188 & 82 & 197 \\
\hline 1989 & & 469 & 2.657 & 93 & 263 \\
\hline 1990 & & 332 & 2.989 & 80 & 343 \\
\hline 1991 & & 345 & 3.334 & 70 & 413 \\
\hline
\end{tabular}

Quellen: Heymann: 1995, 406 Tab. 10; Heyman 1998; Heymann 1995, 407; 417

Weshalb eigentlich ist die Windtechnologie für Kalifornien interessant? Handelte es sich um einen ebensolchen Sonderfall wie die Marktentwicklung Dänemarks?

Um die Situation auf dem kalifornischen Windmarkt zu verstehen ist es erforderlich, sich mit dessen Entstehungsbedingungen zu befassen, die zeitlich in die Perioden 1 und 2 fallen. Daher ist ein zusammenfassender Rückgriff auf die vorherigen Entwicklungen notwendig, obgleich in Kalifornien keine Innovationen von internationaler Tragweite geschaffen wurden. Um Diffusionschancen und den Pioniercharakter technologischer, ökonomischer, politischer und sozialer Innovationen genauer zu bewerten, ist die Frage wesentlich, weshalb in Kalifornien nicht stärker auf die Erfahrungen aus Dänemark gesetzt wurde. 


\subsubsection{Kalifornien in Periode 3}

In den USA, insbesondere Kalifornien, wurden Märkte für erneuerbare Energien bereits seit 1978, bzw. 1980 von der Nachfrageseite her gefördert. Hohe Energiepreise und langfristig drohende Ressourcenknappheit sind die wichtigsten Gründe des Interesses der nationalen Regierung an erneuerbare Energien. ${ }^{185}$ Vor allem um die Ölabhängigkeit zu reduzieren, beschloss die Carter-Administration den am 9. November 1978 in Kraft getretenen National Energy Act (NEA).

Der NEA stellte für den monopolisierten Energiemarkt eine enorme Neuerung dar. Jetzt wurde privaten Stromproduzenten erstmals der Zugang zum Netz ermöglicht. Zwei Teile des Gesetzespaketes, Public Utilities Regulatory Policies Act (PURPA) und Energy Tax Act (ETA) sind für die Windkraftnutzung Kaliforniens besonders wichtig. ETA gewährte Steuerabschreibungen von zunächst 20\%, ab 1980 sogar 25\% bei Investitionen in WEA sowie andere Kraftwerke zur Nutzung erneuerbarer Energie und Kraft-Wärme-Kopplung (Heymann 1995, 393). ${ }^{186}$ Das PURPA verpflichtete die Energiekonzerne, Strom aus kleinen Kraftwerke (maximal 30MW), welche von unabhängigen Akteuren betrieben werden, sogenannten Qualifying Facilities (QF), in ihr Netz einzuspeisen und zu ,fairen Preisen', in Höhe vermiedener Kosten zu vergüten. ${ }^{187}$

In den Augen der EVU ist die Regelung, dass sie den Strom selbst bei hinreichender Kraftwerksleistung einspeisen mussten, ein besonderes Ärgernis. Etliche Versorger zogen gegen das PURPA vor Gericht. In Mississippi und Columbia wurden ihre Anfechtungen bestätigt und das Inkrafttreten des Gesetzes bis 1982 verhindert, als die Urteile vom Supreme Court aufgehoben wurden (ebd., 394).

Im damaligen Elektrizitätsmarkt bedeutete das PURPA eine kleine Revolution gegen die Monopolmacht der EVU. Das Gesetz verlieh den QF eine rechtliche Handhabe in der ungleichen Auseinandersetzung mit den Netzbetreibern. Mit der Garantie des Marktzugangs (NEA), den Steuerabschreibungen (ETA) und der Einspeisungs- und Vergütungspflicht in Höhe vermiedener Kosten (PURPA) waren die gesetzlichen Grundlagen geschaffen, um eine Dezentralisierung und Entmonopolarisierung des Stromsektors zu erwirken und Märkte für erneuerbare Energien zu etablieren.

Das Energieproblem ist in Kalifornien besonders ausgeprägt. Um dem prognostizierten Wachstum des Energiebedarfs gerecht zu werden, gab Präsident Carter 1978 bekannt, dass er in dem Bundesstaat bis zum Jahr 2000 insgesamt 32 Atomkraftwerke bauen lassen wollte (van Est 1999, 37). Bereits seit 1976 führten Umwelt- und Verbraucherschutzgruppen AntiAtom-Kampagnen durch, die sich u.a. auf das Problem radioaktiver Abfälle und die Gefahr von Sabotageakten bezogen (ebd., 33). Die Pläne Carters, Kernkraftwerke an den erdbebengefährdeten Küstenbereichen Kaliforniens aufzustellen, gaben den Protesten einen weiteren Schub. Diese Widerstände haben zur Erhöhung des ohnehin großen bürokratischen

\footnotetext{
${ }^{185}$ Unabhängig von den Prozessen, die sich auf der Bühne politischer Entscheidungen zutrugen fanden immer wieder kleine Scharmützel zwischen ,Rebellen', die ihren eigenen Strom produzieren wollen und EVU statt, welche dieses zu verhindern suchten. Righter (1996, 185ff.) nennt das Beispiel einer New Yorker Nachbarschaftsgemeinde, die ein kleines 2kW-Windrad auf ihrem Dach installierte und dadurch in Konflikt mit Con. Ed, dem zuständigen Versorgungsunternehmen, geriet. Schließlich unterlag Con. Ed und musste den Windstrom in sein Netz speisen. Bemerkenswert ist das mediale Echo, das diesem Fall zuteil wurde. So war auf der Titelseite der New York Times vom 6. Mai 1977 zu lesen: ,State tells Con Ed to buy 2 Kilowatts - From a Windmill' (zitiert nach: ebd, 186). Senator Edward Kennedy nahm das Ereignis zur Kenntnis: ,the little windmill that could' (zitiert nach: ebd, 188).

${ }^{186}$ Diese 25 Prozent setzen sich zusammen aus federal investment tax credit (10\%) und federal business energy investment tax credit in Höhe von 15\% (Wiser/ Kahn 1996, 49).

${ }^{187}$ Über die Frage der Höhe dieser Kosten bestand ein permanenter Dissens zwischen EVU und den QF (vg. Righter 1996, 199 und 220f.). Festgelegt wurde die Vergütungshöhe durch bundesstaatliche Regulierungsbehörden (Heymann 1995, 395).
} 
Aufwands beigetragen, der erforderlich war, um eine Baugenehmigung zu erlangen. Weitere Skepsis schürte der Unfall im Kernkraftwerk von Harrisburg im Jahr 1979.

Unter den möglichen Alternativen schien besonders die Windkraft für Kalifornien geeignet. Die Gebiete entlang der Gebirgswüstenpässe, wiesen zahlreiche potenzielle Standorte auf. Die Pässe wirken als Windkanäle von denen die warme Küstenluft quasi angesaugt wird. Das Land ist weitestgehend unbewohnt und wird teilweise landwirtschaftlich genutzt. Für Windanlagenbetreiber waren die meisten Standorte daher leicht zugänglich. Ein wichtiger Unterschied zum dänischen Markt besteht darin, dass der Impuls zur Marktöffnung in Kalifornien nicht aus der Zivilgesellschaft kam, sondern durch staatliche und föderale Maßnahmen.

\subsubsection{Kalifornien: Das politisch-administrative System in Periode 3}

Der von 1975 bis 1983 amtierende Gouverneur Kaliforniens, Edmund G. Brown, war ein Fürsprecher regenerativer Energien. Nachdem die Pläne zum Bau der Atomkraftwerke zunächst von der California Energy Commission (CEC) genehmigt wurden, reagierte der Gouverneur auf Proteste der Anti-AKW-Bewegung und Beschwerden der Anrainer. Die geplanten Atomreaktoren sollten durch erneuerbare Energien überflüssig gemacht und Strompreise gesenkt werden. Zudem stand die Verringerung der Öl- und Gasabhängigkeit auf der energiepolitischen Agenda Browns. Hoffnungsträger des Gouverneurs war die Windkraft, welche bis zum Jahr 2000 einen Anteil von zehn Prozent an der kalifornischen Stromversorgung erreichen sollte. ${ }^{188}$

Die Realisierung der Ideen Browns setzten einen deutlichen Pfadwechsel der Energiepolitik voraus. In der Administration galt noch immer das grow-and-built-Paradigma, dass auf der Nutzung konventioneller Energieträger und Atomkraft basierte. Seit dem Beginn seiner Amtszeit nahm Brown grundlegende Umstrukturierungen der Administration und personelle Neubesetzungen vor. 1976 gründete er das Office for Appropriate Technology (OAT) ${ }^{189}$, dass für die Entwicklung kleiner WEA zuständig war. Darüber hinaus berief er Fürsprecher regenerativer Energien in die CEC und die California Public Utilities Commission (CPUC), um deren Ausrichtung zu modifizieren (van Est 1999, 35). Jan Hamrin erinnert sich an folgende Worte Browns, die er an die neuen Mitarbeiter seiner Administration richtete und durch die der innovative Politikstil des Gouverneurs auf den Punkt gebracht wird:

,I want you to try something new. Whatever we have been doing hasn't worked that well. If you can think of some new way to do something, try it. That's what I want in my Administration. I want people to try new things.' (zitiert nach: van Est 1999, 35)

Brown umgab sich mit,whiz kids, Ph.D. progressive types', die nun eine Gelegenheit bekamen, ihre Ideen zu realisieren. Solche wurden in Kalifornien schneller aufgegriffen als anderswo. Aufgrund positiver Erfahrungen mit technischen Neuentwicklungen dominiert in der kalifornischen Gesellschaft eine aufgeschlossene Haltung. ${ }^{190}$,Sacramento just became a hot-bed of renewable energy ideas' (Righter 1996, 196).

\footnotetext{
${ }^{188} 1980$ äußerte sich Brown in einer Broschüre der California Energy Commission (CEC):

,Energy from the wind is nondepletable, nonpolluting, and abundant. Wind energy is a good investment, and will conserve our limited nonrenewable resources. California has established a goal that 10 percent of the state's electricity come from wind generation by the year 2000, saving 40 million barrels of oil per year.' (zitiert nach: Heymann 1995, 395).

${ }^{189}$ Die Gründung des OAT kann als der Versuch der Institutionalisierung der Appropriate Technologie Bewegung interpretiert werden. Diese stellt das in der US-amerikanischen Gesellschaft tief verankerte Wachstumsdenken in Frage (van Est 1999, 42).

${ }^{190}$,Modern physics is built upon the pioneerung work at the University of California. Apollo, and the author's beloved microcomputer, all bear the ,Made in California' stamp.' (van Est 1999, 17); ,California is the science center of this planet.' (Georges B. Leonard 1962, 30; zitiert nach: van Est 1999, 17)
} 
Kalifornien verfügte also nicht nur geografisch, sondern auch gesellschaftlich und politisch über optimale Ausgangsbedingungen für Experimente zur Etablierung einer neuen Technologie wie der Windkraft.

Was spricht aus Sicht des Jahres 1980, angesichts dieser Bedingungen gegen die Annahme, dass man in Kalifornien bald ebenso so gute und vielleicht bessere WEA produzieren würde als in Dänemark? Tausende US-Windanlagen würden exportiert und die Windenergie schon nach kurzer Zeit als proven technology gelten. Der tatsächliche Verlauf ist ein anderer, denn die US-Windindustrie scheiterte daran, ausgereifte und zuverlässige WEA zu entwickeln.

,1981 standen die meisten Anlagen aus technischen Gründen etwa die Hälfte der Zeit still, die besten liefen 60\% der Zeit, die schlechteren kaum 10\%, einige gingen nie in Betrieb. Viele Anlagen scheiterten bereits kurz nach ihrer Inbetriebnahme an technischen Defekten oder Totalschäden...Nur ein Drittel der in den 80er Jahren in Kalifornien installierten Anlagen waren erfolgreich.' (Heymann 1995, 399) ${ }^{191}$

Wie war es möglich, dass solche Produkte serienweise produziert und staatlich gefördert worden sind? Zur Klärung dieser Frage ist es wichtig, die Funktionsweise des USFördersystems zu verstehen. Zusätzlich zu den föderalen tax credits beschloss die BrownAdministration 1978 weitere Abschreibungsmöglichkeiten für den Kauf regenerativer und dezentraler Kraftwerke wie Windturbinen. ${ }^{192}$ Seit 1980 addierten sich die Abschreibungen damit auf 50 Prozent der Investition (Heymann 1995, 395). Seitens der California Public Utility Commission (CPUC) wurden die vermiedenen Kosten im Interesse der Windanlagenbetreiber auf eine Höhe von \$0,07 pro Kilowattstunde definiert (Heymann 1995, 395). In Washington, Oregon, Idaho und weiteren Staaten des mittleren Westens lag der Preis nur bei $\$ 0,01$ bis $\$ 0,02$ je Kilowattstunde (Righter 1996, 204). Trotz zusätzlicher Abschreibemöglichkeiten, die auch von anderen Bundesstaaten eingeführt wurden, etablierte sich die Windkraft nur in Kalifornien. Weder die Förderhöhe, noch die Gesamtkombination diverser relevanter Faktoren eines anderen Bundesstaates reichte an die kalifornischen Ausgangsbedingungen heran. ${ }^{193}$

In Kalifornien wurden die höchsten Kilowattstundenpreise gezahlt. Doch auf diesen ,ExtraBonus' waren die Käufer gar nicht angewiesen. Denn für sie lohnte sich eine solche Investition allein aufgrund der tax credits, was durch das folgende Beispiel veranschaulicht wird: Bei einer Investition von $\$ 150.000$ erhielt man bereits nach einem Jahr $\$ 75.000$ an eingesparten Steuern zurück. Hinzu kamen durchschnittlich \$12.000 an jährlichen Einnahmen aus dem Stromverkauf, die als reine Profite angesehen werden können (van Est 1999, 304 Fußnote 69). Sollten die WEA ihre prognostizierte Lebensdauer von 15 Jahren erreichen, erhielt der Investor allein aus den Abschreibungen eine Rendite von 137,8\% (Righter 1996, 218).

Als der NEA 1978 verabschiedet wurde, existiert in Kalifornien mit dem Private Energy Producer Act bereits eine Einspeiseregelung. Dieses Gesetz verpflichtete die Netzbetreiber jedoch nur zur Abnahme von Strom in Höhe des Eigenverbrauchs. Dem PURPA zufolge musste jede beliebige Energiemenge abgekauft werden (ebd., 44f.). Damit war der Weg für den Markteintritt von Investorgruppen geebnet. Das OAT war darum bemüht, auch Kommunen und Einzelkäufer zum Kauf von Windanlagen zu ermutigen. 1979 gab das OAT eine Broschüre heraus, die sich vor allem an diese Käufergruppen richtete. Neben technischen Fragen wurden auch rechtliche, wirtschaftliche und soziale Belange erörtert. In erster Linie wahrgenommen wurde die Broschüre allerdings nicht von diesen Adressaten, sondern von Unternehmen, die Windkraftwerke vor allem zu kommerziellen Zwecken erwerben wollten (ebd., 43). Als die Förderung um Mitte der 80er Jahre stark reduziert wurde und die

\footnotetext{
${ }^{191}$ Zum technischen Stand vg. auch: Gipe 1995, 474f. und van Est 1999, 304 F65

${ }^{192}$ Auch andere Bundesstaaten hatten zusätzliche tax credits verabschiedet, bspw. Arkansas, Hawaii, North Dakota, Ohio und Oklahoma (Righter 1996, 205). Righter (ebd.) zufolge stießen die Initiativen deshalb bei den Investoren auf keinerlei Resonanz, weil dort keine Forschungsergebnisse über regionalen Windresourcen zur Verfügung standen. In Kalifornien dagegen hatte die California Energy Commission bereits 1977 einen Windatlas erstellt (Gipe 1995, 28).

${ }^{193}$ Zur damaligen Situation in Minnesota und Hawaii vg.: Righter 1995; WPM 8/86, 19f.; WPM 11/86, $19 f$.
} 
Energiepreise sanken, bricht der kalifornische Markt zusammen. ${ }^{194}$ Ende 1985 liefen sowohl der federal energy tax credit, als auch der federal investment tax credit aus. Zudem wurde 1986 der kalifornische tax credit auf 15\% reduziert, so dass sich Investitionen in Windkraft nicht mehr lohnten (Gipe 1995, 35).

\section{Zentrale Schwächen des kalifornischen Fördersystems}

Der wichtigste Grund zur Erklärung der Misere des kalifornischen Windmarktes und insbesondere der kalifornischen Windindustrie besteht darin, dass es den Anlagenkäufern ermöglicht wurde, in mangelhafte Anlagentechnik gewinnbringend $\mathrm{zu}$ investieren. Ob und wie viel Strom eine Windanlage produzierte war für die Höhe der Einnahmen zweitrangig. Wichtig war vor allem die Höhe der Investition: je höher die Investition, desto höher die tax credits. Windkraftpionier Paul Gipe berichtet in einem Interview mit Rinie van Est $(1999,305$ F82) von der Inspektion einer WEA:

,I went to one windmill in Tehachapi. I climbed at the top and there was nothing inside it! It had a big bolt that came out in front that had a big peace of wood on it...It was advertised in all the alternative energy magazines.'

Solche Auswüchse hätten durch die Wahl eines anderen Fördersystems vermieden werden können. Sinnvoller gewesen wäre es, weniger die Investition an sich, als vielmehr die produzierte Energie zu subventionieren. Auch obligatorische Zertifikationsverfahren wären hilfreich gewesen. Es war viel zu einfach, tax credits zu erlangen. Angeblich plante die Brown-Administration bereits 1978 die Einführung eines Prüfverfahrens zum Schutz der Käufer vor unseriösen Anbietern. Ein entsprechendes Verfahren für Solaranlagen war bereits vorhanden. Für die Windkraft sei eine solche Regelung deshalb zunächst ausgeblieben, weil die Nachfrage stark unterschätzt wurde (van Est 1999, 53).

Zwar existierte eine Forschungs- und Teststation für kleine Windanlagen in Rocky Flats. Eine Bedeutung, die annähernd mit Risoe vergleichbar gewesen wäre, erlangte das National Renewable Energy Laboratory (NREL) zu keiner Zeit. Für die Zwecke der Fragestellung genügt es, einige wichtige Charakteristika der Arbeit des NREL zusammenzufassen und sie mit der dänischen Teststation zu vergleichen. Zunächst war das NREL kaum auf die Zusammenarbeit mit kommerziellen Herstellern ausgerichtet. In erster Linie arbeitete es mit den Konzernen zusammen, deren Aktivitäten das Energieministerium bspw. im Rahmen des Mod-Programms ohnehin unterstützte. Garud/ Karnoe (2003, 292) kritisieren die Verschleppung von Testergebnissen, mangelnde Systematik und Informativität sowie die Tatsache, dass das NREL hinter der technischen Entwicklung zurückblieb:

,The weak linkage between the SERI/NREL and industry was especially noticeable in the lack of a systematic testing program for commercial turbines. There were tests conducted, but the first reports were delayed by several years. Nor were the reports themselves very informative. Tests, when conducted at all, tended to be done using small older machines, with no follow-up using full-scale newer ones. For example, in 1992, the largest turbine at the test site was a small $20 \mathrm{~kW}, 12$-year-old machine.'

Das NREL war offensichtlich kaum an Modellen interessiert, deren Hersteller nicht dem LSPUmfeld entstammten. Ansonsten hätte das NREL spätestens 1984-85, nachdem in Kalifornien Tausende mittelgroße WEA von unabhängigen Herstellern verkauft wurden, von seiner bisherigen Orientierung abrücken müssen. Für kommerzielle Hersteller wie Zond stand fest, dass sie auf die Unterstützung des NREL nicht zählen konnten. Entsprechend äußerte sich Kevin Cousineau, ein Sprecher der Firma: ,When we need blades, we built our own (rather then wait for NREL)...When NREL decided to build a strain gauge test, we'd had ours in operation for several years.' (zitiert nach: Gipe 1995, 92).

${ }^{194}$ Näheres zu den Hintergründen des abrupten Abbruchs der Förderung: vg. Righter (1996, 215f.). Die Beendigung der tax credits hat innerhalb der Republikaner zu Spannungen geführt. In Zeiten hoher Erwerbslosigkeit arbeiteten etwa 20.000 Kalifornier in der Wind- und Solarbranche, wo Umsätze von \$100 Mio. erwirtschaftet wurden (van Est 1999, 55). Ein Grund der Reduktion der tax credits in Kalifornien ist die Haltung des neuen republikanischen Gouverneurs zu erneuerbaren Energien. Deukmejian, der Nachfolger Browns, hielt die Förderung alternativer Energien für wachstumsschädlich. Aus demselben Grund löste er das von Brown eingeführte OAT auf (ebd., 126). Nicht zuletzt ist das Versagen der US-Windindustrie als ein Grund der Abkehr von der Windkraftförderung zu bewerten. 
Eine wichtige Erfolgsvoraussetzung von Risoe ist der vorsichtige Umgang mit technischen Details, welche an die Teststation weitergegeben wurden. Anders im NREL: 1980 verließen einige Mitarbeiter das Labor. Auf Basis des Know-hows, dass sie bei den Testaktivitäten erworben hatten, gründeten sie die Firma Energy Scieces Incorporated (ESI) und produzierten selbst Windanlagen., Well informed about the state of art wind turbine technology and acquainted with the market demand for larger turbines, the former public servants developed the biggist machine of the day, the 50kW version of the ESI-54.' (van Est 1999, 304). Dieser eine Fall genügte, um das Misstrauen der Industrie gegenüber dem NREL zu schüren. ${ }^{195}$

Das Fördersystem unterstützte nicht nur ineffiziente Windturbinentechnik. Es bot auch keine Anreize, die Anlagen instand zu halten. Viele WEA blieben über Monate außer Funktion, obgleich nur geringfügige Defekte aufgetreten waren. Der Windpark von Cabazon am San Gorgonio Pass war bis 1988 weitestgehend außer Funktion. Righter $(1996,171)$ zufolge wird Cabazon beschrieben als , an eyesore of broken and twisted blades just off I-10 about ten miles east of Palm Springs.'

Die aktuelle Funktionsfähigkeit musste vom Betreiber kaum nachgewiesen werden. Durch kontinuierliche Prüfungen hätte leicht verhindert werden können, dass tax credits für Windanlagen gewährt wurden, die seit geraumer Zeit stillstanden. Erst 1984 wurden die Betreiber von WEA mit insgesamt mehr als $100 \mathrm{~kW}$ verpflichtet, die CEC vierteljährlich über den Funktionsstatus der Anlagen in Kenntnis zu setzen (van Est 1999, 304 Fußnote 71).

Es fragt sich, weshalb ein offensichtliche Mängel wie fehlende Meldepflicht über Jahre hin nicht korrigiert, die Meldepflicht erst 1984 eingeführt wird. Van Est zufolge (1999, 53) befürchteten die Fürsprecher des Gesetzes, ,schlafende Hunde zu wecken': ,The fact that proponents, for fear of its abolishment, were kept from raising this matter, prevented improvement of the tax credit program.'

Eine weitere eklatante Schwäche des Fördersystems besteht in fehlender Kontinuität. 1980, als in Kalifornien die tax credits eingeführt wurden, existierte außerhalb von Dänemark kein Unternehmen, dass mittelgroße WEA herzustellen vermochte. Infolge des Marktrückgangs mussten die meisten Hersteller zu einem Zeitpunkt Konkurs anmelden, als sich entsprechende Lernprozesse noch im Anfangsstadium befanden. Die folgende Tabelle 2.3.1a fasst die wichtigsten Charakteristika des kalifornischen und dänischen Fördersystems zusammen.

Tabelle 2.3.1a Förderung privater Windkraft in Kalifornien und Dänemark

\begin{tabular}{|l|l|l|}
\hline & Kalifornien & Dänemark \\
\hline Einnahmen der Betreiber & profitabel & Senkung von Stromkosten möglich \\
\hline $\begin{array}{l}\text { Technischer Status quo beim Start der } \\
\text { Förderung }\end{array}$ & $\begin{array}{l}\text { Industrie ist noch nicht in der Lage, } \\
\text { zuverlässige Windturbinen herzustellen }\end{array}$ & $\begin{array}{l}\text { seit 1980/81: Herstellung von 55kW- } \\
\text { Windanlagen mit guter Zuverlässigkeit }\end{array}$ \\
\hline Adressaten & wohlhabende Investoren & $\begin{array}{l}\text { Privatpersonen, die ihre Stromkosten } \\
\text { reduzieren wollten }\end{array}$ \\
\hline Teststation & $\begin{array}{l}\text { NREL ist nicht auf Zusammenarbeit mit } \\
\text { unabhängigen Herstellern mittelgroßer } \\
\text { Turbinen orientiert; NREL hält nicht mit } \\
\text { der technischen Entwicklung Schritt. }\end{array}$ & $\begin{array}{l}\text { Risoe leistete wichtige Beiträge zur } \\
\text { technischen Weiterentwicklung und } \\
\text { arbeitete erfolgreich mit den Herstellern } \\
\text { zusammen }\end{array}$ \\
\hline $\begin{array}{l}\text { ja nicht } \\
\text { Kontinuierliche Förderung? }\end{array}$ & $\begin{array}{l}\text { Keine Kontrolle notwendig: Betreiber } \\
\text { hatten aufgrund der Erlöse aus der } \\
\text { Funktionsstatus? } \\
\text { ntromeinspeisung großes Interesse an } \\
\text { der Funktionsfähigkeit ihrer Windmühle }\end{array}$ \\
\hline
\end{tabular}

Quellen: vg. Kap. 2.2 und 2.3

In jedem Punkt, in dem sich das kalifornische Fördermodell von Dänemark unterschied, führten diese Abweichungen eher zur Entstehung neuer Barrieren, als dass Probleme gelöst wurden. Unabhängig von der Veränderung äußerer Bedingungen wie fallender Energiepreise

\footnotetext{
1951986 war ESI das Unternehmen mit dem siebtgrößten Marktanteil, also kommerziell sehr erfolgreich. Die Tatsache, dass ESI-Anlagen technisch weitestgehend versagten (durchschnittlicher Kapazitätsfaktor von sechs Prozent, bis einschließlich 1986, (Heymann 1995, 400) ) dürfte dem Unmut der Konkurrenz keinen Abbruch getan haben.
} 
und der Regierungsübernahme durch die Republikaner, erscheint es, insbesondere vor dem Hintergrund der Bewährung des dänischen Modells offensichtlich, dass ein Fördersystem mit so eklatanten Schwächen nicht langfristig aufrechterhalten werden konnte.

\subsubsection{US-Windanlagenindustrie in Periode 3}

In den 70er Jahren krankt die Weiterentwicklung der Technologie an mangelnder Nachfrage. Der Absatz der US-Hersteller war so gering, dass die Mittel nicht einmal ausreichten, um Neuerungen zu realisieren, die mit hoher Wahrscheinlichkeit zu großen Fortschritten geführt hätten. Produziert wurden vor allem kleine WEA bis $20 \mathrm{~kW}$. Die wenigen größeren Modelle, die auf dem Markt angeboten werden, sind nicht nur unzuverlässig und kurzlebig, sondern auch überteuert (van Est 1999, 53). Solche mittelgroßen Anlagen ab 50kW sind es zugleich, die seit 1980/81 auf dem kalifornischen Markt hauptsächlich nachgefragt werden. Entsprechend wenig Zeit ließen sich die meisten Firmen mit der Entwicklung solcher Produkte, die bereits nach wenigen Tests auf den Markt gebracht wurden (Heymann 1995, 397). Den meisten Unternehmen fehlte es an Know-how, insbesondere was die Serienproduktion betrifft. Um an dem Windenergie-Boom teilzuhaben, starteten viele Unternehmen die Windanlagenfertigung erst 1982 und später, als der Markt schon großteils gesättigt schien. (van Est 1999, 52). Wie selbstverständlich verwendeten sie dabei neue Werkstoffe (z.B. Rotoren aus Fiberglas) und riskante Gestaltungselemente: Leichtbauweise zur Erhöhung der Effizienz, flexible Türme und hohe Schnellläufigkeit (ebd., 54). Technischen Anforderungen werden unterschätzt und die Zuverlässigkeit der meisten Produkte erwies sich als äußerst gering. ${ }^{196}$

US-Windpower ist der Pionier unter den US-Herstellern und zugleich absatzstärkstes Unternehmen auf dem kalifornischen Markt. Unter den Anbietern verfügt der Hersteller über die größten finanziellen Ressourcen. Selbst US-Windpower gelang erst Ende 1983, nach einer langen Serie technischer Fehlschläge, ${ }^{197}$ die Herstellung der ersten zuverlässigen mittelgroßen WEA, die 56-100 (56 Fuß Rotordurchmesser, 100kW-Generator; (van Est 1999, 51). Erst allmählich ziehen die übrigen Produzenten nach, und es setzt sich ein langsamer Reifungsprozess in Gang.

Zwar erhöht sich der Kapazitätsfaktor zwischen 1983 und 1988 von acht auf 17\% (Heymann 1995, 399 Tabelle 6). Dennoch ist die von Heymann (ebd.) gezogene Bilanz der kalifornischen Windindustrie ernüchternd:

,Bis 1988 waren etwa 8\% aller installierten Anlagen Totalausfälle, bei denen Abbau und Verschrottung billiger kamen als eine Reparatur. 60\% aller Anlagen erforderten z.T. umfangreiche Reparaturen mit Kosten zwischen $\$ 1.000$ und $\$ 35.000$ pro Anlage. ${ }^{\prime 198}$

Die Verbesserung ist zu weiten Teilen auf dänische Importprodukte zurückzuführen:

,Im Herbst 1985 waren von insgesamt 8.460 Anlagen nur 4.400 betriebsbereit. Von 1.976 dänischen Anlagen waren hingegen 1.932 betriebsbereit. Während dänische Anlagen also zu $98 \%$ betrieben werden konnten, waren es nur 38\% bei allen übrigen Anlagen...Im Durchschnitt erreichten im Jahr 1986 alle ausländischen Anlagen (überwiegend aus Dänemark stammend) einen Kapazitätsfaktor von 17\%, während alle amerikanischen Anlagen lediglich auf 10\% kamen'. (Heymann 1995, 400f.)

\footnotetext{
${ }^{196}$ Die Erfahrungen von Zond Systems veranschaulichen den Stand der US-Windanlagentechnik am Anfang der 80er Jahre. 1981 kommt es unmittelbar nach Betriebsaufnahme zu einem Totalausfall sämtlicher Prototypen der neuen 40kW-Klasse des Herstellers (van Est 1999, 304). ,The turbines had a coupler between the gearbox and the generator. When they energized them, the coupler flew off the turbine.' (Paul Gipe, zitiert nach: van Est 1999, 304).

${ }^{197}$ Das Unternehmen produzierte bis dahin mehr als 700 Turbinen. Erst die sechste Modifikation der ursprünglichen Anlage genügten den Anforderungen an Zuverlässigkeit und Lebensdauer (van Est 1999, 51).

${ }^{198}$ Der Kapazitätsfaktor der Windturbinen von Fayette, dem Unternehmen, das 1986 über den drittgrößten Marktanteil verfügte, erreichte sogar nur fünf Prozent (Heymann 1995, 400).
} 
Es sind bereits einige Ursachen der Unzulänglichkeit der US-Windtechnologie aufgezeigt worden, an denen die Gesetzgebung maßgeblich Anteil hatte. Im folgenden werden weitere Probleme dargelegt, die nur teilweise, bzw. indirekt aus der Gesetzgebung resultieren.

Mangelnde Transparenz des Marktes Die Förderregelung enthält keinerlei Verpflichtung, die Anlage prüfen zu lassen. Erst seit 1984 wird gefordert, die CEC regelmäßig über Output und Zuverlässigkeit der Maschinen in Kenntnis zu setzen. Aufgrund dieser Situation fiel es den ,schwarzen Schafen' ${ }^{199}$ unter den Anbietern, die wissentlich mangelhafte Windanlagen auf den Markt gebracht hatten relativ leicht, unerkannt zu bleiben. Die Hersteller, deren Marktstrategie auf kurzfristige Gewinne ausgerichtet war, hatten kein Interesse an verbesserter Transparenz (van Est 1999, 53). Während auf dem dänischen Markt ein offener Umgang mit technischen Daten wie Output und Geräuschemissionen üblich war, bemühten sich viele US-Amerikaner, solche ,Geheimnisse', die es laut Gesetz nicht geben durfte, für sich zu bewahren ${ }^{200}$

Dadurch, dass der Gesetzgeber solche Verhaltensweisen duldete, schürte er technologische Stagnation, was den Herstellern die fatale Option zur Ignoranz struktureller Design-Fehler ermöglichte. Weil ein Käufer mangels Informationen nicht zwischen guter und weniger guter Anlagentechnik unterscheiden konnte, wurde verunmöglicht, dass der Markt hätte ausgleichen können, was die Gesetze nicht zu leisten vermochten: die Förderung der Konkurrenz um die effizienteste Windturbine. Mit US-Windpower und ESI gaben zwei der wichtigsten Fabrikanten an, dass sie ihre Mittel weniger in technische Entwicklung, sondern vor allem in die Kostensenkung bereits existierender Modelle investieren würden (Garud/ Karnoe 2003, 287). Angesichts der guten Auftragslage genügte es den Herstellern, sich ausschließlich mit den dringendsten Problemen zu beschäftigen. Die Lösung struktureller Design-Schwächen wurde auf die Zukunft verschoben. In der damaligen Situation habe man dieses als zu zeitaufwendig wahrgenommen (van Est 1999, 54). Auch seitens der Projektentwickler blieben entsprechende Impulse aus: ,Since ignorant wind farm developers did not have the expertise to value proper solutions, structural solutions did not directly lead to more profit.' (van Est 1999, 54).

Diese Inkompetenz und das Desinteresse der Entwickler führte zu einem Mangel an Feedback an die Hersteller. Die Relevanz des Betreiber-Feedbacks für den dänischen Markt ist aufgezeigt worden. Für die Windmüller aus Dänemark war es selbstverständlich, dass sie Fehler unverzüglich an den Produzenten weiterleiteten. Ihnen ging es sowohl darum, Windkraft als alternative Energie zu fördern, als auch ihre Stromkosten zu minimieren. Für beiden Ziele war es hilfreich, dass die Windanlage so gut wie möglich funktionierte. Solche Windmüller sind auf dem kalifornischen Markt eher die Ausnahme. Zusätzlich erschwert wird der Austausch zwischen Hersteller und Betreiber durch zweierlei. Zum einen befanden sich die Produktionsstätten der Hersteller oft weit von den Turbinenstandorten entfernt, so dass es mit ,one hours' driving' ${ }^{201}$ selten getan war. Zum anderen bestand häufig eine große Distanz zwischen dem Wohnort des eigentlichen Besitzers und dem Standort seiner Windanlage/n (vg. Garud/ Karnoe 2003, 288).

Unter den US-Herstellern herrschte seit Öffnung des kalifornischen Marktes eine hohe Konkurrenz. Unzureichende Transparenz ermöglichte es vielen Produzenten, mangelhafte Produkte anzubieten. Einige Hersteller befürchteten, dass ihr Know-how der Konkurrenz bekannt werden könnte. Bei US-Windpower ging diese Angst so weit, dass man den

\footnotetext{
${ }^{199}$ Bei ihnen dürfte es sich in den ersten Jahren um der Mehrheit der Hersteller gehandelt haben.

${ }^{200}$,For example, European manufacturers typically publish estimates of the annual generation they expect from their turbines in various wind regimes. One U.S. manufacturer so jealously guards this data that they withhold it from the California Energy Commission's performance reporting system even though they are required by law to comply. European manufacturers also openly list the expected noise emissions from their products in a standardized format for ready comparison. Few U.S. companies publish noise data, and none report it in a standardized format.' (Gipe 1995, 88)

${ }^{201}$ Maegaard riet den Anlagenherstellern, keine Windanlagen an Kunden zu verkaufen, die weiter als eine Autostunde entfernt lebten (Interview vom 2.7. 2007).
} 
Anlagendesignern verbot, mit Ingenieuren anderer Hersteller zu sprechen (Garud/ Karnoe 2003, 287). Anders als in Dänemark entstanden in der US-amerikanischen Windindustrie keine Netzwerke zwischen Anlagendesignern, Produzenten und Zulieferern (ebd., 284). In Kalifornien existierten bspw. keine unabhängigen Rotorenhersteller und die meisten Unternehmen entwickelten ihre Rotoren selbst (www.windsofchange.dk, Abruf vom 2.4.2008). Ein weiteres Resultat der hohen Konkurrenz auf dem kalifornischen Markt besteht in Versuchen der Hersteller, möglichst große Turbinen $\mathrm{zu}$ produzieren. Diese wurden besonders stark nachgefragt, weil sich die Projektentwickler Skaleneffekte und damit erhöhte Gewinnspannen versprachen. Philip J. DiVirgilio von Zond Systems verweist auf - pro Kilowatt betrachtet - geringere Inspektions- und Wartungskosten, sowie Investitionen, die aufgrund der Schaffung erforderlicher Infrastruktur wie Netzanbindung und Zufahrtsstraßen fällig würden (vg. van Est 1999, 303 Fußnote 62). Noch verschärft wird die Konkurrenz nach dem Eintritt dänischer Unternehmen, welche den US-Herstellern Jahr um Jahr Marktanteile abnahmen. Die Inländer versuchten ihren technischen Rückstand zu kompensieren, indem sie möglichst leistungsstarke Modelle auf den Markt brachten, um die europäische Konkurrenz auf diese Weise zu übertrumpfen. Unter dänischen Herstellern etablierte sich die 100kWKlasse erst im Jahr 1986. Ausgehend von der seit 1980/81 üblich gewordenen 55kWWindanlage unternahmen viele Produzenten noch einen Zwischenschritt, in dem sie 75$80 \mathrm{~kW}$-Generatoren verwendeten. Weniger vorsichtig sind die US-Hersteller. Obgleich ihre 40/50kW-Anlagenklasse kaum als serienreif zu bezeichnen war, entwickelten viele von ihnen die 100kW-Klasse und verkauften sie bereits 1983. Später gingen drei US-Fabrikanten, deren Angebot sich bis dahin im 25-100kW-Segment bewegte, sogar direkt zu 300kW-Generatoren über (vg. Garud/ Karnoe, 286 Fig.3; ebd., 287). Generell lässt sich sagen, dass die USHersteller weniger vorsichtig bei der Einführung neuer Leistungsklassen gewesen sind, als es bei den Dänen üblich war. Während letztere auch zwischen den Entwicklungsschritten, beachtliche Anstrengungen leisteten, um die neuen Modelle zu verbessern, ${ }^{202}$ bemühten sich die US-Hersteller generell darum, Entwicklungskosten so weit wie möglich zu vermeiden (Garud Karnoe 2003, 284).

Abschließend ist auf unterschiedliche Konstruktionsstile dänischer und US-amerikanischer Windanlagen einzugehen. Das wichtigste Unterschied liegt darin, dass die US-Fabrikanten möglichst leichte Baustoffe verwendeten sowie sich einer speziellen Bauweise bedienten, um maximale Gewichtsreduktion zu erzielen und auf diese Art die Effizienz zu optimieren. Dem gegenüber zeichnen sich dänische Windanlagen durch robuste und widerstandsfähige Bauweise aus. Nicht die Maximierung der Effizienz, sondern der Stabilität und Lebensdauer stand hier im Zentrum. ${ }^{203}$ Die in den USA und insbesondere Kalifornien herrschende Begeisterung für Hightech-Lösungen wurde bereits in Zusammenhang mit dem ModProgramm als problematische Rahmenbedingung analysiert. Es muss sowohl auf Hersteller-, als auch Nachfrageseite davon ausgegangen werden, dass die Akteure technische Barrieren bei der Einführung neuer Größenklassen systematisch unterschätzten. Eine solche Diskontinuität, beachtliche Sprünge in der Anlagengröße bei kurzen Intervallen und Leichtbauweise, sind die wichtigsten Merkmale des WEA-Konstruktionsstils, in dem sich der US-amerikanische Technologiepfad widerspiegelt (vg. Garud/ Karnoe 2003; Heymann 1995). Darin besteht eine weitere Ursache des Versagens der US-Industrie. Bemerkenswert ist, dass diese Problematik weder vorrangig auf die Gestaltung der Fördergesetze, noch die Profitinteressen der Industrie und Anlagenkäufer, bzw. Windparkentwickler zurückgeführt

\footnotetext{
${ }^{202}$ Im Abschnitt über Periode 2 ist analysiert worden, mit welchen Schwierigkeiten der Übergang von der 30kWzur 55kW-Klasse verbunden war und welche Zeiträume erforderlich waren, um diese zu beheben.

${ }^{203}$,The Danish design philosophy has been successful since by using heavier, simpler rotors, the engineering risk has been drastically reduced.' (F.S. Stoddart, zitiert nach: Heymann 1995, 404) ,American turbine manufacturers (...) have tried to suck every last kilowatt from the air by using space-age materials and computer-aided design. The result: Danish turbines are heavier, less efficient, but many more times reliable - and that is what matters for wind farms.' (The Economist, 16.2. 1985, zitiert nach: Heymann 1995, 404)
} 
werden kann. Die folgende Tabelle 2.3.1b bietet eine Übersicht der wichtigsten Unterschiede US-amerikanischer und dänischer WEA.

Tab. 2.3.1b Unterschiede im Konstruktionsstil: Windturbinendesign in den USA und Dänemark

\begin{tabular}{|c|c|c|}
\hline & US-Hersteller/ Produkte & DK-Hersteller/ Produkte \\
\hline Entwicklung & bis 1980: & bis 1979: $\quad 30 \mathrm{~kW}$ \\
\hline Größensegmente am Beispiel von US- & ab 1981: & ab 1980: \\
\hline Windpower und DK-Bonus ${ }^{204}$ & ab 1983: & ab 1984: \\
\hline & ab 1993 & ab 1986: \\
\hline & & ab 1987: \\
\hline & & ab 1991: \\
\hline Bauweise/ Konstrukteure & $\begin{array}{l}\text { wissenschaftlich orientiert, Einsatz von } \\
\text { Computersimulationen } \\
\text { theoretischer Modelle, Ingenieure sind } \\
\text { von Anfang als Entwickler tätig }\end{array}$ & \begin{tabular}{llll} 
handwerkliche, & \multicolumn{2}{c}{ zunächst } & durch \\
Faustregeln geprägte & Bauweise, \\
Hersteller gewöhnten sich erst \\
allmählich an den Einsatz von \\
Ingenieuren
\end{tabular} \\
\hline Priorität & $\begin{array}{|lr|}\text { maximale } & \text { Effizienz, } \\
\text { Gewichtsreduzierung, } \quad \text { z.B. } & \text { geringe } \\
\text { Rotorkopfmasse von } 10-40 \mathrm{~kg} / \mathrm{kW} \\
\end{array}$ & $\begin{array}{l}\text { maximale Stabilität/ Zuverlässigkeit, } \\
\text { Gewichtssenkung war sekundär, übliche } \\
\text { Rotorkopfmasse lag bei } 70-90 \mathrm{~kg} / \mathrm{kW}\end{array}$ \\
\hline Baustoffe/ Design-Charakteristika & $\begin{array}{l}\text { leichte Materialien, häufig aus dem } \\
\text { Flugzeugbau übernommen; passive } \\
\text { Windnachführung; Leeläufer (Konzept } \\
\text { nicht erfolgreich) }{ }^{205}\end{array}$ & $\begin{array}{l}\text { robuste Materialien wie Stahl, die in der } \\
\text { metallverarbeitenden Industrie } \\
\text { verwendet werden; aktive } \\
\text { Windnachführung; Luvläufer (dänisches } \\
\text { Design: erfolgreich) }\end{array}$ \\
\hline
\end{tabular}

Quellen: Garud/ Karnoe 2003, 286 Fig. 3; Heymann 1995

Die wichtigsten Ursachen des ausbleibenden Erfolgs der damaligen US-Windindustrie sind also: Fehlende Markt-Transparenz, Ignoranz struktureller Fehler der Konzepte, Mangel an Feedback durch Windparkbetreiber sowie fehlende Eignung des technischen Entwicklungspfades für die Windenergie. Tabelle 2.3.1c stellt die wichtigsten Unterschiede zwischen den Herstellern beider Ländern dar.

Tabelle 2.3.1.2b Unterschiede der dänischen und US-amerikanischen Windindustrie

\begin{tabular}{|l|l|l|}
\hline & USA & Dänemark \\
\hline Grad der Markttransparenz & niedrig & hoch \\
\hline Technische Weiterentwicklung & stagnierend & kontinuierlich \\
\hline $\begin{array}{l}\text { Investitionen in technische } \\
\text { Verbesserungen }\end{array}$ & niedrig & hoch \\
\hline Entwicklung der Anlagengröße & sprunghaft & kontinuierlich \\
\hline Grad der Konkurrenz & hoch & anfangs niedrig, dann zunehmend \\
\hline Feedback an die Hersteller & wenig & viel \\
\hline Anlagentechnik & $\begin{array}{l}\text { Leichtbauweise, an maximaler Effizienz } \\
\text { orientiert }\end{array}$ & $\begin{array}{l}\text { robuste Bauweise, an maximaler } \\
\text { Stabilität/ Zuverlässigkeit orientiert }\end{array}$ \\
\hline Rolle der Zulieferindustrie & $\begin{array}{l}\text { gering, bspw. entwickelten praktisch alle } \\
\text { Hersteller eigene Rotoren }\end{array}$ & $\begin{array}{l}\text { hoch, spez. Zulieferer bieten seit 1977/78 } \\
\text { unterschiedliche Komponenten an }\end{array}$ \\
\hline
\end{tabular}

Quellen: vg. Kap. 2.1, 2.2 und 2.3

Das folgende Schaubild 2.3a stellt die Stagnation der US-amerikanischen Technologie als Gesamtergebnis problematischer Akteurskonstellationen und verfehlter Gestaltung des Fördersystems, dar.

\footnotetext{
204 Ähnlich entwickelte sich die Anlagengröße bei den übrigen Herstellern (Garud/ Karnoe 2003, 286).

${ }^{205}$ Der problematische Bezug auf die Flugzeugindustrie seitens der LSP-Akteure setzt sich im kommerziellen Sektor fort.
} 


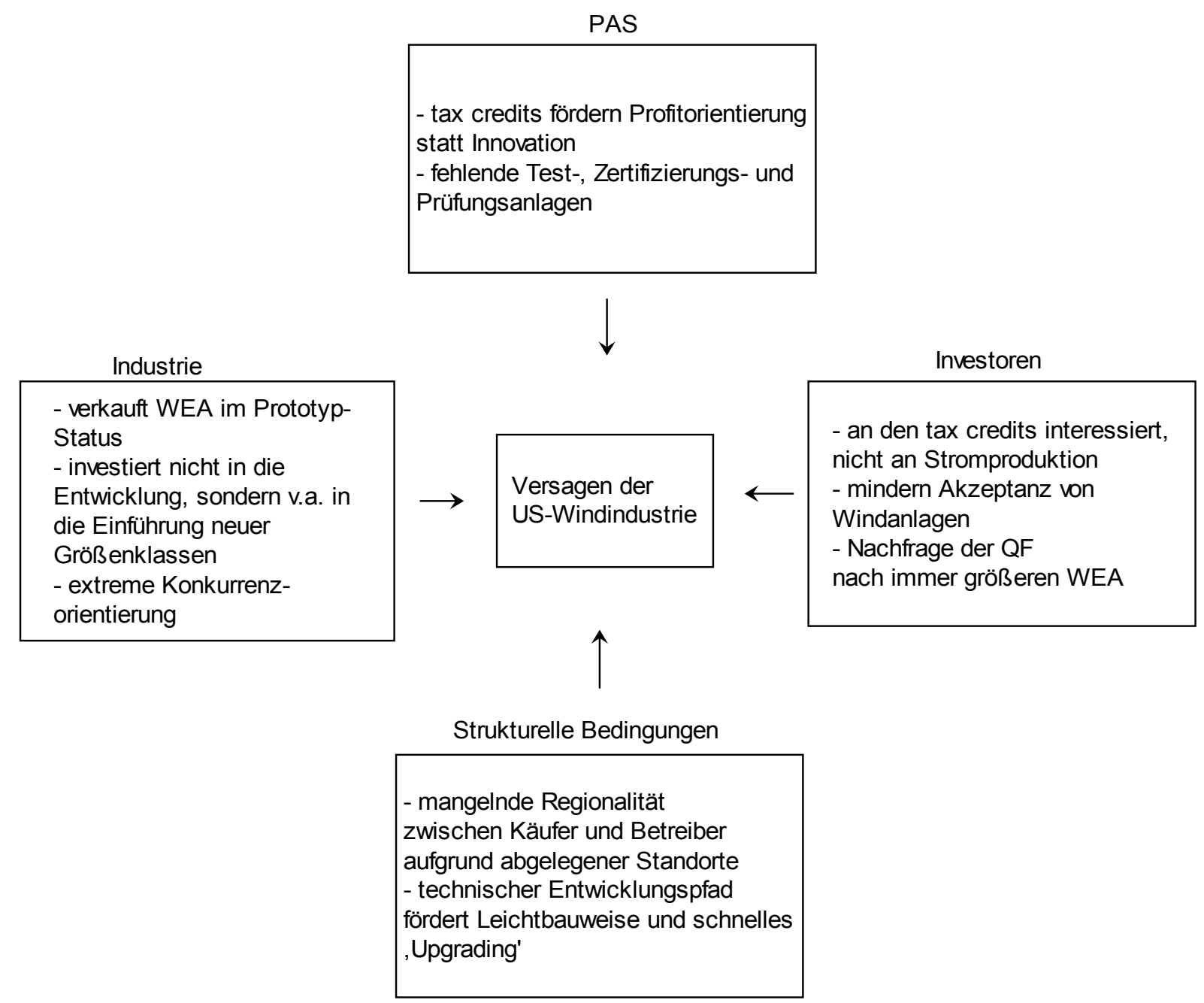

Die Schwierigkeiten, welche die US-Firmen von der Herstellung zuverlässiger WEA abhielten sind zu komplex, als dass sie kurzfristig hätten gelöst werden können. Teilweise wurden die Probleme nicht erkannt, oder man war an ihrer Lösung nicht interessiert. Bewältigt wurden sie z.T. durch eine sukzessive Bedeutungszunahme dänischer Hersteller. Zwischen 1983 und 1986 wächst deren Marktanteil von 11 auf 71\%. ${ }^{206}$ Selbstredend konnte die Verdrängung vom eigenen Markt aus Sicht der US-Hersteller keine befriedigende Lösung sein. Etliche Firmen gingen Bankrott oder zogen sich aus dem Sektor zurück. Andere kauften die Lizenzrechte von dänischen Unternehmen. Airtricity schließt 1985 einen Lizenzvertrag mit Wind Matic zur Verwendung dessen Anlagenkonzepts (WPM 2/86, 4). In den 90er Jahren folgen zahlreiche Hersteller diesem Beispiel. Zond Systems geht 1993 noch einen Schritt weiter. Anstatt nur eines Anlagenkonzeptes, importiert das Unternehmen den Entwicklungsingenieur Finn Hansen, der zuvor bei Vestas tätig war (Gipe 1995, 82).

\footnotetext{
${ }^{206} 1984$ und 1985 betrugen die Anteile am kalifornischen Markt 33, bzw. 62\% (van Est 1999, 59; Heymann 1995, 401).
} 


\subsubsection{Kalifornien: Windturbinenkäufer und -betreiber in Periode 3}

Trotz gewinnverheißender Investitionsbedingungen werden in den ersten zwei Jahren nach Inkrafttreten der tax credits 1980-81 nur einzelne Windturbinen gekauft. Righter $(1996,215)$ hat das Jahr 1981, in dem etwa 150 WEA erworben werden, als ,year of dialogue between developer and investor' bezeichnet. Der CEC zufolge ist die Entwicklung großer Windparks in Kalifornien durch ,investor-owned and municipal utilities, as well as by individuals and private developers' (ebd., 209) initiiert worden. Dominiert wird die Entwicklung allerdings von Betreibergesellschaften aus der Finanzwelt, die ihrer wohlhabenden Kundschaft hohe Profite versprachen. ,The big rush, however, came on the commercial front. Suddenly, windenergy development became trendy in investment circles. Wealthy investors, with $\$ 50.000$ or $\$ 100.000$ to disburse, called their brokers, captivated by the idea of aiding the environment while padding their pocketbooks.' (ebd., 209). Daher hielt sich die Euphorie der Mehrheitsbevölkerung für die staatlichen Fördermaßnahmen der Windkraft und die tax credits im besonderen, die als ,welfare for the welthy' angesehen wurden, in Grenzen. ${ }^{207}$

1982 sind über 1000 WEA errichtet worden, in den nachfolgenden Jahren noch deutlich mehr. Bis Ende 1986 werden in Kalifornien knapp 15.000 WEA mit einer Kapazität von 1.235 MW installiert. ${ }^{208}$ Aufgrund der günstigen Konditionen investierten mehr als 50.000 Personen etwa zwei Milliarden Dollar in den Kauf von WEA (Gipe 1995, 31), durchschnittlich etwa $\$ 40.000$. Es ist unzweifelhaft, dass die Urheber der Fördermaßnahmen in erster Linie wohlhabende Käufer vor Augen hatten. Wer eine WEA erstehen wollte, musste zunächst über Kapitalien verfügen. Entsprechende Investitionen lohnten sich aus monetärer Sicht nur für Personen, die hohe Steuern zahlten. Für Interessenten mit niedrigem Einkommen, die ohnehin kaum Steuern abzuführen hatten, rechnete sich der Kauf einer WEA nicht.

Das PURPA schuf einen neuen Akteurstyp, die sogenannte Qualified Facility (QF). Die QF sind Projektentwicklungsgesellschaften (van Est 1999, 45), die kleine Kraftwerke (bis $30 \mathrm{MW}$ ) wie Windparks betrieben. ${ }^{209}$ Der dort produzierte Strom musste von den Versorgern eingespeist und vergütet werden. Zumeist waren die QF nur Zwischenhändler, welche die WEA an den letztendlichen Käufer veräußerten. Einige QF produzierten die von ihnen genutzten Windturbinen selbst. Pionier unter den QF ist das Unternehmen US-Windpower, welches darüber hinaus als erfolgreichster Windanlagenlieferant auf dem kalifornischen Markt in Erscheinung getreten war. 1979 tritt US-Windpower in New Hampshire als Betreiber des ersten, gemäß dem National Energy Act geförderten Windparks auf. Dabei nahm der Turbinenfabrikant zu Testzwecken 30 Windanlagen à $20 \mathrm{~kW}$ aus eigener Fertigung in Betrieb. In der Branche galt US-Windpower als ,lone wolf...because of its clear-cut, and ,subbornly self-sufficient' course of vertical integration' (van Est 1999, 51). US-Windpower übernahm sämtliche Schritte in Eigenregie, die zum Betrieb von WEA durch Privatakteure notwendig waren: von der Anlagenherstellung, über Projektierung, Aufbau, Einspeiseverträge und Betrieb. Der Kunde sollte eine WEA von US-Windpower erwerben, die anschließend von dem Unternehmen betrieben und verwaltet wurde (van Est 1999, 51). Zwischen 1982 und 1987 akquiriert US-Windpower mehr als \$350 Mio. Gelder privater Investoren für den Aufbau von WEA am Altamont Pass (Righter 1996, 214).

\footnotetext{
207 ,...wind farm developers particularly solicted funds from people in the upper-income brackets, who were seeking a write-off on their federal and state income taxes. This practice nourished the idea that wind farms were no more than tax scams, caused the conservative financial periodical Forbes to sneer about, the great windmill tax dodge' (Paris 1984), (zitiert nach: van Est 1999, 56). An anderer Stelle titelte das Forbes Magazin: ,helped create the fad of the year: the wind park tax shelter.'

${ }^{208}$ Zum Vergleich: Bis zu diesem Zeitpunkt dürfte außerhalb Kaliforniens, eine Windenergie-Kapazität von 100$150 \mathrm{MW}$ der Stromproduktion gedient haben.

${ }^{209} \mathrm{Zu}$ den wesentlichen Aufgaben einer QF zählt die Projektplanung: Auswahl und Pachtung windgünstiger Standorte, Aushandlung der Einspeiseverträge, Auswahl geeigneter WEA.
} 
Die QF avanciert Mitte der 80er Jahre zum wichtigsten Akteur auf Betreiberseite. Gab es 1982 nur 15 Projektentwickler, ${ }^{210}$ so hat sich diese Zahl innerhalb von zwei Jahren verdoppelt (van Est 1999, 52). Die QF lenkten das Interesse wohlhabender und zu Risiken bereiter Investoren auf die Windkraft, indem sie ihnen hohe Renditen versprachen. Eingelöst wurden die Verheißungen nur in wenigen Fällen. So kam es, dass einige den Großteil ihrer Investition verloren (Gipe 1995, 31f.).

So sehr die QF den Profiten der Hersteller zuträglich waren, so sehr waren sie es auch, welche durch ihre, auf kurzfristige Profite ausgerichtete Unternehmensstrategie, der technischen Entwicklung beträchtliche Hindernisse in den Weg legten. Als größter Abnehmer hatten die QF wesentlichen Einfluss auf die Entwicklungsrichtung. Sie entschieden sich stets für die größten Modelle und förderten damit die Abkehr der verhältnismäßig ausgereiften Kleinanlagen im 20kW-Segment. Gerade diese Größenklasse war es allerdings, die für zivilgesellschaftliche Akteure wie Privathaushalte, Landwirte und Betreiber kleiner Fabriken am interessantesten gewesen wäre. Mittelgroße WEA ab 50kW überstiegen nicht nur den Bedarf, sondern auch das Budget der meisten potenziellen Interessenten (van Est 1999, 52). Wie am Beispiel Dänemarks gezeigt wurde, ist die Förderung dezentraler Betreiber von immenser Bedeutung für den Erfolg eines Windsektors in der Pionierphase. Windmüller, die in unmittelbarer Nähe zum Standort leben, haben starkes Interesse am Funktionieren ihrer Windanlage. Sie leiten daher Probleme unverzüglich an den Hersteller weiter. Die meisten kalifornischen Anlagenkäufer dagegen, hatten ihre Windturbine niemals zu Gesicht bekommen (Garud/ Karnoe 2003, 294). Durch die hohe Nachfrage mittelgroßer Anlagen seitens der Projektentwickler stagnierten die Arbeiten an den Konzepten des 20kW-Segments und dezentrale Interessenten wurden sukzessive vom Markt gedrängt. 98\% der kalifornischen WEA sind in nur drei Arealen, auf den freien Flächen entlang der windigen Pässe von Altamont, Gorgonio und Tehachapi installiert worden (Heymann 1995, 396). Die Suche nach passenden Standorten gestaltete sich für eine QF wesentlich leichter als bspw. für dänische Windmüller und insbesondere auch niederländische und britische Windanlagenbetreiber (s.u.). Das Land an den Pässen wird vor allem landwirtschaftlich genutzt. Die Entwickler zahlten lohnende Pachten an die Rancher, die ihr Land bereitwillig zu Verfügung stellten. ${ }^{211}$

\section{EVU und Windkraft}

Bei ihren Investitionen in Windparks ging es den meisten EVU in erster Linie um Public Relations. Diverse EVU waren am LSP-Programm der Föderation beteiligt. Sie kauften einige der Megawattprototypen und betrieben sie so lange, bis zu hohe Reparaturkosten anfielen. Am eigentlichen Aufschwung der Windkraft jedoch, wie er hier beschrieben wird, hatten die EVU keinen aktiven Anteil. ${ }^{212}$

Gipe $(1995,30)$ zufolge verhielten sich die EVU unabhängigen Stromproduzenten gegenüber kooperativ. Righter $(1996,220)$ hebt dagegen hervor, dass die Netzeinspeisung durch eine QF keine Selbstverständlichkeit war, sondern erst durch das PURPA, das gegen den Willen der Elektrizitätswirtschaft verabschiedet wurde, gesetzlich geregelt werden musste. Als das

\footnotetext{
${ }^{210}$ Neben US-Windpower zählten SeaWest Power Systems, Zond Systems, Wintec und FloWind zu den wichtigsten Projektentwicklern (Righter 1996, 220). Einen wichtigen Schub erhielt die Windkraft durch das Engagement des Department of Water Resources (DWR), des größten Einzelabnehmers elektrischer Energie Kaliforniens. 1979 erhielt US-Windpower vom DWR einen Auftrag für den Bau des ersten großen Windparks (100MW-Kapazität). Mit der Installation hunderter 50kW-Maschinen am Altamont Pass wurde das erste der drei großen Windparkareale Kaliforniens erschlossen (van Est 1999, 51). Zugleich bedeutete dieser Schritt eine Weichenstellung für den Erfolg der QF und damit einen zentralisierten Entwicklungspfad.

${ }^{211}$ Der Rancher Hugh Walker (Altamont) erhielt \$300-400 pro WEA und Jahr. Bei 100 WEA auf seinem Land ergaben sich Zusatzeinnahmen in Höhe von ca. \$35.000 im Jahr (Righter 1996, 211).

${ }^{212}$ Ein hawaiianischer Netzbetreiber nahm im April 1985 fast 200 kleine Windturbinen (Jacobs, 17kW) in Betrieb und bildete damit eine Ausnahme. Die Energieversorgung von Hawaii ist zu 90\% ölabhängig, mehr als die aller anderen US-Staaten (vg. WPM 8/86, 18f.).
} 
PURPA einmal in Kraft getreten war und 1982 vom Supreme Court bestätigt worden ist, blieb den Versorgern nichts anderes übrig, als sich mit der neuen Situation zu arrangieren. Tolerantes Verhalten der EVU gegenüber den vereinzelten Windmüllern, die außerhalb Kaliforniens aktiv waren, erforderte nur geringe Konzessionen. Eher wurde die Legitimität des Versorgungsmonopol auf diese Weise noch erhöht. In Kalifornien stellte sich die Situation anders dar. Die beiden großen Versorger, Pacific Gas \& Electric (PG\&E) und Southern California Edison (SCE) sahen ihre Monopole zurecht als gefährdet an. Eine ähnlich tolerante Haltung wie sie von zahlreichen Netzbetreibern anderer Bundesstaaten gezeigt wurde, hätte ihre Marktverlust vermutlich beschleunigt. Sie wurden nun aktiv und bedienten sich zweier Strategien, um die Möglichkeiten der QF einzuschränken. Die erste besteht vor allem darin, sich frühzeitig der Öffentlichkeit als Fürsprecher erneuerbarer Energien zu empfehlen. Bereits 1980 kündigt SCE-Vorsitzender Gould an, bis zum Jahr 2000 keine konventionellen Kraftwerke mehr zu bauen und stattdessen ausschließlich auf erneuerbare Energien zu setzen (vg. Gipe 1995, 473). Bis 1990 wollte SCE 120MW Windkraft in Betrieb nehmen, was nicht geschah. PG\&E schloss mit Windfarms Limited (WFL) 1981 einen Vertrag über die Entwicklung eines großen Windparks (320MW), der an einem windigen Pass in Solano County entstehen sollte (van Est 1999, 47). ${ }^{213}$ Realisiert wurde keines der Projekte. Den EVU ging es vor allem um Absichtserklärungen, denen keinerlei Handlung zu folgen brauchte. Tatsächlich setzten SCE und PG\&E weiterhin auf Kernenergie. Von den 5.200MW zusätzlicher Kraftwerkskapazität, die zwischen 1983 und 1985 ans Netz geschlossen wurde, stammen mehr als 3.500MW aus neuen Atomkraftwerken (van Est 1999, 305 Fußnote 79). Die Tatsache, dass die EVU, trotz veränderter Bedingungen auf dem Strommarkt, auf ,business as usual' setzten, bedeutete nicht, dass diese Milliardeninvestitionen nicht aufgrund der Konkurrenz durch Windparkbetreiber ins Leere laufen konnten. Diese Möglichkeit trieb SCE und PG\&E in offene Gegnerschaft zu diesen. Die EVU versuchten daher, die Situation der QF soweit wie möglich zu erschweren, ohne dabei zu riskieren, dass man ihnen gesetzwidriges Handeln öffentlich vorwerfen konnte. Darin bestand die zweite Strategie der EVU. Man gab sich alle Mühe, Verhandlungen über die Höhe der Einspeisetarife in die Länge zu ziehen. Oft erreichten sie, dass Tarife unterhalb des Niveaus vermiedener Kosten fixiert wurden (van Est 1999, 304 Fußnote 72). Vor diesem Hintergrund gründeten die QF im April 1982 eine Interessenorganisation, die Independent Energy Producers (IEP). ${ }^{214}$ Die IEP arbeitete eng mit der California Public Utilities Commission (CPUC) zusammen. Dadurch erlangte sie eine starke Verhandlungsposition gegenüber den EVU (ebd., 57f.). Auf Initiative der IEP schaltete sich Ende 1982 die Regulierungsbehörde in den Konflikt ein. Sie setzte den EVU eine Frist innerhalb derer sie akzeptable Verträge vorlegen sollten:

,The CPUC told all three California investor-owned utilities, ,You come back in five weeks and you have a long term contract or else we will give you one, and you probably like what you would do better than what we would do.' ' (J. Hamrin, Sprecherin der IEP, zitiert nach: van Est 1999, 57).

Auf diese Weise kamen die sogenannten Interim Standard Offer Numer 4 (ISO4) Verträge zustande, die von der CPUC im September 1983 genehmigt wurden. Für die Windparkbetreiber brachte die Regelung deutliche Vorteile. Unabhängig von den Entwicklungen auf dem Energiemarkt wurde der Abnahmepreis auf dem Niveau aktueller

\footnotetext{
${ }^{213}$ WFL war ein Projektentwickler, der sich von anderen Unternehmen der Branche dadurch unterschied, dass er gezielt die großen EVU umwarb. Das Unternehmen spekulierte auf technische Verbesserungen und Kostensenkungen der Megawattanlagen des Mod-Programms. WFL wollte, dass PG\&E in die Chance der Serienreifung der Großanlagen von Boeing und Hamilton Standard investierte. Als sich gegen Mitte der 80er Jahre das Scheitern des Mod-Programms abzeichnete und zudem noch die Energiepreise fielen, distanzierte sich PG\&E von dem Großprojekt (van Est 1999, 47ff.).

${ }^{214}$ Neben der IEP existierte in den USA mit der bereits seit 1974 existierenden American Wind Energy Association (AWEA) eine weitere Interessenorganisation, welche die Windbranche insbesondere auf nationaler Ebene vertritt. Aufgrund ihrer engen Kooperation mit dem föderalen Energieministerium, kamen der AWEA beachtliche Einflussmöglichkeiten zu (vg. Gipe 1995, 89f.).
} 
vermiedener Kosten auf zehn Jahre festgeschrieben. ${ }^{215}$ Angesichts der hohen Energiepreise führten die langen Festschreibungszeiten der Vergütungstarife zu einem Boom der Windkraft. Seit 1984 fielen die Energiepreise und damit auch die vermiedenen Kosten. Da die Abnahmepreise konstant blieben, entwickelte sich die Windkraft für die EVU zu einem immer größeren Verlustgeschäft. Daher forderten sie die Abschaffung des ISO4. Auch die CPUC sprach sich dafür aus, die Regelung zu beenden. Aufgrund des beschleunigten Zubaus von WEA fürchtete die Behörde das Auftreten von Lastverteilungs- und Regulierungsproblemen (Heymann 1995, 396). Beendet wurde diese für die Windbranche lukrative Regelung im April 1985. Bemerkenswerter Weise geschah dieses in einem Konsens zwischen EVU und Independent Energy Producers. Letztere befürchteten, dass die hohe Nachfrage zu Lieferschwierigkeiten führen und der Industrie möglicherweise Imageschäden zufügen würde (van Est 1999, 58). Nachdem zusätzlich die tax credits abgeschafft wurden, ist die Gefahr zu hoher Nachfrage eher das geringste Problem vieler Hersteller (vg. Tab. 2.3a). ${ }^{216}$ Die Beendigung des ISO4 markiert den Endpunkt der Einflussnahme der EVU auf den kalifornischen Markt für Windanlagen, sowohl innerhalb dieser Periode, als auch der Pionierphase insgesamt. ${ }^{217}$ Das Verhältnis der kalifornischen Energiewirtschaft zur Windkraft ist über die gesamte Pionierphase hindurch von einer ablehnenden Haltung der EVU gekennzeichnet. Da ihr Handeln in der Öffentlichkeit generell kritisch wahrgenommen wurde, handelte es sich für die EVU um einen wahren Glücksfall, dass ISO4 im Konsens mit anderen Akteuren beendigt wurde. Bevor schließlich, mit dem Final Standard Offer 4 (FSO4), eine Nachfolgeregelung des ISO4 im Jahre 1994 beschlossen wird, vergingen nicht weniger als acht Jahre. ${ }^{218}$ Bei fast allen Windturbinen, die bis dahin gekauft wurden, handelte es sich entweder um die Realisierung verzögerter ISO4-Projekte, oder um den Austausch defekter WEA. ${ }^{219}$ Vor dem Hintergrund gefallener Energiepreise und aufgrund des Wegfalls der ISO4Regelung, sinkt die Einspeisevergütung zwischen 1985 und 1990 von 14 auf drei Cents (Heymann 1995, 404).

\footnotetext{
${ }^{215}$ Die meisten QF hatten Verträge mit einer garantierten Abnahme von insgesamt 30 Jahren, wobei die Höhe der Tarife für die verbleibenden 20 Jahre neu ausgehandelt wurden (Righter 1996, 222).

${ }^{216}$ 1990-91 kam es noch einmal zu einem kurzfristigen Run auf WEA, die zügig errichtet wurden. Damit verhinderte man, dass zuvor abgeschlossene ISO4-Verträge unwirksam geworden wären (vg. van Est 1999, 62 und Tab. 2.3a). Für die amerikanischen Projektentwickler hatte die Beendigung der tax credits fatale Auswirkungen. Von den etwa 100 Firmen überlebten die Krise gerade zwei, Kennetech und Zond (Vestergaard 2004, 27).

${ }^{217}$ Auch in der folgenden Zeit war man darum bemüht, Interesse an der Windkraft zu zeigen. So waren auch Experten von PG\&E an einer Studie beteiligt, der zufolge EVU-Windparks um 30-40\% kostengünstiger betrieben werden könnten, als es unabhängigen Betreibern möglich sei (van Est 1999, 62; ebd., 306 Fußnote 95). In Kooperation mit dem von der Energiewirtschaft gegründetem Electric Power Research Institute (EPRI) startete US-Windpower 1989 die Entwicklung der 33M-VS. Hohe Erwartungen hinsichtlich enormer Kostensenkungen durch die 300kW Turbine wurden enttäuscht (van Est 1999, 63f.).

${ }^{218}$ Aufgrund vorhandener Überkapazitäten sah die CPUC geringe Notwendigkeiten für die Installation weiterer WEA. Auch die EVU bemühten sich, den Verhandlungsprozess um eine Neuregelung zu verzögern. Der FSO4 beruhte auf der zweijährlichen Feststellung neu erforderlicher Kapazitäten, die von den QF angeboten werden konnten. Der Strom wurde dann im Rahmen einer Auktion an den meist bietenden Netzbetreiber verkauft (van Est 1999, 60f.).

${ }^{219}$ In größerem Umfang setzte dieser Prozess des ,Repowering' 1994 im Windpark von Palm Springs ein. USWindpower ersetzte ältere WEA durch 115 seiner neuen 33m-VS Maschinen (Gipe 1995, 474).
} 
Windenergie in Kalifornien und Dänemark

Zwischen den Windenergiemärkten Dänemarks und Kaliforniens bestehen wesentliche Unterschiede, sowohl was die Einflussnahme des PAS, als auch die Entwicklung der Windindustrie und -technik betrifft. Ähnlich verhalten sich beide Märkte hinsichtlich der Käufer- und Betreiberstruktur (Tab. 2.3.1d).

Tab. 2.3.1d Windanlagenkäufer und -betreiber in Kalifornien und Dänemark

\begin{tabular}{|c|c|c|}
\hline & Kalifornien & Dänemark \\
\hline Käufer & QF, Investoren & $\begin{array}{l}\text { Landwirte und Kooperativen, seit 1985: } \\
\text { zusätzlich EVU }\end{array}$ \\
\hline Betreiber & QF & $\begin{array}{l}\begin{array}{l}\text { Landwirte, Kooperativen, } \\
\text { zusätzlich EVU }\end{array} \\
\end{array}$ \\
\hline Projektentwickler & QF & $\begin{array}{l}\text { Landwirte, Kooperativen, seit 1985: auch } \\
\text { EVU, Anlagenhersteller }\end{array}$ \\
\hline $\begin{array}{l}\text { Akzeptanz } \\
\text { Windkraftprojekten }\end{array}$ & $\begin{array}{l}\text { Problem stellt sich kaum, da Projekte } \\
\text { abseits dicht besiedelter Gebiete liegen; } \\
\text { Insgesamt werden die QF/ Investoren sehr } \\
\text { kritisch wahrgenommen. }\end{array}$ & $\begin{array}{l}\text { Projekte werden gut akzeptiert. Die } \\
\text { Windmüller stammen aus einem } 3 \mathrm{~km}- \\
\text { Radius, ertragen also Lärm, Schattenwurf } \\
\text { etc. selbst; Als Renditeobjekt eigneten sich } \\
\text { WEA nicht. }\end{array}$ \\
\hline Standortsuche & $\begin{array}{l}\text { Unproblematisch, die meisten Standorte } \\
\text { liegen in dünn besiedelten Regionen }\end{array}$ & $\begin{array}{l}\text { Für Landwirte/ Kooperativen relativ } \\
\text { einfach; für EVU durchaus problematisch }\end{array}$ \\
\hline Interessenvertretung & $\begin{array}{l}\text { Independent Power Producers wirken bei } \\
\text { der CPUC erfolgreich auf die } \\
\text { Reglementierung der EVU hin; insbes. auf } \\
\text { föderaler Ebene wichtig: AWEA }\end{array}$ & $\begin{array}{l}\text { DV ist seit } 1978 \text { schlagfertige } \\
\text { Interessenorganisation der Windmüller }\end{array}$ \\
\hline \begin{tabular}{llll|} 
Verhältnis & der & EVU & zur \\
Windkraft & & &
\end{tabular} & $\begin{array}{l}\text { Per Gesetz zur Kooperation mit } \\
\text { Windanlagenbetreibern } \\
\text { Ansonsten versuchten sie ihre Anti- } \\
\text { Windkraft-Position vor allem durch } \\
\text { Ankündigungen eigener Windparkprojekte } \\
\text { zu kaschieren. }\end{array}$ & $\begin{array}{l}\text { Gegensatz zwischen DV und EVU besteht } \\
\text { auch nach } 1985 \text { fort. DEF lässt sich } 1985 \\
\text { zum aktiven Markteinstieg verpflichten; } \\
\text { Aus Sicht der EVU handelte es sich um } \\
\text { einen notwendigen Schritte:, um bei der } \\
\text { Regierung Restriktionen gegen die } \\
\text { Windmüller zu erwirken }\end{array}$ \\
\hline Vorherrschende Windparkgröße & $\begin{array}{l}98 \% \text { der Turbinen sind in drei Arealen } \\
\text { errichtet worden }\end{array}$ & $\begin{array}{llll}\text { einzelne, sehr wenige Anlagen; } & \text { EVU } \\
\text { beginnen } 1986 \text { mit dem Aufbau } & \text { erster } \\
\text { Windparks mit etwa } 10-20 \text { WEA } & \\
\end{array}$ \\
\hline \begin{tabular}{llll|} 
Entfernung & der & WEA & vom \\
Besitzer & & & \\
\end{tabular} & $\begin{array}{l}\text { groß, Anlagen stehen mehr oder weniger in } \\
\text { der Wüste, während die meisten Besitzer in } \\
\text { Städten wie San Francisco und Los Angeles } \\
\text { ihren Wohnsitz hatten }\end{array}$ & $\begin{array}{l}\text { gering. Besitzer durften nicht weiter als } \\
\text { drei Kilometer von der WEA entfernt } \\
\text { wohnen }\end{array}$ \\
\hline
\end{tabular}

Quellen: vg. Kap. 2.1, 2.2 und 2.3

Der Vergleich der Märkte Kaliforniens und Dänemarks beweist die Abhängigkeit der technischen Entwicklung von den Käufer-/ Betreibertypen - und damit auch von der Gestaltung der Fördergesetze. Es ist ein wichtiger Unterschied, ob jemand den Erwerb einer WEA vor allem als eine lukrative Investition begreift, oder an der Windkraft als alternativer Energiequelle interessiert ist. Wegen der oft hohen Distanzen zwischen Standort und Betreiber, Betreiber und Hersteller sowie Hersteller und Standort, ist die Möglichkeit des Betreibers erschwert, den Produzenten kurzfristig zu alarmieren. Auch hat der Käufertyp großen Einfluss auf die Frage der Akzeptanz eines Projekts und der Windkraft insgesamt. Während sich das Akzeptanzproblem auf dem kalifornischen Markt kaum gestellt ist, war die mangelnde Sympathie in weiten Teilen der Bevölkerung durchaus nicht unproblematisch. Die kalifornischen EVU lehnen Windkraft als Kraftwerksoption ebenso ab wie dänische. Der wichtigste Unterschied besteht darin, dass dänische Energieunternehmen durch die Beliebtheit der Windkraft stärker unter Druck gerieten als die Kalifornier. 


\subsubsection{Dänemark in Periode 3}

Während Periode 2 hat sich die Windtechnologie in Dänemark zum Erfolgsmodell entwickelt. Im Zeitraum 1983 bis 1985 ermöglichen Exporte nach Kalifornien ein durchschnittliches Wachstum der Windanlagenindustrie von über $100 \%$ pro Jahr (vg. Tab. 2.3b). Sowohl industrie-, als beschäftigungspolitisch beginnt die Windkraft zu einem relevanten Faktor zu werden: Zwischen 1982 und 1985 entstehen in dem Sektor etwa 3000 Arbeitsplätze. Dieser Zuwachs entspricht einem Achtel sämtlicher neuer Beschäftigungsverhältnisse (WPM 5/85, 14). 1985 erreicht der Export von WEA ein Volumen von 4,4 Mio. DKK (Hantsch 1998, 54). Trotz beachtlicher Verbesserungen ist die Windkraft noch immer auf staatliche Förderung angewiesen. Vor dem Hintergrund ihrer wirtschaftlichen Erfolge steht eine Abkehr von der Technologie zu keiner Zeit auf der Tagesordnung. Vielmehr werden die Bedingungen für unabhängige Akteure auf dem Inlandmarkt noch verbessert. Erste Windparks entstehen. Energieversorger, kommerzielle Entwicklungsgesellschaften und einzelne Kommunen betreten den Sektor.

In der Stabilisierungsperiode besteht die Anti-Windenergie-Koalition insbesondere aus konservativer Partei und Energiewirtschaft. Nun treten Teile der Bevölkerung hinzu. Die Akzeptanz der Windkraft, bis dahin einer der wichtigsten Erfolgsfaktoren, verringerte sich. Viele Anrainer protestierten gegen den Aufbau von Windparks durch auswärtige Betreiber. Eine zweite Front ist innerhalb der Sektors entstanden: Zwischen den neuen kommerziellen Windparkbetreibern und den Windmüllern entzündet sich ein Konkurrenzkampf um die besten Standorte.

Der Eintritt in den kalifornischen Markt bringt der Industrie nicht nur ein boomartiges Wachstum, sondern konfrontiert sie erstmals mit dem Problem erbitterter Konkurrenz, mit all ihren negativen Folgewirkungen. Die meisten Hersteller sahen sich zur Abkehr von ihrer bis dahin üblichen Praxis des vorsichtigen Upscalings genötigt und reduzierten den Optimierungsaufwand der Prototypen, bevor sie neue Modelle einführten. Viele Produzenten waren nicht hinreichend auf den Zusammenbruch des Exportmarktes vorbereitet. Das Ende der tax credits drängte 1986/87 einen beträchtlichen Teil der Anlagenhersteller an den Rand der Existenz oder führte sie in den Bankrott.

\subsubsection{Dänemark: Das politisch-administrative System in Periode 3}

Der auf 20\% reduzierte Investitionszuschuss, durch den Sturm von 1981 verursachte Havarien und stagnierende Ölpreise führen 1982 zu reduzierter Nachfrage. Im nachfolgenden Jahr verstärkt sich die Krise des Binnenmarktes. Verglichen mit 1981 halbiert sich die Zahl verkaufter WEA im Jahr 1983 (vg. Tab. 2.3b). Um den Markt zu stabilisieren, schafft die Regierung im Dezember 1983 deutliche Verbesserungen für Windanlagenkäufer ${ }^{220}$ Seitdem ist der Betrieb von Windturbinen von der Energiesteuer, die einen Anreiz zur Einsparung von Strom- und Brennstoffen bieten sollte, ausgenommen (etwa 25 Öre, bzw. sieben Pfennig pro eingespeister Kilowattstunde). Mit der Begründung, dass die Windkraft zu Einsparungen beitrage, erhielten die Windmüller sogar eine teilweise Rückvergütung der Energiesteuer in Höhe von 15,5 Öre (ca. 4,3Pf.) pro Kilowattstunde (Heymann 1995, 415). Die wichtigste

\footnotetext{
${ }^{220}$ Von der Windtechnologie ist die konservative Regierung weniger überzeugt. Daran änderten auch die seit 1983 stark zunehmenden Exporte nichts. Vielmehr sahen sie sich der ,grünen Mehrheit' aus SD, SF, RV und VS ausgeliefert, die jederzeit eigenständige Fördermaßen hätte durchsetzen können. Um das Gesicht zu wahren, blieb der Regierung daher kaum eine andere Möglichkeit, als ,das beste aus der Sache zu machen und so tun, als ob sie mit der Entwicklung zufrieden wäre.' (van Est 1999, 88, Übersetzung: M.N.). Aus diesem Grund versprach die Regierung dem Folketing, dass das Förderprogramm auch 1983 fortgesetzt würde, um den Inlandmarkt zu erhalten (ebd.).
} 
Rahmenbedingung dafür, dass sich der Markt seit 1984 wieder regeneriert hatte, besteht im freiwillige Übereinkommen' zwischen EVU und Windmüllern. Darin verpflichteten sich die EVU zu diversen Zugeständnissen (s.u.). Die Übereinkunft kam auf ähnliche Weise zustande wie die provisorische Regelung von 1979. Auch im Falle der Neuregelung übte das Parlament Druck aus, indem es den EVU mit einer gesetzlichen Regelung drohte, sollten sie sich nicht mit den Windmüllern einigen (Hantsch 1998, 54). ${ }^{221}$

Ein Novum der Erprobungsperiode besteht in der Exportorientierung der Windindustrie. Unterstützt werden die Exporteure vom Industrieministerium, dass die Durchführung einer Analyse des US-amerikanischen Marktes mit 250.000 DKK förderte (Heymann 1995, 416). Durch die Kombination aus Export- und Binnenmarktförderung leistete die Regierung wichtige Beiträge zur Regeneration des Sektors.

Dem Aufschwung infolge des Kalifornien-Exports (seit 1983), folgt 1984/85 ein beschleunigtes Wachstum der Inlandnachfrage: Im Vergleich zum Vorjahr wächst die Zahl neu errichteter WEA 1985 um knapp 260\% und die installierte Windkapazität verdreifacht sich (vg. Tab. 2.3b). Hauptsächlich dafür verantwortlich ist die Entkopplung zwischen privatem Verbrauch und der Produktion von Strom aus Windkraft. Da nun jeder beliebig viele WEA betreiben durfte, wird die Branche erstmals für private Investoren und neuen Firmen interessant, die sich zum Zweck der Windparkentwicklung gründeten.

Die Bildung solcher Unternehmen und der daraus resultierende Nachfrageschub war von den EVU nicht erwartet worden. Sie argumentierten, dass sie mit ihrer 1984 eingegangenen Verpflichtung zwar die lokale Nutzung der Windkraft fördern wollten, nicht jedoch die Entstehung kommerzieller Windparks. Diese Kritik wurde durch politische Akteure wie dem Energieministerium gestützt (van Est 1999, 134 und 141). Man befürchtete, dass die Entstehung dezentraler Windparks die Stabilität des Versorgungssystems bedrohen könne. Auch die meisten Befürworter der Windkraft waren mit dieser Entwicklung nicht einverstanden:

,(They) welcomed the municipalities's interest in wind energy, but unmistakable disaproved of non-local private investors getting involved, fearing speculative forces would lead to chaotic development and turn West Jutland into a ,Wild West' ' (van Est 1999, 141).

Der Wachstumsschub und die Unzufriedenheit über dessen Entwicklungsrichtung, auch bei einem Großteil der Windenergie-Fürsprecher, ${ }^{222}$ bildeten die Rahmenbedingungen einer fundamentalen Transformation der Akteursstruktur. Der wirtschaftliche und technische Erfolg der Windkraft hatte die EVU bereits in Vergangenheit unter Druck gesetzt. Mit dem Aufbau der Windparks gerieten sie noch stärker unter Zugzwang. Sie erkannten, dass sie die Etablierung der Windkraft im Elektrizitätssystem nicht verhindern konnten. Aufgrund der industrie- und beschäftigungspolitischen Bedeutung, ergriff mittlerweile auch die konservative Regierung Partei für die Windkraft (van Est 1999, 88).

Für die EVU ging es um Schadensbegrenzung. Sie waren nicht bereit, die Kontrolle des Energiemarktes preiszugeben. Daher begannen sie mit dem Aufbau eigener Windparks, um die Hoheit über Planungsprozesse nicht zu verlieren (Hantsch 1998, 56ff.). Ende 1985, nachdem sie ihren ersten Windpark bei Masnedoe in Betrieb nahmen und einige Projekte das fortgeschrittene Planungsstadium erreicht hatten, trat der DEF auf die Regierung zu. In Geheimverhandlungen $^{223}$ wirkten sie auf die konservative Regierung ein, die

\footnotetext{
${ }^{221}$ Anfang 1984 brachte die Umweltpartei Radikale Venstre (RV) einen Gesetzesantrag ein, wodurch die Position der Windmüller gestärkt wurde (Hantsch 1998, 55).

${ }^{222}$,Von Seiten der Regierung war man ebenfalls unglücklich über die Entwicklung, dass die meisten Windmühlen über spekulative Projekte von großen Investoren erbaut wurden. (...) Man wollte nicht, dass die ,reichen Zahnärzte aus Kopenhagen' an der windigen Westküste Jütlands massenweise Windkraftanlagen errichteten und sich so auf Kosten der ohnedies ärmeren Region bereicherten.' (Hantsch 1998, 57).

${ }^{223}$ Auch die Interessenverbände der Windbranche der DV und FDV waren von den Gesprächen ausgeschlossen. Anhand dieses Beispiel werden die Grenzen ihrer Einflussmöglichkeiten deutlich (van Est 1999, 89). Die etablierte Energiewirtschaft stand der Regierung deutlich näher als die aufstrebende Branche.
} 
Subventionsvergabe für WEA restriktiver $\mathrm{zu}$ handhaben und den privaten Markt einzudämmen. Falls sich die Regierung bereit zeigte, entsprechende Regelungen einzuführen, würden die EVU verstärkt in Windparkprojekte investieren. Die Glaubwürdigkeit dieses Angebots erhöhten die Versorger dadurch, dass sie zum Zeitpunkt der Gespräche bereits einige Projekte in Angriff genommen hatten. Mit der Initiative lief der DEF bei der Regierung, welcher das Wachstum des Sektors zu schnell und unkontrolliert vonstatten ging, offene Türen ein. Sie wünschte sich den Aufbau von Windparks unter Kontrolle der Energiewirtschaft.

,The utility involvement in the Wind Power Program right from the beginning was founded on the expectation that the utilities would most likely be the owners and operators of future large-scale wind turbines connected to the Danish electricity grid system. ${ }^{124}$

Gegen Ende des Jahres einigten sich DEF und Regierung. Letztere nahm per Gesetz einige der wichtigsten Zugeständnisse, die von den EVU selbst im Rahmen der Regelung von 1984 gegeben wurden, zurück. Das Abstandskriterium von 1979, demzufolge alle Besitzer aus einem drei Kilometer Radius stammen mussten, wurde wieder eingeführt, jedoch auf zehn Kilometer ausgedehnt. Während die Besitzer einer Windanlage vormals in der nächstgelegenen Gemeinde leben mussten, dürfen sich nun auch Bewohner der Nachbarorte beteiligen. Ebenfalls galt wieder eine Einspeisungsobergrenze. Während ein Windmüller zuvor die 135\%-Grenze des Eigenverbrauchs nicht überschreiten durfte, gesteht man ihnen jetzt $150 \%$ zu. Darüber hinaus wird die Investitionsförderung von 20 auf $15 \%$ verringert und die Kapazitätsobergrenze für den Betrieb einer Windturbine durch Einzelpersonen auf $250 \mathrm{~kW}$ ausgedehnt (Hantsch 1998, 70). Durch diese Maßnahmen wurden Investorgruppen konsequent (WPM 1/86, 4) vom Markt ausgeschlossen. Diesem Akteur war 1985, auch zum Unmut lokaler Windinitiativen, der größte der Teil der Fördermittel zugeflossen (van Est 1999, 89).

Im Umkehrzug verpflichteten sich Elkraft und Elsam, auf eigene Kosten bis zum Jahr 1990, Windparks mit einer Gesamtkapazität von 100MW aufzubauen. Dieses ,100MWÜbereinkommen' (100MW-aftalen) sah vor, das Elsam 55 und Elkraft 45MW installierte. Für die Regierung ist dieser Kuhhandel in mehrerlei Hinsicht von Vorteil. Sie erreicht das Ziel der Integration der Stromwirtschaft in den Sektor. Der Ausschluss der Investorgruppen sichert die Akzeptanz der Regelung seitens Anrainer und Windmüller. Letztere sollten auch künftig auf dem Strommarkt aktiv bleiben, allerdings als Selbstversorger. Obgleich die Neuregelung auch auf Projekte angewendet wurde, die sich bereits im Planungsstadium befanden, verringerte sich die Inlandnachfrage seit 1986 nur leicht. Garud/Karnoe (2003, 293) gehen davon aus, dass auf diese Weise ein ,Danish wind rush' ähnlich dem kalifornischen Phänomen verhindert wurde. 225

Das Ziel der Regierung, dass die EVU in kürzerer Zeit den Sektor übernehmen würden, erwies sich bald als unrealistisch. Denn vielerorts lehnte die ansässige Bevölkerung die EVUPlanungen ebenso $\mathrm{ab}$, wie sie zuvor gegen die Investorgruppen opponiert hatte. ${ }^{226}$ Die

\footnotetext{
${ }^{224}$ Henning Grastrup (Elsam) und Poul Nielsen (DEF) 1990, 24, zitiert nach: van Est 1999, 84. Zum Zeitpunkt des Starts des DWP war der kommerzielle Erfolg der Kleinanlagen und damit die Einstiegsmöglichkeiten für private Betreiber nicht abzusehen.

${ }^{225}$ Andernfalls hätte die Gefahr bestanden, dass viele Standorte mit zu kleinen und vergleichsweise ineffizienten Turbinen besetzt worden wären (Garud/ Karnoe 2003, 293). In mindestens einem Fall kam diese Regelung unmittelbar den Planungen der EVU zugute. So ,erbte' Versorger SEAS einen Standort von einer privaten Entwicklungsfirma, welche diesen aufgrund der Wiedereinführung des Abstandskriteriums aufgeben musste. (WPM 8/86, 21)

${ }^{226}$ Seitens der Anrainer wurden die Windparks als Fremdkörper wahrgenommen. Jener Konsens, auf welchem die hohe Akzeptanz der Windkraft beruhte, dass die Einnahmen aus der Energieeinspeisung der lokalen Bevölkerung zuteil werden sollten, die schließlich mit den Lärmbelästigungen etc. leben musste, wurde sowohl von den Investoren, als auch den EVU gebrochen (keine Gewerbesteuereinnahmen, keine lokalen Beteiligungen).
} 
Realisierung vieler Projekte verzögerte sich wegen der Proteste. Daher wurden etliche Planungen aufgegeben, oder gar nicht erst genehmigt. Wie Tabelle 2.3.2a zu entnehmen ist, gelingt es den EVU bis 1987 nicht, auf dem Markt Fuß zu fassen. Erst seit 1988 werden sie zu einem signifikanten Faktor. Das 100MW-Ziel erreichen sie bis 1990 nicht.

Tab. 2.3.2a EVU-Windparks 1985-1991

\begin{tabular}{|l|l|l|l|l|}
\hline Jahr & $\begin{array}{l}\text { Installiert durch EVU } \\
\text { pro Jahr (MW) }\end{array}$ & $\begin{array}{l}\text { Installiert durch EVU } \\
\text { insgesamt (MW) }\end{array}$ & $\begin{array}{l}\text { Inlandmarkt } \\
\text { Jahr (MW) }\end{array}$ & $\begin{array}{l}\text { EVU-Anteil (\%) pro } \\
\text { Jahr }\end{array}$ \\
\hline 1985 & 3,8 & 3,8 & 25 & 15,2 \\
\hline 1986 & - & 3,8 & 30 & 0 \\
\hline 1987 & 3,5 & 7,3 & 25 & 14,0 \\
\hline 1988 & 31,0 & 38,3 & 82 & 46,7 \\
\hline 1989 & 2,3 & 40,6 & 93 & 2,4 \\
\hline 1990 & 37,4 & 78,0 & 80 & 46,8 \\
\hline 1991 & 5,0 & 83,0 & 70 & 7,1 \\
\hline
\end{tabular}

Quellen: FDV, 1992; Heymann 1995, 406

Nachfolgend sind die wichtigsten Marktbarrieren dargestellt, bei deren Bewältigung dem PAS eine Schlüsselrolle zugekommen ist (Tab. 2.3.2b).

Tab. 2.3.2b Probleme der Windbranche und Lösungsansätze des PAS (Periode 3)

\begin{tabular}{|c|c|c|c|}
\hline Problem & Lösungsansatz & Akteure & erfolgreich? \\
\hline $\begin{array}{l}\text { Krise der Windindustrie von } \\
1982\end{array}$ & $\begin{array}{l}\text { Verbesserung der Rahmenbedingungen } \\
\text { durch: } \\
\text { Befreiung von Energiesteuer; } \\
\text { Förderung der Analyse des US-Marktes; } \\
\text { Druck auf Energiewirtschaft } \\
\text { Eröffnung des kalifornischen Marktes } \\
\end{array}$ & $\begin{array}{l}\text { PAS, } \quad \text { Brown- } \\
\text { Administration }\end{array}$ & ja \\
\hline $\begin{array}{l}\text { Investoren reduzieren die } \\
\text { Akzeptanz der Windkraft }\end{array}$ & $\begin{array}{l}\text { Ausschluss profitorientierter } \\
\text { Entwicklungsfirmen von der Förderung; } \\
\text { Proteste durch Anrainer }\end{array}$ & PAS, Anrainer & ja \\
\hline $\begin{array}{l}\mathrm{Zu} \text { schnelles Wachstum } \\
\text { verringert } \\
\text { Innovationschancen, } \\
\text { dadurch: Besetzung der } \\
\text { Standorte durch kleine und } \\
\text { ineffiziente Anlagen }\end{array}$ & $\begin{array}{|clr|}\text { Verzögerung durch: } & & \\
- & \text { Verschlechterung } & \text { der } \\
& \text { Förderbedingungen } & \text { für } \\
& \text { Windkooperativen } & \\
- & \text { Anrainer-Proteste } & \text { gegen } \\
& \text { EVU-Windparks } & \\
\end{array}$ & PAS, Anrainer & $\mathrm{ja}$ \\
\hline
\end{tabular}

Quellen: vg. Kap. 2.2 und 2.3

\subsubsection{Dänemark: Windanlagenindustrie in Periode 3}

Bis zur Mitte der $80 \mathrm{er}$ Jahre werden mit der 55kW-Klasse deutliche Fortschritte erzielt. Zwischen 1981 und 1984 gelingt es, die Effizienz um 50\% zu verbessern (Garud/ Karnoe 2003, 290). Liegt die Wahrscheinlichkeit des Totalschadens einer 55kW-Anlage 1979 bei 50\%, so kann sie bis 1984 auf zwei Prozent verringert werden. 1985 wird eine Zuverlässigkeit von 98\% erreicht (Tacke 2004, 165). Grundlage dieser Verbesserungen ist die stabile Nachfrage der Kooperativen. Angesichts der seit 1982 stagnierenden Inlandnachfrage allerdings, droht die neue Industrie an Grenzen $\mathrm{zu}$ stoßen. Denn ihre großen Produktionskapazitäten werden nicht annähernd ausgeschöpft. Erst der immense Nachfrageschub durch den kalifornischen Markt ermöglicht Investitionen in die Ausweitung und Optimierung der Produktion. Auf diese Weise werden Voraussetzungen für den Eintritt in eine neue Entwicklungsphase geschaffen. $\mathrm{Zu}$ diesem Erfolg bei der Suche nach neuen Absatzmärkten leistet der Herstellerverband FDV mit seiner Analyse des US-Marktes einen wichtigen Beitrag. Die im August 1982 veröffentlichte Studie kommt zum Ergebnis, dass in Kalifornien ein sehr großer Markt für Windenergie entstehen würde (WPM 5/85, 13). Unmittelbar danach brechen Repräsentanten der vier großen Produzenten Vestas, Windmatic, 
Bonus $^{227}$ und Nordtank nach Kalifornien auf und bereiten ihren Markteinstieg vor. Noch im selben Jahr exportieren sie die ersten 40 WEA (van Est 1999, 87).

Für die dänische Windindustrie im besonderen sowie den Prozess internationaler Etablierung der Windtechnik im allgemeinen, war es ein Glücksfall, dass die 55kW-Anlage just zu diesem Zeitpunkt eine gute Reife ${ }^{228}$ erreicht und in Serien gefertigt werden kann (Heymann 1995, 413). So entstanden keine Verzögerungen, und die Dänen konnten ihr Produkt sofort liefern. Aufgrund technischer Defizite der 15 US-Hersteller gelingt es den Dänen schnell, auf dem neuen Markt Fuß zu fassen. Auch waren dänische WEA den Modellen der europäischen Konkurrenz deutlich überlegen (Kamp 2002, 156).

Zwischen 1983 und 1986 werden jährlich etliche Hundert Turbinen exportiert, 1985 sind es 3.000 (Tab. 2.3b). Der Exporterfolg hat nicht allein technische Gründe. Der hohe Dollarkurs, der zwischen 1980 und 1985 von 5,6 auf 10,7 DKK gestiegen war, ermöglichte es ausländischen Herstellern, ihre Produkte konkurrenzlos günstig anzubieten (Heymann 1995, 417). Nach 1984 werden die meisten Exporte von dänischen Investoren finanziert, die von der Qualität und Langlebigkeit ihrer Windanlagen überzeugt waren. Diese Situation erlaubte es den Exporteuren, ihre Produkte im Rahmen sogenannter ,package deals' anzubieten. Sie lieferten nicht nur die Windanlagen, sondern kümmerten sich auch um Finanzierung, Versicherung, Garantie ${ }^{229}$ und Serviceverträge (van Est 1999, 59).

Sowohl technisch als auch ökonomisch führt der neue Markt $\mathrm{zu}$ deutlichen Entwicklungssprüngen. 1984 wächst das Nettokapital der fünf größten dänischen Hersteller um Raten zwischen 100 und 250\% an. Ihre Bruttogewinne belaufen sich 1984 zwischen \$1,7 Mio. (Windmatic) und \$8,9 Mio. (Micon ${ }^{230}$ ). Im Vergleich zum Vorjahr gelingt es den Unternehmen im Jahr 1984, ihre Produktion durchschnittlich zu verdoppeln (WPM 9/85, 11). Bemerkenswert ist dabei die Höhe der Profitrate von 11,7\%, welche deutlich oberhalb des Landesdurchschnitts von 6,5\% gelegen ist (van Est 1999, 313 Fußnote 64). Angesichts dieser Extraprofite fällt es den Herstellern leichter, Kapazitäten auszuweiten und die Beschäftigtenzahl zu erhöhen. So verfügt die Windenergieabteilung von Vestas im Jahr 1982 über weniger als zehn Beschäftigte. 1984/85 sind es etwa 650 (www.windsofchange.dk, Abruf vom 15.4.08). In der selben Zeit vergrößert sich die Belegschaft Nordtanks von 30-35 auf circa 200 Beschäftigte (Beuse et al. 2000, 175).

Die zusätzlichen Mittel werden nicht ausschließlich genutzt, um die Produktion auszubauen. Viele Hersteller etablieren Konstruktionsteams, deren Aktivitäten von der Herstellung in der Fabrik und dem Betrieb am Standort getrennt waren. Auch in organisatorischer Hinsicht vollziehen sich mehrere, die Interaktion mit dem Käufer betreffende Formalisierungen. Dänische Versicherungs- und Zertifizierungskonzerne bestehen darauf, dass ihnen präzise Informationen über das Anlagendesign mitgeteilt werden. Dabei werden die

\footnotetext{
${ }^{227}$ Danregn hatte sich 1982 in Bonus umbenannt, weil die Amerikaner Probleme mit der Aussprache ihres Namens hatten.

${ }^{228}$ Paul Gipe vergleicht die dänischen mit den US-Anlagen: ,Sure, maybe the Danish machine would only work for three years before it needed some major fix, but the U.S. turbines would work for only one year or even shorter, before needed a big fix. To me it means three times better.' zitiert nach: van Est 1999

${ }^{229}$ Üblich war eine Garantie von fünf Jahren auf das Gesamtprodukt und drei Jahre auf die Hauptkomponenten (van Est 1999, 59).

${ }^{230}$ Micon wird 1983 durch Peder Moerup, einen vorherigen Mitarbeiter Nordtanks, gegründet. Micons Turbinendesign ähnelt jenem von Nordtank. Das neue Unternehmen wurde schnell sehr erfolgreich. Micon greift in deutlich höherem Umfang auf die Zulieferindustrie zurück als die Konkurrenz. Durch war es dem Unternehmen möglich, sehr schnell eine hohe Produktionskapazität zu erreichen, ohne am eigenen Standort, große Investitionen in den zeitintensiven Aufbau eigener Fabriken tätigen $\mathrm{zu}$ müssen (vg. www.windsofchange.dk, Abruf vom 15.4.08). Vestas verfolgte dagegen eine andere Unternehmensstrategie: So beginnt die Firma 1982 mit der Entwicklung und Produktion eigener Komponenten wie Rotoren und Kontrollsysteme. Angestrebt wird eine maximale Unabhängigkeit von der Lieferzeit und Produktionskapazität der Zulieferer (Kamp 2002, 154).
} 
Konstruktionsteams durch die Maschinenbauagentur Tripod unterstützt. Tripod, dessen Mitarbeiter zuvor am Nibe-Projekt beteiligt waren, hatten Messverfahren und Berechnungsprogramme entwickelt, mit denen bspw. die Aerodynamik des Anlagendesigns optimiert und Vibrationen minimiert werden konnten. Nachdem sich die anfängliche Skepsis vieler Hersteller bzgl. der Weitergabe technischer Details als unbegründet erwies, wird Tripod bald zu einem wichtigen Akteur auf dem Sektor technischer Entwicklung (Kamp 2002, 156). Mit den Turbinenfabrikanten wachsen auch die Zulieferbetriebe. Auch ihnen stehen jetzt beachtliche Mittel zur Verfügung. In den ersten Jahren der Anlagenproduktion verwendeten die Hersteller Standardkomponenten, die ursprünglich für andere Branchen wie den Automobil- und Maschinenbau gefertigt wurden, bspw. Getriebe und Generatoren. Angesichts der hohen Nachfrage ergibt sich für die Zulieferer sowohl die Chance, als auch die ökonomische Notwendigkeit der gezielten Spezialisierung und Optimierung ihrer Modelle (Heymann 1995, 417).

Sowohl in der Technik-, als auch der Stabilisierungsperiode ist die Bedeutung unabhängiger Rotorenhersteller stark betont worden. Hier stand insbesondere Alternegy (vormals Oekaer Vind Energi) im Zentrum des Blickpunkts. Das Beispiel der Entwicklung dieses Unternehmens in der Erprobungsperiode ist charakteristisch für die Zulieferindustrie insgesamt. Entsprechend dem Wachstum der Windturbinenhersteller expandiert auch Alternegy. Neben der Produktionsstätte von Slagelse werden die Rotoren noch an vier weiteren Standorten dänischer Lizenznehmer fabriziert. 1985 wird der 9m-, 1986 der 12mFlügel, für die 100kW-, bzw. 150kW-Klasse entwickelt. Bereits 1984 investiert GroveNielsen, ursprünglicher Gründer des Rotorenfabrikanten, seine Einnahmen aus dem Lizenzverkauf (s.o.), um in Spakaer einen Testring zu installieren. In Risoe können zu dieser Zeit nur Flügel mit einer Maximallänge von elf Metern einem Belastungstest unterzogen werden. Für weitere \$0,8 Mio. lässt Grove-Nielsen seinen Testring vergrößern, so dass dort 20m-Flügel geprüft werden konnten (www.windsofchange.dk, Abruf vom 15.4.08). Diese Tendenz, dass die Teststation von der Privatwirtschaft quasi ,überholt' wird, lässt sich ebenfalls am Beispiel der Gründung von Tripod beobachten. Die Teststation wurde eingerichtet, um einzelne Kleinwindanlagen, die an dänische Stromkonsumenten verkauft werden sollten, auf Betriebssicherheit und Stabilität zu testen. Auf die Anforderungen von Exportprodukten, die in großen Serien hergestellt werden sollten, war Risoe nicht ausgelegt.

Mit dem zunehmenden Exportmarkt wächst der Einfluss der Interessenorganisation der Industrie. In der Technikperiode und der ersten Hälfte der Stabilisierungsperiode, spielt der FDV keine wichtige Rolle. Der Konflikt mit der Käuferorganisation DV schwächte den Verband (s.o.). Zwischenzeitlich löste er sich auf und wird erst 1981 wiedergegründet. In den folgenden Jahren konsolidiert sich der FDV merklich und repräsentiert 1985, etwa 80\% der Windbranche Dänemarks. Er verhandelt mit dem Energieministerium, den Behörden, Energieunternehmen und Stromkonsumentenorganisationen. Die Exportgruppe des Verbands beschäftigt sich mit der Analyse neuer Märkte und nimmt an internationalen Energieausstellungen teil. Im Juni 1984 gibt der FDV eine Studie heraus, der zufolge Windkraft innerhalb der nächsten 15 Jahre kostengünstiger als moderne Kohlekraftwerke sein könnte. Der Verband kooperierte mit Risoe, in dessen Forschungskontrollgremium er Mitglied geworden ist (WPM 5/85, 11ff.).

Krise der Windindustrie

In den Jahren 1986-1988 gerät die Branche anlässlich der Schließung des kalifornischen Marktes in eine schwere Krise. Exportierten dänische Hersteller 1986 noch über 2.000 Windturbinen, reduziert sich diese Zahl 1987 auf 753 und 1988 auf 55 Anlagen. Bereits 1986 schreiben elf der zwölf Hersteller rote Zahlen (van Est 1999, 91). Im selben Jahr meldet Vestas Konkurs an, 1987 folgen Nordtank und Alternegy, 1988 sind es Wincon, Tellus, 
Windmatic und Vindsyssel. (Heymann 1995, 417). Allein 1987 gehen von den 3.000 Arbeitsplätzen der Windbranche 2.400 verloren (Tacke 2004, 165).

Doch lässt sich die Krise der dänischen Industrie nicht allein auf die Beendigung der tax credits zurückführen. Denn tatsächlich beginnt die Misere der dänischen Windindustrie bereits 1985, als sieben der zwölf Unternehmen Verluste einfahren (van Est 1999, 91). Diese Situation ist deshalb bemerkenswert, weil die Krise gerade in jenem Jahr einsetzt, in dem die meisten Turbinen nach Kalifornien exportiert wurden. Es mag wenig verwundern, dass die verschlechterte Fördersituation aufgrund des rapide nachlassenden Absatzes in eine Krise führen musste. Hier wäre eher die Frage nach den Auswirkungen zu stellen und wie die betroffenen Firmen darauf reagierten. Wenn allerdings eine Industrie trotz Rekordumsätze keine positiven Ergebnisse vorzuweisen vermag, so bedarf das näherer Betrachtung. Zur Erklärung sind mehrere Faktoren wichtig. Grundsätzlich ist zu berücksichtigen, dass die dänischen Anlagenhersteller mit dem Exportgeschäft kaum vertraut waren. Dieses ist daher ein Problem, weil sich die Situation auf dem kalifornischen Markt zunehmend verkomplizierte. Kalifornien war zu einem denkbar ungeeigneten Ort geworden, um sich Erfahrungen im Turbinenexport zu verschaffen. Jeder Fehler wurde von nun an hart bestraft. Wodurch also sind die Gewinneinbußen verursacht worden? Hier sind zwei Faktoren zu unterscheiden: Preisverfall und Zunahme der Reparaturkosten. Ein Teil des Preisverfalls lässt sich auf den gefallenen Dollarkurs zurückführen. Der andere Teil hängt mit der sich verschärfenden Konkurrenz zusammen. Es wurde bereits diskutiert, weshalb der kalifornischen Markt verstärkt größere WEA verlangte. Zunehmend entstand ein Wettbewerb darum, die nächstgrößere Leistungsklasse herauszubringen. Das Ende der tax credits vor Augen, kämpfen die Hersteller um den schrumpfenden Markt. ,A technological rat race began, in which manufacturers were forced to develop larger and more cost-effective wind turbines as rapidly as possible.' (Kamp 2002, 157).

Einer der Gründe der Überlegenheit der dänischen Industrie besteht in der Vorsichtigkeit, neue Leistungsklassen einzuführen. Dieses galt insbesondere für die 55kW-Anlage, die lange Zeit auf dem dänischen Markt getestet und erprobt werden konnte. Erst 1984 wird die neue $75 \mathrm{~kW}-$ Klasse serienmäßig hergestellt und angeboten. Seitdem sind, wegen der Nachfrage nach großen Anlagen, ausgiebige Tests und Qualitätskontrollen zu einem Luxus geworden, den sich die meisten Hersteller nicht mehr leisten konnten (oder wollten). Seit 1984 wird praktisch jedes Jahr ein größeres Modell herausgebracht. Mit der Einführung neuer Rotoren, deren Durchmesser zwischen 1984 und 1987 von 17 auf $25 \mathrm{~m}$ angewachsen sind, werden leistungsstärkere Modelle realisiert. Entsprechend nimmt die kW-Zahl im gleichen Zeitraum von 75 auf 200kW zu (Heymann 1995, 407). Die bisher marktüblichen (kleineren) Turbinen können nicht länger zum ursprünglichen Preis verkauft werden, weil die nächstgrößeren Modelle bereits verfügbar waren. Bei der Entwicklung neuer Konzepte überschätzten die meisten Unternehmen ihre Möglichkeiten. Die zusätzlichen Investitionskosten werden nicht hinreichend durch kommerzielle Erfolge technischer Innovationen kompensiert (van Est 1999, 91). Stattdessen führt das Upscaling zu erhöhter Schadensanfälligkeit und damit überproportionalen Reparaturkosten. ${ }^{231}$ Jetzt sind es nicht mehr nur die US-amerikanischen, sondern auch dänische Windanlagen, bei denen sich häufige Defekte einstellten. Allmählich kommt es daher unter dänischen Investoren und Versicherungen zu Vertrauensverlusten gegenüber einer zuvor als sehr zuverlässig wahrgenommenen Technologie. ${ }^{232}$

\footnotetext{
${ }^{231}$ Die häufigsten Probleme vieler kurzfristig auf den Markt gebrachten Turbinen bereiteten die Getriebe und Generatoren sowie deren Ölkühlung (Heymann 1995, 416).

${ }^{232}$ Ein Projekt des dänischen Investors Difko (s.u.) stellt ein Beispiel für diese Problematik dar. 1987 mussten fast 500 Micon-Turbinen, aufgrund eines schwerwiegenden Fehlers am Design der Flügelspitzen, gestoppt werden. Rotorenlieferant Alternegy hatte zu diesem Zeitpunkt bereits Konkurs angemeldet. Um längere (und imageschädigende) Gerichtsprozesse zu vermeiden, übernahm Difko zunächst die Verantwortung und trat mit der Zürich Insurance Co. in Kontakt. Letztere kam schließlich für den Schaden auf. Fälle wie diese trugen dazu bei, dass größere Investoren vorsichtiger wurden und Versicherungen davon Abstand nahmen, mit Windparkentwicklern Verträge zu schließen (van Est 1999, 94; detailliert: WPM 3/88, 8ff.). Auch Deefond, ein
} 
Ein großer Vorteil des dänischen Binnenmarktes besteht in der räumlichen Nähe der Hersteller zu den Turbinenstandorten. In Kalifornien können technische Mängel dagegen nicht mehr ohne Verzögerung an den Fabrikanten weitergeleitet werden. Hinzu kam, dass sich der Enthusiasmus, jede einzelne Anlage regelmäßig zu prüfen und sich bei auftretenden Mängeln mit dem Hersteller in Verbindung zu setzen, bei vielen Betreibern in Grenzen gehalten haben mochte (s.o.). Ein weiterer Grund, weshalb dänische Maschinen in Kalifornien schadensanfälliger als in Dänemark waren, besteht in den anspruchsvollen Bedingungen des heiß-kalten Wüstenklimas. Die ständigen Temperaturwechsel stellen wesentlich höhere Materialanforderungen als das gemäßigte maritime Klima Dänemarks (Hantsch 1998, 51). Inwieweit der Vorwurf dänischer Hersteller, die kalifornischen Wartungsteams der Betreiber seien unfähig und würden schlechte Arbeit leisten (Hantsch 1998, 51) zutrifft, kann hier nicht beurteilt zu werden.

Die Situation verschärfter Konkurrenz ist die Hauptursache der Verluste. Zudem besteht die Konkurrenz nicht mehr nur zwischen dänischen und US-amerikanischen Firmen. Diesen gegenüber hatten die Dänen einen technologischen Vorsprung. Daher war für sie keine Notwendigkeit gegeben, kurzfristig Innovationen auf den Markt zu bringen. Dieses änderte sich, als dänische Exporteure sich auf dem neuen Markt begegneten und damit erstmals auf ebenbürtige Wettbewerber stießen. ${ }^{233}$

Mit dem nahenden Auslaufen der tax credits erhöhte sich die Konkurrenz weiter, und viele der hier dargelegten Schwierigkeiten vergrößerten sich. Der fallende Dollarkurs war für die Hersteller in dieser Weise nicht vorherzusehen. Zwei wirklich schwerwiegende Fehler hingegen basieren auf einer kurzsichtigen Unternehmenspolitik der meisten Exporteure.

Der erste Fehler ist die massive Ausweitung der Produktionskapazität. Diese Haltung, blind von der langfristigen Stabilität eines einzigen neuen Marktes auszugehen, lässt sich kaum anders als fatalistisch bezeichnen. Einmal gebaute Fabriken konnten nicht einfach wieder abgerissen werden. So kam es, dass 1988, dem Tiefpunkt der Krise, die Kapazitäten den Markt um das Zehnfache überstiegen (Maegaard, Interview vom 2.7.07).

Der zweite Fehler besteht in der Trägheit, welche die Hersteller angesichts der Absehbarkeit des Nachfragerückgangs aufwiesen. Die Suche nach neuen Märkten schien eine untergeordnete Rolle gespielt zu haben. Noch 1985, als der Abbruch der Förderung unmittelbar bevorstand, resultiert noch immer der größte Anteil des Umsatzes dänischer Anlagenhersteller (2.100 von 2.275Mio. DKK) aus dem Export nach Kalifornien (Tacke 2004, 165). Beide Fehler können in besonderer Ausprägung bei Rotorenhersteller Alternegy beobachtet werden, der 1986 Konkurs anmeldete. 1984/85 errichtete die Firma in den USA zwei Fabriken. Unabhängig von der drohenden Schließung des Marktes produzierte Alternegy offenbar unbeirrt weiter. 1986 verfügte sie über ein Rotorenlager im Wert von über 30 Mio. DKK (Beuse et al. 2000, 148).

Nicht alle Hersteller waren derart unvorsichtig. Bonus etwa durchstand die Krise ohne größere Schäden und erreichte selbst 1986, als einziger Exporteur, noch eine positive Bilanz des Geschäftsjahres. Wichtigste Unterschiede gegenüber anderen Firmen sind eine behutsamere Expansion der Kapazitäten und ein langsameres Upscaling, wobei verstärkt darauf geachtet wurde, dass die neuen Maschinen vor dem Markteintritt intensiv getestet wurden (van Est 1999, 93). Schaubild 2.3b enthält eine Übersicht der Faktoren zur Erklärung

\footnotetext{
anderer dänischer Investor, sammelte auf dem kalifornischen Markt negative Erfahrungen, allerdings mit Anlagen des belgischen Herstellers HMZ. Deefond verklagte HMZ auf die Zahlung von \$15,5 Mio. (WPM 2/88, 14).

${ }^{233}$ Auf dem heimischen Markt existierte die Konkurrenz vor allem indirekt, über die Veröffentlichung von Output- und Zuverlässigkeitsstatistiken. Ein unmittelbarer Wettbewerb um den Zuschlag für bestimmte Standorte war in Dänemark insbesondere deshalb schwach ausgeprägt, weil sowohl Käufer als auch Verkäufer eine geografische Nähe zwischen Standort und Hersteller anstrebten. Insofern kamen ortsfremde Anbieter generell weniger in Betracht.
} 
der Krise. Aufgrund diverser ,Anfängerfehler' scheitert die dänischen Windanlagenindustrie daran, den Eintritt in die (politisch geförderte) Konkurrenz um die größte WEA zu meiden.

Schaubild 2.3b Ursachen der Krise dänischer Windanlagenexporteure

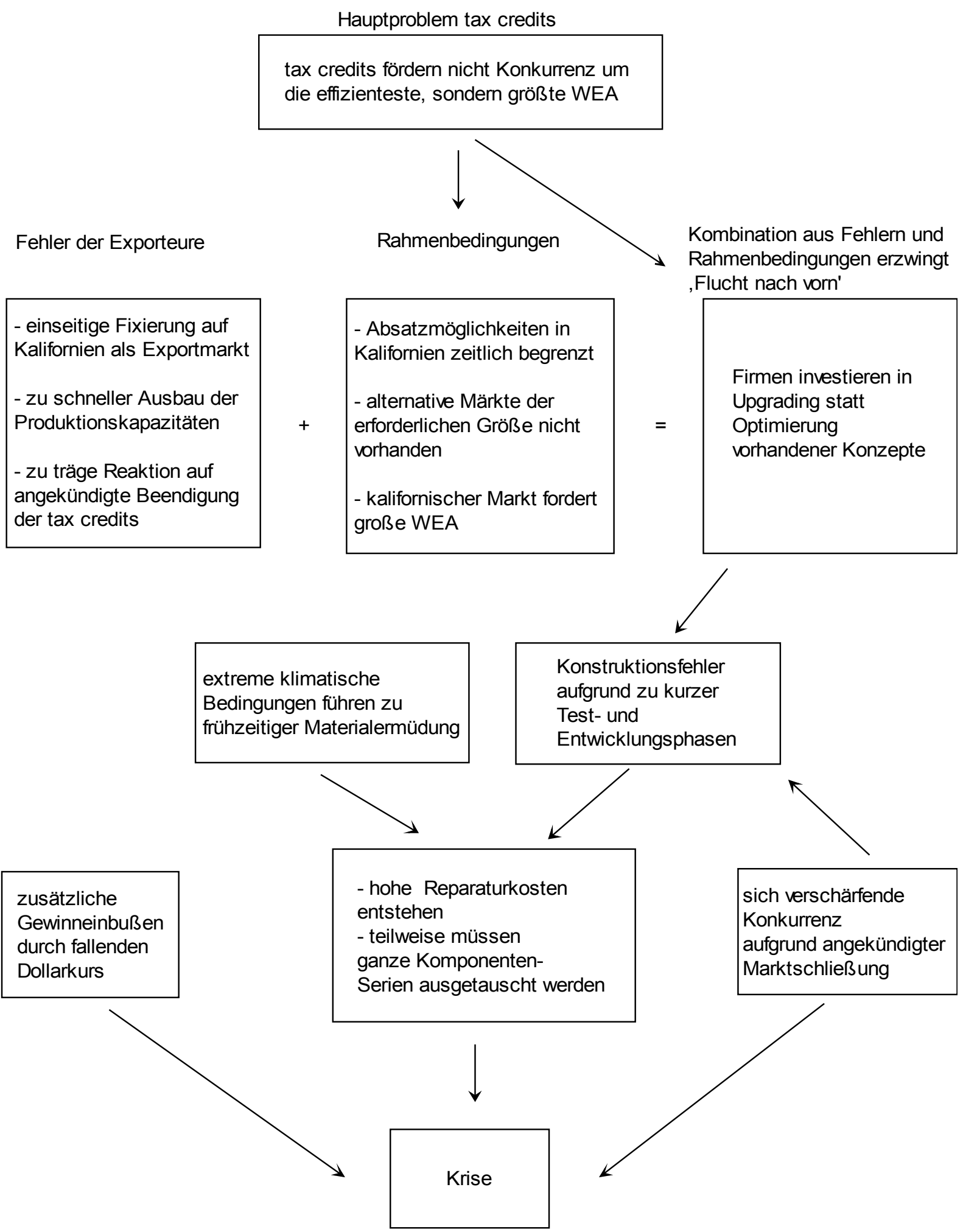


Der kooperative Entwicklungspfad: Ein Nebenstrang im Innovationsprozess

$\mathrm{Zu}$ den Merkmalen der Stabilisierungsperiode zählt die Durchsetzung des konkurrenzbasierten gegenüber dem kooperativen Entwicklungspfad der Windanlagentechnik. Unabhängig von seinem relativen Bedeutungsverlust existiert der letztere weiter. Repräsentiert wird er zum einen durch freie Zugänglichkeit von Konstruktionszeichnungen der Smedemester-, bzw. der Lollandturbine (s.o.). Letztere verzeichnete nicht nur in Dänemark gute Erfolge, sondern wurde auch nach Kalifornien exportiert.

1983 wird das Folkecenter für erneuerbare Energien gegründet. Es sollte künftig den organisatorischen Rahmen bilden, in dem die Schmiedemeistervereinigung ihre Arbeiten auf dem Windsektor durchführte. Dort arbeiteten Ingenieure, welche den Schmieden bei der Konstruktionsarbeit zur Seite standen. Ein wichtiges Kooperationsprojekt zwischen Folkecenter und Schmiedemeistervereinigung wird auf Bornholm realisiert, wo man zehn Windanlagen (je 99kW) herstellte. Die Genossenschaft Dansk Andelsenergi, welche von ihren Mitgliedern durch Einlage von 100.000 DKK je Mitglied gegründet wurde, finanzierte und koordinierte das Projekt (Beuse et al. 2000, 209f.). Insgesamt werden circa 175 Smedemesterturbinen gebaut. Diese Arbeiten sind nicht ohne Einfluss auf den kommerziellen Sektor geblieben. So entwickelten Kim Andersen und Knud Buhl, die am Design der LollandTurbine beteiligt waren, später die erste Windanlage für die Kesselfabrik Nordex (ebd., 209). Das Unternehmen, das wie viele andere Windanlagenhersteller zur metallverarbeitenden Branche zählt, bringt 1985 sein erstes Modell heraus. Nordex zählt gegen Ende der 90er Jahre zu den zehn erfolgreichsten Herstellern von WEA. WindWorld ist ein weiteres Beispiel für Unternehmen, die von der Arbeit der Schmiedemeister profitieren und deren erste Turbinenkonzepte stark den Smedemesteranlagen ähneln (ebd., 211).

Das letzte große Windprojekt des Folkecenters ist eine im Jahr 1987 gestartete EU-geförderte Kooperation zwischen ihm und dem deutschen Getriebehersteller Tacke. Dabei sollten sowohl das Folkecenter, als auch Tacke jeweils in Dänemark bzw. der Bundesrepublik eine große $525 \mathrm{~kW}$-Anlage produzieren. Tacke stellte für das Projekt vor allem die großen 15-TonnenGetriebe bereit. Das deutsche Unternehmen erhielt Gelegenheit, sich umfangreiches Knowhow über Lastanforderungen und Konstruktion anzueignen. 1992 wird das Projekt abgeschlossen. Beide Anlagen können im September 1992 installiert werden und arbeiteten einwandfrei.

Das Folkecenter hatte sich während der 80er Jahre vergeblich darum bemüht, die La Cour Tradition im Windsektor zu etablieren. Bis zur Mitte der 80er Jahre ist die Windkraft zu einer, praktisch ausschließlich durch Marktgesetze bestimmten Branche geworden. Kleinere Anlagenproduzenten, die ihr Konstruktionswissen aus dem Folkecenter erhielten und mitunter keine eigenen Ingenieure beschäftigten, sind auf dem Markt kaum noch überlebensfähig (Tacke 2004, 168). Da der Vorstand des Folkecenter nicht länger bereit war, Ressourcen für ein vollständig kommerzialisiertes Feld einzusetzen, gab man den Windsektor 1992 auf (Beuse et al. 2000, 211ff.).

\section{Zusammenfassung}

Für dänische Windanlagenhersteller kam die Eröffnung des kalifornischen Marktes zum richtigen Zeitpunkt. Sie trug maßgeblich zur Bewältigung der Binnenmarktkrise bei. Die Erfolge auf dem Exportmarkt waren keine Selbstverständlichkeit. Sie basieren darauf, dass es den Dänen nach jahrelanger Arbeit gelungen war, mittelgroße WEA mit hoher Zuverlässigkeit und Effizienz zu entwickeln. Bis 1984 genossen dänische Windturbinen in Kalifornien insbesondere auch deshalb einen sehr guten Ruf, weil die inländischen Hersteller weit hinter den Standard zurückfielen. Daher waren die Anbieter aus Dänemark zunächst ohne Konkurrenz. 1985 ändert sich die Situation. Angesichts der auslaufenden tax credits beteiligen sich nun auch Dänen an dem Wettrennen um immer größere Modelle, die am 
stärksten nachgefragt werden. Aufgrund häufiger Schäden und Konstruktionsfehler entstanden so hohe Reparaturkosten, dass etliche Hersteller Konkurs anmelden mussten. Van Est (1999, 93) konstatiert, dass es den Exporteuren insgesamt nicht gelungen war, ihre führende technologische Position in ,hard cash' zu verwandeln. Ihre Präsenz auf dem großen Exportmarkt stellt eine Pionierleistung dar, die viele mit hohen Lehrgeldern bezahlen mussten.

Angesichts der Fehler und Pannen wie sie auf dem kalifornischen Markt zu beobachten sind, lässt sich trotz und zugleich wegen der umfangreichen Erprobung der Windenergie nicht davon sprechen, die neue Technologie hätte den Status der proven technology erreicht. Tabelle 2.3.2c fasst die Probleme zusammen, mit denen die Windanlagenindustrie im Verlauf der Erprobungsperiode konfrontiert war und zu deren Lösung sie beigetragen hat. Die größte Herausforderung der Windindustrie bildet die Überwindung ihrer Krise, in welche sie, infolge der Beendigung der tax credits geraten ist. Daran scheiterte sie zunächst. Erst 1988/89, in der nachfolgenden Periode 4, erholt sich die Branche.

Tab. 2.3.2c Probleme der Windanlagenindustrie und Lösungsansätze (Periode 3)

\begin{tabular}{|c|c|c|c|}
\hline Problem & Lösungsansatz & Akteure & erfolgreich? \\
\hline Krise der Windindustrie von 1982 & $\begin{array}{l}\text { Verbesserung } \\
\text { Rahmenbedingungen durch: } \\
\text { Befreiung von } \\
\text { Energiesteuer; } \\
\text { Förderung der Analyse des } \\
\text { US-Marktes; Druck auf } \\
\text { Energiewirtschaft } \\
\text { Eröffnung des kalifornischen } \\
\text { Marktes }\end{array}$ & $\begin{array}{l}\text { PAS, } \\
\text { Administration }\end{array}$ & ja \\
\hline $\begin{array}{l}\text { Projekte werden zu groß, als dass sie } \\
\text { allein von Herstellern finanziert und } \\
\text { versichert werden können }\end{array}$ & $\begin{array}{l}\text { Banken, Versicherungen } \\
\text { und Investoren (Difko etc.) } \\
\text { betreten den Sektor; PAS } \\
\text { unterstützt Exporte }\end{array}$ & Finanzakteure, PAS & ja \\
\hline $\begin{array}{l}\text { Dänische Anlagenhersteller sind schlecht } \\
\text { auf die Erfordernisse des kalifornischen } \\
\text { Exportmarktes vorbereitet: dort werden } \\
\text { kurzfristig immer größere WEA verlangt. }\end{array}$ & $\begin{array}{l}\text { Teilnahme an der } \\
\text { Konkurrenz um die größte } \\
\text { (und teuerste) WEA, die am } \\
\text { meisten nachgefragt wird } \\
\text { (,Flucht nach vorn') }\end{array}$ & Windindustrie & $\begin{array}{llr}\text { nein, die } & \text { Errichtung } \\
\text { fehlerhaften } & \text { WEA } \\
\text { schafft mehr Probleme } \\
\text { als sie zu lösen } \\
\text { vermochte } & & \\
\end{array}$ \\
\hline $\begin{array}{l}\text { Nach Beendigung der tax } \\
\text { entstehen Übedits } \\
\text { mangelnder Absatzmärkte }\end{array}$ & - & & $\begin{array}{l}\text { nein, Industrie tritt in } \\
\text { Krise. Zwischen 1986- } \\
88 \text { gehen die meisten } \\
\text { Hersteller Bankrott. }\end{array}$ \\
\hline
\end{tabular}

Quellen: vg. Kap. 2.3

Die wichtigsten Transformationsprozesse der Windanlagenindustrie, welche diese zwischen der Stabilisierungs- und Erprobungsperiode sowie innerhalb der Erprobungsperiode durchlaufen hat, betreffen die Wachstumsgeschwindigkeit der Produktionskapazitäten und Windturbinengrößen, die Absatzmärkte und den Konkurrenzgrad der Hersteller untereinander (Tab. 2.3.2d). 
Tab. 2.3.2d

Transformationsprozesse der Windindustrie: Von der Stabilisierungs- zur Erprobungsperiode

\begin{tabular}{|c|c|c|c|}
\hline & Stabilisierungsperiode & $\begin{array}{|lc|}\begin{array}{l}\text { Erprobungsperiode } \\
(1983-1985)\end{array} & \text { früh } \\
\end{array}$ & \begin{tabular}{|l|}
$\begin{array}{l}\text { Erprobungsperiode } \\
(1986-1988)\end{array}$ \\
\end{tabular} \\
\hline $\begin{array}{l}\text { Entwicklung } \\
\text { Produktion }\end{array}$ & moderates Wachstum & sprunghaftes Wachstum & $\begin{array}{l}1985 \text { setzt Absatzkrise ein, } \\
\text { Tiefpunkt } 1988\end{array}$ \\
\hline $\begin{array}{l}\text { Verhältnis der } \\
\text { Relevanz von Inland- } \\
\text { und Exportmarkt }\end{array}$ & $\begin{array}{l}\text { Absatz bis } 1981 \text { ausschließlich } \\
\text { im Inland }\end{array}$ & $\begin{array}{l}\text { seit 1983: größter Anteil der } \\
\text { Produktion für den Export }\end{array}$ & $\begin{array}{lr}\text { nachlassende } & \text { Exporte, } \\
\text { Inlandnachfrage } & \text { nimm } \\
\text { wieder zu } & \\
\end{array}$ \\
\hline $\begin{array}{l}\text { Konkurrenzgrad unter } \\
\text { dänischen } \\
\text { Turbinenherstellern }\end{array}$ & $\begin{array}{l}\text { zwar: Durchsetzung des } \\
\text { konkurrenzbasierten } \\
\text { Entwicklungsstils; Dennoch: } \\
\text { geringe Konkurrenz der Hersteller } \\
\text { untereinander }\end{array}$ & $\begin{array}{l}\text { Hersteller treten erstmals auf } \\
\text { dem kalifornischen Markt } \\
\text { zueinander in Konkurrenz }\end{array}$ & $\begin{array}{l}\text { Verschärfte Konkurrenz } \\
\text { seit 1985, infolge } \\
\text { nahender Beendigung der } \\
\text { tax credits; kooperativer } \\
\text { Entwicklungspfad führt } \\
\text { weiterhin Nischenexistenz: } \\
\text { Smedemester/ Folkecenter }\end{array}$ \\
\hline Produktionsart & Beginn der Serienfertigung & \begin{tabular}{|lr} 
weitere Formalisierung der \\
Anlagenproduktion, bspw. \\
stärkere Trennung zwischen \\
Konstruktion und Produktion; \\
Kooperation \\
Zertifizierungsunternehmen mit \\
\end{tabular} & - \\
\hline \begin{tabular}{|l|} 
Entwicklung \\
WEA-Größe
\end{tabular} & $\begin{array}{l}\text { Ein Wachstumssprung von } 30 \text { auf } \\
55 \mathrm{~kW}\end{array}$ & \begin{tabular}{|l} 
Vorsichtige \\
Entwicklungsschritte: von 55 , \\
über $65,75,90$ und $100 \mathrm{~kW}$
\end{tabular} & $\begin{array}{l}\text { Entwicklungssprünge seit } \\
\text { 1985: auf } 150 \text { und } 200 \mathrm{~kW}\end{array}$ \\
\hline
\end{tabular}

Quellen: vg. Kap. 2.1, 2.2, 2.3, 2.4

\subsubsection{Dänemark: Windanlagenkäufer und -betreiber in Periode 3}

Schon die vorangegangene Periode zeichnet sich gegenüber der Technikperiode durch eine Diversifikation der Käuferstruktur aus. Diese Entwicklung setzt sich jetzt konsequent fort. Neben die lokalen Kooperativen, treten nun Investoren, Kommunen und Energieversorger. Mit dem Einzug von Investorgesellschaften, die 1984/85 Windparks entwickelten und an ,reiche Zahnärzte aus Kopenhagen' verkauften, tritt auch in Dänemark eine regelrechte Merkantilisierung des Sektors ein. Ein Novum ist auch die Entstehung dänischer Unternehmen, welche mit Geldern dänischer Investoren, Windparks in Kalifornien finanzierten. Der Energiewirtschaft kommt in dieser Periode erstmalig eine aktive Rolle zu. Der Aufbau erster EVU-Windparks im Jahr 1985 und das 100MW-Abkommen zeigen die Bereitschaft der Energiewirtschaft, Windenergie langfristig als Komponente des Stromsektors zu akzeptieren. Schließlich betreten einzelne Kommunen und Anlagenhersteller, die ihre Produkte testen wollten, das Feld. Die lokalen Kooperativen bleiben weiterhin auf dem Markt präsent.

\section{Investoren}

1984 ermöglicht der DEF einen Nachfrageboom. Unter Druck der Regierung muss der Verband den Windmüllern weitgehende Zugeständnisse machen. Im Rahmen dieser freiwilligen Übereinkunft werden zwei der wichtigsten Einschränkungen der Stromeinspeisung durch Windmüller aufgehoben: Die Produktionsgrenze von 130\% des Eigenverbrauchs wird ebenso aufgehoben wie die Entfernungsbeschränkung der Betreiber zum Standort von drei Kilometer. Die E-Werke beteiligen sich von jetzt an zu einem Drittel an den Installationskosten. Jeweils ein Drittel übernehmen Staat und Käufer (Traenes 1997, 8). Neu geregelt werden auch die Einspeisetarife. Selbstversorger, die nur den Überschussstrom ins Netz leiteten, erhielten $70 \%$ des durchschnittlichen Nettostrompreises. ${ }^{234}$

\footnotetext{
${ }^{234}$ Begründet wurde dieser Unterschied damit, dass Selbstversorger entweder nur den Überschussstrom ins Netz speisten, oder, im Fall der Windstille, zu 100\% von den Lieferungen des Versorgers abhängig waren (vg.
} 
$85 \%$ standen denjenigen Betreibern $\mathrm{zu}$, die ausschließlich für die Netzeinspeisung produzierten (Heymann 1995, 415). Die Gültigkeitsdauer dieser Regelungen wird auf zehn Jahre festgelegt. Hervorzuheben ist die Verhandlungsmacht des DV, der sich praktisch in all seinen Forderungen durchzusetzen vermochte. Nie zuvor herrschten in Dänemark so günstige Bedingungen für die Windmüller.

Im Juli 1985 wird in Thyholm der erste kommerzielle Windpark Dänemarks von der Entwicklungsfirma Danish Windmill Park A/S in Betrieb genommen. Das Unternehmen ist die erste, auf dem dänischen Markt präsente Aktiengesellschaft. Sie wurde speziell für Planung und Betrieb dieses Windparks gegründet. Aufgrund des besonderen Charakters des Projekts erhielt Danish Windmill Park A/S zusätzlich zur regulären Investitionsförderung weitere Mittel von der Regierung. Gekauft wurden 20 55kW-Maschinen (jeweils zehn WEA von Vestas und Bonus, WPM 8/85, 4). Der erste Windpark Dänemarks ist ein Pionierprojekt. Den Planern fehlten bspw. wichtige Kenntnisse, um den Aufwand der Installation adäquat zu kalkulieren. Die tatsächlichen Anschlusskosten, die anfangs mit $\$ 240.000$ veranschlagt wurden, überstiegen diesen Wert um das Fünffache (ebd.). Die Genehmigung zum Aufbau weiterer 25 Turbinen in der Nähe der ersten Anlage hatte Danish Windmill Park A/S zu dieser Zeit bereits erhalten. Die Entwicklungsfirma Trameda Engineering plante den Aufbau von 70 $150 \mathrm{~kW}$-Anlagen. Den Anteilseignern versprach das Unternehmen steuerfreie Gewinne bis zu $\$ 10.000$ (WPM 9/85, 12). Taendpibe Windfarm I/S ist eine andere neu gegründete Entwicklungsfirma, die 1985 mit der Realisierung eines Windparks (35 WEA à 75kW) beschäftigt war (WPM 12/85, 6). Auch Hersteller wie Vestas traten als Entwickler auf. Vor allem zu Testzwecken wollte das Unternehmen 35 seiner $75 \mathrm{~kW}$ - und 10 der neuen $150 \mathrm{~kW}$ Turbinen errichten. Für das Projekt erhielt Vestas als zusätzliche Förderung, die Möglichkeit, $25 \%$ der Investition von der Steuer abzusetzen. Zuerst bot Vestas der Belegschaft, anschließend der ansässigen Bevölkerung die Möglichkeit zum Kauf von Anteilen (ebd.).

Die Neuregelung gerät auch bei zahlreichen Unterstützern der Windkraft in Misskredit. Denn sie führte nicht nur dazu, dass sich städtische Investoren auf Kosten der ländlichen Bevölkerung bereicherten. Zudem wurden denkbare Planungen lokaler Betreiber konterkariert, weil potenzielle Standorte ,okkupiert' worden sind. Turbinenfabrikant Nordtank etwa, plante sogar vier Windparkprojekte. Die Umweltpartei von Skagen, wo einer dieser Windparks entstehen sollte, wendete ein, dass den Einwohnern dadurch die Möglichkeit genommen würde, eigene Windmühlen zu betreiben. Aufgrund lokaler Proteste wurde Nordtank die Genehmigung für ein weiteres Projekt in Venoe verweigert (ebd.). Konkurrenz um die Standorte war nicht der einzige Grund einer zunehmenden Polarisierung zwischen Entwicklungsgesellschaften und lokalen Interessenten. So erhielten mehrere Privatpersonen, die in der Nähe des Windparks von Thyholm einzelne WEA installieren wollten vom zuständigen Versorger keine Anschlusserlaubnis. Begründet wurden die Absagen damit, dass das Umspannwerk, nach Inbetriebnahme des Windparks, keine weitere Energie aufnehmen könne und die Installation eines weiteren Umspannwerkes Kosten in Höhe von \$210.000 nach sich ziehen würde (WPM 8/85, 4).

\section{Kommunen}

Auch einzelne Gemeinden wie Ebeltoft, setzten auf Windkraft. 1983 nimmt die Stadt Planungsarbeiten für einen Windpark auf. Sechzehn 55kW-Turbinen und eine 100kWTestanlage von Nordtank werden im Sommer 1985 installiert. Insgesamt betragen die Projektkosten 21 Mio. DKK. Die Hälfte des Betrags musste für den Bau der 800m langen Mole aufgewendet werden, wo die Anlagen errichtet wurden. Das Energieministerium förderte das Projekt mit neun Mio. DKK. Pro Jahr sollte der Windpark Einsparungen in Höhe von 0,5 Mio. DKK. bringen, um zur Preisstabilität und Energiesicherheit beizutragen. Hinzu kommen positive Beschäftigungseffekte. Zwischen 1980 und 1983 sind bei dem

Traenes 1997, 9). 
Turbinenhersteller Nordtank 70 neue Beschäftigungsverhältnisse entstanden. Die Schaffung 35 weiterer Arbeitsplätze erwartete Ebeltoft aufgrund der Arbeiten an dem kommunalen Projekt (WPM 4/85, 10). Hasle auf Bornholm ist in eine weitere Gemeinde, die bereits Mitte der 80er Jahre in den Windsektor eingestiegen war. Sie arbeitete mit einem lokalen Schmiedeunternehmen zusammen, dass ihr zehn 99kW-Turbinen des Smedemester-Typs lieferte (WPM 9/85, 13).

EVU als Windanlagenkäufer

Seit 1985 werden energiewirtschaftliche Akteure, die zuvor ausschließlich an LSP-Projekten interessiert waren, erstmals auf dem kommerziellen Windmarkt aktiv. Der strategische Hintergrund ihrer Initiative, ihr Kuhhandel mit dem Energieministerium und die Probleme bei der Umsetzung des 100MW-Plans sind bereits dargelegt worden. Im folgenden geht es um die Bedeutung der EVU als Anlagenkäufer. Grundsätzlich ist ihr Engagement im Windsektor problembehaftet. Zum einen sind ihre Windparkpläne oft durch Proteste erschwert oder verhindert worden. Durch den Kauf möglichst großer Anlagen, mit einem vergleichsweise geringen Flächenbedarf wollte man diesem Problem beikommen. Unabhängig davon besteht eine prinzipielle Affinität zu Großanlagen. 1985 eröffnet der DEF in Masnedoe seinen ersten Windpark mit fünf $750 \mathrm{~kW}$-Windturbinen, der noch im Rahmen des staatlichen Forschungsprogramms realisiert wird. Bereits kurz nach Betriebsstart zeigt sich, dass die vergleichsweise großen WEA - handelsüblich sind 1985 etwa 100-200kW - bzgl. Effizienzund Zuverlässigkeitswerten, deutlich hinter die kommerziellen Produkte zurückfallen. Es war bekannt, dass die Stromgestehungsanlagen der LSP-Windturbinen um das Drei- bis Vierfache höher lagen als marktgängige Anlagen. Dennoch zeigten sich die EVU zunächst nicht bereit, kommerzielle WEA zu nutzen, deren Nennkapazität unter $300 \mathrm{~kW}$ lag. Sie waren stattdessen an der 300-700kW-Klasse interessiert (WPM 9/86, 6f.). Stromversorger SEAS etwa ließ verlauten, dass das Unternehmen den größten Windpark Europas bei Viborg mit 12-13 400kW-Anlagen aufzubauen gedachte (WPM 10/86, 21). Die Umsetzung des 100MWProgramms der EVU geht anfangs nur schleppend voran. Bis Ende 1987, zwei Jahre nach dem Start des Programms, hatten die EVU erst zwei Windparks installiert, wobei es sich beim Masnedoe-Projekt noch um ein Element des LSP-Programms handelte. Unter den Herstellern wuchs die Sorge, dass die EVU so lange warten würden, bis die Industrie in der Lage gewesen wäre, Turbinen in der von ihnen geforderten Größe zu liefern (van Est 1999, 95). Seitens der Versorger wurde dagegen behauptet, die Projekte verzögerten sich vor allem aufgrund eines ,chaotischen Zusammenspiels zentraler, regionaler und kommunaler Behörden, Standorteigentümern und ansässiger Bevölkerung' (ebd., 95f., Übersetzung: M.N.). Unabhängig davon, ob die Verzögerungen eher auf ein Taktieren der Energiewirtschaft, oder äußere Hemmnisse zurückzuführen sind: Betrachtet man die Statistik der von den EVU schließlich installierten Windparks so fällt auf, das, entgegen ursprünglicher Ankündigungen, zu großen Teilen kleinere Anlagen verwendet werden (Tab. 2.3.2e). Noch 1988, als erstmals mehrere Windparks den Betrieb aufnehmen, lag die durchschnittliche Generatorenkapazität von 164 Windanlagen bei $188,7 \mathrm{~kW}$. Dieser Wert liegt an der oberen Grenzen der im kommerziellen Sektor zu dieser Zeit handelsüblichen Anlagengröße. 
Tab. 2.3.2e

EVU-Windparks 1985-1991

\begin{tabular}{|c|c|c|c|c|}
\hline Ort & Jahr der Installation & $\begin{array}{l}\text { Anzahl, Nennleistung } \\
(\mathrm{kW})\end{array}$ & \begin{tabular}{|l|l|} 
Kapazität & der \\
Windparks & $(\mathrm{MW})$
\end{tabular} & $\begin{array}{l}\text { Durchschnittliche } \\
\text { Turbinengröße } \\
\text { neu installierter WEA } \\
(\mathrm{kW})\end{array}$ \\
\hline Masnedoe & 1985 & $5 \times 750$ & 3,8 & 1985: \\
\hline Velling Maersk 1 & 1987 & $34 \times 90 ; \quad 2 \times 200$ & 3,5 & 1987: \\
\hline Hollandsbjerg & 1988 & $30 \times 130 ; \quad 2 \times 300$ & 4,5 & \\
\hline Ryaa & 1988 & $30 \times 200$ & 8,0 & \\
\hline Noerrekaer Enge 1 & 1988 & $36 \times 130$ & 4,7 & \\
\hline Syltholm & 1988 & $25 \times 400$ & 10,0 & \\
\hline Kyndby & 1988 & $21 \times 180$ & 3,8 & 1988: \\
\hline Torrild & 1989 & $15 \times 150$ & 2,3 & 1989: \\
\hline Öester Marie & 1990 & $7 \times 225$ & 1,6 & \\
\hline Kappel & 1990 & $24 \times 400$ & 9,6 & \\
\hline Oroe & 1990 & $5 \times 200$ & 1,0 & \\
\hline Noerrekaer Enge 2 & 1990 & $42 \times 300$ & 12,6 & \\
\hline Velling Maersk 2 & 1990 & $29 \times 225$ & 6,5 & \\
\hline Vedersoe Kaer & 1990 & $27 \times 225$ & 6,5 & 1990: \\
\hline Vindeby (Offshore) & 1991 & $11 \times 450$ & 5,0 & 1991: \\
\hline
\end{tabular}

Quellen: FDV, 1992; eigene Berechnungen

Das Engagement der EVU hat einerseits strategische Gründe. In ihrem wichtigsten Ziel, die netzunabhängige Konkurrenz zu vermindern, erreichten sie beachtliche Erfolge. Der Boom neuer Windkooperativen wird 1986 gestoppt. Investoren können vom dänischen Markt gedrängt werden. Mit den von ihnen durchgeführten Untersuchungen über Probleme beim Netzanschluss von WEA verfolgten sie offenbar das Ziel, Obergrenzen für die Kapazität neu installierter Windparks zu definieren (WPM 9/86, 7). Für SEAS-Sprecher Ove Moeller hat die Ankündigung, den größten Windparks Europas (Viborg-Projekt) zu errichten, ,ein wenig von einem politischen Schauspiel' (WPM 8/86, 21, Übersetzung: M.N.). ${ }^{235}$ Inwieweit diese Aussage für das Verhältnis der EVU insgesamt zum 100MW-Abkommen gilt, lässt sich an dieser Stelle nicht nachweisen. Jedenfalls wäre es verfehlt, der Energiewirtschaft zu unterstellen, sie würde immer die größten WEA kaufen, um deren Versagen aufzuzeigen. ${ }^{236}$ Vielmehr entscheiden sich Elsam und Elkraft seit 1987 für die effizientesten Windanlagen. 1985 führt der DV eine Umfrage unter 200 seiner Mitglieder durch. Ein Ergebnis der Umfrage ist, dass sich die Beziehung zwischen Windmüllern und jeweiligen Netzbetreibern positiv zu entwickeln schien. ,It is clear that there is beginning to be better understanding and systematization beween WECS owners and the utilities. Some of the local utilities even received a top score of 4.' (DV-Vorsitzender Torgny Moeller in: WPM 9/85, 11). Die Frage nach der Zufriedenheit mit der Kooperationsbereitschaft ihres Versorgers beantworteten 184 der 200 Teilnehmer und kamen dabei, auf einer Skala von 1 bis $4(1=$ sehr zufrieden, $4=$ sehr unzufrieden) zu einem durchschnittlichen Ergebnis von 2,83. Die verbesserte Beziehung mancher Windmüller zu ,ihrem' Versorger, korreliert nicht unbedingt mit dem Verhältnis beider Akteure auf politischer Ebene. Denn die Pläne, die von den EVU mit ihrem aktiven Einstieg in den Markt offenbar verfolgt werden, stießen bei den Windmüllern auf deutliche Ablehnung. Elsam-Vorsitzender Groenborg Christensen artikuliert den Monopolanspruch der EVU:

,It should be the electricity companies, not private individuals, who should build, own and operate windmills in the future.' (zitiert nach: WPM 1/86, 4).

Weiter forderte Christensen die Übernahme der Windanlagenindustrie durch die Energiewirtschaft (ebd.). Angesichts damaliger politischer Kräfteverhältnisses waren solche

\footnotetext{
${ }^{235}$ Ähnlich ist bereits die Beteiligung der EVU am LSP-Programm wahrgenommen worden (vg. Kap. 1).

${ }^{236}$ Zumal wäre es für sie leichter gewesen, ihre Verpflichtung gegenüber dem Energieministerium zu erfüllen, 100MW Windenergiekapazität bis 1990 zu installieren, wenn sie sich konsequent für die leistungsstärksten Modelle entschieden hätten.
} 
Forderungen wenig realistisch. Unterstützung erhielten die EVU lediglich von der konservativen (Minderheits-)Regierung. ${ }^{237}$

Dänische Investoren auf dem kalifornischen Markt

Als ein weiterer neuer Käufertyp sind in dieser Periode Finanzinvestoren zu betrachten, die mit dänischem Kapital Windparks auf dem scheinbar lukrativen Markt Kaliforniens erwarben. Dort waren vor allem zwei Gesellschaften aktiv: DIFKO (Danish Investment Fund) und DEEFOND (Danish Energy Export Fund). ${ }^{238}$ Bei DIFKO handelt es sich um eine große Investmentgesellschaft, die 1990 von 63 Investment-Firmen getragen wird. Über 60.000 Dänen investierten bei DIFKO (van Est 1999, 313). Der Investor finanzierte mehr als 1.100 Windanlagen in Kalifornien. Um den Export dänischer Technologie zu fördern, erhielt DIFKO Investitionszuschüsse von der Regierung (WPM 2/88, 14). In Kalifornien betrieb die Gesellschaft im Jahr 1990 neun Windparks. Von diesen waren vier profitabel, vier schrieben Verluste und einer musste wegen zahlreicher Defekte geschlossen werden (van Est 1999, 313). Bis 1988 verließ sich DIFKO vor allem auf Turbinenhersteller Micon. Wegen schwerwiegender konzeptioneller Mängel der Rotoren entstanden Schäden in Millionenhöhe und der Investor beendete sämtliche Geschäftsbeziehungen zu Micon. Der Turbinenhersteller weigerte sich, den Schadensersatzforderungen DIFKOs nachzukommen (vg. WPM 3/88, 8ff.). $\mathrm{Zu}$ den Unwägbarkeiten zählt nicht allein die Frage der Absicherung des Käufers im Schadensfall. So verzeichnete auch das Finanzunternehmen DEEFOND mit seinen Projekten nur mäßige Erfolge. Bei der Kostenplanung eines Windparks am Altamont Pass hatte DEEFOND die Möglichkeit eines fallenden Dollarkurses offenbar nicht in Betracht gezogen. Der Kurs fiel und das Projekt verlor seine Rentabilität (WPM 8/86, 7). Daraufhin zogen sich viele Investoren von dem Projekt zurück. Dennoch fanden sich immer wieder neue Geldgeber. Noch während der Diskussionen um das Projekt, kündigt DIFKO die Planung seines vierten Windparks in Kalifornien an. Potenzielle Investoren erhielten Angebote über insgesamt 1400 Anteile. Trotz bekannter Unsicherheiten überstieg die Nachfrage das Angebot deutlich und die Anteile waren innerhalb kurzer Zeit vergriffen (WPM 9/86, 11). Erst seit 1987/88 ließ das Interesse an Investitionen in kalifornische Windparks, vor dem Hintergrund einer verschlechterten Fördersituation und dem Offenkundigwerden technischer Mängel der angebotenen Produkte, allmählich nach. ${ }^{239}$

Transformationen der Nachfrageseite innerhalb von Periode 3

Aus Sicht der Käufer, die Windturbinen auf dem dänischen Markt erwarben, lässt sich die Erprobungsperiode in drei Abschnitte unterteilen. In den ersten anderthalb Jahren bleibt die Käuferstruktur aus der vorherigen Periode erhalten. Nach wie vor handelt es sich um Kooperativen und Einzelpersonen, vorwiegend Landwirte, die Windkraft zur eigenen Stromversorgung nutzten und nur den Überschuss ins Netz speisten.

Die erste Zäsur bildet die 84er Regelung zwischen DEF und Windmüllern im Mai 1984. Von nun an werden Entwicklungsgesellschaften aktiv, die Windparkanteile an Investoren verkauften. Nachdem zuvor nur Einzelanlagen betrieben wurden, entstehen jetzt erste kommerzielle Windparks. Diese produzieren nicht für den Eigenbedarf der Besitzer, sondern ausschließlich um Energie an den lokalen Netzbetreiber zu verkaufen. Es kommt zu einem boomartigen Wachstum. Aus unterschiedlichen Gründen lehnen mehrere Akteure die Präsenz der Investoren ab. Die EVU fürchten den Verlust von Marktanteilen. Die Anrainer fühlen sich

\footnotetext{
${ }^{237}$, There are not too many people outside the utility circle that are very interested in seeing the utlities being handed a wind power monopoly.' (WPM 1/86, 4).

${ }^{238}$ Viking Capital und Difconsult sind weitere dänische Finanzunternehmen, die auf dem kalifornischen Markt aktiv waren (WPM 2/88, 14).

${ }^{239}$ Die tax credits werden Ende 1985, bzw. 1986 abgeschafft. Bei den späteren Projekten handelte es sich um die Realisierung von Verträgen, die noch unter dem alten Fördersystem abgeschlossen worden sind.
} 
benachteiligt, weil sie Windparks in ihrer Nachbarschaft ertragen müssen, während andere Geld damit verdienten. Die Investoren führten keine Gewerbesteuer an die Kommune ab ab und die Standorte konnten nicht mehr von lokalen Interessenten genutzt werden. Schließlich sprach sich die konservative Regierung - wenn überhaupt - für einen langsamen Ausbau der Windkraft aus, der optimalerweise unter energiewirtschaftlicher Regie vonstatten gehen sollte.

Die zweite Zäsur bildet die Einigung zwischen EVU und Regierung im Dezember 1985. Während Investoren vom Markt ausgeschlossen werden, verpflichten sich die EVUDachverbände Elsam und Elkraft, eigene Windparks in Betrieb zu nehmen. Allerdings fiel es ihnen, u.a. aufgrund häufiger Proteste gegen ihre Planungen schwer, getroffene Zusagen einzuhalten. Trotz einiger Barrieren, welche die Regierung den privaten Windmühlenbetreibern in den Weg gelegt hatte, wird das Marktwachstum nicht gestoppt, sondern nur zwischenzeitlich verlangsamt (vg. Tab. 2.3b).

Ein Großteil der Windkraft-Investitionen fließt nach Kalifornien, insbesondere im Zeitraum 1984-85. Davor und danach nimmt die Bedeutung Kaliforniens, als Markt für dänische Investoren ab. Tab. 2.3.2f bietet eine Übersicht dieser Transformationsvorgänge.

Tab. 2.3.2f Transformationen der Windanlagenkäufer in Periode 3

\begin{tabular}{|c|c|c|c|}
\hline & 1983 bis Mai 1984 & Mai 1984 bis Dez. 1985 & 1986-1987 \\
\hline $\begin{array}{l}\text { Käufer auf dem dän. } \\
\text { Markt }\end{array}$ & Kooperativen, Landwirte & $\begin{array}{l}\text { Investoren, Kooperativen, } \\
\text { Landwirte }\end{array}$ & $\begin{array}{l}\text { EVU, Kommunen, Kooperativen, } \\
\text { Landwirte }\end{array}$ \\
\hline $\begin{array}{l}\text { Käufer auf dem US- } \\
\text { Markt }\end{array}$ & Investoren & Investoren (Schwerpunkt) & $\begin{array}{lll}\begin{array}{l}\text { Investoren } \quad \text { (seit } \\
\text { abnehmende Bedeutung) }\end{array} & 1987 / 88 \\
\end{array}$ \\
\hline Windparkgröße & einzelne Anlagen & Windparks, Einzelanlagen & Windparks, Einzelanlagen \\
\hline vorwiegender Zweck & Eigenbedarf & $\begin{array}{l}\text { Verkauf an Netzbetreiber, } \\
\text { Eigenbedarf }\end{array}$ & $\begin{array}{l}\text { Aufbau von Windkapazitäten durch } \\
\text { EVU, Strombedarf der Kommunen, } \\
\text { Eigenbedarf }\end{array}$ \\
\hline Motivation & $\begin{array}{l}\text { Kostenreduktion, Anti- } \\
\text { AKW; Unabhängigkeit von } \\
\text { EVU; } \\
\text { Versorgungssicherheit }\end{array}$ & zusätzlich: Profite & $\begin{array}{lrr}\begin{array}{l}\text { Restriktionen } \\
\text { Investoren }\end{array} & \begin{array}{r}\text { gegen } \\
\text { (PAS); }\end{array} & \text { Windpark- } \\
\text { Kontriedung, } & \text { (EVU); } & \text { Kommunen: } \\
\text { Umweltbewusstsein, } & \text { Arbeitsplätze, } \\
\text { Kostenreduktion etc. } & \\
\end{array}$ \\
\hline $\begin{array}{l}\text { Konkurrenz } \\
\text { Standorte }\end{array}$ & Nein & $\begin{array}{lr}\text { Ja, zwischen } & \text { Investoren } \\
\text { und Anrainern }\end{array}$ & Ja, zwischen EVU und Anrainern \\
\hline
\end{tabular}

Quellen: vg. Kap. 2.1, 2.2, 2.3

In Tab. 2.3.2g werden die wichtigsten Barrieren dargestellt, mit denen Windanlagenkäufer konfrontiert sind, bzw. für deren Überwindung ihnen eine wichtige Rolle zukommt.

Tab. 2.3.2g Windanlagenbetreiber in Periode 3: Probleme und Lösungsansätze

\begin{tabular}{|c|c|c|c|}
\hline Problem & Lösungsansatz & Akteur/e & erfolgreich? \\
\hline $\begin{array}{l}\text { Investor-Windparks sorgen } \\
\text { bei diversen Akteuren für } \\
\text { Unmut und bedrohen die } \\
\text { Akzeptanz der Windenergie. }\end{array}$ & $\begin{array}{l}\text { 100MW-Abkommen; PAS } \\
\text { schließt Investoren von } \\
\text { Förderung aus; Anrainer- } \\
\text { Proteste }\end{array}$ & $\begin{array}{l}\text { EVU, PAS, Anrainer, } \\
\text { potenzielle lokale }\end{array}$ & ja \\
\hline $\begin{array}{lr}\text { EVU-Windparks } & \text { bedrohen } \\
\text { die Akzeptanz der } \\
\text { Windenergie; Standorte } \\
\text { können nicht von Anrainern } \\
\text { genutzt werden }\end{array}$ & $\begin{array}{l}\text { Anrainer protestieren, EVU- } \\
\text { Projekte verzögern sich, bzw. } \\
\text { erhalten keine } \\
\text { Genehmigungen }\end{array}$ & $\begin{array}{l}\text { Anrainer, potenzielle lokale } \\
\text { Betreiber }\end{array}$ & ja \\
\hline $\begin{array}{l}\text { Windindustrie braucht Mittel, } \\
\text { um WEA nach Kalifornien zu } \\
\text { exportieren }\end{array}$ & $\begin{array}{l}\text { Dänische Finanzunternehmen } \\
\text { treten als Projektentwickler } \\
\text { auf und bieten dänischen } \\
\text { Investoren Windanlagen zum } \\
\text { Kauf an; Regierung } \\
\text { unterstützt Exporte }\end{array}$ & $\begin{array}{l}\text { Finanzunternehmen, dänische } \\
\text { Investoren, PAS }\end{array}$ & $\begin{array}{l}\text { wirtschaftlich erfolgreich: Ja, } \\
\text { zeitweise } \\
\text { technisch erfolgreich: nein }\end{array}$ \\
\hline
\end{tabular}

Quellen: vg. Kap. 2.1, 2.2, 2.3 
Zwar ist Windenergie am Ende der Periode in großem Umfang erprobt worden. Als eine proven technology gilt sie dennoch nicht. Wie das besagte DIFKO-Micon-Projekt eindrucksvoll bewiesen hatte, bestehen auf technischer und administrativer Ebene noch akute Defizite. Die Frage, ob sich Windkraft $\mathrm{zu}$ einer international erfolgreichen Zukunftstechnologie entwickeln würde, war bisweilen offen. ${ }^{240}$

Alternativ hätte man aufgrund der Erfahrungen in Dänemark und Kalifornien den Schluss ziehen können, dass die Windkraft zwar in ihrer Eignung als ergänzende Energiequelle für den Eigenbedarf und die Versorgung entlegener Gebiete hinreichend erprobt ist, sich jedoch nicht eignet, um industrielle Großkraftwerke zu ersetzen und in größerem Umfang zur Versorgung beizutragen. 1987 ist unklar ob und inwieweit sich die Windanlagenindustrie Dänemarks erholen würde. Ohne Unterstützung von außen wäre der Sektor möglicherweise um Jahre zurückgeworfen worden. Nach dem Zusammenbruch des kalifornischen Marktes ist das skandinavische Land der einzige Markt, in dem von einem gefestigten Status der Windenergie gesprochen werden kann. Die Frage, ob künftig neue und größere Märkte für Windenergie entstehen, oder die Technologie vor allem ein auf Dänemark begrenztes Phänomen bleiben würde, war ungeklärt.

Die Entwicklungen in Kalifornien zeigen, dass die Eigenschaften des dänischen Marktes, wo sich die Windkraft zum Ende der Stabilisierungsperiode gut etabliert hatte, nicht ohne weiteres auf andere Länder übertragen werden kann. Inwieweit ist Kalifornien ein Sonderfall? Was ist mit anderen Märkten? Profitieren sie von Dänemarks Pionierleistungen - oder müssen sie eigene Wege gehen?

\subsection{Periode 4: 1988-1991 \\ Verstetigung internationaler Diffusion \\ (Dänemark, Niederlande, Bundesrepublik Deutschland)}

Während der Erprobungsperiode existieren mit Kalifornien und Dänemark nur zwei größere Windenergiemärkte. Seit 1986/87 werden in Kalifornien, nachdem sich die Investitionsbedingungen verschlechterten kaum mehr Windanlagen nachgefragt. Der kalifornische Windenergieaufschwung basierte nicht darauf, dass man von den Möglichkeiten der neuen der Qualität der neuen Technologie überzeugt gewesen wäre, sondern auf Profiterwartungen. Der tatsächliche Status regenerativer Energien wird offenkundig als, vor dem Hintergrund fallender Energiepreise, sämtliche Fördermaßnahmen gestoppt werden: Sie waren verzichtbar. Daraufhin geriet die Windmühlenindustrie Dänemarks an den Rand des Bankrotts. Nur mit Hilfe von außen vermochte sie sich zu regenerieren. Jetzt war es allein der dänische Markt, der sich kontinuierlich weiterentwickelte. Geglückt ist die Erprobung insofern als dänische Hersteller beweisen konnten, dass sie zur Produktion und Lieferung wirklich großer Stückzahlen in der Lage waren. Trotz aller Widrigkeiten gewann die Windkrafttechnologie erstmals das Vertrauen von Kommunen, EVU und Investoren.

Dennoch sind 1987 einige Fragen offen, deren Klärung für die zukünftige Bedeutung des Energieträgers wesentlich sind. Zwar überlebt die Windindustrie Dänemarks ihre Krise. Wie aber wird garantiert, dass ähnliche Desaster (vg. Kap. 2.3) nicht erneut auftreten würden? Entwickelt sich die Windkraft zur international anerkannten proven technology? Dann darf

\footnotetext{
${ }^{240}$ Die Windbranche bewertet den Status quo der Windkraft optimistischer. 1987 äußerte sich Birger Madsen (Vestas): ,About 0,75 per cent of Denmark's electricity consumption is supplied by wind power, produced by the around 1600 WTGs dotted around the country. The experience gained to date in Denmark can be transferred to any other European country with a well developed grid network. Wind turbines today are considered to be proven technology and wind power economics have been considerably improved upon in the last two to three years.' (WPM 6/87, 4). Noch optimistischer äußert sich Tom Gray, Vorsitzender der American Wind Energy Association, bereits 1986: ,Here we are in 1986 where the technology is proven, where all the questions are answered....' (zitiert nach: WPM 2/86, 6).
} 
ihre Anwendung nicht auf ein Land begrenzt bleiben. Sie muss in andere Länder diffundieren und dort zu einer festen Komponente des Versorgungssystems avancieren.

Ende der 80er Jahre sind in den Niederlanden und der Bundesrepublik zwei neue Märkte für Windkraft entstanden, in denen teilweise ähnliche Akteurskonstellationen, Widersprüche und Dynamiken erkennbar sind wie zuvor in Dänemark und Kalifornien. Die Ursprünge der neuen Märkte fallen in den Zeitraum der Erprobungsperiode. $\mathrm{Ob}$ es $\mathrm{zu}$ vergleichbaren Wachstumsvorgängen wie in den Pioniermärkten kommen würde, war damals nicht absehbar. Gegen Ende der 80er Jahre erreichen die neuen Märkte ein Niveau, dass sich deutlich von allen weiteren Pionierländern abhebt (vg. Tab. 2a).

Von deutschen Windenergie-Akteuren werden viele Elemente des dänischen Marktes importiert. Bereits Anfang der 90er Jahre sprechen zahlreiche Indizien dafür, dass Windkraft sich in den folgenden Jahren, hierzulande gut entwickeln würde. Weniger Anlass zu optimistischen Prognosen bietet die damalige Situation im westeuropäischen Nachbarland. Wie in Kalifornien wird auch dort, ein vom dänischen Modell stark abweichender Pfad beschritten: mit mäßigen Ergebnissen. Nach Beendigung der tax credits ist die Betrachtung Kaliforniens für den weiteren Fortgang der Pionierphase nicht mehr relevant. Abgesehen von den Boomjahren (1983-86) ist der kalifornischen Windenergiesektor als Untersuchungsgegenstand, nicht nur aufgrund der Stagnation weniger interessant. Er ist auch insofern kaum repräsentativ für die Pionierphase als das in den übrigen Märkten auftretende Akzeptanz-Problem, aufgrund der Abgelegenheit der Standorte, kaum eine Rolle gespielt hat. Die Frage, weshalb Windparks von der ansässigen Bevölkerung eher befürwortet, toleriert oder gegen sie protestiert wird und welche Rolle die Akteure im Windenergiefeld jeweils einnehmen, ist für die Erfolge der übrigen Pioniermärkte wesentlich. Anrainerproteste haben bspw. die Umsetzung zahlreicher EVU-Projekte, be-, bzw. verhindert. ${ }^{241}$

Den neuen Märkten stehen zwar Möglichkeiten offen, diese oder jene Neuerung aus Dänemark zu übernehmen. Zugleich aber müssen neue Lösungen für Probleme gefunden werden, die auch in Dänemark noch nicht bewältigt sind. Dazu zählen etwa Fragen der Finanzierung, Versicherung, präzise Windparkentwicklungsverfahren und Aspekte der Standortplanung. Oder es werden alternative Strategien angewendet, die ebenso erfolgreich wie vorhandene Konzepte sind und sich möglicherweise als kompatibler erweisen und damit über bessere Chancen internationaler Diffusion verfügen. Im Vergleich mit den Eigenschaften des dänischen Modells (s.u.), weisen die Akteursstrukturen der neuen Märkte, Großbritannien, Griechenland und Spanien, grundlegende Unterschiede auf. Ihre Entstehung und die Erfolge Spaniens, datieren die Überwindung der Pionierphase der Windenergienutzung auf das Jahr 1992.

\subsubsection{Dänemark in Periode 4}

Das erste Problem, dass im übrigen durchaus als internationale Barriere anzusehen ist, besteht in der Überwindung der Krise der dänischen Windindustrie. Ein Verlust des Know-hows dänischer Windanlagenhersteller und ihrer Produktionskapazitäten hätte die Technologie um Jahre zurückgeworfen. Aufgrund bisheriger technischer, ökonomischer und volkswirtschaftlicher Erfolge fanden sich sowohl staatliche als auch private Akteure, die den Wiederaufbau der Industrie unterstützen. ${ }^{242}$ Dieses verschafft der Industrie die Möglichkeit, aus den Erfahrungen zu lernen. Eine teils zufällig teils vom dänischen Staat geförderte Entstehung neuer Exportmärkte erleichtert ihre Regeneration. Zwei weitgehende Konsequenzen, die aus den technischen Pannen (vg. Kap. 2.3) gezogen werden, sind die Einführung eines formalisierten Entwicklungsverfahrens, das die Errichtung jeder

\footnotetext{
${ }^{241}$ Dieses gilt für die Niederlande und insbesondere auch für Großbritannien (vg. Kap. 3).

2421985 trugen Exporte von WEA mit \$160 Mio. zur Verbesserung der Handelsbilanz bei (Soerentsen 1984, 16).
} 
Windanlage von der Produktion bis zum Netzanschluss regelt und die Gründung einer branchenspezifischen Versicherungsgesellschaft. $\mathrm{Zu}$ den wichtigsten Neuerungen auf technischer Ebene zählen die Optimierung der Anlagendesigns und die Installation des ersten Windparks auf dem Meer. Offshore-Windkraft war in erster Linie ein Ausweg aus dem Problem mangelnder Standorte und fehlender Akzeptanz, der zunächst nur für energiewirtschaftliche Betreiber interessant war. Private Anlagenkäufer sind weiterhin auf Standorte an Land angewiesen. Aufgrund knapper werdender Standorte und bestimmter Neuregelungen wie der Flächenplanung wird es jetzt erstmals auch für die Windmüller schwieriger, einen Standort zu erlangen.

\subsubsection{Dänemark: Das politisch-administrative System in Periode 4}

Der Regierung war, trotz der Kalifornien-Episode, weiterhin an der Förderung des Sektors gelegen. Im April 1990 kündigte sie an, dass in Dänemark bis zum Jahr 2005 mindestens 1.500MW Windanlagenkapazität installiert werden soll (Kamp 2002, 167). Dazu mussten zunächst Maßnahmen zur Stabilisierung der Industrie getroffen werden. Exportmöglichkeiten mussten geschaffen, der Inlandmarkt angekurbelt werden. Flankierend wurde ein neues Zertifizierungsverfahren entwickelt, wodurch das Vertrauen potenzieller Windanlagenkäufer in die Technologie wieder hergestellt werden sollte. Ein Problem des Inlandmarktes bestand in knapper werdenden Standorten. Zusätzlich kam es vermehrt zu Protesten der Anrainer, die mit der Ansiedelung von Windparks, insbesondere wenn diese von den EVU betrieben werden sollten, nicht einverstanden waren. Durch Einführung eines Planungssystems, versuchte die Regierung, Kommunen bei der Entscheidung über die Errichtung neuer Windanlagen stärker einzubeziehen. Der Widerspruch zwischen Windmüllern und EVU existierte noch immer. Mit dem Windenergiegesetz von 1992 bemühte sich der dänische Staat um Vermittlung zwischen beiden Akteuren.

\section{Regeneration der Branche}

Die dänische Gesellschaft vertraute weiterhin auf die Windindustrie. Man ging davon aus, dass die Technologie auf einer soliden Basis beruhte und sich zukünftig durchsetzen werde. Die Welle der Pleiten wurde von vielen als Ausdruck üblicher Reifungsprozesse neuer Technologien in marktbasierten Ökonomien bewertet (van Est 1999, 93). Staatliche Unterstützung hatte guten Anteil daran, dass sich die Brache rasch zu erholen vermochte. Die folgende Tabelle 2.4.1a zeigt inwiefern bereits seit 1988/89, nach Überwindung der Talsohle von 1987, von einer deutlichen Regeneration gesprochen werden kann.

Tab. 2.4.1a Krise und Regeneration der Windanlagenindustrie

\begin{tabular}{|l|l|l|l|l|}
\hline Jahr & $\begin{array}{l}\text { Gesamtumsätze (Mio. } \\
\text { DKK) }\end{array}$ & $\begin{array}{l}\text { Heimmarkt (Mio. } \\
\text { DKK) }\end{array}$ & $\begin{array}{l}\text { Exportmarkt } \\
\text { DKK) }\end{array}$ & (Mio. \\
\hline 1982 & 94 & 64 & 30 & $\begin{array}{l}\text { Beschäftigung } \\
\text { (Mitarbeiter) }\end{array}$ \\
\hline 1983 & 343 & 43 & 300 & 200 \\
\hline 1984 & 895 & 95 & 800 & 500 \\
\hline 1985 & 2275 & 175 & 2100 & 1100 \\
\hline 1986 & 1460 & 160 & 1300 & 3300 \\
\hline 1987 & 570 & 170 & 400 & 2000 \\
\hline 1988 & 630 & 420 & 210 & 900 \\
\hline 1989 & 840 & 400 & 440 & 1200 \\
\hline
\end{tabular}

Quelle: Heymann 1995, 407

Verglichen mit dem Vorjahr wird der Export im Jahr 1989 verdoppelt. Die Erschließung neuer Märkte im Ausland ist ein wichtiger Baustein zur Überwindung der Krise. Mit Unterstützung der Entwicklungshilfeorganisation DANIDA werden bereits seit 1985 Windanlagen nach Indien verkauft. Im Jahr 1989 beträgt der nach Indien gelieferte Anteil des 
Exports sogar 35\% (Heymann 1995, 417). Für dänische Hersteller war es zudem sehr vorteilhaft, dass in der zweiten Hälfte der 80er Jahre allmählich neue Märkte in west- und südeuropäischen Ländern entstehen (s.u.). Gefördert wurde dieser Prozess durch EU und DANIDA. ${ }^{243}$

Zum Teil kann die Krise 1988 durch einen Wachstumsschub der Inlandnachfrage abgefedert werden. Gut 30MW werden in dem Jahr allein durch Stromkonzerne installiert (vg. Tab. 2.3.2e). Die Unterstützung privater Anlagenkäufer bleibt in etwa konstant. Zwar wird die Investitionsförderung Anfang 1989 auf zehn Prozent reduziert und im August des Jahres gänzlich abgeschafft. Auf der anderen Seite wird die Energiesteuer, von der die Windmüller trotz fallender Energiepreise ausgenommen waren, nicht gesenkt. Infolgedessen erhöhte sich die Rückvergütung, welche an die Energiesteuer gekoppelt war. 1989 erreichte sie 23 Öre pro Kilowattstunde. Durch steigende Strompreise erhielten die Windmüller 1989 eine Gesamtvergütung von 60 Öre/kWh, etwa doppelt so viel wie 1985 (Hantsch 1998, 56).

\section{Ein neues Zertifizierungssystem}

Allein die Förderung neuer Absatzchancen im In- und Ausland und die organisatorische Restrukturierung der Industrie reichten nicht hin um sämtliche Zweifel auszuräumen, dass es erneut zum Auftreten vergleichbarer Pannen wie in Kalifornien hätten kommen können. Um dänische Hersteller gegen die wachsende Konkurrenz, insbesondere aus Japan zu schützen, ${ }^{244}$ gründete die dänische Regierung 1991 eine Versicherungsgesellschaft (Vindmoellebranches Garanti A/S), durch welche speziell die Exportgeschäfte abgesichert werden sollten. Dafür werden staatliche Bürgschaften in Höhe von 750 Mio. DKK. zur Verfügung gestellt. Eine wichtige Lehre, die aus dem ruinösen Kalifornien-Export gezogen wird besteht in der Erkenntnis, dass das geltende Zertifizierungssystem nicht hinreichte. Darin wurden die Produkte vor allem auf technische Aspekte des Designs und Berechnungsgrundlagen geprüft. Außerdem bemängelte man, dass ein Zertifikat zu leicht erhältlich gewesen wäre. Stattdessen sollte ein Prüfverfahren den gesamten Prozess bewerten, in den die Hersteller beim Verkauf involviert sind: vom Anlagendesign, über Produktion, Transport und Installation, bis zur Wartung und erforderlichen Reparaturen. Bekannte Prüfungsfirmen wie Germanischer Lloyd und Det Norske Veritas treten jetzt in den Sektor ein und bieten frühzeitig die Durchführung umfassenderer Zertifizierungsverfahren an. Unabhängig davon fordern DV und beteiligte Versicherungsunternehmen die Entwicklung eines neuen einheitlichen Systems, welches die Qualitätsstufe dänischer Windanlagen mit den internationalen Standards der Industrie zur Deckung bringen sollte. $\mathrm{Zu}$ diesem Zweck richtet die Energieagentur der Regierung eine Arbeitsgruppe ein. In Kooperation mit Versicherungs- und Zertifizierungsfirmen, Teststation Risoe und Turbinenherstellern wird 1991 ein neues Verfahren eingeführt. Bis die Arbeitsgruppe das über 300 Seiten umfassende Dokument herausgibt (zuvor waren es 50 Seiten) vergehen zwei Jahre (van Est 1999, 94f.). Seit dem 11. Mai 1991 muss jede zu installierende WEA zunächst diesem Verfahren, dass von der Teststation in Risoe, oder anderen autorisierten Einrichtungen durchzuführen war, unterzogen werden (Kamp 2002, 164). Das Verfahren enthält drei Einzelgenehmigungen: eine allgemeine Genehmigung des

\footnotetext{
${ }^{243}$ Vestas, nach dem Konkurs als ,Vestas, Danish Wind Technology' wiedergründet und Danwin, sind 1989 noch immer auf dem kalifornischen Markt aktiv (WPM 10/89, 8) Zu den neuen Märkten zählt auch Ägypten. DANIDA hat Anfang 1991 DKK 35,3 Mio. (\$ 6,3 Mio.) für ein Windkraftentwicklungsprogramm in Ägypten zur Verfügung gestellt (WPM 3/91, 20). Ein Sprecher von Risoe betont, dass bei dem Projekt ökonomische Aspekte nicht im Vordergrund gestanden hätten: ,This is not a project aimed at fabricating wind turbines, but at providing Egypt with socially economic electricity.' (ebd.)

${ }^{244}$ Große japanische Unternehmen wie Mitsubishi, Sumito und Yamaha hatten sich als Hersteller zuverlässiger Windanlagen auf dem internationalen Markt etabliert (van Est 1999, 94).
} 
Designs, eine für die Qualitätskontrolle der Produktion sowie jeder einzelnen WEA sowie eine Installationsgenehmigung (Kamp 2002, 165). ${ }^{245}$

Die Einführung dieses strengeren und differenzierteren Verfahrens verschafft der Windanlagentechnik eine stabile Vertrauensbasis. Nach einem zwischenzeitlichen Bedeutungsverlust kommt Risoe erneut eine wichtige Rolle zu. Die technische Ausrüstung musste aktualisiert werden. Hier kann Risoe auf die Testeinrichtung (bspw. einen Testring für Flügel bis 20m Länge) des Rotorendesigners Grove-Nielsen zurückgreifen, der zuvor für das in Konkurs gegangene Unternehmen Alternegy tätig war. ${ }^{246}$

\section{Das Windenergiegesetz von 1992}

Sowohl die Kontinuität der Förderbedingungen als auch die verbesserte Situation hinsichtlich der Anlagenqualität sind zwei wichtige Voraussetzungen, weshalb sich der Binnenmarkt in der Periode 1988 bis 1991 auf hohem Niveau stabilisieren kann. Trotz aller Errungenschaften, die auf dem Sektor erreicht werden, gerät der Binnenmarkt 1992 in eine Krise. Der noch immer schwelende Konflikt zwischen Windmüllern und EVU entflammte erneut. Zwar entfalteten manche EVU, gemäß ihrer Verpflichtung (100MW-Abkommen), einige Aktivitäten. Eine möglicherweise daraus abzuleitende positive Grundeinstellung gegenüber der neuen Technologie, darf keinesfalls dahingehend missverstanden werden, dass sich die EVU mit der wachsenden Zahl privat betriebener WEA arrangiert hätten. Am deutlichsten manifestiert sich der Konflikt im Streit über Verteilung und Höhe der Installationskosten. Die Versorger hielten diese für unterbewertet und forderten daher eine Erhöhung um 300\%. Darüber hinaus wollten sie die Regelung beenden, der zufolge sie sich zu 35\% an den Kosten $\mathrm{zu}$ beteiligen hatten. Dem Ergebnis einer vom Energieministerium in Auftrag gegebenen Studie widersprechend, sind die EVU der Meinung, die Windmüller würden für ihre Investitionen Renditen von 26\% pro Jahr einstreichen (Hantsch 1998, 68). ${ }^{247}$ Im Zuge dieser Auseinandersetzungen war in der Branche eine starke Verunsicherung eingetreten, was 1992 zum Eintritt in einer erneute Krise führt (vg. Tab. 2.4).

Typisch für die Konfliktkultur des Landes ist das Suchen und zumeist Finden einer für die Konfliktparteien akzeptablen Lösung, ohne dass staatliche Institutionen eingreifen müssten. Solche Verhandlungslösungen können in den Auseinandersetzungen zwischen Windmüllern und Energiewirtschaft bereits 1979 und 1984 beobachtet werden (s.o.). Dieses Mal scheiterten die Verhandlungen jedoch endgültig im Februar 1992. Insbesondere über die Frage der Anschlusskosten konnte keine Einigung erzielt werden. ${ }^{248}$

Daraufhin kam es erstmals zu einer gesetzlichen Regulierung. Das vom Parlament am 7. Oktober 1992 beschlossene Windenergiegesetz (Vindmoelleloven, Nr. 837) trat am 1. November des Jahres in Kraft. Von nun mussten die Anlagenkäufer die gesamten Anschlusskosten selbst tragen. Dafür verpflichtete das Gesetz die Elektrizitätswerke dazu, für

\footnotetext{
${ }^{245}$ In der Designgenehmigung werden allgemeine Stabilität, Sicherheit und elektrisches System geprüft. Bei der Produktgenehmigung wird sowohl jedes einzelne Produkt getestet, als auch Qualität der Produktion insgesamt. Die Installationsgenehmigung berücksichtigt bisherige Erfahrungen mit Schadensfällen und Reparaturen. Sie bewertet Transport, Installation und Wartung (ebd., 164f.)

${ }^{246}$ Infolge der Pleite Alternegys bleibt die Firma Grove-Nielsen Lizenzgelder in Höhe von 1,3 Mio. DKK schuldig. Für ihn war es ein günstiger Zufall, dass Risoe zu dieser Zeit auf der Suche nach neuer Prüftechnik war. Nur durch Unterstützung seitens des Umweltministerium und privater Sponsoren kann ein Minimalbetrieb der Anlage aufrechterhalten werden. Schließlich übernimmt Risoe die Leitung der Anlage, die von der Teststation zunächst gemietet, bevor sie 1996 von ihr erworben wird (Beuse et al. 2000, 148).

${ }^{247}$ Demgegenüber besagt die Studie, dass Einzelbetreiber mit einer Verzinsung von durchschnittlich fünfeinhalb und Beteiligungen mit gut elf Prozent rechnen durften. Bei einer üblichen Beteiligung in Höhe von 8000kWh, einer Investition von 28.000 DKK und einer Laufzeit von 15 Jahren, ergibt sich ein jährliches Zusatzeinkommen von 1.500 DKK (Hantsch 1998, 6f.).

${ }^{248}$ Während DV und FDV anboten, dass sich die Windmüller mit 200.000 DKK an den Installationskosten einer 225kW-Turbine beteiligten, forderten die EVU 300.000 DKK (Hantsch 1998, 68f.).
} 
alle Netzerweiterungen und -verstärkungen, die aufgrund der Stromeinspeisung durch WEA erforderlich würden, aufzukommen. Begründet wird diese Regelung damit, dass das Stromnetz künftig nicht mehr nur als Verteilungs-, sondern auch als Stromaufnahmenetz für dezentrale Kraftwerke fungieren sollte. Hintergrund dieser Neustrukturierung ist die wachsende Zahl dezentraler Kraftwerkskapazitäten aus Windkraft- und Kraft-WärmeKopplung.

Die 1984 eingegangene Verpflichtung der EVU, den von Windkooperativen eingespeisten Strom mit 85\% des Strompreises zu vergüten, wurde nun auch auf Einzelbetreiber, die zuvor $70 \%$ erhielten, ausgedehnt. Den damaligen Strompreisen entsprechend, lag die Vergütung bei 36 Oere. Die bisherige Obergrenze für die eingespeiste Energie besagte, dass niemand mehr als $135 \%$ des Eigenverbrauchs, mindestens jedoch $9.000 \mathrm{kWh}$ produzieren durfte. Das Windenergiegesetz vergrößerte das Quantum auf 150\%. Während die Besitzer einer WEA bisher alle aus der nächstgelegenen Gemeinde stammen mussten, durften sich nun auch Bewohner der Nachbargemeinden beteiligen. Die Leistungsobergrenze für den Betrieb einer WEA durch Einzelpersonen wurde auf $250 \mathrm{~kW}$ ausgedehnt. Erstmalig bestand für Unternehmen die Möglichkeit, sich unter denselben Voraussetzungen an Windkraftprojekten zu beteiligen wie reale Personen (Hantsch 1998, 70).

Das Windenergiegesetz spiegelt in seiner Gestaltung einen Reifungsprozess der Technologie wider. Zum einen wird durch die teilweise Reinterpretation des Netzes, als Sammlungsnetz für dezentrale Energien, erstmals anerkannt, dass Windkraft nicht nur der lokalen Versorgung dient. Vielmehr wird sie neben der Kraft-Wärme-Kopplung zu einer integralen Komponente im Dezentralisierungsprozess des dänischen Stromsystems (vg. Kap. 4). Zum andern bestätigt das Gesetz, mit seiner Festschreibung der Einspeisetarife auf 85\% des Strompreises, die sukzessive Abkehr von direkter Förderung der Windkraft durch anteilige Zuschüsse. ${ }^{249}$ In dieselbe Richtung wies bereits die Befreiung der Windmüller von der Energiesteuer, welche sogar teilweise rückvergütet wurde. Beiden Regelungen ist gemeinsam, dass sich Investitionen in Windkraft nicht länger z.T. durch den Kaufakt als solchen amortisieren, sondern ausschließlich durch Energieproduktion. Diese Entwicklung stellt den vorläufigen Endpunkt ${ }^{250}$ einer Entwicklung dar, in der sich Turbinenkäufer zunehmend auf die Funktionsfähigkeit der Windanlage verlassen müssen und direkte staatliche Fördermaßnahmen einen geringeren Stellenwert einnehmen.

Die Binnenmarktkrise kann dennoch zunächst nicht überwunden werden. Aufgrund renitenter EVU, die gegen das Windenergiegesetz opponieren, scheitert die neue Regelung daran, den Windmüllern hinreichende Planungssicherheit zu verschaffen (s.u.). Auf Seiten der EVU kann von solcherlei Unsicherheit keine Rede sein. Nichtsdestoweniger gelingt es auch ihnen nicht, ihre Windparkpläne zu realisieren. Im Jahr 1990 werden sie vom Energieministerium dazu verpflichtet, bis 1993, zusätzliche Windparks mit 100MW zu installieren (Kamp 2002, 167).

\section{Das Problem der Standortsuche}

Eine landesweite Studie von 1993 kommt zu dem Ergebnis einer hohen Akzeptanz der Windkraft. Demzufolge sprechen sich mehr als vier Fünftel der dänischen Bevölkerung für die Installierung neuer Windanlagen aus (Gipe 1995, 65). An der Missgunst, die allgemein den Windparkplanungen der Energieversorger entgegengebracht wird, ändert sich auch am Ende der Pionierphase nichts. Anstatt der vereinbarten 200MW hatten die EVU bis Ende 1993, nach Ablauf des zweiten 100MW-Programms, gerade 110MW Windanlagenkapazität an ihre Netze schließen können. Die EVU weigerten sich, Verantwortung für diese Resultate zu übernehmen (van Est 1999, 101). Dieses Problem war seit langem bekannt, und die

\footnotetext{
${ }^{249}$ Zwischen 1979 und 1989 wurden ca. 2550 private Anlagen mit 275 Mio. DKK gefördert (Hantsch 1998, 59).

${ }^{250}$ Abgeschlossen ist diese Entwicklung erst mit der vollständigen Konkurrenzfähigkeit der Windkraft mit konventioneller Energie und Atomkraft.
} 
Regierung bemühte sich frühzeitig darum, Standorte für die EVU zu reservieren. Im November 1987 richtete das Energieministerium eine Kommission für Offshore-Windanlagen ein. Angesichts der Akzeptanzprobleme war der Schritt auf See naheliegend. 1989 definierte die Kommission den ersten Offshore-Standort nördlich von Lolland bei Vindeby. Bereits im Sommer 1989 signalisierte Elkraft die Bereitschaft, den weltweit ersten Offshore-Windpark zu installieren, um auf diesem Sektor Erfahrungen zu sammeln. Mitte 1991 nahm Elkraft die Windanlagen von Hersteller Bonus in Betrieb. Elf WEA (à 450kW) wurden zwischen 1,2 und $2,4 \mathrm{~km}$ vor der Küste Lollands, in einer Wassertiefe von zwei bis sechs Meter, errichtet. Von der Standortgenehmigung bis zur Projektrealisierung vergingen also nicht mehr als zwei Jahre. Hieraus wird ersichtlich, dass das zweite 100MW-Programm zumindest nicht ausschließlich am Umwillen der Energiewirtschaft gescheitert war (Kamp 2002, 170). ${ }^{251}$ Aufgrund erhöhter Kosten waren die Versorger nicht bereit, ihre Verpflichtung ausschließlich durch den Aufbau weiterer Offshore-Windparks zu erfüllen. Im Januar 1991 richtet die Regierung eine Planungskommission (Vindmoelleplaceringsudvalget) ein, welche für die EVU weitere Standorte an Land finden sollte (van Est 1999, 314). Die Kommission gab eine Richtlinie heraus, der zufolge alle Gemeinden und Verwaltungsbezirke seit März 1992 aufgefordert werden, bis Mitte 1995 Flächen für den zukünftigen Windkraftausbau auszuweisen. Sonderlich erfolgreich ist die Richtlinie nicht. Denjenigen, die keine geeigneten Plätze fanden, drohten keinerlei Sanktionen. Politikwissenschaftler Joergen G. Christensen bezeichnet die Richtlinie daher als klassisches Beispiel ,symbolischer Politik' (ebd., 101). Diejenigen, die in ihrem Bezirk, bzw. ihrer Kommune keine Windanlagen aufstellen lassen wollten, verzögerten den Prozess um Jahre, indem sie schlicht behaupteten, dass ihre Suche noch nicht abgeschlossen sei (Hantsch 1998, 65f.). ${ }^{252}$ Die Festlegung von Standorten einzelner WEA ist in der Richtlinie nicht vorgesehen. Stattdessen sollten nur noch Windparks errichtet werden. Für den Ausbau der Windkraft schadete die Richtlinie mehr als sie nützte. Denn sie versagte nicht nur darin, dass Standortproblem der EVU zu lösen. Auch für die Windanlagenkooperativen wird die Standortsuche erstmals zum Problem. Traenes (1997, 5), vom DV charakterisiert die Schwierigkeiten des Planungssystems: ,...a new effectiv weapon against wind turbines has been introduced: Planning. You simply make a tight plan of the whole country borough after borough. You involve everyone who in any way might have anything against wind turbines: nature conservative people, ornithologists, sportsmen like hunters and anglers ec. All point out areas, where they feel that there should be no wind turbines. ${ }^{253}$

\section{Zusammenfassung und Ausblick}

Für das Problem der Standortsuche wird in der Pionierphase keine befriedigende Lösung gefunden. Auch scheitert die Regierung daran, die EVU als hauptsächliche Windparkbetreiber $\mathrm{zu}$ etablieren. ${ }^{254}$ Die Binnenmarktkrise wird nicht überwunden. Vor diesem Hintergrund entscheidet sich die Regierung dafür, die Situation für Privatakteure erneut zu verbessern. Seit 1994 muss nur die Hälfte der Mitglieder einer Windanlagenkooperative aus der näheren

\footnotetext{
${ }^{251}$ Zum Vergleich: Der erste Offshore-Standort wird in Deutschland erst Ende 2001 genehmigt. Voraussichtlich werden 2009 die ersten Anlagen auf See gebracht. Eine Realisierungsdauer von mindestens acht Jahren kann nicht dadurch gerechtfertigt werden, dass die Bedingungen hierzulande anspruchsvoller sind. Das

Forschungsprojekt ,Alpha Ventus', dass mit 50 Mio. Euro staatlich gefördert wird, liegt ca. 50km von der Küste entfernt, bei einer Wassertiefe von etwa 35m (Neukirch 2008).

${ }^{252}$ Im Dezember 1995, d.h. ein halbes Jahr nach Ablauf der Frist, haben von den 275 Gemeinden erst 144 (52\%) einen Plan vorgelegt. Weitere 47 behaupteten, über keine geeigneten Standorte zu verfügen (Hantsch 1998, 76)

${ }^{253}$ Die Administration für Natur und Waldgebiet forderte, das keine Windanlage weniger als drei Kilometer von der Küste entfernt aufgestellt werden sollte (Traenes 1997, 6). Traenes (ebd.) gibt an, dass allein diese Regelung dazu geführt hätte, dass von der Gesamtfläche Dänemarks (44.000 Quadratkilometer), 21.000 Quadratkilometer, als Flächen potenzieller Standorte abgezogen werden müssten.

${ }^{254}$ Bis 1996 gelingt es den EVU, ihren Anteil am dänischen Windenergiemarkt auf 34\% auszudehnen (Kamp 2002, 174).
} 
Region stammen. Anstatt 9.000, dürfen nun 20.000kWh produziert werden. Zudem wird das Repowering, der Austausch alter gegen neue WEA, gefördert (Kamp 2002, 173). ${ }^{255}$ Erst 1995 verzeichnet der Markt wieder deutlich höhere Absatzzahlen.

\subsubsection{Dänemark: Windanlagenindustrie in Periode 4}

Es sind vor allem drei Entwicklungen innerhalb der Windindustrie, die es in dieser letzten Periode der Pionierphase zu analysieren gilt. Nicht nur die Regierung und dem staatlichen Unternehmen Danish Wind Technology (DWT), sondern auch von der Branche selbst, gehen wichtige Impulse zur Restrukturierung der Industrie und Überwindung der Exportkrise aus. Welche Lehren werden aus der Krise gezogen? Schließlich gilt es, weitere Transformationsvorgänge der technischen Entwicklung zu betrachten. Inwieweit lässt sich davon sprechen, dass die Produkte, den Status einer proven technology erreichen?

Wie oben dargestellt ist staatliche Unterstützung bei der Förderung der Binnennachfrage und des Exportsektors, noch immer unerlässlich. 1988 sind unter den verbliebenen Herstellern mehr als ausreichend Kapazitäten frei, um die Nachfrage zu bedienen. Quantitativ gesehen wären die Konkursunternehmen für den Markt verzichtbar gewesen. Das Know-how zahlreicher, dort zuvor tätiger Mitarbeiter war sehr gefragt, weshalb sie von anderen wieder eingestellt werden (Kamp 2002, 163). Hersteller Wincon wird 1988 zu großen Teilen von einem vorherigen Mitarbeiter des Unternehmens gekauft und dadurch vor dem Bankrott bewahrt (WPM 10/88, 9). Mit Vestas, Nordtank und Windmatic gehen u.a. drei zuvor sehr renommierte Hersteller Pleite. Bei der Rettung von Vestas und Windmatic tat sich Staatsunternehmen DWT hervor, dass zuvor in erster Linie im LSP-Sektor aktiv war. DWT ist vom Energieministerium in Kooperation mit den Privatunternehmen Volund und ASEA gegründet worden. Bereits vor der Krise hatte sich Energieversorger SEAS ebenfalls bei DWT eingekauft. DWT fusioniert mit Vestas im Februar 1989 und wird neben US Windpower zum weltweit größten Turbinenfabrikanten. Vestas nimmt die Produktion unter dem Namen Vestas, Danish Wind Technology A/S, wieder auf. Im September 1989 kauft DWT zusätzlich Windmatic. ${ }^{256}$ Die Produktion von Windmatic wird unter demselben Namen fortgesetzt. DWT geht es darum, über diese Fusion auf dem neu entstehenden griechischen Markt Fuß zu fassen (WPM 10/88, 9). Nordtank überlebt die Krise, indem es sich verkleinerte. Die Firma meldet im Juni 1987 Konkurs an und wird im Oktober des Jahres, in geschrumpfter Version neu gegründet (Beuse et al. 2000, 175). Nordtank versucht sich auf dem indischen Markt zu etablieren. Zu diesem Zweck formierte der Hersteller gemeinsam mit Danish Windpower ein Exportunternehmen, DWP-NTK, A/S. Die Firma geht eine Kooperation mit dem indischen Turbinenproduzenten Hindustan Brown Boveri ein. Der indische Markt ist gerade für Hersteller mit geringerer Kapitaldecke interessant, weil Projekte von der Entwicklungsorganisation DANIDA unterstützt wurden (WPM 10/88, 9).

Mit circa zwei Jahren Verzögerung wird auch Danwin von der Krise getroffen. Im April 1990 erklärt die Firma offiziell den Bankrott und gründet sich, ähnlich wie Nordtank, kurze Zeit später neu. Für den finanzkräftigen Eigner Jens Juul-Hansen war dieser Schritt vergleichsweise unproblematisch. ${ }^{257} \mathrm{Zu}$ dieser Zeit ist Danwin der einzige dänische Hersteller, der noch auf dem kalifornischen Markt aktiv war. Nachdem Steuervorteile für Personen, die in kalifornische Windparks investierten, durch den dänischen Staat 1989 abgeschafft wurden, verlor Danwin seine Geschäftsgrundlage (WPM 5/90, 12).

Alte Kapitalgeber verbleiben in der Branche, neue treten hinzu. Wenigen Herstellern, in erster Linie Bonus, ist es aufgrund zurückhaltender Vorgehensweise gelungen, die Krise zu

\footnotetext{
${ }^{255}$ In den folgenden Jahren werden die Beteiligungsschranken weiter abgesenkt. Seit 1999 können sich alle Dänen an Windprojekten beteiligen, seit 2000 alle EU-Bürger (Bolinger 2001, 13).

${ }^{256}$ Charakteristisch für die Firmengeschichte Windmatics ist die hohe der Zahl unterschiedlicher Besitzer des Unternehmens (vg. WPM 3/86, 10f.).

${ }^{257} 35$ Mitarbeiter erlitten durch die Schließung den Verlust ihres Arbeitsplatzes (WPM 5/90, 12).
} 
umgehen (van Est 1999, 93). ${ }^{258}$ Nach dem Konkurs des wichtigsten Rotorenherstellers Alternegy trat für die Turbinenfabrikanten ein neues Problem auf. Ihnen mangelte es an Rotoren. Zur Lösung bedienten sie sich insgesamt dreier Strategien. Sie begannen mit dem Design eigener Rotoren (Vestas), kauften sie von ausländischen Produzenten (Nordtank), oder bezogen sie bei LM, dem vorherigen Konkurrenten Alternegys (Kamp 2002, 166). Auf diese Weise begegnete die Industrie ihrer Krise und leistete wichtige Beiträge, das gesammelte Know-how zu erhalten.

Ihr Überleben ermöglicht es den Herstellern, aus ihren Exporterfahrungen wichtige Lehren zu ziehen. Die Branche übernimmt das vorsichtige Management von Bonus, indem sie künftig mehr Zeit für die Optimierung ihrer Konzepte einplante. Die Etablierung eines vereinheitlichten und umfassenden Zertifikationsverfahren lag in ihrem eigenen Interesse, weil sich ansonsten keine Windpark-Investoren fanden. Die Produzenten gaben ihre vorherige Strategie auf, sich nur auf einen einzigen Exportmarkt zu konzentrieren. Die Märkte waren in noch stärkerem Maße von politischer Flankierung abhängig als heute. Das Risiko des Abbruchs der Förderung wird bewusst einkalkuliert und durch geografische Diversifizierung gemindert. Die Firmen beginnen, sich gegen mögliche Verluste infolge sich verändernder Wechselkurse abzusichern. Von nun an unterhielten sie Geschäftsbeziehungen zu jeweils zwei Komponentenlieferenten. Dadurch wird das Risiko von Lieferengpässen, verursacht durch hohe Nachfrage und Firmenpleiten, minimiert. Sollte eine Komponente Designfehler enthalten, so dass eine gesamte Serie ausgetauscht werden musste, bestände zudem eine Ausweichmöglichkeit, ohne das die Windanlagen über längere Zeit außer Betrieb zu nehmen gewesen wären (van Est 1999, 93).

Aufgrund des Exportrückgangs verfügten die Hersteller über Ressourcen, die von einigen genutzt wurden, um in die Optimierung und Entwicklung neuer Technologien zu investieren. Diejenigen Modelle, welche in den Vorjahren zu schnell herausgebracht worden sind, werden kritisch evaluiert. Man richtete spezielle Abteilungen für Forschung und Entwicklung ein. In der Erprobungsperiode beruht die Einführung neuer Leistungsklassen wesentlich auf einer Vergrößerung des Designs der ersten Modelle von Riisager und Joergensen etc., welche letztlich auf die Gedser-Mühle von Johannes Juul zurückgehen. Jetzt beginnen manche Firmen, teilweise auch in Kooperation mit Risoe, verstärkt wissenschaftliche Verfahren zu nutzen, um ihre Konzepte auf eine fundiertere Basis zu stellen. Erstmals wird das bewährte Stall-Regulierungssystem infrage gestellt. Internationalen Erfahrungen zufolge ist diese Sicherungsmethode für größere Rotorlängen weniger geeignet. ${ }^{259} \mathrm{Zudem}$ stellte sich heraus, dass die Pitch-Regulierung mit steigender Flügelgröße kostengünstiger wird. Daher begannen viele dänische Hersteller, mit dem technisch anspruchsvolleren aerodynamischen Bremssystem zu experimentieren. Besonders Vestas, einer der wenigen Hersteller mit eigener Rotorfabrikation, war mit den Ergebnissen sehr zufrieden und integrierte das neue System in seine Modelle. Danwin entwickelte Rotoren mit kombinierter Stall- und Pitch-Regulierung. Einige Produzenten boten dieselben WEA mit unterschiedlicher Rotorengröße an: größere Flügellängen für Inlandstandorte mit geringeren Windgeschwindigkeiten, entsprechend kleinere Rotoren für Küstenregionen (Kamp 2002, 169). Standorte konnten dadurch auch in weniger windigen Gebieten gewählt werden.

Die Tendenz zur Nachfrage immer größerer Modelle war indessen ungebrochen. In Periode 3 wirkten die tax credits als wichtige Triebkraft zur Entwicklung leistungsstärkerer WEA. Seit etwa 1988 übernehmen dänische EVU diese Rolle. Durch ihre Nachfrage wächst die maximale Generatorenstärke kommerzieller WEA zwischen 1988 und 1990/91 von 250 auf etwa 500kW an (ebd., 165). Die Größenklasse kam den Vorstellungen der EVU näher. Die

\footnotetext{
${ }^{258}$,This company had been careful about stepping up pproduction and expanding, and had secured operational experience by gradually introducing its new turbine models' (ebd.).

${ }^{259}$ Aufgrund des hohen Geschwindigkeitsunterschiedes zwischen Flügelspitze und Verankerungspunkt wird es zunehmend schwieriger, die Stallvorrichtungen an jedem Punkt des Flügels, gleichzeitig auszulösen (Kamp 2002, 169).
} 
Option zur Errichtung kapazitätsstärkerer WEA mindert das Standortproblem aufgrund geringeren Flächenverbrauchs und erleichtert es den EVU, ihre Windparkplanungen zu realisieren. Die Schwierigkeit mangelnder Akzeptanz stellt sich nicht nur der Regierung, welche den Windenergieausbau prinzipiell befürwortete und Windanlagenkäufern, insbesondere energiewirtschaftlicher Provenienz, sondern auch den Herstellern. Selbstredend waren letztere daran interessiert, dass man an ihren Produkten so wenig Anstoß wie möglich nehmen würde. Daher arbeiteten die Konstrukteure daran, Betriebsgeräusche zu minimieren und das äußerliche Design zu verbessern. Die Bereitschaft, den riskanten Einstieg in die Offshore-Technologie zu wagen, war ein weiterer Beitrag, das Akzeptanz- und Standortproblem zu verringern. Im Juni 1990 bot Hersteller Bonus an, seine leistungsstärkste $450 \mathrm{~kW}$-Turbine für den Einsatz unter extremen Wetterbedingungen auf See (Offshore-Projekt Vindeby) auszurüsten.

\section{Ausblick}

Bis Mitte der 90er Jahre wird nach der Export-, jetzt auch die Binnenmarktkrise überwunden. Gegenüber dem Vorjahr nimmt der Export um $75 \%$ zu und umfasst eine Generatorenkapazität von 316MW (1993: 181MW). Seit 1995 erholt sich auch der Binnenmarkt. 1996 nehmen die Installationszahlen gegenüber dem Vorjahr um 132\% zu (1995: 78, 1996: 181MW). Im selben Jahr verfügen dänische Anlagenhersteller über Marktanteile von 61\% an der weltweit neu installierten Windenergiekapazität (Hantsch 1998, 74).

Für die weitere Rolle der Elektrizitätswirtschaft ist der Einstieg in die Offshore-Technologie richtungsweisend. Bis 1995 hat sich der Windpark vor Vindeby gut bewährt. Die Produktion liegt um 60\% höher als bei Standorten an Land. 1995 wird ein zweiter Offshore-Windpark mit bei Tunoe Knob (10 WEA à 500kW) realisiert (Kamp 2002, 176). Mitte der 90er Jahre bringen Nordex, Vestas und Nordtank die ersten Windanlagen im 1MW-Sektor heraus (Hantsch 1998, 77). Bis zur Fertigstellung der ersten großen Offshore-Projekte vergehen noch mehrere Jahre. Aufgrund hoher Baukosten hielten sich die Konzerne lange zurück. Erst 2002, bzw. 2003 werden die Offshore-Anlagen von Horns Rev (160MW) und Nysted (166MW) in Betrieb genommen (Windenergie 28/2003).

\subsubsection{Dänemark: Windanlagenkäufer und -betreiber in Periode 4}

Neben Industrie und PAS leisten auch dänische Windanlagenkäufer, Versicherer, Zertifizierungsunternehmen und Interessenverband DV wichtige Beiträge zur Überwindung der Export-Krise. Gegenüber dem Ende der vorherigen Periode bleibt die Käuferstruktur weitgehend konstant, wobei die Rolle der Kommunen auf dem Markt stagniert. Neuentwicklungen sind eine sich verkomplizierende Beziehung zwischen Windmüllern und EVU. Darüber hinaus verstärken die EVU ihre Aktivitäten auf dem Sektor und beginnen, gestaltenden Einfluss auf die Turbinentechnik zu gewinnen.

\section{Kalifornien-Krise}

Trotz der Krise wollen Investoren, Banken und Versicherungsgesellschaften ihre Aktivitäten im Windenergiesektor fortführen. Voraussetzung dafür bildete die Einführung verbesserter Zertifizierungsverfahren. Entsprechende Forderungen, die auch vom DV unterstützt werden, decken sich mit den Interessen des Energieministeriums und gaben daher wichtige Impulse zu ihrer Umsetzung (van Est 1999, 94; Kamp 2002, 171). Auch in der Forderung, eine unabhängige Versicherungsgesellschaft für Anlagenkäufer einzurichten, ist der DV erfolgreich. Die ,Dänische Windanlagen Versicherung' wird 1991 gegründet und mit 750 Mio. DKK staatlicher Bürgschaften ausgestattet. Betrieben wird die Gesellschaft vom DV (Traenes 1997, 10f.). Der Windmüllerverband trägt damit wesentlich dazu bei, dass Windenergie bei 
den Finanzakteuren als proven technology angesehen wird. Damit sind die wichtigsten Voraussetzungen zur Regeration der Branche prinzipiell erfüllt. Nur waren zahlreiche Hersteller aus Kostengründen nicht bereit, ihre Windanlagen dem Prüfungsverfahren zu unterziehen. Auf diese Weise stieg die Wahrscheinlichkeit an, dass sich Ereignisse wie die ruinöse Micon-Panne (vg. Kap. 2.3) hätten wiederholen können. Im Jahr 1989, als die Bemühungen um neue Zertifizierungsmethoden noch relativ am Anfang standen, war es keineswegs selbstverständlich, dass die Produkte entsprechende Verfahren durchliefen. Christer Ericsson von der Prüfungsfirma Norske Veritas moniert, dass es zur üblichen Praxis vieler Hersteller zähle, die Zertifizierung ihrer Modelle durch bestimmte Darstellungsweisen in ihrer Produktwerbung bloß zu suggerieren. Norske Veritas forderte daher alle Investoren auf, sich die Zertifikate vorlegen zu lassen. Im Januar 1989 haben nur Micon, Danwin, Wind World und Wincon einige ihre Produkte testen lassen. Die am meisten problematische Komponente, die Rotoren, blieben dabei von sämtlichen Tests ausgespart (WPM 3/89, 7).

Solche Bekanntgaben setzten die Industrie unter Druck. Welcher Interessent würde angesichts dieser Warnung und den vergangenen Erfahrungen, noch auf Hersteller vertrauen, die sich weigerten, ihre Produkte nach geltenden Standards zu testen? Gleichzeitig ergehen von hier aus Impulse zur Erstellung eines vereinheitlichten Prüfungsverfahren wie es 1991 eingeführt und im Mai des Jahres für alle angebotenen Windanlagen verbindlich wurde. Durch Herausgabe und Gestaltungsweise des Artikels ,Det Norske Veritas Issues Warning' in der Windpower Monthly, Zeitschrift des DV, unterstützt der Verband, die Öffentlichkeitsarbeit des Prüfungsunternehmens (vg. WPM 3/89, 7).

Trotz dieser Verbesserungen technischer Standards zeigten sich viele potenzielle Geldgeber skeptisch, ob sich eine Investition in den Sektor lohnen würde. Die Begründung des Energieministeriums, dass eine verbesserte Effizienz die Investitionsförderung für den Kauf von WEA überflüssig machte, überzeugte offenbar nicht alle. Nachdem der Zuschuss von zehn Prozent im August 1989 abgeschafft wurde, ziehen sich einige Banken aus der Finanzierung von Windparkprojekten zurück. 14 der damaligen 39 Projekte des Herstellers Wind World etwa, sind aus diesem Grund storniert worden (WPM 11/89, 8).

EVU und Windmüller

Privatakteure, zumeist Kooperativen, stehen als Turbinenkäufer nach wie vor an erster Stelle. Restriktionen wie Einspeisegrenzen und Aufhebung des Investitionszuschusses stellten sicher, dass die Einnahmen ein gewisses Maß nicht überstiegen. Noch immer ist nicht Gewinnstreben, sondern vorwiegend die Sympathie für den neuen Energieträger und alle dieser Sympathie zugrunde liegenden Motivationen (s.o.), der wichtigste Grund für den Kauf einer Windanlage.

Neben den Fragen, ob die Investition zumindest kein Minusgeschäft werden würde und der Finanzierung des Projekts, besteht die größte Schwierigkeit privater Turbinenkäufer darin, mit den EVU zu einer Kompromisslösung zu gelangen. Insbesondere in der Frage der Verteilung der Installations- und Netzerweiterungskosten gelingt keine Einigung. Daher musste die Interaktion beider Akteure mit dem Windenergiegesetz von 1992 verrechtlicht werden. Die Versorger zeigten sich jedoch nicht bereit, das Gesetz ohne weiteres zu akzeptieren. Sie verunsicherten die gesamte Branche, indem sie zentrale Punkte des Gesetzes wie die Vergütungshöhe infrage stellten. Einige EVU definierten die Installationskosten, welche von den Windmüllern vollständig getragen werden mussten, kurzer Hand neu. Der Betreiber sollte die Kabel nicht mehr unbedingt zum nächstmöglichen Anschlusspunkt verlegen, sondern dorthin, wo nach Meinung des Versorgers, die Netzkapazität hinreichend sei. Dabei konnte es sich durchaus um einige Kilometer zusätzlicher Distanz handeln. Auf diese Weise entstanden den Windmüllern weitere Kosten, die eigentlich in den Bereich der Netzverstärkung gehörten und damit laut Windenergiegesetz von den EVU hätten getragen werden müssen (Hantsch 
1998, 71f.). Die restriktive Haltung der EVU verfehlt ihr Ziel nicht. Der Markt für private Windanlagen schrumpfte seit 1992.

\section{EVU als Windanlagenkäufer}

Während sich die Toleranz der Versorger gegenüber den Windmüllern verringert, hat das eigene Engagement auf dem Windsektor seit 1988 stark zugenommen. Das größte Problem der EVU besteht in der Standortfindung, welche durch Anrainer-Proteste stark erschwert ist. Die Erfüllung des zweiten 100MW-Plans wird verunmöglicht. Daher gibt die Regierung 1992 eine Planungsrichtlinie heraus, der zufolge alle Gemeinden Windparkflächen ausweisen sollten. Zahlreiche Gemeinden weigern sich jedoch, der Richtlinie zu entsprechen. Von nun an fiel es daher auch privaten Käufern deutlich schwerer, geeignete Standorte zu finden. Insofern lässt sich sagen, dass die Windparkplanungen der EVU, indirekt dazu beigetragen haben, die Möglichkeiten privater Windanlagenplaner einzuschränken.

Bereits 1989 hat sich Asbjoern Bjerre, Vorsitzender des DV, mit dem Problem des NIMBY Syndroms befasst. Bjerre (WPM 4/89, 6) argumentiert gegen die NIMBY-Mentalität vieler Anrainer: ,Is a man-made landscape unnatural?...Remember, these machines can be removed again, leaving the countryside as good as new. I am quite sure the bees and birds prefer wind turbines to acid rain.' Von der Windindustrie fordert er, verstärkt über Wege zur Geräuschminderung nachzudenken und auf die Ästhetik der Windanlagen mehr Wert zu legen (ebd.). Erfolgverheißender wäre möglicherweise die Umsetzung einer anderen Forderung Bjerres gewesen: ,Finally we should stop focusing attention on windfarms - they are not practical in Denmark, unless placed offshore perhaps...The utilities should be releaved of their windfarm development obligations and instead be required to organise the financing of grid connected machines' (ebd.). Diese Forderung steht im Gegensatz zu den Interessen von Regierung und Energiewirtschaft. Nichtsdestotrotz zählt Dänemark zu den wenigen Industrieländern, in denen sich ein dezentraler Pfad im Stromsystem etabliert hat (vg. Kap. 4). Auf der einen Seite stellt die Nachfrage der EVU einen hemmenden Faktor bzgl. des Binnenmarktvolumens dar. Andererseits werden die EVU zu einer wichtigen Triebkraft technischer Innovation. Für private Käufer ist es bspw. weniger wichtig, eine Windanlage maximaler Größe zu erwerben (Kamp 2002, 172). Diejenigen, deren Budgets und Einnahmechancen stark begrenzt sind, interessieren sich darüber hinaus weniger für technische Neuerungen, die vergleichsweise wenig erprobt sind und den Kaufpreis in die Höhe trieben. Zudem ist die Windanlagenkapazität, die von Einzelkäufern betrieben werden durfte, bis 1992 auf 150kW beschränkt. ${ }^{260}$ Die EVU hatten dagegen mehrere Gründe, sich stets für die größten Anlagen zu entscheiden. Langfristig betrachtet kann die Zukunft der Windkraft aus Sicht der Energiewirtschaft nur in der Multimegawatttechnologie liegen. Diese ermöglicht es, Windparks mit der Kapazität konventioneller Großkraftwerke zu installieren. Auf diese Weise sollte sich die Windenergie leichter in das zentralisierte Stromsystem integrieren lassen. Man ging bei größeren Anlagen von einer höheren Effizienz durch niedrigere Wartungs- und Inspektionskosten aus. Schließlich favorisierte man Großwindanlagen, um die wenigen Standorte optimal zu nutzen (van Est 1999, 96). 1989 gibt Elkraft bekannt, den ersten Offshore-Windpark bauen zu lassen. Das 1991 fertiggestellte Projekt kostet den Versorger circa 80 Mio. DKK, Ausgaben für Windmessungen inklusive (Kamp 2002, 170). Zwar kam der erste Impuls für die Prüfung der Offshore-Option aus dem Energieministerium. Dennoch reagierte Elkraft schon kurze Zeit nach der Ausschreibung. Der Versorger zeigte sich bereit in die neue Technologie zu investieren und damit verbundenen Risiken zu tragen. Angesichts der guten Erfahrungen, die Elkraft seit mit seinen Windparks zu verzeichnen hatte, schrieb das Unternehmen im Jahr 1990 den Auftrag zur Fertigung einer

\footnotetext{
${ }^{260}$ Seit dem Windenergiegesetz vom Oktober 1992 beträgt die Grenze 250kW, was zu diesem Zeitpunkt bereits wieder hinter den Standard zurückfiel.
} 
Prototyp-Windturbine der 1-Megawattklasse aus (ebd.). Bonus und Vestas nutzen diese Gelegenheit, um ihre Komponenten $\mathrm{zu}$ vergrößern und diverse Neuerungen zu testen. Erstmalig stießen kommerzielle Hersteller in den Megawattsektor vor, der bis dahin eine Domäne staatlicher Forschungsförderung gewesen war. Die Erfahrungen, welche aus den Arbeiten mit einem bei Kopenhagen installierten Prototyp gewonnen wurden, konnten die Hersteller teilweise in ihre eigenen Konzepte integrieren (ebd., 101). Durch Nachfrage großer Windanlagen und Experimente im Offshore-Sektor wurden die EVU während der letzten Untersuchungsperiode zum wesentlichen Innovationsträger. ${ }^{261}$

\section{Ausblick}

Bis 1996 erlangen die EVU einen Marktanteil von 34\% (Heymann 1998, 128). Auch in den folgenden Jahren scheitern sie an dem Ziel, die Windmüller aus dem Sektor zu drängen. Die Tendenz, dass Windanlagen für Einzelbetreiber $\mathrm{zu}$ viel Strom produzieren und zu kostenintensiv sind, verstärkt sich. Die Lockerung des Abstandskriteriums ermöglicht die Beteiligung weiterer Personen an kooperativen Windparkprojekten. Im Prinzip ist die Kooperative als typische Organisationsform erhalten geblieben. Der ursprünglich lokale Charakter geht jedoch sukzessive verloren. Denn mit der gewachsenen Turbinengröße nimmt auch die Zahl erforderlicher Mitglieder zu. Die bislang größte Windkooperative darf $50 \%$ des Offshore-Windparks Middelgrunden ihr Eigentum nennen. ${ }^{262}$ Der im Jahr 2000 in Betrieb gehende Windpark (40MW) erforderte die Beteiligung von 7.000 Haushalten. Die ursprüngliche Idee, dass ein Haushalt nur so viel Energie produzieren sollte, wie er selbst verbrauchte, wird angesichts verschiedenster Liberalisierungen und Ausnahmeregelungen zunehmend verwässert (Hantsch 1998, 78f.).Erstmals seit dem Intermezzo der freiwilligen Übereinkunft (1984/85) wird die Technologie wieder für (Klein)Investoren interessant.

\section{Barrieren in Periode 4}

Die größte Aufgabe, die am Beginn der Periode von den Akteuren zu bewältigen war, bestand im Wiederaufbau der Industrie. Finanzakteure, die zwischenzeitlich von der Windenergie Abstand genommen hatten, mussten von der Zuverlässigkeit der neuen Technologie überzeugt werden. Die wichtigsten Beiträge der Regierung lagen in der Förderung neuer Exportmärkte, der Stabilisierung des Inlandmarktes und der Einführung eines vereinheitlichten Prüfungssystems für Windanlagen, das international üblichen Standards für industrielle Produkte entsprach. Bei ihrem Wiederaufbau erhielt die Turbinenindustrie nicht nur Unterstützung durch staatliche, sondern auch zahlreiche privatwirtschaftliche Akteure. Darin spiegelt sich wider wie sehr die Windenergie in Dänemark bereits zu einer Selbstverständlichkeit geworden war. Die Industrie analysierte ihre Fehler und vermochte aus ihnen zu lernen. Dänische Interessenten vertrauen zwar weiterhin auf die Qualität der Anlagen. Dennoch war es wichtig, dass der Windmüllerverband DV sich beim Energieministerium für die Entwicklung komplexerer Testverfahren einsetzte. Dadurch wurde Druck auf die Hersteller ausgeübt, ihre Modelle tatsächlich nach aktuellen Standards prüfen zu lassen. Die Entstehung neuer Exportmärkte während des Untersuchungszeitraums und damit verbunden, wachsende Exportzahlen dänischer Fabrikanten, zeugen vom Erfolg dieser Bemühungen.

Drastisch fallende Nachfrage markiert 1992 den Beginn einer weiteren Krise, dieses mal auf dem Binnenmarkt. Die Ursachen der erneuten Stagnation lassen sich klar lokalisieren:

\footnotetext{
${ }^{261}$ Kamp $(2002,166)$ geht zudem von einer sehr hohen Relevanz der EVU-Nachfrage für die Überwindung Export-Krise aus: ,The main reason why the remaining firms were able to stay in business was the 100MW agreement with the utilities...The lack of demand for turbines from 1986 to 1988 caused by the Danish utilities was an advantage for the manufacturers. It gave them more time to improve their wind turbine designs and to develop new concepts.'

${ }^{262}$ Die andere Hälfte gehört Elkraft.
} 
Zunächst führte die restriktive Haltung der EVU gegenüber den Windmüllern zu starker Vorsicht unter Banken und Investoren. Andererseits scheiterten die Versorger daran, den Mark zu übernehmen. Aufgrund der Proteste vieler Anrainer, einer verfehlten Planungspolitik sowie dem Unwillen kommunaler Verwaltungen, fanden die EVU kaum Standorte. Die Aktivitäten der Versorger erwiesen dem Windsektor einen Bärendienst: Während sie selbst am Aufbau von Windparks weitgehend scheiterten, setzten sie alles daran, den privaten Markt zu behindern. Dieses Patt zwischen Windmüllern und EVU kann in der Pionierphase nicht überwunden werden. Tab. 2.4.1b stellt die Probleme der Windenergiesektors und die Lösungskonzepte der Akteure zusammenfassend dar.

Tab. 2.4.1b Probleme und Lösungsansätze: Verstetigungsperiode

\begin{tabular}{|c|c|c|c|}
\hline Problem & Lösungsansätze & Akteur/e & Erfolgreich? \\
\hline $\begin{array}{l}\text { Kommerzielle und } \\
\text { technische Misserfolge, } \\
\text { sowie unvorsichtige } \\
\text { Unternehmensstrategien } \\
\text { haben die Windindustrie } \\
\text { in schwere Krise geführt. }\end{array}$ & $\begin{array}{l}\text { PAS } \\
\text { a) Förderung neuer Exportmärkte } \\
\text { b) Stabilisierung des Binnenmarktes } \\
\text { c) Einführung umfangreicher Prüfungsverfahren } \\
\text { Industrie } \\
\text { a) Restrukturierung durch Bankrotte, } \\
\text { Neugründungen, Fusionen, neue Investoren } \\
\text { b) vorsichtige Geschäftspolitik (Bonus) } \\
\text { c) Industrie hatte in der Vergangenheit ein } \\
\text { erfolgreiches und beliebtes Produkt entwickelt } \\
\text { d) Industrie lernt aus Fehlern } \\
\text { Käufer } \\
\text { a) Windmüller/ EVU setzen weiterhin auf WE } \\
\text { b) DV: Forderung neuer Zertifikationssysteme } \\
\text { c) DV gründet eigenes Versicherungsunternehmen } \\
\text { d) DV fordert, dass Hersteller ihre Anlagen nach } \\
\text { Industrie-Standards prüfen lassen }\end{array}$ & $\begin{array}{ll}\text { Industrie, } & \text { PAS, } \\
\text { Käufer } & \end{array}$ & $\begin{array}{l}\mathrm{Ja} \text {, alle Akteure } \\
\text { tragen zur Lösung } \\
\text { der Krise bei. }\end{array}$ \\
\hline \begin{tabular}{lr}
\multicolumn{2}{l}{ Binnenkrise seit 1992} \\
Investoren werden durch \\
restriktive & EVU \\
verunsichert; & EVU \\
scheitern v.a. & aufgrund \\
mangelnder & Akzeptanz \\
daran, den & Markt zu \\
übernehmen & (Patt- \\
Situation)
\end{tabular} & $\begin{array}{l}\text { PAS } \\
\text { a) 1992: Einführung des Windenergiegesetzes } \\
\text { b) 1992: Richtlinie verpflichtet Kommunen, } \\
\text { Windparkstandorten festzulegen (kontraproduktiv) } \\
\text { c) Fördert Offshore-Windparks } \\
\text { Industrie } \\
\text { a) Hersteller unterstützen Offshore-Projekt und } \\
\text { bringen größere WEA heraus } \\
\text { b) verbesserte Akzeptanz durch } \\
\text { Designkorrekturen: niedrigere Schallemission, } \\
\text { Ästhetik der Windanlage } \\
\text { Käufer } \\
\text { a) DV fordert Stop von EVU-Windparks } \\
\text { b) DV fordert Anrainer auf, NIMBY-Haltung zu } \\
\text { überdenken } \\
\text { c) DV fordert Industrie auf, Schallemissionen zu } \\
\text { reduzieren und Ästhetik der WEA zu verbessern } \\
\text { d) EVU investieren in Offshore-Projekt } \\
\text { e) EVU investieren in leistungsstarke WEA, um } \\
\text { die wenigen Standorte optimal zu nutzen } \\
\end{array}$ & $\begin{array}{ll}\text { PAS, } & \text { Industrie, } \\
\text { Käufer } & \end{array}$ & $\begin{array}{l}\text { Nein. } \text { Binnenkrise } \\
\text { wird erst ab } 1995 \\
\text { überwunden. }\end{array}$ \\
\hline $\begin{array}{l}\text { Finanzierung ist seit } \\
1989 \text { durch Wegfall der } \\
\text { Investitionsförderung } \\
\text { erschwert. Zahlreiche } \\
\text { Projekter werden } \\
\text { storniert, weil Banken } \\
\text { sich distanzieren }\end{array}$ & $\begin{array}{l}\text { PAS } \\
\text { Energieministerium schafft neue } \\
\text { Fördermöglichkeit: Energieproduktion der WEA } \\
\text { nimmt für Amortisierung maximalen Stellenwert } \\
\text { ein } \\
\text { Industrie } \\
\text { Bessere Effizienz durch optimierte und größere } \\
\text { WEA }\end{array}$ & PAS, Industrie & $\begin{array}{l}\text { Teilweise. Wegfall } \\
\text { der Subvention ist } \\
\text { kein tiefgreifendes } \\
\text { Problem des } \\
\text { Binnenmarktes. } \\
\text { Installationszahlen } \\
\text { bleiben zwischen } \\
1988 \text { und } 1991 \\
\text { weitgehend stabil }\end{array}$ \\
\hline
\end{tabular}

Quellen: vg. Kap. 2.3 und 2.4 


\section{Transformationsprozesse: Von der Erprobungs- zur Verstetigungsperiode}

In den nachfolgenden Tabellen 2.4.1c-2.4.1e sind die wichtigsten Umbrüche zwischen Erprobungs- und Verstetigungsperiode dargestellt.

\section{PAS}

Für die Umstellung des Fördersystems von direkter zu indirekter Förderung stellt der letzte Untersuchungszeitraum einen Endpunkt dar. Seit 1979 hat die Investitionsförderung von ursprünglich 30\% kontinuierlich abgenommen, bis sie im August 1989 gänzlich auslief. Parallel erhöhte sich der Anteil indirekter Förderung. Dieser Prozess reflektiert die technische Reifung. Anfangs wird der Windkraft die Rolle der Selbstversorgung in ländlichen Gebieten zugewiesen. Seit Einführung kommerzieller Windparks um 1984, die ausschließlich der Netzeinspeisung dienten, zeichnete sich ab, dass Strom aus Windkraft mit steigender Tendenz auch Kapazitäten herkömmlicher Kraftwerke ersetzen würde. Diese Realität wird im Windenergiegesetz von 1992 anerkannt.

Tab. 2.4.1c

Transformationen des PAS

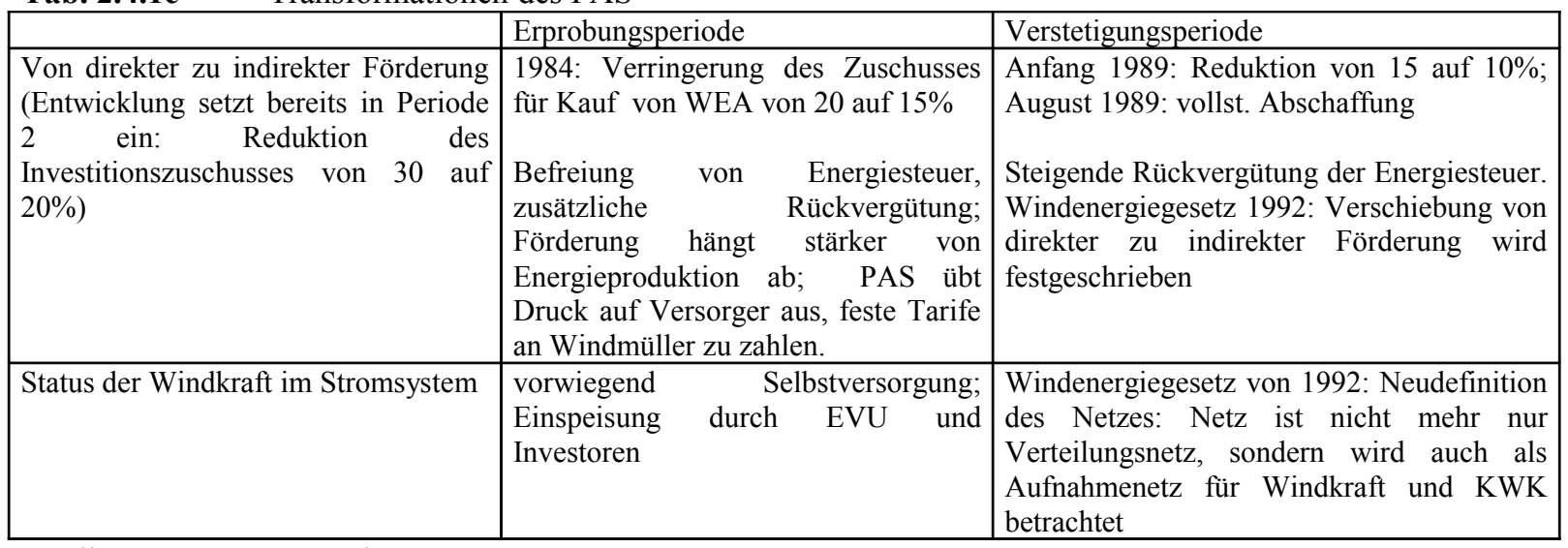

Quellen: vg. Kap. 2.3 und 2.4

Industrie

In der Erprobungsperiode fiel die Produktentwicklung vor allem mit einer Kapazitätserweiterung der Produktion zusammen. Innovation und Anlagenprüfung nahmen angesichts der Notwendigkeiten des kalifornischen Marktes einen geringen Stellenwert ein. Im nachfolgenden Zeitraum kehrte sich dieses Verhältnis um. Nun mussten aufwendige Zertifizierungsverfahren durchlaufen werden. In Kooperation mit den EVU wagten sich einige Hersteller auf neues Terrain vor. Erstmals wurden Offshore-Turbinen hergestellt; Mutig wurde an neuen Größenklassen gearbeitet. Man startete erstmals Experimente mit dem Pitch-System und hinterfragte damit die allgemeine Gültigkeit der Stall-Regulierung. 
Tab. 2.4.1d

Transformationsprozesse der Industrie

\begin{tabular}{|l|l|l|}
\hline & Erprobungsperiode & Verstetigungsperiode \\
\hline Export & $\begin{array}{l}\text { größter Teil dänischer WEA-Produktion } \\
\text { für einen großen Exportmarkt }\end{array}$ & $\begin{array}{l}\text { Export in einige neue Märkte, größerer } \\
\text { Anteil für Binnenmarkt }\end{array}$ \\
\hline $\begin{array}{l}\text { übliche Generatorengröße (kW); } \\
\text { übergreifend }\end{array}$ & $\begin{array}{l}300-500 \\
\text { Technikentwicklung ist dominiert durch } \\
\text { Konkurrenz auf dem kalifornischen } \\
\text { Markt und zügiges Upscaling }\end{array}$ & $\begin{array}{l}\text { Nachfrage, Prüfung von Innovationen } \\
\text { (Offshore-Turbinen, Pitch-Regulierung, } \\
\text { Entwicklung von Komponenten für } \\
\text { 1MW-Turbine) }\end{array}$ \\
\hline $\begin{array}{l}\text { Intensität der Prüfungen vor dem } \\
\text { Markteintritt neuer Produkte; } \\
\text { übergreifend }\end{array}$ & $\begin{array}{l}\text { relativ niedrig } \\
\text { Hech. Umfassende Prüfungsverfahren } \\
\text { international } \\
\text { Zertifizierungsstandards angeglichen. }\end{array}$ \\
\hline Produktionsvolumen der Industrie & $\begin{array}{l}\text { seit 1983 stark gewachsen, 1988 auf } \\
\text { einen Minimalwert zurückgegangen }\end{array}$ & langsam zunehmend den \\
\hline
\end{tabular}

Quellen: vg. Kap. 2.1, 2.2, 2.3 und 2.4

\section{Käufer/Betreiber}

Unterschiedliche Rahmenbedingungen in der Erprobungs- und Verstetigungsperiode haben unterschiedliche Käufertypen hervorgebracht. Investoren, die Mitte der 80er Jahre hohe Summen in Windparks auf dem kalifornischen Markt investiert hatten, gingen ein vergleichsweise hohes Risiko ein, weil noch keine standardisierten Testverfahren vorhanden waren. Das schnelle Geld lockte, Quantität war wichtiger als Qualität. Im Verlauf dieser Periode avancierten dänische EVU, wenn nicht zum markt-, so doch zum innovationsführenden Akteur. Sie investierten Gelder unter völlig anderer Zielgebung als besagte Investoren. Verglichen mit den Windmüllern erwarben sie andere Produkte als private Käufer (größere WEA, teilweise für den Offshore-Einsatz). Die technische Entwicklung der Windkraft folgt keiner logischen Linie. Vielmehr wird sie gestaltet durch die Art der Nachfrage, welche von den Akteuren abhängig ist. Darauf, welche Käufertypen einen Markt dominieren, seien es EVU, Investoren, oder Kooperativen, nehmen politische Rahmenbedingungen maßgeblich Einfluss und beeinflussen damit ebenfalls den Pfad technischer Entwicklung.

Tab. 2.4.1e Transformationen der Käuferstruktur

\begin{tabular}{|l|l|l|}
\hline $\begin{array}{l}\text { Käufer als Gestalter technischer } \\
\text { Entwicklung }\end{array}$ & $\begin{array}{l}\text { Euf dem kalifornischen Markt aktive } \\
\text { Investoren (schnelles Upgrading, } \\
\text { Kapaziätserweiterungen) }\end{array}$ & $\begin{array}{l}\text { EVU (vorsichtiges Upscaling, } \\
\text { technische Neuentwicklungen, WEA für } \\
\text { Offshore, 1MW-WEA als Prototyp) }\end{array}$ \\
\hline Herkunft der Käufer & hauptsächlich Kalifornien, Dänemark & neue Exportmärkte, Dänemark \\
\hline $\begin{array}{l}\text { Verhältnis zwischen Käufern und EVU } \\
\text { als Netzbetreibern }\end{array}$ & $\begin{array}{l}\text { EVU arrangieren sich mit Windmüllern, } \\
\text { nachdem sie, mit Unterstützung des } \\
\text { Energieministeriums, Investoren vom } \\
\text { Markt drängten }\end{array}$ & $\begin{array}{l}\text { Konflikt zwischen EVU und } \\
\text { Windmüllern eskaliert }\end{array}$ \\
\hline $\begin{array}{l}\text { Situation der EVU auf dem Markt für } \\
\text { kommerzielle Windanlagen }\end{array}$ & $\begin{array}{l}\text { EVU treten 1985 erstmals als Betreiber } \\
\text { kommerzieller Windanlagen auf }\end{array}$ & $\begin{array}{l}\text { EVU werden seit 1988 zum } \\
\text { wesentlichen Motor der Innovation: } \\
\text { Nachfrage großer WEA, Realisierung } \\
\text { des ersten Offshore-Windparks 1991 }\end{array}$ \\
\hline Investoren, Banken & $\begin{array}{l}\text { hielten Windtechnik für zuverlässig; } \\
\text { kalifornischer Markt schien hohe } \\
\text { Renditen zu versprechen }\end{array}$ & $\begin{array}{l}\text { verstärkte Aktivitäten auf dänischem } \\
\text { Markt, nur geringe Profite möglich }\end{array}$ \\
\hline EVU-Windparks & starke Proteste gegen EVU-Windparks & $\begin{array}{l}\text { starke Proteste gegen EVU-Windparks } \\
\text { 1991: EVU installieren erstmals } \\
\text { ohne } \\
\text { Offshore-Windpark } \\
\text { Akzeptanzprobleme }\end{array}$ \\
\hline
\end{tabular}

Quellen: vg. Kap. 2.3 und Kap. 2.4 


\subsubsection{Niederlande in Periode 4}

Ein dritter Markt für Windanlagen entsteht Mitte der 80er Jahre in Periode 4. Bis 1985 hat Windenergie hauptsächlich im niederländischen LSP-Sektor eine Rolle gespielt. Ähnlich wie in den übrigen Pioniermärkten sind auch die Arbeiten im Rahmen des NOW (s.o.) von sehr mäßigen Erfolgen gekrönt worden. Verbong $(1999,152)$ verweist explizit auf negative Erfahrungen der USA und der Bundesrepublik, welche die Fürsprecher der Megawatttechnologie dazu bewogen, zunächst die Markteinführung kleiner WEA (50$100 \mathrm{~kW}) \mathrm{zu}$ fördern. Während in Dänemark bereits 1981 mit dem Energiplan 81 die Abkehr vom LSP vollzogen wird, folgen die Niederlande diesem Beispiel 1986. Nach Dänemark und Kalifornien schaffte das westeuropäische Nachbarland legislative Voraussetzungen für die Bildung eines Windanlagenmarktes. Aufgrund des späten Einstiegs in Periode 4 kann der niederländische Markt auf internationale Technologie zurückgreifen. WEA zur Stromproduktion müssen nicht mehr neu erfunden werden. Besonders in Dänemark hat die Windanlagentechnik einen guten Erprobungsgrad erreicht. Seit Anfang der 80er Jahre werden in den Niederlanden vereinzelt kleine WEA zwischen $10-80 \mathrm{~kW}$ betrieben, zumeist von Landwirten, Kleinunternehmen und Windenergiebegeisterten (Jacobsson/Johnson, 2006, 13). Bis 1985 ist der Betrieb von Windanlagen ein Randphänomen. In diesem Jahr gibt die Regierung das Ziel bekannt, bis zum Jahr 2000, 1000MW Windkraftkapazität zu installieren, was in etwa dem damaligen kalifornischen Markt entsprach.

Nicht allein auf dem Gebiet technischen Know-hows bestanden für die Niederländer große Lernchancen. Zahlreiche im Zusammenhang mit dem Betrieb von WEA stehende Probleme konnten in Dänemark erfolgreich bewältigt werden. Dennoch: Nicht alle Lösungen, die für eine Periode erfolgreich waren, müssen es für die nächste auch sein. Andere Strategien lassen sich möglicherweise nicht von Dänemark auf jedes andere Land übertragen wie das Beispiel Kaliforniens gezeigt hat (vg. Kap. 2.5). Weil der niederländische Markteinstieg noch später als der kalifornische erfolgt war, sind die Lernmöglichkeiten hier entsprechend größer. Unabhängig davon, inwieweit das dänische Modell auf die Niederlande übertragen werden kann: Erste Anhaltspunkte sollten die internationalen Erfahrung in jedem Falle bieten. Letztendlich folgte der niederländische Markt, ebenso wie der kalifornische, einem gänzlich anderen Entwicklungspfad.

$\mathrm{Zu}$ Beginn der vierten Periode galt Windenergie noch nicht als proven technology und war, neben dem instabilen kalifornischen Markt, ausschließlich in Dänemark gut etabliert. Verschiedene Fragen sind noch ungeklärt: Wie und durch wen sollten Windanlagen optimalerweise betrieben werden: als einzelne Windmühlen, durch Windradkooperativen oder von EVU und Investoren installierte Windparks? Wie sollten WEA finanziert werden? Welche stabile Einigung zwischen Windmüllern und EVU könnte es geben? Welche Rolle sollten die EVU innerhalb des Sektors einnehmen? Wie kann die Akzeptanz von Windanlagen maximiert werden? Diese Frage ist insbesondere für Länder mit hoher Bevölkerungsdichte wie die Niederlande interessant.

\subsubsection{Niederlande: Das politisch-administrative System in Periode 4}

Das wesentliche Ziel des niederländischen LSP-Programms bestand in der Produktion marktfähiger Großwindanlagen. Als sich hinsichtlich dessen Schwierigkeiten abzeichneten, förderte man auch zunächst den Aufbau eines Windparks mit vorsichtiger dimensionierten WEA $(300 \mathrm{~kW})$. Befriedigende Ergebnisse vermochte man auch hier nicht zu erzielen. Nationale wie internationale Erfahrungen bewogen die Regierung um Mitte der 80er Jahre zur Aufgabe des LSP und einer Neuorientierung der Windenergiepolitik. Nun sollte die 
Technologie von der Nachfrageseite her gefördert werden. Im Rahmen des IPW (Integraal Programma Windenergie) werden zusätzlich Entwicklungstätigkeiten kommerzieller Hersteller gefördert.

Dem Leiter der Abteilung für Energiesparen und Diversifikation Ed Weeda zufolge, war das Vertrauen in die Potenziale der niederländischen Windindustrie eine entscheidende Voraussetzung für die Durchführung des IPW: ,The IPW would not have its present form if we had not been confident there was an industrial base in Holland' (WPM 3/88, 21).

In den Niederlanden ist die Präferenz der Regierung für die EVU als Windparkbetreiber noch deutlich stärker als in Dänemark ausgeprägt. In der Auseinandersetzung zwischen EVU und privaten Windmühlenbesitzern ließ die Regierung den jeweiligen Netzbetreibern weitestgehend freie Hand. Das Problem mangelnder Standorte für Windanlagen stellte sich als noch gravierender als in Dänemark heraus. Es wird zu untersuchen sein, inwieweit beschlossene Planungsverfahren die Situation verbessern konnten.

\section{Integraal Programma Windenergie (IPW)}

Entgültig vollzogen wird die Überwindung des als innovationsfeindlich analysierten LargeScale-Paradigmas, mit dem Start des IPW im Mai 1986. Von den Gesamtmitteln des IPW in Höhe von NLG 135,5 Mio. werden nur noch 15\% in Grundlagenforschung investiert (Tab. 2.4.2a).

Tab. 2.4.2a Ingegraal Programma Windenergie 1986-1990

\begin{tabular}{|c|c|c|c|c|}
\hline & $\begin{array}{l}\text { Grundlagenforschung } \\
\text { Testeinrichtungen etc. }\end{array}$ & $\begin{array}{l}\text { Produkt und } \\
\text { Herstellerbezogene } \\
\text { F\&E }\end{array}$ & Investitionsförderung & \begin{tabular}{|ll}
,Environmental \\
Premium’ \\
Investoren
\end{tabular} \\
\hline $\begin{array}{l}\text { Fördersumme (NLG } \\
\text { Mio.) }\end{array}$ & 21 & 37 & 68,5 & 10 \\
\hline Anteil (\%) & 15,4 & 27,1 & 50,2 & 7,3 \\
\hline
\end{tabular}

Quelle: WPM 12/87, 9

Insofern, als die übrigen Gelder allesamt entweder privaten Herstellern, d.h. Anbietern kleinerer WEA oder Anlagenkäufern zugute kamen, ist die Durchführung von LSP-Projekten im Rahmen des IPW praktisch ausgeschlossen gewesen.

Durch das IPW sind entscheidende Weichenstellungen der zukünftigen Windenergienutzung der Niederlande vorgenommen worden. Darüber hinaus stellt das IPW eine energiepolitische Richtungsentscheidung dar. Über einen Zeitraum von fünf Jahren (1986-1990) werden 15\% des Energiepolitik-Budgets für das Programm aufgewendet (WPM 3/88, 21). Das IPW verfolgt zwei Hauptziele. Erstens soll mindestens eine kommerziell erfolgreiche Windturbine aus der Förderung hervorgehen. Zweitens sollen zum Ende des Programms im Jahr 1990, 100-150MW Windenergiekapazität installiert worden sein. Grundlagenforschung und neue Testeinrichtungen sollen dazu dienen, Anlagen- und Produktionstechnologie weiterzuentwickeln, um Subventionen nach Abschluss des IPW überflüssig zu machen (Verbong 1999, 153). Der wichtigste Bestandteil des Programms besteht in der Investitionsförderung. Der Kauf einer zertifizierten Windanlage wurde zwischen 1986 und 1988 mit etwa $40 \%$ der Investition gefördert. Unternehmen erhielten sogar bis zu 50\%. Zusätzlich zum Investitionszuschuss durften 40\% der selbst getragenen Kosten steuerlich abgesetzt werden (WPM 12/87, 8). 1989 verringerte sich der Zuschuss auf durchschnittlich 37\%, 1990 auf 33\% der Investition. Der zweitgrößte Posten des IPW (27,1\%) bezog sich auf Unterstützung der Hersteller an den Entwicklungskosten neuer Anlagen. Unternehmen, deren Geschäftspläne man befürwortete erhielten $70 \%$ ihrer Aufwendungen. 
Trotz der anscheinend guten Förderung sowohl der Nachfrage-, als auch Angebotsseite, enthält das IPW einige Elemente, welche sich für die Windindustrie nachteilig auswirkten. 1986, im ersten Jahr des Windenergieprogramms, setzt sich die Marktstagnation fort (Tab. 2.4.2b).

Tab. 2.4.2b Windenergiemarkt in den Niederlanden 1982-1996

\begin{tabular}{|l|l|l|l|l|l|l|l|l|l|l|l|l|l|l|l|}
\hline & 1982 & 1983 & 1984 & 1985 & 1986 & 1987 & 1988 & 1989 & 1990 & 1991 & 1992 & 1993 & 1994 & 1995 & 1996 \\
\hline $\begin{array}{l}\text { Kapazität } \\
\text { neu (MW) }\end{array}$ & 1,5 & 1,5 & 1,0 & 2,0 & 0,6 & 9,0 & 7,1 & 12,1 & 16,7 & 33,8 & 23 & 29 & 19 & 100 & 42 \\
\hline $\begin{array}{l}\text { Kapazität } \\
\text { gesamt } \\
\text { (MW) }\end{array}$ & 2,0 & 3,5 & 4,5 & 6,5 & 7,1 & 16,1 & 23,2 & 35,3 & 52,0 & 85,8 & 109 & 138 & 157 & 257 & 299 \\
\hline
\end{tabular}

Quelle: Kamp 2002; Tab. 2a

Die Erklärung dafür besteht in der restriktiven Gestaltung der Kriterien für die Vergabe von Entwicklungskostenbeihilfen an die Industrie. Das Wirtschaftsministerium wollte grundsätzlich nur Unternehmen fördern, deren Anlagendesigns große technische Sprünge zu ermöglichen versprachen. Man war der Meinung, es sei eine Geldverschwendung, die Mittel auf alle 24 Hersteller zu verteilen, die 1986 auf dem Markt aktiv waren. In den 18 Förderträgen, die bis 1988 bei NOVEM (Nederlandse Onderneming voor Energie en Milieu) eingereicht wurden, mussten die jeweiligen Urheber begründen, weshalb ihr Anlagenkonzept förderungswürdig sei. Schließlich hatte NOVEM sechs der Anträge angenommen. ${ }^{263}$ Darüber hinaus werden mit der belgischen HMZ und der dänischen Micon zwei ausländische Hersteller gefördert. Die Förderung schloss die Anlagenprüfung auf dem Testfeld des ECN mit ein. Investitionszuschüsse werden nur auf den Erwerb von Modellen gewährt, die ein Limited Quality Certificate (BKC) erhielten. Aufgrund der hohen und komplizierten Anforderungen wurde das Zertifikat im ersten Jahr von keinem Hersteller erlangt (Kamp 2002, 105f.). Auf diese Weise erklärt sich die Stagnation. Um die Fördermittel des IPW in Anspruch zu nehmen, warteten die Interessenten ab. Erst im Juni 1987 erhält Lagerwey das erste Zertifikat für eine Windanlage mit 75kW-Generator (WPM 7/87, 8). Bis Ende 1987 werden elf Maschinen von acht Herstellern genehmigt. ${ }^{264} \mathrm{Im}$ selben Jahr kommt es erstmals zu einem deutlichen Nachfrageschub. Neun Megawatt Windenenergiekapazität werden in Betrieb genommen. Damit wächst die Gesamtkapazität im Vergleich zum Vorjahr, um mehr als das Doppelte (Tab. 2.4.2b). 1987 werden Anträge zum Kauf von WEA mit insgesamt über 200MW Kapazität gestellt. Um die Mittel für seriöse Antragsteller zu reservieren, hatte man die Klausel eingeführt, dass sich Projektplaner innerhalb von zwei Monaten nach Erhalt der Genehmigung, um eine Baugenehmigung zu bewerben hatten. Von den 200MW werden letztlich nur circa $15 \mathrm{MW}$ gefördert. Um die Realisierung der genehmigten Projekte zu gewährleisten, bzw. zu beschleunigen, sind einige Regelungen aufgeweicht worden. So wird der Realisierungszeitraum des Vorhabens, der ursprünglich auf ein Jahr begrenzt war, ausgedehnt. Teilweise vergibt man die Investitionsförderung auch für den Kauf von Modellen, die zu diesem Zeitpunkt noch gar kein Zertifikat erhalten hatten (WPM12/87, 9).

Das zentrale Problem des IPW besteht weder darin, dass es eine Warmlaufphase von gut einem Jahr benötigte, noch darin, dass zahlreiche Hersteller keine Entwicklungskostenbeihilfen erhielten, oder mit zu hohen Anforderungen konfrontiert worden wären. Dem IPW lag das Ziel zugrunde, die Hersteller zur Entwicklung leistungsstärkerer Konzepte $\mathrm{zu}$ motivieren. Anders in Dänemark galt für den Investitionszuschuss kein fester Prozentsatz. Der Zuschuss wurde pro Kilowatt bezahlt. Mit

\footnotetext{
${ }^{263}$ Dabei handelte es sich um Anträge von Berewoud, Bouma, Lagerwey, NCH, Newinco und Trasco (Kamp 2002, 106).

${ }^{264}$ Darunter befand sich auch die 1MW-Versuchsanlage (vg. Kap.1). Da sich Stork-FDO zu diesem Zeitpunkt bereits aufgelöst hatte, wird das Zertifikat nicht mehr in Anspruch genommen (Kamp 2002, 106).
} 
gewisser Einschränkung ${ }^{265}$ lässt sich sagen: Je größer die Kilowattzahl einer Windanlage gewählt wird, desto mehr Subventionen werden gezahlt. Um die Attraktivität ihrer Produkte $\mathrm{zu}$ erhöhen, gingen viele Hersteller dazu über, stärkere Generatoren $\mathrm{zu}$ verwenden. Nirgendwo boten Hersteller Modelle mit einer höheren spezifischen Generatorenleistung an als in den Niederlanden. Dieses Missverhältnis zwischen überstrichener Rotorfläche und Generatorengröße führte zu einer vergleichsweise niedrigen Energieausbeute (Gipe 1995, 41). Unterstützt wird die Tendenz zur Verwendung übergroßer Generatoren durch die Festschreibung einer rigorosen Degressionen. Zwischen 1986 und 1990 sinkt die Förderung von 700 auf 100 Gulden pro Kilowatt ab. 1991 läuft sie gänzlich aus. Die Förderhöhe hängt damit nicht nur von der Generatorenkapazität, sondern auch vom Zeitpunkt des Markteintritts ab. Mit dem IPW fällt also das Startsignal für einen Wettlauf, möglichst große WEA, schnell auf den Markt zu bringen (siehe Kalifornien). Für die niederländische Windindustrie hat das IPW fatale Folgen. Zunehmend unterliegt sie der ausländischen Konkurrenz. Seit Anfang der 90er Jahre zeichnet sich ab, dass Dänemark auf dem niederländischen Markt die Führungsrolle übernehmen würde (Verbong 1999, 138). Waren zum Zeitpunkt der Einführung des IPW noch 24 niederländische Turbinenproduzenten aktiv, reduziert sich deren Zahl bis Ende 1986 auf zwölf. 1991, nach Beendigung des IPW, bleiben drei Hersteller (Kamp 2002, 117).

\section{Teststation}

Für die niederländische Windenergie spielten Testverfahren offenbar eine wichtige Rolle. Daher werden der Ort der Tests und die Bedingungen ihrer Durchführung im folgenden näher betrachtet. Bereits 1980 installierte Forschungscenter ECN ein Testfeld für kleine Windanlagen. Ziel ist die Förderung der Industrie. Betriebssichere und geprüfte Anlagen sollten in den Niederlanden entwickelt werden (Kamp 2002, 91). Anfangs führte man nur relativ oberflächliche Funktionstests durch. Diverse Akteure forcierten schon bald die Einführung differenzierterer Testverfahren. Die Hersteller waren daran interessiert ihre Produkte zu verbessern. Für sie standen Fragen der Optimierung des Energieertrags und der Minimierung mechanischer Belastungen im Vordergrund. Genehmigungsbehörden wollten mehr über Sicherheits- und Umweltaspekte erfahren Den Käufern ging es in erster Linie um Energieertrag, Lebenspanne und Zuverlässigkeit der Produkte. Die EVU wollten sich vergewissern, das die Anlagen Elektrizität möglichst hoher Qualität produzierten. Forschungsinstitute waren an speziellen technischen Belangen interessiert. Beraterfirmen schließlich, äußerten das Interesse, sich übergreifende Kenntnisse zu verschaffen. Vor diesem Hintergrund wird bereits 1981 ein recht komplexes, vereinheitlichtes Testverfahren entwickelt. ${ }^{266}$ Ähnlich wie die Hersteller Dänemarks waren auch die Niederländer anfangs sehr vorsichtig mit der Offenlegung von Konstruktionsdetails. Auch sie befürchteten die Weitergabe von Details an die Konkurrenz. Seitens des ECN wurde daher die Garantie gegeben, dass die Testergebnisse ausschließlich an den Hersteller des fraglichen Modells

\footnotetext{
${ }^{265}$ Das Potenzial einer WEA zur Energieproduktion ist durch ihre Rotorenlänge bestimmt. Man kann natürlich einen Rotorendurchmesser von 15 Metern mit einen $1000 \mathrm{~kW}-$ Generator kombinieren. Allerdings würde diese Windanlage selbst bei maximaler Windgeschwindigkeit niemals eine Leistung von 1000kW erreichen, wohl aber einen hohen Fördersatz. Um die Entwicklung solcher Modelle zu verhindern, wird ein Grenzwert der Nennleistung eingeführt, den eine Turbine bei gegebener Quadratmeterzahl überstrichener Rotorfläche maximal haben durfte. Bei einem Rotordurchmesser von bis zu 18 Metern darf der Generator eine spezifische Leistung von $0,45 \mathrm{~kW}$ pro Quadratmeter nicht übersteigen. Bei Rotordurchmessern bis 25 Metern betrug der Wert $0,55 \mathrm{~kW}$ pro Quadratmeter, bei größeren Rotoren waren es $0,6 \mathrm{~kW}$ pro Quadratmeter (WPM 2/88, 10).

${ }^{266}$ Geprüft wurden: Konzeptberechnungen, wobei fehlende oder mangelhafte Berechnungen vom ECN ergänzt wurden; elektrisches System, Stabilität der aerodynamischen, mechanischen und elektrischen Komponenten, Zahnkränze, Anlauf- und Stopverhalten (auch unter extremen Bedingungen), Sicherungssysteme, Messungen der mechanischen Belastungen und Vibrationen, Energieertrag, Stromqualität, Besuch der Produktionsstätte, Geräuschmessungen, Inspektion einer bereits laufenden Maschine desselben Typs (Kamp 2002, 96f.).
} 
weitergegeben und nur eine kurze Zusammenfassung der Ergebnisse veröffentlicht würde. In Dänemark sind die Testaktivitäten bis zum Beginn der Erprobungsperiode durch eine unmittelbare Beziehung zwischen den Mitarbeitern der Teststation und den Herstellern dominiert. Dem gegenüber hatte sich um die niederländische Prüfeinrichtung frühzeitig ein komplexes Akteursgeflecht entsponnen. Wegen des hohen Aufwandes entschied der ECN, nicht alle Neuanlagen prüfen zu lassen. Jedes Produkt musste sich zuvor durch Erlangung eines Zulassungszertifikats qualifizieren. Zwischen 1981 und 1982 wurden nur sieben kleine Modelle (11-60kW) getestet. Anstatt der geplanten drei Monate nahm ein Testverfahren circa sechs bis zwölf Monate in Anspruch. Diese Verzögerung erklärt sich vor allem daraus, dass den Herstellern die Möglichkeit gewährt wurde, ihre Konzepte noch während des laufenden Verfahrens zu verbessern (Kamp 2002, 96). Aus den Erfahrungen mit der Anlagenprüfung entwickelten der ECN und andere beteiligte Forschungsinstitute Normen bzgl. des Turbinendesigns und der Geräuschproduktion. Forschung über Materialermüdung und die Prüfung theoretischer Modelle wurde ermöglicht (ebd., 97).

Dennoch verhinderten die Tests nicht, dass die zertifizierten Anlagen noch Fehler enthielten. Seit Einführung des IPW waren die Hersteller verstärkt daran interessiert, dass ihre Modelle das Prüfungsverfahren möglichst schnell durchlaufen. Die sogenannten ,Limited Quality Certificates' (ebd., 109) standen mit diesem Ziel in Einklang. Gleichzeitig ist der Wille der Produzenten gesunken, ihre Konzepte während der Testphase noch zu verbessern. Aufgrund der starken Degression der Investitionsförderung, führte jede Verzögerung des Markteintritts unweigerlich zu Umsatzeinbußen.

Entflechtung des Strommarktes und neue Impulse für die Windkraft

Vor dem Hintergrund der Bemühungen um die Reduktion der CO2-Emissionen beschließt die Regierung im Jahr 1989 einen nationalen Umweltplan (National Environment Policy Plan, NMP). Ziel ist der Ausbau der Kraft-Wärme-Kopplung (KWK) wie auch die Schaffung neuer Kapazitäten aus Solar- und Windenergie.

Im selben Jahr wird das Elektrizitätsgesetz verabschiedet, dass den Strommarkt neu strukturieren sollte. Eine Trennung von Energieproduktion- und Verteilung wird beschlossen. Daraufhin entstehen neue Stromverteilungsunternehmen. Die EVU sind bereits seit Einführung des IPW wichtigster Akteur auf dem Strommarkt (Tab. 2.4.2c).

Tab. 2.4.2c

EVU-Anteil neu errichteter Windanlagen 1986-1991

\begin{tabular}{|l|l|l|l|l|l|l|}
\hline & 1986 & 1987 & 1988 & 1989 & 1990 & 1991 \\
\hline $\begin{array}{l}\text { neu installierte } \\
\text { Windanlagen } \\
(\mathrm{MW})\end{array}$ & 0,6 & 9,0 & 7,1 & 12,1 & 16,7 & 33,8 \\
\hline $\begin{array}{l}\text { EVU-Anteil } \\
(\%)\end{array}$ & 50 & 86 & 76 & 69 & 58 & 89 \\
\hline
\end{tabular}

Quelle: Kamp 2002

Laut Elektrizitätsgesetz ist es den Verteilern erlaubt, eigene Kleinkraftwerke bis $25 \mathrm{MW}$ zu betreiben. Dadurch stärkten sie ihre Position gegenüber den großen Stromproduzenten. Für diesen Zweck eigneten sich Windanlagen hervorragend. Zudem erhoffte man sich Imageverbesserungen. Im Rahmen des NMP schlossen sich acht dieser Verteiler zusammen (,Windplan Foundation') und kündigen im Februar 1990 an, die CO2 Emissionen zu reduzieren (Environmental Action Plan, MAP). Dazu wollen sie vor allem KWK und Windenergie ausbauen sowie, in geringerem Umfang, Solaranlagen. Bis 1995 wurde die Installation von 250MW Windenergie anvisiert (Verbong 1999, 155). ${ }^{267}$ Von den NLG 600-

\footnotetext{
${ }^{267}$ In den MAP waren die sieben windigsten Provinzen der Niederlande integriert. Diese zeigten sich bereit, die erforderlichen Flächen zur Verfügung zu stellen. Auch für die Zeit nach 1995 strebt das MAP ehrgeizige Windenergie-Ziele an. Bis zum Jahr 2000 sollte 1000MW, bis 2010 sogar 2000MW Kapazität installiert werden
} 
900 Mio., welche die Versorger als Investitionen für MAP bereitstellen wollten, wurden 300 Mio. für Windparks eingeplant. Mit NLG 200 Mio. wurden die Planungen zusätzlich durch das Wirtschaftsministerium unterstützt (WPM 3/90, 6). Ein Großteil der Zuschüsse wurde von den EVU nicht abgerufen. Ihr Engagement im Windsektor war nicht erfolgreich und wurde daher 1993 abgebrochen.

TWIN (Toiepassing Windenergie in Nederland)

Ende 1990 wurde das IPW durch das TWIN Programm abgelöst. Trotz mäßiger Erfolge des IPW verlieh man dem TWIN eine dem Vorgängerprogramm ähnliche Gestalt. Das Ziel der Marktförderung steht weiterhin im Zentrum. Obgleich das IPW-Ziel (Inbetriebnahme von 150MW Windkraftkapazität bis 1990), bei tatsächlicher Installation von 86MW deutlich verfehlt wurde, definierte das TWIN, mit 400MW bis 1995 erneut ein sehr ambitioniertes Ziel. Zur Verbesserung der Effizienz sollte die Entwicklung großer WEA sowie die Forschung im Offshore-Windenergiesektor unterstützt werden. Zudem wollte man die Entwicklungsarbeiten kommerzieller Hersteller fördern, indem man versuchte, deren Konzepte auf eine fundiertere wissenschaftliche Basis zu stellen (Kamp 2002, 120). ${ }^{268}$

Anders als noch im IPW ist der größte Teil der Fördermittel des TWIN, von Anfang an für EVU-Projekte reserviert worden. Während in Dänemark und der BRD Energieversorger von der Förderung ausgeschlossen waren, galten die niederländischen Vorzugstarife auch für EVU, welche diese direkt an die Kunden weitergeben durften (WPM 12/91, 13).

Zunächst erhielt die Branche durch die Nachfrage der Versorger einen beachtlichen Schub. Bis Juli 1991 hatten sechs EVU ${ }^{269}$ insgesamt neun Windparks entweder gerade fertiggestellt, oder deren Aufbau gestartet. 1990 belief sich die Kapazität der EVU-Windparks auf 36,1MW, bei insgesamt 52MW. Privaten Entwicklern wurde nur ein begrenzter Anteil zugestanden. Der Markt für Kooperativen und Einzelpersonen war von nun an besonders stark eingeschränkt (WPM 7/91, 10).

\section{Standortplanung}

Die Niederlande sind das EU-Land mit der höchsten Bevölkerungsdichte. Darin könnte ein Grund liegen, weshalb sich die Standortsuche hier vergleichsweise schwierig gestaltete. Einen hohen Erklärungswert hat dieser jedoch nicht. Ende 1991 sind in Dänemark, sowohl pro Kopf, als auch Quadratkilometer gerechnet, deutlich mehr Windanlagen installiert als in den Niederlanden (vg. Tab. 2.4.2d).

Tab. 2.4.2d Windenergie in den Niederlanden und Dänemark 1991

\begin{tabular}{|l|l|l|l|}
\hline & Kapazität (MW) & Watt/ Einwohner & $\begin{array}{l}\text { Kilowatt// } \\
\text { Quadratkilometer }\end{array}$ \\
\hline Dänemark & 420 & 78,5 & 9,8 \\
\hline Niederlande & 92 & 5,8 & 2,2 \\
\hline
\end{tabular}

Quelle: Weltalmanach 2006; eigene Berechnungen

Ähnlich wie in Dänemark war die von Anrainern befürchtete Lärmbelästigung durch Windanlagen ein Problemfaktor bei der Planung von Standorten. Die Gestaltung des TWIN

werden (Gipe 1995, 41).

${ }^{268}$ Die Hersteller Berewoud und Paque erhielten Mittel zur Entwicklung flexibeler Windenergieanlagenkomponenten. Zwar trugen die entwickelten Prototypen die vielversprechenden Namen ,Profitable Wind Turbine' und ,Cost Effective Wind Turbine'. Jedoch stellt sich bald heraus, dass diese Designs nicht konkurrenzfähig waren. Seitdem werden im Rahmen des TWIN nur noch Projekte gefördert, deren Beitrag zur Weiterentwicklung der kommerziellen Anlagentechnik außer Frage stand (ebd., 110; 120).

${ }^{269}$ Dabei handelt es sich um PEN, PNEM, IJsselmij, PGEM, GEB und EGD (WPM 7/91, 10). Mit Ausnahme

EGDs sind alle Mitglieder der Wind Foundation ( Kooperation des 250MW-Plans). 
trug insofern zur Erhöhung der Akzeptanz bei, als es Planern erhöhte Zuschüsse gewährte, die sich für geräuschärmere Modelle entschieden, oder speziell deklarierte Standorte wählten (WPM 2/92, 12). Wolsink (1996, 1079ff.) zeigt einige wichtige Aspekte der Schwächen des niederländischen Planungssystems auf. Ihm zufolge ist die mangelhafte Planungspolitik eines der zentralen Hemmnisse des niederländischen Sektors: ,There was no programme on making sites available and there were no instruments to stimulate crucial actors in the process of decision making of sites. This started a vicious circle: economic feasibility has not been reached, because there is no mass production of turbines, which in turn is a result of the lack of available sites.' (Wolsink 1996, 1079).

Aufgrund der hohen öffentlichen Akzeptanz ${ }^{270}$ wird die Standortfindung seitens der Zentralregierung zu keiner Zeit als Problem wahrgenommen. Weiterer Ausgangspunkt der nationalen Planungspolitik ist die Annahme, dass die ansässigen Behörden im allgemeinen zu Gunsten der Windenergie entscheiden würden. Immerhin wird die Förderpolitik für Windkraft von allen Provinzen befürwortet (ebd., 1081f.). Die Tatsache, dass es dennoch so viele Probleme bei der Standortfestlegung gab, analysiert Wolsink (ebd., 85f.) als Ergebnis des hierarchischen Planungssystems. Der Zentralstaat beauftragte die Provinzen, jeweils eine bestimmte Windkraftkapazität aufzubauen. Provinzen hatten die Befugnis, regionale Flächenplanungen vorzunehmen. Sie gaben ihre vergleichsweise groben Planungsvorstellungen an die entsprechenden Gemeinden weiter, die nun eine detaillierte Planung vorzunehmen hatten. Aufgrund verschiedener Details, die nicht von der Planung der Provinzebene berücksichtigt werden konnten, können beide Flächenpläne starke Differenzen aufweisen. Daher wäre es Wolsink zufolge besser gewesen, die Kommunen von Anfang in die Flächenplanung mit einzubeziehen: ,Although there would be a large number of relevant municipalities involved, an agreement with them would have been more effective than with provinces without effective power in siting issues' (ebd., 1085f.).

Zusammenfassung und Ausblick

In verschiedener Hinsicht ist die Förderpolitik der Niederlande zur Etablierung der Windkraft wenig hilfreich. Sie brachte die Industrie frühzeitig in ein Konkurrenzverhältnis, wodurch den Herstellern kaum Spielräume zur Optimierung ihrer Konzepte gelassen wurde. Durch die Präferenz für überproportional große Generatoren etablierte sie technische Fehlentwicklungen. Die Politik ließ den Netzbetreibern weitestgehend freie Hand, indem sie deren restriktives Verhalten gegenüber den Windmüllern nicht sanktionierte. Die Förderpolitik war zudem darauf ausgerichtet, hauptsächlich energiewirtschaftliche Akteure als Betreiber für Windanlagen zu gewinnen. Damit setzte sie, wie weiter unten diskutiert wird, ,auf das falsche Pferd'.

Auch in den folgenden Jahren sind auf dem niederländischen Windenergiemarkt keine Durchbrüche zu verzeichnen. 1992-94 werden nur jeweils ca. 20MW neu in Betrieb genommen. 1994 wird eine Abnahmepflicht für Strom aus privaten Windparks eingeführt, wobei die Einspeisetarife sehr niedrig gehalten sind. 1996 läuft der Investitionszuschuss aus (Wolsink 1996, 1084). Trotz der Tatsache, dass die Branche vor diesem Hintergrund 1995 einen kleinen Boom verzeichnen kann, wird das Installationsziel von 400MW für 1995 verfehlt (vg. Tab. 2.4.2b). Mit dem Verschwinden der Investitionszuschüsse verringert sich die Nachfrage deutlich. Auch scheitern Regierung und Administration daran, ein geeignetes Planungssystem für die Festlegung von Standorten zu entwickeln (Kamp 2002, 122).

\footnotetext{
270 'Attitudes generally are positive in the case of wind energy and there is no dominant negative trend in the public debate. If the press coverage is taken as an indicator for the latter, the image of wind power projects appears to be favourable. The average picture from newspaper content is positive, without prejudice.' (Wolsink 1996, 1086).
} 


\subsubsection{Niederlande: Windanlagenindustrie in Periode 4}

Die Anfänge der niederländischen Windindustrie gehen auf die späten 70er Jahre zurück. Bis 1980 ist ein knappes Dutzend kleiner Firmen mit weniger als zehn Beschäftigten präsent (Kamp 2002, 90f.). Zunächst werden ausschließlich Einzelexemplare gefertigt, die auf internationalen Märkten, also insbesondere Kalifornien und Dänemark, nicht konkurrenzfähig sind. Bevor die erste WEA in Serie gefertigt werden, vergehen noch mehrere Jahre.

Dänische Hersteller verzeichneten 1983 bereits deutliche Erfolge. Dort ist seit 1979 das kontinuierliche Anwachsen eines Turbinenmarktes zu beobachten. Seit 1983 werden große Stückzahlen produziert und nach Kalifornien exportiert. Im selben Jahr gibt das niederländische ECN einen Bericht heraus, der auf Testergebnissen mehrerer Modelle niederländischer Hersteller basiert. Darin kommt der ECN zum Schluss, dass sich sämtliche WEA noch im Prototyp-Status befanden. Ähnlich wie bei dänischen Herstellern während Periode 1 hatten auch die Niederländer große Probleme mit der Konstruktion aerodynamischer Bremssysteme. Des öfteren kam es bei Sturm zu Totalschäden, weil die Bremsen versagten. Alle getesteten Modelle wiesen Fehler im elektrischen System auf. Darüber hinaus schätzten sämtliche Produzenten die Energieausbeute zu optimistisch ein (Kamp 2002, 96f.). Die Forschungspolitik im Rahmen des NOW hat Innovationsprozesse im kommerziellen Sektor kaum vorangebracht. Der ECN ist zu theoretisch ausgerichtet, als dass die Hersteller von dessen Erfahrungen hätten profitieren können. Das dänische Beispiel zeigt die Wichtigkeit sukzessiven Lernens.

Solche Lernprozesse werden erst mit Einführung des IPW und daraufhin zunehmender Nachfrage ermöglicht. Daher setzt die Betrachtung niederländischer Anlagenhersteller erst 1986/87 ein. Im Zentrum stehen dabei die Fragen, ob und wie Hersteller durch das IPW gefördert werden und inwiefern sich das IPW in der technischen Gestaltung widerspiegelte. Ähnlich wie in Dänemark bereits während der Stabilisierungsperiode (1979-82) setzte auch hier, infolge des IPW, ein Professionalisierungsprozess der Branche ein. $\mathrm{Zu}$ dessen wichtigsten Kennzeichen zählt die Einbeziehung wissenschaftlicher Methoden in die Entwicklung der Anlagenkonzepte. Dadurch verringerte sich die Distanz zwischen den Herstellern und der Test- und Forschungsanlage des ECN. Aufgrund des hohen Zeit- und Konkurrenzdrucks, der durch das IPW erzeugt wurde, blieb für die Hersteller kaum Zeit, die Korrekturvorschläge des ECN zu berücksichtigen (Kamp 2002, 119).

An der Entstehung des Konkurrenzdrucks hatten auch die Hersteller einen Anteil. Ein Teil der Mittel des IPW wurde für projektbezogene Forschungsförderung ausgewählter Unternehmen reserviert. Der Branche war es freigestellt, Konsortien zwecks gemeinsamer Nutzung der Mittel zu bilden, oder sich als einzelne Hersteller um Förderung zu bewerben. Aufgrund des gegenseitigen Misstrauens kam die Bildung solcher Konsortien nicht zustande (ebd., 105f.).

Ziel der Förderpolitik war es, die Mittel auf diejenigen Hersteller mit den aussichtsreichsten Konzepten zu konzentrieren. U.a. dadurch reduzierte sich die Zahl der Unternehmen während des IPW-Zeitraums (1986-90) von zwölf auf drei. Bis 1988 erhielten sechs niederländische und zwei dänische Hersteller Projektförderung. Elf Modellen von acht Produzenten kam bis 1987 die Investitionsförderung zu, nachdem sie entsprechende Zertifikate erhalten hatten. Im folgenden werden die drei Firmen näher betrachtet, die aus dem Auswahlverfahren des IPW als Sieger hervorgingen und das Ende der Pionierphase überdauerten: Lagerwey, Windmaster und Nedwind. Bei Lagerwey handelt es sich um das einzige unabhängige Unternehmen, während die übrigen Tochterfirmen von Maschinenbaukonzernen waren, die kleinere Windanlagenhersteller aufkauften und in technische Neuentwicklungen investierten.

Lagerwey

Gegründet wurde das Unternehmen 1979 durch Elektroingenieur Henk Lagerwey. Um das 75kW-Modell zu verbessern, wurde Lagerwey mit IPW-Mitteln gefördert. Im Juni 1987 erhält sie als erste WEA das IPW-Zertifikat, d.h. ihr Kauf wird seitdem bezuschusst (s.o.) Die in 
Periode 1 entstandene Komponentenwindmühle hat auf dem niederländischen Markt eine geringere Bedeutung. Anders als Windmaster und Nedwind produzierte Lagerwey nicht alle Komponenten selbst. So äußerte sich Henk Lagerwey über seine Unternehmensstrategie: ,Others often make their own blades because that is the most vital part for reliability and cost effectivness. But we have found that a close cooperation with blade sub-contractors works just as well. Effective development of a wind turbine is the selection of the optimum configuration of standard components, where this is possible. The blades are our own design, but our sub-contractors are very much involved in the design and mould processes' (WPM 5/92).

Von den meisten Herstellern wurden wissenschaftliche Berichte bspw. aus dem ECN kaum zur Kenntnis genommen. Lagerwey dagegen, stand in engem Kontakt mit der Technischen Universtität von Delft. Von dort erhielt er wichtige Impulse zur Verbesserung seiner Anlagenkonzepte (Kamp 2002, 112). ${ }^{271}$ Im Unterschied zu den großen Produzenten hatte Lagerwey nicht die EVU als Hauptabnehmer vor Augen. 1991 bspw. verkaufte das Unternehmen nur fünf Prozent der Produktion an EVU (ebd.). Gern grenzt sich Lagerwey von seiner Konkurrenz ab: ,We will never develop large turbines simply because the utility market is asking for them' (WPM 5/92).

Die meisten Anlagen verkaufte Lagerwey an dezentrale Akteure wie Kooperativen, Landwirte und Kleinunternehmen. Während die anderen zur Entwicklung größerer Modelle übergingen, hielt Lagerwey bis in die 90er Jahre hinein an der 75/80kW-Maschine fest. Dieses Vorgehen entsprach den Interessen seiner Zielgruppe: ,The bulk of our consumers are farmers. They have the land and the capital for installation of $75 \mathrm{~kW}$ turbines' (WPM 3/91, 19).

Der Zweiflügler mit 15m-Rotordurchmesser verkaufte sich hundertfach. Dadurch war dieser sehr gut erprobt und konnte sukzessive verbessert werden. Zudem führte die Serienfertigung zu Kostensenkungen (Kamp 2002, 111).

Erst 1992 startete Lagerwey die Entwicklung eines größeren Designs mit 250kW-Generator, welches 1994 zertifiziert wurde. Aufgrund des Standortmangels waren die Kommunen kaum noch bereit, Standorte für Einzelanlagen auszuweisen, was die Geschäftsgrundlage des Unternehmens torpedierte. Seitdem konzentrierte sich Lagerwey verstärkt auf den Export und lieferte die meisten Exemplare des neuen 250kW-Modells auf dem indischen Markt (ebd.,122f.). Lagerwey ist erfolgreichster Akteur der Sektors. Die Firma überlebte die gesamte inländische Konkurrenz und war zeitweise der einzige Fabrikant, der netzgekoppelte WEA in größerer Stückzahl angeboten hat.

\section{Nedwind}

Nedwind entsteht 1990 aus einer Fusion von Bouma und Newinco. Bouma war zuvor ein unabhängiges Unternehmen, Newinco gehörte zu Grootint, einem Maschinenkonzern. 1989 erhielt Nedwind, damals noch als Newinco, ein Zertifikat für einen neuen 500kW-Prototyp. Wegen technischer Probleme an den Flügelspitzen verlängerte sich die Testphase um ein halbes Jahr. Dennoch verkaufte Newinco noch im selben Jahr 15 Exemplare des Modells an den Versorger von Rotterdam (ebd., 110). Polenko, ein Tochterunternehmen des zuvor im LSP-Sektor aktiven Holec, ging ebenfalls in Nedwind auf (WPM1/91, 12). Nedwind setzte die Strategie Newincos fort und produzierte vor allem für den EVU-Markt. 1990 und 1991 verkaufte Nedwind 71\% seiner Produktion, 51 WEA, an Energieunternehmen (ebd., 112).

Ein Ansatz zur Überwindung des Standortproblems, besteht in der Überlegung, Windturbinen auf den zahlreichen niederländischen Deichen zu installieren. Sowohl genehmigungsrechtlich, als auch die Frage der Akzeptanz betreffend, ist die Realisierung von Windparks auf den Deichen alles andere als eine Selbstverständlichkeit. ${ }^{272}$ Insbesondere die Möglichkeit von

\footnotetext{
${ }^{271}$ Bspw. rüstete er seine Modelle mit technischen Neuerungen wie einem passiven pitch-Kontrollsystem aus und führte unterschiedliche Rotorgeschwindigkeiten ein. Darüber hinaus war er der einzige Hersteller, von dem das Versuchsfeld der Universität von Delft genutzt wurde (Kamp 2002, 112).

272 Der Vorstellung, an den Deichen irgendwelche Veränderungen vorzunehmen, stehen die meisten Niederländer grundsätzlich kritisch gegenüber. Die Gesetze besagen, dass die Deiche nicht bebaut werden
} 
Stabilitätsverlusten der Deichfundamente, aufgrund der beim Turbinenbetrieb entstehenden Vibrationen, wurde als Problem gesehen. Bei der Entwicklung vibrationsärmerer Modelle und der Erschließung von Deichstandorten leistete Nedwind wichtige Pionierarbeit. Das Unternehmen errichtete einige Windräder nahe Enkhuizen, auf einem Deich ohne schützende Funktion. Die WEA wurden mit einer speziellen Technik ausgestattet, um die Vibrationen zu verringern (WPM 10/91, 24).

1992 startete Nedwind die Entwicklung eines 1MW-Designs und erhielt dafür Unterstützung seitens der EU. 1994 wurden zwei Prototypen installiert. Angesichts des stagnierenden niederländischen Marktes und der starken internationalen Konkurrenz, verschlechterten sich die Bilanzen Nedwinds. 1998 wurde das Unternehmen vom dänischen Konkurrenten Micon übernommen (Kamp 2002, 124f.).

\section{Windmaster}

Im Jahr 1984 gründete HMZ, eine belgische Maschinenbaufirma, den Windanlagenhersteller.1990 wurde Windmaster von der großen niederländischen Begemann Gruppe übernommen. ${ }^{273}$ Ebenso wie Lagerwey und Nedwind (Newinco) erhielt auch Windmaster im Rahmen des IPW Projektförderung. Bis Ende 1990 bot Windmaster zwei größere Modelle mit 250-, bzw. 500/550kW-Generatoren an (WPM 1/91, 12). Windmaster gelang es im Januar 1989, als erstem niederländischen Unternehmen, eine 500kW-Anlage in Betrieb zu nehmen und damit eine neue Größenklasse einzuführen. Von Anfang an richtete sich der Hersteller auf den EVU-Markt aus. 1990 und 1991 verkaufte Windmaster ausschließlich an EVU (Kamp 2002, 112). Im Laufe der 90er Jahre investierte das Unternehmen große Summen in technische Neuerungen. Dabei überschätzte Windmaster seine Möglichkeiten, insbesondere nachdem erhoffte Innovationen ausgeblieben sind. Im Dezember 1998 meldete Windmaster Konkurs an. Die Patente der Firma wurden von Lagerwey aufgekauft, die meisten Beschäftigten übernommen. Auf diese Weise sind der Branche Fähigkeiten und Know-how Windmasters erhalten geblieben (Kamp 2002, 124). Die folgende Tabelle 2.4.2e fasst die wichtigsten Unterschiede zwischen Lagerwey, sowie Nedwind und Windmaster zusammen:

Tabelle 2.4.2e Niederländische Windanlagenhersteller

\begin{tabular}{|l|l|l|l|l|l|l|}
\hline & $\begin{array}{l}\text { Status des } \\
\text { Unternehmens }\end{array}$ & $\begin{array}{l}\text { vorwiegender } \\
\text { Markt }\end{array}$ & $\begin{array}{l}\text { hauptsächlich } \\
\text { verkauftes Modell }\end{array}$ & $\begin{array}{l}\text { Kooperation } \\
\text { Zulieferern? }\end{array}$ & $\begin{array}{l}\text { Zusammenarbeit } \\
\text { mit der TU } \\
\text { Delft? }\end{array}$ & $\begin{array}{l}\text { technisch und } \\
\text { kommerziell } \\
\text { erfolgreich? }\end{array}$ \\
\hline Lagerwey & unabhängig & $\begin{array}{l}\text { Landwirte, } \\
\text { Kooperativen }\end{array}$ & $75 / 80 \mathrm{~kW}$ & Ja & Ja & ja \\
\hline Windmaster & $\begin{array}{l}\text { abhängig, } \\
\text { geh. } \\
\text { Begemann zu }\end{array}$ & EVU & $250-500 \mathrm{~kW}$ & nein & nein & eingeschränkt \\
\hline Nedwind & $\begin{array}{l}\text { abhängig, } \\
\text { geh. } \\
\text { Grootint }\end{array}$ & EVU & $250-500 \mathrm{~kW}$ & nein & nein & eingeschränkt \\
\hline
\end{tabular}

Quellen: vg. 2.4.2

Probleme der niederländischen Windindustrie

Zum Zeitpunkt der Einführung des IPW fällt die niederländische Windkrafttechnologie weit hinter den internationalen, insbesondere von dänischen Firmen gesetzten Standard, zurück. Wie oben gezeigt, trägt das IPW nur bedingt dazu bei, an diesem Status etwas zu ändern. Das Programm förderte Konkurrenz innerhalb der Branche, kurze Testzeiten, zu schnelles Upscaling und technische Fehlentwicklungen. Grundlegende konzeptionelle Fehler konnten nicht ausgeschlossen werden. Im Jahr 1989 mussten von Windmaster, 25 Maschinen, die das Unternehmen erst zwei Jahre zuvor verkauft hatte, zurück in die Fabrik transportieren und generalüberholen lassen. Ein Großteil des LSP-Windparks von SEP (s.o.) ist außer Betrieb genommen worden, weil die meisten der 18 Prototypen versagten. Entsprechende Pannen

dürfen. Ausnahmen werden nur unter speziellen Umständen gewährt. Von 2.200 Kilometer Deichlänge eigneten sich mindestens 500 Kilometer hervorragend für Windparks. (WPM 10/91, 24).

${ }^{273}$ Begemann erwirtschaftete 1989 einen Umsatz von ca. NLG 12 Mrd. und beschäftigte über 5.000 Mitarbeiter. Bei Windmaster waren zur selben Zeit 200 Personen tätig (WPM 10/91, 19). 
stellten sich auch bei Bouma ein: Eine Maschine des Herstellers erlitt Totalschaden, an mehreren weiteren Rotoren wurden kleine Risse festgestellt, zwei Bouma-Windparks daraufhin außer Betrieb genommen. Vergleichsweise zuverlässig arbeiteten die kleineren Modelle der 75-85kW-Klasse von Lagerwey und Newinco (WPM 5/89, 10).

Diese Schwächen führten dazu, dass die Niederländer auf dem Exportmarkt kaum Fuß fassen konnten. Zudem etablierten sich seit Ende der 80er Jahre dänische Hersteller auf dem Inlandsektor. Prinzipiell förderte das IPW auch den Kauf ausländischer Windanlagen. 1989 kaufte das holzverarbeitende Unternehmen Idufor sechs Micon Anlagen à 250kW, die an einem südwestlichen Küstenstandort in Betrieb gingen (WPM 9/89, 25). 1992 nahm Micon, gemeinsam mit der niederländischen Molens voor Millieu (Tochterfirma des Stromversorgers EGD), die Arbeiten zur Planung eines großen Windparks auf. Das 10MW-Projekt erhielt NLG 8 Mio. Förderung aus dem TWIN (WPM 5/92, 9).

Zur Erklärung der geringen Nachfrage lassen sich neben mangelnder Konkurrenzfähigkeit der niederländischen Turbinenindustrie zwei weitere Gründe heranziehen. Zum einen wurde der Absatz durch fehlende Standorte reduziert, der neben einer objektiven Grenze (kleines Land mit hoher Bevölkerungsdichte), auf die NIMBY-Mentalität vieler Anrainer sowie eine ineffiziente Planungspolitik zurückzuführen ist. Zum anderen ist die Branche durch Beendigung des von regionalen Stromverteilern ins Leben gerufenen MAP weiter geschwächt worden. Dieses war für die Industrie besonders deshalb ein Problem, weil sich die meisten großen Hersteller (ausgenommen Lagerwey) auf die EVU als Abnehmer festgelegt hatten und ihre Produkte an deren Bedürfnisse ausrichteten. Als die EVU den MAP aufgaben und einen Großteil ihrer Aufträge stornierten, fanden die Hersteller, weder im In- noch Ausland, Abnehmer für diese Windanlagen.

Ergebnisse und Ausblick

Aufgrund der Absatzschwächen der niederländischen Hersteller, die teilweise Produkt einer unzweckmäßigen Förderpolitik gewesen ist, können die WEA zumeist nur in geringer Stückzahl produziert werden. Dadurch sind sowohl Kostensenkungen, als auch Investitionen zur Optimierung weitgehend ausgeschlossen. Demgegenüber stellt die 75/80kW Turbine von Lagerwey eine Ausnahme dar. Der Erfolg des Herstellers basiert u.a. darauf, dass er, die gesamte Pionierphase hindurch, vor allem ein einziges Modell anbot: eine kleineres, häufig verkauftes Modell, dass in Kooperation mit der Universität von Delft immer weiter verbessert wurde.

Bis 1998 meldeten Windmaster und Nedwind Konkurs an. Sie sind die letzten Hersteller, die neben Lagerwey, auch nach der Pionierphase noch am Markt vertreten sind. Während der 90er Jahre wird die niederländische Anlagentechnik allmählich von dänischen Herstellern verdrängt. 1996 verkauften letztere 89 WEA auf dem niederländischen Markt, die Inländer nur 50 (Verbong 1999, 156). 


\subsubsection{Niederlande: Windanlagenkäufer und -betreiber in Periode 4}

Vor Einführung des IPW waren ausschließlich zivilgesellschaftliche Akteure auf dem Sektor präsent. Dabei handelte es sich insbesondere um Landwirte, Umweltaktivisten und Kleinunternehmen. Dieses ändert sich im Jahr 1987 grundlegend, als die Förderung des IPW zu greifen begann. Jetzt erhielt der Markt nicht nur einen quantitativen Schub, sondern veränderte sich in der Akteursstruktur. Die bisherigen Käufergruppen verloren seitdem an Bedeutung. Die meisten Windanlagen wurden von EVU gekauft, teilweise auch von Privatinvestoren erworben. Vereinzelt bildeten unabhängige Kooperativen. Gefördert wurde das zivilgesellschaftliche Segment von Banken wie der umwelt- und entwicklungspolitisch engagierten Triodosbank. Einer Studie des NOVEM zufolge wurden innerhalb des IPWZeitraums 58\% der Investitionen für Windparks von EVU getätigt. 38\% entfielen auf Unternehmen, Privatinvestoren und Landwirte, 4\% auf Kooperativen (WPM 7/91, 9f.). ${ }^{274}$

EVU als Betreiber von Windparks

Anders als in Dänemark, Kalifornien und der Bundesrepublik durften niederländische EVU als Käufer von WEA ebenso auf die Investitionsförderung zuzugreifen wie Privatakteure. Daher waren mehrere EVU seit Einführung des IPW sehr an der Windtechnologie interessiert. Das Interesse der EVU an der Windkraft erklärt sich nicht allein aus betriebswirtschaftlichen Gründen. Angesichts ihre Atomkraftstrategie öffentlich in die Kritik geraten, sahen sie in der populären Windenergie eine Möglichkeit, ihr Image aufzubessern. Infolge des Marktliberalisierungsgesetzes sind im Jahr 1990 Verteilungsunternehmen entstanden, die ihre Position gegenüber den Betreiber der großer Kraftwerke stärken wollten. Ähnlich wie in Dänemark, waren die niederländischen EVU nicht bereit, das Feld den Windmüllern zu überlassen. Unter den gegebenen Bedingungen waren Investitionen in Windenergie für sie ein sinnvoller, wenn nicht gar notwendiger Schritt (vg. auch Verbong 1999, 154).

Der erste EVU-Windpark ist 1986, außerhalb des IPW, noch im Rahmen des NOW realisiert worden und diente als Forschungsanlage (s.o.). Ähnlich wie in Dänemark bestand auch unter den niederländischen EVU die Tendenz, möglichst große Modelle in hoher Zahl zu installieren. Paradigmatisch dafür ist ,Projekt Megawind'. Ein Konsortium niederländischer Energieunternehmen plante den Aufbau von 18 NEWECS 50 (18 x 1MW) und war bereit zur Investition von NLG 70Mio., bzw. \$35Mio. (WPM 7/87, 8). ${ }^{275} \mathrm{Im}$ November 1987 entschied sich Auftragnehmer Stork, die Arbeiten an der Großwindanlage vorerst einzustellen. Zur Realisierung des ,Projekt Megawind' kam es daher nicht (WPM 12/87, 10). Gegen Ende der 80er Jahre stellt sich in der VEEN (Organisation der EVU) eine kritischere Haltung gegenüber Großwindanlagen ein. So äußerte sich Henk Bontius, ${ }^{276}$ ein Sprecher der VEEN:

,We have realised the hopes we had for MW machines were premature. They take much more time to develop than we had expected. But as the most promising long term option they deserve uninterrupted R\&D support' (WPM 10/89, 11).

Künftig wolle man Forschungsprojekte im MW-Bereich von der Installation mittelgroßer Windanlagen des 250-500kW Segments trennen (WPM 10/89, 11). Mit diesen größten kommerziell erhältlichen Turbinen, rüsteten die EVU ihre Windparks aus. In der folgenden Tabelle 2.4.2f sind alle niederländischen Windparks aufgeführt, die bis 1988 installiert werden. Von den insgesamt fünf Windparks wird nur einer durch Privatakteure betrieben, die restlichen durch EVU.

\footnotetext{
${ }^{274}$ Die geringe Zahl der Kooperativen führt Kamp $(2002,107)$ darauf zurück, dass Kooperativen in der niederländischen Kultur weniger stark verankert sind, als bspw. in Dänemark.

${ }^{275}$ Näheres zu dem Projekt, vg. WPM 7/87, 8f.

${ }^{276}$ Bontius war zuvor als Fürsprecher der , bigger is better'-Philosophie bekannt (WPM 10/89, 11).
} 


\begin{tabular}{|l|l|l|l|l|l|l|l|}
\hline Ort & Provinz & $\begin{array}{l}\text { Gesamtkap. } \\
\text { (MW) }\end{array}$ & Betreiber & $\begin{array}{l}\text { WEA- } \\
\text { Zahl }\end{array}$ & kW-Zahl & Hersteller & $\begin{array}{l}\text { Jahr } \\
\text { Inbetriebnahme }\end{array}$ \\
\hline Sexbierum & Friesland & 5,40 & $\begin{array}{l}\text { EVU/ } \\
\text { Wirtschaftsministerium- } \\
\text { Kooperation }\end{array}$ & 18 & 300 & Holec & 1986 \\
\hline Urk & Ijsselmij & 7,5 & $\begin{array}{l}\text { Ijsselcentral Utility/ } \\
\text { EVU }\end{array}$ & 25 & 300 & $\begin{array}{l}\text { HMZ } \\
\text { Windmaster }\end{array}$ & 1987 \\
\hline Zijpe & Zeeland & 0,86 & PEN/ EVU & 15 & unterschiedlich & unterschiedlich & 1988 \\
\hline Callantsoog & $\begin{array}{l}\text { North- } \\
\text { Holland }\end{array}$ & 2,56 & PEN/ EVU & 16 & 160 & Bouma & 1988 \\
\hline Vlissingen & Zeeland & 2,08 & SBWN/ privat & 13 & 160 & Bouma & 1988 \\
\hline
\end{tabular}

Quelle: EWEA-Konferenzbericht 1992, 35; WPM 2/87, 8; WPM 9/88, 25; WPM 5/89, 10

In dieser Statistik sind ausschließlich größere Windparks berücksichtigt. Im selben Zeitraum werden darüber hinaus viele einzelne Windlagen (v.a. Lagerwey $75 / 80 \mathrm{~kW}$ ) errichtet. Der wesentliche Teil des ersten Nachfrageschubs stammte allerdings nicht wie in Dänemark, von privaten Betreibern einzelner Windmühlen, sondern den Windparks der EVU. ${ }^{277}$

Mit dem Urk-Projekt (Tab. 2.4.2f) als erstem kommerziellen Windpark der Niederlande, kommt den EVU als Windparkbetreiber eine Pionierrolle zu. Ein Boom wie in Kalifornien erwächst daraus indes nicht. Den langsamen Windkraftausbau begründete Huub Paes, Sprecher des Versorgers der Provinz Ijsselmij:

,Utilities don't make hasty decisions. IJsselmij is at moment the leader in the field of wind energy, but even in our company the directors will not seriously look at new wind energy plans until we have about a year's experience with the HMZ project' (WPM12/87, 10).

Trotz der Mängel sämtlicher bis 1988 installierter Windparks, intensivierten die EVU ihr Engagement während der nachfolgenden Jahre. Neben den bereits oben genannten Argumenten (Förderung der EVU durch IPW, drohende Konkurrenz durch Windmüller, Marktliberalisierungsgesetz, Imageverbesserungen) existieren dafür weitere Gründe. Für die EVU ist die Perspektive wichtig, in absehbarer Zeit größere Modelle einsetzen zu können. Daher kam es ihnen gelegen, dass sich die großen Hersteller, Nedwind und Windmaster, bereit zeigten, ihre Produktion gänzlich auf die Nachfrage der EVU zuzuschneiden. Ihr Interesse an der Technologie stellte sicher, dass den EVU auch im IPW-Nachfolgeprogramm TWIN, eine führende Rolle auf dem Windsektor zuerkannt wurde. Privatbetreibern sollte künftig ausschließlich eine Nischenrolle zukommen. Entsprechend zufrieden mit der Gestaltung des TWIN war Kees Wiechers, Vorsitzender der PNEM (größter Versorger der Niederlande): ,We certainly don't want to claim a monopoly on wind power subsidies. I agree with the ministry that the presence of more than a token private market is a healthy thing. There are niches we can't fill...' (WPM 10/90, 19).

Komplizierte Verhandlungen mit unabhängigen Betreibern wollte Wiechers verhindern. Zur Frage, ob die EVU, den Etat für private Entwicklungen unter ihre Verwaltung stellen wollten, äußerte er sich:

,As a matter of fact we are going to do just that for the first time, for example for energy efficient lighting. That is a sensible thing since we have a direct relation with the customer. But with independent producers such as turbine operators it woundn't be elegant. They would be discussing rates and subsidies' (ebd.).

Bis 1988 sind vor allem der Ijsselmij Versorger und PEN im Sektor aktiv. Dieses änderte sich seit im Februar 1990, als sich acht Versorger zur Windplan Foundation zusammenschlossen,

${ }^{277}$ Die offiziellen Statistiken spiegeln diese Situation nicht adäquat wider, da sie sich auf die Projektentwickler beziehen. Von den Windparks mit einer Gesamtkapazität von 44,5 MW, die zwischen 1986 und 1989 entweder bereits aktiv sind, oder sich in der Bauphase befinden, wurden nur 30\% von Energieversorgern entwickelt. Entwickler aus dem Energiesektor erhielten circa 20\% weniger Projektförderung als private Investoren. Daher kam es häufig vor, dass die Projekte von netzfremden Akteuren wie IBRO und Triodosbank entwickelt und nach Erhalt des Investitionszuschlags - zu großen Teilen an EVU verkauft wurden. Für sie war es günstiger, die Entwicklung auszulagern. Wenn die Beteiligungen an Privatprojekten miteingerechnet werden, erhält man einen Anteil der Stromwirtschaft von etwa $60 \%$ (WPM 1/90, 15). 
u.a. um bis 1995 250MW Windanlagenkapazität zu installieren. Bis Juli 1991 sind darüber hinaus PNEM, PGEM, GEB und der Versorger von Friesland in den Sektor eingestiegen. ${ }^{278}$ Infolge dessen ist eine Verankerung der Windkraft in vielen unterschiedlichen Provinzen eingetreten. ${ }^{279}$ Dieser Diffusionsvorgang findet zwischen 1989 und 1991 einen Niederschlag in einem vorübergehenden Anwachsen der Installationszahlen (vg. Tab. 2.4.2b). Trotz dieser Anfangserfolge wird der Trend nicht gehalten. Tatsächlich nahmen die im NMP zusammengeschlossenen EVU bis 1991 nicht mehr als 20 MW (vg. WP 12/91, 13) in Betrieb. Weil sich an der Stagnation des 250MW-Plans auch in der folgenden Zeit nichts änderte, wurde er 1993 abgebrochen.

Das Scheitern des Plans hat vor allem zwei Gründe. Zunächst ist es im Verlauf der Pionierphase nicht gelungen, effiziente Planungsroutinen für die Standortgenehmigung zu entwickeln (s.o.). Daher mussten manche Projekte aufgegeben werden, oder verzögerten sich um Jahre. Es hat den Anschein, als hätte man bei der Festlegung des 250MW-Ziels, diese Schwierigkeiten unterschätzt (Kamp 2002, 115). ${ }^{280}$ Eine weitere Ursache des Scheiterns besteht darin, dass die Hersteller von den EVU, trotz gegenteiliger Aussage eines VEENSprechers, ${ }^{281}$ zur Entwicklung immer größerer Modelle genötigt wurden. Die Nutzung der Polder-Standorte wird seitens der EVU von Nord Holland (PEN) und Friesland (PEB) von der Verfügbarkeit größerer Modelle, als der 1991 handelsüblichen 500kW-Anlage, abhängig gemacht. ${ }^{282}$ Damit wird der schwarze Peter an die Industrie weitergegeben. Gipe $(1995,41)$ fasst zusammen:

,The utilities subsequently created an unwieldy program dubbed Windplan, which required Dutch manufacturers to meet unusual technical requirements not found in other wind energy programs.'

Als die EVU 1993 ihren Windplan aufgaben, ließen sie verbrannte Erde zurück. Mit dem Abbruch des Windplans verloren Windmaster und Nedwind ihre Hauptabnehmer (ebd.). ${ }^{283}$

Aus der Reihe fiel EGD, Stromverteiler der nördlich gelegenen Provinzen Groningen und Drenthen. Als einziger Versorger windiger Regionen war EGD nicht Mitglied der, Windplan Foundation'. Anstatt wie die übrigen Versorger auf Windparks und große Modelle zu setzen, kaufte EGD insgesamt etwa 50 kleine WEA (à 80kW) bei Lagerwey. Für den Hersteller, der ansonsten ausschließlich mit unabhängigen Betreibern zusammenarbeitete, war es die erste

\footnotetext{
${ }^{278}$ PNEM: 3,75MW Windpark, Windmaster (Provinz West Brabant); PGEM: 10 MW Windpark, Windmaster (Provinz Ijsselmij); GEB: 4,5MW Windpark, Nedwind (Provinz Nord Rotterdam); vg. WPM (7/91, 10); Friesland-EVU: 2,5 MW, Newinco (Provinz Holland), WPM 9/89, 26.

${ }^{279}$ Das in Dänemark über lange Zeit zu beobachtende Phänomen der regionalen Bindung zwischen Anlagenhersteller und -käufer ist hier kaum zu beobachten.

${ }^{280} \mathrm{Zu}$ den Auseinandersetzungen um ein letztlich in Herbayum (Holland) realisiertes Windpark-Projekt des Friesland-Versorgers, vg. WPM 9/89, 26. Nachdem zwei Standorte abgelehnt werden, sind die Planer im dritten Anlauf erfolgreich (ebd.). In Wervershoof scheitert PEN an acht Landwirten, die nicht bereit waren, einen Teil ihrer Ländereien an den Versorger zu verpachten, obwohl PEN eine Pacht oberhalb des Marktpreises angeboten hatte und die Landwirte, das die WEA umgebende Land hätten weiter nutzen können (WPM 2/92, 20).

${ }^{281}$, The $250 \mathrm{MW}$ target for wind power is to be met by existing technology, using turbines in the $250 \mathrm{~kW}$ to 500 kW range.' (WPM 3/90, 6).

${ }^{282}$ Jaap Duizend (PEN): ,For larger machines, dikes could be a solution, but the construction of large quantities of turbines on dikes presents many legal and technical complications.' (WPM 9/91, 18); Pieter Wiersma (PEB): ,When Megawatt scale turbines are ready, we will be able to install very large amounts of wind power generating capacity on the dikes.' (WPM 10/91, 25).

${ }^{283}$ Die Frage, auf welche Gründe dieses scheinbar widersprüchliche Verhalten der, Windplan foundation' und das so drastische Scheitern des Windplans letztendlich zurückzuführen sind, muss an dieser Stelle offen bleiben. Auch Verbong $(1999,150)$ und Kamp $(2002,115)$ beziehen sich hier auf Gipe. Keiner von ihnen nimmt jedoch näheren Bezug darauf, worin die besondere Problematik der EVU-Nachfrage gelegen hätte. Zur Erklärung der Situation bezieht sich Verbong (1999, 160 Fußnote 8) auf ein Interview mit H.J.M. Beurskens (10.8.1996): ,According to Beurskens, disagreement between Economic Affairs and Energiened (the branch organisation of the energy distribution companies), played a role. One of Economic Affairs' primary objectives was to support Dutch industry. This did not interest Energiened, which was accused of having a very negative attitude toward Dutch industry.'
} 
große Lieferung an ein Energieunternehmen. Das Standortproblem des Windplans war auch deshalb so schwerwiegend, weil die Mitglieder der, Windplan Foundation' ausschließlich die Errichtung großer Windparks in Erwägung zogen. Von dieser Strategie abweichend, erschloss EDG viele Standorte für Einzelanlagen oder ,Anlagengrüppchen', wo aus planungsrechtlichen oder technischen Gründen keine Windparks errichtet werden konnten (WPM 11/91, 8). ${ }^{284} \mathrm{Zu}$ dieser Vorgehensweise und den positiven Erfahrungen mit den Kommunen äußerte sich Unternehmenssprecher Dick Brügemann (ebd.):

,Especially in the Netherlands, where siting problems are even greater than elsewhere, the installation of smaller turbines can add to optimum realisation of the potential...The municipal authorities in our operating area are enthusiastic about wind power and are ready to fully cooperate.'

Bis April 1992 wurde für jede der 50 WEA ein Standort gefunden.

\section{Unabhängige Betreiber von Windanlagen}

Neben den EVU sind auch Privatakteure auf dem Windmarkt aktiv. Dabei handelte es zum einen um Investoren, welche Energie ausschließlich zur Netzeinspeisung produzierten, zum anderen um Einzelbetreiber und Kooperativen, welche die Windräder vorwiegend zur Eigenversorgung nutzten. Die Windmüller erwarben zumeist die $75 / 80 \mathrm{~kW}$-Windanlage von Lagerwey und installierten sie, in erster Linie als Einzelanlagen, oder in kleinen Windparks bis zu fünf WEA.

Kommerzielle Windparks

Vergleichsweise große Windparks wie sie das holzverarbeitende Unternehmen Idufor betrieb, waren eher die Ausnahme. Der 1,5MW-Micon-Windpark in Vlissingen erhielt eine Investitionsförderung von 50\% der Gesamtkosten (NLG 1,5 Mio.). Der Betreiber startete das Projekt unter der Annahme, dass sich die Investition nach etwa sechs Jahren amortisiert hätte. Eine so verheißungsvolle Ausgangssituation war für niederländische Windparkinvestoren keineswegs eine Selbstverständlichkeit. Der Windpark, der in der südwestlichen Provinz Zeeland gelegen war, speiste Energie in das Netz der PZEM (WPM 9/89, 25). Dabei, dass sämtliche kommerzielle Windparks und die meisten Privatanlagen an das Netz des ZeelandVersorgers geschlossen waren, handelte es sich nicht um einen Zufall (vg. Tab. 2.4.2g).

Tab. 2.4.g Kommerzielle Windparks bis 1990

\begin{tabular}{|l|l|l|l|l|l|l|l|}
\hline Ort & Provinz & $\begin{array}{l}\text { Gesamtkap. } \\
(\mathrm{MW})\end{array}$ & Investor & WEA-Zahl & $\begin{array}{l}\text { Nennleistung } \\
\text { der Wersteller } \\
(\mathrm{kW})\end{array}$ & $\begin{array}{l}\text { Jahr } \\
\text { Inbetriebnahme }\end{array}$ \\
\hline Vlissingen & Zeeland & 2,08 & SBWN & 13 & 160 & Bouma & 1988 \\
\hline $\begin{array}{l}\text { Vlissingen } \\
\text { II }\end{array}$ & Zeeland & 1,5 & Idufor & 6 & 250 & Micon & 1989 \\
\hline $\begin{array}{l}\text { Vlissingen } \\
\text { III }\end{array}$ & Zeeland & 2,25 & Idufor (?) & 9 & 250 & Micon & 1990 \\
\hline $\begin{array}{l}\text { Neeltje } \\
\text { Jans }\end{array}$ & Zeeland & 2,0 & Triodosbank & 8 & 250 & Bouma & 1990 \\
\hline Kreekrak & Zeeland & 1,5 & Triodosbank & 6 & 250 & Newinco & 1990 \\
\hline
\end{tabular}

Quellen: WPM 9/88, 25; WPM 5/89, 10; WPM 9/89, 25; WPM 11/89, 12

Nur in Zeeland war der zuständige Versorger bereit, den Windstrom mit einem festen Tarif zu vergüten, der deutlich über dem niederländischen Durchschnitt lag und darüber hinaus auf zehn Jahre garantiert wurde (WPM 9/89, 20). Unabhängigen Planern bot PZEM Einspeisetarife in Höhe von NLG 0,13-0,14 pro Kilowattstunde. Selbstversorger erhielten

\footnotetext{
${ }^{284}$ Windpower Monthly $(11 / 91,8)$ bezeichnete EDG als ,Renegade utility'. Von der Qualität niederländischer Produkte der Hersteller Windmaster und Nedwind, von denen die EVU üblicherweise beliefert wurden, war man bei EGD anscheinend weniger überzeugt. 1992 startete der Versorger Projekte mit der dänischen Micon sowie US-Windpower (WPM 4/92).
} 
sogar NLG 0,17. In den Niederlanden wurden Flächen ausgewiesen, die zur Nutzung speziell für Windprojekte vorgesehen waren. Dort errichtete Windanlagen wurden mit einem Umweltbonus in Höhe von NLG 100 pro Kilowatt honoriert. Die Tatsache, dass die meisten dieser Flächen in Zeeland gelegen waren, erhöhte die Attraktivität dieser Standorte (WPM 11/89, 12; Kamp 2002, 114). In den meisten übrigen Provinzen betrug der Einspeisetarif selten mehr als NLG 0,05. Zwar wurden die Einspeisetarife zu Beginn der 90er Jahre auch in anderen Provinzen erhöht. Längerfristige Garantien für die Geltung dieser Tarife blieben jedoch aus. Manchmal wurden Tarife für nur ein Jahr festgelegt, so dass Investitionen kaum geplant werden konnten (WPM 8/91, 14). ${ }^{285}$

Ähnlich wie in Dänemark und Kalifornien wurden die Windmüller auch in den Niederlanden von den EVU als unliebsame Konkurrenz wahrgenommen. Zwar waren die niederländischen Stromversorger per Gesetz verpflichtet, den Windstrom in ihre Netze einzuspeisen und zu vergüten. Die Höhe der Tarife allerdings, durften die Netzbetreiber selbst bestimmen. Die meisten EVU orientierten sich an der Höhe vermiedener Kosten als angemessene Basis zur Bestimmung des Abnahmetarifs, eben jene NLG 0,05. Angesichts dieser Bedingungen waren Windenergie-Projekte unabhängiger Akteure außerhalb Zeelands kaum zu realisieren. Manche Versorger erteilten Aufträge an private Entwickler zur Installation von Windparks, um diese später zu erwerben. Über diesen Umweg erhielten die EVU Zugang zu der erhöhten Investitionsförderung, die eigentlich Privatakteuren vorbehalten war. ${ }^{286}$

\section{Kooperativen}

Für die Windmüller stellte sich die Situation ähnlich dar wie für kommerzielle Windparkbetreiber. Auch sie fanden in Zeeland die besten Einspeisebedingungen vor. ${ }^{287}$ Die Offenheit der PZEM gegenüber lokalen Windmüllern ist am Beispiel ihres fairen Umgangs mit der Kooperative Zeeuwind ${ }^{288}$ deutlich zu erkennen. Für den eingeleiteten Windstrom erhielt Zeeuwind tatsächlich $100 \%$ der für Privathaushalte geltenden Strompreise des Versorgers. Tom Kannekens (Direktor der PZEM) begründet diesen (ungewöhnlichen) Schritt: ,Statistical calculations show that at that level, between 80 and 90 per cent of a turbine's production is directly absorbed by the user. We take it to be hundred per cent and pay accordingly to help wind energy along' (WPM 5/88, 25).

Daher wurde das Netz kaum belastet und es entstanden keine Erweiterungskosten. Die Gefahr destabilisierender Leistungsschwankungen wurde zum Großteil ausgeschlossen (WPM 5/88, 25). ${ }^{289}$ Bei der vollständigen Einspeisung sind diese Vorteile nicht gegeben, weshalb PZEM Windstrom aus kommerziellen Windparks niedriger vergütete.

Grundsätzlich war es für die Betreiber einzelner Turbinen am leichtesten, einen Standort zu erhalten (WPM 9/88, 20). Für viele Einzelbetreiber war die seit 1988/89 unter lokalen Betreibern übliche Lagerwey-75kW zu groß geworden. Kooperativen wie Zeeuwind war es dagegen möglich, die Vorzugstarife optimal zu nutzen. Der gemeinschaftliche Betrieb von

\footnotetext{
${ }^{285}$ Entsprechend äußerte sich Jaap Langenbach von der ODE (Organisation für erneuerbare Energie) in Windpower Monthly (8/91, 14): ,A turbine only gives return on investment if it is at least ten years in operation...No farmer or land owner will invest NLG 200.000, if he is only sure of a tarif of NLG 0,15 until 1992'.

286 'Outside Zeeland only a few private windfarms exist and these are no more than developments with a private party as a token owner' (WPM 11/89, 12).

${ }^{287}$ Auch PEN, der regionale Versorger North Hollands zeigte sich an der Technologie interessiert. Um zu prüfen, welche WEA sich am Besten für den Gebrauch von Privathaushalten eigneten, errichtete PEN eine kleine Testanlage. Dabei sollte die Anlagengröße möglichst exakt auf den Haushaltskonsum abgestimmt werden, so dass kein überschüssiger Strom eingespeist werden musste. Den Verbrauchern wurde die Möglichkeit angeboten, solche WEA zu pachten. Kooperativen erhielten für die Einspeisung immerhin NLG 0,125 pro kWh, was deutlich über dem Landesdurchschnitt lag (WPM 7/86, 4 und 10/89, 13).

${ }^{288} \mathrm{Im}$ April 1988 nimmt Zeeuwind drei Lagerwey-Turbinen (à $75 \mathrm{~kW}$ ) in Betrieb.

${ }^{289}$ Um sicherzustellen, dass tatsächlich der größte Anteil des Stroms direkt verbraucht würde, trafen PZEM und Zeeuwind die Vereinbarung, dass ein Haushalt maximal 750kWh pro Jahr zu den günstigen Konditionen einspeisen durfte. Diese Menge entspricht 25\% des Verbrauchs eines Durchschnittshaushalts (WPM 5/88, 25).
} 
Windturbinen schien also, ähnlich wie in Dänemark, auch für die Niederlande, ein geeignetes Modell zu sein. Wie in dem skandinavischen Land trug die lokale Verankerung der Kooperativen durch enge Kontakte zu den Anrainern dazu bei, dass kaum Akzeptanzprobleme auftraten und Genehmigungen zumeist innerhalb der gesetzlichen Frist erteilt wurden. Die erste Vereinigung für gemeinschaftlichen Windturbinenbetrieb (VCBW) installierte eine Windanlage im September 1987 in Delft. Bis Ende 1988 hatten sich insgesamt $25 \mathrm{VCBW}$ gegründet, die bis zu diesem Zeitpunkt neun Windmühlen in Betrieb nahmen, fast alle in Zeeland, Noord Holland und Friesland. Nur dort fanden die Kooperativen akzeptable bis gute Einspeisebedingungen vor. ${ }^{290}$ Insgesamt waren etwa 3.000 Personen Mitglied einer VCBW (WPM 1/89, 15). Die Kooperative Zeeuwind war bis dahin die größte VCBW, in der 300 Privatpersonen aus 15 Gemeinden organisiert waren. An der Realisierung des Zeeuwind-Projektes hatte die Triodos-Bank einen Anteil. Sie unterstützte die Kooperative durch Vergabe eines Kredites in Höhe von NLG 108.000, bei einer Gesamtinvestition von NLG 540.000 (WPM 5/88, 25).

Neben einem geringfügigen Jahresbeitrag zahlten die Mitglieder einer VCBW einmalig einen Betrag zwischen $\$ 250$ und 10.000, um nach zehn bis fünfzehn Jahren einen Gewinn zwischen zwei und fünf Prozent zu erzielen. Sämtliche VCBW wählten die $75 \mathrm{~kW}$-Maschine von Lagerwey, die günstigste, vom IPW geförderte WEA. Darüber hinaus hatte die Affinität der VCBW zu dem Lagerwey-Modell auch einen ideologischen Grund. So steht die ,small is beautiful'-Idee vieler VCBW-Mitglieder in Einklang mit der Unternehmensphilosophie Lagerweys (WPM 1/89, 15).

\section{Interessenvertretung}

Der Anteil der VCBW an den von Nicht-EVU betriebenen Windturbinen ist deutlich geringer als derjenige kommerzieller Betreiber. Was die Interessenvertretung der Branche insgesamt und die Akzeptanzförderung betrifft, ist den Kooperativen ein vergleichsweise hohes Eigengewicht zuzuerkennen. Vor 1987 waren unter Privatakteuren ausschließlich Einzelbetreiber aktiv, die jeweils allein einen Vertrag mit dem zuständigen Versorger aushandeln mussten. Zwar gründeten die wenigen Betreiber im Jahr 1982 einen Interessenverband, die ,Vereniging van Windmolengebruikers'. Diesem gelang es jedoch nicht, an Einfluss zu gewinnen (Kamp 2002, 100). ${ }^{291}$

Die meisten Kooperativen bildeten sich im Umfeld von Umweltgruppen und der Anti-AKWBewegung. Zahlreiche Mitglieder konnten auf Erfahrungen in der Öffentlichkeitsarbeit zurückgreifen. Sie schrieben bspw. Artikel, in denen sie für die Vorteile der Windkraft argumentierten. Eine kooperative Bewegung gemeinschaftlicher Windanlagenbetreiber wie in Dänemark, ist in den Niederlanden nicht entstanden. Dennoch sind es die VCBW, die wesentlich am Aufbau einer professionellen Interessenvertretung der Windmüller beteiligt waren. Sie arbeiteten mit der Organisation für erneuerbare Energien (ODE) zusammen, wo sie ein Büro einrichteten (WPM 1/89, 15). Mit dem Pawex (De Vereniging van Particuliere Windenergie Exploitarien) gründete sich 1987 ein Interessenverband der Windmüller. Diesem gelingt es, den Hauptkonflikt zwischen ihnen und den EVU, die Höhe der Einspeisetarife, verstärkt in die Öffentlichkeit zu tragen. Stärkstes Argument des Pawex für höhere Einspeisetarife besteht in der Vermeidung von Umwelt- und Klimaschäden durch Windenergienutzung. Dieser Gesichtspunkt werde bei der bisherigen Preiskalkulation, nach

\footnotetext{
${ }^{290}$ Manche VCBW zeigten sich darin erfinderisch, ihre Projekte trotz der niedrigen Tarife zu realisieren, bspw. indem sie den Windstrom zu günstigeren Konditionen an öffentliche Einrichtungen verkauften. Die besagte Delfter Kooperative (Zuid Holland) etwa, schloss einen Vertrag mit der Universität von Delft (WPM 1/89, 15).

${ }^{291}$ Kamp (ebd.) führt die Schwäche des Verbands auf organisatorische Mängel zurück. Bspw. scheiterte die Interessenvereinigung an der kontinuierlichen Herausgabe einer eigenen Zeitung. Das Magazin ,Windstoot', welches der Verband anfangs herausgab, erschien nicht länger als ein Jahr.
} 
Maßgabe vermiedener Kosten, nicht berücksichtigt. ${ }^{292}$ Während Pawex NLG 0,20 pro Kilowattstunde als Einspeisetarif forderte, bot EVU-Organisation VEEN nur NLG 0,095. Unterstützt wurde PAWEX durch die Triodosbank, dem zu dieser Zeit größten Entwickler privater Windparks (WPM 12/91, 12). Gegen Ende des Untersuchungszeitraums erzielte Pawex wichtige Teilerfolge: Seit November 1991 zahlten die ,toleranten' Versorger Noord Hollands (PEN) und Frieslands (PEB) den Windmüllern NLG 0,15. Mit PGEM (Versorger von Gelderland und Flevoland) distanzierte sich Anfang 1992 ein weiteres Mitglied der VEEN von dessen Standpunkt (der Angemessenheit vermiedener Kosten als Einspeisetarif für Windenergie). Mit einem Verweis auf die Umweltvorteile der Windenergie erhöhte PGEM die Einspeisetarife ebenfalls auf NLG 0,15 (WPM 2/92, 13).

Die im PAWEX organisierten Windmüller betrieben nur etwa $20 \%$ der in den Niederlanden installierten WEA. Der Rest gehörte der niederländischen Energiewirtschaft. Diese Akteurskonstellation ist maßgeblich Produkt der Gestaltung von IPW/TWIN. Windparks sollten von der Energiewirtschaft betrieben werden. Private Windanlagen waren von der Gunst regionaler EVU abhängig. Insgesamt befanden sich die Windmüller in einer schwachen Verhandlungsposition. Peter Blom, Sprecher der Triodosbank, definierte die Windmüller nicht als Konkurrenz der EVU, sondern als ihre zweckmäßige Ergänzung: So entwickle die Triodosbank ausschließlich kleinere Standorte mit weniger als fünf Megawatt, die für EVU kaum interessant gewesen wären. Zudem sei es für lokale Akteure leichter, eine Baugenehmigung zu erhalten (WPM 4/90, 14). ${ }^{293}$

\section{Finanzierung}

Für große Energieunternehmen sind Investitionen in drei- und vierstelliger Millionenhöhe keine Besonderheit. Die Finanzierung damaliger Windparks lag eher im unteren zweistelligen Millionenbereich. Entweder wurden diese aus Eigenkapitalien finanziert, oder es fanden sich leicht Banken, die den EVU ihr Vertrauen entgegenbrachten. Für unabhängige Entwickler und besonders für VCBW stellte sich die Situation umgekehrt dar. Eigenkapital war knapp. Die Frage, ob die Banken ihre Gelder zurückerhalten würden, war in manchen Fällen unmittelbar an den kommerziellen Erfolg des fraglichen Projekts verknüpft. Entsprechend zurückhaltend waren die meisten Banken daher, wenn es um die Förderung privater Windanlagen ging.

Den gesamten Untersuchungszeitraum hindurch war die Triodosbank wichtigster Akteur im Sektor, welcher die Entwicklung und Finanzierung privater Windanlagen unterstützte. Von anderen Banken unterschied sich die Triodosbank darin, dass sie an der Förderung kleinerer Projekte von sozialer und ökologischer Bedeutung interessiert war und daher nicht allein die Höhe der Rendite für Investitionsentscheidungen ausschlaggebend war (WPM 12/87, 10). Neben der Triodosbank waren kleinere Projektentwickler wie PAFA Baheer, Windparken Nederland und IBRO Energy auf dem Markt präsent (WPM 9/89, 21). Anfang 1990 betrat die European Investment Bank (EIB) erstmals den Sektor. Zur Finanzierung von WEA mit insgesamt 7,75MW stellt die non-profit-Institution Kredite in Höhe von \$ 4Mio. bereit. Diese Kredite waren sehr niedrig verzinst (1-2\%). Zugänglich waren sie ausschließlich für Planer, welche die Vorgaben der EIB exakt erfüllten. So mussten die Planer u.a. nachweisen, dass ihr Projekt auch ohne Subventionen wirtschaftlich wäre. Die EIB finanzierte ausschließlich kommerzielle Windparks in Zeeland, welche mit 250kW-Anlagen ausgestattet waren. Für diese Bank, die jährlich Kredite in Höhe von \$2 Mrd. zur Finanzierung von Energieprojekten vergab, stellten Kredite für den Aufbau damaliger Windparks keine Herausforderung dar. Entscheidend war weniger die Höhe insgesamt vergebener Kredite, als vielmehr die Tatsache,

\footnotetext{
${ }^{292}$ Auf diese Weise wird später das deutsche Stromeinspeisungsgesetz begründet.

${ }^{293}$ Blom hat seine Sichtweise auf den Punkt gebracht: ,After filling a box with footballs, there is still room for tennis and ping-pong balls' (ebd.).
} 
dass Windkraft überhaupt von einer Großinstitution wie der EIB unterstützt wurde (WPM $2 / 90,8)$.

\section{Proteste gegen Windanlagen}

Neben EVU-Willkür und mangelnden Finanzierungsmöglichkeiten stellt das Erlangen einer Baugenehmigung die dritte große Hürde für unabhängige Projektentwickler und Betreiber dar. Fehlende Akzeptanz geplanter Windenergie-Projekte, seitens Anrainer und weiterer Akteure wie der ansässigen Forstwirtschaft, Tourismusbranche und Naturschutzorganisationen, führten oft $\mathrm{zu}$ jahrelangen Verfahren, die nicht selten mit einer Ablehnung endeten. In den Niederlanden genügt die Klage einer einzelnen Person, um eine schon erteilte Genehmigung gerichtlich verhandeln zu lassen (Wolsink 1996, 1086).

Andererseits zeigten über $90 \%$ der Niederländer, laut einer Umfrage vom Ende der $80 \mathrm{er}$ Jahre, eine positive Haltung gegenüber der Windenergie (ebd., 1081). In der niederländischen Zeitungslandschaft überwog eine wohlwollende Darstellung (ebd., 1086). Der Schluss auf eine weit verbreitete NIMBY-Haltung liegt nahe. Diese Erklärung weist Wolsink jedoch zurück:

,It was found that the NIMBY syndrome actually exists for some individuals, but that is a minor factor in the motives of most opponents...Concerns about building wind turbines are not of a global nature, they are always dependent on local variables: they are site specific.' (ebd., 1087).

Wolsink sieht das Hauptproblem stattdessen im hierarchischen Planungsverfahren, das Abstimmungsschwierigkeiten zwischen den unterschiedlichen administrativen Ebenen Vorschub leistete und den kommunalen Entscheidungsträgern zu wenig Spielräume ließe (s.o.). Wolsink zufolge (ebd., 1087) beziehen sich die Einwände der Kläger jeweils auf spezielle Standorte: Optische Beeinträchtigung, Lärmbelästigung, ,Diskoeffekt', Einfluss auf Vögel und Natur. Wie hoch die Toleranzgrenze der klagenden Anrainer tatsächlich gewesen war, müsste jeweils im Einzelfall geprüft werden. Manchmal handelte es sich um ökonomische Interessen, manchmal war es eine Frage der Sichtweise. In zahlreichen Fällen etwa, setzte sich die Tourismusbranche gegen die Ansiedelung von Windparks ein. Demgegenüber gab es Orte, an denen Windanlagen nicht als Störfaktor wahrgenommen wurden. Stattdessen bemühte man sich, sie in Tourismuskonzepte zu integrieren (vg. Gipe 1995, 49 Fußnote 13). ${ }^{294}$

Ob NIMBY-Haltung oder nicht: Die Gestaltung der Planungsverfahren trug gewiss wenig dazu bei, solchen Einstellungen entgegenzuwirken. Ansätze des PAS und der Windanlagenindustrie, um das Akzeptanzproblem zu verringern, sind oben dargelegt worden: Förderung geräuschärmerer WEA und Nutzung speziell ausgewiesener Flächen, Entwicklung geräuschärmerer Modelle durch Industrie, Erschließung denkbarer Polder-Standorte und Herstellung von Windanlagen mit verminderter Vibration. Die Projektentwickler waren um einen Dialog mit den Kritikern und Klägern bemüht. Ein Beispiel erfolgreichen Dialogs ist die Planung eines Windparks in Kreekrak durch Windparken Nederlande. Hier kann eine Klage von Vogelschützern verhindert werden, indem sich der Entwickler für deren Anliegen offen zeigte. ${ }^{295}$ Standort-bezogene Strategien wie diese waren in einzelnen Fällen erfolgreich. Insgesamt gelingt es den Akteuren während der Pionierphase jedoch nicht, das Problem mangelnder Akzeptanz zu bewältigen.

\footnotetext{
${ }^{294}$,Brochures, maps, and booklets propose modern wind turbines as stops along itineraries that include traditional windmills, museums, and tulip beds.' (Gipe 1995, 40)

${ }^{295}$ Der geplante Windpark, dessen Standort innerhalb der Flugstrecke seltener Wandervögel lag, sollte zunächst gebaut werden. Nach dessen Inbetriebnahme sollten Ornithologen eine Studie über das Verhalten der Vögel durchführen. In Abhängigkeit von den Ergebnissen der Beobachtungen entschieden die Vogelschützer, ob sie sich weiterhin gegen den Aufbau von Windparks an vergleichbaren Standorten einsetzen würden. Für den Fall sehr negativer Ergebnisse, erklärte sich Windparken Nederlande bereit, sämtliche Turbinen innerhalb von zwei Jahren zurückzubauen. Im Falle eines positiven Ausgangs der Studie würden die Vogelschützer ihre Zustimmung zur Installation 15 weiterer Turbinen an dem Standort geben (WPM 11/89, 13).
} 


\section{Zusammenfassung}

In der zweiten Hälfte der 80er Jahre und auch über die Pionierphase hinaus hat sich in den Niederlanden, ein wenngleich langsam, so doch kontinuierlich wachsender Markt für Windanlagen gebildet. Ausgangspunkt ist die industrie- und umweltpolitisch begründete Investitionsförderung durch das IPW. Das Programm nimmt für die Markt- und Technologieentwicklung eine zentrale Rolle ein. Die niederländische Windkraft ist eine Domäne der Energiewirtschaft. Nur $20 \%$ der Windanlagen werden von kommerziellen Windparkentwicklern, Konsumgenossenschaften, Landwirten und kleineren Unternehmen betrieben. An dieser Situation ändert sich auch während der 90er Jahre wenig. Aufgrund des Mangels an Standorten geraten zivilgesellschaftliche Akteure zunehmend ins Hintertreffen. Kommunen geben meist größeren Windanlagen den Vorzug (Kamp 2002, 122ff.). Unter Billigung der Administration weigerten sich die meisten EVU, für den eingespeisten Windstrom Tarife jenseits der Höhe vermiedener Kosten zu gewähren. Die Zentralregierung sah auch gegen Ende des Untersuchungszeitraumes keine Notwendigkeit, zugunsten der Windmüller einzugreifen, obwohl sich abzeichnete, dass die Ausbauziele, mit einer EVUkoordinierten Entwicklung nicht zu erreichen sein würden. Dichte Besiedelung, verfehlte Planungspolitik der Zentralregierung und eine schwer zu quantifizierende NIMBY-Haltung führen zu massiven Standortproblemen und langwierigen Genehmigungsverfahren. Den Windenergieakteuren gelingt es angesichts dieser Voraussetzungen nicht, für die Ansiedelung von Windparks größeren allgemeinen Zuspruch zu gewinnen.

Erfolgreich waren ausschließlich die Fürsprecher dezentraler Windkraft: Lagerwey, lokale Kooperativen, PAWEX, Triodosbank und einzelne Versorger. Diesen Akteuren kommt allerdings insgesamt nur geringere Bedeutung zu. In der folgenden Tabelle 2.4.2h werden die wichtigsten Transformationsprozesse der niederländischen Windkraftnutzung während der Zeit 1985 bis 1992 zusammengefasst.

Tab. 2.4.2h Transformationsprozesse 1985-1992

\begin{tabular}{|c|c|c|c|c|}
\hline & vor 1986 & $\begin{array}{l}\text { Verstetigungsphase } \\
\text { früh: } 1986-87\end{array}$ & $\begin{array}{l}\text { Verstetigungsphase } \\
\text { mitte: } 1988-90\end{array}$ & $\begin{array}{l}\text { Verstetigungsphase } \\
\text { spät: 1991-92 }\end{array}$ \\
\hline $\begin{array}{l}\text { Windanlagenkäufer- } \\
\text { und betreiber }\end{array}$ & $\begin{array}{l}\text { Landwirte, } \\
\text { Windenergiebegeis- } \\
\text { terte }\end{array}$ & $\begin{array}{l}\text { zusätzlich: } \quad \text { EVU, } \\
\text { Kooperativen }\end{array}$ & $\begin{array}{l}\text { Zusätzlich seit 1988: } \\
\text { Investoren, insbes. } \\
\text { Triodosbank }\end{array}$ & vg. $1988-90$ \\
\hline $\begin{array}{l}\text { Dominierende } \\
\text { Betreiber }\end{array}$ & $\begin{array}{l}\text { Landwirte, } \\
\text { Windenergiebegeis- } \\
\text { terte }\end{array}$ & EVU & EVU & EVU \\
\hline $\begin{array}{l}\text { Bevorzugte } \\
\text { Anlagentechnik des } \\
\text { EVU-Sektors }\end{array}$ & Multimegawattanlagen & $\begin{array}{l}\text { Multimegawattanlagen } \\
\text { EVU akzeptieren } \\
\text { darüber hinaus WEA } \\
\text { ab } 250 \mathrm{~kW}\end{array}$ & $\begin{array}{l}\text { Vorläufige Abkehr von } \\
\text { Großwindanlagen, } \\
\text { EVU wählen größte } \\
\text { serienmäßige WEA } \\
\text { (bis 500kW) }\end{array}$ & vg. $1988-90$ \\
\hline $\begin{array}{l}\text { Quantitative } \\
\text { Entwicklung der EVU- } \\
\text { Nachfrage }\end{array}$ & - & $\begin{array}{l}\text { EVU-Einstieg } \\
\text { kommerzielle } \\
\text { Windkraft }\end{array}$ & $\begin{array}{l}\text { Wachsende Nachfrage } \\
\text { bis } 1991\end{array}$ & $\begin{array}{lr}\text { Stagnation } & \text { seit } 1992, \\
\text { Auflösung } & \text { der } \\
\text { Windplan } & \text { Foundation } \\
1993 & \end{array}$ \\
\hline $\begin{array}{l}\text { Provinzen mit } \\
\text { überdurchschnittlichen } \\
\text { Einspeisetarifen }\end{array}$ & - & Zeeland (PZEM) & Zeeland (PZEM) & $\begin{array}{ll}\text { Zusätzlich: } & \text { Noord } \\
\text { Holland } & \text { (PEN), } \\
\text { Friesland } & \text { (PEB), } \\
\text { Gelderland } & \text { (PGEM), } \\
\text { Flevoland (PGEM) }\end{array}$ \\
\hline $\begin{array}{ll}\text { Zahl der } & \text { der } \\
\text { Anlagenhersteller }\end{array}$ & $\begin{array}{l}\text { Vor Einführung des } \\
\text { IPW: } 24\end{array}$ & $\begin{array}{l}\text { Ende 1986: } \\
12\end{array}$ & Abnehmend & $\begin{array}{l}\text { Seit 1990: } 3 \text { (ab 1999: } \\
\text { nur noch Lagerwey) }\end{array}$ \\
\hline
\end{tabular}

Quellen: vg. Kap. 2.4 
Der EVU-geführte Sektor entwickelte sich in der Pionierphase nicht zu einem Erfolgsmodell. Vielmehr ist zu konstatieren, dass die meisten anstehenden Probleme, von den Akteuren nicht, bzw. nicht zufriedenstellend, gelöst werden können (vg. Tab. 2.4.2i).

Tab. 2.4.2i Schwierigkeiten der Windenergiebranche

\begin{tabular}{|c|c|c|c|}
\hline Problem & Lösungsansatz & Akteur/e & erfolgreich? \\
\hline $\begin{array}{l}\text { keine Innovation durch } \\
\text { LSP-Forschungspolitik }\end{array}$ & $\begin{array}{l}\text { Seit 1986: } \text { Marktförderung } \\
\text { durch IPW }\end{array}$ & PAS & $\begin{array}{l}\text { Ja, langsam wachsender Markt seit } \\
1987\end{array}$ \\
\hline $\begin{array}{lr}\text { IPW fördert } & \text { Konkurrenz. } \\
\text { Daher: kurze } & \text { Testphasen, } \\
\text { schnelles } & \text { Upscaling: } \\
\text { Mangelhafte } & \text { WEA } \\
\text { werden auf den } & \text { Markt } \\
\text { gebracht. } & \end{array}$ & $\begin{array}{l}\text { 1)Lagerwey hält über Jahre an } \\
\text { einem Konzept fest, dass er } \\
\text { sukzessive verbessert und } \\
\text { nimmt dafür niedrigere } \\
\text { Gewinnspannen in Kauf. } \\
\text { 2) Übrige Hersteller entscheiden } \\
\text { sich gegen Bildung von } \\
\text { Konsortien, um Fördermittel } \\
\text { gemeinsam zu nutzen und } \\
\text { setzen auf maximale Rendite. }\end{array}$ & Industrie & $\begin{array}{llr}\text { 1) } & \text { ja. } \\
\text { 2) } & \text { nein, Hersteller sind nicht } \\
& \text { konkurrenzfähig und } \\
& \text { verschwinden bis } 1990 \\
& \text { vom Markt }\end{array}$ \\
\hline $\begin{array}{l}\text { Von wem sollten die } \\
\text { Windparks } \\
\text { optimalerweise betrieben } \\
\text { werden? }\end{array}$ & $\begin{array}{l}\text { Regierung entscheidet sich für } \\
\text { EVU-geführten Markt. EVU } \\
\text { setzen auf Windparks und } \\
\text { möglichst große WEA }\end{array}$ & PAS, EVU & $\begin{array}{l}\text { Nein, EVU erweisen sich als } \\
\text { Betreiber ungeeignet. Ihre } \\
\text { Windpark-Pläne erregen Proteste } \\
\text { der Anrainer. Sie verwenden } \\
\text { unzureichende Technologie und } \\
\text { hemmen Innovationsprozess. }\end{array}$ \\
\hline $\begin{array}{l}\text { EVU geben MAP auf. } \\
\text { Industrie } \\
\text { wichtigste Kunden. }\end{array}$ & $\begin{array}{l}\text { 1) Hersteller verlassen sich auf } \\
\text { Absichtserklärungen der EVU } \\
\text { 2) Lagerwey produziert nicht } \\
\text { für EVU-Markt }\end{array}$ & Industrie & $\begin{array}{l}\text { 1)Nein, EVU-Lieferanten Nedwind } \\
\text { und Windmaster gehen in den 90er } \\
\text { Jahren Bankrott. } \\
\text { 2) ja }\end{array}$ \\
\hline $\begin{array}{l}\text { Standortmangel aufgrund } \\
\text { hoher Besiedelungsdichte }\end{array}$ & 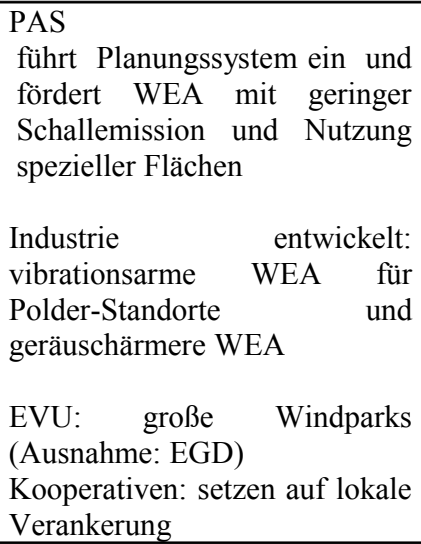 & $\begin{array}{l}\text { PAS, Industrie, EVU, } \\
\text { Windmüller }\end{array}$ & Nein (Ausnahme: Windmüller) \\
\hline $\begin{array}{lr}\text { WEA können } & \text { von } \\
\text { netzfremden } & \text { Akteuren } \\
\text { aufgrund } & \text { niedriger } \\
\text { Einspeisetarife } & \text { nicht } \\
\text { kostendeckend } & \text { betrieben } \\
\text { werden. } & \end{array}$ & $\begin{array}{l}\text { 1)Interessenvertretung durch } \\
\text { PAWEX; } \\
\text { 2)einzelne EVU wie PZEM } \\
\text { (Zeeland): gewähren } \\
\text { überdurchschnittliche Tarife } \\
\text { 3)Betreiber finden spezielle } \\
\text { Abnehmer }\end{array}$ & $\begin{array}{l}\text { PAWEX, } \\
\text { Betreiber }\end{array}$ & $\begin{array}{l}\text { 1)PAWEX erzielt Einzelerfolge, seit } \\
1991 \text { zahlen einige EVU höhere } \\
\text { Einspeisetarife (vg. Tab. } 2.4 .2 \mathrm{~h} \text { ). } \\
\text { 2) ja } \\
\text { 3) ja, in einzelnen Fällen }\end{array}$ \\
\hline $\begin{array}{ll}\text { Kapitalmangel } & \text { privater } \\
\text { Betreiber } & \end{array}$ & $\begin{array}{lr}\text { Bildung von } & \text { Kooperativen; } \\
\text { Unterstützung } & \text { durch } \\
\text { Triodosbank, EIB } & \end{array}$ & $\begin{array}{l}\text { Kooperativen, } \\
\text { Triodosbank, EIB }\end{array}$ & teilweise \\
\hline
\end{tabular}

Quellen: vg. Kap. 2.4 
Erste kommerzielle Windanlagen werden 1986/87 errichtet. Davor existierten hierzulande nur vereinzelte Windmühlen, die großteils im Selbstbau entstanden sind. Wesentliche Triebkraft der Marktstehung sind Programme zur Förderung der Windturbinenindustrie und Investitionszuschüsse für Anlagenkäufer. Bis Mitte der 80er Jahre wurden ausschließlich Großwindanlagen gefördert. Wichtigste Rahmenbedingungen dieser Trendwende bilden das eklatante Versagen Growians (vg. Kap. 1) und der Erfolg mittelgroßer WEA in Dänemark. Die Neuorientierung findet allmählich statt. Auch in der zweiten Hälfte der Dekade werden noch LSP-Projekte wie Aeolus II subventioniert, wenngleich mit niedrigerer Förderquote. Erfolgreich ist keines der ,Post-Growian-Projekte' (s.o.). Die Unzulänglichkeit der LSPPolitik tritt insbesondere nach der Atomkatastrophe von Tschernobyl im April 1986 zunehmend ins öffentliche Bewusstsein. ${ }^{296}$

Von einer professionell arbeitenden Windanlagenindustrie wie sie in Dänemark während der Erprobungsperiode entstanden ist, kann hierzulande nicht gesprochen werden. In der ersten Hälfte der 80er Jahre dominierten Selbstbauer das Feld. Daneben waren auch Teilnehmer des LSP-Programms, MAN und MBB, aktiv. Sozusagen als Abfallprodukte ihrer Megawattanlagen brachten sie Kleinwindanlagen auf den Markt. Letztere dienten den großen Prototypen zuvor als Modelle. 1984-85 betraten Enercon und Tacke den Sektor. Diese mittelständischen Unternehmen entwickelten sich innerhalb der Pionierphase zu den erfolgreichsten Akteuren der Windanlagenindustrie. Gegen Ende der 80er Jahre gewann die Branche an Dynamik.

Nach den Bastlern interessierten sich auch technisch versierte Landwirte für die neue Technologie. Gegen Ende der 80er Jahre wurden einzelne Stadtwerke und regionale EVU vorübergehend $\mathrm{zu}$ sehr wichtigen Akteuren. Anfang der 90er Jahre übernehmen Bürgerwindgesellschaften und zunehmend professionell arbeitende Windparkentwickler den Sektor. Das Januar 1991 in Kraft tretende Stromeinspeisungsgesetz ermöglichte den endgültigen Durchbruch.

\subsubsection{Bundesrepublik Deutschland:}

Das politisch-administrative System in Periode 4

Die Marktförderung erneuerbarer Energien ist in der Bundesrepublik über lange Zeit, insbesondere vom Wirtschaftsministerium mit der Begründung zurückgewiesen worden, dass es keine geeignete Technik gegeben hätte (Jacobsson et al. 2006, 262). Spätestens nach dem Erfolg dänischer Windtechnologie auf dem kalifornischen Markt, greift dieses Argument nicht mehr. Angesichts massiver öffentlicher Diskussionen über Atomkraft und erneuerbare Energien, gelingt es dem Wirtschaftsministerium seit der zweiten Hälfte der 80er Jahre nicht mehr, sich mit seiner Blockadehaltung durchzusetzen. Auch die Wirtschaftspresse entdeckte die Windenergie: ,Politik und EVU müssen für eine faire Startchance sorgen. Strom aus Windkraftanlagen kann auch hierzulande durchaus wirtschaftlich werden...Voraussetzung ist allerdings, dass man die Nutzung wirklich will - und das ist eine politische Entscheidung.' ${ }^{297}$

Im Vorfeld der Wahlen vom Januar 1987 forderte die Regierung Kohl die EVU zur Nutzung erneuerbarer Energien auf, u.a. um das Image der ansonsten umweltpolitisch weniger profilierten CDU aufzubessern (vg. WPM 12/86, 8). Nachdem die Aufforderung der EVU, auf freiwilliger Basis verbesserte Rahmenbedingungen für die Nutzung erneuerbarer

\footnotetext{
${ }^{296}$ Windpower Monthly $(6 / 86,7)$ verweist in diesem Zusammenhang auf einen zeitgenössischen Bericht im ,Spiegel'. Angesichts des GAU wurden 20 Mio. DM für Windenergieforschung als ,etwas dürftig' betrachtet. Der Artikel moniert die Erfolge kommerzieller Windkraft Dänemarks (1200 Inlandanlagen, Exporterfolge), wohingegen in der Bundesrepublik keine vergleichbare Entwicklung abzusehen wäre.

${ }^{297}$ Handelsblatt vom 12.11.1986, zitiert nach: Tacke 2004, 171f.
} 
Energien zu schaffen, wirkungslos blieb, distanzierten sich Teile der CDU-geführten Bundesregierung vom Wirtschaftsministerium (Jacobson 2006, 264).

Eine endgültige Zäsur der Windkraftpolitik markiert die Verabschiedung des 100MWProgramms für Windkraft im Jahr 1988. Wichtige Impulse erhält dieser Schritt bereits in den Vorjahren als die Bundesregierung, unter Regie des BMFT, verschiedene Maßnahmen zur Förderung der Windanlagenhersteller und -betreiber durchführen ließ. Darüber hinaus startete das Land Niedersachsen bereits im Februar 1987 ein 100MW-Programm zur Windkraft. Schaubild 2.4.3a bietet eine Übersicht der Rahmenbedingungen zur Neuorientierung der deutschen Förderpolitik.

Schaubild 2.4a

Rahmenbedingungen zur Transformation der deutschen Windenergiepolitik

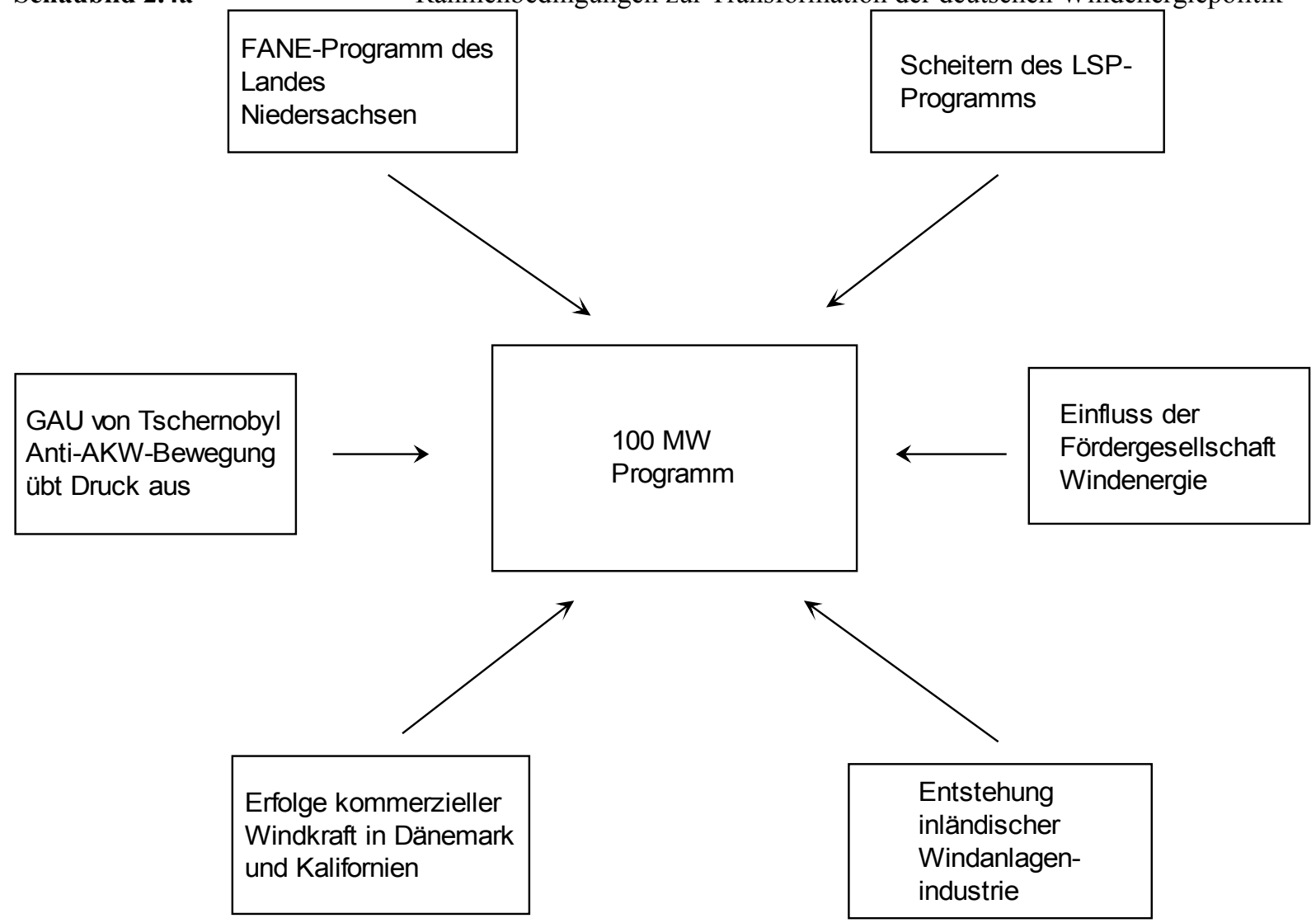

Förderaktivitäten des BMFT und der Bundesländer vor dem Start des 100MW-Programm

Bereits im Juni 1980 eröffnete das BMFT ein Testfeld für kleine WEA auf Pellworm, dass unter die Obhut der Gesellschaft für Kernenergieverwertung in Schifffahrt und Schiffbau (GKSS) gestellt wurde. Vier Jahre später wurde es geschlossen, weil es den Herstellern der geprüften Modelle an Mitteln fehlten. Anlagenplanung, Produktion und Installation auf dem Testfeld mussten von den kleinen Firmen selbst getragen werden. Ausschließlich die Versuchskosten übernahm das BMFT (Tacke 2004, 157), dass für die Testanlage insgesamt 
4,6 Millionen DM aufwendete (Oelker et al. 2005, 83). Im Rahmen des LSP-Programms stellt die Testanlage eine Besonderheit dar. Die Namen kleiner Unternehmen wie Noah Energiesysteme GmbH und Wind- und Wasserkraftanlagen $\mathrm{KG}$ tauchten ansonsten in den Aktivitäten des BMFT nicht auf. Ein wichtiges Ergebnis besteht in der Feststellung der Rückständigkeit der deutschen, gegenüber der dänischen Windindustrie. Von den neun getesteten Anlagen konnten nur drei das Testprogramm vollständig absolvieren, die anderen erlitten Totalschäden (Oelker et al. 2005, 82). Die einzige dänische WEA (Hersteller Windmatic) war zugleich das einzige Modell mit zufriedenstellenden Ergebnissen (Tacke 2004, 157).

1986 ließ das BMFT im Rahmen des ,Sonderdemonstrationsprogramm für Windenergieanlagen bis $250 \mathrm{~kW}$ Nennleistung' die Testaktivitäten fortsetzen. Bis 1988 wurden insgesamt 48 Maschinen von 13 Herstellern getestet (Oelker et al. 2005, 364). ${ }^{298}$ 1986 startete das BMFT ein weiteres Demonstrationsprojekt: ,Errichtung und Betrieb eines Windparks mit 1 MW Leistung'. ${ }^{299}$ Im August 1987 wird der Windpark Westküste im KaiserWilhelm-Koog bei Dithmarschen ${ }^{300}$ von der Schleswag AG in Betrieb genommen. Der Windpark umfasst Modelle von Enercon, MAN, Südwind und Köster. Das Erkenntnisziel des Vorhabens besteht darin, die ,technische Machbarkeit des Netzparallelbetriebs' nachzuweisen und ,genehmigungsrechtliche Belange' aufzuzeigen (Heymann 1995, 428). ${ }^{301}$ Faktisch war der erste kommerzielle Windpark in Deutschland entstanden - und zwar mittels einer staatlichen Förderquote von 75\% (2,4 Mio. DM). Heymann (ebd.) bezeichnet das Projekt als ,revolutionären Schritt' innerhalb der deutschen Forschungspolitik für Windkraft: ,Erstmals übersprang das BMFT die bisher sehr eng gezogenen Grenzen von Forschungsund Technologieförderung.'

Seit 1987 erhält die kommerzielle Windkraftnutzung auch seitens einiger Bundesländer Unterstützung. ${ }^{302}$ Mit dem Start des ,Förderprogramms zur forcierten Anwendung und Nutzung neuer und erneuerbarer Energieträger' (FANE) im Februar 1987 ist Niedersachsen das erste Bundesland, dass kommerzielle Windkraft förderte (Oelker et al. 2005, 364). Private Anlagenkäufer erhielten dort einen Investitionszuschuss von 30\%, in Ausnahmefällen sogar 50\% (WPM 4/90, 12). 1988 legte das Land Nordrhein-Westfalen mit dem REN (Rationale Energieverwendung und Nutzung unerschöpflicher Energiequellen) ein ähnliches Programm auf, durch das u.a. die Installierung von über 700 Windanlagen unterstützt wurde

\footnotetext{
${ }^{298}$ Getestet wurden bis zu fünf Exemplare eines Typs. Alle teilnehmenden Hersteller mussten ihre Produkte einem Messverfahren unterziehen lassen.

${ }^{299}$ Innerhalb der Bundesregierung bestand eine Kontroverse über die Einführung der Investitionszuschüsse für WEA zwischen dem BMFT und dem Umweltministerium einerseits, sowie dem Wirtschafts- und Finanzministerium andererseits. Erstere befürworteten die Förderung, letztere lehnten sie ab (Tacke 2004, 172). ,Da sich das von der FDP geführte Bundeswirtschaftsministerium prinzipiell staatlichen Förderprogrammen zur Markteinführung von Windkraftanlagen widersetzte, ersann das BMFT einen neuen Typ von Forschungsvorhaben: sogenannte ,Demonstrationsprojekte" (Heymann 1995, 428). Zum Demonstrationsprojekt wurde der Windpark Westküste erst dadurch, dass der Betrieb 1987 bis 1989 von einem Messprogramm begleitet wurde (ebd.); Zur Kritik an der FDP-Position vg. auch: Tacke 2004, 175f.

${ }^{300}$ Dabei handelte es sich um den Growian-Standort. Forschungspolitische Kontinuitäten zwischen dem Windpark Westküste und Growian gab es dagegen kaum. Das Gegenteil behauptete Frede Jörgensen, Direktor von Vestas Westdeutschland: ,The first farm is being installed in Ditmarschen and will comprise 20 small machines of various design. The intention is to centralize control with them. That will never be possible as here we have another example a la Growian machine. After spending 100 Millions on it, the giant turbine is being pulled down as it doesn't work. One can't avoid the feeling that conscious efforts are being made to discredit wind power. In addition we were turned down as suppliers to the first windfarm because Vestas turbines are fully tested and they only wanted machines which hadn't been tested.' (zitiert nach: WPM 6/87, 8). Anscheinend war Frede Jörgensen vor allem über den Absatz seines Unternehmens besorgt.

${ }^{301}$ Berichtsblatt des Projekts, in: Windenergienutzung, Geförderte Projekte seit 1980, S.90 (vg. Heymann 1995, 428).

${ }^{302}$ Das Interesse der windigen Bundesländer Westdeutschlands war relativ jung. Zu dieser Zeit setzten viele Landes- und Kommunalpolitiker einiges daran, potenziellen Windmüllern die Baugenehmigung zu versagen.
} 
(Suck 2004, 25). Seit Januar 1989 erhielten auch die Windmüller Schleswig-Holsteins, eine Investitionsförderung von bis zu 30\% ihrer Kosten (Oelker et al. 2005, 366). ${ }^{303}$

\section{0/ 250 MW-Programm}

1988 beschloss der Bund, weitere Fördermaßnahmen zum Aufbau von 100MW Windenergiekapazität bis zum Jahr 1995. Das erklärte Ziel bestand darin, die labile Windanlagenindustrie zu stärken. 1989 wurde das föderale Windbudget stark ausgeweitet. Standen im Vorjahr noch 16 Mio. DM zur Verfügung, waren es 1989 bereits 34 Mio. DM. ${ }^{304}$ Mit dem 100MW-Programm dehnte sich die Förderung der Windkraft erstmals auf das gesamte Bundesgebiet aus. Dennoch wurden die meisten Windturbinen weiterhin in den Küstenregionen und Nordrhein-Westfalen errichtet.

Auch das 100MW-Programm galt offiziell als Demonstrationsvorhaben. Daher wurden an den Turbinen umfangreiche Messungen und Evaluierungsarbeiten durchgeführt. Forschungsminister Riesenhuber gesteht ein, dass er ,mit diesem Großprojekt bis an die Grenze seine Zuständigkeit gegangen' sei (Süddeutsche Zeitung vom 10.3. 1989, zitiert nach: Tacke 2004, 177).

Ist die Windkraftnutzung in Deutschland bis 1988 eher ein Randphänomen, so erhält sie von nun an einen bemerkenswerten Aufschwung:

Tab. 2.4.3a

Windkraft in der Bundesrepublik Deutschland (1985-1997)

\begin{tabular}{|l|l|l|l|l|l|l|l|l|l|l|l|l|l|}
\hline & 1985 & 1986 & 1987 & 1988 & 1989 & 1990 & 1991 & 1992 & 1993 & 1994 & 1995 & 1996 & 1997 \\
\hline $\begin{array}{l}\text { pro Jahr } \\
\text { installierte } \\
\begin{array}{l}\text { Nennleistung } \\
\text { (MW) }\end{array}\end{array}$ & 0,4 & 0,6 & 2 & 5 & 19 & 41 & 42 & 73 & 151 & 298 & 505 & 409 & 535 \\
\hline $\begin{array}{l}\text { Nennleistung } \\
\text { kumuliert } \\
\text { (MW) }\end{array}$ & 0,4 & 1 & 3 & 8 & 27 & 68 & 110 & 183 & 334 & 632 & 1137 & 1546 & 2081 \\
\hline
\end{tabular}

Quelle: Oelker et al. 2005, 368ff.

Seit März 1989 erhielten die Windmüller acht Pfennig pro Kilowattstunde vom BMFT. Darüber hinaus zahlten die Netzbetreiber für den eingespeisten Strom durchschnittlich etwa neun Pfennig (Berechnungsgrundlage: vermiedene Kosten), so dass sich insgesamt eine Vergütung von etwa 17 Pfennig pro kWh ergab. Privatpersonen (häufig Landwirte) hatten darüber hinaus die Option, sich anstatt der Pauschale von acht Pfennig für einen 50\%igen Investitionszuschuss zu entscheiden (Suck 2004, 26f. FN 17).

Bevor eine Windanlage sich für das Investitionsprogramm qualifizierte, musste sie ein Testverfahren durchlaufen und ein Zertifikat erlangen. Die Anforderungen an die Hersteller waren dabei vergleichsweise niedrig. Ein Modell sollte zumindest das Potenzial zur Serienfertigung haben, wobei man dieses Kriterium recht niedrig angesetzte. So wurden auch Unternehmen mit sehr geringen Verkaufszahlen gefördert. Die meisten deutschen Hersteller erhielten schließlich Zertifikate für ihre Produkte. ${ }^{305} \mathrm{Um}$ die Industrie systematischer zu unterstützen, begrenzte man die Mittelvergabe auf inländische Hersteller (WPM 1/89, 13). ${ }^{306}$

\footnotetext{
${ }^{303}$ Als erstes Bundesland verabschiedete Schleswig-Holstein bereits im September 1984 verbindliche Richtlinien für den Aufbau und Betrieb von Windanlagen (ebd., 362). Die Bedeutung solcher Regelungen wird deutlich, wenn man die Probleme betrachtet, mit denen in NRW agierende Windmüller zu kämpfen hatten, bevor sie von der Landesregierung eine Genehmigung erhielten (s.u.).

${ }^{304}$ Tatsächlich abgerufen wurden davon letztlich nur 12 Mio. Die Industrie war außerstande, die Aufträge rechtzeitig zu erfüllen. Daher wurde der Etat 1990 auf 27 Mio. reduziert (WPM 4/90, 13).

${ }^{305}$ Abgelehnt wurden Vorschläge, traditionelle Windmühlen mit elektrischen Generatoren auszustatten sowie Selbstbauer, die für kommerzielle Produktfertigung ungeeignet schienen (WPM 10/89, 9).
} 
Bei der Kernforschungsanlage Jülich, welche für die Vergabe von Genehmigungen zuständig war, gingen bis zum 8. August 1989, fünf Monate nach dem Start des Programms, bereits Anträge zur Förderung von etwa 500 WEA ein. 67 der insgesamt 400 Projektplanungen hatten zu diesem Zeitpunkt eine Genehmigung erhalten, was auf eine effiziente Arbeitsweise dieser Behörde schließen lässt.

Viele Projekte wurden zusätzlich von Länderseite gefördert. So kam es, dass sich die Zuschüsse mitunter auf das definierte Fördermaximum von 75\% addierten. Ohne die zusätzliche Flankierung durch die Länder hätte das 100MW-Programm kaum eine solche Anfangsdynamik entfalten können. Erwartungsgemäß verzeichneten jene Länder die größte Windanlagen-Nachfrage, in die Windkraft ohnehin gefördert wurde. 93\% der beantragten WEA und 97\% der Windenergie-Kapazität stammten aus Nordrhein-Westfalen, SchleswigHolstein und Niedersachsen (WPM 10/89, 9).

Da sich das 100MW-Programm als erfolgreich erwiesen hat, kündigte das BMFT noch im Oktober 1989 eine Ausweitung auf 200MW an. Ansonsten hätten viele der beantragten Projekte nicht mehr realisiert werden können (WPM 11/89, 6). Zum März 1991 erfolgte eine weitere Ausdehnung auf 250MW. Für das gesamte Programm hatte das BMFT 350 Mio. DM zur Verfügung gestellt (WPM 2/91, 10).

\section{Stromeinspeisungsgesetz (SEG)}

Mit dem Beschluss des Stromeinspeisungsgesetzes vollzog der Bundestag am 7. Dezember 1990 einen weiteren entscheidenden Schritt in der Windkraftpolitik. Tacke $(2004,176)$ geht davon aus, dass der einstimmige Beschluss des Bundestags zur Annahme des SEG für die Branche sehr wichtig war. Dadurch erhielt die mittelständische Windindustrie einen starken Rückhalt, der sie zu Investitionen für die Entwicklung neuer Konzepte ermutigte (ebd., 205f.). Das zum 1. Januar 1991 in Kraft getretene Gesetz garantierte unabhängigen Produzenten von Strom aus erneuerbaren Energien den Netzzugang. Von nun existierte ein Rechtsanspruch der Windmüller, Energie in das nächstgelegene Stromnetz zu speisen. ${ }^{307}$ Der Betreiber des Netzes musste für die Energie mindestens $90 \%$ des durchschnittlichen Stromtarifs für Privatkunden bezahlen.

Zuvor wurden erneuerbare Energien wie die Windkraft als Möglichkeit wahrgenommen, fossile Energie einzusparen. Daher rührte die Festlegung des Einspeisepreises auf Höhe der vom Stromproduzenten vermiedenen Kosten. Das SEG legte den Preis deutlich oberhalb dieses Niveaus fest. Dabei stellte das Gesetz in Rechnung, dass es sich um saubere Energiequellen handelte, für welche ein ,politischer Preis' zu zahlen sei (WPM 10/90, 10). Für die Windmüller brachte das SEG erstmals weitreichende Planungssicherheit. Zuvor hatte es grundsätzlich in der Macht der EVU gelegen, die Stromabnahme zu verweigern. Die Versorger hatten letztlich Definitionsmacht über die Höhe vermiedener Kosten. In den meisten Fällen wurde die Tarife zu ungunsten der Windmüller bestimmt. Im SEG waren sie an die Strompreishöhe gekoppelt, deren Senkung einzig als Folge sinkender Strompreise denkbar war.

Mit Einführung des SEG lief eine grundlegende Transformation des Fördersystems einher. Durch die im SEG festgeschriebenen Abnahmepreise war eine zusätzliche Subventionierung,

\footnotetext{
${ }^{306}$ Dieser ,Protektionismus' verstieß einem Gerichtsurteil zufolge nicht gegen entsprechende EU-Gesetze, weil es sich bei dem 100MW-Programm um F\&E-Aktivitäten handelte (WPM 1/89, 13).

${ }^{307}$ Das Phänomen der Stromeinspeisung durch unabhängige Akteure war auf dem deutschen Elektrizitätsmarkt kein Novum. Bereits vor der Kommerzialisierung der Windkraft waren EVU-fremde Betreiber industrieller Kraftwerke auf dem Sektor präsent. Geregelt wurde die Einspeisung durch eine Vereinbarung zwischen dem Bundesverband der Industrie e.V. (BDI), dem Verband der Elektrizitätswirtschaft (VDEW) und dem Verband der Industriellen Energie- und Kraftwirtschaft e.V. (VIK). Dabei handelte es sich um eine Selbstverpflichtung der Netzbetreiber. Für viele Stadtwerke und Regionalversorger bedeutete die Einspeisung ein lukratives Geschäft, weil sie den Strom unterhalb der Grenze vermiedener Kosten vergüteten (Suck 2004, 26f.).
} 
wie sie im Rahmen des 250MW-Programms gewährt wurde, überflüssig geworden. Zudem bewertete das BMFT die Windkraft mittlerweile als eine so ausgereifte Technologie, dass sie nicht länger Forschungsgelder zu erhalten brauchte. Daher wurde das 250MW-Programm Ende 1991 abgebrochen (WPM 3/92, 11). Diese Entwicklung wirkte sich zum Nachteil der EVU aus. Denn im Rahmen der bisherigen Förderung waren sie unabhängigen Stromproduzenten gleichgestellt. Das SEG hatte sie als Betreiber dagegen nur eingeschränkt vorgesehen. So galt das Gesetz nur für Windparks, die zu mehr als $75 \%$ in privater Hand lagen (vg. $\S 1){ }^{308} \mathrm{Im}$ Falle eigener Windparks war es den EVU demnach nicht erlaubt, die Tarife des SEG auf die Strompreise zu schlagen. Dadurch leistete das SEG einer weiteren Polarisierung zwischen EVU und Windmüllern Vorschub. Erst mit Einführung des Erneuerbare-Energien-Gesetzes (EEG) im Jahr 2000 war es den EVU erlaubt, für eigene, mit regenerativen Energieträgern betriebene Kraftwerke, die EEG-Tarife an die Stromkunden weiterzugeben. ${ }^{309}$ In den Jahren zuvor herrschte zwischen den beiden Akteuren eine permanente Konfliktsituation. Die EVU klagten mehrfach gegen das SEG. Der VDEW forderte seine Mitglieder sogar dazu auf, die Zahlung der Einspeisetarife zu verweigern. Erst ein Urteil des Europäischen Gerichtshof, durch welches das SEG bestätigt wurde, schaffte eine gewisse Beruhigung der Situation.

\section{Standorte für Windanlagen}

Bei der Vergabe von Baugenehmigungen waren im Untersuchungszeitraum sowohl die Bundesländer, als auch kommunale Verwaltungen die wichtigsten Akteure. Regelungen auf föderaler Ebene existierten während der Pionierphase nicht. Im Bundesbaugesetz waren WEA nicht vorgesehen. Generell lässt sich sagen, dass sämtliche Verwaltungen, bis in die zweite Hälfte der 80er Jahre hinein, gegenüber der Installation von Windanlagen, eine restriktive Haltung aufwiesen. Dort, wo es den Windmüllern vor 1986/87 gelungen ist, eine Genehmigung zu erhalten, musste ein hohes Maß an Ausdauer, Idealismus und Kampfgeist an den Tag gelegt werden. Die ersten verbindlichen ,Richtlinien für die Auslegung, Aufstellung und das Betreiben von Windkraftanlagen' wurden 1984 von Schleswig-Holstein herausgegeben und von den übrigen Bundesländern weitgehend übernommen (Tacke 2004, 170).

Vor 1989 wurden nur vereinzelt Anträge für Baugenehmigungen gestellt. Seit 1989/90 ging bei einigen Behörden, etwa in den Landkreisen Nordfriesland und Dithmarschen, eine regelrechte Antragsflut ein. Mit dem bisherigen Verfahren, jeden Antrag einzeln zu bearbeiten, hätten die Anträge gar nicht bewältigt werden können. Häufig war im Zuge der Prüfung des fraglichen Standorts festgestellt worden, dass ein Windpark zu Landschaftsverschandlungen geführt, oder der Tourismusindustrie hätte Schaden zufügen können. Daher gingen einige Behörden zu einem neuen Verfahren über. Sie erstellten Gesamtflächenpläne in denen bestimmte Gebiete für Windparks reserviert wurden (WPM 2/91, 11). Ihnen kommt damit eine Pionierrolle in einer zweckmäßigen Gestaltung der Genehmigungsverfahren zu. Entsprechende Pläne wurden später von anderen Bundesländern und Landkreisen erstellt. Seit 1992 erhielt der Bau von WEA im niedersächsischen Landes-Naturschutzgesetz einen privilegierten Status. Eine ähnliche Reform wurde 1994 in Nordrhein-Westfalen beschlossen. Von daher kamen entscheidende Impulse zur Abänderung des Bundesbaugesetzes im Jahr 1996. Von nun an war eine Bevorzugung der Windanlagen gegenüber alternativer Nutzung auch bundesrechtlich verankert. Diese Neuerung erweiterte die Planungskompetenz der Kommunen: Ihnen wurde

\footnotetext{
${ }^{308} \mathrm{http} / / /$ www.umwelt-online.de/recht/energie/einspei.htm, Abruf vom 14.5.2009

${ }^{309}$ Ferner hob das EEG gewisse Unsicherheit im Abnahmepreis auf. Von nun an wurde über fünf Jahre lang ein fester Preis von 17,8 Pf. pro Kilowattstunde gezahlt, anschließend noch 13,8Pf. Darüber hinaus unterlagen diese Tarife einer Degression, die durch technische Innovation kompensiert werden sollte (Byzio et al. 2002, 353f.; vg. auch Suck 2004, 40ff.).
} 
offiziell das Recht zugesprochen, Vorranggebiete für Windparks zu definieren. Dadurch konnten andere Gebiete als potenzielle Standorte ausgeschlossen werden konnten (Suck 2004, 31). Um die Wertschöpfung aus dem Stromverkauf der Region zugute kommen zu lassen, waren viele Gemeinden bemüht, lokale Akteure in ihren Planungen zu bestärken, während sie den Aufbau von Windparks durch auswärtige Investoren zu verhindern suchten (Toke 1999, 6).

Ergebnisse

Auf Grundlage des SEG erhält die Windkraft in der Bundesrepublik seit 1991 einen enormen Aufschwung (vg. Tabelle 2.4.3a). Bis zur Verabschiedung des Gesetzes muss eine Reihe von Lernprozessen durchlaufen werden. Nach dem Scheitern Growians bilden erste Versuche mit kommerzieller Windturbinentechnik den Auftakt zu einer erfolgreichen Neuausrichtung der Windenergiepolitik. Die ersten umfangreichen Investitionsprogramme stammen aus Niedersachsen, Nordrhein-Westfalen und Schleswig-Holstein. In Bezug auf den Start des 100MW-Programms durch das BMFT, kommt insbesondere dem Land Niedersachsen eine Vorreiterrolle zu. Diese ersten, aufeinander aufbauenden Schritte - kleine Demonstrationsprogramme des Bundes, Länderinitiativen und das erfolgreiche 100/250MWProgramm - bilden das Fundament des Stromeinspeisungsgesetzes. Auch Regionen und Kommunen tragen zu den Erfolgen bei. Sie entwickelten effiziente Verfahren zur Bestimmung von Windanlagenstandorten. In diesem Zusammenhang ist die hohe Planungsautonomie der Kommunen, gegenüber den höheren Ebenen sehr zweckmäßig.

\subsubsection{Bundesrepublik Deutschland: Windanlagenindustrie in Periode 4}

Aus der Ferne betrachtet scheint es, als wären Anfang der 80er Jahre ausschließlich Großakteure damit beschäftigt gewesen, hoffnungslose Megawattprototypen herzustellen. Tatsächlich existierte bereits ein rudimentärer Markt für kleine Windanlagen, zu dessen Akteuren neben den am Forschungsprogramm beteiligten Konzernen MAN, MBB und Dornier, ${ }^{310}$ auch Selbstbauer und Kleinunternehmen zählten. Im Frühjahr 1984 stammten $58 \%$ der in Deutschland betriebenen Windanlagen von Selbstbauern. Die meisten davon wurden nicht zur Netzeinspeisung, sondern zur Wärmeproduktion genutzt (Oelker et al. 2005, 84). Ähnlich wie in der dänischen Technikperiode existierte auch hierzulande ein fließender Übergang zwischen Selbstbauern ${ }^{311}$ und semi-professionell arbeitenden Herstellern.

Die Ergebnisse der Windanlagen, die zwischen 1980 und 1983 auf Pellworm getestet wurden, sind ein deutlicher Indikator der Rückschrittlichkeit der deutschen Windindustrie gegenüber den Windanlagenherstellern aus Dänemark. Die meisten Windturbinen überstanden die Dauer der Tests auf Pellworm nicht, weil sie zuvor Totalschäden erlitten.

Um die Akteursstruktur der Industrie im Untersuchungszeitraum richtig einzuordnen, ist der Rückgriff auf die erste Hälfte der 80er Jahre unerlässlich. Technische Aspekte sind zu dieser Zeit weniger relevant. Die wesentlichen technischen Pionierleistungen waren zwischen 1975

\footnotetext{
${ }^{310}$ Die Konzerne bemühten sich um die Kommerzialisierung von Kleinanlagen, die als Modelle ihrer Großanlagen gedient hatten (Oelker et al. 2005, 46).

${ }^{311}$ Die Landwirte Friedrich Böse und Heinrich Dove waren Pioniere im Selbstbau. Böses 10kW-Anlage erlangte einen gewissen Kultstatus. Als die Turbine 1980 in Betrieb genommen wurde, kamen 1.200 Besucher, um die Windanlage in Augenschein zu nehmen. Ähnlich wie dänische Selbstbauer verwendete auch Böse eine LKWAchse als Antriebswelle. Seine Bauphilosophie war an die Vorgehensweise angelehnt, die in Dänemark zu dieser Zeit üblich ware: ,Lieber ein Zentner Eisen zu viel, als ein Pfund zu wenig.' (F. Böse, zitiert nach: Oelker et al. 2005, 85). Heinrich Dove trug aufgrund seiner vielen Erfindungen im Bereich Wind- und Solarenergie sowie kleinen Blockheizkraftwerken den Beinamen ,Daniel Düsentrieb aus Barenburg'. 1986 stellte Dove eine $70 \mathrm{~kW}$-Windanlage fertig, die seinen Hof mit Strom versorgte. Es war die größte privat hergestellte Windanlage Deutschlands, die zu 90\% aus Schrottteilen gefertigt wurde (ebd.).
} 
und 1978 in Dänemark bereits erbracht worden. Zu den wichtigsten Rahmenbedingungen der deutschen Windindustrie zählt die Tatsache, dass Mitte der 80er Jahre im nördlichen Nachbarland eine gut erprobte Technologie schon vorhanden ist. Durch Übernahme dieser Erfahrungen gelang es einigen deutschen Firmen, sich zahlreiche Lernschritte zu ersparen. Eine weitere Verbesserung der Ausgangslage bedeutete die seit 1986 einsetzende Förderung kommerzieller Hersteller durch den Bund und einige Länder. Seit den Marktentstehungen in Niedersachsen, Schleswig-Holstein und Nordrhein-Westfalen sind dänische Hersteller und Lagerwey aus den Niederlanden, auf dem deutschen Markt sehr aktiv geworden. Das 100MW-Programm, dass deutsche Unternehmen bevorzugte, verschaffte einigen Inländern genug Raum, um Rückstände gegenüber dieser Konkurrenz aufzuholen.

Zur Analyse der deutschen Windanlagenindustrie werden die Hersteller in zwei Gruppen geteilt: diejenigen mit guten kommerziellen Erfolgen und diejenigen ohne, bzw. geringen Erfolgen. Zur ersten Gruppen zählen alle deutschen Unternehmen, die sich zwischen 1982 und 1995 in der Top 10 des deutschen Marktes bewegen. Dabei handelt es sich um die Mittelständler Enercon, Tacke und die Husumer Schiffswerft. Die zweite Gruppe ist vergleichsweise heterogen: $\mathrm{Zu}$ ihr zählen Klein- und Kleinstunternehmen ebenso wie Großkonzerne. Die Analyse startet mit der zweiten Gruppe, wobei nur die relevanteren Hersteller berücksichtigt werden.

\section{Hersteller ohne kontinuierliche wirtschaftliche Erfolge}

\section{MAN, MBB und Dornier}

Obgleich auch MAN's Aeroman auf Pellworm nur durchschnittliche Ergebnisse aufwies, wurde dem Modell der Status der Serienreife zuerkannt.

Der Aeroman bewährte sich nicht nur auf Pellworm. 1982 wurden fünf Exemplare des Typs ausgewählt, um auf der griechischen Insel Kythnos den ersten europäischen Windpark zu installieren. 1984 erhielt MAN den Zuschlag für das BMFT-Projekt,Windkraftanlagen in Entwicklungsländern'. In diesem Rahmen wurden 50 Aeroman zur Netzeinspeisung errichtet, z.B. auf Mauritius, den Azoren und in Argentinien. Seit 1984 exportierte MAN den Aeroman nach Kalifornien, insgesamt über 350 Exemplare (Oelker et al. 2005, 47). Der Aeroman gilt in der zweiten Hälfte der 80er Jahre als gut erprobt. Dennoch ist die Windanlage mit ihrem 30kW-Generator zu klein geworden, um sich auf dem Markt noch durchzusetzen. Die Konzernleitung war nicht bereit, Investitionen zur Entwicklung eines größeren Modells zu tätigen. Ursprünglich setzte MAN darauf, dass EVU vom Konzern große Windanlagen erwerben würden. Jedoch blieben die Erfolge der Großwindanlagen aus und entsprechend die Kundschaft aus dem Energiesektor. Potenzielle Aeroman-Kunden, ,Bauer X und Bauer Y', wie Erich Hau es auf den Punkt bringt, passten dagegen nicht in das Verkaufskonzept des Konzerns (ebd., 49). Daher gab MAN seine Aktivitäten im Windsektor 1990 auf.

Auch MBB war neben dem Bau von Megawattprototypen, auf dem Feld kleiner Windmühlen tätig. Vor allem versuchte sich MBB an der Einflügeltechnik (,Monopetrus'). Diverse Einblattmaschinen unterschiedlicher Größe wurden produziert, von denen jedoch keine in Serie gegangen war. 1989 verkaufte der Konzern 15 kleine Einflügler an die Überlandwerke Hannover-Nord (ÜHN). Da die Anlagen schlechter als erwartet arbeiteten, wurden sie drei Jahre später wieder abgebaut. 1993 zog sich der Konzern aus der Windbranche vollständig zurück (ebd., 57f.). Auch Flugzeughersteller Dornier, der ebenfalls am LSP-Windprogramm beteiligt war, stellte Kleinwindturbinen her. Dabei handelte es sich um Darrieus-Anlagen, welche allerdings noch geringeren Absatz fanden als die Einflügler von MBB.

Generell lässt sich über das Engagement der Konzerne im Windsektor sagen, dass sich die Begeisterung für die Windtechnologie auf einzelne Mitarbeiter beschränkte. Als sich 
abzeichnete, dass die erhofften kommerziellen Erfolge nicht zu realisieren waren, schwand das Interesse.

Weitere am Pellwormer Testverfahren teilnehmende Unternehmen

Neben der dänischen Windmatic, MAN und Dornier waren noch sechs weitere inländische Hersteller auf dem Pellwormer Testfeld vertreten: NOAH Energiesysteme GmbH, HansDietrich Goslich (Selbstbauer), Maschinen- und Apparatebau Hüllmann (Schlossereibetrieb), Krampitz Klärtechnik GmbH, Böwe Maschinenfabrik GmbH und Brümmer Wind- und Wasserkraftanlagen KG (ebd., 81).

Hans-Dietrich Goslich, ein Ingenieur der seit den 70er Jahren an diversen Rotorkonzepten arbeitete. Als Vorstandsmitglied der Deutschen Gesellschaft für Windenergie sprach er sich für die stärkere Förderung kleiner WEA aus. Hauptsächlich arbeitete Goslich an einem Einblattrotor mit schrägem Schlaggelenk, wodurch der Flügel plötzlichen Böen ausweichen konnte. Später brachte Südwind dieses Konzept zur Serienreife (ebd., 82).

Eine bemerkenswerte Person ist Walter Schönball (NOAH Energiesysteme). Schönball zählte zu den Begründern der modernen Windkraftbewegung. Auf seine Initiative ging 1974 die Gründung des Vereins für Windenergieforschung und -anwendung (VWFA) zurück. Der VWFA ist der früheste Vorläufer des heutigen Bundesverbandes Windenergie. Schönballs 10kW-Turbine ist die erste auf Pellworm getestete Anlage. Bei Stürmen musste Schönball aus Bonn anreisen und den Rotor per Hand, d.h. über eine Seilwinde, aus dem Wind steuern. Als die GKSS seine Modell nach Sturmschäden demontieren wollte, stieg Schönball auf die Gondel, verschanzte sich dort und startete sogar einen Hungerstreik, um den Abriss seiner Mühle zu verhindern. Diese Erfahrung bedeutete eine schwere Niederlage für Schönball. Darüber hinaus war er Mitte der 80er aufgrund der langsamen Fortschritte der Windbranche enttäuscht. Da er finanziell nicht von wirtschaftlichen Gewinnen aus der Windkraft abhängig war, gab er den Windmühlenbau auf (ebd., 80ff.).

Eine weiterer Pionier ist der Elektrotechniker Hermann Brümmer. Bereits in den 60er Jahren entschied er sich, das elterliche Elektrogeschäft aufzugeben und stattdessen Windräder herzustellen. Aufgrund der reichhaltigen Erfahrungen, es kein Zufall, dass Brümmers Modell, neben denen von Windmatic und MAN zu den drei besten Pellwormer Modellen gezählt wurde. Nach eigenen Angaben hatte Brümmer 380 seiner WEA verkauft und zählte zu den wenigen, die bereits in den 60er/70er Jahren mit der Windenergie Geld verdienten. Das Unternehmen hatte immerhin bis zu zwölf Beschäftigte. Der GKSS-Abschlussbericht attestiert Brümmers Maschine, aufgrund ihrer einfachen Herstellungsweise, gute Wettbewerbschancen für die Fertigung und den Betrieb in Entwicklungsländern.' (ebd., 83). Um die erforderlichen Investitionen zu tätigen, die für den Einstieg in einen internationalen Markt erforderlich waren, mangelte es Brümmer an Kapital (ebd., 83). ${ }^{312}$

Aerodyn (1983-1988) 313

1983 gründen drei Konstrukteure ein Ingenieurbüro zur Entwicklung von Windkraftanlagen: Aerodyn. Die erste zweiflügelige Prototyp-Windanlage Aerodyns, Aeolus 11 mit 18kWGenerator, wurde bis 1985 von der GKSS und dem Germanischen Lloyd auf Pellworm getestet. Die reichhaltigen Versuchsergebnisse an der Aeolus 11 bildeten später wichtige Grundlagen der vom Germanischen Lloyd erarbeiteten Auslegungsrichtlinien für Windanlagen. Im Dezember 1987 wurden fünf Prototypen einer leicht vergrößerten Variante von Aeolus 11

\footnotetext{
${ }^{312}$ Ein Weg wäre die Teilnahme des Unternehmens am 1984 ausgeschriebenen staatlichen Projekt ,Windkraftanlagen in Entwicklungsländern', gewesen. Obgleich Brümmer die Projektausschreibung gewann, erhielt schließlich MAN den Zuschlag für die Lieferung von 100 WEA in Entwicklungshilfeländer. Brümmer vermutete, dass man das Projekt einem Einzelkämpfer wie ihm nicht zugetraut hatte (ebd.).

${ }^{313}$ Die Angabe des Endjahrs 1988 verweist nicht auf ein endgültiges Ausscheiden Aerodyns aus der Branche. Nur verlagerte das Unternehmen seine Aktivitäten vom Entwicklungssektor zur technischen Beratung.
} 
installiert. Deren Herstellung gab Aerodyn bei der Husumer Schiffswerft in Auftrag. Um eine Serienfertigung einzurichten, fehlten den jungen Ingenieuren die Mittel. Sie hätten einen Kredit aufnehmen müssen, was sie ablehnten. 1988 verkauften sie die Lizenz zur Produktion des Modells an die Husumer Schiffswerft. Aerodyn selbst konzentrierte sich anschließend auf das Windanlagendesign. Das Unternehmen wurde daraufhin zum einzigen Entwicklungsbüro, dass nicht an einen Hersteller gebunden war. Insgesamt profitierten bislang mehr als 30 Turbinenproduzenten vom Know-how Aerodyns (ebd., 119f.).

Windkraftzentrale (1981-1989)

Ebenso wie Goslich (s.o.) gehörte auch Ingenieur Horst Frees zu den Gründungsmitgliedern des VWFA. Seit 1977 erwarb Frees Windanlagen von Svend Jenssen aus Dänemark. Diese Windrosen (vg. Kap. 2.1) bot er in Schleswig-Hostein an, insbesondere zur Warmwasserbereitung. Als Jenssen 1981 Konkurs anmeldete, übernahm Frees dessen Konstruktionszeichnung. Frees erweiterte die Windrose zu einer 16flügeligen Windmühle, dem ,12kW-elektrOmat'. Daraufhin gründete er im Dezember 1981 ein eigenes Unternehmen, die Windkraftzentrale. Für 60.000 DM erlangte er 1982 die erste Typenprüfung und begann, seine Windanlage in Serie zu produzieren. Angesichts der Forderungen nach größeren und netzgekoppelten Maschinen waren die anstehenden Arbeiten von den drei festen Mitarbeitern kaum zu bewältigen. Frees tat sich schwer mit der Entwicklung und Produktion größerer Modelle. Erst im Oktober 1985 gelang es ihm, die Typengenehmigung für eine neue 20kWTurbine zu erlangen. Zwar wurde der neue elektrOmat durchaus nachgefragt. Aufgrund problematischer Genehmigungsverfahren und mangelnder Unterstützung durch die Schleswig-Holsteinische CDU-Regierung verkaufte Frees jedoch nur wenige Exemplare. 1987 wurde ein $25 \mathrm{~kW}$-elektrOmat im Windpark Westküste geprüft. Zu dieser Zeit sind bereits Nennleistungen von mindestens $100 \mathrm{~kW}$ üblich geworden. Für das erforderliche Upscaling fehlte Frees die erforderliche Liquidität. Um seine Produktion auszuweiten, scheiterte er daran, finanzstärkere Partner zu finden. 1990 verstarb der Pionier an Krebs (ebd., 86f.).

Südwind GbR/GmbH (1982-1993)

Windkraftpionier Robert Gasch von der TU Berlin gründete 1977 am Institut für Luft- und Raumfahrt (ILR) die Arbeitsgruppe Windkraftanlagen. Beteiligt waren, an der Windtechnologie interessierte Wissenschaftler, Mitarbeiter und Studierende (ebd., 114). Aus diesem Umfeld fanden sich drei junge Ingenieure zusammen, die 1982 die Südwind GbR gründeten. 1983 entwickelte Südwind den ersten Prototyp mit 15kW-Generator. Die Bewerbung für eine Prüfung auf dem Pellwormer Testfeld wurde abgelehnt. Geld verdienten die Mitglieder der GbR mit ihrem Unternehmen nicht. Um ihren Lebensunterhalt zu bestreiten, mussten sie weiterhin am ILR arbeiten. Unterstützt wurde Südwind von windenergiebegeisterten Studenten. 1984 nahmen bspw. drei Examenskandidaten im Rahmen ihrer Abschlussarbeiten die Berechnung der Statik der 15kW-Anlage vor und optimierten die Fertigungstechnologie. Im November 1986 verkaufte Südwind die erste Windanlage in den Landkreis Cuxhaven (ebd., 115). Um sich gegen finanzielle Risiken abzusichern, bildete Südwind im April 1988 eine $\mathrm{GmbH}$, ergänzend zur GbR. Gefördert durch ein staatliches Demonstrationsprogramm verkaufte das Unternehmen 1989 fünf kleine WEA des neu entwickelten Typ N1230 (30kW Nennleistung/ 12,5 Meter Rotordurchmesser). Aufgrund der Investitionszulage aus dem 100MW-Programm stieg die Nachfrage seit 1990 deutlich an. Während der frühen 90er Jahre wuchs der Mitarbeiterstamm auf 35 Beschäftigte. Produziert wurde trotz des Wachstums noch immer im zweiten Stock eines Kreuzberger Hinterhauses. Auch bei Südwind musste man nun feststellen, dass eine 30kW-Turbine für den Markt zu klein geworden war. Um konkurrenzfähig $\mathrm{zu}$ bleiben, bedurfte es eines deutlichen 
Entwicklungssprunges auf 200-300 kW. ${ }^{314}$ Im August 1993 installierte Südwind den ersten Prototyp ihrer neuen 270kW-Anlage, die auf einem, für die Kreuzberger, völlig neuen Konzept basierte, dem international bewährten danish Design (ebd., 116). Auch das neue Modell erwies sich als zu klein, um auf dem Markt zu bestehen. Geschäftsführer Twele war der Meinung, dass es sich bei der Südwind GmbH eher um ein Ingenieurbüro, als einen Fertigungsbetrieb handeln sollte: viel Know-how, dass zudem ständig durch neue Studierende von der TU aufgefrischt wurde, aber wenig Kapital. Das Unternehmen entschied sich daher, vor allem auf ausländischen Märkten zu verkaufen und zwar per Lizenzvergabe. Den größten Absatz erzielte Südwind durch einen Lizenzvertrag mit dem indischen Hersteller Suzlon, der zuvor in der Textilbranche tätig war. ${ }^{315}$ Auf dem deutschen Markt war Südwind trotz wechselnder, kapitalstarker Eigentümer, nicht konkurrenzfähig. 2001 ging die Südwind-Technologie in der Nordex AG auf (ebd., 117).

Erfolgreiche Hersteller der Pionierphase

Im Zeitraum 1982 bis 1995 befanden sich unter den zehn auf dem deutschen Markt führenden Turbinenproduzenten nur drei Unternehmen, die ursprünglich in der Bundesrepublik gegründet worden waren: die Mittelständler Enercon, Tacke und die Husumer Schiffswerft. Enercon und Tacke zählten über die Pionierphase hinaus zu den absatzstärksten Herstellern auf dem deutschen Markt. Gemeinsam mit der Husumer Schiffswerft verfügten sie zwischen 1982 und 1995 über $48 \%$ der Anteile installierter Kapazität und 40\% der verkauften WEA (Tab. 2.4.3b).

Tabelle 2.4.3b $\quad$ Führende Hersteller auf dem deutschen Markt (1982-1995)

\begin{tabular}{|l|l|l|l|l|l|}
\hline Hersteller (Land) & Position & $\begin{array}{l}\text { Installierte } \\
\text { Kapazität (MW) }\end{array}$ & Anteil (\%) & $\begin{array}{l}\text { Anzahl } \\
\text { installierter WEA }\end{array}$ & Anteil (\%) \\
\hline Enercon (BRD) & 1 & 325,04 & 28,60 & 892 & 24,40 \\
\hline Tacke (BRD) & 2 & 186,39 & 16,40 & 442 & 12,10 \\
\hline Vestas (DK) & 3 & 159,11 & 14,00 & 420 & 11,50 \\
\hline Micon (DK) & 4 & 117,06 & 10,30 & 292 & 8,00 \\
\hline $\begin{array}{l}\text { AN-Bonus (DK, } \\
\text { BRD) }\end{array}$ & 5 & 95,47 & 8,40 & 256 & 7,00 \\
\hline Nordtank (DK) & 6 & & & & \\
\hline Nordex (DK) & 7 & 67,05 & 5,90 & 183 & 5,00 \\
\hline HSW (BRD) & 8 & 39,78 & 3,50 & 179 & 4,90 \\
\hline Wind World (DK) & 9 & 29,55 & 2,60 & 124 & 3,40 \\
\hline Lagerwey (NL) & 10 & 22,73 & 2,00 & 88 & 2,40 \\
\hline gesamt & 15,91 & 1,40 & 175 & 4,80 \\
\hline
\end{tabular}

Quelle: Fleckenstein (1996), 32

Husumer Schiffswerft (1985-1999)

1985 initiierte Udo Postmeyer, ein vorheriger Betriebsleiter der Husumer Schiffswerft (HSW), die Entwicklung zweier neuer Windanlagen $(100 / 200 \mathrm{~kW})$. Unterstützung erhielt er von der Kieler Landespolitik, die sich um die Erhaltung des Werftstandortes sorgte (Oelker et al. 2005, 121). Die nordfriesische Entwicklungsbehörde erhoffte sich positive Beschäftigungseffekte und Chancen, qualifizierte Arbeitskräfte in der Region zu halten (WPM 8/91, 16). So entwickelten die Konstrukteure der HSW ein 200kW-Modell nach dänischen Vorbild. Januar

\footnotetext{
${ }^{314}$ Für ihre 30kW-Anlagen hatten die Kreuzberger noch das Konzept der Gelenkflügel von Goslich nutzen können. Man war sich bei Südwind darüber einig, dass ein solches Rotordesign für deutlich größere Modelle nicht in Frage kam. Denn der Einsatz von Gelenkflügeln bei Turbinen im Bereich von 200-300 kW bedeutete nicht nur immense Kostensteigerungen, sondern führte darüber hinaus, wegen steigender Rotormasse $\mathrm{zu}$ Effizienzverlusten (ebd., 86).

${ }^{315}$ Suzlon produzierte in den 90er Jahren über 300 WEA, ohne dafür jedoch Lizenzgebühren an die Südwind GmbH zahlen zu müssen. (ebd., 117).
} 
1987 nahmen sie einen ersten Prototyp in Betrieb. Im folgenden Jahr wurde die Anlage optimiert, mit einem 250kW-Generator ausgestattet und im Rahmen eines BMFTDemonstrationsprogramms getestet. Im selben Jahr verkaufte HSW die ersten WEA, zunächst hauptsächlich an öffentliche Unternehmen, insbesondere Stadtwerke. Diese HSW-250 ist 1988 die größte in der Bundesrepublik erhältliche Windanlage. Für private Nutzer lohnte sich der Kauf eines so großen Modells aufgrund geringer Einspeisevergütungen zunächst nicht. Die wartungsfreundliche Turbine war das erfolgreichste Produkt von HSW. Seit 1989 betätigte sich die Werft auch als Projektentwickler. Man wollte einen großen Windpark installieren, um die Kosten der HSW 250 zu senken. 1990/91 realisierte die HSW in Nordfriesland den bis dahin größten Windpark mit 50 Exemplaren der 250kW-Klasse, insgesamt 12,5MW. Der kommerzielle Erfolg der HSW war nicht von Dauer (Oelker et al. 2005, 121f.). Die HSW 250 ist $\mathrm{zu}$ diesem Zeitpunkt noch wenig erprobt. Wenige Monate nach Inbetriebnahme des Windparks mussten sämtliche Generatoren ausgetauscht werden (WPM 8/91, 16). Insgesamt war die Verfügbarkeit der HSW 250 geringer als bei den ausgereifteren Modellen der Konkurrenz aus Dänemark. Aus diesem Grund entschieden sich die meisten privaten Betreiber für dänische Fabrikate. Das SEG förderte den Betrieb deutscher und internationaler Modelle gleichermaßen. Ein weiterer Grund, weshalb sich HSW nicht behaupten konnte, besteht darin, dass die HSW 250 Anfang der 90er für den deutschen Markt bereits zu klein dimensioniert war. 1993 installierte die Werft den Prototyp einer großen 750kW-Windanlage. Dieser wurde 1995, unter Mitarbeit der Aerodyn-Ingenieure, zur HSW 1000/57 ausgebaut wird (1 MWGenerator, 57m Rotordurchmesser). Seitens der Werftleitung wurde die Windsparte des Unternehmens noch immer nicht ernst genommen. Es war die Rede von ,Postmeyers Hobby' (Oelker et al. 2005, 122). Die Aktivitäten im Windsektor erhielten eine zunehmend geringere Priorität im Unternehmen. ${ }^{316}$ Trotz begrenzter kommerzieller Erfolge der HSW 1000/57 gelang es der Windsparte nicht, noch immer bestehende Defizite auszugleichen. Am 30. November 1999 meldete die HSW Konkurs an (Oelker et al. 2005, 121f.).

Renk Tacke/ Tacke GmbH/ Tacke Windtechnik GmbH (1984-1997)

Das Maschinenbauunternehmen Tacke KG wurde 1886 in Rheine gegründet. Angesichts des insgesamt stagnierenden Industriesektors strebte Betriebsleiter Franz Tacke seit Anfang der 80er Jahre eine Diversifizierung der Produktion an. Daher entschied er sich 1984 für die Annahme eines Auftrags zur Produktion von 40 Windanlagen, nachdem sich die Ingenieure positiv über die Machbarkeit des Projekts geäußert hatten. Die Windturbinen sollten nach Kalifornien exportiert werden. Wie andere, unterschätzte auch Tacke die technischen Barrieren der Windanlagentechnik ebenso wie Unwägbarkeiten des kalifornischen Marktes. Ein im kalifornischen Tehachapi errichteter Prototyp des Wagner-Rotors - benannt nach dem Konstrukteur Günter Wagner- erlitt sehr bald Totalschaden. Als das Unternehmen eine verbesserte Version der $150 \mathrm{~kW}$-Maschine fertiggestellt hatte, war der eigentliche Käufer bereits in Konkurs gegangen. Tacke hielt dennoch an der Windenergie fest und installierte schließlich selbst 15 Exemplare der neuen TW-150 auf dem vorgesehenen Standort (Oelker et al. 2005, 123). Bei der Entwicklung der TW-150 entschieden sich die Konstrukteure für das dänische Konzept (Tacke 2004, 179; 182). Dieselbe Bauweise verwendete Tacke für alle übrigen Modelle, welche das Unternehmen in den folgenden Jahren entwickelte. Speziell für den Export konstruierte die Firma eine 300kW-Anlage. Die internationale Nachfrage entsprach jedoch nicht den Erwartungen. Tacke musste erkennen, dass ,die dänische Konkurrenz einen 10jährigen Vorsprung hatte, der nicht in kurzer Zeit eingeholt werden konnte.' (ebd., 190). Wichtiges Know-how erhielt Tacke aus Dänemark. Im Rahmen einer EU-geförderten Kooperation entwickelte das Folkecenter 1986, gemeinsam mit Tacke, eine größere WEA mit

\footnotetext{
${ }^{316}$ Von 600 Beschäftigten der HSW waren 60 im Windsektor tätig. Sarah Knight zufolge (WPM 8/81, 17) hatte Windkraft bei der HSW keine hohe Priorität: ,It seems that tools are dropped in the wind workshop whenever a ship repair calls for labour.'
} 
500kW-Generator. Tacke, der u.a. die Marine mit großen Getrieben belieferte, steuerte das 15 Tonnen-Getriebe der Windanlage bei. Im Umkehrzug erhielt Tacke aus dem Folkecenter ,eine Menge Wissen über Lastanforderungen und Konstruktion, das den deutschen bisher gefehlt hatte.' (Beuse et al. 2000, 212). Hergestellt wurden zwei Exemplare des Prototypen auf Borkum und Hanstholm. Beide Maschinen erhielten LM-Rotoren aus Dänemark. Seitdem lieferte LM die Rotoren für Tackes Windanlagen (ebd.).

1986 übernahm Tacke sämtliche Aktivitäten der MAN-Tochter Renk im Windkraftsektor. Daraufhin entstand die Renk-Tacke GmbH. In dem neuen Unternehmen konnten beide Teile ihr Know-how im Getriebesektor gemeinsam nutzen. In erster Linie produzierte die Renk Tacke GmbH Schiffsgetriebe und Spezialgetriebe für Industrieanlagen, die weltweit verkauft wurden. Windanlagen waren eher ein untergeordnetes Geschäftsfeld (Oelker et al. 2005, 124). Vor dem Hintergrund einsetzender Fördermaßnahmen konzentrierte sich Renk Tacke auf den deutschen Markt. $\mathrm{Zu}$ den ersten Kunden zählten einige Stadtwerke, welche vorwiegend die TW-150 kauften. 1990 erfolgte ein Upscaling zur TW-250 mit 250kW-Generator. Im Herbst des Jahres gründete sich die Tacke Windtechnik GmbH (TWT), die von den beiden Söhnen Tackes geleitet wurde. TWT war für die Bereiche Entwicklung, Vertrieb und Service zuständig, während die Produktion bei Renk Tacke verblieb. Als erstem Windanlagenhersteller gelang es TWT, für sämtliche Unternehmenssektoren das Qualitätszertifikat ISO $9001 \mathrm{zu}$ erhalten (ebd.).

TWT avancierte in den 90er Jahren zu einem erfolgreichen Windanlagenproduzenten. Auf Grundlage der TWT-500, nahm TWT 1996 den Prototyp der TWT-600 (600kW) in Betrieb. Bei nur zehn Prozent höheren Kosten gegenüber der TWT-500, erbrachte das neue Modell einen um 40\% höheren Ertrag. Kommerziell betrachtet war die TWT-600 ein enormer Erfolg. Innerhalb von zwei Jahren verkaufte TWT 230 Exemplare (ebd., 125). Daher wuchs die Beschäftigtenzahl des Unternehmens zwischen 1991 und 1996 von fünf auf 235 Mitarbeiter an. Angesichts der rasanten Kapazitätsexpansion blieb für intensive Tests zu wenig Zeit. Technische Mängel in der Konstruktion verursachten zahlreiche Pannen und damit kostspielige Garantiefälle (ebd., 126). Die Antiakzeptanz-Kampagne und die Diskussionen um das SEG führten zu einer Destabilisierung des Sektors. Von der Krise, welche daraus resultierte, war TWT besonders hart getroffen worden. Langfristige Verträge mit den Zulieferern mussten eingehalten werden. Der Betrieb verschuldete sich stark und ging im Juli 1997 in die Insolvenz. Im Oktober des Jahres wurde TWT vom texanischen Energiekonzern Enron Corporation übernommen (ebd., 126ff.). ${ }^{317}$

Enercon Gesellschaft für Energieanlagen \& Co. KG

Elektroingenieur Aloys Wobben sammelte seit den späten 70er Jahren praktische Erfahrungen mit der Konstruktion kleiner WEA. Mitte 1984 gründete er gemeinsam mit dem Eigentümer einer Getriebebaufirma die Enercon Gesellschaft für Energieanlagen \& Co. KG. Anfangs bestand das Unternehmen aus vier Mitarbeitern. Wobben begann mit der Konstruktion der E15 (55kW Nennleistung, 15m Rotordurchmesser). Ebenso wie bei der HSW und Tacke, fiel auch Wobbens Entscheidung auf das dänische Konzept. Von der Steuerung abgesehen, die er selbst entwickelte, erwarb er sämtliche Komponenten auf dem Markt (ebd., 130). Bemerkenswert ist darüber hinaus, dass sich auch Wobben für Rotoren aus Dänemark entschied (Oekaer Vind Energi). Die Rotoren transportierte Wobben im alten Mercedes zum Standort nach Aurich (www.windsofchange.dk, Abruf vom 26.2. 2009). Die Stahlbauarbeiten gab man bei einer kleinen Schlosserei in Auftrag. Mai 1985 wurde der erste E-15-Prototyp errichtet. Den ersten Windpark, bestehend aus fünf E-16 (Rotordurchmesser 16m, 55kW

\footnotetext{
${ }^{317}$ Franz Tacke bewertet die Pleite von TWT später als Ergebnis politischer Fehler. Tacke moniert, dass der Konkurs einiger deutscher Baukonzerne mit staatlichen Finanzspritzen in dreistelliger Millionenhöhe verzögert worden sei. Seiner Ansicht nach hätte TWT eine Bürgschaft für ein halbes Jahr genügt, um sich zu regenerieren. Trotz eingestandener Fehler des Unternehmens verortet Tacke die Ursachen des Einbruchs und damit der Krise des Unternehmens darin, dass sich die Kohl-Regierung nicht eindeutig hinter das SEG gestellt hatte (ebd., 127).
} 
Nennleistung), verkaufte Enercon 1986 an die Stadtwerke Norden. November 1987 gingen die Windanlagen in Betrieb und zeichneten sich durch hohe Zuverlässigkeit aus. Einige an der Windtechnologie interessierte Stromversorger wurden auf Enercon aufmerksam. Unternehmen wie Schleswag AG und ÜHN kauften Enercon-Anlagen, um sie mit Produkten der Hersteller MAN und MBB zu vergleichen. Die E-16 Maschinen, die im Windpark Westküste und in Cappel Neufeld installiert wurden, hielten dem Vergleich stand und galten von nun an als konkurrenzfähig.

Im Auftrag des Energieversorgers EWE konstruierte Wobben die E-32, eine größere Maschine mit 300kW-Generator. Ende 1988 installierte Enercon den Prototyp, der zufriedenstellend lief. 1989 beauftragte EWE den Hersteller mit der Lieferung von zehn E-32. Errichtet wurden die WEA im damals größten Windpark Deutschlands in Krummhörn. Durch diesen Auftrag entwickelte sich Enercon 1989 zum führenden Hersteller auf dem deutschen Markt (ebd., 131). Seit 1991 fertigte Enercon die E-32 in Serie und stieg in den Exportsektor ein.

1992 konstruierte Wobben, erneut im Auftrag von EWE, eine getriebelose E-36 (450kWGenerator). Damit leistete Enercon internationale Pionierarbeit. Denn die Herstellung eines getriebelosen Modells dieser Größe war neu. Nachdem sich die E-36 mehrere Monate im Test bewährt hatte, wurde sie zur E-40 mit 500kW ausgebaut. ${ }^{318}$

Die E-40, die Enercon in den folgenden Jahren immer weiter optimiert hatte, bildete die wichtigste Grundlage des Erfolgs der Auricher. Bis 2005 werden international mehr als 4.100 WEA dieses Typs betrieben. Typisch für Enercon ist das erfolgreiche Bestreben, eine neue Größenklasse stets als erster auf den Markt zu bringen. 1995 installierte das Unternehmen eine erste E-66 mit 1,5 MW Nennleistung (ebd., 133). Gut zehn Jahre später werden Prototypen der 6MW-Klasse gefertigt. Seine marktführende Position verteidigte Enercon. Ende 2006 beanspruchte der Hersteller 38,4\% des deutschen Marktes für sich (Neue Energie 2/07, 47).

Erfolgsbedingungen der deutschen Windindustrie

Um zu verstehen, weshalb gerade Enercon, Tacke und die Husumer Schiffswerft als erfolgreiche Unternehmen aus der Pionierphase hervorgetreten waren, sind mehrere Aspekte zu berücksichtigen.

Unternehmensgröße Bereits die kleinen, aber sehr erfolgreichen Hersteller aus Dänemark, scheiterten um 1980 daran, erforderliche Serienfertigungen aufzubauen, um konkurrenzfähig zu bleiben. Der technische Quantensprung von 30 auf 55kW war in den Handwerksbetrieben kaum zu leisten. Allen fehlte es Kapital. Ein ähnliches Phänomen ist circa fünf bis zehn Jahre später in Deutschland zu beobachten. Firmen wie Aerodyn, Windkraftzentrale und Südwind waren durchaus innovativ, jedoch zu klein, um sich auf dem wachsenden Markt zu etablieren.

Beinahe umgekehrt stellt sich die Problematik bei den Konzernen MAN, Dornier und MBB dar. Zur Windkraft waren sie über ihre Einbindung in das staatliche Forschungsprogramm gekommen. Ihr Ziel war es, Großwindanlagen zu entwickeln und an Energiekonzerne zu verkaufen. Als sich während Periode 4 abzeichnet, dass dieses Ziel kurzfristig nicht erreicht werden kann, verloren die Windenergieakteure innerhalb der Konzerne den Rückhalt. Für Unternehmen mit Milliarden-Umsätzen konnte es keine Perspektive sein, kleine WEA zu produzieren und Geschäftsbeziehungen mit Landwirten, Kommunen und lokale Betreibergesellschaften zu unterhalten.

Offenbar dürfen die Firmen weder zu groß, noch zu klein sein. Einerseits ist ein Mindestmaß an Kapitalien und Professionalität erforderlich. Andererseits muss eine gewisse

\footnotetext{
${ }^{318}$ Der wesentliche Vorteil einer getriebelosen Turbine besteht in geringerer Materialermüdung. Das Getriebe einer Windanlage hat die Funktion einer Übersetzung der relativ niedrigen Geschwindigkeit des Rotors, in eine deutlich höhere Geschwindigkeit, die in den Generator eingespeist wird. Maschinenteile, die sich schnell bewegen haben geringere Lebenserwartung. Unter Verwendung eines Generators dessen Polzahl an die niedrige Rotorgeschwindigkeit angepasst war, konnte Wobben auf ein Getriebe verzichten (ebd., 132).
} 
,Bodenständigkeit' gegeben sein. Diese Anforderungen erfüllen ausschließlich die mittelständischen Firmen Tacke, Enercon und Husumer Schiffswerft. ${ }^{319}$

Dänisches Anlagenkonzept Dreiflügelige Modelle mit horizontaler Achse, Aufwindorientierung, Stallregulation und Asynchrongenerator haben sich seit 1981/82 auf dem dänischen Markt bewährt und durchgesetzt. Seit 1985/86 ist ihre Überlegenheit gegenüber US-amerikanischen Konzepten evident geworden. Die gesamte Erfolgsgruppe hat sich frühzeitig für eine Bauweise nach dänischem Vorbild entschieden. Enercon und Tacke sind innerhalb der Gruppe wirtschaftlich und technisch erfolgreicher als HSW. Dieses hatte vermutlich komplexe Ursachen, die hier nicht im einzelnen diskutiert werden können. Ein bemerkenswerter Unterschied ist die größere Nähe Enercons und Tackes zur dänischen Windindustrie und dem Folkecenter. ${ }^{320}$

Wissenschaftlich-technisches Know-how 1986, als in der Bundesrepublik ein Markt für WEA entsteht, hat die internationale Anlagentechnik ein Niveau erreicht, dass die Mitarbeit von Ingenieuren unentbehrlich machte. Anders als in Periode 1, beim Markteinstieg Dänemarks, ist die Abwesenheit spezifischen Know-hows hierzulande kaum problematisch. Die Entwicklung ist von Anfang an stärker durch den Einsatz von Ingenieuren der Elektronikund Maschinenbausparte beherrscht, als durch den handwerklichen Sektor.

Zugang zu Fördermitteln Eine weitere Voraussetzung besteht in staatlicher Förderung, die 1986 einsetzt. Von ihr profitierten nur Hersteller, die sich bis dahin auf dem Sektor halten konnten, oder später gegründet wurden.

Tab. 2.4.3c Charakteristika deutscher Windanlagenhersteller

\begin{tabular}{|c|c|c|c|c|c|c|}
\hline Unternehmen & \begin{tabular}{l}
\multicolumn{2}{l}{ Lebensspanne, } \\
bzw. als \\
Hersteller \\
aktiv
\end{tabular} & \begin{tabular}{|l} 
zum \\
Mittelstand \\
gehörig?
\end{tabular} & $\begin{array}{l}\text { Technologie } \\
\text { aus } \\
\text { Dänemark? }\end{array}$ & \begin{tabular}{|l|} 
technisch- \\
wissenschaftliches \\
Know-how \\
vorhanden?
\end{tabular} & $\begin{array}{l}\text { 1986 und später } \\
\text { aktiv (Zugang } \\
\text { zu } \\
\text { Fördermitteln)? }\end{array}$ & $\begin{array}{l}\text { Kommerzielle } \\
\text { und } \\
\text { technische } \\
\text { Erfolge über } \\
1992 \text { hinaus? }\end{array}$ \\
\hline MAN & bis ca. 1990 & nein & nein & ja & ja & nein \\
\hline Dornier & bis ca. 1990 & nein & nein & ja & ja & nein \\
\hline MBB & bis ca. 1993 & nein & nein & ja & ja & nein \\
\hline NOAH & ca. $1978-1985$ & nein & nein & ja & nein & nein \\
\hline Brümmer & ca. $1965-85$ & nein & nein & ja & nein & nein \\
\hline H.-D. Goslich & 70/ 80er Jahre & nein & nein & ja & nein & nein \\
\hline Aerodyn & 1983-1988 & nein & nein & ja & ja & nein \\
\hline Windkraftzentrale & $1981-1988$ & nein & $(\mathrm{ja})^{321}$ & ja & ja & nein \\
\hline Südwind & $1982-1994$ & nein & ja & ja & ja & nein \\
\hline $\begin{array}{l}\text { Husumer } \\
\text { Schiffswerft }\end{array}$ & 1985-1999 & ja & ja & ja & ja & ja \\
\hline Enercon & $1985-$ & ja & $\begin{array}{l}\mathrm{ja}, \quad \text { enge } \\
\text { Kooperation } \\
\text { mit dänischer } \\
\text { Windindustrie } \\
\end{array}$ & ja & ja & ja \\
\hline Tacke & 1984-1997 & ja & $\begin{array}{ll}\text { ja, } & \text { vg. } \\
\text { Enercon } & \end{array}$ & ja & ja & ja \\
\hline
\end{tabular}

Quellen: vg. Kap. 2.4

Dänische Industrie auf dem deutschen Markt

Anders als beim 100MW-Programm sind in den Förderprogrammen der Länder keine Klauseln enthalten, die ausländischen Herstellern den Markteintritt erschwert hätten. Der Kauf erprobter

\footnotetext{
${ }^{319}$ Die HSW hätte möglicherweise ihren Niedergang verhindern können, wenn sie sich während der 90er Jahre vollständig auf den dynamischen Windenergiesektor umgestellt hätte (Oelker et al. 2005, 122).

${ }^{320}$,If you look at first successful german manufacturers: Wobben from Enercon, Tacke also. They became successful, because they went to Denmark and bought blades and other components from the independent danish manufacturers.' (Maegaard, Interview vom 2. Juli 2007)

${ }^{321}$ Zwar stammt das Konzept der Windrose aus Dänemark von S.J. Windpower. Jedoch entspricht die Windrose nicht dem eigentlichen dänischen Anlagenkonzept und ist nur mäßig erfolgreich.
} 
dänischer oder niederländischer Windanlagen wird gleichberechtigt gefördert. Aufgrund ihres technologischen Vorsprungs gegenüber den Inländern erreichten sie schnell eine marktführende Stellung auf den norddeutschen Märkten. Lagerwey (NL) und Vestas (DK) dominierten den niedersächsischen bzw. schleswig-holsteinischen Markt. Beide Unternehmen werden von diesen Bundesländern stärker unterstützt als sämtliche inländischen Hersteller (WPM 7/89, 12). Dadurch sind industrie- und arbeitsmarktpolitische Ziele der Programme in Gefahr geraten. Im 100MW-Programm ist diese Schwäche der Länderförderungen behoben worden. Eine Reihe dänischer Hersteller umging die eigens für sie geschaffene Barriere, indem sie in Deutschland eigene GmbHs gründeten, die ihre Modelle unter Lizenz verkauften. Gegen Ende der 80er Jahre entschieden sich die meisten großen Hersteller aus Dänemark für diesen Schritt.

\section{Vestas Deutschland GmbH als Pionier}

Der Vertrieb der Vestas-Anlagen in der Bundesrepublik startete offiziell im Juli 1986 mit der Gründung der Vestas Deutschland GmbH, als 1-Personen-Unternehmen, Jahre vor Einführung des 100MW-Programms. Leiter der GmbH, Klaus Burmeister, stand bereits seit 1984 mit der Vertriebsleitung von Vestas in Kontakt und organisierte den Verkauf einzelner Turbinen nach Deutschland. Im Oktober 1986 gelang es Burmeister, für die V17 (75kW, 17 Meter Rotordurchmesser) eine Typengenehmigung zu erlangen. Damit ist die V17 die erste von ausländischen Herstellern produzierte Windturbine, die in ganz Deutschland verkauft werden durfte. Zuvor sind nur Einzelgenehmigungen ausgesprochen worden. Anfangs war die Nachfrage zögerlich. Öffentliche Kunden wie Stadtwerke und Klärwerke entschieden sich i.a. für inländische Fabrikate, obwohl diese weniger erprobt waren. Mit Einführung des SEG nahm der Absatz von Vestas-Produkten der deutschen Zweigstelle stark zu. Im Mai 1991 errichtete Vestas eine eigene Produktion in Deutschland (Oelker et al. 2005, 156f.).

Vestas Deutschland $\mathrm{GmbH}$ hatte gegenüber den übrigen dänischen Unternehmen, die auf dem deutschen Markt erfolgreich waren, eine Vorreiterposition inne. Sie alle gründen zwischen 1988 und 1991 Zweigstellen in Deutschland, oder einigten sich mit bereits existierenden Unternehmen zum Vertrieb ihrer Modell. Wichtig ist der aktive Beitrag deutscher Windenergiepioniere zur Entstehung dieses Branchensektors.

Tab. 2.4.3d

Diffusion dänischer Anlagentechnik in die Bundesrepublik

\begin{tabular}{|c|c|c|c|c|}
\hline Unternehmen & $\begin{array}{l}\text { Zweigstelle } \\
\text { in Deutschland }\end{array}$ & Gründungsjahr & \begin{tabular}{|l|} 
Position \\
deutschem Mark \\
1982-1995 (\%-Anteil \\
an inst. Kapazität) \\
\end{tabular} & Gründungskontext \\
\hline Vestas & $\begin{array}{l}\text { Vestas } \\
\text { Deutschland GmbH }\end{array}$ & Juli 1986 & $3(14,0)$ & $\begin{array}{l}\text { 1-Personen-Unternehmen; Büro } \\
\text { in Container; Gründer organisiert seit } \\
1984 \text { Vertrieb für Vestas in BRD }\end{array}$ \\
\hline Bonus & $\begin{array}{l}\text { AN Maschinenbau un } \\
\text { Umweltschutzanlagen }\end{array}$ & Juni 1988 & $5(8,4)$ & $\begin{array}{l}\text { AN ist mittelständisches Unternehmen, } \\
\text { das mit Bonus Partnerschaft eingeht }\end{array}$ \\
\hline Nordtank & $\begin{array}{l}\text { Nordtank } \\
\text { Windkraftanlagen } \\
\text { GmbH }\end{array}$ & April 1989 & $6(5,9)$ & $\begin{array}{l}\text { 1-Peronen-Unternehmen; Keller- } \\
\text { Büro im Wohnhaus; Gründung der } \\
\text { GmbH unter Vermittlung } \\
\text { einer Windkraft-Journalistin }\end{array}$ \\
\hline Micon & Ingenieurbüro Fries & $\begin{array}{l}\text { Frühsommer } \\
1989\end{array}$ & $4(10,3)$ & $\begin{array}{l}\text { 1-Personen-Unternehmen; } \\
\text { Kooperation zwischen Fries und } \\
\text { Micon per Handschlag }\end{array}$ \\
\hline Nordex & $\begin{array}{l}\text { Nordex } \\
\text { Energieanlagen } \mathrm{GmbH}\end{array}$ & Anfang 1991 & $7(3,5)$ & $\begin{array}{l}\text { Zwei IWB-Aktivisten übernahmer } \\
\text { Vertrieb }\end{array}$ \\
\hline
\end{tabular}

Quelle: Oelker 2005, 156-165

Während der Pionierphase ist die Windindustrie aus Dänemark auch den erfolgreichsten deutschen Herstellern Tacke und Enercon technisch um einige Jahre voraus. Die Etablierung 
dänischer Windtechnik kam damit einem Quantensprung auf dem deutschen Markt gleich. Insofern als Tacke, Enercon und HSW ebenfalls das dänische Anlagenkonzept verwendeten, trug die inländische Industrie selbst zur Realisierung dieses technologischen Schubs bei. Das gleiche gilt für die kleinen Vertriebsunternehmen, von denen ein direkter Import dänischer WEA organisiert wurde.

\section{Interessenvertretung der Windindustrie}

1985 gründete sich die Forschungsgesellschaft Windenergie (FGW). Die Gründung erfolgte im Umfeld jener Wissenschaftler und Ingenieure, die im Forschungsprogramm des BMFT Erfahrungen mit dem Windanlagenbau gesammelt haben. Die FGW bildete eine Plattform, durch welche die Akteure mit politischen Entscheidungsträgern zusammengeführt wurden, um über die Förderung kommerzieller Windkraft zu diskutieren. Bereits 1984 konstituierte sich die Deutsche Gesellschaft für Windenergie (DGW). Deren Mitglieder hatten die Growian-Politik des BMFT massiv kritisiert. Seitens des BMFT herrschten daher Vorbehalte gegenüber der DGW. FGW, der etabliertere Windenergieverband war aus diesem Grunde eher in der Lage, zwischen BMFT und Windindustrie eine Vermittlerrolle einzunehmen, und eine solche kam der FGW auch tatsächlich zu. Denn auf Initiative dieses Verbands geht der Entschluss des Ministeriums zurück, im Rahmen des Forschungsprogramms, auch einen Windpark mit kleinen Windturbinen zu testen, den Windenergiepark Westküste (ebd., 60).

Die Arbeit der Journalistin Luise Junge war in verschiedener Hinsicht von herausragender Bedeutung. Sie war federführende Redakteurin des Windkraft-Journals (Verbandszeitschrift des DGW). Ihr wichtigstes Anliegen bestand darin, dass die Bundesrepublik dem dänischen Windkraft-Vorbild folgen sollte. Sie ,bildete als Autorin und aufmerksame Chronistin damals nicht nur das Sprachrohr für alle Windinteressierten, sondern fungierte auch als Vermittlerin, Schlichterin und Ideengeberin für die gesamte Windszene' (ebd., 158).

Junge organisierte Busreisen nach Dänemark zu denen sie Landespolitiker Schleswig-Holsteins einlud, um sie mit dänischen Windkraftakteuren in Kontakt zu bringen. ${ }^{322}$ Die Einrichtung der ,Husumer Windenergietage' ist zu großen Teilen auf ihre Initiative zurückgegangen. Junge hatte den damaligen Husumer Bürgermeister Kneer vom Nutzen der Windenergiemesse überzeugt (ebd., 159). Die von der DWG organisierte Messe hat sich heute zur weltweit größten Messe für Windkraft entwickelt.

Aufgrund der positiven Wirkung auf regionale Industrie und Beschäftigung, nimmt die Windenergiebrache indirekt Einfluss auf Kommunal- und Landespolitiker. Akteure wie Enercon-Chef Wobben waren darum bemüht, unmittelbar Einfluss auf die niedersächsische Landesregierung zu gewinnen. ,Sein Engagement führte zum Erfolg. Niedersachsen legte 1987 als erstes Bundesland ein Förderprogramm auf Landesebene auf, dass den Betreibern von Windkraftanlagen einen Investitionskostenzuschuss gewährte.' (ebd., 131).

Auch Turbinenhersteller Franz Tacke war aktiv geworden. Er hatte frühzeitig erkannt, dass die Stromkonzerne sich nicht mit dem SEG zufrieden geben würden. Um das Gesetz, das für den Aufschwung der Windkraft eine so wichtige Rolle gespielt hatte zu verteidigen, hielt er den Aufbau einer gemeinsamen Interessenvertretung der Branche für notwendig. Auf Initiative Tackes wurde 1993 innerhalb des Verbands deutscher Maschinen- und Anlagenbau e.V. (VDMA) eine Branchenvertretung, bestehend aus zehn Windanlagenherstellern gebildet. Gegenüber der Bundesregierung leistete der VDMA, als Vertretung mittelständischer Industrie,

\footnotetext{
${ }^{322}$ Durch ihre Einflussnahme trug sie zur Beschleunigung des Markteintritts von Nordtank bei. Sie vermittelte den ersten deutschen Betreiber einer Nordtank-Maschine an einen der Windkraft wohlgesonnenen Prüfingenieur. Die Journalistin hielt den unternehmerisch versierten und ökologisch engagierten Landwirt Preißler dazu geeignet, als Partner eines dänischen Windanlagenherstellers aktiv zu werden. Unter ihrer Vermittlung ist tatsächlich eine funktionierende Kooperation zwischen Preißler und Nordtank entstanden (ebd., 159).
} 
wichtige Lobbyarbeit. Diese Einflussnahme trug u.a. dazu bei, dass die Diskussion um die Abschaffung des SEG 1997 beendet wurde (ebd., 127).

\section{Ergebnisse}

In der ersten Hälfte der 80er Jahre sind in Deutschland zahlreiche Firmen unterschiedlicher Größe mit der Herstellung von Windanlagen beschäftigt: Selbstbauer, Kleinstunternehmen, mittelständische Firmen und einige Großkonzerne. Erfolgreich in der Anlagenherstellung sind weder kleine, noch große Unternehmen. Ersteren fehlte es an Liquidität, um Serienfertigungen aufzubauen und größere Modelle herzustellen. Die Großkonzerne verloren das Interesse an der Windkraft, als das Scheitern des LSP offenkundig geworden war. Erfolgreich sind mittelständische Firmen. Einerseits verfügten sie über die erforderlichen finanziellen Mittel. Andererseits bewegten sich die Investitionen in einem Umfang, der sich in ähnlichen Dimensionen wie die übrigen Geschäftsfelder der Unternehmens bewegten. Sowohl Tacke und Enercon als auch HSW setzten auf das erprobte dänische Anlagenkonzept. Damit verschafften sie sich gegenüber der Konkurrenz weitere Tempovorteile. Obgleich der Erfolg des dänischen Konzepts spätestens 1982/83 von deutschen Windpionieren hätte übernommen werden können, hielten viele Hersteller noch lange Zeit an eigenen Designs fest. Die Abwesenheit wissenschaftlich-technischen Knowhows hat in Deutschland von Anfang an weniger eine Barriere der Entwicklung dargestellt als in Dänemark. Eine notwendige Bedingung des Erfolgs der inländischen Anlagenindustrie war die Einführung von Industrie- und Marktförderprogrammen, wie sie seit 1987/88 auf Bundesebene und in einigen Ländern üblich geworden war.

Weil dänische Fabrikate besser erprobt waren als Windanlagen deutscher Hersteller, wurden erstere insbesondere von zahlreichen privaten Käufern bevorzugt. Die Tatsache rascher Verfügbarkeit dänischer Windturbinen war keine Selbstverständlichkeit. Der Aufbau dazu erforderlicher Vertriebsstrukturen war in diesem Tempo nur möglich, weil er von einigen deutschen Pionieren und Windenergiefürsprechern gezielt forciert worden ist.

\subsubsection{Bundesrepublik Deutschland:}

\section{Windanlagenkäufer und -betreiber in Periode 4}

Nach dem Atomunfall vom April 1986 in Tschernobyl erwachte die zwischenzeitlich eingeschlafene Anti-AKW-Bewegung zu neuem Leben. Viele ihrer Mitglieder entdeckten in der Windkraft ein neues Aktivitätsfeld. Sie wollten nicht länger nur protestieren, sondern die Realisierbarkeit von Alternativen beweisen. Ähnlich wie in Dänemark organisierten sie sich in Betreibergemeinschaften, den Bürgerwindgesellschaften. Letztere entwickelten sich innerhalb der Pionierphase zu einer festen Komponente des deutschen Windenergiemarktes. Der erste Nachfrageschub kam allerdings nicht von den Bürgerwindgesellschaften, sondern von kommunalen und regionalen EVU. Seitdem sie mit Einführung des SEG vom Sektor gedrängt wurden und der Markt nun von unabhängigen Akteure übernommen wurde, sind die Versorger zu erbitterten Gegnern der Windkraft geworden. Zu den wichtigen Käufer- und Betreibergruppen zählten auch Landwirte und Hersteller, die ihre Produkte testen wollten. Trotz des Widerstands der EVU: Am Ende der Pionierphase ist die Energieeinspeisung durch Windmüller, in die Netze der Stromkonzerne, beinahe etwas Normales geworden.

Einige Jahre zuvor stellte sich die Situation gänzlich anders dar. In der ersten Hälfte der 80er Jahre hatten Windmüller kaum eine Chance, sich auf dem Markt zu etablieren. Zunächst war es alles andere als unkompliziert, bei den zuständigen Behörden überhaupt eine Bau- und Betriebsgenehmigung zu erhalten. Das zweite große Problem bestand darin, mit den EVU 
über Anschlusskosten und Einspeisebedingungen des überschüssigen Stroms zu verhandeln, sofern eine Einspeisung stattfinden sollte. Um sich Kosten und Mühe $\mathrm{zu}$ ersparen, verzichteten die meisten darauf, ihre Turbine ans Netz zu schließen. Von den ca. 500 WEA, die 1986 betrieben wurden, sind nur 32 an ein Stromnetz geschlossen worden (Heymann 1999, 126).

\section{Pioniere vor 1986}

Die Beispiele einiger Windmüller geben Aufschluss über die schwierige Situation mit der sie in den 80er Jahren konfrontiert waren. Zu dieser Zeit erhielten sie weder staatliche Förderung, noch existierten irgendwelche Regelungen zur Stromeinspeisung.

Ende 1982 erwarb der nordfriesische Landwirt Hansen eine Vestas 55kW-Turbine für 95.000 DM. Zunächst musste Hansen die Windanlage ein Jahr in der Scheune lagern, weil noch keine Baugenehmigung vorlag. Die Einzeltypenprüfung kostete den Pionier 30.000, Fundament und Bodengutachten 26.500 DM. Für den Netzanschluss verlangte Regionalversorger Schleswag zusätzlich 8.000 DM (Oelker et al. 2005, 248f.). Bevor die Turbine im Oktober 1983 auf dem Hof des Landwirts in Betrieb genommen werden konnte, waren Hansen Gesamtkosten von etwa 160.000 Mark entstanden (ebd.). ${ }^{323}$

An der Langwierigkeit der Genehmigungsverfahren hatte sich in Schleswig-Holstein auch Jahre später nicht viel geändert, wie Claus Engelbrechtsen erfahren musste. Bevor der Busfahrer und Landwirt seine im Jahr 1985 gekaufte Nordtank-Anlage installieren durfte, vergingen etwa anderthalb Jahre. Ohne die Unterstützung der Journalistin Luise Junge (s.o.) und einer enormen Beharrlichkeit in der Auseinandersetzung mit den Behörden, wäre eine Inbetriebnahme der Windmühle im Januar 1987 kaum denkbar gewesen. Noch immer gab es keine vereinheitlichte Typenprüfung. Betreiber mussten sich daher Genehmigungen für Fundamente, Turm und Rotoren einzeln ausstellen lassen (ebd., 251).

Anfang der 80er Jahre erwarb der Lehrer Dietrich Koch aus Mettingen bei Osnabrück eine der ersten Windmühlen des Niederländers Henk Lagerwey. Seine Baugenehmigung erhielt Koch, indem er gegenüber den Behörden vorgab, einen Schutzbunker errichten und diesen per Windanlage mit Energie versorgen $\mathrm{zu}$ wollen. ${ }^{324}$ Zollämter und Regierungspräsidium in Münster taten alles, um den Aufbau der Mühle zu verhindern, oder hinauszuzögern. Die Tatsache, dass der Aufbau wie geplant am 16. September 1982 stattfinden konnte, verdankte Koch einem Redakteur des westdeutschen Regionalfernsehens, der die Vorgänge um die Lieferung und die Installation begleitet hatte (ebd., 221). ${ }^{325}$ Netzbetreiber RWE war nicht daran gelegen, dass Koch anderen als Vorbild diente. Daher erhielt Koch von RWE nicht mehr als zwei Pfennig je eingespeiste Kilowattstunde Nachtstrom, wobei er selbst 28 Pfennig an den Versorger zahlen musste (ebd.).

Nachdem Koch 1982 seine Turbine in Betrieb genommen hatte, wurden in den nächsten fünf Jahren nicht mehr als zwei weitere Windanlagen in NRW genehmigt. Nordrhein-Westfalen gehörte zu denjenigen Ländern, deren Behörden sich gegenüber Genehmigungsanträgen für

\footnotetext{
${ }^{323}$ Vom Erfolg Hansens ließ sich einer seiner Nachbarn, der Landwirt Ehlers, inspirieren und erwarb 1985 ebenfalls eine Windturbine. Dabei fand Ehlers bereits günstigere Bedingungen vor. Denn er entschied sich für die Teilnahme am BMFT-Projekt zum ,Einsatz kleiner Windkonverter', in dessen Rahmen bundesweit MANTurbinen (Aeroman) getestet und mit 50\% der Kosten gefördert wurden (ebd., 249).

${ }^{324}$ Angesichts des nuklearen Wettrüstens zwischen den Großmächten, wuchs in Deutschland zu Beginn der 80er Jahre die Angst vor einem Atomkrieg. Da nicht genügend Bunker vorhanden waren, beschloss die Bundesregierung, den Bau privater Schutzbunker grundsätzlich zu genehmigen. Koch erhielt Baugenehmigungen für Bunker und Mühle. Wie Koch bekannt war, konnte in dem felsigen Untergrund jedoch kein Bunker gebaut werden, was die Behörden akzeptieren mussten (ebd., 220f.).

${ }^{325}$ Koch betrieb intensive Öffentlichkeitsarbeit und erlangte nach kurzer Zeit einen beachtlichen Bekanntheitsgrad. ,Am Anfang kamen hier ganze Busse mit interessierten Menschen von nah und fern an. Ich war bekannt wie ein bunter Hund.' (Dieter Koch, zitiert nach: Oelker et al. 2005, 221).
} 
Windmühlen besonders restriktiv verhielten. Voraussetzung war, das WEA eindeutig landwirtschaftlichen Betrieben zugeordnet werden konnten. In einigen westfälischen Landkreisen mussten die Windmühlen zugleich einen Abstand von mindestens 200 Meter vom Hof haben - und konnten damit nicht mehr eindeutig zugeordnet werden. Diese Blockadehaltung führt Koch (zitiert nach: Oelker et al. 2005, 223) auf die Monopolmacht des Netzbetreibers RWE und eine teilweise korrupte Administration zurück: ,Unsere Generaldirektoren rechneten damit, irgendwann einen lukrativen Job im Aufsichtsrat oder einem der Beiräte der RWE zu bekommen.'

Ob nun ,gekauft' oder nicht: Windmüller fanden nicht nur in Nordrhein-Westfalen, sondern in der gesamten Bundesrepublik so restriktive Startbedingungen vor, dass sie aus eigener Kraft außer Stande gewesen wären, einen Diffusionsvorgang der Windtechnologie, über den Kreis einiger Idealisten hinaus, in Gang zu setzen. Dieses änderte sich erst seit 1986 bis 1988 allmählich, mit dem Einsetzen der Förderung auf Bund- und Länderebene - und zwar vor allem in Niedersachsen und Schleswig-Holstein. ${ }^{326}$ Auch in Nordrhein-Westfalen verbesserte sich die Situation mit dem ,Zörpel-Erlass' (benannt nach Bauminister Zörpel) vom 13. März 1989. Darin wird die Privilegierung aller Windanlagen im Land klar geregelt. Seitdem erhielt die Nachfrage nach Windmühlen bis $80 \mathrm{~kW}$ Nennleistung einen deutlichen Schub. Dieses Datum markiert den politischen Durchbruch der Windkraft in NRW. (Oelker et al. 2005, 224). Allmählich breitete sich die neue Technologie auf immer mehr Bundesländer aus. Bis Ende 1995 sind in jedem der 16 Bundesländer WEA installiert (Fleckenstein 1996, 30). ${ }^{327}$

Diffusion und Transformation der Anlagenkäufer

Windenergiebegeisterte Idealisten blieben auch weiterhin auf dem Markt aktiv. ${ }^{328}$ Neben sie treten jetzt zahlreiche Landwirte, die angesichts wenig optimistischer Zukunftsperspektiven, auf der Suche nach alternativen Verdienstmöglichkeiten waren, bzw. ihrer Existenzgrundlage ein zweites Standbein verschaffen wollten.

Ein beachtlicher Anteil der in den Jahren 1987 bis 1990 installierten Windturbinen werden nicht als Einzelanlage, sondern im Verbund mit mehreren WEA errichtet (Tab. 2.4.3e). Betrieben werden die Windparks insbesondere durch regionale EVU, Stadtwerke und vereinzelt Investoren. Hervorzuheben sind insbesondere die Versorger EWE und Schleswag, sowie die Stadtwerke Norden. Den mit 35 WEA und 8,75 MW Kapazität bis 1990 größten Windpark Deutschlands realisierte eine Fondsgesellschaft.

\footnotetext{
${ }^{326}$ Die Tatsache, dass in Schleswig-Holstein bereits seit 1984 ,Richtlinien für die Auslegung, Aufstellung und das Betreiben von Windenergieanlagen' existierten (Tacke 2004, 170), hatte offenbar keinen durchschlagenden Einfluss auf die Installationszahlen. Wichtiger waren Förderprogramme und die Neuausrichtung des politischen Diskurses.

${ }^{327}$ Dabei lässt sich sagen, dass das Interesse der Windkraft nach Osten (vg. dazu: Oelker et al. 2005, 274ff.) und nach Süden hin abnimmt. Im Osten fehlte das Kapital, im Süden das Interesse (vg. WPM 3/91 und 4/92). Beide verfügen über geringere Windressourcen. Noch heute befinden sich mehr als $80 \%$ der installierten Kapazität in den Bundesländern Niedersachsen, Schleswig-Holstein, Nordrhein-Westfalen und Mecklenburg-Vorpommern.

${ }^{328} \mathrm{Zu}$ diesen zählte Volker König, der im Sommer 1989 eine 50kW Maschine von Krogmann auf seinem Grundstück installierte. Der monetäre Aspekt stand bei Königs Planungen nicht im Vordergrund. Bald musste er erkennen, dass sich das Projekt nicht rechnen würde. Für den Windmüller war es ein glücklicher Zufall, dass exakt zu diesem Zeitpunkt das 100MW-Programm startete. Königs Windmühle war die erste, die in diesem Rahmen eine Förderung, in Höhe von 90.000 DM, erhielt (Oelker et al. 2005, 164).
} 
Tab. 2.4.3e EVU und Stadtwerke als Windparkbetreiber 1987-1990

\begin{tabular}{|l|l|l|l|l|}
\hline Jahr & Windpark & Betreiber & Kapazität (MW) & Hersteller \\
\hline 1987 & Windpark Westküste/ Kaiser- & $\begin{array}{l}\text { Schleswag } \\
\text { Wilhelm-Koog/ SH } \\
\text { mbH (30\%); HEW (20\%) }\end{array}$ & $\begin{array}{l}\text { MAN, } \\
\text { u.a. }\end{array}$ \\
\hline 1988 & Windpark Norden & Stadtwerke Norden & 1,00 & Enercon \\
\hline 1988 & Windpark Cappel-Neufeld & ÜNH & 0,28 & Enercon, MBB \\
\hline 1988 & Windpark Pilsum & EWE & 0,88 & Enercon \\
\hline 1988 & Windpark Bredsted & EVU Bredsted & 0,30 & HSW \\
\hline 1989 & Windpark Krummhörn & EWE & 0,75 & Enercon \\
\hline 1989 & Windpark Cappel-Neufeld/NDS & ÜNH & 3,00 & Enercon, Dornier \\
\hline 1989 & Jade Windpark & EVU/ Bund/ Nds. & 0,45 & MBB \\
\hline 1989 & Vogelsberg/ Hessen & OVAG (50\%)/ Land Hessen (50\%) & 1,92 & verschiedende \\
\hline 1990 & $\begin{array}{l}\text { Windpark Friedrich-Wilhelm- } \\
\text { Lübke-Koog/SH }\end{array}$ & Fondsgesellschaft & 8,75 & HSW \\
\hline 1990 & Helgoland & MAN & 1,20 & MAN \\
\hline 1990 & Windpark Langen-Wremen & $\begin{array}{l}\text { Bremer Stadtwerke (49\%)/ Heinz } \\
\text { Bollwig (51\%) }\end{array}$ & 3,75 & $\begin{array}{l}\text { Enercon, } \\
\text { Bonus }\end{array}$ \\
\hline
\end{tabular}

Quelle: Oelker 2005; WPM 1/89; 9/89; 1/91

\section{EVU und Stadtwerke als Käufer von Windanlagen}

In der grundsätzlichen Ablehnung netzfremder Einspeiser sind sich die EVU weitgehend einig. Davon abgesehen, stößt man immer wieder auf Gründe, weshalb manche Stromversorger den Aufbau eigener Windparks als sinnvoll erachteten, bspw. Imageverbesserung und das Ziel, Marktverluste durch Besetzung von Windpark-Standorten zu reduzieren. Für die meisten kleinen und mittleren EVU und Stadtwerke ${ }^{329}$ Norddeutschlands allerdings war der neue Energieträger aus ökonomischen Gründen uninteressant. Oder es mangelte ihnen schlicht an der erforderlichen Offenheit, neue Ideen und Konzepte auszuprobieren. Für die kleine Gruppe der bis 1990 auf dem Sektor aktiv gewordenen Versorger existierte, neben den genannten Gründen, möglicherweise auch eine langfristige Planung. Angesichts fortschreitender Effizienzsteigerung erschien die Windkraft zunehmend als wirksames Mittel gegen die Abhängigkeit von monopolistisch agierenden Energiekonzernen und die Gefahr steigender Energiepreise. Bei geeigneten politischen Rahmenbedingungen, wie sie durch Einführung des 100/250MW-Programm geschaffen wurden, war der Aufbau von Windparks eine sich potenziell lohnende Investition. Darüber hinaus hatten Stadtwerke und Versorger selbstredend weniger Schwierigkeiten eine Baugenehmigung zu erhalten als die Windmüller. Denn beim Bau neuer Kraftwerke werden EVU privilegiert behandelt (Oelker et al. 2005, 300).

Suck $(2004,23)$ verweist auf existierende Monopolisierungstendenzen der Verbundebene. Trotz der EU-Direktive zur Liberalisierung des Strommarktes haben sich diese Tendenzen im Verlauf der 90er Jahre weiter verfestigt. Nichtsdestotrotz besteht während der Untersuchungsperiode ein hoher Grad an Autonomie der städtischen und regionalen Versorger, gegenüber den Betreibern der Übertragungsnetze und großer Kraftwerke. Damalige Windparks mit Kapazitäten unter 20MW waren vom Versorgungsaspekt her, ausschließlich für dezentral agierende EVU interessant.

Insbesondere für große und mittlere Versorger ist der Aspekt der Forschung zentral, um in kleinere Windanlagen $\mathrm{zu}$ investieren. Preußen Elektra (heute Eon), einziger auf dem Windsektor agierender Energiekonzern, kündigte Ende 1986 an, 500 Mio. DM für den Aufbau von Windturbinen der Größe 100-1000kW bereitzustellen. Preußen Elektra ging es darum, herauszufinden, inwieweit mit der Windenergie Strom in großen Mengen zu konkurrenzfähigen Preisen produziert werden konnte (WPM 12/86, 8). ${ }^{330}$

\footnotetext{
${ }^{329}$ Für Energiekonzerne wie RWE, die üblicherweise Kraftwerke mit mehreren hundert Megawatt betreiben, war der Betrieb kleiner Windanlagen keine Option. Darüber hinaus betreibt RWE hauptsächlich Kohle- und Atomkraftwerke. Aufgrund hoher Regulierungskosten sind diese Kraftwerke schwer mit Windanlagen kombinierbar.
} 
Der Windpark Westküste (s.o.) ist nicht nur ein Meilenstein für die Marktentwicklung, sondern war ursprünglich als Forschungsprojekt konzipiert. Regionalversorger Schleswag investierte 2,5 Mio. DM für die Installation des Windparks Westküste und wurde damit zu 50\% Eigentümer der Anlage (WPM 9/88, 15). Hintergrund der Beteiligung Schleswags waren Forschungszwecke. Entsprechend äußert sich Gert Nimz von Schleswag, der die Windpark Westküste GmbH leitete: ,Wir kümmern uns um alles, was mit Stromerzeugung und -verteilung zu tun hat' (zitiert nach: Oelker et al. 2005, 60). Nimz spricht von einer ,Mitverantwortung' der Energiewirtschaft für die Windtechnologie. Im Zentrum dieser Untersuchungen stand die Frage der Netzverträglichkeit von WEA. Aus den Ergebnissen wurde später eine Netzrückwirkungs-Richtlinie erarbeitet, nach der Netzbeeinflussungen von WEA bewertet und zertifiziert wurden (ebd., 60f.).

Auch die hessische OVAG legte Wert auf die Erforschung der neuen Technologie. Gemeinsam mit dem Land Hessen gründete die OVAG die Windenergiepark Vogelsberg GmbH. Diese realisierte den Aufbau von neun unterschiedlichen Windanlagen, die auf dem Vogelsberg getestet wurden. Die Investitionssumme von sechs Millionen DM trugen OVAG und das Land Hessen jeweils zur Hälfte. Das Hauptziel bestand darin, neue Erkenntnisse über das Verhalten von WEA in hügeligem Gelände, sowie das Quantum nutzbarer Windressourcen der Region zu gewinnen (WPM 9/89, 24).

Hersteller Enercon profitierte davon, dass sich einige EVU hauptsächlich für seine Modelle entschieden. Dieses galt für die ÜNH, Stadtwerke Norden und insbesondere EWE (Oldenburg) (vg. Tab. 2.4.3e). ${ }^{331}$ Die geografische Nähe des Windkraft-interessierten Versorgers zu Enercon, war für den Hersteller aus Aurich ein glücklicher Zufall. Ähnlich wie dänische und niederländische EVU, war auch EWE daran interessiert, möglichst große Windturbinen zu erwerben. In den Anfangsphase Enercons bildete die Nachfrage von EWE eine wichtige Triebkraft zur Entwicklung größerer Modelle. Eine 300kW-Maschine (E-32) war genau an den Ansprüchen der EWE orientiert. 1989 erteilte der Versorger Enercon den Auftrag zur Lieferung von zehn Exemplaren der neuen Größenklasse. Auch für die Entwicklung der 500kW-Turbine kooperierte EWE mit dem Hersteller. Im März 1992 nahm der Versorger den ersten Prototyp auf einem seiner ostfriesischen Windparks in Betrieb (Oelker et al. 2005, 131f.).

Unter den Windenergieakteuren des Energiesektors sind die Stadtwerke Norden ein Sonderfall. Sie zählten 1987 zu den ersten, welche das niedersächsische Förderprogramm für Windkraft in Anspruch nahmen (ebd., 135). Insgesamt kam den Stadtwerken im Sektor keine sehr wesentliche Rolle ein. ${ }^{332}$ Ebenso wie EWE entschieden sich auch die Stadtwerke Norden für den Auricher Hersteller. Für Enercon war die Bestellung von fünf 55kW-Maschinen bis 1987 der zweitgrößte Auftrag.

Zur Erklärung des Engagements der Stadtwerke Norden reicht ein Verweis auf betriebswirtschaftliche Gründe nicht hin. Die Stadtwerke kauften Strom von EWE. Durch einen höheren Eigenanteil an der Stromproduktion ging man von einer jährlichen Ersparnis von 220 DM pro Kilowatt aus (ebd., 300). Ähnliche Situationen herrschten auch bei vielen anderen Stadtwerken, die trotz guter Ressourcen keine eigenen Windparks betreiben wollten. ${ }^{333}$

\footnotetext{
${ }^{330}$ Ausgehend von den Growian-Erfahrungen muss angenommen werden, dass der Konzern seine Investition, auch im Falle negativer Ergebnisse, keineswegs als Fehler betrachtet hätte.

${ }^{331}$ EWE produzierte selbst keinen Strom, sondern bezog seinen Bedarf von der damaligen Preußen Elektra. Letztere war zu 26\% Teilhaber der EWE (WPM 3/90, 8).

3321990 betraten die Husumer Stadtwerke den Windkraftsektor. Im Rahmen eines Forschungsprojektes nahmen sie 1992 einen Windpark mit 15 250kW-Maschinen der Husumer Schiffswerft und Tacke in Betrieb. Finanziert wird der Windpark zu 50\% von den Stadtwerken. Zuschüsse in Höhe von 35\% kamen vom BMFT, die verbleibenden 15\% vom Land Schleswig-Holstein (Oelker et al. 2005, 125; Tacke 2004, 182).

${ }^{333}$ Noch weniger als die meisten Stadtwerke, waren die Kommunen an der Windkraft interessiert. Erst im November 1994 geht im sächsischen Jöhstedt der erste Windpark der Bundesrepublik ans Netz, der mehrheitlich einer Kommune gehörte. Mit dem Projekt strebte die Kommune folgende Ziele an: Umweltschutz,

Tourismusförderung, finanzielle Vorteile für Jöhstedt. Die Turbinen wurden in einer Höhe von 800-830m über
} 
Der Unterschied besteht in der Offenheit der Stadtwerke Norden für regenerative Energien. Die Geschäftsführer reisten nach Dänemark, um dort einige Windparks in Augenschein zu nehmen. Dann warfen sie einen Blick auf die Produktionsstätte Enercons und überzeugten sich von der Zuverlässigkeit der Auricher Mühlen. Um 1990 eröffneten die Stadtwerke Norden einen weiteren Windpark mit drei Megawatt Kapazität. Der Stadt Norden kommt nicht nur für die Windkraft, sondern für erneuerbare Energien und dezentrale Versorgung insgesamt, eine Vorreiterrolle zu. 1990 sind dort 14 Blockheizkraftwerke in Betrieb. Darüber hinaus erzeugen zwei mit Holzhackschnitzeln betriebene Heizwerke eine Wärmeleistung von jeweils 4,8 Megawatt. 1990 ist Norden diejenige Stadt Deutschlands mit dem höchsten Anteil erneuerbarer Energien im Versorgungsnetz (ebd., 301).

Es bleibt festzuhalten, dass den wenigen EVU und Stadtwerken, die während der Pionierphase Investitionen in Windparks tätigten, eine große Mehrheit der Versorger gegenüberstand, welche die Windkraft mieden. Wenn man die Situation des deutschen Energiesektors mit den Niederlanden vergleicht, so wird offenkundig, dass dort vor allem zwei Probleme für Windparkplaner existierten, welche hierzulande nicht in derselben Ausprägung vorhanden waren. Erstens ist die Entwicklung der niederländischen Windtechnologie teilweise einer unzweckmäßigen Förderpolitik zum Opfer gefallen (vg. Kap. 2.4.2). Anders als dort, sind in der Bundesrepublik bereits seit 1990 zuverlässige Windanlagen der Größenklasse 200-300kW erhältlich. Zweitens war es in Deutschland, aufgrund dünner Besiedelung der Küstengebiete und effizienter Planungsverfahren, vergleichsweise einfach, einen Windparkstandort zu erhalten.

Trotz optimaler Bedingungen zum Aufbau von WEA, die seit 1987 für deutsche Versorger galten, war deren Interesse insgesamt gering. Dennoch waren diese Aktivitäten ausreichend, um der neuen Industrie einen ersten Schub $\mathrm{zu}$ verleihen. Mit Einführung des Stromeinspeisungsgesetz, dass die EVU als Windpark-Betreiber, nicht in erster Instanz vorsah, ließ das ohnehin geringe Interesse weiter nach. Nun übernahmen Privatakteure das Feld.

Private Windanlagenbetreiber

Bei den unabhängigen Akteuren sind prinzipiell drei Gruppen zu unterscheiden. Bei der ersten Gruppe handelt es sich um Einzelkäufer, hauptsächlich Landwirte. Wegen der steigenden Investitionskosten für die zunehmende Mindestgröße geförderter Modelle, verlor diese Gruppe gegen Ende der Pionierphase an Bedeutung. Die zweite Gruppe besteht aus kollektiven Anlagenkäufern, den Bürgerwindgesellschaften, entsprechend den Windradkooperativen Dänemarks. Zwischen der zweiten und dritten Gruppe existiert ein fließender Übergang. Formal handelt es sich auch bei der dritten Gruppe um Bürgerwindgesellschaften. Tatsächlich aber, besteht diese Gruppe aus zunehmend kommerziellen Projektierungsfirmen, die in erster Linie wohlhabenderen Personen Windparkbeteiligungen offerierten. Zum Erfolg der Windkraft in der Bundesrepublik leisteten die lokal agierenden und nicht auf Gewinn ausgerichteten Bürgerwindgesellschaften (Gruppe 2), den wichtigsten Beitrag. Sie stehen daher im Zentrum des Interesses und werden entsprechend ausführlicher behandelt. Die Vollendung des Übergangs von der zweiten zur dritten Gruppe fällt in die späten 90er Jahre und reicht damit weit über den Untersuchungszeitraum hinaus. Unabhängig von dieser Entwicklung, stößt man auch in der Pionierphase bereits auf einige ausschließlich kommerzielle Projekte.

Finanzierung

Für die Energieversorger war die Finanzierung von WEA unproblematisch, da sie i.a. über hinreichende Kapitalreserven verfügen und ihnen darüber hinaus seitens der Banken ein hohes

NN aufgestellt. Teilweise sollte der Windpark als Forschungsanlage für den Turbinenbetrieb in hohen Mittelgebirgslagen dienen. Zu diesem Zweck wurde das Projekt von der KFA Jülich gefördert (vg. Fleckenstein 1996, 5ff.). 
$\mathrm{Ma}$ an Vertrauen entgegengebracht wird. Umgekehrt stellt sich die Situation der meisten Privatpersonen dar. Sie waren auf günstige Kreditmöglichkeiten und Vertrauensvorschüsse seitens der Banken angewiesen.

$\mathrm{Zu}$ den ersten Privatbanken, die Windprojekte unterstützten, zählt die Commerzbank Brunsbüttel. 1989 vergibt sie das erste Darlehen in Höhe von 1 Mio. DM an einen Landwirt, der zwei Adler-Turbinen auf seinem Hof errichten wollte. ${ }^{334}$ Die Bank setzte ihre Aktivitäten in der Windbranche anschließend fort. Bis Ende 1990 vergab sie Kredite von 50 Mio. DM. Insgesamt finanzierte die Bank rund 600 WEA, darunter keine einzige Pleite. Innerhalb des firmeninternen Rankings stieg die Commerzbank Brunsbüttel zwischen 1989 und 1995 von Platz 486 auf Rang 2 auf (Oelker et al. 2005, 194f.).

Anfang der 90er Jahre betrat das Bundeswirtschaftsministerium den Sektor. In dessen Auftrag gewährte die bundeseigene Deutsche Ausgleichsbank (DtA) seit 1991 langfristige Kredite mit Laufzeiten von 12-15 Jahren und festen Zinssätzen, die etwa 1-2\% unterhalb marktüblicher Angebote lagen. Die Gelder flossen aus dem ERP-Umwelt- und Energiesparprogramm sowie dem Umweltprogramm der DtA. Insgesamt standen aus beiden Quellen zwischen 1991 und 1994 etwa 1,3 Mrd. DM für Umwelt- und erneuerbare Energieprojekte zur Verfügung. Mit dem Löwenanteil der vergebenen Darlehen, knapp 1,1 Mrd. DM, wurden Windkraftprojekte finanziert (Tab. 2.4.3f).

Tab. 2.4.3f Förderung erneuerbarer Energien durch Kreditzusagen 1991-1994 (Mio. DM)

\begin{tabular}{|l|l|l|l|l|l|}
\hline $\begin{array}{l}\text { ERP-Energiespar- } \\
\text { programm }\end{array}$ & 1991 & 1992 & 1993 & 1994 & gesamt \\
\hline Wind & 56,7 & 66,2 & 213,9 & 439 & 775,8 \\
\hline Wasser & 9,9 & 17,1 & 24,3 & 40 & 91,3 \\
\hline Biomasse & 5,5 & 3,9 & 73,2 & 39,5 & 122,1 \\
\hline Sonne & 0,2 & 1,2 & 0,3 & 3,7 & 5,4 \\
\hline Sonstiges & 0,2 & 0,7 & - & 7,6 & 8,5 \\
\hline Summe & 72,5 & 89,1 & 311,7 & 529,8 & $\mathbf{1 0 0 3 , 1}$ \\
\hline & & & & & \\
\hline $\begin{array}{l}\text { DtA- } \\
\text { Umweltprogramm }\end{array}$ & 1991 & 1992 & 1993 & 1994 & gesamt \\
\hline Wind & 20,1 & 35,9 & 89,5 & 172,3 & 317,8 \\
\hline Wasser & 2,1 & 6,8 & 10,1 & 19,8 & 38,8 \\
\hline Biomasse & 6,3 & 1,2 & 7,3 & 20,3 & 35,1 \\
\hline Sonne & - & - & - & 0,8 & 0,8 \\
\hline Sonstiges & - & - & - & - & 213,2 \\
\hline Summe & 28,6 & 43,9 & 106,9 & 662 & $\mathbf{3 9 2 , 6}$ \\
\hline Gesamtsumme & 101,1 & 133 & 418,6 & $\mathbf{1 3 1 4 , 7}$ \\
\hline
\end{tabular}

Quelle: Fleckenstein 1996, 25

Über diese Kredite finanzierten die Windanlagenkäufer bis zu 75\% der Investition, den Rest durch Eigenkapital. Vor allem Bürgerwindgesellschaften favorisierten dieses Modell. Bis 1998 wurden 80-90\% der Windparks auf diese Weise realisiert (Byzio et al. 2002, 315).

Mit den Darlehen der Kreditanstalt für Wiederaufbau (KfW) stand seit 1994 eine weitere Finanzierungsoption zur Verfügung. Im Rahmen des ,Programms für Erneuerbare Energie und rationelle Energie' vergab die KfW zwischen 1994 und 1996 Darlehen in Höhe von 900 Mio. DM für den Aufbau von Regenerativkraftwerken (Fleckenstein 1996, 17). ${ }^{335}$

\footnotetext{
${ }^{334}$ Die Tatsache, dass sich gerade diese Bank so frühzeitig auf Windkraftprojekte einließ, war kein Zufall. Denn Bankdirektor Hugo Denker kam selbst aus der Landwirtschaft und zwar aus dem für die Windkraftnutzung geradezu geschichtsträchtigen Ort Kaiser-Wilhelm-Koog. Die Herkunft Denkers wird zu der Offenheit, die er dem Anliegen des Landwirts Peter Thomsen (,Ich wöll twee Windmölln buun.') entgegenbrachte, einiges beigetragen haben (Oelker et al. 2005, 194).
}

${ }^{335}$ Weitere Finanzierungsquellen des Bundes, vg. Fleckenstein 1996, 17f. In der zweiten Hälfte der 90er Jahre nimmt das Engagement der KfW stark zu. 1999 werden etwa 90\% aller deutschen Windparkprojekte durch KfWDarlehen gefördert (Bolinger 2001, 32). 
Mit der Entscheidung des Bundeswirtschaftsministeriums, Windanlagen über Kredite der DtA zu fördern, stellt das Jahr 1991 eine Zäsur dar. Zuvor war die Finanzierung von Windanlagen durch Privatleute eine komplizierte Angelegenheit, die mitunter von zufälligen Faktoren abhängig war. Mit der wachsenden Nachfrage und der zusätzlichen Stabilisierung durch das SEG, geht eine deutliche Erhöhung der Realisierungschancen für Windanlagenprojekte einher.

Einzelkäufer: Landwirte, Turbinenhersteller und Idealisten

Ein wirklich hohes Maß an Idealismus ist jenen Turbinenkäufern und Selbstbauern zu attestieren, die vor 1987/88 aktiv geworden sind, als man noch nicht auf die Investitionsförderung aus dem 100MW-Programm oder Förderung der Länder zugreifen konnte. Zwar waren finanzielle Risiken allmählich gesunken. Dennoch lässt sich für diese Zeit kaum von der Windkraft als ,ethischer Kapitaloption' sprechen. Ähnlich wie in Dänemark, seit Anfang der 80er Jahre, ermöglichte das 100/250MW-Programm zahlreichen Windmüllern eine gute Chance zur Verringerung ihrer Stromkosten.

Mit den Landwirten, die ihre Windmühle in erster Linie als eine potenziell existenzsichernde Investition ansahen, betrat nach den Energieunternehmen, ein zweiter neuer Akteur den Sektor. Anders als die EVU sind Landwirte als Windanlagenbetreiber eine Konstante innerhalb des Untersuchungszeitraums und auch einige Jahre darüber hinaus. Ein Ziel des Stromeinspeisungsgesetzes ist die Förderung technischer Innovation. Um für neue Modelle eine Nachfrage zu schaffen, wurden Untergrenzen der Nennleistung definiert. Kleinere Windmühlen erhielten keine Förderung durch das SEG. Seit 1996 etwa wurden nur noch Anlagen gefördert, die über eine Nennleistung von mindestens einem Megawatt verfügten (Fleckenstein 1996, 94). Entsprechende Investitionen gingen über die Möglichkeiten der meisten Landwirte hinaus. Viele von ihnen, die keine eigenen Mühlen installieren konnten oder wollten, waren bereit, Standorte insbesondere an Bürgerwindgesellschaften, günstig zu verpachten (,Der Standort war noch keine Ware.', Byzio et al. 2002, 299). Hintergrund dieser Kooperationsbereitschaft ist die Tatsache, dass es vielen Pionieren der Bürgerwindbewegung nicht ums Geldverdienen ging. Als der kommerzielle Aspekt seit Mitte der 90er Jahre zunehmend die Oberhand gewann, war es mit der Freigiebigkeit der Landwirte vorbei (ebd.).

Bürgerwindgesellschaften

Im Jahr 1989 wird das dänische Modell der Windradkooperative nach Deutschland importiert. Damals erwarben einige Atomkraftgegner aus Hamburg/ Wedel eine 75kW-Maschine vom Niederländer Henk Lagerwey. Die Turbine wurde in Sichtweite des Atomkraftwerks Brunsbüttel errichtet und von dieser Gruppe, die sich bereits Anfang 1987 als Verein ,Umschalten e.V.' konstituierte, gemeinsam betrieben (Oelker et al. 2005, 302). Es war ihr erklärtes Ziel, ein Signal gegen Atomenergienutzung zu setzen. Die Perspektive, sich durch Selbstversorgung von den Energiekonzernen unabhängig zu machen, genügte ihnen nicht. Vielmehr sollte die Atomkraft durch Einspeisung von Windstrom sukzessive überflüssig gemacht werden. Dieser kleine Verein, bestehend aus sieben Mitgliedern, bildete den Ausgangspunkt der Bürgerwindbewegung (Byzio et al. 2002). Schon bald folgten ähnliche Zusammenschlüsse, mit ähnlicher sozialer Konstellation (s.u.) und derselben Zielsetzung. Diese ursprünglichen Bürgerwindgesellschaften sind Basisorganisationen, für welche ökonomische Aspekte eine nachgeordnete Priorität hatten. Manche dieser Organisationen entwickelten sich im Verlauf der 90er Jahre zu gewöhnlichen kommerziellen Unternehmen. Andere, die in der zweiten Hälfte der 90er Jahre auf den Erfahrungen der Pioniere aufbauen konnten, gründeten sich zwar formal nach demselben Muster, hatten jedoch von Anfang an 
rein kommerzielle Ziele. Entscheidend ist, dass Atomkraftgegner mit politischer Motivation, durch ihre Erfindung der Bürgerwindgesellschaft, die Initialzündung der ,Erfolgsstory Windkraft' lieferten. Die Tatsache, dass die Windkooperative hierzulande etabliert werden konnte, obwohl in der Bundesrepublik keine, dem nördlichen Nachbarland vergleichbare kooperative Tradition gepflegt wird, bedarf näherer Erklärung.

Byzio et al. (2002, 272ff.) analysieren die politischen Entstehungsgründe der Bürgerwindgesellschaften. Ausgangspunkt ist der GAU von Tschernobyl im April 1986:

,Schon vorher war in der Bundesrepublik eine starke Antiatomkraftbewegung entstanden, aber es war erst die Tschernobyl-Katastrophe, die einen Teil der Aktivisten zur Überzeugung brachte, dass Demonstrationen und politischer Druck gegen die Kernkraftwerke nicht mehr ausreichten, sondern eine positive Alternative zur nuklearen Stromerzeugung gefunden und propagiert werden musste....Das besondere Profil der Protagonisten der Bürgerwindbewegung ist das Ergebnis einer doppelten Abgrenzung: einerseits von einer Gesellschaft, die sich den anonymen Großunternehmen und der von ihnen getragenen zerstörerischen Alternative von Atomenergie und Verbrennung fossiler Treibstoffe ausliefert, und andererseits von einer Protestbewegung, die demgegenüber in reiner Negation verharrt. In der Protestbewegung verkörpern sie ein neues Selbstbewusstsein: Wir sind nicht nur gegen etwas, sondern auch für etwas, und nehmen dies konkret in Angriff...Gemeinsam wollte man demonstrieren, dass die Produktion von Atomstrom nicht nur gefährlich, sondern auch überflüssig ist.'

Die Idee des gemeinschaftlichen Windmühlenbetriebs stammt aus Dänemark. Der Erfolg des kooperativen Organisationsmodell hatte dort nicht nur ökonomische und politische, sondern auch historische Gründe (s.o.). Die deutsche Anti-AKW-Bewegung ist als soziale Bewegung auf kollektives Handeln ausgerichtet. Als solche bildete sie einen Kanal, der eine Adaption des kooperativen Modells ermöglichte.

Die soziale Zusammensetzung der Gründergeneration weist eine bemerkenswerte Homogenität auf. Einer der heutigen Geschäftsführer von ,Windstrom Wedel' (damals ,Umschalten e.V.') beschreibt dieses Milieu:

,Außer ein paar besonders aktiven Pensionären waren es in der Mehrzahl Leute im mittleren Alter, so um die 40 herum..., aus ganz unterschiedlichen beruflichen Bezügen, in der Mehrheit mit Hochschulabschluss...Es waren die frustrierten Brokdorf-Demonstranten, jedenfalls hier im Hamburger Raum...Also insgesamt Leute, die zu über 90\% aus dem Spektrum der Anti-AKW-Bewegung kamen.' (zitiert nach: Byzio et al. 2002, 283).

Unter allen von Byzio et al. (2002) untersuchten Initiativen gab es keine, zu deren Gründern und späteren Geschäftsführern nicht mindestens ein Maschinenbau- oder Elektroingenieur, Naturwissenschaftler oder Mathematiker gezählt hätte (ebd. 291f.). Erforderlich sind auch kaufmännische und betriebswirtschaftliche Kenntnisse, sowie insbesondere organisatorische Fähigkeiten. ,Was gerade die Macher auszeichnet, ist eine spezifische pragmatisch-organisatorische Kompetenz...Man trifft hier auf den Typ des Mittelständlers und unternehmenden Generalisten, der sich mit Elan und entschiednem Zugriff in seine ehrenamtliche Aufgabe verbeißt und seine Gratifikation aus der hier möglichen autonomen Gestaltungsfreiheit und sozialen Anerkennung zieht. Oft waren sie schon vorher beruflich selbständig,...oder sie hatten (und haben) in mittelständischen Unternehmen eine Position inne, in denen sie einen Großteil des nun gefragten Bündels von Qualifikationen erwerben konnten' (Byzio et al. 2002, 293). ${ }^{336}$

Diese ,Techniker-Kaufmänner' (ebd., 275) trafen in den Bürgerwindgesellschaften mit dem grün-alternativen Milieu zusammen, dass von ,neuen sozialen Mittelschichten - insbesondere Sozialarbeiter und Lehrerinnen - dominiert wird' (ebd., 292). Da sich die beiden Gruppen im Habitus, Lebensstil, in der Weltanschauung und den Interessen stark unterscheiden, gehen Byzio et al. (2002, 292) davon aus, dass deren Zusammenwirken nicht immer frei von Spannungen verlaufen war.

\footnotetext{
${ }^{336}$ Folgende Aufgaben mussten bewältigt werden: Auswahl einer Windanlage mit optimalem Preis-LeistungsVerhältnis und niedriger Reparaturanfälligkeit; Wahl eines Standortes mit guten Windressourcen und günstiger Netzanbindung; Einholen und kritisches Bewerten eines Windgutachtens; Wartung und Kontrolle; zuverlässige Buchführung; Verhandlungen mit EVU, Behörden und Banken (Byzio et al. 2002, 292ff.).
} 
Zur Organisation der ersten Bürgerwindgesellschaften

Die Übernahme des dänischen Modells durch die Pioniere der Bürgerwindbewegung hatte neben den dargelegten Motiven, auch einen praktischen Hintergrund. Denn bei den Pionieren handelte es sich zumeist um Normalverdiener, von denen niemand allein den Kauf einer Windanlage hätte bewerkstelligen können. Durch den Gemeinschaftserwerb wurden die finanziellen Risiken auf mehrere Schultern verteilt (ebd., 274). Viele der ersten Bürgerwindgruppen hatten sich anfangs als Verein, GbR, oder Genossenschaft konstituiert. Die größte Schwäche diese Organisationsformen besteht darin, dass die Mitglieder im Konkursfall unbeschränkt haftbar gewesen wären. Daher folgten die meisten dem Beispiel des Vereins ,Umschalten e.V.', der sich im März 1989 in eine GmbH \& Co. KG umwandelte, ,Umschalten Windstrom Wedel GmbH \& Co. KG' (ebd., 302). Auf diese Weise hafteten die Anleger nur mit dem selbst aufgebrachten Kapital. Dies ist deshalb wichtig, weil ein großer Teil der Investition i.a. durch Bankkredite finanziert wurde. ${ }^{337}$ Die Windmüller waren von einem Mindestmaß an Kooperationsbereitschaft staatlicher Behörden, Energieversorger und Banken abhängig. Um hier optimale Voraussetzungen zu schaffen, war es für sie wichtig als berechenbarer Geschäftspartner akzeptiert zu werden. Als anerkannte Rechtsform eines Unternehmens, ist die Gründung einer $\mathrm{GmbH}$ diesem Zweck dienlich. Darüber hinaus verschaffte sie den Mitgliedern Zugang zu steuerlichen Vorteilen, wobei aufgrund der niedrigen Einkommen der Pioniere, kaum einer davon profitieren mochte (ebd., 302f.).

Dieser Schritt von egalitären Organisationsstrukturen wie dem Verein, in dem allen Mitgliedern formal derselbe Status zukam, zur GmbH \& Co. KG., war unter den Mitgliedern der Bürgerwindgruppen nicht unumstritten. Die Gegner dieser neuen Rechtsform monierten die Entstehung einer ,Zwei-Klassen-Gesellschaft'. Denn die Mitglieder der $\mathrm{GmbH}$ hatten entscheidende Kompetenzen. ${ }^{338}$ Der Kommanditgesellschaft kam dagegen in erster Linie die Rolle zu, auf jährlichen Treffen einige Grundsatzentscheidungen zu treffen, bzw. abzusegnen (ebd., 304). Trotz dieser Angleichung an die im Wirtschaftsleben der Bundesrepublik üblichen Gepflogenheiten, weisen die ersten Bürgerwindgesellschaften viele Charakteristika auf, die sie eindeutig als Graswurzelinitiativen auszeichnen.

\section{Die Urform}

Das Ziel der Beteiligung an einer WEA bestand nicht darin, Gewinne zu erwirtschaften, sondern den eigenen Verbrauch virtuell durch Windstrom zu ersetzen. Daher definierte Windstrom Wedel Beteiligungsobergrenzen in Höhe von 5.000-10.000 DM. Viele Kommanditisten gaben deutlich weniger. Aus zwei Gründen akzeptierte man Beteiligungen ab 100 DM. Zum einen wollte man Interessenten mit geringem Gehalt nicht ausschließen. Zum andern wurde angestrebt, den Kreis der Beteiligten auszuweiten, um an politischer Schlagkraft zu gewinnen (ebd., 305). ${ }^{339}$

Der Aspekt des Geldverdienens war für die meisten Pioniere von sekundärer Bedeutung. Einem Geschäftsführer Windstrom Wedels zufolge rechneten die ersten Geldgeber von 1988/89 nicht damit, ihr Geld wieder zu sehen und betrachteten ihre Beteiligung als Spende für eine gute Sache. Er beschreibt die Motivlage der Geldgeber: ,Mit diesem Geld ist dort meine Windkraftanlage mit gebaut worden, dort wird mein Strom erzeugt mit meinem Geld, auch wenn ich keine Verzinsung kriege und auch, wenn ich das Kapital verliere.' (zitiert nach: Byzio et al. 2002, 289). ${ }^{340}$

\footnotetext{
${ }^{337}$ Trotz der internationalen Erfahrungen bedeuteten Windenergieprojekte für die Pioniere der Bürgerwindbewegung ein finanzielles Risiko. Es existierten noch viele Unsicherheiten, etwa bezüglich technischer Qualität und Lebensdauer der Anlagen, der zu erwartenden Strommenge sowie der zu überwindenden Probleme bei Behörden und Banken (ebd., 320).

${ }^{338}$ Dazu zählen etwa: Entwicklung eines Finanzierungskonzept, Vorschläge für Standort und Anlagentyp sowie Verhandlungen mit Behörden (ebd., 304).

${ }^{339} \mathrm{Um}$ den Verwaltungsaufwand zu reduzieren, wurde die Mindestbeteiligung bald auf 500 und ein knappes Jahrzehnt später auf 2000 DM angehoben (ebd., 306).

${ }^{340}$ Wichtig war es den Beteiligten, dass sie über den eingezahlten Betrag hinaus nicht haftbar gemacht werden konnten (ebd., 289).
} 
Für die Geschäftsführung galt der Grundsatz der Ehrenamtlichkeit. Um dem gerecht zu werden, war man bemüht, den Verwaltungsaufwand möglichst gering zu halten. Viele hielten es für unangemessen, sich von denjenigen bezahlen zu lassen, die ihnen ihr Geld anvertraut hatten. Für die Geschäftsleitung der ,Initiative Solling Vorland' war die Arbeit für ihr Projekt ,kein Job, sondern unsere Überzeugung' (ebd., 306).

Die Windanlage sollte in der Nähe des Gründungsortes der Initiative errichtet werden. Die Kommanditisten sollten möglichst aus der Region stammen. Daher erfolgte die Anwerbung von Geldgebern keinesfalls durch das Schalten überregionaler Annoncen. Geworben wurde zumeist durch ,Mund-zu-Mund-Propaganda', Info-Tische auf Straßenfesten, Vorträge in Schulen und Anzeigen in lokalen Zeitungen. Angestrebt wurde eine ,lokale Gemeinschaftsbildung' (ebd., 296 f.). Viele der ersten Bürgerwindgesellschaften hatten kein Interesse daran, noch weitere Windturbinen aufzustellen. Die Windanlage sollte über die nächsten 10-15 Jahre weiter betrieben und die Einnahmen aus dem Stromverkauf an die Kommanditisten zurückgezahlt werden (ebd., 277). Die GmbH \& Co. KG ist für die Pioniere in erster Linie ein Mittel zum Zweck, um ihr Projekt zu realisieren. Im Bewusstsein der Gründergeneration blieb das Leitbild der Genossenschaft erhalten. Dieses basisdemokratische Ideal ist jedoch durch die Bildung einer $\mathrm{GmbH} \&$ Co. KG torpediert worden. Denn das Stimmrecht der Kommanditisten richtete sich nach der Höhe der individuellen Anteile am Windpark. Um zu verhindern, dass einzelne Mitglieder über die Beschlüsse der Gesellschaft entschieden, war es üblich, die maximalen Anteile zu begrenzen. Andere ließen zwar größere Beteiligungen zu, beschränkten jedoch den Stimmenanteil auf zehn Prozent, unabhängig von der tatsächlichen Anteilshöhe (ebd. 2002, 323f.).

$\mathrm{Zu}$ den wesentlichen Charakteristika der ersten Bürgerwindgesellschaften zählt die kooperative Haltung untereinander. Die Pioniere betrachteten einander nicht als ,ökonomische Konkurrenten, sondern als politisch motivierte Mitkämpfer für eine alternative Energieproduktion' (ebd., 317). Die Weitergabe von Know-how wurde nicht als Dienstleistung angesehen. Vielmehr war es üblich, dass man aufeinander zuging und Informationen austauschte. So wurden relevante Vertragsentwürfe interessierten Nachbarn und anderen Projektplanern zugänglich gemacht und zum Kopieren angeboten (ebd.).

Triebkräfte zur Expansion und Kommerzialisierung der Bürgerwindbewegung

Die Urform ist in ihrer Diffusionsfähigkeit zu großen Teilen auf Aktivisten und Fürsprecher der Anti-AKW-Bewegung reduziert. Zugleich sind die Triebkräfte ihrer eigenen Überwindung bereits in ihrer Struktur enthalten. Eine Konsequenz des Erfolgs der Pioniere ist die Abkehr vom Verzicht auf ,Expansion'. Der Aufbau der Windturbinen wurde von vielen ursprünglich als symbolische Handlung angesehen. Als sich der Erfolg abzeichnete, stellte sich die Frage, weshalb man die erworbenen Kenntnisse nicht nutzen sollte, um ein neues Windrad, bzw. weitere Windanlagen aufzustellen. Die schnelle Entwicklung der Technologie bot darüber hinaus neue ökologische und wirtschaftliche Chancen (ebd., 328).

Mit der Größe der gekauften Anlagen wuchs die Zahl der Kommanditisten. Der Anonymisierungsgrad nahm zu, die Partizipationsbereitschaft der Anteilseigner verminderte sich. Die Haltung, Entscheidungen ausschließlich der Geschäftsführung zu überlassen, verbreitete sich (,Es ist schon gut, wie ihr das macht.' (ebd.326f.)). Anfangs hatte die Trennung in GmbH und KG, für die man sich aufgrund äußerer Sachzwänge entschieden hat, auf die Interaktion der beteiligten kaum Einfluss genommen. Nun begann sich diese Trennung auch innerhalb der Bürgerwindgruppe geltend zu machen.

Zunächst war es eine Selbstverständlichkeit, dass die Geschäftsführung ehrenamtlich arbeitete. Keiner wusste, wie groß der Anteil des Geldes sein würde, dass an die Kommanditisten zurück fließen würde. Die Geschäftsführung sah die Anleger, die häufig aus ihrem Bekanntenkreis stammten, als politische Mitstreiter an. Diese Wahrnehmung der KG änderte sich mit der Verstetigung der Einnahmen und der wachsenden Zahl der Anleger: 
,...wenn für die Kommanditisten, die sich nur finanziell engagieren, eine gute Rendite abfällt, warum sollen dann diejenigen, die durch den Einsatz von Zeit und Know-how, die für das Gelingen des Projekts notwendigen Dienstleistungen erbringen, dies nur ehrenamtlich tun?' (ebd., 341). Ein Geschäftsführer ärgert sich über die Situation: 'Wir reißen uns die Hacken auf und machen alles ehrenamtlich, nur damit sich die Gesellschafter später ein Prozentchen mehr in die Tasche stecken können.' (zitiert nach: Byzio et al. 2002, $341) .{ }^{341}$

Die im SEG festgelegte Progressivität der Anlagengröße stellte für lokale Initiativen eine zunehmende Barriere dar. Angesichts der wachsenden Mindestgrößen geförderter Windturbinen wuchsen die Investitionskosten, welche von Bürgerwindgruppen mit ehrenamtlicher Geschäftsleitung und einem guten Dutzend Kommanditisten allmählich nicht mehr zu bewältigen waren. Betrug die Mindestgröße bei Einführung des SEG noch 225kW, erreichte sie 1993 500kW und verdoppelte sich 1996 auf ein Megawatt. Für die ersten Anlagen mit einer Leistung zwischen 50 und $100 \mathrm{~kW}$, die von Windstromwedel 1989/1990 errichtet wurden, zahlte sie zwischen 200.000 und 300.000 DM. Im Jahr 2000 kostete eine 1MW-Turbine etwa zwei Millionen DM (ebd., 276f.).

Diese Triebkräfte bewirkten einen Trend zur Kommerzialisierung des Sektors. Dabei verlief der Prozess nicht kontinuierlich, sondern war beachtlichen Ungleichzeitigkeiten unterworfen. Manche Projektentwickler starteten bereits Ende der 80er Jahre als kommerzielle Unternehmen. Andere entfernten sich schrittweise von der dargestellten Urform der Bürgerwindgesellschaft, oder sie verkauften ihre Windanlage später an Entwicklungsgesellschaften wie Prokon und Windwärts. ${ }^{342}$ Schließlich gibt es diejenigen, die am Prinzip der klassischen Bürgerwindgesellschaft festhielten. Byzio et al. (2002) teilen die Bürgerwindgesellschaften in drei Gruppen ein (Tab. 2.4.3g), die zueinander in Kontinuität stehen. ${ }^{343}$ Der wichtigste Unterschied zwischen Form 2 und 3 besteht in der Frage der Ehrenamtlichkeit der Geschäftsführung. Während der Übergang zwischen Form 1 und 2 fließender ist, stellt die Tatsache, dass aus den zuvor ehrenamtlich tätigen GmbH-Mitgliedern, plötzlich Vollzeitbeschäftigte werden sollten, eine deutliche Hürde dar. Byzio et al. (2002, 342) zufolge ist Windwärts Energie GmbH das einzige Unternehmen, das den Schritt von der Ehrenamtlichkeit zur Professionalität wagte. Der Einstieg Prokons markiert 1995 das Ende der Gründungsphase der Bürgerwindinitiativen. Neue Akteure treten seitdem vorwiegend als professionell und auf Gewinn ausgerichtete Unternehmen in Erscheinung (ebd., 350). Die Prokon Energiesysteme GmbH hatte sich von Anfang zum Ziel gesetzt, ,drei oder vier Windparks mit ungefähr 10 Anlagen' zu errichten (ebd., 342).

\footnotetext{
${ }^{341}$ weitere Gründe der sukzessiven Verdrängung des Prinzips der Ehrenamtlichkeit werden von Byzio et al. (2002, 337ff.) ausgeführt: Geschäftsführung erfordert hohen Arbeitsaufwand; keine Reduktion dieses Aufwands nach der Realisierungsphase; Know-how ist weitgehend monopolisiert, daher können motivierte Gesellschafter der Geschäftsführung kaum Hilfestellung leisten; Nachlassen der Anfangseuphorie.

${ }^{342}$ Seit 2000 beschäftigt die Windwärts GmbH elf hauptamtliche Mitarbeiter. Bis Ende 2001 werden acht Kommanditgesellschaften gegründet und 33 WEA betrieben. Zu diesem Zeitpunkt realisierte Prokon bereits 104 WEA, von denen 58 durch eigene Gesellschaften betrieben werden (ebd., 281).

${ }^{343}$ Die Autoren unterscheiden noch zwei weitere Formen, in denen ökonomische Aspekte noch stärker ausgebildet sind. Zu diesen zählen sie bspw. Prokon, Winkra und Plambeck neue Energien GmbH (vg. Kap. 3).
} 
Tabelle 2.4.3g

Formen der Bürgerwindgesellschaften

\begin{tabular}{|c|c|c|c|}
\hline & Form 1 & Form 2 & Form 3 \\
\hline $\begin{array}{l}\text { ehrenamtliche } \\
\text { Geschäftsführung? }\end{array}$ & ja & ja & nein \\
\hline Gewinninteresse der KG & $\begin{array}{l}\text { nein, man möchte Verluste } \\
\text { begrenzen und ein Symbol } \\
\text { gegen Atomenergie schaffen; } \\
\text {,Bestandsgarantie' }\end{array}$ & $\begin{array}{l}\text { Aspekt des Geldverdienens } \\
\text { wird wichtiger (,Idealismus } \\
\text { lässt sich mit Rendite } \\
\text { verbinden') }\end{array}$ & $\mathrm{ja}$ \\
\hline Expansionsinteresse? & nein, höchstens vier WEA & $\begin{array}{l}\text { ja, vorsichtiger, begrenzter } \\
\text { Ausbau }\end{array}$ & ja \\
\hline $\begin{array}{lll}\text { Werbung } & \text { vor } & \text { Ort/ } \\
\text { überregional? } & & \end{array}$ & $\begin{array}{l}\text { Schneeballprinzip, Mund-zu- } \\
\text { Mund-Propaganda, } \\
\text { Lokalanzeigen }\end{array}$ & vg. Form 1 & \begin{tabular}{|lrr} 
regionale Bindung & wird \\
schwächer, jedoch & nicht \\
gänzlich aufgehoben & \\
\end{tabular} \\
\hline $\begin{array}{l}\text { Bedeutung der Trennung in } \\
\text { Geschäftsführung und } \mathrm{KG}\end{array}$ & $\begin{array}{l}\text { Trennung zwischen } \mathrm{GmbH} \\
\text { und KG aufgrund äußerer } \\
\text { Sachzwänge }\end{array}$ & $\begin{array}{lrr}\text { Trennung } & \text { verstärkt } & \text { sich, } \\
\text { höherer } & \text { Professionalisie- } \\
\text { rungsgrad, } & \text { wachsende } \\
\text { Tendenz } & \text { zur } \\
\text { Monopolisierung des } & \text { Know- } \\
\text { how } & & \\
\end{array}$ & $\begin{array}{l}\text { starke Trennung; Gelder } \\
\text { werden oft erst akquiriert, } \\
\text { wenn die Projektplanung } \\
\text { bereits abgeschlossen ist }\end{array}$ \\
\hline Höhe der Investition & $\begin{array}{l}\text { insgesamt maximal 1-2 Mio. } \\
\text { DM }\end{array}$ & max. 5-10 Mio. DM & 20 Mio. DM und mehr \\
\hline Beispiele (Gründungsjahr) & $\begin{array}{lr}\text { Windstrom Wedel } & (1987)^{344} \text {; } \\
\text { Solling-Vorland } & (1993) ; \\
\text { Windkraft } & \text { Vienenburg } \\
\text { (1993); } & \text { Energieverbund } \\
\text { Angerstraße (1994) }\end{array}$ & $\begin{array}{l}\text { Windkraft Diemarden GmbH } \\
(1993)^{345} \text {; Buker Windkraft } \\
\text { GmbH (gegründet 1992, } \\
\text { sechs WEA) }\end{array}$ & $\begin{array}{ll}\text { Windwärts Energie } \mathrm{GmbH} \\
(1993)\end{array}$ \\
\hline
\end{tabular}

Quelle: Byzio et al. 2002, 267ff.; Oelker et al. 2005, 226ff.

Projektentwickler und Investoren

Bei der dritten Gruppe netzunabhängiger Betreiber von Windanlagen handelt es sich um gewinnorientierte Projektentwickler. Wie oben dargestellt führt keine direkte Linie von den ersten Bürgerwindgesellschaften zu mittelständischen Firmen wie Prokon. Auch kann nicht von einem vollständigen zeitlichen Aufeinanderfolgen zivilgesellschaftlicher und zunehmend kommerziell und finanzkräftigerer Akteure ausgegangen werden.

Denn bereits im Jahr 1989, als Windstrom Wedel das erste Bürgerwindrad ans Netz schließt, gründet sich mit der Winkra-Energie GmbH die erste deutsche Planungsgesellschaft für WEA (Oelker 2005, 343). Winkra-Gründer Uwe T. Carstensen ist seit Mitte der 80er Jahre Vorsitzender der DGW. Als Energieberater für Industrieunternehmen und Kommunen brachte Carstensen sein betriebswirtschaftliches Know-how in die neue Firma ein (ebd.). 1991 installierte Winkra den ersten eigenen Windpark auf Fehmarn (Byzio et al. 2002, 348). 1993 wurde das Unternehmen zum größten Windanlagenkäufer Deutschlands (Gipe 1995, 40). Bis Ende 2002 errichtete Winkra über 500MW Windenergie, $140 \mathrm{MW}$ davon betreibt das Unternehmen selbst (http://www.udo-leuschner.de/energie-chronik/021215.htm, Abruf vom 8.10.2008).

Ein weiteres Beispiel dieser Gleichzeitigkeit des Agierens kleiner und größerer Akteure auf dem Sektor, liefert der Windanlagenhersteller HSW. Dieser begann 1988/89 mit der Planung, eines für die Verhältnisse der Pionierphase ,europäischer Ausprägung', sehr großen Windparks (50 WEA). Mit dem Projekt wollte HSW ein neues Geschäftsfeld erschließen und zugleich eine Serienfertigung installieren, um Kosten zu sparen. Wie im Schiffbau üblich, gründete HSW zu diesem Zweck eine Fondsgesellschaft, die ,Nordfriesland Windpark Verwaltungsgesellschaft mbH \& Co. KG' (WPM 3/89, 6). Zuerst erhielten die Bürger der Standortregion um Friedrich-Wilhelm-Lübke-Koog die Möglichkeit, Anteile des 12,5MWWindparks zu kaufen. Jedoch lohnte sich eine Beteiligung aufgrund steuerlicher

\footnotetext{
${ }^{344}$ Später kaufte Windstrom Wedel ein Blockheizkraftwerk und ein kleines Wasserwerk hinzu (Oelker 2005, 303).

${ }^{345}$ Die Windkraft Diemarden GmbH installierte bis Herbst 2000 fünf WEA (Byzio et al. 2002, 278). Seitdem hat das Unternehmen in der Region südlich Göttingens einige weitere Anlagen in Betrieb genommen.
} 
Abschreibungsmöglichkeiten nicht für einfache Landwirte, sondern in erster Linie für wohlhabendere Personen (Oelker 2005, 303f.). Unabhängig davon, ob jemand viel oder wenig Steuern zahlte: Aufgrund der hohen Mindestbeteiligung von 30.000 DM (WPM 5/90, 11) sind die meisten Normalverdiener ohnehin ausgeschlossen. Der größte Anteil der Gewinne floss zu den Investoren aus Bayern und Baden-Württemberg. Obgleich ein Großteil der 200 Einwohner des Ortes dem Projekt skeptisch gegenüberstand, stimmten die Gemeindevertreter fast einstimmig für den Bau des Windparks (,Wenn nicht wir etwas für die Umwelt tun, wer dann?', Oelker 2005, 304).

Für die Hersteller hat der Betrieb von Windparks auch die Funktion eines Testfeldes. Neben HSW investierte auch Tacke in den Aufbau eines eigenen Windparks. Der ursprüngliche Eigner des kalifornischen Standorts meldete Konkurs an, worauf Tacke an dessen Stelle getreten war (s.o.).

Bemerkenswert ist ein weiteres Großprojekt. Einige Bürger aus Friedrich-Wilhelm-LübkeKoog ließen sich von dem HSW-Windpark inspirieren (,Vielleicht ist das ja auch was für uns.', Mitinitiator Hans-Detlef Feddersen, zitiert nach: Oelker 2005, 304). Im März 1991, einige Monate nachdem die ersten $8,5 \mathrm{MW}$ des HSW-Windparks installiert wurden, gründete sich die ,Bürgerwindpark Lübke-Koog $\mathrm{GmbH}^{\prime}$ (ebd.). Jeder der 44 Gesellschafter musste mindestens $3.000 \mathrm{DM}$ anlegen. Für 22 Enercon Maschinen à $300 \mathrm{~kW}$ wurden insgesamt 16 Mio. DM investiert, wobei der Eigenanteil der Kooger 2,3 Mio. betrug. Die ersten 14 WEA gingen im Dezember 1992 in Betrieb. Hier handelt es sich um ein, für den Untersuchungszeitraum merkwürdiges Zwitter-Projekt. Vom lokalen Gründungskontext her ähnelt das Projekt sehr der Vorgehensweise der frühen Bürgerwindbewegung. ${ }^{346}$ Auch die relativ niedrige Beteiligungsuntergrenze von $3.000 \mathrm{DM}$ spricht für eine entsprechende Zuordnung. Andererseits bewegen sich Projektgröße und erforderliche Investition deutlich im Bereich kommerzieller Windparks. Auch ging der Impuls weniger von anderen Bürgerwindanlagen aus, sondern von einem auf Gewinn orientierten Großprojekt. ${ }^{347}$

EVU und Windmüller

Während der Pionierphase haben sich einige norddeutsche Versorger im Sektor kleiner und mittelgroßer WEA engagiert. Unabhängig davon, ob sie eigene Windparks betrieben: Die aus den übrigen Pionierländern bekannte, ablehnende Haltung findet sich auch in der Bundesrepublik wieder. Die EVU wollten die Einspeisung von Windstrom durch externe Produzenten am liebsten gänzlich verhindern. Den rechtlichen Hintergrund ihrer Restriktionen bot ihnen ein Gesetz, das regionalen Versorgern ein Monopol auf die Stromproduktion und Verteilung in ihrem Gebiet zugestand. ${ }^{348}$ Sie waren darum bemüht, Windenergie auf den Status der Selbstversorgung einzelner Haushalte festzuschreiben, um den ,perspektivischen Impuls zu einer flächendeckenden Energiewende' zu entmutigen (Byzio et al. 2002, 301). Wie aus den übrigen Pionierländern bekannt, waren auch die deutschen EVU nicht bereit, für eingespeisten Windstrom, mehr als den Gegenwert vermiedener Kosten zu zahlen. Da dieser Begriff stets unterschiedlich ausgelegt wird, existierten vor der Einführung des SEG, deutliche regionale Unterschiede in der Vergütung. 1990 lagen die durchschnittlichen Vergütungen in Berlin bei 0,11 DM, in Schleswig-Holstein bei 0,093 DM, in Baden-Württemberg bei 0,07 DM pro

\footnotetext{
${ }^{346}$ Die ersten Projektplanungen fanden im Rahmen der ,Interessengemeinschaft für den Bau von Windenergieanlagen' statt. Auf lokaler Ebene wurde für die Beteiligung am Windpark geworben. Auf eine formale Trennung zwischen Geschäftsführung und Kommanditisten verzichtete man (Oelker 2005, 304).

${ }^{347}$ Ebenfalls 1989 startete die Planungsphase eines noch größeren Windparkprojektes. 254 WEA (Gesamtkapazität 59MW) wollte Großinvestor Hans Peter Jacobsen auf der Halbinsel Eiderstedt installieren. Ein Drittel der Investition von 195 Mio. DM wollte Jacobsen selbst aufbringen (WPM 11/89, 6). Vor allem aufgrund lokaler Proteste wurde das Projekt jedoch nicht genehmigt: ,Protest groups sprang up in Tatenbüll and other villages, claiming the project was too big, conceived too fast and decrying the lack of information.' (WPM 7/90, 8).

${ }^{348}$ Die Wirksamkeit dieses Gesetzes wurde durch eine entsprechende EU-Direktive von 1990 aufgehoben.
} 
Kilowattstunde. Am niedrigsten waren sie in Nordrhein-Westfalen mit 0,065 DM (WPM 4/90, 12), bei einem Durchschnitt von 0,09DM (WPM 7/90, 19). Hauptsächlich für diese Region zuständig ist Energiekonzern RWE, der in Vergangenheit immer wieder durch HardlinerPositionen gegenüber Windmüllern aufgefallen ist. Aufgrund seiner Überkapazitäten war die Einspeisung von Windstrom für den Konzern ein doppeltes Ärgernis. Im Jahr 1990 musste der Konzern deswegen bereits einige Kraftwerke vorübergehend abschalten (WPM 4/90, 12). ${ }^{349}$ Es wurde bereits aufgezeigt wie wenig kooperativ sich die meisten Behörden bei der Erteilung von Baugenehmigungen verhielten. Die zweite Barriere lag in der ,Aushandlung' der Anschlusskonditionen zwischen EVU und Windmüllern, wobei nicht von einer gleichberechtigten Interaktion beider Akteure ausgegangen werden sollte. In einem besonders extremen Fall verlangte RWE für die Installationskosten einer Windmühle 100.000 DM (Oelker 2005, 223). Etwas anders war der Fall im Versorgungsgebiet der EWE in Ostfriesland gelagert. 1990/91 hat EWE bereits einige Windparks in Betrieb genommen. Bis dahin war EWE der einzige Windturbinenbetreiber der windigen Region. Möglicherweise plante EWE, die guten Ressourcen selbst zu nutzen. Jedenfalls schienen die zuständigen Verwaltungen mit der Situation nicht unzufrieden. Denn sie lehnten über lange Zeit sämtliche Bauanträge, die von privaten Interessenten gestellt wurden, ab. Erst 1991 wird das EWE-Monopol, nach langen Verhandlungen, durch die Installation einer 100kW-Turbine auf einem Bauernhof gebrochen (WPM 7/91, 14).

Insgesamt versuchten die EVU nach Kräften, unabhängige Windanlagenbetreiber zu diskriminieren. ${ }^{350}$ Vor dem Hintergrund allerdings, dass die Windmüller seit 1989 deutliche Unterstützung aus der Bundespolitik und einigen Ländern erhielten, verengten sich die Spielräume der EVU für allzu große Willkür. Zum Ende der Pionierphase wurde das Stromeinspeisungsgesetz verabschiedet, wodurch die Position der Windmüller gestärkt wird. Bis zuletzt hatten alle großen Elektrizitätsverbände gegen die Ratifizierung des Gesetzes opponiert. ${ }^{351}$ Sie monierten eine unerwünschte staatliche Einflussnahme auf die Preise für erneuerbare Energien. Zudem waren sie der Meinung, der Staat solle regenerative Energien lieber direkt subventionieren, anstatt die höheren Zahlungen auf die EVU, bzw. letztlich die Kunden, abzuwälzen. Für die Versorger küstennaher Gebiete wie Schleswag und EWE barg das SEG ein unmittelbareres Problem: In diesen Regionen waren die meisten Einspeisungen zu erwarten (WPM 10/90, 11). Daher würde die Hauptlast der aus dem SEG für die Versorger zusätzlich entstehenden Kosten, von diesen EVU getragen werden müssen.

Suck $(2004,28)$ geht davon aus, dass die Energiewirtschaft ,eine erfolgreiche Implementation des Gesetzes für nicht wahrscheinlich hielt und deshalb auf stärkeren Widerstand gegen das Gesetz verzichtete.' Als der Erfolg des SEG in der ersten Hälfte der 90er Jahre manifest wurde, gingen die EVU, vor allem repräsentiert durch den VDEW, zu einem Frontalangriff auf die gesamte Windbranche über. Eine regelrechte Anti-Windkraftkampagne wird gestartet (Tacke 2004, 170f.). Der VDEW rief seine Mitglieder auf, die SEG-Tarife nicht, bzw. nur unter Vorbehalt zu zahlen. Sie wollten Klagen provozieren, um das SEG zu Fall zu bringen. Die EVU verloren sämtliche Gerichtsprozesse. Die Bundespolitik hielt an dem Gesetz fest und verurteilte das Verhalten des VDEW fraktionsübergreifend als Rechtsbruch. Trotz erfolgreicher Verteidigung des SEG war im Windenergiesektor deutliche Verunsicherung entstanden. ${ }^{352}$ Bei der Vergabe von Krediten wurden die Banken vorsichtiger. Sie forderten

\footnotetext{
${ }^{349}$ Dabei handelte es sich um ein AKW (1.300 MW) und einige Braunkohle-Kraftwerksblöcke (je 200-300MW) (WPM 4/90, 12).

${ }^{350}$ Eine bemerkenswerte Ausnahme bildete die kooperative Haltung Schleswags, als es um die Einspeisekonditionen für den großen Windpark der HSW ging (s.o.)

${ }^{351}$ Dazu zählen der VDEW, VIK (Verein der Industriekraftwerke), regionale und kommunale Verbände wie ARE und VkU (WPM 10/90, 11).

${ }^{352}$ Damals war das Stromeinspeisungsgesetz für die Windindustrie von immenser Bedeutung. Denn der größte Teil der Produktion wurde im Inland abgesetzt. Konträr dazu, die Situation in Dänemark: Dort produziert die Industrie praktisch nur für den Export.
} 
höhere Zinsen und erhöhten die notwendige Eigenkapitalsquote auf 30\% (Tacke 2004, 206ff.). Daraufhin geriet die Industrie in eine schwere Krise. 1996 stellen sich Umsatzrückgänge bis zu 25\% ein. Es kommt zu Entlassungen, Kurzarbeit und Firmenzusammenbrüchen (ebd., 215). Nachdem in der Zeit 1988-1990 die Spannungen zwischen EVU und Windmüllern nachließen, nahmen sie gegen Ende der Pionierphase erneut zu. Sie erreichten in der Mitte der 90er Jahre ihren Höhepunkt und verringerten sich erst 1999, als die Versorger mit ihrer Klage gegen das SEG vor dem Europäischen Gerichtshof scheiterten.

\section{Interessenvertretung}

In der Geschichte der deutschen Windkraftnutzung ${ }^{353}$ sind zwischen 1985 und den späten 90er Jahren drei Ereignisse hervorzuheben, ohne die der Erfolg der Windkraft hierzulande nicht denkbar gewesen wäre. Für alle drei Ereignisse ist der Einfluss außerparlamentarischer Interessengruppen von hoher Relevanz. Es handelt sich erstens um die Förderung kommerzieller Windkraft (seit 1986), zweitens um die Verabschiedung des SEG (1990) und drittens um die Verteidigung dieses Gesetzes gegen den Widerstand der EVU, seitens der Bundespolitik (1993-1999). Auf alle drei Entscheidungen und Entwicklungen hatten außerparlamentarische Organisationen des Windenergiesektors wichtigen Einfluss genommen. So erhielt die Förderung kommerzieller Hersteller wichtige Impulse von der Fördergesellschaft Windenergie (FGW). Darin waren viele der vorherigen Growian-Wissenschaftler und -Ingenieure miteinander vernetzt. Die FGW fungierte als Bindeglied zwischen BMFT und Windindustrie. ,Im Forschungsministerium gab es einige Berührungsängste mit den Amateuren, die in der DGW organisiert waren. Die zuständigen Abteilungen wollten lieber mit Professoren und Firmen wie Siemens, MAN oder den Energieversorgern zusammenarbeiten.' (Oelker et al. 2005, 60).

Neben dem IWB war die DGW in der zweiten Hälfte der 80er Jahre zum wichtigsten Interessenverband geworden. Bereits seit 1981 gab Luise Junge die Zeitschrift ,WindkraftJournal' heraus. Als offizielle Publikation des DGW wurde das Magazin 1990 durch ,Windenergie aktuell' abgelöst (ebd., 368). ${ }^{354}$

Im Verlauf der Pionierphase gründeten Pioniere aus dem Umfeld des VWFA 1985 die ,Interessengemeinschaft Windpark Nordwestdeutsches Binnenland' (IWB), ${ }^{355}$ die sich zur wichtigsten Lobbyorganisation der Branche entwickelte. Im Vorfeld der Verabschiedung des SEG gelang es dem IWB, durch geschickte Bündnispolitik, insbesondere mit dem Bundesverband der Wasserwerker, Einfluss auf das Gesetzgebungsverfahren zu erlangen. Wichtig ist, dass sich der IWB bei seiner Einflussnahme explizit auf eine ,bereits funktionierende staatliche Preisregulierung in Dänemark' bezogen hatte (Byzio et al. 2002, 313). Der Einfluss der Bürgerwindbewegung insgesamt lässt sich nur schwer quantifizieren. Viele ihrer Mitglieder waren im IWB organisiert und somit an den Diskussionen um die Einführung des SEG beteiligt. Als sehr hoch ist der Einfluss der Bürgerwindgesellschaften auf kommunaler Ebene einzuschätzen. Sie hatten auf die öffentliche Wahrnehmung der Windkraft durch Anrainer, Lokalpolitiker und Medien einen ähnlich positiven Einfluss wie die Windradkooperativen Dänemarks.

Seit 1991 gibt der IWB die bis heute erscheinende Zeitschrift ,Neue Energie' heraus (Oelker et al. 2005, 225). Während der 90er Jahre hat sie sich zum wichtigsten Sprachrohr der Erneuerbarenergien-Branche entwickelt. Der Erfolg der Windkraft führte gegen Ende der Pionierphase zur Bildung weiterer Interessenverbände und Institutionen. Im Januar 1990 wurde

\footnotetext{
${ }^{353}$ Die Pioniere um Walther Schönball gründeten schon 1974 den ,Verein für Windenergieforschung und -anwendung' (VWFA). Der VWFA bildete in erster Linie eine Plattform für Bastler und Hobby-Konstrukteure (Oelker et al. 2005, 80). In seinen Versuchen, auf eine Verbesserung der politischen Rahmenbedingungen für den embryonalen Windmarkt hinzuwirken, war er kaum erfolgreich.

${ }^{354} 1998$ ging aus ,Windenergie aktuell', die Zeitschrift ,Erneuerbare Energien' hervor (Oelker et al. 2005, 368).

${ }^{355}$ IWB wird 1988 in ,Interessenverband Windkraft Binnenland' umbenannt (ebd., 225). 1997 fusioniert der IWB mit der DGW zum Bundesverband Windenergie (Byzio et al. 2002, 313).
} 
in Wilhelmshaven das Deutsche Windenergie-Institut (DEWI) durch das Land Niedersachsen gegründet. Im Dezember 1991 formierte sich der Interessenverband Windkraft SchleswigHolstein (IWSH) in Husum (ebd., 368ff.). Infolge der Förderung durch das SEG nahm der wirtschaftliche Erfolg der Windindustrie rasch zu. Durch ihre Vertretung im VDMA erhielt die Branche seit 1993 einen weiteren Verankerungspunkt. Zusammenfassend lässt sich sagen, dass sich in der ersten Hälfte der 90er Jahre ein dichtes Netzwerk verschiedener Interessenorganisationen herausbildete.

Die Tatsache, dass die Bundespolitik Mitte der 90er Jahre das SEG und damit den Erfolg der Windbranche gegen die Angriffe der EVU verteidigte, war keine Selbstverständlichkeit. Das besagte Netzwerk, dessen Hauptgrundlagen ausschließlich von zivilgesellschaftlichen Akteuren wie Ingenieuren, Wissenschaftlichern und Graswurzelinitiativen geschaffen wurden, hat sich zu einem zu einem wichtigen Einflussfaktor entwickelt. Ohne diese Netzwerk hätte das Stromeinspeisungsgesetz womöglich nicht gegen den VDEW verteidigt werden können.

\section{Ergebnisse}

In der Pionierphase existiert eine Mannigfaltigkeit von Betreiber-Akteuren: Windenergieenthusiasten, Landwirte, EVU, Stadtwerke, Investoren, Bürgerwindgesellschaften und Anlagenhersteller. Dabei lassen sich deutlich Zeiträume ausfindig machen, während derer bestimmte Akteure dominieren. Vor 1986 dominierten Idealisten, darunter viele Bastler und Selbstbauer das Feld. In der Zeit von 1986-1989/90 waren einige Stadtwerke und regionale Versorger, sowie Landwirte führend. Seit 1990 bestimmten die Bürgerwindgesellschaften zunehmend den Sektor. Zusätzliche Akteure sind Investoren, die seit 1989 auf dem Markt präsent sind. Kommerzielle Projekte wie der HSW-Windpark (12,5MW, 50 WEA) bildeten jedoch die Ausnahme.

Die EVU spielten eine zwiespältige Rolle. Insgesamt waren sie ebenso wenig mit der Stromeinspeisung durch die Windmüller einverstanden wie die EVU der übrigen Pioniermärkte. Agierten sie in der Anfangszeit der Förderung noch zurückhaltend, gingen sie 1993/94, als der Erfolg des SEG manifest wird, zu einer, teilweise gesetzeswidrigen Fundamentalopposition über. Dieses Vorgehen der EVU ist möglicherweise dadurch motiviert, dass die EVU aufgrund der Gestaltung des Gesetzes kaum Möglichkeiten hatten, den Markt durch den Kauf eigener Windparks, unter ihre Kontrolle zu bringen. So restriktiv sich die EVU insgesamt den Windmüllern gegenüber verhielten, so unerlässlich waren einige Stadtwerke und Regionalversorger, welche der neuen Technologie, durch ihre Nachfrage in den späten 80er Jahren, wichtige Starthilfe verliehen.

Die geringe Besiedelungsdichte an den Küsten trug ebenso zur Lösung des aus anderen Pionierländern bekannten Problem der Standortfindung bei wie eine effiziente Planungspolitik der Kommunen und Landkreise. An der Bewältigung des Standortproblems hatte auch die Bürgerwindbewegung maßgeblich Anteil. Sie überzeugte die Anrainer durch Beteiligungsangebote und ihre vorwiegend nicht kommerzielle, sondern politische Motivlage. Die kleinen, lokal orientierten Betreibergruppen, die nur ein, bzw. wenige Windräder aufstellen wollten, hatten es leichter, einen Standort zu finden als auswärtige kommerzielle Projektplaner. Zivilgesellschaftliche Bürgerwindgruppen stärkten die Interessenverbände, denen bzgl. der administrativen Regulierung des Sektors eine aktiv-gestaltende Rolle zukommt.

Anders als in den Niederlanden, hat der deutsche Markt, wesentliche Vorteile aus der relativ späten Einführung der Windtechnologie ziehen können. Zentrale Errungenschaften aus dem Windenergiesektor Dänemarks sind importiert worden. Das dänische Windanlagendesign hat sich in Deutschland seit den ersten Demonstrationsprogrammen von 1986 etabliert. Das Modell garantierter Mindesteinspeisetarife stammt aus Dänemark. Die Bürgerwindgesellschaften sind nichts anderes als die deutsche Variante der Windradkooperativen. Zusammenfassend lässt sich sagen, dass die Akteursstruktur in 
mehrerlei Hinsicht dem dänischen Markt gleicht. Den Akteuren gelingt es, für die auftretenden Probleme entweder geeignete Lösungen zu finden, oder erfolgreiche Strategien aus Dänemark zu importieren. Eine Besonderheit des deutschen Marktes ist das Verhältnis zwischen EVU und Windmüllern. Nach einem anfänglich relativ konstruktiven Verhältnis, eskaliert der Konflikt, als das SEG zu einem deutlichen Aufschwung der Windenergie führt. Insgesamt betrachtet lässt sich dennoch sagen, dass die Windtechnologie in Deutschland, die Pionierphase erfolgreich überwunden hat.

Tab. 2.4.3h Schwierigkeiten der Windenergiebranche und Lösungsansätze

\begin{tabular}{|c|c|c|c|}
\hline Problem & Lösungsansatz & Akteur/e & erfolgreich? \\
\hline $\begin{array}{l}\text { Wirtschaftsministerium will } \\
\text { Forschungsförderung trotz } \\
\text { Growian-Erfahrung } \\
\text { weiterführen und obwohl sich } \\
\text { Industrie- } \\
\text { Marktförderung in Dänemark } \\
\text { als erfolgreich erwiesen hat }\end{array}$ & $\begin{array}{l}\text {,Tarnung' marktfördernder } \\
\text { Maßnahmen als } \\
\text { forschungspolitische } \\
\text { Programme; Beweisen, dass } \\
\text { kommerzielle Produkte in der } \\
\text { Praxis überzeugen; Dän. } \\
\text { Konzept überzeugt }\end{array}$ & BMFT/ Industrie & $\begin{array}{l}\text { Ja. Ohne den Erfolg des } \\
\text { 100/250MW } \\
\text { Demonstrationsprogramms } \\
\text { und erfolgreicher inländischer } \\
\text { Windindustrie wäre der } \\
\text { Beschluss des } \\
\text { undenkbar gewesen. }\end{array}$ \\
\hline $\begin{array}{lr}\text { Vor 1986: } & \text { keine } \\
\text { Windanlagenindustrie } & \\
\text { vorhanden; } & \text { daher: } \\
\text { Markteinführung } & \text { nur } \\
\text { eingeschränkt möglich } & \\
\end{array}$ & $\begin{array}{l}\text { PAS schafft Nachfrage durch } \\
\text { 100MW. EVU und Landwirte } \\
\text { kaufen WEA. Mittelständler } \\
\text { übernehmen } \\
\text { Design }\end{array}$ & \begin{tabular}{|lr} 
PAS, EVU, & Landwirte, \\
mittelständische & \\
Unternehmen, & dänische \\
Windindustrie &
\end{tabular} & $\mathrm{Ja}$ \\
\hline $\begin{array}{l}\text { Akzeptanzproblem: Anrainer } \\
\text { lehnen Windparks ab, weil } \\
\text { ihre Umgebung beeinträchtigt } \\
\text { wird. }\end{array}$ & $\begin{array}{l}\text { Lokale } \text { Bürgerwindgruppen } \\
\text { gewinnen Sympathie, weil sie } \\
\text { nicht gewinnorientiert } \\
\text { arbeiteten. Sie bemühten sich } \\
\text { darum, Anrainer für } \\
\text { Beteiligungen zu gewinnen. } \\
\end{array}$ & Bürgerwindgesellschaften & $\begin{array}{l}\text { Ja. Zumindest so lange, bis in } \\
\text { der zweiten Hälfte der 90er } \\
\text { Jahre offenkundig wird, dass } \\
\text { die zunehmend } \\
\text { kommerziellen Interessen der } \\
\text { Betreiber dominieren. } \\
\end{array}$ \\
\hline $\begin{array}{l}\text { Initiativen müssen sich gegen } \\
\text { finanzielle Risiken absichern } \\
\text { und von Behörden u.a. als } \\
\text { Verhandlungspartner } \\
\text { akzeptiert werden. }\end{array}$ & $\begin{array}{l}\text { Bildung einer } \\
\mathrm{GmbH} \& \mathrm{Co} . \mathrm{KG}\end{array}$ & Bürgerwindgesellschaften & $\begin{array}{llr}\text { Ja. Für die } & \text { Geldgeber ist } \\
\text { sichergestellt, } & & \text { dass } \\
\text { potenzielle } & \text { Verluste den } \\
\text { eingezahlten } & \text { Betrag nicht } \\
\text { übersteigen konnten. } & \\
\end{array}$ \\
\hline $\begin{array}{l}\text { Hohe Zahl der Anträge hat in } \\
\text { manchen Regionen } \\
\text { verhindert, dass die } \\
\text { beantragten Standorte schnell } \\
\text { hätten genutzt werden } \\
\text { können. }\end{array}$ & 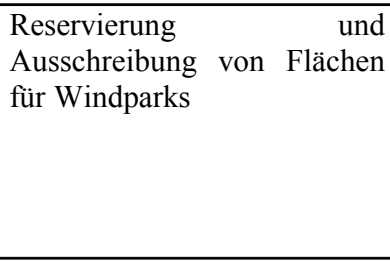 & $\begin{array}{l}\text { Kommunal- } \\
\text { Kreisverwaltungen }\end{array}$ & 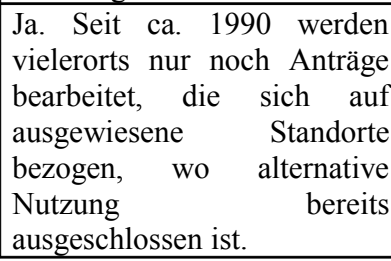 \\
\hline
\end{tabular}

Quellen: vg. Kap. 2.4

Der wichtigste Transformationsvorgang besteht im Wandel staatlicher Windkraftpolitik von der Technologie- zur Marktförderung. Während kommerzielle Hersteller in der ersten Hälfte der 80er Jahre zahlreiche unterschiedliche Windanlagenkonzepte verwendeten, setzte sich innerhalb der ersten zwei bis drei Jahre des Untersuchungszeitraums, das dänische Design durch. War der Markt zunächst durch kleine Firmen und einige Konzerne geprägt, dominierten seit Ende der 80er Jahre mittelständische Unternehmen den Sektor. Von den EVU wird die Produktion von Strom aus Windenergie zumeist abgelehnt. Dieses gilt insbesondere, wenn es sich um externe Produzenten handelt. Gegen Ende der Pionierphase verlieren die Landwirte als Windmüller an Bedeutung. Seit Anfang der 90er Jahre werden nur noch größere Modelle gefördert, welche die Möglichkeiten der meisten Landwirte überstiegen. Investoren spielten auf dem deutschen Markt zunächst eine nachgeordnete Rolle. Gegen Ende der Pionierphase avancieren Bürgerwindgesellschaften, sowohl ökonomisch, als auch interessenpolitisch und die lokale Akzeptanz von Windanlagen betreffend, zum Hauptakteur. 
Tab. 2.4.3i Transformationsprozesse im PAS

\begin{tabular}{|l|l|l|l|}
\hline & bis 1985 & $\mathbf{1 9 8 6 - 1 9 9 0}$ & seit 1991 \\
\hline Förderpolitik & Technologieförderung & $\begin{array}{l}\text { Demonstrationsprogramme/ } \\
\text { Industrie- } \\
\text { Marktförderung }\end{array}$ & Marktförderung (SEG) \\
\hline $\begin{array}{l}\text { Energiepolitischer Status der } \\
\text { Windenergie }\end{array}$ & $\begin{array}{l}\text { Prüfen, ob sich WE für } \\
\text { großtechnische Nutzung } \\
\text { eignet }\end{array}$ & $\begin{array}{l}\text { Windkraft soll dazu } \\
\text { beitragen, konventionelle } \\
\text { Brennstoffe einzusparen } \\
\text { (Einspeisepreis = vermiedene } \\
\text { Kosten) }\end{array}$ & $\begin{array}{l}\text { Windkraft soll konventionelle } \\
\text { Kraftwerke ersetzen; höhere } \\
\text { Tarife für die Windmüller } \\
\text { werden umweltpolitisch } \\
\text { begründet }\end{array}$ \\
\hline Förderung auf Länderebene & - & $\begin{array}{l}\text { Niedersachsen (1987), } \\
\text { Nordrhein-Westfalen (1988), } \\
\text { Schleswig-Holstein (1989) }\end{array}$ & vg. 1986-1990 \\
\hline Standortfestlegung & $\begin{array}{l}\text { Verwaltung auf allen Ebenen } \\
\text { generell restriktiv }\end{array}$ & $\begin{array}{l}\text { Administrationen werden } \\
\text { kooperativer, insbesondere } \\
\text { dort, wo Förderprogramme } \\
\text { durchgeführt wurden }\end{array}$ & $\begin{array}{l}\text { Effizientes Standortfestlegung } \\
\text { Kommunen } \\
\text { heitgehend durchgesetzt }\end{array}$ \\
\hline
\end{tabular}

Quellen: vg. Kap. 2.4

Tab. 2.4.3j Transformationsprozesse der Industrie

\begin{tabular}{|c|c|c|c|}
\hline & bis 1985 & 1986-1990 & seit 1991 \\
\hline marktführende Unternehmen & $\begin{array}{l}\text { sehr kleine Hersteller und } \\
\text { Konzerne wie MAN }\end{array}$ & $\begin{array}{l}\text { dt. Mittelständler (Enercon, } \\
\text { Tacke, HSW); dän. } \\
\text { Hersteller; MAN; Lagerwey }\end{array}$ & $\begin{array}{l}\text { Enercon, Tacke; dänische } \\
\text { Hersteller, Lagerwey (NL) }\end{array}$ \\
\hline Anlagenkonzept & $\begin{array}{ll}\text { viele } & \text { unterschiedliche } \\
\text { Konzepte werden angeboten }\end{array}$ & $\begin{array}{|ll|}\text { führende } & \text { Hersteller } \\
\text { verwenden dän. Design }\end{array}$ & vg. 1986-1990 \\
\hline $\begin{array}{l}\text { Dänische Hersteller auf dem } \\
\text { dt. Markt }\end{array}$ & kein Markt vorhanden & $\begin{array}{ll}\text { führende } & \text { Hersteller } \\
\text { Dänemarks } & \text { gründen } \\
\text { Zweigstellen in der BRD }\end{array}$ & $\begin{array}{l}\text { Etablierung dänischer } \\
\text { Hersteller auf dt. Markt } \\
\text { weitgehend abgeschlossen }\end{array}$ \\
\hline
\end{tabular}

Quellen: vg. Kap. 2.4

Tab. 2.4.3k

Transformationsprozesse der Betreiberstruktur

\begin{tabular}{|c|c|c|c|}
\hline & bis 1985 & 1986-1990 & seit 1991 \\
\hline $\begin{array}{l}\text { wesentliche Betreiber (in der } \\
\text { Reihenfolge ihrer Bedeutung) }\end{array}$ & Idealisten & $\begin{array}{l}\text { EVU, Landwirte, Investoren, } \\
\text { Bürgerwindgesellschaften }\end{array}$ & $\begin{array}{l}\text { Bürgerwindgesellschaften, } \\
\text { Investoren, Landwirte }\end{array}$ \\
\hline $\begin{array}{l}\text { Finanzierungssituation } \\
\text { Privatkäufer }\end{array}$ & prekär & $\begin{array}{lr}\text { prekär, seit } & 1989 \\
\text { Finanzierung } & \text { zahlreicher } \\
\text { Projekte durch } & \text { Commerzbank } \\
\text { Brunsbüttel } & \\
\end{array}$ & $\begin{array}{l}\text { Deutsche Ausgleichsbank } \\
\text { gewährt seit 1991 Kredite }\end{array}$ \\
\hline $\begin{array}{l}\text { Windanlagenbetrieb } \\
\text { Einnahmequelle riskant? }\end{array}$ & Gewinne ausgeschlossen & $\begin{array}{l}\text { seit } 1989 \text { (Länderprogramme } \\
+\quad \text { 100MW-Programm): } \\
\text { Gewinne nicht kalkulierbar; } \\
\text { viele Unwägbarkeiten; Rolle } \\
\text { der } \quad \text { Windenergie als } \\
\text { Geldanlage ist marginal }\end{array}$ & $\begin{array}{l}\text { garantierte } \\
\text { durch SEG; Position der } \\
\text { Windmüller gegenüber EVU } \\
\text { wird durch SEG gestärkt }\end{array}$ \\
\hline
\end{tabular}

Quellen: vg. Kap. 2.5

\subsection{Pioniermärkte in vergleichender Perspektive}

Für die Markteinführung der Windkraft hat sich die LSP-basierte Technologieförderung als prinzipieller Irrweg herausgestellt (vg. Kap. 1). Je länger sie fortgesetzt wurde, desto länger ist die Aufmerksamkeit von Erfolgen mittelgroßer Windanlagentechnik aus Dänemark abgelenkt worden. Die Ressourcen, die für Projekte wie Growian aufgewendet wurden, fehlten zur Förderung kleiner und mittelständischer Windanlagenhersteller sowie der Nachfrageförderung (Investitionszuschüsse für Anlagenkäufer etc.) Dieser Wandel der Förderpolitik von der Technologie- zur Marktförderung, wird in allen Pioniermärkten vollzogen. Ohne gezielte Unterstützung von Windanlagenherstellern und -betreibern ist eine Marktentstehung während der Pionierphase ausgeschlossen. Zwischen beiden Förderstrategien lässt sich zwar ein zeitliches Nacheinander feststellen, jedoch existiert keine 
deutliche Trennlinie. Eine solche besteht am ehesten noch in Dänemark (Energiplan 81, 1981) und Niederlande (Integral Programma Windenergie, 1986). Nichtsdestoweniger werden parallel zur Marktförderung diverse LSP-Projekte weitergeführt. Insbesondere aufgrund des Föderalismus sind diese Überlappungen in den USA besonders stark ausgeprägt. So startet der Zentralstaat, auch nach der Verabschiedung des PURPA und nachdem eine Markteinführung in Kalifornien bereits gelungen war, weitere LSP-Projekte. Eine starke Ungleichzeitigkeit besteht darüber hinaus zwischen den Zeitpunkten der Markteinführung (Dänemark: 1979, Kalifornien: 1980, Niederlande: 1986, Deutschland: 1987).

Anhand der Betrachtung einiger Indikatoren geht es zunächst darum, anhand quantitativer (Abschnitt 2.5.1) und qualitativer Indikatoren (2.5.2) zu bestimmen, welche der Pioniermärkte am Ende der Pionierphase als erfolgreich, bzw. weniger erfolgreich einzustufen sind. Es folgt eine Interpretation dieser Ergebnisse (2.5.3). Welche Akteure und welche Fördermethoden waren in der jeweiligen Periode erfolgreich - und warum? Neben einer Reihe struktureller Ähnlichkeiten der Pioniermärkte, sind in der Akteursstruktur deutliche Unterschiede zu konstatieren. Bezüglich der Erfolgschancen eines Pioniermarktes ist offenbar nicht nur in Rechnung zu stellen, welche Akteure beteiligt sind, sondern auch, ob es sich dabei um große, kleine, oder mittelgroße Akteure handelt (2.5.4). Dänemark hat sich als Erfolgsmodell der Pionierphase herauskristallisiert. Worin bestehen die zentralen Eigenschaften des dänischen Marktes, worin also, besteht das dänische Modell (vg. 2.5.5)? Nur vom deutschen Markt werden zentrale Eigenschaften des dänischen Modells aufgegriffen. Die Strukturen der Windenergiesektoren Kaliforniens und der Niederlande unterscheiden sich deutlich. Angesichts der mangelhaften Ergebnisse dieser Pioniermärkte liegt die These nahe, dass in der Pionierphase nur eine Konstellation erfolgreich ist, das dänische Modell. In Abschnitt 2.6 wird untersucht, unter welchen Bedingungen Eigenschaften des dänischen Marktes übernommen werden konnten.

\subsubsection{Quantitative Begründung: Erfolgreiche Pioniermärkte}

Anhand der nachfolgenden Indikatoren lässt sich zeigen, inwieweit sich die nationalen Märkte nach dem Ende der Pionierphase - hier wird das Jahr 1992 als Bezugspunkt gewählt erfolgreich entwickelt haben. Ein erster Indikator ist die installierte, absolute und relative Windkraftkapazität (bezogen auf Einwohnerzahl und Landesfläche, Tab. 2.5a). Weitere Indikatoren sind die Kontinuität der Marktentwicklung und deren Geschwindigkeit (Tab. 2.5b). Schließlich stellen die jeweiligen Exporterfolge der Windindustrie einen Faktor dar, der ebenfalls in die Bewertung einfließt. Tab. 2.5c enthält ein Ranking, das all diese Faktoren berücksichtigt.

Tab. 2.5a

Absolute und relative installierte Windenergiekapazität (1992)

\begin{tabular}{|l|l|l|l|l|}
\hline & Windkapazität absolut (MW) & $\begin{array}{l}\text { Windkapazität pro Kopf } \\
\text { (Watt pro Einwohner) }\end{array}$ & $\begin{array}{l}\text { Windkapazität pro Fläche } \\
\text { (Kilowatt } \\
\text { Quadratkilometer) }\end{array}$ \\
\hline Dänemark & 458 & 85,0 & 10,6 \\
\hline Kalifornien & 1.655 & 46,1 & 3,9 \\
\hline Niederlande & 109 & 6,7 & 2,6 \\
\hline Deutschland & 183 & 2,2 & 0,5 \\
\hline
\end{tabular}

Quellen: vg. Kap. 2, Fischer Weltalmanach 2006, eigene Berechnungen

Die absolute und relative installierte Windenergiekapazität ist offenbar kein adäquater Indikator, um zu beurteilen, inwieweit sich die jeweiligen Marktstrukturen für die Etablierung der Windtechnologie eignen. Zumindest gilt dieses für den deutschen Markt, dessen Erfolge erst im weiteren Verlauf der 90er Jahre manifest geworden sind. Zudem wird die Tatsache 
späterer Markteinstiege Deutschlands und der Niederlande nicht berücksichtigt. Die folgende Übersicht (Tab. 2.5b) verwendet zwei weitere Indikatoren, um die Entwicklungen der Pioniermärkte zu bewerten, die vom Zeitpunkt des Markteinstiegs unabhängig sind: Kontinuität und Entwicklungsgeschwindigkeit. Zudem bietet ein Blick auf das Jahr 1997 darüber Aufschluss, inwieweit während der Pionierphase die Grundlagen für einen weiteren Marktausbau geschaffen wurden. Diese Indikatoren ermöglichen eine deutlichere Trennschärfe zwischen Dänemark und Deutschland als ,Erfolgsmärkten', sowie Kalifornien und Niederlande, mit stagnierender, bzw. langsamer Entwicklung.

Tab. 2.5b Weitere Faktoren zur Beurteilung des Erfolgs der Pionierländer

\begin{tabular}{|c|c|c|c|c|}
\hline & Deutschland & Dänemark & Niederlande & Kalifornien \\
\hline $\begin{array}{lr}\text { Kontinuität/ } & \text { Dynamik } \\
\text { innerhalb der } \\
\text { Pionierphase, auch } \\
\text { unter Berücksichtigung } \\
\text { des Markteinstiegs }\end{array}$ & $\begin{array}{lr}\text { seit } & 1987 \\
\text { kontinuierliche } & \text { und } \\
\text { dynamische } & \\
\text { Entwicklung } & \end{array}$ & $\begin{array}{ll}\text { seit } & 1978 \\
\text { kontinuierliches } & \\
\text { Wachstum } & \\
\end{array}$ & $\begin{array}{ll}\text { seit } & 1987 \\
\text { kontinuierliches, aber } & \text { langsames Wachstum }\end{array}$ & $\begin{array}{l}\text { Dynamische } \\
\text { Entwicklung zwischen } \\
1981 \text { und 1987, } \\
\text { anschließend: } \\
\text { Stagnation } \\
\end{array}$ \\
\hline $\begin{array}{l}\text { Entwicklungsdynamik: } \\
\text { Zwischen } 1993 \text { und } \\
1997 \text { neu installierte } \\
\text { Windkapazität (MW) }\end{array}$ & 1898 & 608 & 210 & 18 \\
\hline
\end{tabular}

Quellen: vg. Kap. 2

Ein letzter Indikator schließlich, der hier berücksichtigt werden soll, besteht in möglichen Exporterfolgen der jeweiligen Windindustrie. Weist ein Produkt gute Exportergebnisse auf, spricht einiges dafür, dass mit dem Produkt auch im Inland positive Erfahrungen gemacht wurden. Diese Annahme spiegelt die Realität der Pioniermärkte gut wider und stimmt mit den Aussagen von Tab. 2.5b überein. Dänemark hatte bis zum Ende der Pionierphase Windturbinen in alle übrigen Pioniermärkte exportiert, insbesondere nach Kalifornien. Auch auf dem niederländischen und deutschen Markt zählen dänische Hersteller bis heute zu marktführenden Unternehmen. Demgegenüber war es niederländischen (Lagerwey ausgenommen) und US-amerikanischen Herstellern (US-Windpower ausgenommen) weder in der Pionierphase, noch in den nachfolgenden Jahren gelungen, sich im Inland zu behaupten, geschweige denn, auf dem internationalen Markt $\mathrm{Fuß} \mathrm{zu}$ fassen. Im Verhältnis zur erfolgreichen dänischen Industrie und den gescheiterten Industrien der Niederlande und den USA gegenüber, nehmen deutsche Hersteller während der Pionierphase eine mittlere Position ein. So hatte die inländische Windindustrie gegenüber der Konkurrenz aus Dänemark einen Rückstand von fünf bis zehn Jahren aufzuholen. Dennoch gelingt es zwei deutschen Unternehmen, Tacke und Enercon, bereits am Ende der Pionierphase, zu den führenden Akteuren des Inlandmarktes zu avancieren. Hauptsächlich Enercon reüssiert im Verlauf der 90er Jahre zunehmend auch auf dem Exportsektor.

Die in Tab. 2.5a und 2.5b verwendeten Indikatoren werden in Tab.2.5c, unter Berücksichtigung des Faktors ,Exporterfolge', zu einem Länder-Ranking zusammengefasst. Aufgrund der angesprochenen Problematik der Faktoren ,absolute' und ,relative Windenergiekapazität' werden diese schwächer gewichtet und zu einem ,1992-Faktor' zusammengefasst. Alle vier Indikatoren werden paritätisch gewichtet. Aus der Durchschnittsbildung der einzelnen Positionen ergibt sich das Gesamtranking:

Tab. 2.5c Ranking der Pionierländer

\begin{tabular}{|l|l|l|l|l|l|}
\hline & $\begin{array}{l}\text { 1992-Faktor } \\
\text { (Position) }\end{array}$ & $\begin{array}{l}\text { Entwicklungsdynamik } \\
\text { (Position) }\end{array}$ & $\begin{array}{l}\text { Kontinuität } \\
\text { (Position) }\end{array}$ & $\begin{array}{l}\text { Exporterfolge } \\
\text { (Position) }\end{array}$ & Durchschnittsposition \\
\hline 1. Dänemark & 1 & 2 & 1 & 1 & 1,25 \\
\hline 2. Deutschland & 4 & 1 & 2 & 2 & 2,25 \\
\hline 3. Niederlande & 3 & 3 & 3 & 3 & 3,0 \\
\hline 4. Kalifornien & 2 & 4 & 4 & 3 & 3,25 \\
\hline
\end{tabular}

Quellen: vg. Tab. 2.5a, Tab. 2.5b, Kap. 2, eigene Berechnungen 
Auch diese Übersicht bietet keine hohe Trennschärfe zwischen Dänemark und der Bundesrepublik einerseits, sowie den Niederlanden und Kalifornien andererseits.

\subsubsection{Qualitative Indikatoren: Akteursstruktur und Fördersystem in den Pioniermärkten}

Die folgende qualitative Darstellung der jeweiligen Akteursstrukturen auf Angebots- und Nachfrageseite, sowie der Fördersysteme, bilden die Situation adäquater ab als das Ranking von Tab. 2.5c. Von den Ergebnissen der Untersuchung ausgehend, werden allgemeine Aussagen getroffen, inwieweit die Pioniermärkte erfolgreich waren:

a) im Aufbau einer Windanlagenindustrie

b) in der Einführung eines zweckmäßigen Fördersystems

c) in der Schaffung kontinuierlicher Nachfrage durch Betreiber-Akteure, von denen ggf. Impulse zur Technik- und Marktgestaltung ausgingen.

Bemerkenswerterweise lässt sich jedes nationale Fördersystem, jede Windanlagenindustrie und Betreiberstruktur mit großer Trennschärfe einer der Kategorien ,erfolgreich'/ ,nicht erfolgreich' zuordnen.

Dänemark-Industrie Die wesentlichen technischen Grundlagen moderner Windanlagentechnik werden in Dänemark bis 1978 während Periode 1 geschaffen. Bis zu diesem Zeitpunkt sind wichtige Vorentscheidungen zur Durchsetzung des dänischen Windanlagenkonzepts zunächst nur in Dänemark - bereits gefallen. Hinsichtlich der technischen Entwicklung zeichnen sich die folgenden Jahre in erster Linie durch inkrementelle Verbesserungen aus: technische Optimierung, Upscaling und Serienfertigung. In der Technikperiode sind Kleinund Kleinstunternehmen aus dem Handwerk, sowie OVE-Ingenieure und Tvind-Leute aktiv. 1979/80 übernehmen mittelständische Firmen den Sektor. Anders als die Handwerksbetriebe sind diese in der Lage, ihre Produktion parallel zur wachsenden Nachfrage auszubauen.

(erfolgreich)

Kalifornien-Industrie Auf dem kalifornischen Markt werden seit 1980/81 ausschließlich Modelle angeboten, die stark vom dänischen Design abwichen. Diese Windturbinen wiesen fundamentale Schwächen auf. Ein Großteil erlitt bereits nach wenigen Betriebsmonaten schwere Schäden und Totalausfälle. Die zunehmende Verdrängung inländischer Hersteller durch Konkurrenz aus Dänemark, beweist die Überlegenheit der dänischen Windanlagenindustrie. Die am Markt verbliebenen US-Hersteller übernahmen das dänische Konzept erst gegen Ende der Pionierphase. Bei diesen Unternehmen handelte es sich vorwiegend um kleinere Firmen, die über begrenzte Kapitalien verfügten und den riskanten Schritt in einen neuen Sektor gewagt hatten.

(nicht erfolgreich)

Niederlande-Industrie Grundsätzlich weichen die niederländischen Windanlagen weniger stark vom dänischen Konzept ab als die US-Designs. Dennoch scheitert die niederländische Industrie weitestgehend. Abgesehen von Lagerwey handelt es sich bei den Turbinenproduzenten, die bis Ende der Pionierphase noch aktiv waren, um etablierte Unternehmen, die zuvor bereits am nationalen Forschungsprogramm mitwirkten. Die letzten Jahre der Pionierphase sind durch starke Konzentrationsprozesse gekennzeichnet. Schließlich existieren nur noch drei Hersteller mit industrieller Turbinenfertigung. Auf dem Inlandmarkt verlor die Industrie immer mehr Anteile an dänische Anbieter.

(nicht erfolgreich)

Deutschland-Industrie Alle drei großen Hersteller der Pionierphase orientierten sich sehr eng am dänischen Modell. Insbesondere Enercon und Tacke, aber auch die Husumer Schiffswerft 
erzielten während der Verstetigungsperiode gute bis sehr gute kommerzielle und technische Erfolge. Die gesamte Pionierphase hindurch werden WEA sowohl von mittelständischen, als auch sehr großen und kleinen Unternehmen verkauft. Kommerziell und technisch erfolgreich sind ausschließlich mittelständische Unternehmen, die sich während der vierten Periode zunehmend durchsetzen.

(erfolgreich)

Dänemark-Fördersystem 1979 wird eine Investitionsförderung für den Kauf von WEA in Höhe von 30 Prozent eingeführt. Dabei muss jeder Turbinentyp ein Zertifikat erhalten, welches allerdings vergleichsweise leicht zu erhalten war. Während der 80er Jahre wird diese Unterstützung schrittweise reduziert, bis sie 1989 gänzlich ausläuft. Seit 1984 erhalten Kooperativen für jede eingespeiste Kilowattstunde 85 Prozent des aktuellen Strompreises, einzelne Betreiber 70 Prozent. Mit dem Windenergiegesetz von 1992 werden 85 Prozent des Tarifs als einheitliche Vergütung festgelegt. Von der Energiesteuer sind die Windmüller ausgenommen. Zusätzlich kann ein Teil der Investitionskosten steuerlich abgeschrieben werden.

(erfolgreich)

Kalifornien-Fördersystem Mit dem National Energy Act von 1978 erhalten Windanlagenbetreiber einen Rechtsanspruch auf Stromeinspeisung in die Netze der EVU, welche den Strom zum Preis vermiedener Kosten vergüten müssen. Wie die Untersuchung gezeigt hat, sind diese Tarife i.a. nicht kostendeckend. Für den kommerziellen Erfolg eines Windturbinenbetreibers wichtiger als die Einnahmen aus dem Stromverkauf sind die ihnen gewährten tax credits. In Kalifornien beträgt die Abschreibungsrate 50 Prozent, so dass sich der Kauf von WEA für viele zu einem lukrativen Geschäftsfeld entwickelte. Geprüft werden die Mühlen in den ersten Jahren nach Einführung des NEA i.a. gar nicht. (nicht erfolgreich)

Niederlande-Fördersystem Seit 1986 wird der Erwerb einer WEA mit einer Zuzahlung von 35 bis 40 Prozent der Investition unterstützt. Damit man die Förderung erhielt, musste das erworbene Modell zuvor ein vergleichsweise anspruchsvolles Prüfungsverfahren durchlaufen haben. Auch die wichtigsten Hersteller erhielten Fördergelder zur Realisierung neuer Konzepte. Dabei bevorzugte das Gesetz leistungsstärkere Windanlagen, die an den Bedürfnissen der EVU orientiert waren. Als Einspeisetarif erhielten die wenigen privaten Betreiber nicht mehr als den Preis vermiedener Kosten. Daher war der Kauf von Windturbinen in den meisten niederländischen Provinzen für Privatakteure nicht attraktiv. EVU wurden im niederländischen System privilegiert behandelt.

(nicht erfolgreich)

Deutschland-Fördersystem Zwischen 1987 und 1989 führen drei Bundesländer Investitionsförderungen zwischen 30 und 50 Prozent ein. Seit 1988 wird die produzierte Kilowattstunde mit acht Pfennig durch den Zentralstaat gefördert (100MW-Programm). Diesen Betrag erhielten die Windmüller zuzüglich zum Einspeisetarif in Höhe vermiedener Kosten. Ende 1990 wird diese Regelung durch ein Einspeisegesetz ähnlich dem dänischen System ersetzt. Von nun an muss der eingespeiste Strom zu 90 Prozent des durchschnittlichen Tarifs vergütet werden. Zusätzlich waren die deutschen Windmüller steuerlich besser gestellt, ebenso wie US-amerikanische und dänische Anlagenkäufer.

(erfolgreich)

Dänemark-Betreiberstruktur Während der Technikperiode haben viele Windmüller ihre Anlage noch eigens gebaut. Ein Markt hat sich erst gegen Ende dieser Periode herausgebildet. Die ersten Betreiber, die ihre Windmühle tatsächlich gekauft hatten, sind Bastler und Windenergieenthusiasten. 1979 treten Landwirte hinzu. Seit Anfang der 80er Jahre avancieren Windradkooperativen zum wichtigsten Betreiber-Akteur. Investoren haben in der Pionierphase nur vorübergehend eine Rolle gespielt. In der dritten Periode verpflichten sich 
EVU zum Kauf eigener WEA. Bis zum Ende der Pionierphase entwickeln sie sich auf dem Windenergiesektor zu einer festen Komponente.

(erfolgreich)

Kalifornien-Betreiberstruktur Käufer sind überwiegend große Planungsgesellschaften, die Beteiligungen an wohlhabende Investoren verkauften. Sowohl diese, als auch jene waren vor allem an Profiten interessiert. Ob die Windanlagen tatsächlich Strom produzierten war von sekundärer Bedeutung.

(nicht erfolgreich)

Niederlande-Betreiberstruktur Die meisten Windanlagen werden von EVU gekauft. Für Privatakteure war der Markt aufgrund unzureichender Fördersituation und einer Energiewirtschaft, die ihre Monopolstellung konsequent gegen die Windmüller in Stellung brachte, kaum zugänglich.

(nicht erfolgreich)

Deutschland-Betreiberstruktur Der erste große Nachfrageschub (1987-1989) stammt überwiegend von den EVU. Seit 1990 ist eine zunehmende Nachfrage seitens der Bürgerwindbewegung zu beobachten. Auch Landwirte und kommerzielle Windparkplaner zählen während der Pionierphase zu wichtigen Akteuren auf Betreiberseite. (erfolgreich)

Diese Eigenschaften der Pioniermärkte sind in Tab. 2.5d zusammengefasst. Die Übersicht manifestiert die Erfolge Dänemarks und der Bundesrepublik deutlicher als das Ranking (Tab. 2.5.1c). Bemerkenswert ist, dass sich die Erfolgsmärkte offenbar in zentralen Eigenschaften ähneln.

Tab. 2.5d Markteigenschaften der Pionierländer und Bewertung

\begin{tabular}{|l|l|l|l|l|l|l|}
\hline & $\begin{array}{l}\text { Konzept } \\
\text { erfolgreich? }\end{array}$ & $\begin{array}{l}\text { Vorwiegende } \\
\text { Herstellergröße } \\
\text { (erfolgreich?) }\end{array}$ & $\begin{array}{l}\text { Konkurrenz der } \\
\text { Industrie } \\
\text { (hoch/niedrig) } \\
\text { (erfolgreich?) }\end{array}$ & $\begin{array}{l}\text { zentrale } \\
\text { Eigenschaften des } \\
\text { Fördermodells } \\
\text { (erfolgreich?) }\end{array}$ & $\begin{array}{l}\text { Zugänglichkeit } \\
\text { der Zertifikate } \\
\text { (erfolgreich?) }\end{array}$ & $\begin{array}{l}\text { Hauptsächliche Betreiber } \\
\text { (erfolgreich?) }\end{array}$ \\
\hline Dänemark & dänisch (ja) & $\begin{array}{l}\text { erst klein, dann } \\
\text { mittelständisch } \\
\text { (ja) }\end{array}$ & $\begin{array}{l}\text { anfangs niedrig, } \\
\text { aufgrund des } \\
\text { Kalifornienexports } \\
\text { wachsend (ja) }\end{array}$ & $\begin{array}{l}\text { Investitionsförderung, } \\
\text { feste Einspeisetarife } \\
\text { (ja) }\end{array}$ & eher leicht (ja) & $\begin{array}{l}\text { Kooperativen, Landwirte, } \\
\text { EVU (ja) }\end{array}$ \\
\hline Deutschland & dänisch (ja) & $\begin{array}{l}\text { mittelständisch } \\
\text { (ja) }\end{array}$ & relativ niedrig (ja) & $\begin{array}{l}\text { kWh-Zuschuss, feste } \\
\text { Einspeisetarife (ja) }\end{array}$ & eher leicht (ja) & $\begin{array}{l}\text { Bürgerwindgesellschaften, } \\
\text { Landwirte, EVU (ja) }\end{array}$ \\
\hline Niederlande & $\begin{array}{l}\text { andere } \\
\text { (nein) }\end{array}$ & groß (nein) & hoch (nein) & $\begin{array}{l}\text { (spezieller) } \\
\text { Investitionszuschuss } \\
\text { (nein) }\end{array}$ & $\begin{array}{l}\text { relativ schwer } \\
\text { (nein) }\end{array}$ & $\begin{array}{l}\text { EVU, Landwirte, kleinere } \\
\text { Investoren (nein) }\end{array}$ \\
\hline Kalifornien & $\begin{array}{l}\text { andere } \\
\text { (nein) }\end{array}$ & $\begin{array}{l}\text { heterogen } \\
\text { (nein) }\end{array}$ & hoch (nein) & $\begin{array}{l}\text { Steuerabschreibungen } \\
\text { (nein) }\end{array}$ & $\begin{array}{l}\text { keine } \\
\text { geeignete } \\
\text { Teststation } \\
\text { vorhanden } \\
\text { (nein) }\end{array}$ & Investoren (nein) \\
\hline
\end{tabular}

Quellen:vg. Kap. 2

\subsubsection{Vergleichende Interpretation}

Warum sind die unterschiedlichen Marktstrukturen mehr oder weniger von Erfolg gekrönt? Unter Bezugnahme auf zentrale Ergebnisse der Untersuchung soll dieser Frage im folgenden nachgegangen werden.

\section{Industrie}

Dänisches Windanlagendesign $\quad$ Seit 1981/82 hat sich dieses Konzept auf dem dänischen Markt, gegenüber allen anderen, als überlegen erwiesen. Die deutsche Windindustrie war zu großen Teilen deshalb erfolgreich, weil sich ihre wichtigsten Akteure sehr eng am dänischen Konzept orientierten. Schlechtere Ergebnisse erzielten niederländische und kalifornische Hersteller, die stärker eigene Wege verfolgten. 

Windenergie der Pionierphase nicht zu. Bis zum Ende von Periode 2 bewegten sich dänische Hersteller quasi in geschützten Räumen. Die meisten Windmüller wollten ihre Turbine von einem in der Region ansässigen Unternehmen erwerben. Eine solche regionale Beziehung zum Käufer lag ebenso im Interesse der Hersteller. Dadurch standen letztere kaum unter Druck, zügig größere Maschinen herzustellen und diese als Innovationen anzupreisen. Sie konnten ihre Designs mit jeder gelieferten Windanlage verbessern. So ideale Bedingungen finden die deutschen Windanlagenbauer seit 1986/87 nicht mehr vor. Denn sie haben es bereits mit einer gut entwickelten internationalen Konkurrenz zu tun. Dennoch: Ein gewisser regionaler Bezug zwischen Hersteller und Käufer existiert auch in der Bundesrepublik. Insbesondere die EVU (gilt auch für die Niederlande) entscheiden sich vorwiegend für inländische Konzepte, obwohl dänische Modelle effizienter waren.

Das 100MW-Programm schützte die deutschen Hersteller vor der anfänglich überlegenen Konkurrenz aus Dänemark und den Niederlanden (Lagerwey). Ebenso wenig wie das dänische Fördersystem, enthält auch das deutsche zunächst keine Elemente, welche die Hersteller zu übereilten technischen Neuentwicklungen gezwungen hätten. Nicht zuletzt bedurfte die deutsche Industrie keiner so langen Entwicklungsphase in ruhigem Fahrwasser wie die Dänen, weil sie von deren Erfahrungen sehr stark profitieren konnten. Vollständig umgekehrt war die Situation auf den kalifornischen und niederländischen Märkten. In Kalifornien setzt Anfang der 80er Jahre eine explosionsartige Nachfrage ein. Verpflichtende Anlagentests existieren nicht. Für die kalifornische Industrie ging es also darum, Windanlagen schnellstmöglich und vor allem schneller als die zahlreichen Konkurrenten, auf den Markt zu bringen. Bei den niederländischen Herstellern ging der Konkurrenzdruck weniger von einer zu schnell wachsenden Nachfrage, als vielmehr der Gestaltung des Fördersystems aus. Zunächst konkurrierten die Hersteller um staatliche Fördermittel. Dazu sollten sie große, technisch anspruchsvolle Konzepte vorlegen. Aufgrund der Konkurrenz herrschte ein hoher Entwicklungsdruck und die vorgelegten Designs waren entsprechend wenig ausgereift. Für allmähliche Lernprozesse blieb keine Zeit.

Mittelstand Sei es im Bereich staatlicher Forschungsförderung, oder auch der kommerziellen Produktion kleiner und mittelgroßer Windanlagen: die gesamte Pionierphase hindurch, ist nicht ein einziges erfolgreiches Turbinendesign durch einen Konzern hervorgebracht wurden. Die Konzerne wollten Großanlagen für Kunden aus dem Energiesektor herstellen. Im Fall des Scheiterns bildeten staatliche Gelder eine hinreichende Absicherung gegen jegliche Risiken. An der Herstellung kleinerer Modelle hatten sie kein Interesse. Ihre Hightech-Konzepte und Baumaterialien waren für die Windanlagenentwicklung in der Pionierphase nicht notwendig und in manchen Fällen sogar hinderlich (bspw. der einflügelige Monopetrus von MBB). Klein- und Kleinstunternehmen sind nur in der Technikperiode erfolgreich. Zum Aufbau einer Serienfertigung, die in der Stabilisierungsperiode erforderlich wird, fehlten ihnen die Mittel. Viele Selbstbauer und kleine Hersteller gaben deshalb zwischen 1979 und 1981 den Windmühlenbau auf. Seitdem traten mittelständische Unternehmen, häufig aus dem Maschinenbausektor, in die Branche ein. Für die Mittelständler ist die serienmäßige Fertigung kleinerer Windanlagen weder ein zu kleines, noch zu großes Geschäftsfeld. Ähnliche Restrukturierungen der Industrie sind Mitte der 80er Jahre in den Niederlanden und der Bundesrepublik zu beobachten.

Zulieferindustrie Anfangs verfügte keiner der Hersteller über hinreichende Kenntnisse zur Herstellung sämtlicher Komponenten einer Windanlage. Deshalb bildete die im Kontext des OVE-Netzwerkes während der Technikperiode entstandene Komponentenmühle, also die Entwicklung standardisierter Hauptkomponenten durch unterschiedliche Firmen, die Voraussetzung wichtiger technologischer Durchbrüche. Seitdem bedienen sich alle führenden 
dänischen Hersteller der neu entstandenen Zulieferindustrie. Das gleiche gilt für die erfolgreichen Anbieter der Bundesrepublik und Lagerwey. Insbesondere was die Rotoren betrifft, greifen sie auf erfahrene dänische Produzenten wie LM und Alternegy zurück. In den USA war es unter den Herstellern lange Zeit üblich, alle Komponenten selbst herzustellen. Aufgrund der schnellen Marktexpansion blieb für den Aufbau einer Zulieferindustrie keine Zeit. Die niederländischen Firmen setzten stärker auf eigene Designs. Einige der Hersteller waren bereits am LSP-Forschungsprogramm beteiligt und versuchten, ihre Erfahrungen auf kommerzielle Windanlagen zu übertragen. Erfahrene Zulieferer aus Dänemark spielten auf dem niederländischen Markt keine Rolle.

\section{Fördersystem}

Anti-AKW-Bewegung Keine Regierung der Pioniermärkte hat ihr Förderprogramm damit begründet, den Forderungen außerparlamentarischer Akteure wie der Anti-AKW- und Umweltbewegung nachzukommen. Solche Proteste sind in allen Pioniermärkten stark ausgeprägt. Insbesondere für Dänemark und Niederlande konnte der unmittelbare Einfluss auf die Energie- und Umweltpolitik nachgewiesen werden. In den übrigen Pionierländern mit Forschungsprogrammen für Windenergie sind solche Akteure nicht in derselben Intensität präsent. Diese empirische Situation begründet die These einer sehr hohen Relevanz der AntiAKW- und Umweltbewegung für die Einführung der Förderprogramme zur Windkraft.

Niedrige Zertifikationskriterien Damit der Kauf einer bestimmten Windanlage gefördert wird, musste sich diese qualifizieren. Dänische Hersteller ließen ihre Modelle daher in der Teststation von Risoe prüfen. Bei dieser Prüfung standen anfangs ausschließlich Sicherheitsaspekte, insbesondere das Vorhandensein eines doppelten Bremssystems im Vordergrund. Erst allmählich werden die Verfahren umfangreicher. Auch das deutsche Testsystem war tolerant konzipiert. Durch diesen Ansatz relativ schwacher Kriterien verhinderte man, dass der Markt in einer frühen Phase eingeschränkt und potenziell innovativer Teilnehmer beraubt wurde. Letzteres war in den Niederlanden der Fall. Das niederländische Fördersystem hatte von Anfang so stark Einfluss auf den technischen Entwicklungspfad genommen, dass nur wenige unterschiedliche Konzepte erprobt werden konnten. Nach vier Monaten Laufzeit des deutschen 100MW-Programm hat die zuständige KfA Jülich bereits 67 Genehmigungen ausgesprochen. Demgegenüber war das niederländische IPW bereits ein volles Jahr in Kraft getreten, bevor das erste Zertifikat vergeben wurde. Das andere Extrem bildete der kalifornische Markt. Hier ist praktisch jedes Modell für die tax credits zugelassen worden. Es spielte offenbar keine Rolle inwieweit eine Windanlage den Prototypstatus überwunden hatte. Eine Teststation wie in den übrigen Pioniermärkten war nicht vorhanden.

Investitionsförderung besser als Abschreibungsvorteile

Während in Kalifornien Steuerabschreibungen die Haupteinnahmequelle der Anlagenbetreiber darstellten, wurde den europäischen Käufern ein Zuschuss zur Investition in Höhe von 30 bis 50 Prozent gewährt. Eine Amortisierung war nur möglich, wenn die Windanlage Strom produzierte, der von den Betreibern zu bestimmten Preisen an die EVU verkauft werden musste. Für Akteure auf dem kalifornischen Markt war es dagegen prinzipiell egal, wie viel Strom hergestellt wird. Ihre Investition rentierte sich allein aufgrund der Abschreibungen nach einigen Jahren. Noch Jahre nach der Marktöffnung wurde in der Regel nicht einmal kontrolliert, ob die Anlage überhaupt intakt war. Auch viele Betreiber interessierten sich diesbezüglich nicht und die Hersteller erhielten in Schadensfällen kaum Feedback. Entsprechend selten wurden Garantieansprüche geltend gemacht und entsprechend wenige Impulse erhielten die Hersteller zur Verbesserung ihrer Konzepte. Das Abschreibungsmodell lohnte sich darüber hinaus nur für wohlhabende 
Personen. Für die Mehrheitsgesellschaft kam die Beteiligung an einer Windanlage nicht in Frage, weil ihre Mitglieder weder genug Steuern zahlten, als dass sich eine solche Investition für sie gerechnet hätte, noch die erforderlichen Kapitalien hätten aufbringen können. Dadurch wird die Akzeptanz von Windparks ebenso vermindert wie die allgemeine Sympathie gegenüber der Windkraft als Energietechnik. Gerade in Dänemark und der Bundesrepublik garantierte der lokale Charakter der Kooperativen, bzw. die Möglichkeiten für Anrainer, sich an Windparkprojekten zu beteiligen, einen Großteil der Akzeptanz der Projekte. In den Niederlanden, wo das Fördermodell stark auf EVU-Windparks ausgelegt war, standen Beteiligungen durch Anrainer häufig gar nicht zur Disposition.

Transformation von der Investitionsförderung zu Festpreistarifen

Bis in die Erprobungsperiode hinein (Mitte der 80er Jahre) hatte sich der Kostenzuschuss als Fördermittel bewährt, sofern die Vergabe nicht zu restriktiv gehalten war. Je stärker sich Investitionen in Windanlagen erst durch Einnahmen aus dem Stromverkauf amortisierten, desto mehr achten Käufer darauf, welche Modelle die besten Kosten-Nutzen-Bilanzen aufwiesen. Je häufiger die Anlagen in der Praxis getestet werden, desto präziser lassen sich entsprechende Vorhersagen treffen. Eine Subventionsförderung, die weiterhin das gesamte Angebot gleichmäßig fördert, verwischt die Unterschiede zwischen guten und weniger guten Produkten. Nur durch Fixpreismodelle (Stromeinspeisungsgesetz, Windenergiegesetz (DK)) oder kWh-bezogene Förderungen (100MW-Programm) wird die Entwicklung von Maschinen mit maximaler Effizienz konsequent gefördert. Am weitesten von diesem Ideal entfernt ist das US-amerikanische Abschreibungsmodell ohne Testsystem. In den Niederlanden wurde noch bis 1995 an der Investitionsförderung festgehalten, während die EVU bis dahin die Definitionsmacht über die Höhe der Einspeisetarife behielten.

\section{Windanlagenkäufer und -betreiber}

Investoren als Hauptakteure problematisch Als Windanlagenbetreiber ist die Gruppe der Investoren für die Pionierphase ungeeignet. Sie verringert die lokale Akzeptanz von Windparks und die Sympathie für Windkraft insgesamt. Investoren sind in Dänemark bis weit über die Pionierphase hinaus vom Markt ausgeschlossen worden. In den Niederlanden und der Bundesrepublik spielten sie während der Pionierphase eine nachgeordnete Rolle.

Energiewirtschaft als Hauptakteur problematisch Die gesamte Pionierphase hindurch und in manchen Ländern noch weit darüber hinaus, betrachteten Energieversorger, die Errichtung von Windparks als Bauernopfer. Sie begrüßten die Forschungsarbeiten an Großwindanlagen, u.a. weil dadurch von den technischen und wirtschaftlichen Erfolgen dänischer Hersteller kleinerer Windanlagen abgelenkt wurde. Als das nicht mehr möglich war, weil 1987, als Ergebnis staatlicher Förderung, Märkte in zwei weiteren westeuropäischen Ländern entstanden sind, änderten die EVU ihre Strategie. Seit 1986 bis 1988 finden sich in sämtlichen europäischen Pioniermärkten EVU, die eigene Windparks betreiben. In Dänemark wird die Energiewirtschaft während der Verstetigungsphase sogar zum wichtigsten Innovationsträger (bspw. Offshorewindpark). Einige kleinere, für küstennahe Gebiete zuständige Netzbetreiber und Stadtwerke verliehen dem deutschen Windenergiemarkt wichtige Impulse. Während der Energiesektor Dänemarks am Ende der Pionierphase einen Marktanteil von etwa 30 Prozent erlangte, war das Engagement der deutschen EVU von eher vorübergehendem Charakter. Das niederländische Fördersystem zielte auf die Energiewirtschaft als Betreiber größerer Windparks. Die EVU waren es, welche der angeschlagenen Windindustrie den ,Gnadenstoß' versetzte (vg. Kap. 2.4.2). Aus Sicht der dänischen und deutschen Windindustrie lässt sich nicht behaupten, dass die EVU als Turbinenkäufer ein Hemmnis darstellten. Unabhängig davon, dass einigen Regionalversorgern ein nicht-taktisches Interesse an der Windenergienutzung zuzusprechen ist: Insgesamt wird die Windkraft von den EVU 
abgelehnt. Dabei erstreckt sich die Ablehnung keineswegs nur auf netzfremde Produzenten. Das Akzeptanzproblem tritt bei Investoren-, ebenso wie bei EVU-Windparks verstärkt auf. In beiden Fällen verbleibt die Wertschöpfung nicht am Ort ihrer Produktion. Proteste gegen den Aufbau von Windparks sind in den Niederlanden ein größeres Hemmnis als in allen anderen Pioniermärkten. In Dänemark sind es vor allem EVU-Windparks, die mit Protesten bedacht werden. Dabei handelt es sich jedoch um den geringeren Anteil der Projekte.

Kooperativen als Hauptakteur geeignet Lokale Windanlagenkooperativen sind in Dänemark über die gesamte Pionierphase hinweg der wesentliche Akteur. Jedes Mitglied der Kooperative erwarb Anteile einer Turbine, nur entsprechend seines Strombedarfs. Ein Finanzierungsproblem existierte daher nicht, weil die meisten Durchschnittsverdiener ohne weiteres leisten konnten, in den Windmühlenbetrieb einzusteigen. Größere Gewinne konnte niemand erwarten, Profitabsichten können daher nicht unterstellt werden. Den Windmüllern ging es darum, gegen Atomenergienutzung zu protestieren, über eine sichere Energiequelle zu verfügen und Stromkosten $\mathrm{zu}$ sparen. Diese Motive der Windmüller gelten als sozial erwünscht. Aufgrund der Gewerbesteuer-Einnahmen und der lokalen Beteiligungen verbleibt die Wertschöpfung großteils am Standort. Die Errichtung von Windturbinen ist daher gut akzeptiert und die Standortfindung entsprechend unkompliziert.

Die Vorteile der Windkooperativen treffen für deutsche Bürgerwindgesellschaften in gleicher Weise zu. Unter den deutschen Windmüllern befinden sich zahlreiche Atomkraftgegner, welche ihrer Mitgliedschaft in Bürgerwindgesellschaften explizit politisch verstehen. Diese Aktivisten haben Erfahrung mit politischer Arbeit wie der Organisation von Veranstaltungen und dem Verfassen von Flugblättern und Artikeln. Sie brachten die Windkraft verstärkt ins öffentliche Gespräch und trugen zur Stärkung der Interessenorganisationen bei. Die dänische Windmüller-Organisation DV ist im Umfeld der ökologischen Praktiker der OVE entstanden. Aus einem ähnlichen Kontext stammen die Vorläufer-Organisationen des einflussreichen BWE. Wichtigster Entstehungshintergrund war stets die Durchsetzung gegen Restriktionen der EVU. ${ }^{356}$ Im Konflikt ,klein-gegen-groß' kommt den Windmüllern die sympathieträchtige David-Rolle zu. Großakteure wie Investoren und Konzernen können diesen Bonus nicht für sich in Anspruch nehmen.

\subsubsection{Kleine oder große Akteure? Windkraft und Zivilgesellschaft}

Wiederholt sind kleine und mittelgroße Akteure als Erfolgsfaktoren analysiert worden. Darüber hinaus scheint das, was bereits für die LSP-Programme nachgewiesen wurde, für die Pionierphase insgesamt zu gelten: Dort, wo die Entwicklung von Großakteuren dominiert ist, scheitert die Etablierung der Windkraft. Welche Schlüsse lassen sich ziehen? Um zu allgemeinen Aussagen zu gelangen, werden im folgenden die wichtigsten Akteure und ihre Pionierleistungen für jedes Land und jede Periode zusammenfassend dargestellt.

Dänemark: Technikperiode (1975-1978)

Die in der ersten Periode eingeleiteten Entwicklungen gehen fast ausschließlich auf Pionierleistungen kleiner und kleinster Akteure zurück. Dem Handwerker Riisager gelingt es, die erprobte Gedser-Mühle nachzubauen und an das lokale Stromnetz zu schließen. Dadurch erhielt die Selbstbau-Bewegung wichtige Impulse. Umweltpolitisch motivierte Ingenieure entwarfen Konstruktionszeichnungen, die sie in Kooperation mit talentierten Handwerkern in die Realität überführten. Während dieser Periode entstehen die ersten kleinen Unternehmen, die Windmühlen für den Markt produzierten. Für die Diffusion von Know-how ist sowohl das OVE-Netzwerk, als auch der Bau der Tvindmühle sehr wichtig. Letzterer trägt darüber hinaus zur Popularität der Windenergie bei.

\footnotetext{
${ }^{356}$ Dieses gilt ebenso für die Niederlande und Kalifornien.
} 
1977 nimmt die Idee, bestimmte Hauptkomponenten wie Rotoren durch Zulieferer herstellen zu lassen, mit der Gründung des ersten unabhängigen Rotorenherstellers konkrete Formen an. Bereits 1978 sehen zahlreiche Akteure das dänische Anlagenkonzept, unter vielen alternativen Windmühlen, als das erfolgverheißenste Design an. Von entscheidender Bedeutung ist die Tatsache, dass sich diese Prozesse technischer Entwicklung und Marktentstehung praktisch ohne staatliche Unterstützung vollziehen. Der größte Teil der Windmühlen wird von Selbstbauern betrieben, ein anderer Teil von Bastlern und Anti-Atom-Aktivisten erworben.

Dänemark: Stabilisierungsperiode (1979-1982)

Jetzt kommt es zu vielfältigen Umbrüchen. Mittelständische Unternehmen der metallverarbeitenden Branche, die über größere Finanzkraft verfügen, haben 1980/81 den Markt übernommen, indem sie, auf Basis der Konzepte der Pioniere, größere Modelle herstellen und Serienfertigungen einrichten. Die kleinen Handwerksbetriebe verschwinden allmählich vom Markt.

Seit 1979 unterstützt die dänische Regierung den Kauf von WEA mit 30 Prozent der Investition. Zusätzlich übt sie Druck auf die Netzbetreiber aus, Windmühlen ans Netz zu schließen und den eingespeisten Strom zu vergüten. Die staatliche Teststation für kleine Windanlagen in Risoe etabliert sich und wird für die Industrie $\mathrm{zu}$ einem wichtigen Kooperationspartner. Seit 1981/82 hat sich das dänische Anlagendesign auf dem Markt durchgesetzt. Als neue Käufer- und Betreibergruppen treten, neben den Landwirten, verstärkt auch lokale Kooperativen hinzu. Letztere tragen entscheidend zur Überwindung der Finanzierungs- und Akzeptanzproblematik bei.

Dänemark: Erprobungsperiode (1983-1987)

Das wichtigste Ereignis ist die Öffnung des großen Windanlagenmarktes in Kalifornien. Dort erhält die dänische Industrie Gelegenheit, die Zuverlässigkeit der eigenen Produkte auf schwierigem Terrain zu testen. Nicht nur US-amerikanische, sondern auch dänische Projektentwickler nutzen die großzügigen Förderbedingungen Kaliforniens und der USFöderation. Sie erwerben Windparks, um Beteiligungen an reiche Dänen zu verkaufen, die von den Steuerabschreibungen profitieren wollten. 1984 werden die EVU durch die Regierung zu weitgehenden Zugeständnissen an die Windmüller genötigt. Infolge dessen sind auch auf dem dänischen Markt Investorgesellschaften präsent geworden. Diese Entwicklung, welche der Akzeptanz von WEA abträglich war, wird 1985, im Zuge eines Kompromisses zwischen Regierung und Energiewirtschaft beendet: Nun verpflichten sich die EVU zum Kauf eigener Windparks. Als Gegenleistung sorgte die Regierung dafür, dass Windparks als Spekulationsobjekte schnell an Attraktivität verloren. Zum Ende der Periode gerät die Industrie in eine schwere Krise, großteils aufgrund der Beendigung der tax redits in Kalifornien/ USA. Die Investitionsförderung wird von 30 auf 20 Prozent gesenkt. Seit 1984 garantiert die Energiewirtschaft den Windmüllern feste Einspeisetarife.

Dänemark: Verstetigungsperiode (1988-1991)

Angesichts bisheriger technischer und besonders auch wirtschaftlicher Erfolge, überrascht es wenig, dass die am Boden liegende Windindustrie mannigfaltige Unterstützung durch staatliche und privatwirtschaftliche Akteure erhielt. Dadurch konnte die Krise bald überwunden werden. Bestehende Zertifizierungsverfahren hatte nicht verhindert, dass technische Mängel zu Schäden in Millionenhöhe führten. Daraufhin treten Prüfungsfirmen wie Det Nordske Veritas und Germanischer Lloyed in die Branche ein und entwickeln, gemeinsam mit der Teststation und den Herstellern, ein umfassenderes Zertifizierungssystem. Kooperativen sind noch immer die Hauptabnehmer der Windanlagen. Technische Innovationen und die Einführung neuer und größerer Windanlagen sind für sie, anders als die EVU, kein sehr wichtiges Kriterium zur Entscheidung für ein bestimmtes Modell. Daher 
werden die zur Installation eigener Windparks verpflichteten EVU, zum wesentlichen Innovationsträger, obgleich sie nur über geringere Marktanteile verfügten. Die Windparkplanungen der EVU waren häufig starken Protesten der Anrainer ausgesetzt. Daher war es aus ihrer Sicht ein logischer Schritt, dass sie sich frühzeitig in den Offshore-Sektor vorwagten. Innerhalb dieser Periode wird die Investitionsförderung gänzlich aufgehoben und stattdessen die Vergütung durch feste Einspeisetarife per Gesetz definiert. Tab. 2.5e bietet eine Übersicht zur Entwicklung der Akteursstruktur der dänischen Windbranche innerhalb der Pionierphase.

Tab. 2.5e Bedeutung kleiner, mittlerer und großer Akteure für die Pionierphase: Dänemark

\begin{tabular}{|c|c|c|c|c|}
\hline Akteure & \begin{tabular}{|l|} 
Relevanz für \\
die \\
Technikperiode
\end{tabular} & \begin{tabular}{|l} 
Relevanz für die \\
Stabilisierungsperiode
\end{tabular} & \begin{tabular}{|l|} 
Relevanz für die \\
Erprobungsperiode
\end{tabular} & $\begin{array}{l}\text { Relevanz für die } \\
\text { Verstetigungsperiode }\end{array}$ \\
\hline \multicolumn{5}{|l|}{ kleine Akteure } \\
\hline Antiatombewegung (allgemein) & hoch & mittel & mittel & mittel \\
\hline $\begin{array}{l}\text { Antiatombewegung (OVE- } \\
\text { Netzwerk, Tvind) }\end{array}$ & hoch & mittel & gering & gering \\
\hline Selbstbauer & hoch & gering & gering & gering \\
\hline $\begin{array}{ll}\text { Handwerksbetriebe } & \text { als } \\
\text { Windturbinenhersteller } & \\
\end{array}$ & hoch & gering & gering & gering \\
\hline $\begin{array}{l}\text { Interessenorganisationen (DV, } \\
\text { FDV) }\end{array}$ & hoch & hoch & hoch & hoch \\
\hline Landwirte als Betreiber & gering & hoch & mittel & mittel \\
\hline Kooperativen als Betreiber & - & hoch & hoch & hoch \\
\hline \multicolumn{5}{|l|}{ mittlere Akteure } \\
\hline $\begin{array}{l}\text { mittelständische } \\
\text { Turbinenhersteller/ Zulieferer }\end{array}$ & gering & hoch & hoch & hoch \\
\hline $\begin{array}{ll}\text { kleine/ } & \text { mittlere } \\
\text { Planungsgesellschaften } & \\
\end{array}$ & - & - & mittel & - \\
\hline Teststation (Risoe) & - & hoch & hoch & hoch \\
\hline \multicolumn{5}{|l|}{ große Akteure } \\
\hline PAS (zentral) & gering & hoch & hoch & hoch \\
\hline $\begin{array}{lr}\text { Investoren, } & \text { große } \\
\text { Windparkplanungsgesellschaften } \\
\end{array}$ & - & - & \begin{tabular}{|l|} 
hoch (besonders \\
Kalifornien-Export) \\
\end{tabular} & mittel \\
\hline EVU als Betreiber & - & - & mittel & hoch \\
\hline Zertifizierungsunternehmen & - & - & - & hoch \\
\hline
\end{tabular}

Quellen: vg. Kap. 2

Kalifornien: Stabilisierungs- und Erprobungsperiode (1980-1987)

In Kalifornien wirkte sich die Energiekrise besonders stark aus. Durch Proteste seitens AntiAKW-Bewegung und Anrainer wurden die Planungen neuer Atomkraftwerke erschwert und verteuert. Darüber hinaus ließ sich die Brown-Administration auf das Wagnis erneuerbarer Energien ein und garantierte Investoren zusätzliche Abschreibungsvorteile. Auf dem Markt für Windkraft waren fast ausschließlich Investoren aktiv, welche die Beteiligungen an Windparks vor allem als lohnende Investition ansahen. Zertifikationsverfahren gab es keine.

US-amerikanische Hersteller boten i.a. unzureichend erprobte Windanlagen zum Kauf an, die häufig bereits nach kurzer Betriebsdauer Totalschäden erlitten. Bei diesen Herstellern handelte es sich um risikofreudige Unternehmen, die über ausreichend Kapitalien verfügten, um Serienfertigungen einzurichten.

Nachdem die Energiepreise um Mitte der 80er Jahre gefallen waren und die USamerikanische Windindustrie gescheitert war, gaben sowohl die Föderalregierung, als auch die republikanische Nachfolgeregierung der Brown-Administration, die Förderung der Windenergie weitgehend auf. Infolgedessen kollabierte der Markt (vg. Tab. 2.5f). 
Tab. 2.5f Bedeutung kleiner, mittlerer und großer Akteure für die Pionierphase: Kalifornien

\begin{tabular}{|l|l|}
\hline Akteur & Relevanz \\
\hline kleine Akteure & \\
\hline Anti-AKW-Bewegung als politischer Akteur & hoch \\
\hline Landwirte als Betreiber & gering \\
\hline & \\
\hline mittlere Akteure & \\
\hline Windanlagenhersteller & hoch \\
\hline & \\
\hline große Akteure & \\
\hline PAS (Kalifornien/ USA) & hoch \\
\hline Investoren, große Windparkplanungsgesellschaften & hoch \\
\hline
\end{tabular}

Quellen: vg. Kap. 2

Niederlande: Verstetigungsperiode (1986-1991)

Der Markt für Windanlagen wird 1986 mit Einführung des IPW eröffnet. Das IPW setzte die, vorwiegend dem etablierten Mittelstand zuzurechnenden, bzw. mit Konzernen liierten Hersteller, frühzeitig in Konkurrenz zueinander. Die Industrie wurde genötigt, größere Modelle auf den Markt zu bringen, die schlecht getestet waren. Gekauft wurden die WEA insbesondere von EVU und kleineren Investoren. Erstere hatten wichtigen Einfluss auf die technische und ökonomische Entwicklung der Windindustrie genommen. Großunternehmen, die sich gegen Ende der Pionierphase als Turbinenhersteller betätigten mussten den Sektor aus finanziellen Gründen aufgeben, weil sie ihr Angebot zu sehr an der EVU-Nachfrage ausgerichtet hatten. Einzig Lagerwey, ein mittelständischer Hersteller, der kleine Anlagen für den privaten Markt produzierte, war vergleichsweise erfolgreich, insbesondere auch auf dem deutschen Exportmarkt (vg. Tab. 2.5g).

Tab. 2.5g Bedeutung kleiner, mittlerer und großer Akteure für die Pionierphase: Niederlande

\begin{tabular}{|l|l|}
\hline Akteur & Relevanz \\
\hline kleine Akteure & \\
\hline Antiatombewegung (allgemein) & hoch \\
\hline Kleinunternehmen & gering \\
\hline Landwirte/ Kooperativen als Betreiber & gering \\
\hline & \\
\hline mittlere Akteure & \\
\hline mittelständische Turbinenhersteller & mittel \\
\hline Teststation & hoch \\
\hline mittelständische Entwicklungsgesellschaften, Investoren & mittel \\
\hline & \\
\hline große Akteure & \\
\hline PAS (Zentralstaat) & hoch \\
\hline Konzerne als Turbinenhersteller & hoch \\
\hline EVU als Betreiber & hoch \\
\hline
\end{tabular}

Quellen:vg. Kap. 2

Deutschland: Verstetigungsperiode (1986-1991)

Nachdem das BMFT den Aufbau einiger Windparks zu Testzwecken unterstützt hatte, stellt das 100MW-Programm von 1988 den eigentlichen Auftakt einer beschleunigten Marktentwicklung dar. Die Betreiberstruktur zeichnet sich in der Anfangsphase durch eine hohe EVU-Beteiligung aus. Während des Untersuchungszeitraums spielen Investoren eine geringere Rolle. Kleinakteure, insbesondere Landwirte und Bürgerwindgesellschaften dominieren die Pionierphase. Unter den anfangs kleinen, großen und mittelständischen 
Turbinenherstellern, kristallisierten sich bis zum Ende der Pionierphase vor allem drei Mittelständler heraus, die auf Basis des dänischen Anlagenkonzeptes, kommerzielle Erfolge verzeichneten. Mit dem Inkrafttreten des Stromeinspeisegesetz werden seit 1990/91 die EVU weitgehend vom Markt ausgeschlossen. Bis zum Ende der Pionierphase dominieren zivilgesellschaftliche Akteure den Sektor. Erst allmählich, im weiteren Verlauf der 90er Jahre, werden mittelständische Planungsgesellschaften zum Hauptakteur.

Tab. 2.5h Bedeutung kleiner, mittlerer und großer Akteure für die Pionierphase: Deutschland

\begin{tabular}{|l|l|}
\hline Akteur & Relevanz \\
\hline kleine Akteure & \\
\hline Antiatombewegung (allgemein) & hoch \\
\hline Kleinunternehmen & gering \\
\hline Landwirte/ Bürgerwindgesellschaften als Käufer & hoch \\
\hline & \\
\hline mittlere Akteure & \\
\hline mittelständische Turbinenhersteller & hoch \\
\hline Teststation & hoch \\
\hline mittelständische Entwicklungsgesellschaften, Investoren & mittel \\
\hline Stadtwerke/ Regionale EVU als Betreiber & hoch \\
\hline & \\
\hline große Akteure & \\
\hline PAS & hoch \\
\hline Zertifizierungsunternehmen & hoch \\
\hline Konzerne als Turbinenhersteller & gering \\
\hline große EVU als Betreiber & gering \\
\hline
\end{tabular}

Quellen: vg. Kap. 2

\section{Auswertung}

Innerhalb der Pionierphase nimmt die erste Periode einen Sonderstatus ein. Sämtliche Erfolge werden von kleinen Akteuren erreicht. Insbesondere der Zentralstaat, der aufgrund seiner Förderung, in allen übrigen Perioden, international zum wichtigsten Großakteur geworden ist, spielt in Periode-1-Dänemark praktisch keine Rolle. Zudem sind als Turbinenhersteller, Anlagenkäufer und Betreiber ausschließlich kleine und sehr kleine Akteure aktiv. Für die Perioden 2 bis 4 lässt sich über alle Pioniermärkte sagen, dass es sich bei den erfolgreichen Anbietern ausschließlich um mittelständische Unternehmen handelt.

Unter den Betreibern wurde eine starke Heterogenität festgestellt: Hier finden sich kleine, mittlere und große Akteure. In der Bundesrepublik und Dänemark herrschen, über die gesamte Pionierphase hinweg, Landwirte und kleine Betreibergemeinschaften vor. Insbesondere in der Verstetigungsperiode kommt energiewirtschaftlichen Akteuren in Dänemark und der Bundesrepublik eine nicht zu unterschätzende innovationsfördernde Bedeutung zu. In den Niederlanden und Kalifornien herrschen dagegen große Akteure, EVU, bzw. Investoren vor. Tab. 2.5i bietet eine Übersicht der in den jeweiligen Pioniermärkten zu bestimmter Zeit jeweils vorherrschenden Akteursgröße. 
Tab. 2.5i Zusammenfassende Übersicht: Akteure auf der Angebot- und Nachfrageseite

\begin{tabular}{|c|c|c|c|c|}
\hline & Technikperiode & \begin{tabular}{|l|} 
Stabilisierungsperiode \\
\end{tabular} & Erprobungsperiode & Verstetigungsperiode \\
\hline Dänemark & $\begin{array}{l}\text { Industrie: klein } \\
\text { Käufer/ Betreiber: klein } \\
\text { (Selbstbauer, Bastler, } \\
\text { Windenergieenthusiasten) }\end{array}$ & \begin{tabular}{|l|} 
Industrie: \\
mittelständisch \\
Käufer: \\
(Kooperativen, \\
Landwirte) \\
\end{tabular} & $\begin{array}{l}\text { Industrie: mittelst. } \\
\text { Käufer: klein/ } \\
\text { mittelst./ groß } \\
\text { (Kooperativen, } \\
\text { Investoren, EVU) } \\
\end{array}$ & $\begin{array}{l}\text { Industrie: mittelst. } \\
\text { Käufer: klein/ mittel/ groß } \\
\text { (Kooperativen, EVU) }\end{array}$ \\
\hline Kalifornien & & \begin{tabular}{|ll}
$\begin{array}{l}\text { Industrie: mittelst. } \\
\text { Käufer: } \\
\text { (Investoren) }\end{array}$ & groß \\
\end{tabular} & \begin{tabular}{|l}
$\begin{array}{l}\text { Industrie: mittelst. } \\
\text { Käufer: } \\
\text { (Investoren) }\end{array} \quad$ groß \\
\end{tabular} & \\
\hline Niederlande & & & & $\begin{array}{|lr|}\text { Industrie: } & \text { mittelst./ } \\
\text { Käufer: } & \text { mittelst./ groß } \\
\text { (EVU, } & \text { mittelgroße } \\
\text { Investoren) } & \\
\end{array}$ \\
\hline Deutschland & & & & $\begin{array}{l}\text { Industrie: mittelst. } \\
\text { Käufer: klein/ mittel } \\
\text { (Landwirte, Unternehmen, } \\
\text { Bürgerwindgesellschaften, } \\
\text { zumeist kleinere EVU/ } \\
\text { Stadtwerke) }\end{array}$ \\
\hline
\end{tabular}

Quellen: vg. Kap. 2

Bezüglich der Größe der Akteure lassen sich folgende Schlüsse über die Pionierphase ziehen. Dabei beziehen sich alle Aussagen ausschließlich auf die Perioden 2 bis 4 . Für die Marktentwicklung sind Fördermaßnahmen durch die Zentralregierung unerlässlich. Dieses Ergebnis wird durch den Zusammenbruch des kalifornischen Marktes nach dem Rückzug föderaler und bundesstaatlicher Förderung eindrucksvoll bestätigt. Als Turbinenhersteller sind überwiegend mittelständische Firmen aktiv, die häufig bereits zuvor im Maschinenbau tätig waren. $\mathrm{Zu}$ den erfolgreichen Herstellern aus Dänemark und Deutschland zählen ausschließlich Mittelständler. Kleinunternehmen und Konzerne scheitern.

Großakteure auf Betreiberseite, also EVU und Investoren, haben sich für die Pionierphase in den meisten Fällen als ungeeignet erwiesen. Dieses gilt insbesondere dort, wo sie Hauptakteur sind. Erfolgreich sind zivilgesellschaftliche Akteure wie Windradkooperativen, Bürgerwindgesellschaften und Landwirte, die nur bedingt kommerzielle Zwecke verfolgt haben. Insbesondere während der dritten und vierten Periode gesellen sich diesen Betreibern auch mittlere und große Akteure hinzu. Weder in Dänemark, noch in der Bundesrepublik erreichen sie marktführende Positionen. Als Ergebnis ist festzuhalten: Die Kombination aus mittelständischer Windanlagenindustrie und zivilgesellschaftlichen Betreibern ist eine wichtige Voraussetzung für den Erfolg der Pioniermärkte Dänemark und Deutschland.

\subsubsection{Das dänische Erfolgsmodell der Pionierphase}

Die komplette Pionierphase absolviert ausschließlich der dänische Markt. Vorangehend sind die wichtigsten Eigenschaften des dänischen Erfolgsmodells, auch in Abgrenzung gegen die übrigen Pioniermärkte, herausgearbeitet worden. Diese bestehen in:

a) den Entwicklungsvoraussetzungen zur Kommerzialisierung des dänischen Konzeptes (Periode 1):

- erfolgreiches Konzept ist bereits vor Einsetzen der Pionierphase vorhanden (GedserMühle von Johannes Juul)

- handwerkliche Tradition korrespondiert mit siegreichem Anlagenkonzept, dessen Realisierung keinerlei Technologie voraussetzt, auf die ein Handwerker nicht Zugriff hätte 
- umweltpolitisch motivierte Ingenieure wollen ihre Ziele selbst in die Praxis übersetzen, ohne sich von Entscheidungen der Politik abhängig zu machen

- kooperative Tradition: Zusammenarbeit zwischen Handwerkern und Ingenieuren an den Volkshochschulen

b) den folgenden Eigenschaften einer mittelständischen Windindustrie, welche das Knowhow und die Konzepte der Graswurzelaktivisten und kleiner Handwerksbetriebe übernommen hat

- Unternehmen gehören zur metallverarbeitenden Industrie, was der Herstellung von Windturbinen zuträglich war

- Hersteller können auf Zulieferbetreibe zurückgreifen, wodurch sich die Produktion einer Windturbine wesentlich vereinfachte

- aufgrund regionaler Beziehungen zwischen Käufer und Hersteller bestand zunächst nur geringe Konkurrenz und die Hersteller hatten genug Zeit ihre Konzepte zu optimieren

- aus demselben Grund war es den Herstellern leicht möglich, schnelles Feedback von den Betreibern einzuholen und etwaige Mängel zu korrigieren

c) einer aus vorwiegend lokalen Kooperativen, also zivilgesellschaftlichen Akteuren, bestehenden Käufergruppe. Ihre Präsenz und ihr Erfolg erklärt sich durch folgende Gründe:

- kooperative Tradition, welche durch den Windmühlenbetrieb zu neuem Leben erweckt wird

- Kooperativen werden gut akzeptiert, weil sie lokal verankert, nicht primär kommerziell motiviert waren und die Wertschöpfung in der Region verblieb

d) einer adäquaten politischen Förderung

- Investitionszuschüsse, die zu Beginn von Periode 2 (1979) eingeführt, sukzessive reduziert und in der Verstetigungsperiode (1989) beendet werden

- seit 1984: Garantie fester Tarife, die 1992 im Windenergiegesetz festgeschrieben werden

- niedrige Zertifikationskriterien, um eine Windanlage zur Förderung zuzulassen

$\underline{\text { Import des dänischen Modells nach Deutschland }}$

Viele dieser Eigenschaften werden vom deutschen Markt adaptiert. Besonders wichtig und in dieser Ausprägung einmalig ist die weitgehende Übernahme dänischer Technologie durch die erfolgreichsten Windanlagenhersteller der Bundesrepublik (Enercon, Tacke und HSW). Zum Zeitpunkt des Markteinstiegs dieser Firmen, um 1985, ist sich das danish design bereits gut bewährt. Bei den deutschen Herstellern handelt es sich, ähnlich wie bei den Dänen, um Mittelständler aus dem Maschinen- und Schiffsbau. Ebenso wie dänische, greifen auch deutsche Firmen auf Rotoren von Zulieferern aus Dänemark zurück. Seit ihrem Markteintritt sind die deutschen Hersteller einem höheren Konkurrenzdruck ausgesetzt als dänische Unternehmen in der Stabilisierungsperiode. Zugleich ist der Wettbewerb unter deutschen Herstellern schwächer ausgeprägt, als derjenige der Niederlande und Kaliforniens. Auch das Kriterium der Regionalität ist auf dem deutschen Markt zwar weniger gegeben als in Dänemark, ist nichtsdestotrotz deutlich eher erfüllt als in Kalifornien. Beides ist in der Verstetigungsperiode bereits nicht mehr so wichtig, wie noch Anfang der 80er Jahre, als die Anlagentechnik insgesamt weniger erprobt war. Auch unter schwierigeren Bedingungen können deutsche Unternehmen die Rückstände gegenüber anderen Marktteilnehmern relativ schnell aufholen. 
Sehr hohe Ähnlichkeiten weisen das deutsche und dänische Fördermodell auf: anfangs kWhZuschlag, bzw. Investitionszuschlag (100MW-Programm), später garantierter Netzzugang und Mindesteinspeisetarif (SEG). Auch sind die Zulassungskriterien der KFA Jülich, zum Erhalt eines Zertifikats als Fördervoraussetzung einer Windturbine, ähnlich wie in Risoe, eher tolerant gehalten.

Etwas komplexer stellt sich die Situation beim Vergleich der Käufergruppen dar. Zwar nehmen Kooperativen auf dem deutschen Markt während der Pionierphase einen geringeren Stellenwert ein als in Dänemark. Dafür kommt den ersten Bürgerwindgesellschaften als dezidierten Atomkraftgegnern ein beachtliches politisches Eigengewicht zu. Ähnlich wie in Dänemark haben kleine Akteure auch hierzulande eine führende Stellung eingenommen. Auch Landwirte spielen als Einzelbetreiber eine sehr wichtige Rolle. Anders als in Dänemark etablieren sich deutsche EVU nicht im Windsektor, sondern bleiben, von einigen Anfangsaktivitäten abgesehen, eine Randerscheinung.

Trotz einiger Unterschiede lässt sich sagen, dass der deutsche Markt insgesamt eine ähnliche Akteursstruktur wie der dänische aufweist. In diesen vier Punkten zeigt sich die Ähnlichkeit mit dem dänischen Erfolgsmodell am deutlichsten:

- in der Übernahme des dänischen Designs durch die erfolgreichsten Akteure der deutschen Windanlagenindustrie

- in der Dominanz kleiner Akteure, insbesondere gemeinschaftliche Betreiber als Anlagenkäufer und -betreiber

- in der Etablierung eines toleranten Testsystems

- $\quad$ in der Übernahme einer an den Strompreis gekoppelten Einspeisevergütung

- im Erfolg mittelständischer Unternehmen bei der Herstellung von WEA

\subsubsection{Zur Diffusionsfähigkeit des dänischen Modells}

Die wesentlichen Charakteristika des dänischen Modells hatten sich bereits nach Abschluss der Stabilisierungsperiode herausgebildet. Ein erfolgreiches Überwinden der Pionierphase setzt allerdings voraus, dass sich die Windkraft auch in anderen Ländern zu etablieren vermag. Nun hätte eine Pionierphase diesen Namen nicht verdient, wenn darin nicht viele Erkenntnisse gewonnen worden wären, die von anderen Märkten mit Erfolg hätten aufgegriffen werden können. Dieses ist im Falle der Windenergie offenbar keine Trivialität. Zwar ist die neue Technologie von drei weiteren Märkten innerhalb der Erprobungs-, bzw. Verstetigungsperiode eingeführt worden. Jedoch sind zwei dieser Märkte weitgehend gescheitert. Nur in der Bundesrepublik, wo die Entwicklung deutlich am dänischen Modell orientiert ist, reüssiert sie. Aus dieser empirischen Situation lässt sich eine zentrale Eigenschaft der Pionierphase ableiten: Nur das dänische Modell ist erfolgreich. Stärkere Abweichungen von diesem Modell führen in der Pionierphase zum Scheitern dieser Märkte.

Die Frage, weshalb Windkraft nicht bereits seit Beginn der dritten oder vierten Periode, auch in vielen anderen Ländern zum Einsatz gekommen war, scheint einfach zu beantworten: Um Mitte der 80er Jahre ist die Windkraft keine proven technology. Sie war es auch 1987/88 nicht, nachdem in Kalifornien an mehreren Hundert dänischen Windanlagen schwere Mängel festgestellt wurden. Investitionen in die Windkraft gingen daher mit hohen Risiken einher.

Allen vier Pioniermärkten sind nicht nur gute Windressourcen bei gleichzeitigem Energiemangel gemeinsam, sondern auch Probleme bei der Einführung, bzw. dem Ausbau der Atomenergie infolge von Protesten. Hervorzuheben ist, dass die Graswurzelakteure auch in den Niederlanden und der Bundesrepublik eine wichtige Rolle bei der Markteinführung spielten, obwohl sie erst in der zweiten Hälfte der Pionierphase eingestiegen waren. In einigen südeuropäischen Ländern wie Spanien, Italien und Griechenland, mit akutem Energiemangel, massivem Nachfragewachstum und guten Windressourcen, wird kein Markteinstieg 
vollzogen, obgleich dort erste Erfahrungen mit großer und kleiner Windkraft vorliegen. In keinem dieser Länder sind stärkere Anti-AKW-Bewegungen aktiv gewesen. Nur in wenigen Ländern sind alle drei Faktoren gegeben, die, ganz allgemein, als der staatlichen Förderung der Windkraft zuträglich, analysiert wurden. Daher muss für die Pionierphase von einer begrenzten Diffusionsfähigkeit der Windtechnologie ausgegangen werden. Möglicherweise ist die Diffusionsfähigkeit des dänischen Modells der Windenergienutzung ebenso so engen Grenzen unterworfen, wie die Einführung der neuen Technologie in der Pionierphase. Zur Klärung dieser Frage soll im folgenden diskutiert werden, ob prinzipiell ein großer Anteil der Eigenschaften des dänischen Modells, von den übrigen Pioniermärkten hätte adaptiert werden können.

Die Tatsache hoher Spezifik der Entwicklungen manifestiert sich bereits in der Technikperiode. Dass die Kommerzialisierung der Juulschen Designs gerade in Dänemark gelingt, ist alles andere als ein Zufall. Erstens ist die Gedser-Mühle den Dänen nicht nur als Objekt präsent. Auch ist die Konstruktionszeichnung frei zugänglich. Zweitens dominiert in Dänemark ein handwerklicher Entwicklungspfad, als ein Ausdruck dessen, man die vergleichsweise einfache Gestaltung der Gedser-Mühle interpretieren kann. Viele dänische Handwerker waren von der Juulschen Turbine auch deshalb begeistert, weil ihre Versuche, die Mühle nachzubauen, nicht ohne Aussichten auf Erfolg zu sein schienen. Drittens existiert im sozialen und ökonomischen Leben des Landes eine kooperative Tradition. Zu den wichtigsten Orten an denen diese Tradition gelebt wird, zählen die Volkshochschulen. Dort trafen begabte Handwerker und Bastler auf politisch ambitionierte Ingenieure. Die Kommerzialisierung des Juul-Designs war nur möglich, weil beide Gruppen zusammenarbeiteten und ihre Kenntnisse in die Konstruktion und Realisierung von Windmühlen einbrachten. Diese Ausführungen zeigen, dass sich die Technikperiode in dieser Weise nur in Dänemark hatte ereignen können. Mit dem Fortschreiten der Pionierphase verbreitern sich die Diffusionschancen. Man kann die Stabilisierungsphase als eine Periode erfolgreicher Erprobung des dänischen Konzeptes in Dänemark begreifen.

\section{Windenergie in Kalifornien: Wie viele Wege führen nach Rom?}

Etliche Fehlentwicklungen des kalifornischen Marktes sind aufgezeigt worden. Es stellt sich die Frage, ob nicht ein Großteil der Fehler hätte vermieden werden können, wenn man sich seitens Industrie und Administration die Mühe gemacht hätte, den dänischen Markt eingehender zu studieren. Jedoch gibt es starke Argumente gegen den hohen Erklärungswert einer solchen ,Ignoranz-These'. Anhand von Beispielen soll im folgenden diskutiert werden, weshalb Kalifornien nur wenig von den Erfahrungen aus Dänemark hätte profitieren können. Die Überlegenheit der Investitionsförderung für den Kauf zertifizierter WEA, bzw. definierter Einspeisetarife, gegenüber den tax credits ist hinreichend diskutiert worden. Im November 1978, als in den USA die Steuerabschreibungen im Rahmen des National Energy Act beschlossen wurden, lagen noch keine Erfahrungen, bzgl. der Förderpolitik für Windenergiemärkte vor. Zudem sind 1980, als in Kalifornien zusätzliche tax credits beschlossen wurden, weder die Probleme dieses Fördersystems, noch die Erfolge der dänischen Regelung offenkundig geworden. In Bezug auf die Fördergesetze ist Kalifornien 1980 in derselben Weise Pionierland wie Dänemark. Ein wichtiger Grund dafür, weshalb man die tax credits auch dann nicht modifiziert oder abgeschafft hatte, als deren Scheitern nach kurzer Zeit manifest wurde, liegt teilweise in den Beharrungskräften eines einmal etablierten Systems. Die Macher des Gesetzes hätten Fehler eingestehen und die Regelung auf föderaler Ebene in Frage stellen müssen. Auch mochte die Tatsache, dass ein kleiner Staat wie Dänemark, gegenüber dem innovativen Hightech-Land Kalifornien Recht behalten sollte, nicht ohne weiteres zu akzeptieren gewesen sein. Schließlich ist in Frage zu stellen, ob die dänische Gesetzgebung in Kalifornien überhaupt erfolgreich gewesen wäre. Tausende 
Windmüller waren in Dänemark bereit, auch ohne Profitaussichten, ein begrenztes finanzielles Wagnis einzugehen. Haupteinnahmequelle sind erhoffte Vergütungen aus dem Stromverkauf, bzw. Stromeinsparungen, nicht garantierte Steuerrückzahlungen. Die Windanlagen mussten also funktionieren. Dazu bedurfte es dreier Voraussetzungen, die nicht in Kalifornien, wohl aber in Dänemark gegeben waren: Zuverlässige Technik dank Anwendung des dänischen Konzeptes, Anlagenzertifizierung, enger Austausch zwischen Käufer und Hersteller.

Die Kommerzialisierung der erfolgreichen dänischen Bauweise war in den USA so lange undenkbar, bis sich die Technik als Importprodukt bewährt hatte. 1980 sind die US-Hersteller ebenso Pioniere im Windanlagenbau wie die Dänen. In den USA herrscht ein vollständig anderer technischer Entwicklungspfad als in Dänemark. Anstatt auf einfache handwerkliche Methoden und robuste Bauweise zu setzen, ist man daran gewöhnt, technische Barrieren durch den Einsatz neuer Materialien und theoretischer Lösungsmodelle zu überwinden. Vom Erfolg des dänischen Konzeptes lässt man sich erst überzeugen und inspirieren, nachdem sich in der zweiten Hälfte der 80er Jahre, dänische Hersteller den kalifornischen Markt zunehmend untereinander aufteilten. Was für die Fördermodelle gilt, trifft auf die Bauweise in derselben Weise zu: Eine kurzfristige und radikale Umstellung auf das dänische Konzept hätte zu hohen Kosten geführt und wäre einem weitgehenden Neubeginn gleichgekommen.

Ein drittes Problem, weshalb Kalifornien als Pionierland der Windenergietechnik denkbar ungeeignet war, besteht in der Geografie des Landes. Die besten Standorte sind dort gelegen, wo nur wenige Menschen leben. Sowohl Anlagenkäufer, als auch Betreiber und Hersteller lebten häufig weit von den Mühlen entfernt. Demgegenüber war die Regionalität als einer der wichtigsten Erfolgsfaktoren Dänemarks herausgearbeitet worden.

Eine wichtige, in Dänemark hervorgebrachte Pionierleistung hätte vom kalifornischen Pioniermarkt frühzeitig und ohne größere Kosten übernommen werden können: die Etablierung einer Teststation für kleine Windanlagen und eines Zertifikationssystems. Beides wäre leicht möglich gewesen, insbesondere nachdem der Erfolg der Teststation in Risoe 1981/82 offenkundig wird. Die Frage, ob die Ursache dieses schweren Fehlers in mangelnder Aufmerksamkeit der verantwortlichen, oder anderen Gründen wie einem unangemessen hohen Vertrauen in die Privatwirtschaft zu suchen ist, muss an dieser Stelle offen bleiben.

Die meisten der hier angeführten Beispiele demonstrieren die mangelnde Kompatibilität des kalifornischen Marktes mit dem dänischen Modell (vg. Schaubild 2.5a). Ein Großteil der spezifischen Voraussetzungen ist in Kalifornien nicht gegeben. Erschwerend kommt die Tatsache des frühen kalifornischen Markteinstiegs hinzu. Denn zu diesem Zeitpunkt ist der Erfolgscharakter wichtiger dänischer Pionierleistungen noch gar nicht abzuschätzen. Für die Bewertung des Handelns US-amerikanischer und kalifornischer Policy-Maker und Windanlagenhersteller ist die ,Ignoranz-These' daher zurückzuweisen. 
Wichtigste Eigenschaften des dänischen Modells

Technologie
Dänisches Konzept
hat sich in Dänemark
seit 1981 bewährt

keine Übernahme dänischer Technlogie möglich

$\longrightarrow$

Diffusionshemmnisse:

- Marktöffnung bevor Erfolg des dänisches Konzepts offenkundig ist

- Unterschiede in der Tradition technischer Entwicklung

- Fördersystem Kaliforniens schafft keine Spielräume und keine Anreize zur Reflexion der Konzepte
Kalifornien

Technlogie (seit 1980)

- stark abweichend vom dänischen Konzept

- hohe Schadensanfälligkeit keine Übernahme des Fördersystems möglich

\section{Fördersystem}

Investitionsförderung seit 1979

Seit 1984 werden zusätzlich Mindestabnahmetarife garantiert

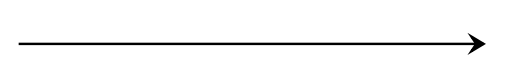

Diffusionshemmnisse

- US-Fördersystem ist zeitlich vorgelagert - Föderales System der tax credits schafft Pfadabhängigkeit für Kalifornien

- Urheber der Regelung sind nicht bereit, Fehler einzugestehen

- Vertrauen der Administration auf neue Technologien und Investmentfonds, daher: keine Installierung von Zertifikationsverfahren, Teststation wird nicht etabliert keine Übernahme dänischer

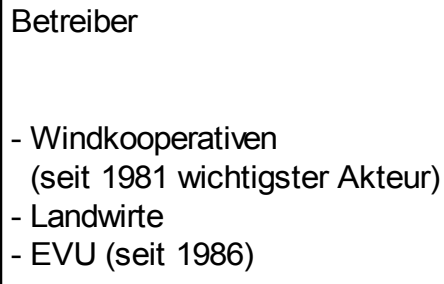

\section{Betreiberstruktur möglich}

Diffusionshemmnisse:

- keine kooperative Tradition habende Investoren
Betreiber (seit 1980/81)

- Fördersystem bevorzugt wohl-

- Für Durchschnittsverdiener, die nur geringfügige Steuern zahlen, wäre die Investition zu einem Minusgeschäft geworden gesellschaften/ Investoren

\section{Fördersystem}

tax credits: seit 1978

föderal, seit 1980 zusätzlich

in Kalifornien; Einspeisetarife auf Basis vermiedener Kosten 
Windenergie in den Niederlanden: Verpasste Lernchancen?

Anders als in Kalifornien stellt sich die Situation in den Niederlanden dar. 1986, zum Zeitpunkt des niederländischen Markteinstiegs, liegen bereits umfangreiche Erfahrungen vor, auf die hätte zurückgegriffen werden können. Folgende Elemente haben sich bis Mitte der 80er Jahre gut bewährt: danish design; Kooperativen als wesentliche Käufer und Betreiber; breit angelegte Förderung (Investitionsförderung/ Mindesteinspeisetarife/ niedrig angesetzte Zertifizierungskriterien); Schaffung von Restriktionen gegen EVU, um zu verhindern, dass sie ihre Monopolmacht ausspielen, um die Windmüller vom Markt zu drängen. Der niederländische Windenergiesektor hat demgegenüber konträre Eigenschaften: Mindesteinspeisetarife gab es nicht. Als Richtlinie galt der Preis vermiedener Kosten, über dessen Höhe die regionalen Versorger autonom entscheiden durften. Gefördert wurden technisch anspruchsvolle Konzepte, wobei auf rasche Steigerung der Generatorengröße gesetzt wird. Kooperativen und andere private Betreiber spielen in den Niederlanden eine nachgeordnete Rolle; Hauptakteur ist die Energiewirtschaft. Eine größere Ähnlichkeit besteht in der Anlagentechnik, wobei zu weiten Teilen auf das dänische Konzept rekurriert wird. In der Herstellungsweise unterscheiden sich die Firmen vom dänischen Markt. Statt der Verwendung standardisierter Komponenten von Zulieferbetrieben, produzierten die Niederlande zumeist alle Bauteile selbst.

Ein Großteil dieser Unterschiede lässt sich erklären, wenn man sie in Beziehung zu den speziellen Voraussetzungen des niederländischen Marktes bringt. Dabei kommt der EVUDominanz eine Schlüsselrolle zu. Bis 1985/86 hat sich der Erfolg kleinerer private Betreiber, insbesondere Kooperativen herausgestellt (Dänemark). Das gleiche gilt für den Misserfolg der Investoren (Kalifornien). EVU als Betreiber kommerzieller mittelgroßer Windturbinen sind zu diesem Zeitpunkt ein Novum. Die Probleme, welche mit ihrem Einstieg einhergingen, konnten noch nicht präzise eingeschätzt werden. Nichtsdestotrotz: Die Frage, weshalb sich die niederländische Windkraftpolitik für die Energiewirtschaft, anstatt Privatakteure als zentrale Betreiber von WEA entscheidet, bleibt zunächst offen. Zur Klärung lassen sich vier Gründe anführen:

Erstens ist die Präferenz der für große Windparks, unter den Regierungen der Pioniermärkte, in den Niederlanden besonders stark ausgeprägt. Aufgrund hoher Besiedelungsdichte verfügt das Land über weniger potenzielle Standorte für Windanlagen als etwa Dänemark. Durch wenige große Windparks wie sie nur von EVU betrieben können, so das Kalkül, würden die begrenzten Flächen wesentlich besser genutzt als durch Hunderte Einzelanlagen.

Zweitens existiert zwischen den Akteuren des LSP-Programms und des kommerziellen Marktes keine so starke Trennung wie in Dänemark. Der Windpark von Sexbierum wurde als ein Übergangsprojekt analysiert. Mit seiner für niederländische Planungen niedrigen Zahl von 18 WEA und Generatorenstärke von $300 \mathrm{~kW}$ ist der Windpark kein eigentliches LSP-Projekt mehr. SEP und Forschungsinstitut KEMA, zwei wichtige Akteure des Energiesektors sind in dieses ,mittelgroße' Projekt eingebunden. Werden die Aktivitäten dänischer EVU im Windsektor als Fremdkörper wahrgenommen, stellt der frühzeitige Einzug niederländischer Versorger eher eine Normalität dar.

Diese Situation ist drittens auf die schwächere Ausprägung zivilgesellschaftlicher Proteste, Selbstbau-Aktivitäten und kooperativer Tradition zurückzuführen, als sie in Dänemark zu beobachten sind. Aufgrund ihrer Atomkraft-Planungen, stand die dänische Energiewirtschaft unter permanenter öffentlicher Kritik. Mit der Realisierung der Tvindmühle ist es der dänischen Anti-AKW-Bewegung nicht nur gelungen, einen symbolischen Beweis für die Redundanz der Kernenergie zu liefern, sondern auch ein dauerhaftes Symbol für die Möglichkeiten alternativer Elektrizitätsversorgung ohne Konzerne zu schaffen. Ein wichtiges Element der dänischen Zivilgesellschaft ist die kooperative Tradition. Die Zusammenarbeit zwischen Handwerkern und Akademikern ist in Dänemark etwas normales. Ohne die Windtreffen und Energiebüros an den Volkshochschulen wäre der frühe kommerzielle Erfolg 
kleiner WEA unvorstellbar gewesen. Anfang der 80er Jahre werden die Kooperativen zum wichtigsten Akteur, lange bevor kommerzielle Windenergie bei den EVU überhaupt zur Disposition steht. Entsprechende kooperative Traditionen existieren in den Niederlanden nicht.

Viertens ist die grüne Mehrheit im dänischen Parlament als ein wichtiger Unterschied zu den niederländischen Bedingungen hervorzuheben. Das dänische Parlament, getragen von einem progressiven, gesamtgesellschaftlichen Klima, hat die Energiewirtschaft dazu genötigt, mit den Windmüllern zu kooperieren.

Unter diesen Rahmenbedingungen lag die Entscheidung der niederländischen Administration, für einen EVU-dominierten Windenergiesektor, nahe. Für die Gestaltung des IPW ist die Kritik, sich nicht hinreichend an dänischen Erfahrungen orientiert zu haben, nur bedingt gerechtfertigt. Diese scheinbare Lernresistenz setzt sich 1990 mit dem Start des IPWFolgeprogramms fort. Anstatt auf kommunale Windenergie zu setzen, wird die Marktführerschaft der EVU bestätigt, mit fatalen Konsequenzen für die niederländische Industrie. $^{357}$

Zusammenfassend lässt sich sagen: 1986, zum Zeitpunkt des niederländischen Markteinstiegs sind die technologischen und wirtschaftlichen Erfolge des dänischen Modells weitgehend offenkundig geworden. Daher kommt der ,Ignoranz-These' für den niederländischen Markt grundsätzlich eine stärkere Bedeutung zu, als für Kalifornien. Allerdings ist zu konstatieren, dass sich, für die EVU-Präferenz der niederländischen Administration eine Reihe plausibler Gründe anführen lässt. Zutreffend ist der Vorwurf, Lernchancen nicht genutzt zu haben, bezogen auf weite Teile der Industrie (vg. Schaubild 2.5b).

\footnotetext{
${ }^{357}$ Davon abgesehen beweisen die Erfolge Lagerweys, dass die Misere der übrigen Hersteller, von diesen, aufgrund ihrer Festlegung auf den EVU-Markt und ihrer Ignoranz erprobter Konzepte dänischer Zulieferer, mit verschuldet worden ist.
} 
Wichtigste Eigenschaften des dänischen Modells

\begin{tabular}{|l|}
\hline Technologie \\
Dänisches Konzept \\
hat sich in Dänemark \\
seit 1981 bewährt
\end{tabular}

\section{Fördersystem}

Investitionsförderung seit 1979

Seit 1984 werden zusätzlich Mindestabnahmetarife garantiert

Betreiber

- Windkooperativen

(seit 1981 wichtigster Akteur)

- Landwirte

- EVU (seit 1986)

\section{Diffusionshemmnisse}

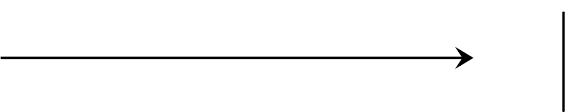

- Fördersystem zwingt Hersteller zur kurzfristigen Entwicklung großer

Modelle und bietet geringe

Spielräume zur Optimierung

zusätzliche Fehler

- mangelnde Kooperation mit dänischer

Zulieferindustrie

- einseitige Festlegung auf EVU-Markt
Niederlande

Technologie (seit 1986):

- Industrie scheitert weitestgehend

- Lagerwey ist erfolgreich, weil das Unternehmen zentrale Fehler der Konkurrenz gemieden hat

Fördersystem (seit 1986)

- Investitionsförderung mit diversen Spezifika

Energiewirtschaft weniger in öffentlicher Kritik; keine ,grüne Mehrheit'; mangelnde Trennung zwischen LSP- und kommerziellem Sekor

zusätzliche Fehler: Hersteller werden frühzeitig in Konkurrenz gesetzt; System schränkt Vielfalt der Konzepte ein; restriktive Zertifizierungskriterien

- EVU werden als Betreiber bevorzugt

- EVU dürfen Einspeisetarife selbst gestalten

Betreiber

Fördersystem erschwert Marktzugang für unabhängige Akteure

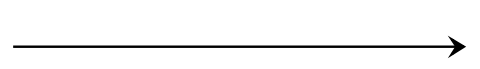

Zur Bildung von Windkooperativen kommt es nicht nur aufgrund der Restriktionen des PAS nur vereinzelt, sondern auch, weil diese Unternehmensform in den Niederlanden weniger verbreitet gewesen ist 
Windenergie in der Bundesrepublik Deutschland: Adaption des dänischen Modells

Es wurde aufgezeigt, dass der deutsche Pioniermarkt zahlreiche Eigenschaften mit dem dänischen Modell gemeinsam hat, bzw. von dort übernehmen konnte. Wie die Beispiele der Niederlande und Kaliforniens verdeutlicht, handelt es sich dabei keinesfalls um eine Selbstverständlichkeit. Worin bestehen die besonderen Voraussetzungen, welche die Übernahme ermöglichten? Ein wesentliches Hemmnis der niederländischen Entwicklung ist die scheinbare Unvermeidlichkeit der EVU-Dominanz. Aus welchen Gründen ist der Energiesektor hierzulande entbehrlich? Der erste Grund ist geografischer Art. Insbesondere die als Standorte besonders attraktiven Küstenbereiche Norddeutschlands, sind zugleich dünn besiedelt. Eine, mit den Niederlanden vergleichbare Notwendigkeit, die vorhandenen Standorte mit maximaler Effizienz zu nutzen, besteht nicht. Im Zuge des Growian-Projekts ist das konträre Verhältnis der Energiewirtschaft zur Windenergienutzung insgesamt, sehr deutlich zu Tage getreten. Infolge der Nuklearkatastrophe von Tschernobyl gewann die deutsche Anti-AKW-Bewegung an Stärke. Vor diesem Hintergrund hätten Restriktionen gegen Windmüller, zugunsten der Erhaltung der Versorgungsmonopole der Netzbetreiber, weitere Polarisierungen auslösen können.

Sowohl in den Programmen auf Länderebene, als auch im 100/250MW-Programm sind keinerlei Präferenzen für diese oder jene Akteure festgeschrieben worden. Dadurch, dass die Hersteller, anders als in den Niederlanden, kaum dazu genötigt waren, den EVU möglichst leistungsstarke Windanlagen zu bieten, war es möglich, das bewährte Laissez-Faire-System, den Ansatz der Förderung zahlreicher unterschiedlicher Konzepte, aus Dänemark zu übernehmen. Insbesondere dort, wo Graswurzelakteure, mit ihren geringen finanziellen und logistischen Mitteln aktiv werden, hat sich die geografische Nähe beider Länder als diffusionsfördernd herausgestellt. Als die später marktführenden Anbieter, Enercon, Tacke und HSW, die Windanlagenfertigung um Mitte der 80er Jahre aufnehmen, hat sich der Erfolg des dänischen Konzeptes bereits erwiesen. Für die neuen Hersteller war daher naheliegend, von Anfang dieses Konzept zu nutzen. Eine kooperative Tradition spielt in der deutschen wie der niederländischen Gesellschaft, keine sehr wichtige Rolle. Es bedurfte jener Pioniere der Bürgerwindbewegung, mit ihrer besonderen Motivlage ${ }^{358}$, um die Windradkooperative nach Deutschland $\mathrm{zu}$ importieren. Im Umfeld dieses politisch ambitionierten und in der Öffentlichkeitsarbeit geschulten Akteurs gelingt es, mit dem IWB eine schlagfertige, dem DV ähnliche Interessenvertretung zu etablieren. Der IWB hatte Einfluss auf die Gestaltung des Stromeinspeisungsgesetzes genommen und sprach sich mit Erfolg für eine Übernahme des dänischen Modells garantierter Einspeisetarife aus.

In Tabelle $2.5 \mathrm{j}$ werden einige Faktoren aufgeführt, welche Einfluss auf die Adaptionschancen des dänischen Modells in die übrigen Pioniermärkte nehmen.

\footnotetext{
${ }^{358}$ Gemeint ist jene doppelte Abgrenzung: Einerseits setzten sich die Bürgerwindpioniere von einer, in der Negation verhafteten Anti-AKW-Bewegung ab, andererseits von einem zerstörerischen und nur auf Profit ausgerichteten Energieversorgungssystem.
} 
Tab. 2.5j

Einflussfaktoren auf Importchancen des dänischen Modells*

\begin{tabular}{|c|c|c|c|c|c|c|}
\hline Faktor & Kalifor & & Nieder & & Deu & \\
\hline Standortmangel? & nein & + & ja & - & nein & + \\
\hline $\begin{array}{l}\text { Antiatombewegung im } \\
\text { Sektor aktiv? }\end{array}$ & nein & - & nein & - & $\mathrm{ja}$ & + \\
\hline $\begin{array}{l}\text { EVU stark in öffentlicher } \\
\text { Kritik? }\end{array}$ & nein** & - & nein** & - & ja & + \\
\hline $\begin{array}{lll}\text { Geografische } & \text { Nähe } \quad \text { zu } \\
\text { Dänemark? } & & \\
\end{array}$ & nein & - & ja & + & ja & + \\
\hline $\begin{array}{lrc}\begin{array}{l}\text { Einstieg } \\
\text { Desgin/ }\end{array} & \text { nach } 1983 \text { (DK- } \\
\text { bewährt)? } & \text {-Fördermodell } \\
\end{array}$ & nein & - & ja & + & ja & + \\
\hline $\begin{array}{l}\text { Waren EVU frühzeitig in die } \\
\text { Nutzung kommerzieller } \\
\text { WEA eingebunden? }\end{array}$ & nein & + & ja & - & nein & + \\
\hline $\begin{array}{l}\text { Werden Lernprozesse durch } \\
\text { regionale Beziehung } \\
\text { zwischen Hersteller und } \\
\text { Betreiber begünstigt? }\end{array}$ & nein & - & ja & + & ja & + \\
\hline gesamt & 2 & & 3 & & 7 & \\
\hline gesamt & 5 & & 4 & & 0 & \\
\hline
\end{tabular}

Quellen: vg. Kap. 2

* Ein Pluszeichen steht für eine verbesserte Adaptionschance, ein Minuszeichen für eine Verminderung.

** Jedenfalls haben sich die EVU der Niederlande und Kaliforniens keine Schnitzer à la Growian geleistet, als dass sie sich für den Windenergiesektor unmittelbar disqualifiziert hätten.

Aus diesen Ergebnissen lässt sich eine hohe Adaptionsfähigkeit des dänischen Modells durch den deutschen Pioniermarkt ableiten (vg. Schaubild 2.5c). Ebenso kann die These einer Inkompatibilität des dänischen Modells mit den Marktstrukturen Kaliforniens und der Niederlande begründet werden. Damit lässt sich als zentrale Eigenschaft der Pionierphase formulieren:

Ausschließlich das dänische Modell ist erfolgreich. Umfangreiche internationale Diffusionsvorgänge bleiben während der Pionierphase aus, weil die Voraussetzungen der übrigen Pionierländer, Deutschland ausgenommen, mit der Spezifik des dänischen Modells inkompatibel sind. 


\section{Schaubild 2.5c}

Wichtigste Eigenschaften des dänischen Modells

\begin{tabular}{|l|}
\hline Technologie \\
Dänisches Konzept \\
hat sich in Dänemark \\
seit 1981 bewährt \\
\end{tabular}

Fördersystem

Investitionsförderung seit 1979

Seit 1984 werden zusätzlich Mindestabnahmetarife garantiert
Diffusionschancen des dänischen Modells nach Deutschland

Rahmenbedingungen der Diffusion

Deutschland

Übernahme des dänischen

Windanlagenkonzepts
- später Markteinstieg
- räumliche Nähe zu Dänemark
- strukturelle Nähe der Windanlagen-
industrie: Mittelständler aus dem
Maschinenbau
- tolerantes Zertifizierungssystem
hat keine Einschränkungen
der Konzepte erzwungen

\section{Übernahme des}

Fördersystems

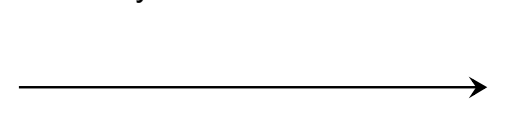

- später Markteinstieg

- keine Festlegung auf Energiewirtschaft als Betreiber

- kein Standortmangel, Windparks werden nicht als notwendig erachtet

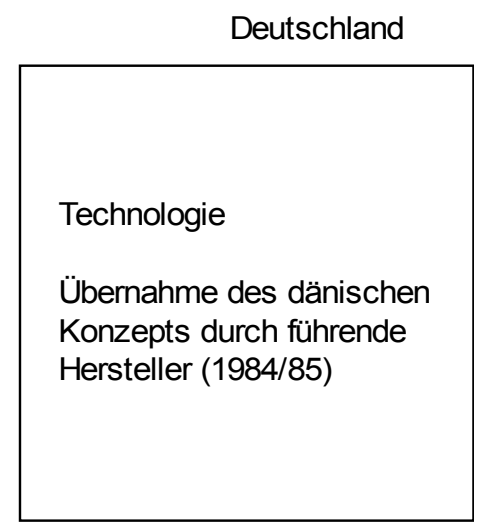

Fördersystem

- seit 1988 Investitionsförderung/ kWh-Subvention (100/ 250 MW Programm)

- seit 1990 garantierte

Einspeisetarife

(Stromeinspeisungsgesetz)
Diffusion der Windkooperative

\section{Betreiber}

- Windkooperativen

(seit 1981 wichtigster Akteur)

- Landwirte

- EVU (seit 1986)

\section{$\longrightarrow$}

- räumliche Nähe zu Dänemark

- Offenheit des deutschen Fördersystems

- keine kooperative Tradition, dafür: spezifischer Hintergrund der Bürgenwind-Pioniere (,doppelte Abgrenzung') 


\section{Phase internationaler Diffusion: Veränderte Akteurskonstellationen und ein neues Erfolgsmodell}

Während der Pionierphase werden in Dänemark und der Bundesrepublik die Grundlage prosperierender Märkte für Windenergie geschaffen. Ein leistungsfähiger Industriezweig entwickelt sich. Durch sukzessive Fortschritte in der Anlagentechnologie ist Windkraft zu einer proven technology geworden. Zwischen 1980 und 1992 ist der Standard von 50 auf $500 \mathrm{~kW}$ Generatorenkapazität gewachsen. Die Verlässlichkeitsrate liegt bei über 95 Prozent. Jede Windturbine wird einem Prüfungsverfahren unterzogen, das internationalen Standards genügt. Aufgrund von Effizienzverbesserungen, bspw. durch Gewichtsreduzierung, Skaleneffekte durch Fertigung größerer Serien und zunehmender Anlagengröße werden deutliche Kostensenkungen erreicht. ${ }^{359}$

Bis Anfang der 90er Jahre hat sich in den Pioniermärkten nicht nur das erfolgreiche dänische Windturbinenkonzept durchgesetzt. Auch weitere allgemeine Schwierigkeiten, die mit dem Betrieb von WEA verbunden waren, können überwunden werden. Geeignete Testverfahren werden entwickelt. Später werden, unter Einbindung etablierter Zertifizierungsunternehmen wie Det norske Veritas und Germanischer Lloyd, umfassendere Prüfungsverfahren eingeführt. Um Privatakteuren, die insbesondere in Dänemark und der Bundesrepublik als Betreiber von Windanlagen sehr wichtig waren und sind, den Aufbau weiterer Windparks zu ermöglichen, ist die Schaffung geeigneter Rahmenbedingungen erforderlich. Hier bewährten sich insbesondere Stromeinspeisegesetze, welche die Abnahme des Stroms durch die Netzbetreiber zu festen Tarifen sicherstellen und den Betreibern damit eine gewisse Planungssicherheit lieferten. Neue Möglichkeiten zur Versicherung und Finanzierung der Windanlagen eröffnen sich.

Gerade in den dicht besiedelten Ländern Westeuropas hat sich eine zweckmäßige Planung als ebenso nützlich erwiesen wie die Partizipation der Anrainer. Durch kommunale Verankerung der Projekte wird die Akzeptanz verbessert.

Seit der zweiten Hälfte der 80er Jahre ist in den Pioniermärkten ein wachsendes Interesse der Energiewirtschaft am Windsektor zu beobachten. Obgleich das Engagement der EVU häufig mit Ambivalenz betrachtet wird, so spiegelt sich in dieser Entwicklung die Windkraft als gereifte Energietechnik wider. Für manche EVU, insbesondere kleinere regionale Netzbetreiber und Stadtwerke, ist die Windkraft aufgrund ihrer Förderung durch den Staat und der Möglichkeit, die Abhängigkeit von großen Energielieferanten zu verringern, ökonomisch attraktiv geworden. Insgesamt ist zum Engagement der EVU und ihrem Vertrauen in kommerzielle WEA jedoch kritisch anzumerken: Zunächst sind die meisten Versorger in erster Linie aktiv geworden, um sich gegen öffentliche Kritik zu schützen, oder zu verhindern, dass sich die Windmüller zu ernsthaften Konkurrenten entwickelten. Einzig in den Niederlanden kommt den EVU eine, staatlich gewollte markführende Stellung zu. In den übrigen Pioniermärkten agierten die Energiekonzerne aus der zweiten Reihe. Ihre Rolle in den Pioniermärkten insgesamt sollte nicht überschätzt werden. Zum einen ist nur ein geringer Anteil der Versorger überhaupt als Windparkbetreiber aktiv geworden. Zum andern werden, wenn überhaupt, nur minimale Teile ihrer fossil-nuklearen Kraftwerkskapazitäten durch

\footnotetext{
${ }^{359}$ Für die Zeit von 1980-1989 geht Birger Madsen (Heymann 1995, 409) von einer Verringerung von 35 Pfennig auf 8,5 Pfennig pro Kilowattstunde aus. Gipe $(1995,234)$ schätzt die Preisentwicklungen ähnlich ein: Anfang der 80er Jahre: \$ 0,45; Anfang der 90er Jahre: \$ 0,1. Zu diesen Einschätzungen ist anzumerken, dass es sich bei Madsen, ebenso wie bei Gipe um dezidierte Fürsprecher der Windenergie handelt.
} 
Windanlagen ersetzt. Diese ambivalente Rolle der EVU als Käufer und Betreiber von WEA ist charakteristisch für die letzte Periode der Pionierphase. Ein weiteres wichtiges Ergebnis der Untersuchung besteht darin, dass WEA ausschließlich dort angemessen gefördert worden sind, wo es neben der Minderung der Energieknappheit vor allem darum ging, den radikalen Forderungen der Atomkraftgegner beschwichtigend entgegenzutreten. Erfolgreiche Marktentwicklungen sind des weiteren nur in Dänemark und der Bundesrepublik zu beobachten, wo zentrale Eigenschaften des dänischen Modells übernommen werden. Diese drei wichtigen Merkmale der Pionierphase: Ambivalente Rolle der EVU als Windparkbetreiber, Förderung der Windkraft, nicht nur, aber auch als Reaktion auf Proteste gegen Atomkraftnutzung und der ausschließliche Erfolg des dänischen Modells, gelten seit Anfang der 90er Jahre offenbar nicht mehr uneingeschränkt.

Tabelle 3a stellt die internationale Diffusion der Technologie seit Ende der Pionierphase dar. Zwischen 1991 und 1997 hat die Zahl der Märkte mit mehr als 10MW Windanlagenkapazität von sechs auf 20 zugenommen. Mit dem Einstieg Spaniens, Griechenlands und Großbritanniens, den 92er-Märkten, markiert das Jahr 1992 den Beginn einer neuen Phase internationaler Diffusion. Technologische und ökonomische Durchbrüche können während der Pionierphase in den 92er-Märkten nicht erzielt werden.

Dieser neue Entwicklungsabschnitt verweist nicht allein auf eine geografische Expansion, sondern auch auf eine qualitative Veränderung der Akteurskonstellationen im Vergleich zu den Erfolgsmodellen der Pionierphase. Im folgenden geht es weniger darum, den Begriff einer internationalen Diffusionsphase in ähnlicher Weise $\mathrm{zu}$ begründen wie zuvor die Pionierphase. Vielmehr legitimiert sich die Definition der Pionierphase bislang allein aufgrund gemeinsamer Eigenschaften der Pioniermärkte, Gemeinsamkeiten und nationaler Unterschiede bei der Überwindung einschlägiger Barrieren. Ein weiterer Bezugspunkt ist der geringe Verbreitungsgrad. Jetzt soll die Definition der Pionierphase durch die Herausarbeitung wesentlicher Unterschiede zwischen alten und neuen Märkten zusätzlich begründet werden. Als Beispiele dienen die 92er-Märkte, darunter insbesondere Spanien, als einem neuen Erfolgsmodell.

Tab. 3a Windenergiemärkte ab 10MW 1991-1997

\begin{tabular}{|l|l|l|}
\hline Jahr & Windmärkte ab 10MW & Gesamtzahl \\
\hline 1991 & $\begin{array}{l}\text { USA, Dänemark, BRD, Niederlande, Schweden, } \\
\text { Indien }\end{array}$ & 6 \\
\hline 1992 & $\begin{array}{l}\text { zusätzlich: } \\
\text { Spanien, Großbritannien, Griechenland }\end{array}$ & 9 \\
\hline 1993 & zusätzlich: Kanada, China, Italien & 12 \\
\hline 1994 & & 12 \\
\hline 1995 & zusätzlich: Japan & 13 \\
\hline 1996 & zusätzlich: Österreich, Irland, Portugal & 16 \\
\hline 1997 & zusätzlich: Costa Rica, Frankreich, Iran, Finnland & 20 \\
\hline
\end{tabular}

Quelle: vg. Kap. 2.1, Kap. 3, Neue Energie 9/99 u.a.

Ähnlich wie bei den Pioniermärkten ist der Faktor Energieknappheit bei guten Potenzialen erschließbarer Windressourcen, in den 92-Ländern ebenso gegeben. Obgleich die Nutzung der Kernenergie auch dort mit Protesten verbunden ist, erlangen Anti-AKW-Bewegungen keine vergleichbare Relevanz wie in den Pioniermärkten. Für alle drei Länder geht Müller-Rommel (1993, 168) von einem, im europäischen Vergleich niedrigen Umweltbewusstsein, aus. Für Griechenland und Spanien wird diese Position von Dede $(1993,1)$ bestätigt. ${ }^{360}$ Als Triebkräfte wichtiger sind EU-Programme zur Marktförderung, deren Existenz als Produkt bisher erzielter Erfolge der neuen Technologie aufzufassen ist.

\footnotetext{
${ }^{360}$,Sowohl in Spanien als auch in Portugal und Griechenland bleibt die Ökologiebewegung organisatorisch und politisch-konzeptionell einigermaßen schwach,...' (ebd.)
} 
Im folgenden werden die Ausgangsbedingungen zur Förderung der Windkraft in den 92erLändern dargelegt. Die Marktstrukturen werden analysiert und anschließend mit den Pioniermärkten verglichen.

\subsection{Griechenland}

Mehr als die Hälfte des griechischen Strombedarfs wird aus heimischer Braunkohle gewonnen. Darüber hinaus spielt die Wasserkraft eine wichtige Rolle. Ein Versuch zur Etablierung der Nukleartechnik ist gescheitert. 1978 werden die Pläne zum Bau eines AKW bekannt gegeben. Aufgrund von Protesten verschiebt man das Projekt in die Zukunft. Nach der Katastrophe von Tschernobyl werden die Atompläne entgültig aufgegeben. Dede (1993, 147) zufolge erreichen die Antiatomproteste zu keinem Zeitpunkt den Charakter einer Massenbewegung wie in Deutschland. Zwar existiert in Griechenland eine grüne Partei. Nennenswerte Stärke erlangte sie jedoch nicht (vg. Müller-Rommel 1993, 85).

Öl muss größtenteils zu hohen Preisen importiert werden. Infolge der Ölkrise bemühte sich der griechische Staat, diese Abhängigkeit $\mathrm{zu}$ verringern. Dabei hatte der staatliche Energiekonzern PPC (Public Power Corporation) gute Erfolge vorzuweisen: 1973 liegt der Öl-Anteil des Gesamtenergieverbrauchs noch bei 76 Prozent. Bis 1986 kann der Anteil auf 58 Prozent reduziert werden (WPM 9/88, 19). Ein Teil des Ölbedarfs soll durch Windenergienutzung ersetzt werden. Entsprechend äußerte sich PPC-Sprecherin Tassiou und begründet das Interesse an der Windkraft: ,Another factor...is the positive experience which has been reported from other countries which have grid connected wind power, especially Denmark, Holland, U.K. and U.S.A. Consistently good reports and cumulative experience from windfarms in those countries are factors that cannot be ignored easily.' (WPM 6/88, 21)

Insbesondere auf den vielen Inseln ist die Versorgung mit Elektrizität sehr kostspielig. Hier eignet sich der Aufbau von WEA, die häufig mit Dieselgeneratoren kombiniert und manchmal durch Solaranlagen ergänzt werden. Aufgrund der unebenen Topografie sind die Winde oft wenig konstant, d.h. sie ändern sich häufig in Stärke und Richtung. Dieses Problem erschwert die Zugänglichkeit der Ressourcen und erfordert die Errichtung zahlreicher Messstationen (EC Windenergiekonferenzbericht 1988, 651ff.)

Ein weiterer Faktor sind die EU-Programme. 1988-1989 vergibt die EU an Griechenland 2,78 Mio. ECU zur Durchführung von Demonstrationsprojekten. Damit erhielt das Land höhere Zuschüsse als jedes andere EU-Mitglied (WPM 2/90, 21). ${ }^{361}$

\subsubsection{Pionierphase}

Ende 1985 verabschiedete das Parlament ein Gesetz zur Etablierung erneuerbarer Energien. Laut Energieminister Peponis besteht dessen Ziel darin, die Entstehung unabhängiger Stromproduzenten in abgelegenen Gebieten zu fördern (WPM 11/87, 12). Der PPC musste den überschüssigen Strom in sein Netz speisen und dafür an den Produzenten einen festen Tarif zahlen (WPM 5/86, 20). Kommunen dürfen eigene Kraftwerke ausschließlich zur kommerziellen Nutzung betreiben und erhalten einen Aufschlag von 25 Prozent auf die Tarife. In der Praxis allerdings konnte das Gesetz nicht in Anspruch genommen werden, weil sein Inkrafttreten durch PPC und Energieministerium systematisch blockiert worden war. Der PPC, Monopolist des griechischen Stromsektors, verfügte über die Kompetenz zur Festlegung der Einspeisetarife, was er jedoch über lange Zeit verweigerte. ${ }^{362}$

\footnotetext{
${ }^{361}$ Die meisten griechischen Windparkprojekte werden durch EU-Mittel unterstützt. Die Durchführung einiger Studien des Zentrums für erneuerbare Energiequellen wird 1988 mit \$8,5 Mio. gefördert (WPM 1/89, 14).

${ }^{362}$ Erst am 16. Februar 1988 gab PPC schließlich die Tarife bekannt, deren Höhe zwischen \$0,043 und \$0,065 gelegen hatte, was starke Proteste nach sich zog. Ein Importeur von WEA äußerte sich dazu: ,With the exception of Crete and Rhodes where proposed tariffs make some economic sense, wind turbine projects for all other
} 
Laut Gesetz sind die Stromlieferungen erst mit Vertragsunterzeichnung zum festgelegten Preis zu vergüten - und nicht rückwirkend. ${ }^{363}$ Der Versorger wollte sich die Option erhalten, die Standorte selbst zu nutzen, anstatt sie an unabhängige Produzenten zu vergeben (WPM $3 / 88$, 13). Zudem ist der PPC berechtigt, Planungen der unabhängigen Akteure einzuschränken, bzw. zu untersagen. Angesichts dieser Bedingungen erklärt sich die Stagnation der Windenergienutzung. Bis Juni 1988, d.h. innerhalb von dreieinhalb Jahren werden nur sechs Einzelanlagen (insgesamt etwa 400kW) durch unabhängige Betreiber ans Netz des PPC geschlossen (WPM 6/88, 20). ${ }^{364}$

Der Hauptteil der, wenngleich marginalen Aktivitäten im Windkraftsektor, wird vom PPC selbst getragen. Der erste - und bis Mitte der 80er Jahre einzige - Windpark entsteht bereits 1982 auf der Insel Kythnos. Dort ließ der Monopolist fünf Exemplare des MAN-Aeroman (je $20 \mathrm{~kW}$ ) installieren. Der Windpark trägt mit etwa 30\% nicht unerheblich zur Stromversorgung der Insel bei (WPM 5/87, 7). Für die zweite Hälfte der 80er Jahre stellt PPC eine Summe von insgesamt \$26,5 Mio. für WEA bereit, die auf den Inseln errichtet werden sollten (WPM 5/86, 20). Eine wichtige Motivation besteht in der massiven Unterstützung durch die EU. Über den MAN-Windpark hinaus sind bis 1988 sieben Windanlagen als Demonstrationsprojekte von der EU gefördert worden. 1988 sind die WEA (alles Einzelanlagen) entweder bereits in Betrieb, oder befinden sich in der Planungs-, bzw. Aufbauphase (EUWindenergiekonferenzbericht 1988, 651). Im Rahmen des Hors quota Programms beteiligt sich die EU zur Hälfte an den Kosten der Installation 50 kleiner WEA (50-100kW) mit einer Gesamtkapazität von 3,8MW, die alle vom PPC gekauft und betrieben werden sollten (WPM 11/87, 12).

Trotz der EU-Förderung, gewisser Anfangserfolge und vergleichsweise ambitionierter Planungen des PPC: Tatsächlich existiert in Griechenland bis Ende 1988 nicht mehr als ein Megawatt netzgekoppelter Windenergiekapazität (WPM 3/89, 14). Unter diesen Bedingungen sind die Chancen der Etablierung einer inländischen Windanlagenindustrie gering. Die meisten WEA wurden entweder direkt von dänischen Herstellern geliefert, oder im Rahmen dänisch-griechischer Kooperationen gefertigt. Mit der Herstellung besagter 50 WEA beauftragte der Stromkonzern den ebenfalls staatlichen Flugzeugbauer Hellenic Aerospace Industry (HAI). Da es HAI am erforderlichen Know-how fehlte, entschied sich dieser für eine Zusammenarbeit mit der dänischen Windmatic (WPM 11/87, 12). Produziert wurden die WEA, nach Windmatic-Design, teils in Dänemark, teils in Griechenland (WPM 6/88, 24). ${ }^{365}$

Es lässt sich zusammenfassen: Ohne EU-Förderung und technische Zusammenarbeit mit ausländischen Herstellern wären selbst diese zaghaften Ansätze zur Markteinführung der Windkraft undenkbar gewesen. Zur Erklärung der mangelnden Erfolge der griechischen Windkraftstrategie bis zum Jahr 1988, ist insbesondere ein Grund heranzuziehen: So scheiterte das Gesetz zur Stromeinspeisung durch private Windanlagenbetreiber, weil die Administration keinerlei Schritte einleitete, den PPC zur Einhaltung des Gesetzes zu zwingen. Die Einspeisebedingungen, welche der Konzern diktierte, waren so restriktiv gehalten, dass unabhängige Interessenten, Unternehmen und Einzelpersonen, ebenso wie Kommunen, in den meisten Fällen abgeschreckt wurden (vg. WPM 7/88, 15). Verglichen mit den

locations are doomed with failure.' Prof. Rigos Rigopoulos zufolge, einem Fürsprecher der erneuerbaren Energien, ,verspotteten die angekündigten Tarife die gesamte Idee, dass kleine Gemeinden und Betriebe ihren Strom selbst produzierten' (WPM 3/88, 13; Übersetzung aus dem englischen: M.N. ).

${ }^{363}$ Aus diesem Grund erhielt etwa der Landwirt John Delezios, der auf der Insel Syros eine WEA betrieb, bis November 1987 vom PPC keine Bezahlung seiner Stromlieferungen. Bis dahin hatte er bereits drei Jahre lang Strom in das Netz des Monopolisten geleitet (WPM 6/88, 24).

${ }^{364}$ Bei diesen Betreibern handelt es sich um drei Unternehmen, zwei Landwirte und eine Kooperative (WPM 6/1988, 20).

${ }^{365}$ Sowohl PPC, als auch die EU investierten in den Aufbau einer griechischen Windturbinenindustrie. So beauftragte PPC die HAI bereits 1986 mit der Entwicklung eines 80kW-Prototyps. Unterstützt wurden auch zwei Projekte von Windsol, dem damals einzigen Hersteller Griechenlands (WPM 5/86, 20). 
Pioniermärkten, ähnelt der griechische Markt am ehesten den Niederlanden. Auch die niederländische Zentralregierung unternahm keinerlei Anstalten, der in den meisten Provinzen herrschenden Willkür der EVU gegenüber den Windmüllern, Einhalt zu gebieten. Der Hauptunterschied zwischen beiden Märkten besteht darin, dass das Bündnis zwischen Regierung und EVU in Griechenland einen noch festeren Charakter hatte als in den Niederlanden. Zwar hat der PPC selbst, einige, bis 1988 allerdings recht halbherzige Schritte auf dem Windenergiesektor unternommen. An dieser zögerlichen Haltung änderte auch die Tatsache zunächst nichts, dass sich, mit der Windkraft auf den Inseln, gemeinsam mit DieselGeneratoren, deutlich kostengünstigerer Strom produzieren ließ als auf dem Festland.

\subsubsection{Diffusionsphase}

Die ersten Durchbrüche manifestieren sich 1992. Innerhalb eines Jahres nimmt die installierte Windkapazität von etwa fünf auf 26 Megawatt zu. Ausgelöst wird diese Entwicklung weder durch den Druck von Umweltbewegungen, noch seitens der Initiative unabhängiger Akteure, die ihre Interessen gegenüber dem PPC nun erfolgreich durchgesetzt hätten. Vielmehr tritt der Monopolist selbst als wichtigster Betreiber auf. Zivilgesellschaftliche Kräfte sind nach wie vor ohne Einfluss. Die gesamte Konstellation weist kaum Ähnlichkeiten mit dem dänischen Modell auf. Die größte Übereinstimmung liegt darin, dass die bewährten Anlagenkonzepte dänischer Hersteller in dem südeuropäischen Land zum Einsatz gelangten.

In Griechenland bestehen für die Windenergienutzung gute Voraussetzungen: Windressourcen, Energiemangel, Inseln ohne Anbindung an das Festlandnetz. Die hohe Autonomie des PPC gegenüber der Regierung zählt zu den wichtigen Faktoren, weshalb sich die Entwicklung, die bereits um Mitte der 80er Jahre einsetzt, um einige Jahre verzögerte. Seit 1989 stellt sich beim PPC offenbar ein Umdenken ein. Nachdem der Monopolist ankündigte, bis 1992 Windparks mit der Kapazität von $20 \mathrm{MW}$ in Betrieb zu nehmen, schreibt er im Jahr 1989 Aufträge zur Lieferung von WEA mit zunächst 10,5MW aus. Insgesamt fünf Windparks sollen zu maximal 55\% aus EU-Mitteln gefördert werden. Um die vollständige Zuzahlung zu erhalten, mussten die Projekte bis Oktober 1991 (VALOREN-Programm), bzw. Dezember 1992 (Mediterrean Integration Programmes) realisiert worden sein (WPM 5/89, 8). Jedoch stellte der PPC so hohe Anforderungen an die Hersteller, dass sich kaum Interessenten für die Aufträge meldeten. Auf die Turbinen sollte eine Garantiefrist von mindestens fünf Jahren gegeben werden. Die geforderte Anlagenkapazität sollte mehr als $200 \mathrm{~kW}$ betragen. Zudem sollte der Anlagentyp bereits mindestens ein Jahr auf dem Markt getestet worden sein. Schließlich forderte der PPC, dass griechische Konstruktions- und Maschinenbauunternehmen so weit wie möglich in die Fertigungsprozesse integriert würden. Angesichts dieser Ansprüche meldeten sich nach mehreren Monaten nur zwei dänische Hersteller, Danwin und Wincon, die bereit waren, den Auftrag zu übernehmen. Mit dieser Angebotssituation war der PPC nicht zufrieden, weil er seine Möglichkeiten eingeschränkt sah, unter mehreren Angeboten das günstigste auszuwählen. Andererseits befand sich der Konzern aufgrund der Fristen der EU-Programme unter Zeitdruck (WPM 2/90, 10). Schließlich dauert es bis Mitte 1991 bevor die Lieferverträge, letztendlich mit völlig anderen Herstellern, abgeschlossen werden. Für einen Windpark auf der Insel Evia (5,1MW) bestellte der PPC 17 WEA à 300kW beim belgisch-niederländischen Unternehmen HMZ/Windmaster. Gefertigt wurden die Turbinen in Kooperation zwischen HMZ/Windmaster und dem griechischen Konstruktionsunternehmen Biokat. Weitere 36 WEA à $225 \mathrm{~kW}(8,1 \mathrm{MW})$ für insgesamt vier Windparks auf Inselstandorten (Andros, Samos, Chios und Lesvos) bestellte der PPC bei Vestas. Auch für diese Projekte wurde eine Kooperation mit einer inländischen Firma angestrebt. Die Wahl fiel auf die Maschinenfabrik Rokos, welche die Türme produzierte (WPM 10/91, 12). Erst jetzt wurden besagte 50 kleinere Windanlagen (Joint Venture zwischen Windmatic und HAI von 1987), unter dem Namen Aeolos produziert und in fünf kleineren Windparks verbaut. Fast alle Windparks wurden in die autonomen Inselnetze 
integriert und lieferten bis zu 25 Prozent der Stromnachfrage (WPM 9/92, 27). Ende 1991 betreibt PPC Windanlagen mit 4,5MW Kapazität. Im nachfolgenden Jahr nimmt er zusätzlich Windparks mit insgesamt über $20 \mathrm{MW}$ in Betrieb (Tab. 3b).

Tab. 3b PPC-Windparks (Bis Sommer 1992 fertiggestellt, oder im Bau)

\begin{tabular}{|c|c|c|c|c|}
\hline Ort & $\begin{array}{ll}\text { Jahr } & \text { der } \\
\text { Installation }\end{array}$ & $\begin{array}{l}\text { Gesamtkapazität } \\
\text { (kW) }\end{array}$ & Hersteller & EU-Programm \\
\hline Kythnos & 1982 & 165 & MAN & Demonstration \\
\hline Mykonos & 1984 & 108 & Micon & $"$ \\
\hline Karpathos & 1986 & 175 & HMZ & $"$ \\
\hline Ikaria & $1991 / 92$ & 385 & Vestas/ Windmatic & Hors Quota \\
\hline Samothraki & $1991 / 92$ & 220 & " & " \\
\hline Lemnos & $1991 / 92$ & 700 & $"$ & $"$ \\
\hline Lemnos & $1991 / 92$ & 440 & $"$ & $"$ \\
\hline Karapathos & $1991 / 92$ & 275 & $"$ & " \\
\hline Chios & $1991 / 92$ & 1000 & $"$ & $"$ \\
\hline Samos & $1991 / 92$ & 900 & $"$ & $"$ \\
\hline Andros & $1991 / 92$ & 1.575 & $"$ & $"$ \\
\hline Samos & $1991 / 92$ & 2.000 & $"$ & $"$ \\
\hline \multirow[t]{3}{*}{ Chios } & $1991 / 92$ & 2.500 & $"$ & $"$ \\
\hline & & & & \\
\hline & & insges.:10,4 MW & & \\
\hline Skyros & \begin{tabular}{|lr}
$\begin{array}{l}\text { Sommer } \\
\text { noch in der } \\
\text { Bauphase }\end{array}$ \\
\end{tabular} & 100 & $\begin{array}{l}\text { NTU } \\
\text { (Griechenland) }\end{array}$ & - \\
\hline Skyros & $"$ & 140 & $"$ & - \\
\hline Andros & $"$ & 350 & Adecon & Demonstration \\
\hline Kreta & $"$ & 500 & Nordtank & $"$ \\
\hline Kreta & $"$ & 1.000 & Tacke & Thermie \\
\hline Kreta & " & 500 & Holec & Demonstration \\
\hline Lesbos & " & 2.500 & Vestas & Valoren \\
\hline Psara & $"$ & 2.500 & Vestas & $"$ \\
\hline Evia & $"$ & 5.000 & HMZ & $"$ \\
\hline \multirow{2}{*}{ Kreta } & $"$ & 5.000 & HMZ & $"$ \\
\hline & & insges.: 17,6 MW & & \\
\hline
\end{tabular}

Quelle: WPM 9/92, 26

Von allen Windparks des PPC (28MW) werden mehr als 27MW 1991/92 in Betrieb genommen, oder befinden sich Sommer 1992 in der Realisierungsphase. Bereits oben wurde auf die Problematik ablaufender Fristen hingewiesen, welche der PPC einzuhalten hatte, um die maximale EU-Förderquote auszuschöpfen. Ein Großteil der Projekte, die Sommer 1992 noch nicht abgeschlossen waren, ging bis Ende des Jahres in Betrieb. Damit ist die Analyse von Griechenland-Korrespondent Costis Stambolis des Branchenmagazins Windpower Monthly zu bestätigen: ,The sudden activity after years of foot dragging is a direct result of pressure applied by the European Commission.' (WPM 9/92, 26).

In den nachfolgenden Jahren nimmt der PPC so gut wie keine weiteren Projekte in Angriff. Der Aufschwung der Windkraft von 1991/92 endete ebenso abrupt wie er begann (vg. Tab. 3c). Obgleich die Windkraft während der 90er Jahre auf immer neuen Märkten Präsenz erhielt, verlor der PPC jegliches Interesse an der Technologie, nachdem Fördermittel der EU ausgeblieben sind.

Tab. 3c Installierte Windenergiekapazität in Griechenland 1990-1997

\begin{tabular}{|l|l|l|l|l|l|l|l|l|}
\hline Jahr & 1990 & 1991 & 1992 & 1993 & 1994 & 1995 & 1996 & 1997 \\
\hline $\begin{array}{l}\text { Windenergie- } \\
\text { Kapazität } \\
\text { (MW) }\end{array}$ & 3 & 4 & 29 & 26 & 27 & 28 & 28 & 29 \\
\hline
\end{tabular}

Quellen: WPM 2/93, 16; vg. Kap. 3 
Neben dem Betrieb vorhandener Windparks beschränkt sich das Engagement des PPC seit etwa 1993, als die neuen Windparks in Betrieb genommen worden sind, darauf, den Marktzugang anderer Akteure so weit wie möglich zu erschweren. Darin war der Monopolist scheinbar ähnlich erfolgreich wie in den Jahren zuvor. Bis Sommer 1994 wurden im Lande nicht mehr als 29 WEA (insgesamt 3,3MW) von anderen Akteuren betrieben (WPM 10/94, 24). ${ }^{366}$ Zwar ist der PPC seit 1988 verstärkt darauf bedacht, seine restriktive Haltung gegenüber unabhängigen Stromproduzenten zu verbergen. In diesem Jahr veröffentlicht der Konzern erstmals die Einspeisetarife und erhöhte diese, kurze Zeit später um sechs Prozent. Als Reaktion auf öffentliche Kritik willigte der Konzern ein, die Einspeisungen, entgegen ursprünglicher Ankündigungen auch rückwirkend zu vergüten (WPM 6/88, 24). Zudem erhielten die Kommunen nun den vereinbarten Aufschlag von 25\% auf die normalen Einspeisetarife (WPM 7/89, 14). Jedoch waren die Vergütungen zu niedrig, als dass sich ein kontinuierlicher Markt jenseits der PPC-Nachfrage hätte etablieren können. Damalige technische und ökonomische Analysten gingen davon aus, dass die Tarife dazu mindestens 20 GRD hätten betragen müssen. Tatsächlich rangierten sie jedoch zwischen 4,5 GRD (Festland) und zwölf GRD pro Kilowattstunde auf den Inseln.

Im September 1994 wird ein Stromeinspeisegesetz beschlossen, wie es sich im dänischen Modell bewährte. Unabhängige Produzenten von Strom aus regenerativer Energie erhallten von nun an eine Einspeise- und Vergütungsgarantie in Höhe von 70\% (Standorte mit Netzanbindung) bis 90\% (auf Inseln mit separaten Netzen) der aktuellen Strompreise für private Konsumenten. Unter damaligen Bedingungen ergaben sich Einspeisetarife zwischen 17,5 und 21 GRD, so dass sich Investitionen in Windparks auf guten Inselstandorten bereits nach drei Jahren amortisieren konnten. Zudem wurde dem PPC die Kompetenz entzogen, über Windpark-Anträge eigenständig zu entscheiden. Von nun an wurden die Anträge direkt beim Ministerium für Energie und Industrie gestellt. Im Fall einer Zusage musste der PPC die Anlagen an seine Netze schließen. Nichtsdestotrotz kamen dem Monopolisten noch immer wichtige Einflussmöglichkeiten zu (WPM 10/94, 24f.). Falls der Konzern die Netzstabilität durch den Anschluss eines Windparks bedroht sah, so war es wenig wahrscheinlich, dass der Antragsteller vom Ministerium eine Zusage erhielt. Die Marktöffnung hatte nur formalen Charakter. Bis 1997 werden nur vereinzelt Windanlagen neu installiert (Tab. 3c). ${ }^{367}$

Das Beispiel Griechenlands zeigt: Seit 1990 hat die Windtechnologie international einen solchen Status der Anerkennung erreicht, dass sie auch in Ländern, die man bislang weniger mit der Nutzung ,neuer' erneuerbarer Energietechniken (bspw. Photovoltaik, Biogas und Windenergie) in Verbindung brachte, zum Einsatz gelangt. Dabei ist es wichtig zu sehen, dass sie nicht durch Aktivitäten an der Peripherie (bspw. Windanlagenkooperativen, Landwirte, Bastler) ins Zentrum diffundiert, wie es in Dänemark zu beobachten ist, sondern es sich von Anfang um eine top-down-Entwicklung handelt. Von zentraler Bedeutung ist die Mittelvergabe der EU. Das Interesse des PPC wäre vermutlich nicht verebbt, wenn die EUGelder in derselben Weise weiter geflossen wären.

\footnotetext{
$\overline{366}$ Betreiber sind (WPM 10/94, 24): Privatakteure (15 WEA, 1,5 MW), Kommunen (6 WEA, 1,0 MW), staatliche Telefongesellschaft (8 WEA, 0,84 MW).

${ }^{367}$ Gegenüber der Regierung hat der Staatskonzern seine restriktive Haltung auch damit begründet, dass wichtige Einnahmequellen verloren gingen, wenn die Standorte an Privatakteure vergeben würden. Dieses galt insbesondere dann, wenn EU-Mittel vergeben würden (WPM 10/94, 24f.).
} 


\subsection{Großbritannien}

Die britische Energieversorgung war gegen die Energiekrise gut abgesichert. Großbritannien verfügt über große Vorräte an Öl, Kohle und Erdgas. Als weitere Energiequelle dient die Atomkraft, deren Nutzung weniger kontrovers ist als in einigen westeuropäischen Ländern. Trotz ihrer zahlenmäßigen Stärke - Rothgang (1990, 31) zufolge gehörten der Umweltbewegung während der 80er Jahre etwa 2,5-3 Mio. Mitglieder an - vermochte sie kaum Einfluss auf die staatliche Energiepolitik zu nehmen. ${ }^{368}$ Die Ausgangsbedingungen der Förderung erneuerbarer Energieträger sind denkbar unvorteilhaft. Eine Markteinführung der Windenergie wurde während der Pionierphase nicht angestrebt. Daran änderte auch die Tatsache nichts, dass Großbritannien über größere Windressourcen verfügt als jedes andere europäische Land.

Zur Diversifizierung der Energieversorgung führte das Energieministerium während der 70er und 80er Jahre Forschungsprogramme zur Windkraft durch, um die Möglichkeiten der Stromproduktion durch den Aufbau großer Windanlagen $\mathrm{zu}$ untersuchen. Im Zuge dieser Aktivitäten war eine kleine Windanlagenindustrie entstanden. Nachdem das Scheitern des LSP-Ansatzes akzeptiert werden musste, ist die erforderliche Transformation zur Nachfrageförderung kleinerer Windanlagen nicht erfolgt (vg. Niederlande, BRD). Britische Windanlagenhersteller wie Howden, Wind Energy Group (WEG) und Vertical Axis Wind Turbines (VAWT) waren daher fast ausschließlich auf dem Exportsektor tätig. Aufgrund der Existenz inländischen Know-hows herrschte eine günstigere Ausgangssituation als in Griechenland. Ansonsten ist eine Reihe von Ähnlichkeiten mit dem griechischen Windenergiesektor zu bemerken: Erstens ist der britische Strommarkt während der 80er Jahre ebenfalls stark monopolisiert; Größter Stromproduzent und Netzbetreiber ist zweitens ebenfalls ein staatlicher Akteur, der Konzern Central Electricity Generating Board (CEGB), der ebenso wie der PPC, gegenüber dem Staat einen hohen Grad an Unabhängigkeit besaß. Kraftwerksentscheidungen traf er weitgehend autonom. Drittens bestehen Ähnlichkeiten in der Topographie: Insbesondere in Schottland sind viele abgelegene Gebiete und Inseln gelegen, die nicht mit dem Zentralnetz verbunden sind, sondern häufig mit Dieselgeneratoren versorgt werden. ${ }^{369}$ Für solche Regionen wurde die Windkraftnutzung, ähnlich wie in Griechenland, zu einer hilfreichen Ergänzung. Schließlich erhielt Großbritannien wie das südeuropäische Land einen vergleichsweise hohen Anteil der verfügbaren EU-Mittel für Windenergieprojekte der Mitgliedsländer (vg. WPM 11/91, WPM 2/92).

\footnotetext{
${ }^{368}$ Zur Erklärung werden zwei Gründe herangezogen (vg. Rothgang 1990): Zum einen positionierte sich die britische Umweltbewegung nicht geschlossen gegen die Kernenergienutzung. Ein Teil der Aktivisten setzte der nuklearen Bewaffnung die friedliche Nutzung der Atomkraft positiv entgegen (,atoms for peace'). Zum anderen zielte man weniger auf Eskalation (vg. etwa BRD), sondern plädierte für Kompromisslösungen (,working within the system').

${ }^{369}$ Für die britische Windenergienutzung kommt dem schottischen Energieversorger North Scottish Hydro Electric Board (NSHEB) eine Pionierrolle zu (WPM 12/85, 9). Auf den abgelegenen Fair Islands installierte der Versorger 1982 eine Windanlage, wodurch ein Dieselgenerator großteils ersetzt werden konnte. Während der Dieselverbrauch um zwei Drittel reduziert wurde, verdreifachte sich die Stromproduktion. 1983 nimmt der NSHEB in Fenwick Moor an der Südwestküste Schottlands eine Teststation für Windanlagen in Betrieb. Die Scottish Development Agency erhoffte sich die Ansiedlung von Windturbinenherstellern in der strukturschwachen Region (WPM 10/86, 22). Für den Aufbau der großen Testanlage LS-1 wurde mit den Orkney Inseln ebenfalls ein schottischer Standort, unter Leitung des NSHEB, gewählt (vg. Kapitel 1).
} 


\subsubsection{Pionierphase}

Während der gesamten 80er Jahre beteiligten sich die staatlichen Energieversorger, insbesondere CEGB (England und Wales) und NSHEB (Schottland) an Forschungsprogrammen zur Entwicklung und Erprobung großer Windturbinen. Investitionen mit dem Ziel der Markteinführung kleiner und mittelgroßer Windanlagen tätigte der britische Staat nicht. Der Regierung ging es um die Einschränkung des Verbrauchs fossiler Rohstoffe. Zwischen CEGB und Energieministerium herrschte der Konsens, dass dieser Zweck weniger durch den Einsatz erneuerbarer Energien, als vielmehr durch Ausbau der Atomenergienutzung zu verfolgen sei. Von den insgesamt 500 Mio. Pfund werden in den Haushaltsjahren 1984/85 und 1985/86 nur 2,8\% (14 Mio. Pfund) für regenerative Energieträger, davon $0,96 \%(4,8$ Mio.) für Windkraft aufgewendet. Die Nuklearenergie erhielt dagegen jeweils 200 Mio. Pfund (WPM 12/85, 8). Gemäß der 1989 gestarteten Non-fossil-fuel-obligation (NFFO) müssen die EVU zu einem bestimmten Zeitpunkt ihre Kraftwerkskapazitäten zu definierten Anteilen durch nicht-fossile Energieträger ersetzen. Dazu wurde die Atomkraft ebenso gerechnet wie erneuerbare Energien. Der CEGB plante, die NFFO-Ziele bis zum Jahr 2000, durch den Neubau von Atomkraftwerken mit einer Kapazität von 3.120MW zu erreichen. Regenerative Technologien dagegen, rangierten mit 600 MW auf den hinteren Plätzen (WPM 1/89, 18f.).

Die Entstehung eines Privatmarktes für WEA ist in Großbritannien während der Pionierphase weitestgehend ausgeschlossen. Zwar verabschiedete das Parlament bereits im Mai 1983 ein Energiegesetz zu Liberalisierung des Stromsektors. Die Thatcher-Administration wollte unabhängigen Produzenten den Netzzugang gewähren (WPM 1/86, 8). Für die Windkraft ist dieses Ziel, auch drei Jahre später, nicht erreicht worden. Bis Mitte 1986 sind in Großbritannien nur 22 WEA installiert, von denen sich 14 auf dem staatlichen Testfeld in East Kilbride/ Schottland befanden (WPM 10/86, 22). Bei der Windenergiekapazität von 4,75MW (Ende 1986), handelt es sich fast ausschließlich um staatlich geförderte Demonstrationsanlagen (WPM 5/87, 14) wie LS-1, die allein über eine Nennleistung von drei Megawatt verfügt.

Tab. 3d Installierte Windenergiekapazität in Großbritannien

\begin{tabular}{|l|l|l|l|l|l|l|l|l|l|l|l|l|l|l|}
\hline & 1986 & 1987 & 1988 & 1989 & 1990 & 1991 & 1992 & 1993 & 1994 & 1995 & 1996 & 1997 & 1998 & 1999 \\
\hline $\begin{array}{l}\text { Gesamtkapazität } \\
\text { (MW) }\end{array}$ & 5 & 5 & 6 & 8 & 10 & 12 & 29 & 129 & 153 & 200 & 269 & 319 & 333 & 344 \\
\hline Zubau (MW) & $?$ & 0 & 1 & 2 & 2 & 2 & 17 & 100 & 53 & 47 & 69 & 50 & 14 & 11 \\
\hline
\end{tabular}

Quellen: WPM 5/87, vg. Kap. 3, Neue Energie 9/99 u.a.

Einzelne, von Privatakteuren betriebene Anlagen sind die Ausnahme. $\mathrm{Zu}$ diesen gehörte Arthur Williamson, der auf Shetland (Scalloway) eine 55kW-Vestas Turbine betrieben hatte, um damit einige Ferienwohnungen sowie den Haushalt zu versorgen. Eine einheitliche Regelung für die Höhe der Einspeisetarife existierte nicht. Stattdessen legten die regionalen Netzbetreiber die Vergütung selbst fest. Erwartungsgemäß niedrig, den Erfahrungen anderer Märkte ohne Mindesteinspeisetarife entsprechend, war die Vergütung auch im Falle Williamsons. Während er 0,045 Pfund pro Kilowattstunde an den NSHEB zahlte, erhielt er nur 0,025Pfund pro eingespeister Kilowattstunde zurück (55,5\%). Während des Steuerjahres 1986/87 musste Williamson zudem 2.400Pf. (\$3.900) an die lokalen Behörden abführen. Diese Summe entsprach zwei Dritteln des Erlöses, den er aus dem Verkauf des Überschussstroms an den NSHEB erhalten hatte. Ohne Förderung durch EU-Mittel von 50.000Pf. (\$82.000) EU-Geldern, wäre ein wirtschaftlicher Betrieb der Windanlage ausgeschlossen (WPM 5/87, 6). ${ }^{370}$ Die besagte Steuer war auch für den Betrieb einer

\footnotetext{
${ }^{370}$ Williamson selbst investierte 41.000Pf. (\$65.600), entsprechend 45\% für den Kauf und die Installation der Turbine. Dem schottischen Experten Gurudo Saluja zufolge, sollte sich die Investition unter gegebenen Umständen nach 9,6 Jahren amortisieren (WPM 6/87, 21). Dazu kam es jedoch nicht: Im Dezember 1988 geriet die Maschine während eines Sturms außer Kontrolle und erlitt Totalschaden (WPM 2/89, 7).
} 
Windanlage auf Fair Isle ein großes Problem. Die 55kW-Maschine trug deutlich zur Versorgung der 26 Haushalte zählenden Inselgemeinde bei. Mit 0,03 Pf. pro Kilowattstunde produzierte sie deutlich günstigeren Strom als der Dieselgenerator $(0,07 \mathrm{Pf} . / \mathrm{kWh})$. Angesichts der drohenden Steuerlast von 2.000Pf. pro Jahr hätten sich die Erzeugungskosten auf 0,12Pf. pro Kilowattstunde vervierfacht. Der Betrieb der Anlage musste daher eingestellt werden (WPM 5/89, 12).

1988 kündigte CEGB den Bau von drei großen Windparks (jeweils etwa acht Megawatt) an. Die Investition von 28 Mio. Pfund sollte vom Energieministerium mit zehn Mio. Pfund gefördert werden (WPM 5/88, 10). Das Ziel bestand darin zu prüfen, ob Windenergie einen zwanzigprozentigen Beitrag zur britischen Stromversorgung zu leisten vermochte. Darüber hinaus sollte erprobt werden, inwieweit die Windparks von der ansässigen Bevölkerung akzeptiert würden (WPM 10/88, 20). ${ }^{371}$ Jedoch sollten die Windparks erst 1992/93 in Betrieb genommen werden. Der CEGB begründete diese Verzögerung damit, dass sich die Windparks, unter Anwendung der damals verfügbaren Technologie, als Fehlinvestitionen herausgestellt hätten (WPM 5/88, 11). Für Privatakteure war der Betrieb von Windanlagen selbst in den entlegensten Gebieten nicht wirtschaftlich. Das Energiegesetz von 1983 schuf nur einen formalen Rahmen zur Netzeinspeisung durch unabhängige Produzenten. Letztere scheiterten an den Restriktionen der Monopolisten, denen der Gesetzgeber keine Schranken zu setzen bereit war. Die Vormachtstellung der staatlichen Versorger wurde durch die Legislative auch unmittelbar gestützt. So mussten private Kraftwerksbetreiber, verglichen mit CGEB und NSHEB, ein Vielfaches der Steuerlast an die nächstliegende Kommune abführen. Während der Marktzugang unabhängiger Akteure daher praktisch ausgeschlossen war, hatten die staatlichen Energiekonzerne kein Interesse am Aufbau von Windparks. Mit ihrer Lösung des Energieproblems befanden sie sich im Konsens mit der Thatcher-Administration: Ausbau der Atomkraft.

\subsubsection{Diffusionsphase}

Im Zuge der EU-Direktive zur Liberalisierung der nationalen Strommärkte wurde der CEGB privatisiert. Aus ihm gehen 1989 die Kraftwerksbetreiber National Power und Powergen hervor (WPM 8/92). Seitdem sind zwölf regionale Netzbetreiber in England und Wales für die Stromverteilung zuständig. Mit der Privatisierung wurde die Strafsteuer für unabhängige Kraftwerksbetreiber (s.o.) abgeschafft. In dieser Hinsicht waren sie von nun an den EVU gleichgestellt. Letztere wurden gemäß NFFO verpflichtet, einen bestimmten Anteil ihres Stroms aus erneuerbarer Energie zu produzieren, bzw. zu verteilen. Insgesamt handelte es sich dabei um 60MW Kraftwerksleistung aus regenerativer Energie bis 1992, bzw. 600MW bis zum Jahr 2000 (WPM 4/89, 8). Bemerkenswert ist, dass die NFFO ursprünglich zur Förderung der Atomkraft konzipiert worden ist. Technische Erfolge und das damit verbundene Interesse an der Windkraft führten $\mathrm{zu}$ einer teilweisen Umwidmung der NFFO (WPM 8/92, 10). ${ }^{372}$

Die NFFO funktioniert nach dem Auktionsprinzip. Potenzielle Betreiber von Regenerativkraftwerken bewarben sich um Anteile der ausgeschriebenen Kapazitäten. Dabei boten sie die Energie zu bestimmten Kilowattstundenpreisen an, die allerdings ein Maximum nicht überschreiten durften. Zugelassen wurden i.a. diejenigen Projekte mit den niedrigsten Preisvorschlägen. Diese Kraftwerke mussten vom zuständigen Netzbetreiber angeschlossen

\footnotetext{
${ }^{371}$ Naturschutzorganisationen befürchteten, insbesondere aufgrund ihrer Erfahrungen mit dem mangelnden Umweltbewusstsein des CEGB, negative Folgen für die Landschaft (WPM10/88, 21).

${ }^{372}$ Die ursprünglich geplante Expansion der Atomenergienutzung ließ sich nicht umsetzen. Tatsächlich wurden seit Einführung der NFFO im Jahr 1990 nur zwei Reaktoren neu in Betrieb genommen (1991 und 1995).

Deutlich mehr Reaktoren wurden seitdem stillgelegt (http://www.global2000.at/pages/tatomgrossbritannien.htm; Abruf vom 2.9.2008).
} 
werden. Letztere waren ferner verpflichtet, die eingespeiste Energie mit den entsprechenden Tarifen zu vergüten.

In der ersten Ausschreibungsrunde vom September 1990 wurden neun Windparks genehmigt, von denen einige zu diesem Zeitpunkt bereits in Betrieb waren (vg. Tab. 3e).

Tab. 3e Genehmigte Windparkprojekte der ersten NFFO-Ausschreibungsrunde von 1990

\begin{tabular}{|c|c|c|c|c|}
\hline Projekt/ Standort & Entwickler/ Betreiber & Hersteller & $\begin{array}{l}\text { Gesamtkapazität } \\
\text { (MW) }\end{array}$ & Status Ende 1990 \\
\hline Richborough, Kent & Powergen & Howden & 1,0 & in Betrieb \\
\hline Carmarthen, Wales & National Power & WEG/ Howden & 0,6 & in Betrieb \\
\hline Scilly Islands & National Power & VAWT & 0,1 & in Betrieb \\
\hline $\begin{array}{l}\text { Huntingdon, } \\
\text { Cambrideshire }\end{array}$ & $\begin{array}{|ll|}\text { Wood Green Animal } \\
\text { Shelters }\end{array}$ & Vestas & 0,23 & in Betrieb \\
\hline & & & $\begin{array}{l}\text { insgesamt: } 1,9 \mathrm{MW} \text { in } \\
\text { Betrieb }\end{array}$ & \\
\hline Delabole, Cornwall & $\begin{array}{l}\text { Peter Edwards/ National } \\
\text { Windpower }\end{array}$ & Vestas & 4,0 & $\begin{array}{l}\text { in Planung, realisier } \\
11 / 91\end{array}$ \\
\hline $\begin{array}{ll}\text { Chelker } & \text { Reservoir } \\
\text { Yorkshire } & \\
\end{array}$ & Yorkshire Water & WEG & 1,2 & $\begin{array}{l}\text { in Planung, realisier } \\
12 / 92\end{array}$ \\
\hline Cemmaes, Wales & National Wind Power & WEG & 7,2 & $\begin{array}{l}\text { in Planung, realisier } \\
11 / 92\end{array}$ \\
\hline $\begin{array}{ll}\text { Ovenden } & \text { Moor, } \\
\text { Yorkshire } & \\
\end{array}$ & $\begin{array}{l}\text { Yorkshire Water/ } \\
\text { Yorkshire Electric }\end{array}$ & Vestas & 9,2 & $\begin{array}{l}\text { in Planung, realisier } \\
6 / 93\end{array}$ \\
\hline Kirkby Moor, Cumbria & National Windpower & WEG & 7,5 & $\begin{array}{l}\text { in Planung, realisier } \\
9 / 93\end{array}$ \\
\hline & & & insgesamt: $29,1 \mathrm{MW}$ & \\
\hline
\end{tabular}

Quelle: WPM 12/90, 6; 1/93, 30; Website der BWEA

Die Tarife betrugen zumeist 0,06Pf. pro Kilowattstunde, oder lagen geringfügig darunter. Gezahlt wurden sie aus den Steuern, welche die Netzbetreiber pro gekaufter Kilowattstunde Strom aus fossiler Energie, ansonsten an den Staat hätten abführen müssen (WPM 12/91, 4). Daher lohnte sich der Betrieb von Windparks auch für die EVU. Seitens der Windparkbetreiber bestand ein dringendes Interesse, ihre Windanlagen so bald wie möglich ans Netz zu schließen. Denn der Vorzugstarif von 0,06Pf. pro Kilowattstunde galt nur bis 1998. Anschließend erhielten die Betreiber nur noch den üblichen ,Poolpreis' von 0,02-0,03 Pf./kWh (WPM 3/91, 22). Insofern ist es zunächst bemerkenswert, dass der erste der geplanten fünf Windparks erst im Dezember 1991 ans Netz geschlossen wurde (DelaboleProjekt). Bevor Betreiber Peter Edwards eine Baugenehmigung erhielt, vergingen über zweieinhalb Jahre zäher Verhandlungen (WPM 11/92, 23). Dem Projekt des Landwirts und Vorsitzenden der Landbesitzervereinigung von Cornwall standen große Widerstände entgegen. Da zu diesem Zeitpunkt in Großbritannien kaum Erfahrungen mit dem Betrieb von WEA vorlagen, waren die Anrainer leicht zu verunsichern. Dieses galt insbesondere bzgl. der Frage zu erwartender Schallemissionen. Eine Kampagne monierte die Gefahr hoher Lärmbelästigung und beendete damit die anfängliche Zustimmung. Daraufhin weigerte sich der Gemeinderat, den Windpark zu genehmigen (WPM 1/90, 8f.). Erst im zweiten Versuch erhielt Edwards die Zustimmung für sein Projekt durch den North Cornwall District Council (WPM 5/90, 8). Bei den Erfahrungen mit der Planung des Delabole Windparks handelte es sich um keinen Einzelfall. Klagen und Beschwerden seitens Anrainer und Naturschutzorganisationen wie dem ,Council for the Protection of Rural England/ Wales' führten zur Verzögerung der meisten Projekte (WPM 12/90, 7). Der letzten beiden, der 1990 bewilligten NFFO-Windparks, wurden erst 1993, drei Jahre später, in Betrieb genommen. Trotz dieser Barrieren erhält die Windkraft in Großbritannien zu Beginn der 90er Jahre einen imposanten Aufschwung (vg. Tab. 3d). Im folgenden soll näher untersucht werden, welche Akteure diese Entwicklung getragen haben. 
Diejenigen NFFO-Windparks, die im September 1990 bereits in Betrieb sind, gehörten zu $75 \%$ den beiden großen CEGB-Nachfolgekonzernen, Powergen und National Power, bei der angeschlossenen Kapazität sind es $88 \%$ (vg. Tab. 3e). Diese Statistik vermag nicht darüber hinwegzutäuschen, dass das Interesse an der neuen Technologie insgesamt, zu diesem Zeitpunkt noch immer kaum vorhanden war. ${ }^{373}$ Ein Blick auf die Betreiberstruktur und die Größe der übrigen NFFO-Projekte zeigt, dass die EVU jetzt mehr Aktivitäten auf dem Sektor entfalten. Neben der Beteiligung des Versorgers von Yorkshire (Yorkshire Electric) am Projekt Ovenden Moor, ist hier insbesondere das Engagement des größten britischen Energiekonzerns National Power hervorzuheben. Gemeinsam mit den Teilhabern der WEG, British Aerospace und Taylor Woodrow, gründet National Power 1991 die neue Windparkentwicklungsgesellschaft National Wind Power (NWP). NWP gehörte National Power $\mathrm{zu}$ 50\%. Die neue Gesellschaft übernahm sämtliche Windpark-Planungen des Energiekonzerns. Gemeinsam mit Dulas Engineering leitete NWP die Entwicklung eines 7,2MW-Windparks in Cemmaes/Wales. Am Windpark von Peter Edwards (Delabole) beteiligte sich NWP zudem mit 750.000Pf., entsprechend 30\%. South Western Electricity investierte 250.000Pf. in das Projekt (WPM 10/91, 12;18). Schließlich zählte der finanzkräftige Hersteller WEG nicht nur als Turbinenlieferant, sondern auch als Windparkbetreiber $\mathrm{zu}$ den wichtigsten Akteuren der ersten NFFO-Ausschreibungsrunde (NFFO I).

Auch für die zweite Ausschreibungsrunde (NFFO II) vom September 1991 galten die Vorzugstarife nur bis 1998. Daher entschied man sich dafür, die Tarifobergrenze von 0,06 auf 0,11Pf. auszudehnen. Im Rahmen der NFFO II erhielten 28 Entwickler Zuschläge für insgesamt 49 Windparkprojekte mit einer Gesamtkapazität von 190MW (WPM 12/91, 4ff). Etliche der Planungen wurden gar nicht, oder erst Jahre später realisiert (vg. WPM 1/93, 20). Um mehr über diese erste Phase der britischen Marktentwicklung zu erfahren, werden im folgenden die Akteursstrukturen der größten NFFO II - Projekte untersucht, die vergleichsweise zeitnah, d.h. bis Ende 1993, realisiert werden konnten (vg. Tab. 3.2.2b).

Tab. 3f Realisierte NFFO-II-Windparks bis Ende 1993 (Auswahl)

\begin{tabular}{|l|l|l|l|l|l|}
\hline Projekt/ Standort & $\begin{array}{l}\text { Entwickler/ } \\
\text { Betreiber }\end{array}$ & $\begin{array}{l}\text { EVU beteiligt } \\
\text { (ja/nein) }\end{array}$ & Hersteller & $\begin{array}{l}\text { Gesamtkapazität } \\
(\mathrm{MW})\end{array}$ & in Betrieb seit \\
\hline $\begin{array}{l}\text { Carland Cross, } \\
\text { Cornwall }\end{array}$ & $\begin{array}{l}\text { Renewable Energy } \\
\text { Systems/ Wa } \\
\text { Ressources Ltd. }\end{array}$ & Vestas & 6,0 & $8 / 92$ \\
\hline $\begin{array}{l}\text { Coal Clough, } \\
\text { Lancashire }\end{array}$ & $\begin{array}{l}\text { Renewable Energy } \\
\text { Systems/ ja Wind } \\
\text { Ressources Ltd. }\end{array}$ & Vestas & 9,6 & $12 / 92$ \\
\hline $\begin{array}{l}\text { Cold Northcott, } \\
\text { Cornwall NWP/ jational } \\
\text { Power ja }\end{array}$ & WEG & 6,4 & $4 / 93$ \\
\hline $\begin{array}{l}\text { Llangwyryfon, } \\
\text { Dyfed (Wales) }\end{array}$ & $\begin{array}{l}\text { NWP/ National } \\
\text { Power }\end{array}$ & ja & WEG & 6,0 & $5 / 93$ \\
\hline $\begin{array}{l}\text { Llandinam P\&L, } \\
\text { Powys }\end{array}$ & Ada Projects Ltd. & nein & Mitsubishi & 30,9 & $12 / 92$ \\
\hline $\begin{array}{l}\text { Ryd-y-Groes, } \\
\text { Anglesey }\end{array}$ & Ada Projects Ltd. & nein & Bonus & 8,4 & $4 / 93$ \\
\hline $\begin{array}{l}\text { Goonhilly Downs, } \\
\text { Cornwall }\end{array}$ & $\begin{array}{l}\text { Cornwall Light \& ja } \\
\text { Power }\end{array}$ & Vestas & 5,6 & insgesamt 72,9MW & \\
\hline
\end{tabular}

Quelle: WPM 1/93; Hompage des BWEA

\footnotetext{
${ }^{373} 1988$ gab der CEGB die Planung von drei Windparks bekannt (s.o.). Unter den NFFO-geförderten Projekten befanden sie sich nicht (WPM 12/90,7). Nur einer dieser Windparks (Cold Northscott) wird unter der zweiten NFFO Ausschreibungsrunde errichtet und im April 1993 durch National Power eröffnet (WPM 6/93, 12).
} 
Wichtigste Betreiber sind NWP/National Power (s.o.), Ada Projects Ltd. und Renewable Energy Systems (RES). Bei Ada Projects Ltd. handelt es sich um eine Kooperation zwischen dem japanischen Energiekonzern Tomen, dem US-amerikanischen Windparkentwickler Seawest und Ecogen aus Cornwall. Tomen hielt 60\%, Seawest 30\% und Ecogen 10\% von Ada Projects. Nur aufgrund dieser finanzstarken Partner war Econgen in der Lage, Großprojekte wie den Windpark von Llandinam - zu dieser Zeit der größte Windpark Euopas - zu realisieren. Die Wahl des Turbinenherstellers Mitsubishi ist maßgeblich auf die Beteiligung Tomens zurückzuführen (WPM 12/91, 6). Neben Ada Projects und NWP ist Renewable Energy Systems der dritte große Akteur auf dem Sektor. RES gehört zur Sir Robert McAlpine Gruppe. Mit der Wind Ressources Ltd. gründete RES ein Windparkentwicklungsunternehmen, an dem auch zwei EVU beteiligt waren: Manweb (Nordwest England) und South West Electricity (WPM 9/92). Wind Ressources Ltd. realisierte 1992 zwei Windparks (insgesamt 15,6MW Windenergiekapazität).1993 wurden zudem drei weitere Windparks installiert, die ausschließlich von EVU (National Power, Cornwall Light \& Power) finanziert, entwickelt und betrieben wurden (Gesamtkapazität: 18MW, vg. Tab. 3f).

Für den britischen Windenergiesektor kommt die Akteursstruktur der sieben hier betrachteten NFFO-II-Projekte eine hohe Repräsentativität zu. Nur zwei dieser Windparks werden ohne EVU-Beteiligung realisiert. Insbesondere dem größten britischen Energiekonzern NWP kommt für die erste Aufschwungphase eine herausragende Bedeutung zu. Neben weiteren EVU wie Powergen, Manweb und South West Electricity dominierten internationale Konzerne wie Tomen, Sir Robert McAlpine, Taylor Woodrow und British Aerospace das Feld. Die Akteursstruktur - EVU und Konzerne - blieb damit, gegenüber derjenigen der NFFO-I-Projekte im wesentlichen erhalten. Bemerkenswert ist das Hinzutreten von Ada Projects. Sowohl die Bedeutung finanzstarker internationaler Firmen und die Größe des von ihnen in Llandinam aufgebauten Windparks stellen europaweit ein Novum dar. Lokale Betreiber einzelner Anlagen und kleiner Windparks sowie Kommunen, sind deutlich in der Minderheit.

\section{$\underline{\text { Schwierigkeiten }}$}

Tabelle 3d zeigt: 1993 ist das Boomjahr im Aufbau britischer Windparks. Trotz wachsender Anlagengröße wird der Maximalwert neu installierter Windenergiekapazität von 100MW pro Jahr, während der 90er Jahre nicht mehr erreicht. Aus zwei Gründen hat sich die Entwicklung Anfang der 90er Jahre nicht noch schneller vollzogen. Zum einen konnten die windigsten Standorte in Schottland, wo sich zwei Drittel der britischen Windressourcen befinden (WPM 9//92) nicht genutzt werden, weil das Land von den ersten beiden NFFOAusschreibungsrunden ausgeschlossen war. Zum anderen bildete die kurzfristige Geltung der NFFO-Tarife (bis 1998) ein deutliches Hemmnis.

Eine der großen Schwierigkeiten der dänischen und deutschen Windanlagenbetreiber bestand in der Finanzierung der Windparks. Für die, auf dem britischen Markt führenden Großunternehmen, hat sich das Problem mangelnder Liquidität nicht gestellt. Auch stand die Rentabilität der NFFO-II-Projekte kaum in Frage. So wurden die Einspeisetarife zwischen NFFO-I und NFFO-II von 0,06 auf 0,11Pf. angehoben. Zusätzlich erhielten einige Betreiber EU-Gelder zur Realisierung der Projekte. ${ }^{374}$ Das zentrale Problem der britischen Windkraftnutzung während der 90er Jahre besteht also weder in unzureichender Förderung, noch im Marktausschluss netzunabhängiger Stromproduzenten, noch dem Unwillen der EVU,

\footnotetext{
${ }^{374}$ Die EU unterstützte das Projekt von Peter Edwards mit 442.000 Euro. 370.000 erhielt die Yorkshire Water Authority für ihren Windpark im Chelker Reservoir (WPM 2/90, 20). Eine als Demonstrationsprojekt deklarierte Windparkplanung des CEGB erhielt eine frühzeitige Zusage seitens der EU, dieses Projekt mit 518.000 Euro zu fördern (ebd.).
} 
oder dem Kapitalmangel der Akteure. In der Literatur herrscht Einigkeit darüber, dass der wesentliche Grund der Verlangsamung in mangelnder Akzeptanz der Windparks, durch Anrainer und Naturschutzorganisationen, $\mathrm{zu}$ sehen ist. ${ }^{375}$ Es kommt $\mathrm{zu}$ langwierigen Genehmigungsfristen und dadurch erschwerten Planungsarbeiten. Zwischen der Zulassung eines Projekts für die NFFO und dessen Inbetriebnahme vergehen häufig drei Jahre und mehr. Nichtsdestotrotz werden im Zeitraum 1991-93 75 Prozent der Projekte (neun von zwölf) genehmigt. Zwischen 1994 und 1998 dagegen, erhalten nur zwei von 17 Planungen eine Genehmigung (Toke 2003, 208). Elliot $(1997,160)$ verortet die Trendwende 1993, infolge der Reaktionen auf den großen Windpark von Llandinam (103 Mitsubishi-WEA), als Wendepunkt in der Akzeptanzdebatte. Elliot analysiert die Begrenzung der Vorzugstarife auf den Zeitraum bis 1998 als einen Ursachen des Problems. Um die Wirtschaftlichkeit zu garantieren, mussten die Projekte schnellstmöglich umsetzt werden. Für einen Dialog mit den Anrainern bleibt daher zu wenig Raum. Die Anhebung der Tarifobergrenze von 0,06 auf 0,11Pf. zwischen NFFO-I und -II sicherte zwar die Wirtschaftlichkeit der Projekte. Zurecht moniert Elliot (1997, 155), dass diese Erhöhung dazu beigetragen hat, dass die Windkraft von der Öffentlichkeit als eine sehr teuere Energiequelle wahrgenommen worden ist. Man hat den Windparkentwicklern vorgeworfen, in erster Linie an Profiten interessiert zu sein, ohne auf Naturschutzaspekte Rücksicht zu nehmen.

In seinen Aufsätzen von 1999 und 2003 erklärt David Toke diese Situation aus einer mangelnden Einbindung der ansässigen Bevölkerung. Der lokale Charakter der Windenergienutzung ist als einer der wichtigsten Erfolgsfaktoren des dänischen Modells analysiert worden (s.o.). Auch hat die EVU-Dominanz auf dem niederländischen Markt stark dazu beigetragen, die Akzeptanz der Windkraft zu verringern. Anders als in Großbritannien, sind Betreiber einzelner Windturbinen und kleiner Windparks (Landwirte, Kooperativen etc.), in den Niederlanden keine Exoten, sondern stellen eine feste Komponente des Sektors dar. Um die Akzeptanzproblematik zu überwinden, fordern Bolinger (2001) und Toke (1999; 2005) eine Neustrukturierung des britischen Windmarktes im Sinne eine stärkeren Einbindung der Anrainer: ,Community Ownership - The only way ahead for UK wind power?' (Toke 1999). Bolinger (2001, 35) kritisiert, dass die NFFO große auswärtige Entwickler gegenüber lokalen Akteuren strukturell bevorzuge. In den Auswahlverfahren würden letztere i.a. nicht berücksichtigt, weil der Realisierung ihrer Vorschläge geringere Chancen beigemessen werden, als den Planungen etablierter Investoren. Bolinger (ebd.) moniert zudem, dass in Großbritannien, anders als in mehreren europäischen Ländern, weder Kapitalzuschüsse, noch Steuerabschreibungsmöglichkeiten angeboten würden. Lokale Kooperativen als Betreiber von WEA, wie etwa die Baywind Energy Cooperative von Harlock Hill, ${ }^{376}$ sind die Ausnahme.

Trotz der Stagnation sahen die politisch verantwortlichen wenig Anlass, die Akteursstruktur durch eine Neuausrichtung der Fördermaßnahmen zu modifizieren. ${ }^{377}$ Die Krise der britischen Windkraft wird erst in den letzten Jahren überwunden. Dieses geschieht nicht etwa durch Stärkung kommunaler Windkraft, wie sie von Bolinger und Toke favorisiert wird. Vielmehr konnte dem Akzeptanzproblem ausgewichen werden, indem zunehmend schottische Standorte genutzt und seit neuestem verstärkt Offshore-Windparks realisiert werden.

\footnotetext{
375 vg. Toke 1999; Toke 2003; Elliot 1997; Bolinger 2001

${ }^{376} 1995$ erhielt die Kooperative für fünf der beantragten sieben Windturbinen (je 500kW) eine Genehmigung. An der Finanzierung der ersten Anlage, die im Januar 1997 in Betrieb ging, sind etwa 1.200 Personen beteiligt (vg. Bolinger 2001, 39). Die Realisierung des Projekts vollzog sich sehr langsam. Weniger die mangelnde Akzeptanz als vielmehr die Kapitalakquirierung war der Hauptgrund der Verzögerungen.

377 Teilweise als Reaktion auf die Kritik am britischen Fördersystem, wird seit der 3. NFFO-

Ausschreibungsrunde ein geringer Anteil der geplanten Neukapazitäten für kleine Projekte reserviert (Bolinger 2001, 35). Nachdem die NFFO-Regelung nach der 5. Ausschreibungsrunde beendet wurde, entfiel auch dieser Spielraum für lokale Interessenten (Bolinger 2001, 41). Jeder der sieben Windparks, die 2001 in Großbritannien neu ans Netz gingen, wurde von einem Energieunternehmen realisiert (Neue Energie 5/02, 105).
} 


\subsection{Spanien}

Ähnlich wie Großbritannien verfügt auch Spanien über große Ressourcen an Windkraft. Zudem ist das Land vergleichsweise dünn besiedelt, so dass die Planung von Windparks insgesamt einfacher war, als etwa in den Niederlanden und Großbritannien. Energiearmut ist für Spanien ein großes Problem, zu dessen Bewältigung die Windenergie beitragen sollte. Anfang der 90er Jahre werden die im Kyoto-Protokoll eingegangenen Verpflichtungen zu einer wichtigen Rahmenbedingung der Förderung erneuerbarer Energien. Der kommerzielle Sektor hatte während der Pionierphase kaum eine Bedeutung. Vereinzelte inländische Windanlagenhersteller waren nicht konkurrenzfähig. Vor dem Hintergrund internationaler Erfolge der Windenergienutzung wächst das Interesse an der neuen Technologie zu Beginn der 90er Jahre. Noch stärker als in Griechenland ist der gesamte spanische Windsektor durch einen einzigen Akteur bestimmt: den staatlichen Energiemonopolisten Endesa, zugleich das viertgrößte Unternehmen des Landes (WPM 10/90, 13).

\subsubsection{Pionierphase}

Im Rahmen des Energiespargesetzes von 1980 wurde die Einspeisung erneuerbarer Energie durch unabhängige Stromproduzenten erstmals geregelt. Seitdem erhielten diese vom Staat eine definierte Vergütung pro Kilowattstunde. Problematisch ist, dass die Tarife jährlich neu bestimmt wurden. Für potenzielle Investoren bestand daher eine hohe Unsicherheit. Entsprechend zögerlich waren daher die Banken bei der Finanzierung solcher Projekte. Diese Probleme existierten wohl für unabhängige Investoren, nicht aber für die Endesa Gruppe. Entsprechend leichtfertig äußerte sich Emilio Menendez, Windenergieexperte des Konzerns: ,This is a latin country - we're not Germans or Japanese. We don't make a rigid plan and implement it precisely....There has to be an agreement in this country about the need for wind energy and the price has to be resolved accordingly.' (zitiert nach: WPM 9/92, 25f.)

Für die Banken bedeutete die Beteiligung Endesas hinreichende Planungssicherheit. Daher finanzierten sie die Projekte, obwohl deren Rentabilität jedes Jahr erneut zur Disposition gestellt werden konnte (WPM 9/92, 25). Der wichtigere Grund, weshalb sich der Windsektor, über die gesamte Pionierphase hindurch, sich nur sehr träge entwickelte, hatte weniger finanzielle, als vielmehr technische Gründe. Die spanischen Modelle entsprachen den internationalen Standards weder in Größe noch Qualität. Daher blieb es zunächst bei zögerlichen Experimenten. Der erste Windpark Spaniens wurde im Jahr 1984 in Katalonien errichtet und mit fünf $20 \mathrm{~kW}$-Anlagen von Ecotecnia ausgestattet. Bei diesem spanischen Unternehmen handelt es sich um eine Kooperative, die bereits 1981 von einigen Ingenieuren gegründet wurde (Wind Directions 7-8/05, 27). ${ }^{378}$

Durch drei Töchterunternehmen ist die Endesa Gruppe seit 1982 auf dem Windenergiesektor aktiv: Endesa (Projektentwicklung/ Betrieb), Gesa (F\&E) und MADE (Herstellung) (WPM 10/90, 13). Im Jahr 1982 nahm Gesa (Netzbetreiber der Balearen) auf Mallorca eine 24kWWindmühle und eine kleine Testeinrichtung in Betrieb. 1986 ließ die Endesa Gruppe auf den kanarischen Inseln (Granadilla/ Teneriffa) einen Windpark zu Versuchszwecken errichten. Installiert wurden zehn $30 \mathrm{~kW}$-Anlagen der damaligen drei spanischen Hersteller Gesa, Ecotecnia und Canarian Wind Turbines (WPM 12/87, 17). Betreiber war Unelco, Regionalversorger der Kanaren. ${ }^{379}$ Damals verfügten die Firmen vor allem über Erfahrungen mit der Produktion deutlich kleinerer WEA. ${ }^{380}$ In La Muela (Aragón) installierte die Endesa

\footnotetext{
${ }^{378}$ Seine ersten Modelle entwickelte Ecotecnia vollständig selbst - inklusive Rotor. Später kooperierte das Unternehmen mit etablierten Herstellern wie US Kentech sowie Zulieferbetrieben. Ausschließlich die Türme und elektrische Kontrolle entwickelt Ecotecnia weiterhin selbst (Wind Directions 7-8/05, 27).

${ }^{379}$ Unelco gehörte zu 99\% der Endesa Gruppe (WPM 9/92, 24).

${ }^{380}$ Allein 1985 werden etwa 180 WEA auf den kanarischen Inseln mit einer Gesamtkapazität von etwa 500kW errichtet, durchschnittlich weniger als drei Kilowatt pro Turbine (WPM 12/87, 16).
} 
Gruppe 1987 einen weiteren Windpark, wobei zwölf des auf den Kanaren getesteten GesaModells zum Einsatz gekommen sind. Im selben Jahr nahm auch Ecotecnia zwei Windparks mit jeweils zehn seiner 30kW-Turbinen in den Provinzen La Mancha, bzw. Andalusien (Tarifa) in Betrieb. Sämtliche Windparks, die bis 1990 in Betrieb gingen, erhielten Fördergelder der Zentralregierung. Die folgende Tabelle $3 \mathrm{~g}$ veranschaulicht die zentrale Rolle Endesas.

Tab.3g Spanische Windparks bis Mitte 1990

\begin{tabular}{|c|c|c|c|c|c|}
\hline Windpark/ Provinz & \begin{tabular}{|l|}
$\begin{array}{l}\text { Eigentümer/ } \\
\text { Betreiber }\end{array}$ \\
\end{tabular} & Hersteller & \begin{tabular}{|l|} 
Anlagenzahl $x$ \\
Größe (kW) \\
\end{tabular} & Kapazität (kW) & \begin{tabular}{|l|}
$\begin{array}{l}\text { Installation } \\
\text { (Jahr) }\end{array}$ \\
\end{tabular} \\
\hline $\begin{array}{l}\text { Granadilla/ } \\
\text { Teneriffa }\end{array}$ & Endesa & $\begin{array}{ll}\text { MADE/ } & \\
\text { Ecotecnia/ } \\
\text { Canarian Wind } \\
\text { Turbines }\end{array}$ & $10 \times 30 \mathrm{~kW}$ & 300 & 1987 \\
\hline La Muela/ Zaragoza & Endesa/ IDEA & $\begin{array}{|ll|}\text { MADE } & \text { (Endesa } \\
\text { Gruppe) } & \\
\end{array}$ & $\begin{array}{l}12 \times 30 \mathrm{~kW} \\
1 \times 75 \mathrm{~kW} \\
1 \times 110 \mathrm{~kW}\end{array}$ & 545 & 1987 \\
\hline $\begin{array}{l}\text { Estaca de Bares, La } \\
\text { Coruna }\end{array}$ & Endesa/IDEA & $\begin{array}{|ll|}\text { MADE } & \text { (Endesa } \\
\text { Gruppe) } & \\
\end{array}$ & $12 \times 37 \mathrm{~kW}$ & 444 & 1987 \\
\hline Cabo Creus/ Gerona & Endesa & $\begin{array}{|ll|}\text { MADE } & \text { (Endesa } \\
\text { Gruppe) } & \\
\end{array}$ & $\begin{array}{l}2 \times 75 \mathrm{~kW} \\
4 \times 110 \mathrm{~kW}\end{array}$ & 590 & 1987 \\
\hline Ontalafia/ Albacete & Ecotecnia & Ecotecnia & $10 \times 30 \mathrm{~kW}$ & 300 & 1988 \\
\hline Tarifa/ Cadiz & Ecotecnia & Ecotecnia & $\begin{array}{l}10 \times 30 \mathrm{~kW} \\
1 \times 15 \mathrm{~kW} \\
\end{array}$ & 315 & 1988 \\
\hline Monte Ahumada & Endesa & MADE & $7 \times 150 \mathrm{~kW}$ & 1050 & 1988 \\
\hline $\begin{array}{ll}\text { Cabo } & \text { Villano/ } \\
\text { Galizien } & \end{array}$ & $\begin{array}{l}\text { Union Fenosa } \\
\text { (gehörte anteilig zur } \\
\text { Endesa Gruppe) } \\
\end{array}$ & $\begin{array}{l}\text { MAN } \\
\text { MADE }\end{array}$ & $\begin{array}{l}1 \times 1200 \mathrm{~kW} \\
1 \times 110 \mathrm{~kW} \\
1 \times 75 \mathrm{~kW} \\
\end{array}$ & 1385 & 1989 \\
\hline $\begin{array}{l}\text { Granadilla/ } \\
\text { Teneriffa }\end{array}$ & Endesa/ JointVenture & $\begin{array}{l}\text { MADE, } \\
\text { Ecotecnia, WEG, } \\
\text { Vestas, Cenemesa }\end{array}$ & $\begin{array}{l}2 \times 150 \mathrm{~kW} \\
1 \times 250 \mathrm{~kW} \\
1 \times 200 \mathrm{~kW} \\
1 \times 300 \mathrm{~kW}\end{array}$ & 1050 & 1990 \\
\hline
\end{tabular}

Quellen: WPM 12/87, 17; WPM 10/90, 13

Bis Ende 1987 umfasste der spanische Windenergiesektor nur etwa zwei Megawatt (WPM 12/87, 17). Von einem Markt für Windanlagen wie er $\mathrm{zu}$ diesem Zeitpunkt in den Pioniermärkten existierte, kann nicht gesprochen werden.

Die notorischen Konflikte zwischen unabhängigen Windmüllern und Netzbetreibern existierten zunächst nicht, weil die ersten Windparks ausschließlich von den Versorgern betrieben wurden. Das Hauptproblem bestand darin, dass die Windindustrie Dänemarks und andere internationale Hersteller wie US-Windpower, gegenüber den spanischen Herstellern über einen Erfahrungsvorsprung mehrerer Jahre verfügten. Erstere produzierten und exportierten erprobte Windanlagen mit 100-200kW-Generatoren. In Spanien befand sich die 30kW-Klasse zu dieser Zeit im fortgeschrittenen Prototyp-Stadium. Über deren Qualität äußerte sich Manuel Cendagorta, Direktor des Technologischen Instituts für erneuerbare Energien (Betreiber des Granadilla-Windparks): ,They are too small. The cost of maintaining them is high...They have many drawbacks. There's not much sense in moving them.' (WPM 10/91, 26).

Angesichts dieser Situation zeigte sich niemand bereit, größere Investitionen in spanische Windanlagen zu tätigen. Daher forderte das zuständige Energieministerium ausländische Turbinenhersteller dazu auf, in den neuen Markt einzusteigen, sofern sie gewillt wären, ihr Know-how an spanische Firmen weiter zu geben (WPM 12/87, 17). 


\subsubsection{Diffusionsphase}

Auf der europäischen Windenergiekonferenz von 1990 kündigte das spanische Energieministerium an, die damalige Windenergiekapazität von 5,3MW, bis 1995 im Rahmen des ,PER-89' auf 80MW auszuweiten. Die Weichen zur Umsetzung des Plans sind frühzeitig gestellt worden. Denn zu diesem Zeitpunkt waren bereits Verträge für die Lieferung von 369 Windanlagen unterzeichnet worden. Die Hälfte der erforderlichen Investition in Höhe von $\$ 95$ Mio. wurde von staatlichen Trägern übernommen. Mit den Interessen der großen Stromkonzerne, insbesondere der Endesa Gruppe, standen die Pläne in Einklang (WPM $10 / 90,12 \mathrm{f}.)^{381}$

Der Durchbruch gelang unter Verwendung internationaler Technologie. Sämtliche ersten größeren Projekte werden auf Basis internationaler Kooperationen realisiert. Dabei stellen die ausländischen Hersteller i.a. ihr Design zur Verfügung. Produziert wurden die Anlagen vom jeweiligen spanischen Partner, unter Lizenz. Charakteristisch für den Beginn der Diffusionsphase (vg. Großbritannien, Griechenland) ist der Aufbau größerer Windparks unter Verwendung leistungsstärkerer Modelle. Um ein besseres Verständnis der Akteurskonstellation zu erlangen, werden im folgenden zwei, für damalige Verhältnisse große Windparkprojekte näher betrachtet.

Beide Standorte befinden sich in der Nähe von Tarifa in Andalusien, wenige Kilometer voneinander entfernt. Das erste Projekt ,PESUR' (Parque Eolico del Sur) wurde von einem Konsortium, bestehend aus der Endesa Gruppe, Abengoa (Energieversorger von Sevilla), dem Instituto Fomento Andalucia (einer regionalen Entwicklungsbehörde) und dem USamerikanischen Anlagenhersteller US-Windpower, finanziert (Kosten: \$33,5 Mio.). Turbinenfabrikant war die Endesa-Tochter MADE. 34 Windanlagen à $150 \mathrm{~kW}$ und damit ein Viertel der Kapazität des Windparks (insgesamt 20MW) lieferte MADE nach eigenem Design, dass sich eng am dänischen Konzept orientierte. Für die Rotoren griff MADE auf internationales Know-how zurück. Diese entstanden nach einem Design des niederländischen Aeropac (WPM 10/91, 14). Die übrigen Turbinen fertigte das spanisch-US-amerikanische Joint Venture AWP Plantas Eolicas SA (Abengoa und US-Windpower), unter Verwendung des Designs vom US-Windanlagenbauer (WPM 4/91, 11).

Beim anderen Projekt handelt es sich um den Windpark ,Energia Eolica del Estrecho' (kurz: E3, 10MW Kapazität). Finanziert wurde es von einem dem PESUR ähnlichen Konsortium, bestehend aus Abengoa (gehörte zu 32\% der Endesa Gruppe), Ecotecnia, IDEA, Endesa und IFA (WPM 10/90, 8; WPM 9/92, 24). Bei der Rotorenherstellung bediente sich Ecotecnia eines Designs des langjährigen dänischen Rotorenherstellers L\&M. E3 umfasst 66 WEA, von denen 50 von Ecotecnia geliefert wurden, der Rest von MADE.

Beide Projekte wurden gegen Ende des Jahres 1992 in Betrieb genommen. Der Markt erreichte eine neue Qualität. Allein diese Neukapazität von 30MW führte 1992 zu einer Vervierfachung der zum Vorjahresende installierten Windenergiekapazität.

Die Tarifa-Windparks ähneln einander nicht nur in Größenordnung, Standort und Eröffnungszeitpunkt, sondern auch der Akteurskonstellation. In beiden Projekten nimmt die Endesa Gruppe jeweils eine gewichtige Rolle ein. Das Unternehmen ist nicht nur als Entwickler, sondern auch über seine Töchter, Hersteller MADE und den Regionalversorger von Sevilla, an beiden Projekten beteiligt. Sowohl das PESUR-Projekt, als auch E3 erhielten eine 25\%ige Investitionsförderung aus dem EU-Programm Valoren, der Zentralregierung und der Provinz Andalusien (WPM 4/91, 10f.; WPM 9/92, 24). In beiden Fällen wurde auf Knowhow der Pioniermärkte zurückgegriffen. Beide Konsortien legten darüber hinaus großen Wert darauf, möglichst viele Aufträge an inländische Hersteller zu vergeben.

\footnotetext{
${ }^{381}$ Dem NEP (National Energy Plan) zufolge, sollte bis zum Jahr 2000 eine Windpark-Kapazität von 175 MW erreicht werden (WPM 2/93, 10).Endesa verkündigte für diesen Zeitpunkt stattdessen ein ehrgeizigeres Ziel: $750 \mathrm{MW}$.
} 
Was für die Betreiberstruktur der spanischen Pionierphase gültig war, gilt auch für den spanischen Markt Anfang der 90er Jahre, insbesondere für die großen Tarifa-Windparks: Endesa ist an sämtlichen größeren Projekten beteiligt. Finanzierte die Gruppe einen Windpark nicht direkt, so ist sie häufig durch ihre Töchterunternehmen beteiligt. Neben Hersteller MADE zählen dazu regionale Energieversorger. ${ }^{382}$

Eine wichtige Barriere des Windenergieausbaus in den Pioniermärkten ist der Konflikt zwischen unabhängigen Windmüllern und EVU. Da die ersteren auf dem spanischen Markt praktisch nicht präsent waren, stellte dieser Konflikt kein größeres Hemmnis dar. Das Beispiel der Entwicklung eines Windparks auf Fuerteventura (Jandia) zeigt, dass der Netzzugang - auch in Spanien - für unabhängige Akteure nicht reibungslos zu erlangen war. Das dortige Wasserwerk plante seit 1990 einen großen Windpark (10MW) mit 45 Turbinen von Vestas. Hergestellt werden sollten die Anlagen in lokaler Produktion von Aerogeneradores Canarios SA (ASCA). Das Kraftwerk sollte vornehmlich dazu dienen, die Meerwasserentsalzungsanlage mit Strom zu versorgen. Da die Insel über keine eigenen Trinkwasservorkommen verfügt, muss ein Großteil der Kapazitäten für diesen Zweck aufgewendet werden. Unelco, zuständiger Netzbetreiber und 99\%ige Endesa-Tochter, war jedoch nicht bereit, den Windpark in geplanter Größe zu installieren. Der Stromkonzern argumentierte, dass die Einspeisung einer so großen Menge Windstroms zu Destabilisierungen im Netz führen würde. Unelco war bereit, vier Megawatt anzuschließen und forderte das Wasserwerk auf, weitere Kapazitäten ausschließlich zur Versorgung der Saline zu nutzen (WPM 6/92, 6f.). ${ }^{383}$ Der eigentliche Grund, weshalb sich Unelco gegen das Projekt zur Wehr setzte, besteht weniger in befürchteten Netzdestabilisierungen, als vielmehr in der Beteiligung eines ausländischen Partners, in diesem Fall Vestas, zu Ungunsten inländischer Fabrikanten. Daher machte Unelco seinen Einfluss geltend, um das dänische Unternehmen zum Rückzug zu drängen. Stattdessen wurden die Turbinen von EndesaTochter MADE gefertigt. Unmittelbar nach der Entscheidung für MADE als Lieferant schien sich das Problem zu hoher Windstromanteile aufgelöst zu haben (WPM 1/94, 20ff.). Entsprechend äußerte sich Marrero O' Shanàhan (Leiter von ASCA):

,Once MADE joined the project, all of a sudden all difficulties disappeared overnight. No restrictions regarding grid connections on our 10MW output, nothing...Y You don't have to be Einstein to come to the same conclusions we came some time ago. Made amd Unelco are sister subsidiaries of Endesa the state-run power company.' (zitiert nach: WPM 1/94, 23)

Ende 1993 errichtete MADE die ersten Windturbinen an dem Standort auf Fuerteventura. 1994 ersetzte Spanien das bis dahin geltende Energiespargesetz durch eine dem dänischen Modell ähnliche Regelung fester Einspeisetarife. Im Vergleich zum bisherigen Verfahren besteht die wichtigste Änderung darin, dass der Windanlagenbetreiber die Vergütung nicht länger vom Staat erhielt, sondern die zugeführte Energie direkt vom Versorger bezahlt wurde. Der Unsicherheitsfaktor jährlich neu zu bestimmender Tarifhöhe existierte weiterhin. Nichtsdestoweniger führte diese Regelung zu einer Stärkung von Privatakteuren. Die Einspeisepflicht wurde bestätigt, der Umweg über staatliche Subventionierung des Windstroms, durch die Etablierung unmittelbarer Geschäftsbeziehungen zwischen EVU und Windmüller, ersetzt.

Trotz der vielfältigen und teilweise erzwungenen Nachfrage von MADE-Turbinen, gelang es der Endesa-Tochter noch immer nicht, international konkurrenzfähige Produkte

\footnotetext{
${ }^{382}$ Anfang der 90er Jahre entwickelte FECSA (Endesa-Anteil: 40\%) einen Windpark (3,6MW) in Baix Ebre. Einen weitere Anlage (4MW) errichtete Union Fenosa (Endesa-Anteil: 9,7\%) in Cabo Villano (WPM 9/92, 24).

${ }^{383}$ Der Widerstand Unelcos führte nicht nur zu Verzögerungen, sondern bedrohte das gesamte Projekt. Ein Drittel der Kosten von \$ 16,43 Mio. sollten von der EU (Valoren-Programm) getragen werden. Jedoch galt die Zusage für die Mittel nicht unbegrenzt (WPM 6/92, 6f.). Wurde eine Frist nicht eingehalten, mussten die Förderanträge neu gestellt werden. Zudem hätte die Installation von nur vier Megawatt zu einem Rückzug der involvierten Banken geführt, welche die Wirtschaftlichkeit unter den neuen Bedingungen anzweifelten (WPM $1 / 94,21)$.
} 
hervorzubringen. 1994 betritt der neue Anlagenhersteller Gamesa Eolica den Markt. Das Unternehmen ist als Joint Venture zwischen dem spanischen Technologiekonzern Gamesa und Vestas entstanden. Die Vestas-Anlagen wurden von nun an in Pamplona/Navarra hergestellt (Neue Energie 3/98, 31f.). Durch diesen Schritt gelang Vestas der Einstieg in den spanischen Markt.

Die Standort Gamesa Eolicas in Navarra und dessen Entscheidung für Vestas-Technologie, bilden zwei wichtige Rahmenbedingungen des Einstieg der Provinz Navarra in den Windkraftsektor. Hier ist die Pionierrolle des regionalen Energieversorgers Energia Hidroelélectrica de Navarra (EHN) zu betonen. Das zur Hälfte (48\%) öffentlich (Region Navarra) und zur anderen Hälfte privat $(52 \%)^{384}$ geführte Unternehmen setzte vor allem auf Wasserkraft (Wind Directions 5-6/03, 34). Bereits 1989 plante EHN die Errichtung eines Windparks. Da der Versorger mit der damaligen Anlagentechnik nicht zufrieden war, nahm EHN von dem Projekt Abstand (Neue Energie 9/92, 97). Diese Einschätzung änderte sich mit der Entstehung Gamesa Eolicas. 1994, im Gründungsjahr des neuen Herstellers, nimmt EHN den ersten Windpark, mit sechs Vestas/ Gamesa Turbinen, in Betrieb. Zu diesem Zeitpunkt plante EHN bereits fünf weitere Projekte. Esteban Morrás, Leiter des Regionalversorgers, begründet die Aktivitäten im Windsektor mit den verfügbaren Ressourcen an erneuerbaren Energien: ,Navarra has the natural resources to produce all the power it consumes without producing $\mathrm{CO} 2$ emissions.' (zitiert nach: WPM 7/94, 14).

1994 gab die Regierung von Navarra das Ziel aus, bis zum Jahr 2000 eine Windenergiekapazität von 100MW an das regionale Netz zu schließen (WPM 7/94, 14). Die Realisierung eines 18,5MW-Windparks (Hersteller: Gamesa/ Vestas, 500kW-Modell) im folgenden Jahr 1995 bewies die Ernsthaftigkeit der Planung (Oelker et al. 2005, 374).

Nach den Windenergie-Aktivitäten in den Regionen Andalusien, Galizien, Aragon und den Kanarischen Inseln, stellt die Initiative Navarras, seit 1994 einen weiteren Schritt zur Etablierung der neuen Technologie dar. ${ }^{385}$

\section{Analyse}

Die wachsenden Installationszahlen während der 90er Jahre manifestieren die Dynamik des Windenergiesektors (Tab. 3h). Zum Vergleich: Im Jahr 1992 bewegt sich die Marktgröße der 92er-Märkte auf ähnlichem Niveau: Griechenland: 26MW, Großbritannien: 29MW, Spanien: 46MW. Während die Windenergiekapazität im Jahr 2000 in Griechenland den Wert 226MW und in Großbritannien 406MW erreicht, umfasst der spanischen Markt 2.535MW.

Tab. 3h Installierte Windenergiekapazität in Spanien 1987-2000

\begin{tabular}{|l|l|l|l|l|l|l|l|l|l|l|l|l|}
\hline Jahr & 1987 & 90 & 91 & 92 & 93 & 94 & 95 & 96 & 97 & 98 & 99 & 2000 \\
\hline $\begin{array}{l}\text { Gesamtkapazität } \\
\text { (MW) }\end{array}$ & 2 & 5 & 12 & 46 & 52 & 75 & 115 & 211 & 427 & 834 & 1542 & 2535 \\
\hline $\begin{array}{l}\text { Neuinstallation } \\
\text { pro Jahr (MW) }\end{array}$ & 2 & 3 & 7 & 34 & 6 & 23 & 40 & 96 & 216 & 407 & 708 & 993 \\
\hline
\end{tabular}

Quellen: Neue Energie 4/02, 91; vg. Tab 2a

Die Grundlage dieser Entwicklung wird in der ersten Hälfte der 90er Jahre geschaffen. Die Erfolge auf dem spanischen Windsektor und die Entscheidung der zentralen Administration, die neue Technologie zu fördern, sind durch mehrere Faktoren begünstig worden: Knappheit fossiler Brennstoffe, Atomausstiegsbeschluss (vg. Kap. 1), geringe Bevölkerungsdichte, gute Windparkstandorte und das Ziel der Minderung der Treibhausgas-Emissionen.

Das 1991 von der Zentralregierung anvisierte Ziel des Ausbaus der Windenergiekapazität für das Jahr 2000 lautete 175MW. Die besondere Dynamik des Sektors entfaltete sich aus den

\footnotetext{
${ }^{384} 1992$ verfügt Iberdrola, nach Endesa zweitgrößter Energieversorger Spaniens, über einen Aktienanteil von $37 \%$ an EHN (Neue Energie 9/02, 98).

${ }^{385}$ Näheres zum Erfolg erneuerbarer Energien in Navarra: vg. Faulin et al. 2006, 2201-2216
} 
Regionen. Auch Navarra, Galizien, Katalonien, Andalusien und Aragonien hatten sich ehrgeizige Windpark-Installationsziele gesetzt. Diese gehen in ihrer Summe weit über die Planungen der Föderation hinaus (Neue Energie 3/98, 30ff.). Der ausgeprägte Föderalismus Spaniens ist als wichtige Rahmenbedingung der Erfolge auf dem Windsektor zu begreifen.

Die Tatsache, dass Proteste von Naturschützern gegen Windanlagen keine Ausmaße annahmen wie in Großbritannien, ist nicht allein auf die geringere Bevölkerungsdichte Spaniens zurückzuführen. Anders als auf dem Inselstaat, existiert in Spanien keine in der Landeskultur verwurzelte Tradition des Naturschutzes. Anders als in der Bundesrepublik und Dänemark ist die Nutzung der Windenergie in Spanien zu keiner Zeit ein zivilgesellschaftliches Projekt gewesen. Dennoch waren neben einigen Naturschutzgruppen auch die beiden größten Umweltverbände des Landes, Greenpeace und Aedenat, präsent, die Windenergie befürworteten (vg. WPM 7/92, 19). Von einer Kontroverse um den Aufbau eines Windparks war auch die Planungsphase des Jandia-Projektes (s.o.) auf Fuerteventura begleitet. Die von Naturschutzorganisationen wie der Canary Islands Friends of Wildlife Association befürchteten Bedrohungen für die Vogelwelt der Insel wurden seitens Greenpeace und Aedenat nicht geteilt (vg. WPM 6/92, 7; WPM 2/93, 4). Dieser innerökologische Streit (globaler Nutzen vs. lokale Schäden) schwächte die Proteste gegen den Aufbau von Windanlagen insgesamt. Denn die Befürworter der Greenpeace-Position konnten für sich in gleicher Weise einen moralischen Standpunkt in Anspruch nehmen wie die Naturschützer.

Für die Erfolge auf dem Windsektor war es von zentraler Bedeutung, dass die Entwicklung durch einen mächtigen Stromkonzern wie Endesa vorangetrieben wurde. Das Vertrauen des Konzerns in die neue Technologie konnte sich kaum aus den Erfahrungen des Tochterkonzerns Made, bzw. dem spanischen Konkurrenten Ecotecnia speisen. Wesentliche Bezugspunkte sind Durchbrüche in den Pioniermärkten, insbesondere Dänemark. Zusätzlichen Antrieb verschafften die Fördergelder aus dem Valoren Programm der EU zur regionalen Entwicklung. Damit die Industrie überhaupt eine Chance hatte, sukzessive Anschluss an den internationalen Standard zu erlangen, mussten zügig größere Modelle entwickelt und in hoher Stückzahl aufgebaut werden. Für einen solchen Kraftakt bedurfte es von Anfang an großer Akteure. Aufgrund der Finanzstärke und seiner Zugehörigkeit zum spanischen Staat, vermochte Endesa jederzeit auf Bankkredite zurückgreifen, sofern es erforderlich wurde. Das aus einigen Pioniermärkten bekannte Problem des Kapitalmangels war also für Spanien ohne Belang. Zur Planung von Windparkprojekten bevorzugte Endesa Standorte in denjenigen Provinzen, wo der Konzern über Anteile des regionalen Netzbetreibers verfügte. Dadurch stellte Endesa sicher, dass sich der Windenergieausbau nicht nur im Konsens mit der Zentralregierung, sondern auch den jeweiligen Regionen vollziehen würde. Daher war die Wahrscheinlichkeit, dass ein Windpark aufgrund von Einsprüchen regionaler Behörden nicht realisiert werden würde, minimal. Ein notorisches Problem der Pioniermärkte besteht in zähen Konflikten zwischen EVU und Windparkbetreibern bzgl. der Einspeisekonditionen. Dieses Problem entfiel auf dem spanischen Markt, weil es sich insbesondere in der Anfangszeit, größtenteils um Windparks der zuständigen Netzbetreiber handelte.

Der Zentralregierung geht es bei der Förderung der Windkraft nicht allein um energie- und klimapolitische Gründe. Darüber hinaus erhoffte sie sich positive Auswirkungen auf Industrie und Arbeitsmarkt. Endesa musste daher eine Gradwanderung gehen: Einerseits war der Einsatz internationalen Know-hows der Pioniermärkte unvermeidlich, um überhaupt an den bisherigen Erfolgen der Windenergienutzung teilzuhaben. Andererseits durften die Aufträge nicht einfach an ausländische Hersteller wie Vestas und US-Windpower vergeben werden. Dieses hätte möglicherweise eine technische und ökonomische Stagnation der inländischen Hersteller zufolge gehabt. Darüber hinaus wären positive Arbeitsmarkteffekte ausgeblieben und die Wertschöpfung ins Ausland geflossen. Die Gradwanderung Endesas bestand sowohl 
in der Anwendung internationalen Know-hows durch Lizenzproduktionen, als auch darin, den spanischen Markt gegen ausländische Hersteller abzuschotten (vg. Jandia/ Fuerteventura Projekt). ${ }^{386}$

Wie bereits am Extremfall Großbritanniens deutlich zu beobachten war, ist der Erfolg der Windkraft als dezentral einzusetzender und weithin sichtbarer Energietechnik, ebenso von der Sympathie der Bevölkerung wie der Bereitschaft der Anwohner abhängig, Windparks in ihrer näheren Umgebung zu tolerieren. Anstatt allein die negativen Aspekte zu betonen (,Naturzerstörung', ,Horizontverschandlung') können Windturbinen auch als Symbole für Prosperität und zweckmäßige Energie-, Umwelt- und Klimapolitik wahrgenommen werden. Dieses war Spanien gelungen: nicht ausschließlich, gleichwohl zu wesentlichen Teilen, aufgrund der politischen Steuerung, unter der Ägide von Endesa.

Angesichts der hohen Erwerbslosigkeit von 20\% (Neue Energie 3/98, 31) trugen positive Arbeitsmarkteffekte dazu bei, die beiden größten Gewerkschaften des Landes, Comisiones Obreras (CCOO) und Unión General de Trabajadores (UGT) für die Windkraft zu gewinnen. In Rahmen einer 1993 getroffenen Vereinbarung einigten sich Endesa und Umweltorganisation Aedenat gemeinsam mit CCOO und UGT auf die Installation von 750MW Windenergiekapazität bis zum Jahr 2000. Die Gewerkschaften gingen davon aus, dass durch Konstruktion, Betrieb und Wartung der Windparks mehr neue Arbeitsplätze entständen, als durch den Neubau von Atomkraftwerken (WPM 2/93, 10). ${ }^{387}$

Geplante EVU-Windparks sind in den Pioniermärkten sehr häufig von Protesten der Anrainer begleitet worden. Anders als etwa lokale Windkooperativen, mussten die EVU keine Steuern an die Gemeinde abführen. In Spanien dagegen erhält die anliegende Gemeinde beachtliche Einnahmen aus dem Betrieb der Windanlagen, was deutlich zur Verbesserung der Akzeptanz geführt hatte (Toke 2005, 306).

Die Situation des Ortes La Muela ${ }^{388}$ bei Zaragoza/ Aragón zeigt, welche Möglichkeiten die Ansiedelung von Windparks in Spanien geboten haben, sofern sie sich im Konsens mit den Anwohnern befindet. Bereits 1987 wurde in La Muela einer der ersten kleinen Windparks des Landes errichtet (Tab. 3g). 1989, zum Zeitpunkt als sich die junge Bürgermeisterin Mariá Bielsa mit Erfolg für den Aufbau neuer Windturbinen stark gemacht hatte, lebten in La Muela nur 740 Menschen. ${ }^{389}$ Nach anfänglicher Skepsis erklärten sich $90 \%$ der Landbesitzer auf dem Plateau bereit, einen Teil ihres Grundstücks an Windparkbetreiber zu verpachten. Die ausgeschriebenen Flächen befinden sich je zur Hälfte auf Privat- und Gemeindeland. 1990 setzte ein bis heute andauernder Bauboom ein. Bis Ende 2005 sind mindestens 450 Windanlagen mit einer Gesamtkapazität von $235 \mathrm{MW}$ bei La Muela errichtet worden. Daraus ergeben sich für die Gemeinde direkte Steuereinnahmen in Höhe von 750.000 Euro pro Jahr. Hinzu kommen 2,4 Mio. Euro für die Vergabe von Baulizenzen. Im Zuge dieser Entwicklung hat sich La Muela zu einer der wohlhabendsten Gemeinden Spaniens entwickelt. Bis 2005 ist die Einwohnerzahl auf 3.500 angewachsen. Zwischen 1985 und 2005 hat sich der Etat von 0,2 Mio. auf 15 Mio. Euro um das 75 fache vergrößert. Ein Großteil der Einnahmen kommt der Bevölkerung unmittelbar zu Gute. Zahlreiche Dienstleistungen in den Sektoren Bildung und

\footnotetext{
${ }^{386}$ Die Zugehörigkeit des größten inländischen Herstellers Made zur Endesa Gruppe garantierte, dass der Konzern seine Strategie in der gewollten Weise umzusetzen vermochte. So war es bspw. ausgeschlossen, dass sich Made mehr als nötig Komponenten ausländischer Hersteller bedient hätte, oder allzu leichtfertig internationale Kooperationen eingegangen wäre.

${ }^{387}$ Joaquín Nieto, Vorsitzender der Umweltabteilung der CCOO, begründet diese Position mit den Ergebnissen der Studie ,State of the World' vom World Watch Institute. Demnach produzierte Nuklearenergie die wenigsten, Windenergie hingegen die meisten Arbeitsplätze pro Kilowatt (WPM 2/93, 11).

${ }^{388}$ Der Ort ist auf einem windigen Hochplateau gelegen, das sich etwa 600 Meter oberhalb des Meeresspiegels befindet und an seinen Rändern steil abfällt (Neue Energie 9/05, 101).

${ }^{389}$ Bielsa beschreibt die damalige Situation von La Muela: ,Ein Drittel lebte von der Viehzucht, ein Drittel von der Landwirtschaft. Die übrigen hatten einfache Arbeiten in Zaragoza. La Muela war ein kleines Dorf mit winzigem Kern: eine alte Kirche, die Schulen herunter gekommen und kein Hausgiebel, der nicht einzustürzen drohte. Es gab nichts, nicht einen einzigen Baum im Dorf.' (zitiert nach: Neue Energie 9/05, 107).
} 
Gesundheit stehen den Einwohnern kostenfrei zur Verfügung: Bibliotheksnutzung, Internetzugang, Computerkurse, Krebsvorsorge, Musikschule, Auslandsstipendium für Studierende. Sogar Zuschüsse zu jährlichen Fernreisen vergibt die Gemeinde, als Ausgleich dafür, dass La Muela heute komplett von Windanlagen umgeben ist (Neue Energie 9/05, 103). Anders als das dänische Modell, $\mathrm{zu}$ dessen integralen Bestandteilen die Initiative zivilgesellschaftlicher Akteure zu rechnen ist, handelt es sich im Fall der Etablierung der Windtechnologie in Spanien, um eine top-down Entwicklung. Investitionszuschüsse und Einspeisevergütungen, denen im dänischen Modell eine wesentliche Bedeutung zukommt, ist in Spanien zunächst unwichtig, weil Endesa als Staatsunternehmen nicht auf Förderung angewiesen war. Privatakteure wie Ecotecnia spielten anfangs nur eine geringe Rolle. Folglich unterscheiden sich die zur Förderung der Windkraft adäquaten Maßnahmen in Spanien, deutlich von den Pioniermärkten. Anders als dort, befürwortete man die Windkraft in Spanien weniger aus umwelt- und klimapolitischen, sondern wirtschaftlichen Gründen. Es lassen sich zwei Kernziele identifizieren, welche die spanische Regierung verfolgte, um einen weiten Konsens über die Windkraftnutzung zu erlangen: Aufbau einer Windanlagenindustrie (damit verbunden: Prosperität und Schaffung neuer Arbeitsplätze) und die Akzeptanz von Windparks/ Sympathie für Windkraft. Sowohl der technische und ökonomische Erfolg der Windkraft, als auch ihre positive Wahrnehmung in der Gesellschaft, stellen für die Regierung ein wichtiges Argument dar, die neue Technologie weiterhin zu fördern (vg. Schaubild 3a).

\section{Ausblick}

Nach der Einspeiseregelung im Jahr 1994 wird die Situation privater Investoren 1998, mit dem königlichen Dekret 2818/1998, weiter verbessert. Nicht nur die Tarife, sondern auch die Planungssicherheit wurde erhöht. Zuvor variierte der Einspeisetarif von Jahr zu Jahr. Jetzt wird ein relativ fester Tarif bestimmt (Überprüfung alle vier Jahre), welchen die Windparkbetreiber, zusätzlich zum stündlich ermittelten Marktpreis, vom zuständigen Versorger erhielten. Alternativ konnten sich die Windstromproduzenten auch für einen festen Tarif von etwa 0,06 Euro/kWh entscheiden (Neue Energie 4/02, 91).

Bis weit in die 90er Jahre hinein, ist Endesa sowohl als Betreiber, als auch Hersteller (über MADE) führend. Anhand der Bedeutungszunahme der Privatunternehmen Iberdrola (zweitgrößter Energieerzeuger Spaniens und Windparkentwickler) sowie des Windturbinenherstellers Gamesa, lässt sich der Wandel des Marktes leicht überschauen. Als Anlagenbauer erlangte Gamesa ${ }^{390} 2004$ einen Marktanteil von 51,6\%, gegenüber einem Made/ Endesa-Anteil von 12,2\%. In der Projektentwicklung kommt dem Staatskonzern 2004 noch ein Anteil von $10 \%$ zu, während Iberdrola mit 38\% den größten Teil für sich beanspruchen kann (Wind Directions 7-8/05, 19).

Diese Verschiebung der Akteursstruktur hat die Entwicklung des Sektors offenbar nicht geschwächt. Eher noch, lässt sich von einer forcierten Entwicklung sprechen, seitdem in der zweiten Hälfte der 90er Jahre verstärkt private Investoren an Einfluss gewinnen. Allein 2007 etwa, sind in Spanien über 3.000MW Windpark-Kapazität neu an die Netze geschlossen worden.

\footnotetext{
${ }^{390} 2001$ hat Gamesa den 40\%-Anteil von Vestas zurückgekauft (Neue Energie 4/02, 94). Mit diesem Schritt befindet sich das Unternehmen im Konsens mit dem Ziel staatlicher Windenergiepolitik, den größtmöglichen Teil der Wertschöpfung im Inland zu halten.
} 
Import von Know-how bei

gleichzeitiger

,intelligenter'

Abschottung gegen

internationale Konkurrenz
Förderung durch Zentralstaat und Regionen:

allg. begünstigende Faktoren:

- Importabhängigkeit der Energieversorgung

- Atomausstiegsbeschluss

- Windressourcen

- dünne Besiedelung
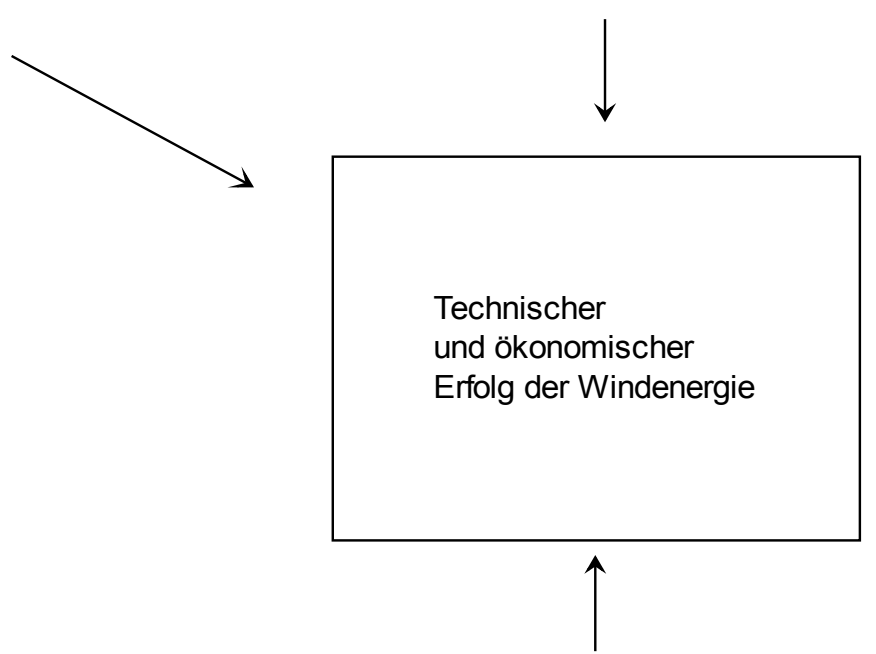

Technische

und ökonomischer

Erfolg der Windenergie

Allgemeine Sympathie für Windkraft und

hohe lokale Akzeptanz

von Windparks

positives Feedback an

die Politik

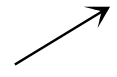

Windparkbetreiber
zahlen
Abgaben an
Kommune

Gewerkschaften befürworten Windenergie aufgrund positiver Beschäftigungseffekte

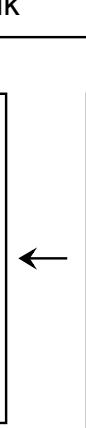

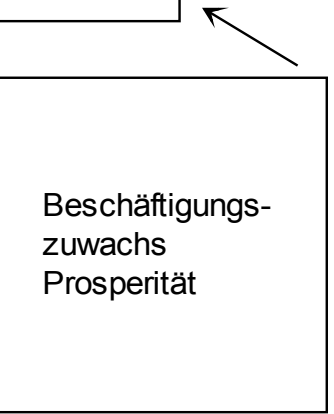

Finanzstarke

Endesa-Gruppe

setzt auf Windenergie
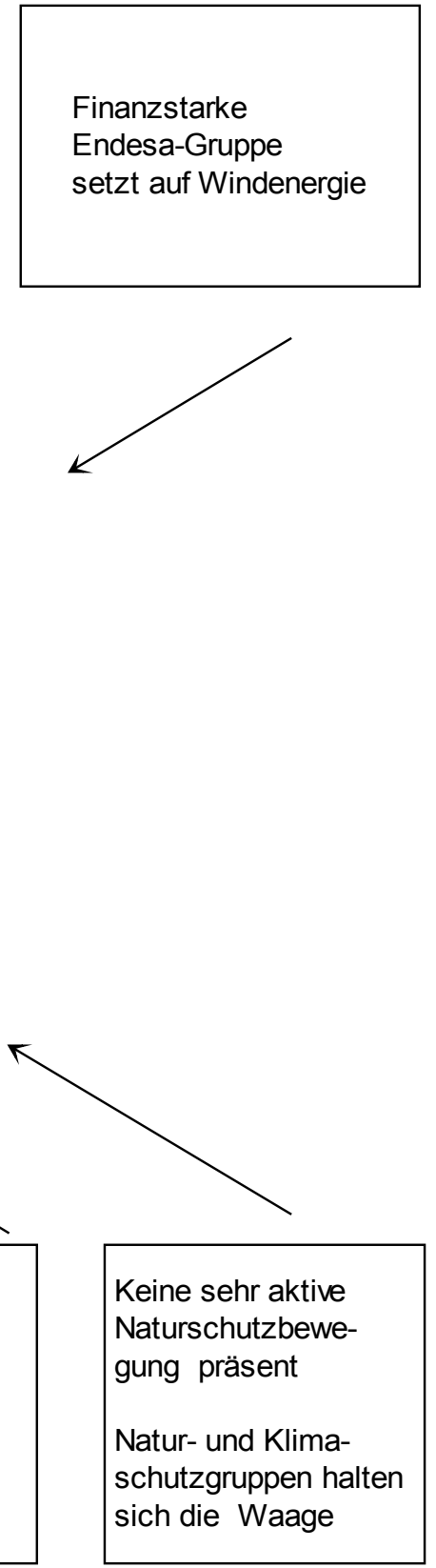

dänischen Modells

Zwischen den Anfang der 90er Jahre neu entstandenen Windenergiemärkten bestehen zentrale Unterschiede, aber auch einige Gemeinsamkeiten, die sie eindeutig vom dänischen Modell der Pionierphase abgrenzen.

Spanien ist erfolgreich

Anhand von vier Indikatoren (Anfangsdynamik, Kontinuität, Erfolg der Windindustrie, Sympathie/Akzeptanz) soll zunächst der Etablierungsgrad der Windtechnologie ermittelt werden.

Tab. 3i 92er Märkte im Vergleich

\begin{tabular}{|l|l|l|l|l|}
\hline & $\begin{array}{l}\text { Anfangsdynamik: } \\
\text { Neue Windparks } \\
1992-93(\mathrm{MW})\end{array}$ & $\begin{array}{l}\text { Kontinuität: } \\
\text { Windenergie- } \\
\text { Kapazität im Jahr } \\
2000(\mathrm{MW})\end{array}$ & $\begin{array}{l}\text { Erfolgreiche } \\
\text { Windindustrie? }\end{array}$ & $\begin{array}{l}\text { Sympathie } \\
\text { Akzeptanz } \\
\text { Windkraft/ } \\
\text { Windparks? }\end{array}$ \\
\hline Spanien & 2.535 & ja & ja \\
\hline Großbritannien & 125 & 406 & nein & nein \\
\hline Griechenland & 21 & 226 & nein & $*$ \\
\hline
\end{tabular}

Quellen: vg. Kap. 3;

* Hier eine Aussage zu treffen ist kaum möglich, weil der Sektor in erster Linie durch andere Faktoren gehemmt wurde (s.o.)

Abgesehen von der hohen Anfangsdynamik des britischen Marktes, schneidet Spanien bei den übrigen und mittelfristig wichtigeren Indikatoren, deutlich besser ab als Großbritannien und Griechenland. 2004 erlangt der spanische Windanlagenhersteller Gamesa einen Weltmarktanteil von $18 \%$.Griechische und britische Hersteller haben für den internationalen Markt keine Bedeutung, bzw. keine Bedeutung mehr (GB-Industrie). Insgesamt fällt der griechische Markt so weit zurück, dass er in mancherlei Hinsicht für den Ländervergleich kaum hilfreich ist.

Domäne der Energiekonzerne

$\mathrm{Zu}$ den Ergebnissen der Analyse der Pioniermärkte zählt, dass Energiekonzerne auf dem Sektor insgesamt eher verhalten agierten, bzw. ihre Aktivitäten selten von dauerhaften Erfolgen gekrönt waren. Sämtliche 92 er Märkte sind bis in die 90er Jahre zunächst von einem großen Energieunternehmen bestimmt worden: In Großbritannien handelte es sich dabei um den staatlichen Energiemonopolisten CEGB. Nach dessen Privatisierung übernahmen seine Nachfolger, Powergen und National Power, das Feld. In Griechenland ist Staatskonzern PPC zum Hauptakteur geworden. Der höchste Grad der Zentralisierung kann auf dem spanischen Markt beobachtet werden. Dort ist die staatliche Endesa Gruppe nicht nur an der Entwicklung sämtlicher großer Windparks beteiligt, sondern beherrscht auch den Windturbinenmarkt über Tochterunternehmen Made. Mit Spanien existiert erstmals ein erfolgreicher Markt, in dem ein Energiekonzern zugleich Impulsgeber und über längere Zeit Hauptakteur gewesen ist. Auch PPC und CEGB kommt die Rolle der Impulsgeber zu. Insbesondere im Falle Großbritanniens lässt sich feststellen, dass die Stagnation, die sich seit 1994 einstellt und erst in jüngerer Zeit überwunden werden kann, nicht unmittelbar mit dem Handeln des Konzerns, bzw. seiner Nachfolger zusammenhängt.

In den 92er Ländern sind die beteiligten EVU bereits während des Zeitraums der Pionierphase auf dem Sektor aktiv. Größere Investitionen werden noch nicht getätigt. In Griechenland und Spanien fehlte es am spezifischen Know-how. Endesa-Tochter Made arbeitete noch 1987 mit kleinen $30 \mathrm{~kW}$-Anlagen, während der international übliche Standard bereits die $100 \mathrm{~kW}$ Grenze überschritten hatte. Erst 1990 traf Endesa die Entscheidung, mit dem Aufbau der 
beiden Tarifa-Windparks (zusammen 30MW Kapazität), erstmals größere Summen in den Kauf und die Produktion von Windanlagen zu investieren. Ein Großteil der Anlagen wurde im Rahmen internationaler Kooperationen hergestellt.

Ein noch deutlicherer Kontrast zwischen dem Interesse am Kauf von Windanlagen während der Pionier- und Diffusionsphase kann in Griechenland beobachtet werden. Trotz gegenteiliger Ankündigungen des PPC, investierte der Staatskonzern nur vereinzelt in Windparks. Von der Ausschreibung der ersten größeren Aufträge zur tatsächlichen Unterzeichnung der Lieferverträge vergingen oft mehrere Jahre. Kein einziger Vertrag zur Lieferung der Anlagen der ersten größeren Windparks wurde vor 1990/91 zum Abschluss gebracht.

In Großbritannien markiert die erste NFFO-Ausschreibungsrunde (NFFO-I) von 1990 die Zäsur. Von der großen Orkney-Anlage aus dem LSP-Programm abgesehen, waren bis 1989 nur fünf Megawatt angeschlossen. Erst im Rahmen von NFFO-I wurden größere Investitionen getätigt. Wichtigste Betreiber sind: National Power, Yorkshire Wasserwerke und Landbesitzer Peter Edwards. Bis 1992/1993 wurden vier Windparks mit jeweils vier bis neun Megawatt realisiert (vg. Tab. 3e). Im Unterschied zu den monopolartigen Strukturen des griechischen und spanischen Marktes, dominiert in Großbritannien eine vergleichsweise heterogene Konstellation.

Der frühen und späten Pionierphase, vor 1985, bzw. seit 1987 und der Diffusionsphase, lässt sich anhand der untersuchten Fälle, jeweils ein bestimmtes Verhältnis der EVU zur Windkraft erkennen: Vor 1985 wird der neue Energieträger, sofern es sich um nicht LSP-Anwendungen handelt, ignoriert. Die Verstetigungsperiode ist durch eine vorsichtige Annäherung der Energieversorger europäischer Pioniermärkte zu beobachten (Dänemark, Niederlande, BRD). Dabei kam jedoch nicht ihnen, sondern den Windmüllern die Rolle des Impulsgebers zu. In den 92er Märkten stellt sich das Verhältnis zwischen EVU- und Privatsektor eher umgekehrt dar. Eine Initialzündung durch zivilgesellschaftliche Akteure wäre unvorstellbar gewesen.

Windenergie ist nicht länger, ökologisches Feigenblatt'

Ein Merkmal der Verstetigungsperiode ist der Einzug verschiedener EVU in den Sektor. In Dänemark, den Niederlanden und der Bundesrepublik sind einige von ihnen, seit etwa 1986/87 aktiv geworden. Druck aus der Anti-AKW-Bewegung war dabei ein wichtiger Motivationsfaktor. Längerfristig ist das Engagement der EVU zunächst nur in Dänemark, wo es darum ging, Verpflichtungen gegenüber der Politik nachzukommen. Im EVU-geführten Markt der Niederlande kam es zur Stagnation. Demgegenüber entwickelte sich die Windkraft für deutsche EVU zu einem ,roten Tuch' und wurde seit Einführung des SEG gemieden.

Angesichts relativ schwacher Proteste gegen Umweltverschmutzung und Atomkraftwerke bestand für die wichtigsten EVU der 92er Märkte Endesa, PPC und National Power kein Grund, aus Imagegründen Windparks zu betreiben.

Die britischen EVU wurden durch die NFFO dazu gezwungen, einen Teil des produzierten, bzw. zu verteilenden Stroms, aus nicht-fossilen Energien herzustellen. Windenergie war gegenüber allen anderen erneuerbaren Energieträgern die erste Wahl. Ein zügigerer Ausbau wurde in erster Linie durch Proteste von Anrainern und Naturschutzorganisationen verhindert. Griechenland ist stark ölabhängig. Insbesondere auf den Inseln, wo Strom mit Dieselgeneratoren hergestellt wird, tragen Windparks dazu bei, Öl einzusparen. Aus ökonomischen und technischen Gründen verfolgte der PPC die Windenergieoption zunächst nicht konsequent weiter. ${ }^{391}$

\footnotetext{
391 Ansonsten verfügt Griechenland über keine guten so Voraussetzungen für die Nutzung der Windkraft wie Spanien oder Großbritannien: Der Staat ist vergleichsweise arm und muss daher verstärkt andere Prioritäten setzen. Das Stromnetz ist schwach ausgebaut und hätte erweitert und modernisiert werden müssen. Zudem verfügt das Land quantitativ und qualitativ (Schwankungen der Windstärke) über relative geringe Vorkommen.
} 
Der spanische Staat verfolgte mit seiner Windkraftstrategie insbesondere industrie- und arbeitsmarktpolitische Ziele. Erst an zweiter Stelle folgten energie- und klimapolitische Gründe. In Spanien sind die Ausgangsbedingungen für die Etablierung der Windkraft grundsätzlich besser als auf dem griechischen und britischen Markt. Spanien ist nicht nur wohlhabender als Griechenland, sondern verfügt auch über größere Ressourcen. Gegenüber Großbritannien ist es u.a. im Vorteil, weil dort weniger Naturschutzinitiativen aktiv gewesen sind, die gegen den Aufbau von Windanlagen mobil machten.

\section{Zivilgesellschaftliche Akteure als Marktbarriere}

Das dänische Modell zeichnet sich durch lokale Kooperativen als wichtigsten Akteur auf der Windanlagenbetreiberseite aus. Durch Anti-AKW-Bewegungen und Organisationen wie Greenpeace erhielten sie Unterstützung. Gegenüber Politik und EVU gelingt es den Windmüllern, schlagfertige Interessenvertretungen $\mathrm{zu}$ etablieren. Demgegenüber waren Naturschutzinitiativen, die versuchten, den Aufbau von Windanlagen und kleinen Windparks zu verhindern, personell und moralisch in der schwächeren Position.

Verglichen mit der Situation in Dänemark und der BRD kommt es auf den 92er Märkten zu einer vollständigen Bedeutungsverschiebung zivilgesellschaftlicher Akteure. Letztere spielen nun weder als Betreiber von Windanlagen eine Rolle, noch existierten einflussstarke Umweltakteure, die Windkraft als Energiequelle ,passiv' befürworteten. In Großbritannien schlug das Pendel sogar nach der anderen Seite aus: Dort trugen die Proteste von Naturschützern entscheidend dazu bei, dass viele Standorte nicht genehmigt wurden. ${ }^{392}$ Solche Konflikte haben beim Aufbau spanischer Windparks nur in einzelnen Fällen eine kritische Dimension erreicht. Anhand eines Beispiels (s.o.) wurde aufgezeigt inwiefern die Positionierung zweier großer Umweltorganisationen, die sich für die Windkraftnutzung ausgesprochen hatten, gleichsam das moralische Fundament der Naturschützer in Erschütterung zu bringen vermochten. In Griechenland waren solche Auseinandersetzungen, zumindest in der fraglichen Zeit, offenbar ohne Einfluss.

\section{Windkraftindustrie in den 92er Märkten}

$\mathrm{Zu}$ den Kennzeichen des dänischen und deutschen Windenergiesektors gehört die Existenz prosperierender und exportorientierter Windturbinenhersteller. Wirtschaftlicher Erfolg stellt immer auch ein Argument dar, einen Markt, so erforderlich, weiterhin zu fördern. Dort, wo inländische Hersteller der internationalen Konkurrenz unterlegen sind und daher auf Importprodukte zurückgegriffen wird, ist man eher geneigt, Fördermaßnahmen auslaufen zu lassen (vg. Niederlande, Kalifornien). Deutschland, Spanien, USA und Dänemark zählen seit Jahren zu den größten Märkten für Windenergie. Es handelt sich um keinen Zufall, dass in jedem dieser Länder, führende Hersteller von Windanlagen ansässig sind.

Mit Howden, VAWT und Wind Energy Group verfügte der britische Markt bereits in den 80er Jahren über Herstellerfirmen, die sich auch auf dem Exportsektor bewährten. Jedoch scheiterten sie frühzeitig daran, sich auf dem inländischen Markt zu behaupten. Die meisten NFFO-Projekte wurden mit dänischen Anlagen ausgestattet. Für den größten Windpark der ersten und zweiten NFFO-Ausschreibungsrunde erwarben die Investoren aus Japan und den USA etwa 100 WEA von Mitsubishi. Dennoch erklärt sich die Stagnation nicht aus der relativ schwachen Industrie, sondern der mangelnden Akzeptanz.

Der griechischen Industrie gelang es trotz diverser internationaler Kooperationen nicht, vom Know-how ausländischer Hersteller so weit zu profitieren, dass sich griechische Firmen im Sektor hätten festigen können. Dazu fehlte die Nachfrage. Unter den gegebenen Umständen bedeutete der Status quo der inländischen Windindustrie ein weiteres Argument gegen die Windkraft. Die Industrie befand sich also in einem Teufelskreis: Keine technische

\footnotetext{
${ }^{392}$ Die Hegemonie der Naturschutzargumente konnte Anrainer dabei unterstützen, ihre NIMBY-Haltung hinter Naturschutzargumenten zu verbergen.
} 
Weiterentwicklung ohne Nachfrage. Aber: keine Nachfrage ohne weitere Förderung - und keine Förderung ohne Technologie.

Auch die spanische Industrie war auf die Zusammenarbeit mit internationalen Herstellern angewiesen. Jedoch schuf der Staat, durch die Endesa Gruppe einen künstlichen, präzise gesteuerten Markt, so dass die Nachfrage zu jeder Zeit gesichert war und die Hersteller (insbesondere Made) im geschützten Raum lernen konnten.

\section{Erfolgreich: System Endesa}

Für einen privaten Anlagenkäufer sind Qualität und Effizienz einer Windturbine zwei sehr wichtige Kriterien, sich für einen Anbieter zu entscheiden. Volkswirtschaftlich betrachtet (Arbeitsplätze, Wirtschaftswachstum, Exportchancen), ist es dagegen von Vorteil, sich für einen inländischen Hersteller zu entscheiden, obgleich dessen Modelle möglicherweise nicht vollständig dem internationalem Standard entsprechen. Nun denken Investoren nicht unbedingt volks-, sondern betriebswirtschaftlich. Das gilt bspw. für die meisten niedersächsischen und schleswig-holsteinischen Landwirte, die sich im Rahmen der Länderförderung für Produkte von Lagerwey und Vestas entschieden. Dieser Vorgehensweise schob das 100/250MW-Programm einen Riegel vor. Gefördert wurden nur die Produkte inländischer Hersteller. Dieser Protektionismus bildete eine wichtige Voraussetzung dafür, dass Firmen wie Enercon innerhalb weniger Jahre zur internationalen Konkurrenz aufschließen konnten.

Das Scheitern der Windindustrien der USA und Niederlande wurde eingehend analysiert und hängt nur bedingt damit zusammen, dass es den Inländern an Nachfrage gefehlt hätte. Anders stellte sich die Situation britischer Hersteller dar. Der Einstieg in die Windkraft fiel zeitlich mit dem Vorgang konsequenter Privatisierung des Energiemarktes zusammen. Die meisten Investoren der großen NFFO-I und NFFO-II-Projekte entschieden sich für dänische Hersteller, in einem Fall Mitsubishi. Lediglich CEGB Nachfolger National Power setzte konsequent auf die Modelle der Wind Energy Group (vg. Tab. 3.2.2a und 3.2.2b).

Endesa hatte den spanischen Markt so weit wie möglich gegen ausländische Investoren und Turbinenhersteller abgeschirmt. An allen Großprojekten war die Endesa Gruppe in irgendeiner Weise beteiligt. Als Windparkentwickler entschied sich der Staatskonzern grundsätzlich für Tochterunternehmen Made. Erst 1994, zu einem Zeitpunkt als sich Made gut auf dem Markt gefestigt hatte, wird ein Stromeinspeisegesetz beschlossen, dass Privatunternehmen zum Einstieg in den Sektor motivierte. Insbesondere sind hier Gamesa als Hersteller und Iberdrola als Projektentwickler zu nennen. Gamesa entschied sich für eine dauerhafte Kooperation mit Vestas. Iberdrola setzte beim Anlagenkauf konsequent auf das importierte Vestas-Design von Gamesa. Obgleich sich der neue Hersteller in den nachfolgenden Jahren zum führenden Unternehmen der Branche entwickelt, bleibt auch Made als feste Komponente des Sektors erhalten.

In mehrerlei Hinsicht ist die Ausgangssituation des griechischen Marktes dem spanischen ähnlich. Auch griechische Hersteller waren auf Kooperationen angewiesen, der griechische Markt war ebenso durch eine Staatskonzern beherrscht wie der spanische. In Griechenland hatte sich kein ,System PPC' herausgebildet. Eine Windturbinen produzierende PPC-Tochter existierte nicht. Die wenigen Exemplare, die letztlich hergestellt wurden, entstanden im Rahmen von Kooperationen mit internationalen Firmen. Nachdem einige Windparks aufgebaut worden sind, fehlte es an Folgeaufträgen, die es den Griechen ermöglicht hätten, das erworbene Know-how zur Anwendung zu bringen. Es scheint beinahe, als hätte es dem PPC schlicht an Geduld gefehlt, einen Reifungsprozess der Industrie zu fördern.

Heute existiert kein prosperierender Markt für Windenergieanlagen, der anstatt durch Investoren, von einem Staatskonzern dominiert wäre. Der Vergleich zwischen Spanien und Großbritannien sowie ein Blick auf den deutschen Markt, haben allerdings gezeigt, wie wichtig es sein kann, eine vollständige Marktliberalisierung nicht $\mathrm{zu}$ früh $\mathrm{zu}$ vollziehen. In 
Abgrenzung gegen den abrupten Ein- und Ausstieg des PPC, bietet die Vorgehensweise des Patriarchen Endesa Aufschluss über die Bedeutung kontinuierlicher Nachfrage bei Tochterfirma Made, um den Aufbau einer nationalen Industrie zu garantieren.

Akzeptanz von Windparks: noch immer eine große Herausforderung

Der Fall Großbritannien hat bewiesen, dass der Ausbau von Windparks durch mangelnde Zustimmung und Proteste nicht nur verlangsamt, sondern praktisch gänzlich zum Stillstand gebracht werden kann. Das Wissen darum, dass Windanlagen nicht mehr ihre Rotorblätter verlieren und mittlerweile sehr zuverlässig funktionieren, war im Zweifelsfall kaum ein hinreichender Grund, Windparks in der Umgebung zu befürworten. Die lokale Verankerung der Windkraft, d.h. die regionale Herkunft der Windmüller, ist einer der wichtigsten Erfolgsfaktoren des dänischen Modells. Lokale Verankerung ist in den EVU-geführten Märkten ausgeschlossen. Anders als Spanien, verzichtete Großbritannien auf einen beträchtlichen Teil der Wertschöpfung durch den Aufbau von Windparks. Förderung von Arbeitsmarkt und Konjunktur ist einer der zentralen Akzeptanzgründe. Ein weiterer Faktor, der in Großbritannien ebenfalls nicht gegeben war, liegt in einer Art Bestechung der Anrainer. Somit erfüllte die passive Rolle der Einwohner von La Muela, als Nutznießer von Transferleistungen, eine ähnliche Funktion wie die aktive Beteiligung vieler Dänen an lokalen Windprojekten. Die Proteste der Naturschützer hätten in Großbritannien und auch den Niederlanden keinesfalls eine solche Durchschlagskraft erlangt, wenn die Politikplanung das Akzeptanzproblem stärker berücksichtigt hätte.

Föderalismus und Windkraft

In der Literatur wird von einem positiven Einfluss des Föderalismus auf die Etablierung erneuerbarer Energien ausgegangen. In seiner vergleichenden Studie erklärt Suck (2004) die Erfolge der BRD und die Misserfolge Großbritanniens, bei der Einführung erneuerbarer Energien, aus der föderalen, bzw. zentralistischen Staatsstruktur. Er geht davon aus, dass die kleineren Budgets der Bundesstaaten eher mit einer dezentralen Anwendbarkeit regenerativer Energietechniken korrelierten (Suck 2004, 26).

Reiche (2002a, 116) identifiziert den schwach ausgeprägten Föderalismus der Niederlande als eine der Ursachen für die problematische top-down Orientierung. Dem Argument Mourelatous (2001, 50; 81), dass eine föderale Staatsstruktur schon deshalb hilfreich für erneuerbare Energien ist, weil die Regionen zwar über föderale Zielsetzungen hinausgehen können, jedoch nicht hinter sie zurückfallen dürfen, ist grundsätzlich zuzustimmen. Die Ergebnisse dieser Untersuchung bestätigen die Annahme einer wichtigen Funktion des Föderalismus für die Bundesstaaten Kalifornien, Niedersachsen, Schleswig-Holstein, sowie einige spanische Provinzen. Die These einer sehr starken Bedeutung der Staatsstruktur für den Erfolg erneuerbarer Energien, ist zumindest für den Fall der Windkraft, aufgrund folgender Befunde zurückzuweisen:

Großbritannien: Für die Windenergie hätten wichtige Impulse aus Schottland kommen können. Windenergie zählt zu den wichtigsten Energieressourcen des Landes.

Dänemark: Die politische Förderung der Windkraft war sehr erfolgreich, obgleich sie ausschließlich zentralstaatlich geplant und durchgeführt wurde.

Spanien: Zwar ist der spanische Föderalismus sehr stark ausgeprägt. Auch trugen die Initiativen aus Provinzen wie Navarra und Galizien dazu bei, dass die Windenergie den heutigen Status erlangt hat. Wichtig ist jedoch $\mathrm{zu}$ sehen, dass die ersten Impulse vom Zentralstaat ausgingen und einige Provinzen zu einem späteren Zeitpunkt aufgesprungen sind, als sich bereits erste Erfolge abzeichneten. Paradigmatisch sind die Vorgänge in Navarra (s.o.) Vier der sieben hier betrachteten Märkte existieren in Ländern mit starkem Föderalismus (USA/ Kalifornien, BRD, Spanien und Großbritannien). Die übrigen drei Staaten (Dänemark, Niederlande, Griechenland) verfügen über keine, bzw. schwach ausgeprägte föderale Struktur. 
Es spricht einiges dafür, dass Sucks These (Korrelation dezentraler Energietechnologien mit kleinen Budgets), nicht nur auf Bundesländer anzuwenden ist, sondern auf kleine Staaten wie Dänemark und die Niederlande ausgeweitet werden kann. Diese Einschätzung gilt sowohl für die Pionier-, als auch Diffusionsphase.

Das dänische Modell: Eingeschränkte Diffusionsfähigkeit

Ein wichtiges Ergebnis der Beschäftigung mit den 92er Märkten besteht darin, dass sich die Adaptionsfähigkeit des dänischen Modells auch in den, auf die Pionierphase folgenden Jahren, nicht erhöht hat. Lokale Windparkbetreiber, die sich am dänischen Vorbild orientierten, tauchen bestenfalls rudimentär auf. In Griechenland und Spanien, wo sich die Märkte unter Kontrolle von Staatsakteuren befanden, wurde der Schaffung von Einspeiseregelungen und der Vergabe von Investitionszuschüssen keine größere Bedeutung beigemessen. Die Einführung entsprechender Gesetze, deren Erfolg in den Pioniermärkten erprobt war, wäre der marktliberalen Wirtschaftspolitik Großbritanniens zu wider gelaufen. Das marktorientierte Ausschreibungsverfahren (s.o.) setzte die britischen Anlagenhersteller frühzeitig einem sehr hohen Konkurrenzdruck aus und war entsprechend kontraproduktiv. Da lokale Initiativen in keinem der 92er Länder präsent waren, mussten für das Akzeptanzproblem andere Lösungen gefunden werden (vg. La Muela). Seit Mitte der 90er Jahre, als der spanische Markt für Privatinvestoren geöffnet wurde, galt auch in dem südeuropäischen Land ein Einspeisegesetz, welches sich dort als ebenso erfolgreich erwiesen hat wie in Dänemark und der BRD. ${ }^{393}$

Das wichtigste aus den Pioniermärkten übertragene Element ist die Technologie selbst. Ohne internationale Kooperationen wäre die Einführung der Windkraft in Spanien und Griechenland Anfang der 90er Jahre undenkbar gewesen. ${ }^{394}$

\subsection{Das dänische Modell in der Phase internationaler Diffusion \\ Ein Vergleich mit den 92er Märkten}

Sowohl in der Akteursstruktur, als auch in der Entwicklung der 92er Märkte sind grundlegende Unterschiede zum dänischen Modell zu beobachten. Was hat sich an den Windenergiesektoren Dänemarks und der Bundesrepublik während der Diffusionsphase verändert? Hat das dänische Modell ,überlebt', oder gibt es grundlegende Transformationen? Lässt sich eher von Konvergenz oder Divergenz zwischen dem dänischen Modell und den 92er Märkten sprechen? Diese Frage zielt darauf, ob auch in der Diffusionsphase nur ein einziges Erfolgsmodell ${ }^{395}$ existiert. In diesem Fall müssten sich Ähnlichkeiten, zumindest jedoch wechselseitige Annäherungen zwischen dem dänischen Modell und den Akteurskonstellationen auf den 92er Märkten nachweisen lassen.

Die Frage, ob nur ein altes, nur ein neues, oder auch ein altes und ein neues Erfolgsmodell existiert, wird im folgenden anhand unterschiedlicher Aspekte diskutiert. Welche Entwicklungen sind in den Pionier- und 92er Märkten zu beobachten, hinsichtlich: Förderregelungen, Rolle der EVU und Größe der Investoren? ${ }^{396}$

\footnotetext{
${ }^{393}$ Es ist aufgezeigt worden, dass der Erfolg der Windkraft auf zahlreiche Einflussgröße zurückzuführen ist. Nichtsdestotrotz ist bemerkenswert, dass in den, bis zum Jahr 2000 einzigen Ländern mit Stromeinspeisungsgesetz, über etliche Jahre, deutlich mehr WEA errichtet wurden, als in jedem anderen Land. ${ }^{394}$ In Großbritannien ist die Technologie zu weiten Teilen unabhängig von den Pioniermärkten entwickelt worden.

${ }^{395}$ Besonders interessant ist hier, selbstredend, der Vergleich zwischen Spanien und den erfolgreichen Pioniermärkten.
} 


\subsubsection{Das dänische Modell in der Diffusionsphase}

Bundesrepublik Deutschland

Seit der zweiten Hälfte hat die Bürgerwindbewegung immer stärker an Bedeutung verloren. Atomkraftgegner, die in ihrem Freundes- und Bekanntenkreis Geld sammelten, um mit kleinen Windparks die Machbarkeit des Energiewechsels $\mathrm{zu}$ demonstrieren, sind als Anlagenkäufer vom Markt verschwunden. Als Betreiber bleiben sie weiterhin aktiv, sofern sie ihre Windanlagen nicht an Planungsgesellschaften verkauft haben. Mittlerweile sind es in erster Linie solche Unternehmen, die üblicherweise Windparks entwickeln und betreiben. Aufgrund des SEG vermögen sie, Investoren lukrative Angebote zu unterbreiten. Windenergie ist in Deutschland zur wichtigsten Komponente eines grünen Kapitalmarktes geworden. ${ }^{397}$

Byzio et al. (2002, 276ff.) unterscheiden insgesamt fünf Entwicklungsstufen von Windstromunternehmen. Die ersten drei, in der Bürgerwindbewegung verwurzelten Gruppen, wurden in Kapitel 2.4 behandelt. Bei den übrigen beiden, nun vorherrschenden Entwicklungsformen 4 und 5, handelt es sich um normale Unternehmen, die von Anfang an professionell und gewinnorientiert arbeiteten und mit vollem unternehmerischen Risiko tätig sind. Regionale Grenzen für Geldgeber gibt es prinzipiell nicht mehr. Davon abgesehen gilt es, als ,ein Gebot unternehmerischer Klugheit, sich zwecks Akzeptanz um Kommanditisten im regionalen Einzugsbereich der Projekte zu bemühen' (ebd., 279). Die Formen 4 und 5 unterscheiden sich vor allem in Größe, Kapitalgrundlage und Rechtsform. Dabei reicht die Spanne von mittelständischen Existenzgründungen, die in den ersten Jahren ihres Bestehens nur über sehr knappe Mittel verfügten, bis zu Aktiengesellschaften wie Plambeck Neue Energie AG. ${ }^{398}$ Bei den eigentlichen Windturbinenkäufern handelt es sich um Geldgeber, die zumeist mindestens 20.000DM investieren und zusätzliche Gewinne durch steuerliche Abschreibungsvorteile erzielen (Bolinger 2001, 31). Der lokale Bezug der Projekte ist vollständig verloren gegangen und muss dadurch künstlich erhalten werden, dass man den Anrainern Beteiligungen $\mathrm{zu}$ günstigen Konditionen anbietet. ${ }^{399}$ Anfang der 90er Jahre rekrutierten die Projektplaner viele Anrainer als Kommanditisten, die in ihrer Mehrzahl, gewiss nicht zu Protagonisten der Bürgerwindbewegung geworden sind. Dennoch sind die beteiligten, aktiv in einen Prozess, basisdemokratischer Restrukturierung des Energiesektors eingebunden. Von einem Gewinninteresse kann darüber hinaus nicht ausgegangen werden.

Knapp zehn Jahre später erschöpft sich ihre Rolle darin, als Anteilsnehmer, die lokale Akzeptanz zu fördern. Sowohl auf Seiten der Projektplaner, als auch der Investoren, sind die 90er Jahre als ein Zeitraum sukzessiver Kommerzialisierung und damit einer Verdrängung zivilgesellschaftlicher Akteure, deren Hauptmotivation nicht ökonomisch, sondern gesellschaftspolitisch ist, zu betrachten.

Ähnlich wie es in Großbritannien von Anfang an üblich war treten nun auch hierzulande Bürgerinitiativen nicht länger als Fürsprecher der Windkraft auf, sondern als Gegner, die teilweise mit Naturschutzgründen argumentieren und die kapitalistische Motivation der Projektplaner offen legen (vg. Byzio et al. 2002, 363ff.). ${ }^{400}$

So hoch der Erfolg des Stromeinspeisungsgesetz für die Windenergiebranche insgesamt zu bewerten ist, so ungünstige Folgen hatte es für die Situation der Energieversorger. Einerseits

\footnotetext{
${ }^{396}$ Die Entwicklung der Industrie wird hier nicht betrachtet. Es ist unmittelbar evident, dass die dauerhaft ansteigende Nachfrage, weitere Konzentrations- und Wachstumsprozesse unausweichlich macht. Hierzu zählt bspw. der Einstieg von Großkonzernen wie Siemens, dessen Erfolg ohne die Übernahme eines erfolgreichen Anlagenherstellers wie Bonus undenkbar gewesen wäre.

${ }^{397}$ Die Tatsache, dass der Begriff ,Bürgerwind-Park' noch immer gebräuchlich ist, bleibt davon unbenommen.

${ }^{398}$ Nachdem das Unternehmen 1999 an die Börse ging und die Aktien verkauft waren, verfügte Plambeck über 26,9 Mio. DM.

${ }^{399}$ Byzio et al. $(2002,361)$ sprechen in diesem Zusammenhang von einer Marketingstrategie.

${ }^{400} \mathrm{Zu}$ dieser Entwicklung haben Byzio et al. (2002, 372ff.) Pioniere der Bürgerwindbewegung befragt.
} 
werden sie durch das Gesetz vom Markt gedrängt. Sofern ihr Anteil an einem Windpark 25\% übersteigt, dürfen sie die SEG-Tarife nicht an die Kunden weitergeben. Auf der anderen Seite müssen sie mit ansehen, wie ihnen durch den Zubau immer neuer Windparks Jahr für Jahr Marktanteile verloren gehen. Über Jahre hin klagten die EVU gegen das Gesetz und finanzierten diffamierende Kampagnen gegen die Windkraft. Der VDEW beschritt alle Instanzen. Im Zuge der entstandenen Unsicherheiten distanzierten sich einige Banken von der Windparkfinanzierung oder verlangten höhere Zinsen. Erst als der VDEW vor dem europäischen Gerichtshof scheiterte, beginnt er, seine teilweise gesetzwidrige Renitenz aufzugeben. Im Jahr 2000 wurde das SEG durch das Erneuerbare-Energien-Gesetz (EEG) ersetzt, wodurch u.a. die Position der EVU auf dem Windsektor gestärkt wird. Erstens dürfen EVU und Stadtwerke, die Strom aus Windanlagen einspeisen, für sie entstehende Kosten auf die nächst höhere Regional-, bzw. Verbundene abwälzen, sofern der Anschluss eines Windparks dazu führt, dass der Anteil eingespeisten Windstroms oberhalb von fünf Prozent liegen würde. Zweitens erhalten Netzbetreiber das Recht, eigene Windparks zu betreiben und die erhöhten Tarife vollständig auf die Stromkunden umzulegen. Zwar hat die Neufassung des Einspeisungsgesetzes dazu beigetragen, den Konflikt zwischen EVU und Windanlagenbetreibern zu entschärfen. Gelöst ist er in insofern nicht, als das EEG ebenso wie zuvor das Stromeinspeisungsgesetz, den materiellen Grund des Konflikts nicht aufgehoben hat: den Ausbau der Windkraft durch unabhängige Produzenten. Auch hat das EEG bislang kaum dazu geführt, einen Markteinstieg der EVU zu fördern. Davon ausgehend, dass Eon und Vattenfall projektierte Offshore-Standorte teilweise seit Jahren nicht weiterentwickeln, nährt den Verdacht, dass man die Standorte vor allem deshalb erworben hat, um sie für andere zu blockieren. ${ }^{401}$

Dänemark

Auch im nördlichen Nachbarland zeigt sich die Tendenz der Verdrängung zivilgesellschaftlicher Akteure, wie Flemming Traenes $(1997,12)$ schildert:

,In many established guilds the engagement in the environmental aspects of wind power is of less importance and is no longer the principal interest. To a higher degree it is the prospect of a good investment and a reasonable rate of return, which today makes people gravitate towards wind turbine projects.'

Verglichen mit dem deutschen Markt hat sich die Kommerzialisierung des kooperativen Marktsegments - in Abgrenzung zum dänischen EVU-Markt - eher behutsam vollzogen und ist bis heute nicht abgeschlossen. Paradigmatisch ist die allmähliche Aufhebung der Abstandsbeschränkungen und die Anhebung der Investitionsgrenze. Bis zum Windenergiegesetz von 1992 darf jedes Kooperativmitglied nur so viele Anteile an einer Windanlage erwerben, dass die produzierte Menge Windstroms, die Grenze ,Eigenkonsum + 35\%' nicht überstiegen hätte. Die Mitglieder mussten zudem in der nächstgelegenen Gemeinde leben. Das Windenergiegesetz brachte eine erste vorsichtige Liberalisierung: Die Investitionsgrenze wird auf ,Eigenkonsum $+50 \%$ ' angehoben. Die Anleger dürfen nun auch aus einer der umliegenden Gemeinden stammen (Hantsch 1998, 70). 1994 wird die Untergrenze der Anteile auf maximal 20.000kWh pro Jahr ausgedehnt (Kamp 2002, 173). Aufgrund weiterer Liberalisierungen beginnt der Sektor, um 1997 für kleinere Investoren interessant $\mathrm{zu}$ werden. Diverse Ausnahmeregelungen des Abstandskriteriums ${ }^{402}$ werden eingeführt, und man darf Anteile entsprechend 30.000kWh erwerben. Die Anteilsnehmer können sich entweder für einen Teil ihrer Einnahmen von der Steuer befreien lassen, oder ihre

\footnotetext{
${ }^{401}$ Die Frage, ob und wann die Offshore-Standorte von den EVU (insbesondere Eon und Vattenfall) realisiert werden, ist offen. Näheres zur Stagnation des deutschen Offshore-Sektors: vg. Neukirch 2008

${ }^{402}$ Anteile kaufen kann jetzt auch, wer mindestens zwei Jahre in der Region gelebt hat, dort eine Zweitwohnung hat, ein Ferienhaus besitzt oder dort arbeitet. Auch diese Regelungen können von der Gemeinde bei Bedarf aufgehoben werden (Hantsch 1998, 78).
} 
Abschreibungen und Betriebskosten vollständig geltend zu machen (Hantsch 1998, 78f.). Seit 1999 darf jeder Däne, unabhängig von seinem Wohnort, Anteile erwerben, seit 2000 jeder EU-Bürger.

Trotzdem erreicht der dänische Markt, aufgrund der Investitionsobergrenze nicht denselben Kapitalisierungsgrad wie der deutsche. Der pragmatische Teil der kooperativen Bewegung hält die Marktöffnung für notwendig. Sein Anspruch war es, diesen Prozess so demokratisch wie möglich zu gestalten. Als Schlüssel dazu wird die Zusammenarbeit zwischen Experten, deren Know-how als unerlässlich galt und den einfachen Mitgliedern der Kooperative angesehen. Dabei sollte den Experten lediglich eine beratende Funktion zukommen, während die Entscheidungen letztlich von den Mitgliedern getroffen werden. Eine andere Fraktion, insbesondere repräsentiert durch das westjüdländische Folkecenter, propagiert nach wie vor einen dezentralen Ansatz. Sie lehnt den Aufbau großer Windparks und die damit verbundene Integration der EVU in den Sektor ab. Stattdessen werden am Folkecenter Hybridkraftwerke aus Solar-, Biogas und kleinen Windanlagen erprobt, die unabhängig von den Stromnetzen arbeiten sollen. Beide Ansätze werden staatlich gefördert. Das Forschungszentrum in Risoe bemüht sich vermehrt um die Optimierung kleiner Windturbinen (van Est 1999, 295f.). Der Administration geht es einerseits darum, Privatpersonen für Investitionen in Windparks zu gewinnen, andererseits diese Investitionen zu begrenzen. So soll verhindert werden, dass Einzelpersonen sehr hohe Summen anlegten und sich Windenergie zur reinen Kapitalanlage entwickelte. Dadurch bleibt der Konsens zwischen staatlicher Förderpolitik und der, auf die Interessen der Kooperativmitglieder ausgelegten Konsumentenorganisation DV, erhalten. Auch dient eine solche ausgewogene Vorgehensweise der Akzeptanzförderung.

Zwischen den dänischen EVU und den Windmüllern hatte eine Polarisierung wie in der Bundesrepublik zu keiner Zeit bestanden. Um die Verluste auf dem Strommarkt so gering wie möglich zu halten, lässt sich der Dachverband der Versorger DEF bereits 1985 zum Einstieg in den Sektor verpflichten. Bis 1996 nimmt der Kapazitätsanteil der EVU kontinuierlich zu (1987: 5\%, 1990: 30\%, 1996: 34\%, Heymann 1999, 128). Dieser Trend setzte sich nicht unbegrenzt fort. Vielmehr haben Kooperativen und Landwirte ihren Marktanteil bis zum Jahr 2002 auf 85\% gesteigert (Bechberger et al. 2007, 204).

Seit Ende der 80er Jahre sind die EVU, aufgrund ihrer Nachfrage der leistungsstärksten und technisch anspruchsvollsten Turbinen, zum Innovationsführer geworden. Der DEF gründete eine Tochterfirma, die speziell für die Bereiche Windparkplanung und -betrieb zuständig ist. Insbesondere aufgrund der Akzeptanzprobleme, mit denen die EVU bei der Realisierung ihrer Standorte konfrontiert sind, entschieden sie sich für den Einstieg in die Offshore-Technologie. Seit 1991 installierten sie mehrere Windparks auf See. Aufgrund positiver Ergebnisse kündigten sie in den 90er Jahren Pläne zum Aufbau weiterer Offshore-Anlagen (4.000MW Kapazität) an. Mittlerweile haben Versorger wie Elsam zwei große Offshore-Windparks (jeweils etwa 160MW) errichtet. Für die Realisierung solcher Anlagen sind Aufwendungen im dreistelligen Millionenbereich keine Besonderheit mehr. Diese Projekte liegen jenseits von dem, was Kooperativen umzusetzen im Stande sind, sowohl finanziell als auch organisatorisch. Hinsichtlich dessen handelt es sich bei dem im Jahr 2000 in Betrieb genommenen Offshore-Windpark Middelgrunden (40MW), um einen interessanten Sonderfall. Zum einen ist eine Kooperative zu 50\% an dem Projekt beteiligt. Gerade aus deutscher Sicht, ist es zum andern bemerkenswert, dass es sich hier bei um eine Zusammenarbeit zwischen einer Kooperative und den Stadtwerken Kopenhagens, also einem Akteur des etablierten Energiesektors, handelt (Kamp 2002, 174ff.). Die Tatsache, dass ein Offshore-Windpark auf diese Weise finanziert werden kann zeugt davon, dass zwischen den Energieversorgern und den Windmüllern trotz der Interessenwidersprüche, ein konstruktives Verhältnis besteht. Projekte mit ähnlicher Konstellation sucht man unter den, in deutschen Hoheitsgewässern geplanten Offshore-Anlagen vergeblich (http://www.offshorewind.de/page/index.php?id=4761, Abruf vom 28.5. 2009). 


\subsubsection{Diffusionsphase: Windenergie in Dänemark, Deutschland und den 92er Märkten}

Mit Einführung, einer dem dänischen Windenergiegesetz und dem deutschen SEG ähnlichen Einspeiseregelung, vollzieht der spanische Markt 1998 einen großen Schritt in Richtung auf das dänische Modell zu. Die Wirksamkeit solcher Einspeisungsgesetze wird durch die hohen Zahlen neu installierter Windanlagen bestätigt.

Der spanische Markt zeichnet sich während der ersten Hälfte der 90er Jahre durch Dominanz der staatlichen Endesa Gruppe aus. Seit 1995 tritt der private Energiekonzern Iberdrola zunehmend als Windparkentwickler- und Betreiber in Erscheinung. In dieser Verschiebung der Marktführerschaft von der öffentlichen Hand $\mathrm{zu}$ privaten Investoren besteht eine Annäherung an das dänische Modell. Sowohl in der Bundesrepublik, als auch in Dänemark ist ein grundsätzliches Anwachsen des Investor-Anteils zu beobachten. Dabei ist diese Tendenz auf dem deutschen Markt stärker ausgeprägt als in Dänemark. Der Unterschied ist teilweise dadurch bedingt, dass deutschen Investoren von Anfang an keine Schranken auferlegt waren. Anders als in Dänemark, gibt es daher hierzulande, unter den vielen kleinen Geldgebern, neben Unternehmen, auch manche Privatperson, die wohl ein paar Hunderttausend Euro in den Kauf von Windanlagen angelegt haben mochte. Gemeinsam ist beiden Märkten eine niedrige Ausgangsbasis der Investitionen. Gegenüber Großinvestoren, welche den spanischen und britischen Markt dominieren, stellen diese Unterschiede zwischen den Pioniermärkten eher feine Nuancierungen dar. ${ }^{403}$ Was die Frage der Konvergenz bzgl. Betreiberstrukturen in Dänemark und der Bundesrepublik einerseits sowie den 92er Märkten andererseits betrifft, so ist bestenfalls von einer vorsichtigen Annäherung seitens der ersteren zu sprechen.

Dieser Unterschied spiegelt sich in der Windanlagenstruktur wider. Während in den Pioniermärkten noch immer viele kleinere Windparks (unter 20MW) errichtet werden, installiert man in Spanien heute praktisch keine Anlage mehr unter 50MW. Der Aufbau einiger großer Offshore-Windparks in Dänemark, können als Indiz für eine Bedeutungszunahme der Energiewirtschaft interpretiert werden. Letztere war auf den 92er Märkten von Anfang der zentrale Akteur. Angesichts der moderaten EVU-Integration in Dänemark und der möglichen Offshore-Windparks, die in den nächsten Jahren von deutschen Energiekonzernen in der Nord- und Ostsee errichtet werden könnten, erscheint ein Annäherungsprozess des dänischen Modells an die 92er Märkte, perspektivisch möglich. Insgesamt hat sich der EVU-Anteil an der dänischen Windkraft seit Mitte der 90er Jahre jedoch eher verringert. In Deutschland liegt er bei etwa fünf Prozent.

Ebenfalls eine vorsichtige Annäherung lässt sich für die Konfliktstärke zwischen EVU und privaten Windanlagenbetreibern feststellen. In Deutschland hat die Einführung des EEG zu einem Abschwächen der Polarisierung geführt. Zudem haben sich die Energiekonzerne, durch Projektierung von Offshore-Standorten, die Option geschaffen, verlorene Marktanteile zurückzugewinnen. Auf dem dänischen Markt hatte der Konflikt um die Einspeisung von Windstrom zu keinem Zeitpunkt eine ähnliche Intensität erlangt. Frühzeitig wird von den EVU die Möglichkeit gewählt, lokalen Konflikten durch Offshore-Anlagen auszuweichen. In den 92er Ländern hat sich die Eröffnung der Märkte weitestgehend unter Kontrolle der Energiewirtschaft vollzogen. Unabhängige Windparkbetreiber stießen erst allmählich hinzu: in Großbritannien deutlich früher als in Spanien und Griechenland. Zusammenfassend dargestellt sind die Ergebnisse in Tab. 3j.

\footnotetext{
${ }^{403}$ In den letzten Jahren vereinfachten sich Großunternehmen wie der spanische Baukonzern Acciona den Einstieg in die Branche, indem sie sich bei großen EVU einkauften. So erwarb Acciona 20\% der Anteile Endesas und sogar die Aktienmehrheit von EHN (Sonne, Wind \& Wärme 1/07, 104).
} 
Tab. 3j

Konvergenz vs. Divergenz: 92er Länder und Pioniermärkte in der Diffusionsphase

\begin{tabular}{|c|c|c|c|c|}
\hline & Marktförderung & $\begin{array}{l}\text { Verhältnis zwischen Netz- } \\
\text { und privaten } \\
\text { Windanlagenbetreibern }\end{array}$ & $\begin{array}{l}\text { Netzbetreiber als } \\
\text { Käufer von WEA }\end{array}$ & $\begin{array}{l}\text { Investoren } \\
\text { klein) }\end{array}$ \\
\hline Dänemark & $\begin{array}{l}\text { Stromeinspeisungsreg. seit } \\
\text { 1984; sukzessiver, aber } \\
\text { begrenzter Abbau von } \\
\text { Investitionsschranken }\end{array}$ & $\begin{array}{l}\text { Beide Akteure sind i.a. auf } \\
\text { verschiedenen } \\
\text { Marktsegmenten aktiv; } \\
\text { konstruktiver Umgang mit } \\
\text { Interessenwiderspruch } \\
\text { besteht über lange Zeit } \\
\end{array}$ & $\begin{array}{l}\text { EVU seit } 1985 \text { auf } \\
\text { dem Markt aktiv; } \\
\text { Seit 1987: EVU sind } \\
\text { stabiler Marktakteur } \\
\text { (ca. 20-30\% Anteile) }\end{array}$ & $\begin{array}{l}\text { Anfangs sehr klein, } \\
\text { dann langsam } \\
\text { wachsend; parallel } \\
\text { verlaufender } \\
\text { Entwicklungsstrang: } \\
\text { EVU-Windparks } \\
\end{array}$ \\
\hline Deutschland & $\begin{array}{l}\text { Stromeinspeisungsgesetz } \\
\text { (1990), von Anfang an } \\
\text { keine } \\
\text { Investitionsschranken }\end{array}$ & $\begin{array}{l}\text { nach Einführung des SEG: } \\
\text { tiefer Konflikt; seit dem } \\
\text { EEG: deutliche Mäßigung }\end{array}$ & $\begin{array}{l}\text { EVU hatten nur bis } \\
\text { Anfang der 90er } \\
\text { Jahre nennenswerte } \\
\text { Marktanteile, } \\
\text { seitdem liegt ihr } \\
\text { Anteil bei etwa fünf } \\
\text { Prozent } \\
\end{array}$ & $\begin{array}{l}\text { erst sehr klein, dann } \\
\text { wachsend; Großteil der } \\
\text { Käufer: } \\
\text { Privatpersonen, } \\
\text { mittelständische } \\
\text { Planungsgesellschaften }\end{array}$ \\
\hline Spanien & $\begin{array}{l}\text { Einspeisungsgesetz ab } \\
\text { 1994, bzw. } 1998\end{array}$ & $\begin{array}{l}\text { Bis Mitte der 90er Jahre: } \\
\text { keine Privatbetreiber; } \\
\text { später kaufen unabhängige } \\
\text { Investoren häufig EVU- } \\
\text { Anteile; Konflikte sind } \\
\text { eher von lokaler Bedeutung }\end{array}$ & $\begin{array}{l}\text { EVU verfügen seit } \\
\text { Öffnung des Marktes } \\
\text { über die größten } \\
\text { Anteile }\end{array}$ & $\begin{array}{l}\text { von Anfang an: große } \\
\text { EVU (erst staatlich, } \\
\text { dann auch privat) }\end{array}$ \\
\hline Großbritannien & $\begin{array}{l}\text { Im Rahmen der } \text { NFFO } \\
\text { waren EVU und } \\
\text { netzfremde } \\
\text { Windanlagenbetreiber von } \\
\text { Anfang an gleichgestellt }\end{array}$ & $\begin{array}{lr}\text { NFFO } & \text { erzwingt } \\
\text { konstruktive } & \text { Beziehung } \\
\text { zwischen EVU und } \\
\text { Investoren, sofern diese } \\
\text { nicht bereit gewesen sind, } \\
\text { selbst hinreichende } \\
\text { Kapazitäten erneuerbarer } \\
\text { Energie zu installieren }\end{array}$ & $\begin{array}{l}\text { EVU verfügen zwar, } \\
\text { ebenso wie in } \\
\text { Spanien, über die } \\
\text { größten } \\
\text { Marktanteile: häufig } \\
\text { handelt es um } \\
\text { netzfremde EVU, die } \\
\text { ihre erneuerbare } \\
\text { Energie-Quote } \\
\text { erfüllen, indem sie } \\
\text { Strom für andere } \\
\text { Netze produzieren }\end{array}$ & $\begin{array}{l}\text { von Anfang an: } \\
\text { Finanzkräftige } \\
\text { Unternehmen, } \\
\text { vorwiegend aus dem } \\
\text { Energiesektor }\end{array}$ \\
\hline $\begin{array}{|ll|}\text { Konvergenz/ } & \\
\text { Divergenz } & \\
\text { zwischen } & \text { dem } \\
\text { dänischen } & \text { und } \\
\text { deutschen } & \\
\text { Markt } & \\
\end{array}$ & $\begin{array}{l}\text { Konvergenz bis } 2002 . \\
\text { Seitdem gilt in Dänemark } \\
\text { ein Quotenmodell, was } \\
\text { zur } \\
\begin{array}{lll}\text { Stagnation vollständigen } \\
\text { geführt hat }\end{array}\end{array}$ & $\begin{array}{l}\text { BRD: Konflikt seit EEG } \\
\text { moderater, daher: leichte } \\
\text { Annäherung des deutschen } \\
\text { Marktes an Dänemark }\end{array}$ & $\begin{array}{lr}\text { DK/BRD } & \\
\text { gemeinsam: relativ } \\
\text { niedriger } & \text { EVU- } \\
\text { Anteil; Unterschied: } \\
\text { DK verfügt über } \\
\text { mehr } & \text { EVU- } \\
\text { Windparks als } & \text { BRD; } \\
\text { Unterschied } & \text { bleibt } \\
\text { erhalten: } & \text { keine } \\
\text { Konvergenz }^{404} & \\
\end{array}$ & $\begin{array}{l}\text { DK/ BRD gemeinsam: } \\
\text { Käufer } \\
\text { vorwiegend } \\
\text { Einzelpersonen } \\
\text { Unterschied: } \\
\text { Investitionsgrenze in } \\
\text { Dänemark } \\
\text { (Annäherung von } \\
\text { dänischer Seite) }\end{array}$ \\
\hline \begin{tabular}{|l|} 
Konvergenz/ \\
Divergenz r dem \\
zwischen \\
dänischen Modell \\
und den 92er \\
Märkten
\end{tabular} & $\begin{array}{l}\text { Spanien: } r \text { Konvergenz } \\
\text { (Stromeinspeisungsgesetz) } \\
\text { GB setz weiterhin auf } \\
\text { stärker marktbasierte } \\
\text { Regelungen: NFFO-III, } \\
\text { später Quotenmodell }\end{array}$ & $\begin{array}{l}\text { In Großbritannien und } \\
\text { Spanien hat der Konflikt } \\
\text { hauptsächlich lokale } \\
\text { Bedeutung (und nimmt im } \\
\text { Verlauf der 90er Jahre eher } \\
\text { noch weiter ab). }\end{array}$ & $\begin{array}{l}\text { Divergenz: in } \\
\text { DK/BRD } \\
\text { dominieren nicht- } \\
\text { EVU noch immer, in } \\
\text { SP/GB: EVU sind } \\
\text { wichtigster Akteur }\end{array}$ & $\begin{array}{l}\text { Divergenz: 92er } \\
\text { Märkte: } \\
\text { Großinvestoren, } \\
\text { DK/BRD: mehr oder } \\
\text { weniger solvente } \\
\text { Einzelpersonen/ } \\
\text { Mittelständler }\end{array}$ \\
\hline
\end{tabular}

Quellen: vg. Kap. 2 und 3

\footnotetext{
${ }^{404}$ Konvergenz möglich, sofern deutsche EVU-Windprojekte auf See realisiert werden.
} 
Zusammenfassung

In den wesentlichen Eigenschaften bleibt das dänische Modell, d.h. die Struktur der Windsektoren in Dänemark und der Bundesrepublik, auch nach Einsetzen der Diffusionsphase erhalten. Stromeinspeisungsgesetze sind nach wie vor die effizienteste Komponente der Förderpolitik. Der grundsätzliche Interessenwiderspruch zwischen Netzbetreibern und netzfremden Produzenten von Windstrom besteht fort. Letztere bleiben wichtigster Akteur des Sektors. Noch immer handelt es sich überwiegend um mehr oder weniger wohlhabende Einzelpersonen, welche die Windparks letztendlich finanzieren. Trotz einiger struktureller Unterschiede zwischen dem deutschen und dänischen Markt, überwiegen die Gemeinsamkeiten.

Das exakte Gegenteil gilt für den Vergleich zwischen dem dänischen Modell und den 92er Märkten, insbesondere Spanien. Neben der verwendeten Technologie (dänisches Konzept) besteht die wichtigste Gemeinsamkeit in der Geltung eines Stromeinspeisungsgesetzes. Der für das dänische Modell charakteristische permanente Widerspruch zwischen EVU und Windmüllern existiert in keinem der 92er Märkte. Während letztere durch Energiekonzerne bestimmt werden, spielen die Versorger in den Pioniermärkten bis heute eine nachgeordnete Rolle. Die Investoren unterscheiden sich nicht nur qualitativ, sondern auch durch ihre Größe voneinander. Auch wenn die kleinen Windparks in Deutschland und Dänemark heute nicht mehr von Graswurzelakteuren entwickelt und betrieben werden: finanziert werden sie noch immer vorwiegend durch die Geldeinlage Tausender Kleininvestoren.

Es lässt sich zusammenfassen: Zwischen dem dänischen Modell und der Akteurskonstellation auf dem spanischen Markt bestehen in der genutzten Technologie und des Fördersystems die wichtigsten Übereinstimmungen. Von diesen Gemeinsamkeiten abgesehen, unterscheiden sich die Akteurskonstellationen so stark, dass vom spanischen Markt tatsächlich als einem neuen spanischen Erfolgsmodell gesprochen werden muss. Dessen wichtigste Kennzeichen sind: Verwendung dänischer Technologie bei weitest möglicher Abschottung der Industrie gegenüber ausländischer Konkurrenz, anfangs zentrale Steuerung durch Staatskonzern Endesa, Stromeinspeisungsgesetz, passive Einbindung der Anrainer (Gewerbesteuereinnahmen), zentrale Rolle der Energiekonzerne als Windparkbetreiber (staatlich und privat).

Das dänische Modell ist, mit relativ geringen Modifikationen auch in der Diffusionsphase erfolgreich. Mit dem Erfolg des spanischen Modells manifestiert sich im Verlauf der 90er Jahre, dass eine gelungene Etablierung der neuen Technologie nicht mehr notwendig einem einzigen Entwicklungspfad folgen muss. Es wurde die Begrenztheit der Kompatibilität des dänischen Modells mit den Voraussetzungen für die Windenergienutzung anderer Staaten analysiert. Bis heute ist das dänische Modell auf zwei Pioniermärkte eingeschränkt geblieben. In den letzten Jahren hat die Windenergie einen weiteren enormen Aufschwung erfahren. Die Frage inwieweit die Entwicklung auf eine bessere Diffusionsfähigkeit des spanischen Modells zurückzuführen ist, müsste an anderer Stelle erörtert werden. 


\section{Windkraft als neue Komponente des Elektrizitätssystems- Ein Beitrag zur Debatte um die Dynamik großer technischer Systeme}

Die Untersuchung hat gezeigt, unter welchen Bedingungen sich die Windkraft als neue Technologie zur Energieversorgung etabliert hat. Voraussetzung zum Eintritt in die Diffusionsphase war die konseqente technologische Weiterentwicklung und die Schaffung geeigneter institutioneller Rahmenbedingungen (Einspeisereglungen, Genehmigungsverfahren, Sicherheitsstandards u.a.) Zwischen beiden Faktoren besteht eine Interdependenz, die von noch anderen Bedingungen abhängt, welche über den speziellen Kontext hinaus reichen (bspw. gesellschaftspolitische Diskurse um Energieversorgung, ökonomische Bedeutung der Windenergie, spezielle Regierungskonstellationen). Zwar lässt sich sagen: Durch die Weiterentwicklung der Windenergie zur proven technology sind die Voraussetzung zur Schaffung eines geeigneten institutionellen Umfeldes gesunken wie die Existenz der 92er Märkte beweist. Eine harte technikdeterministische Position, "Technologische Erfolge der Windenergie ziehen die Schaffung erforderlicher institutioneller Bedingungen nach sich.", ist indes zurückzuweisen. Eher bestätigt wird dagegen folgende, das Eigengewicht der Technik relativierende Aussage: ,Eine Technik setzt sich nicht durch, weil sie technisch überlegen ist, sondern sie gilt als technisch überlegen, weil sie sich im institutionalisierten Innovationssystem durchgesetzt hat.' (Rammert 1995, 20)

Für die Pioniermärkte sind beide Seiten der Entwicklung ausführlich betrachtet worden. Immer wieder ist das ambivalente, kontradiktorische, oder taktische Verhältnis der EVU zur Windkraft als neuer Komponente des Stromsystem deutlich geworden. Die zukünftige energiepolitische Rolle der Windenergie hängt davon ab, welcher Status ihr innerhalb des Sektors zukommen wird. Diese Frage ist dort konkret geworden, wo dem neuen Energieträger mittlerweile deutlich wahrnehmbare Schritte aus der anfänglichen Nische gelungen sind: in Dänemark, Spanien und Deutschland. Lässt sich von einheitlichen Auswirkungen des Hinzutretens der Windkraft sprechen, oder überwiegen landespezifische Differenzen bzgl. der Entwicklung der Elektrizitätssysteme?

Um dieser Frage nachzugehen, bietet es sich an, die Ergebnisse dieser Studie zur Debatte um die Entwicklungsmöglichkeiten großer technischer Systeme und deren Beharrungsvermögen in Beziehung zu setzen. Mit dieser Diskussion eng verknüpft sind die Konzepte der Unterscheidung zwischen inkrementeller und radikaler Innovation, Pfadabhängigkeiten und Pfadwechsel' sowie des institutionellen Wandels. Lassen sich infolge der Windenergienutzung Pfadwechsel beobachten? Ist der neue Energieträger als radikale Innovation zu bewerten, oder ist er Teil eines inkrementellen Wandels?

$\mathrm{Zu}$ welchen neuen Erkenntnissen führt die Anwendung dieser Konzepte, wenn sie auf die Empirie der Windkraftnutzung bezogen werden? Werden die Ergebnisse bestätigt, oder weichen die Vorhersagen stark von der Empirie ab?

Es geht im folgenden sowohl darum, die Ergebnisse konzeptionell einzuordnen, als auch die empirische Basis der betreffenden innovationssoziologischen Ansätze zu erweitern und ggf. Anstöße für Modifizierungen zu bieten. Relativierend vorweg zu schicken ist noch, dass eine Theorie in ihrer Gesamtheit, durch gute oder mangelhafte Erklärung eines einzelnen Falls, i.a. weder zu verifizieren ist, noch vollständig widerlegt werden kann. 


\subsection{Darstellung des innovationssoziologischen Diskurses: Ansätze und Kontroversen}

\section{Inkrementelle und radikale Innovation}

Bei inkrementellen Verbesserungen handelt es sich um Vorgänge, welche auf der Optimierung des bisherigen Status quo beruhen. ${ }^{405}$ Radikale Innovationen ermöglichen deutliche größere Fortschritte, weil sie typischerweise auf vollständig neuen Prinzipien beruhen. Klassische Beispiele sind: das Dampfschiff gegenüber dem Segelschiff, das Automobil gegenüber der Pferdekutsche, die Umstellung von Gleich- auf Wechselstrom, die Einführung von Telefon, Computer, Internet und Handy.

Die Anwendung neuer Technologien wie dieser stellen Geels (2005) zufolge ,Systeminnovationen' dar, weil sie Transformationen von einem sozioökonomischen System in ein anderes nach sich ziehen. Die Einführung der Dampfschifffahrt machte bspw. den Aufbau neuer Infrastruktursysteme erforderlich. In den Häfen mussten riesige Kohlespeicher eingerichtet werden, so dass die Schiffe mit Energie versorgt werden konnten. Weil sie nicht länger vom Wind abhängig war, breitete sich die Schifffahrt über Flüsse und neu geschaffene Kanäle zunehmend auf das Inland aus. Daher konnten die Fahrtzeiten recht präzise vorhergesagt werden. Fahrpläne entstanden und die Schifffahrt gewann für den Personentransport an Bedeutung (vg. Geels 2005). Über mehrere Jahrhunderte wurden die Segelschiffe immer weiter optimiert. Man lernte, den Wind effizienter zu nutzen und größere Schiffe zu konstruieren. Dennoch: Segelschiffe waren dem aufkommenden Industriezeitalter nicht länger gewachsen. Während sich die zu erwartenden technischen Fortschritte in der Segelschifffahrt stark verringerten, nahmen die Anforderungen bzgl. der Zuverlässigkeit und Transportkapazität immer mehr zu. Dampfschiffe sind keine verbesserten Segelschiffe, sondern beruhen stattdessen auf einem vollständig neuen Antriebsprinzip. Auf derartig grundlegende Neuerungen, die sogar Systeminnovationen ausgelöst haben, trifft der Terminus radikale Innovation zu. Während innerhalb der Entwicklung eines Produktes ausschließlich inkrementelle Innovation $\mathrm{zu}$ finden ist, sind wirklich durchgreifende Verbesserungen nur durch radikale Innovationen und nur durch grundlegend neue Produkte zu schaffen. Insofern ist der Begriff radikale Innovation etwas weiter $\mathrm{zu}$ fassen und bezieht sich nicht nur auf technische Neuerungen, welche Systeminnovationen zufolge hatten. Radikale Innovationen basieren auf grundlegend neuen Funktionsprinzipien und ermöglichen dem Anwender deutliche Vorteile (bspw. Internet und Mobiltelefon).

\section{Große technische Systeme $e^{406}$}

Bei einem großen technischen System (GTS) handelt es sich um eine netzwerkartig organisierte Struktur, die über große Flächen und lange Zeiträume darauf ausgelegt ist, einen bestimmten Funktionszweck zu erfüllen (bspw. Transport von Personen, Gütern und Energie). $\mathrm{Zu}$ den wichtigsten Eigenschaften eines GTS zählt die hohe Kapitalintensität der aufgebauten Infrastruktur. Die unterschiedlichen Systemkomponenten sind wechselseitig aufeinander bezogen. Man stelle sich ein Eisenbahnnetz vor, mit seinen Schienen, Zügen und Bahnhöfen. Alle drei sind für das Funktionieren notwendig, eine einzelne erfüllt keinen Zweck. Ein anderes Beispiel stellt das Verhältnis zwischen dem zentralen Stromnetz und Großkraftwerken dar: Ohne die Leitungen, welche elektrischen Strom über Hunderte Kilometer zu transportieren vermögen, wäre der Bau großer Kraftwerke zwecklos, weil vor Ort nur ein kleiner Teil der produzierten Energie gebraucht wird.

Zur Erklärung des Entstehens großtechnischer Systeme gibt es Joerges zufolge (1992, 49) unterschiedliche Ansätze: „Die Macht großer Organisationen', ,Steuerungsinteressen

\footnotetext{
${ }^{405}$ Beispiele sind etwa die Erhöhung des Wirkungsgrades thermischer Großkraftwerke von 30 auf $40 \%$ und die Minderung des Benzinverbrauches eines PKW von sieben auf fünf Liter pro 100 Kilometer.

${ }^{406}$ Geprägt wurde dieser Begriff 1983 von Thomas Hughes (Hughes/ Mayntz 1988, 5).
} 
politischer Akteure', „Kapitalverwertungsinteressen', ,staatliche Vorsorgefunktionen', ,nationale Verteidigung', ,internationale Wettbewerbsfähigkeit', ,technische Eigenlogik' und ,Evolution'. Baedeker (2002) hat kritisch darauf hingewiesen, dass zur Realisierung bestimmter Funktionszwecke wie Telekommunikation, sowie Personen- und Gütertransport der Aufbau großer technischer Systeme eine Notwendigkeit darstellt (,zwingend translokal'). Für andere, ,potenziell lokal' zu realisierende Funktionszwecke wie die Versorgung mit Wärme, Strom und Wasser, erscheint die Entstehung großer Infrastruktursysteme nicht als Notwendigkeit.

Wenn ein großtechnisches System einmal etabliert ist, beginnt es gemäß Hughes, ein ,Momentum' auszubilden. Damit wird auf ein zunehmendes Beharrungsvermögen verwiesen, dass solche Strukturen mit der Zeit ausbildeten. Eine Modifizierung des inneren Gefüges wird daher stark erschwert. Aufgrund dieser Beharrungstendenz erscheint die Pfadabhängigkeitstheorie prinzipiell als geeignet, um Gesetzmäßigkeiten der Veränderung oder Konstanz großtechnischer System zu verstehen (Hughes/ Mayntz 1988).

\section{Zur Diskussion um Pfadabhängigkeit und -stabilität}

Grundsätzlich versucht die Pfadabhängigkeitsthese $\mathrm{zu}$ erklären, weshalb bestimmte Technologien, Anwendungsverfahren und Organisationsstrukturen, trotz des Vorhandenseins besserer Alternativen, weiterhin verwendet werden. Der aus der Ökonomie stammende Ansatz steht der Meinung entgegen, dass die entsprechenden Korrekturen durch die ,unsichtbare Hand' des Marktes vorgenommen würden (klassischer Wirtschaftsliberalismus). Arthur (1988) und David (1985) konzentrieren sich darauf, die weitere Verwendung eigentlich überkommener Technologien zu erklären. Arthur (1988) geht von fünf Quellen sogenannter ,increasing returns to adaption' aus: Optimierung der Technologie durch langjährige Erfahrung (learning by using), Herstellung ähnlicher Produkte und solcher, die mit der fraglichen Technologie kompatibel sind (network externalities), Preissenkung durch große Produktionszahlen (scale economies in production), größerer internationaler Bekanntheitsgrad unter den Nutzern (informational increasing returns) und Entwicklung ergänzender Technologien (technological interrrelatedness, Geels 2005, 54f.).

Verschiedene Autoren haben sich mit der Frage der Pfadstabilität großtechnischer Systeme auseinandergesetzt. Etablierte Systeme reproduzieren sich durch gesetzliche Rahmenbedingungen (Walker 2000). Innerhalb der GTS haben sich zwischen Akteuren und Organisationen unabhängige Netzwerke herausgebildet, die so etwas wie ein ,organisatorisches Kapital' repräsentieren. Die Stabilität des GTS speist sich aus wechselseitigen Rollenerwartungen. Vertreter der ,evolutionären Ökonomie' argumentieren, dass die Ingenieure aufgrund der vertrauten Herangehensweise, zur Lösung von Problemen von vorn herein einen bestimmten Blickwinkel einnehmen, so dass andere Lösungsansätze gar nicht erst in Betracht gezogen werden. Konzepte wie ,technologisches Regime' und ,technologisches Paradigma' werden von dieser Strömung vorgeschlagen, um die Herausbildung sogenannter Trajektoren zu erklären (Dosi, 1982; Nelson/ Winter, 1982). STFForscher (Socio-technological Science) betonen die gesellschaftliche Dimension der Pfadstabilität. Die Menschen haben ihren Lebensstil in Einklang mit bestimmten institutionalisierten Regelungen gebracht. Als Folge sind entsprechende Infrastrukturen entstanden, wodurch ein GTS gestärkt wird. Unruh (2000) hat in diesem Zusammenhang von einem ,techno-institutional complex' gesprochen, Callon (1991) von ,techno-economic networks' (vg. Geels 2005, 8). Rammert (1995) geht ebenfalls von einer evolutionären Technologieentwicklung aus, wobei er die Bedeutung sozialen Handels besonders hervorhebt. Er führt das Beispiel der Konsumenten an, die angesichts von Problemen wie Preissteigerung, Ölknappheit und der Einführung neuer Steuern trotzdem am Automobil festhalten. Manche Autoren scheinen die Trägheit großtechnischer Systeme als lebensnotwendig anzusehen. 
Joerges $(1988,28)$ zufolge können sie durch plötzliche Veränderungen stark geschädigt werden. Aufgrund der engen physischen Verbindung der Systemkomponenten, müssen Fehler und Probleme von innen heraus korrigiert werden. Dieses setzt zentrale Kontrolle und zentrale Interventionsfähigkeit voraus. Auf diese Weise versuchen die GTS, sich gegen Interventionen von außen, bestmöglich abzuschotten. Am Beispiel des Energiesystems bestätigen Markard/Truffer (2006) dessen hohe Stabilität und attestieren ihm eine hohe Widerständigkeit gegen radikale Veränderungen.

So sehr diese Konzepte zur Erklärung der Pfadstabilität beitragen, so wenig Beachtung scheinen sie der Möglichkeit eines Pfadwechsels und seiner speziellen Voraussetzungen zuzugestehen. Hier setzt Beyers Kritik an (2005, 5ff.). Beyer problematisiert den ,impliziten Konservativismus' der Pfadabhängigkeitsthese. So werden ,nicht-lineare Verursachungszusammenhänge, spontane Koinzidenzen, statistische Seltenheiten oder Singularitäten' von Anfang an nicht ausreichend zur Kenntnis genommen, weil sie sich dem ,sozialwissenschaftlichen Kausalerklären' entziehen. Starke Pfadabweichungen und Pfadwechsel werden demzufolge als Ausnahmefälle betrachtet. Beyer $(2005,10 \mathrm{f}$.) benennt die wichtigsten Gründe, die von den Vertretern der Pfadabhängigkeitsthese für eine hohe Pfadstabilität genannt werden: increasing returns, hohe Transaktionskosten, unvollständige Rationalität der Akteure, Reproduktion aufgrund von Macht, legitimatorischer und funktionaler Grundlagen. Beyer geht von unterschiedlichen ,Destabilisierungsoptionen' aus (ebd., 15ff.). So kann es bei geringen Transaktionskosten, trotz increasing returns zu einem Pfadwechsel kommen. Dieses gilt für den Fall, dass die Transaktionskosten niedriger eingeschätzt werden, als die erwarteten Vorteile der Neuerung. Im Rahmen eines institutionellen Wandels (s.u.) können durch fortwährende inkrementelle Veränderungen, allmählich deutliche Pfadkorrekturen erreicht werden. Impulse können vom Wettstreit verschiedener Organisationen, oder auch den Eigeninteressen bestimmter Akteure ausgehen. Machtbasierte Pfadabhängigkeit kann aufgehoben werden, wenn es innerhalb der Machtelite zu veränderten Kräfteverhältnissen kommt. Als weitere Destabilisierungsoptionen können die Entstehung von Gegenmacht, die Delegitimierung der Machtelite, oder die Durchsetzung neuer Leitvorstellungen, mit denen das alte System nicht länger zu vereinbaren ist, fungieren. Leichter möglich sind Pfadwechsel auch an wichtigen Entscheidungspunkten (,critical junctures'). Hughes (1988) geht von der Notwendigkeit einer parallelen Entwicklung der Systemkomponenten aus. Bleibt eine der Komponenten hinter der Enterwicklungslinie zurück (,reverse salient'), kann daraus ein kritisches Problem (,bottle neck') erwachsen. Sofern dieses nicht innerhalb des alten Systems gelöst werden kann, bilden solche reverse salients möglicherweise Ausgangspunkte für Systemtransformationen (vg. Baedecker 2002, 20ff.). ${ }^{407}$ Anders als die Vertreter der Pfadabhängigkeitsthese geht Summerton (1994) davon aus, dass die Stabilität eines Netzwerkes oder eines technischen Systems stets nur von provisorischem Charakter sein kann. Vielmehr handele es sich bei ihnen um ,dynamic entities' (Geels 2005, 31). Neben Hughes ,reverse salients' sieht Summerton vier weitere Destabilisierungsgründe: (1) negative Externalitäten: bspw. Umweltrisiken, öffentliche Kritik, Druck von Verbraucherseite und Sicherheitsbedenken; (2) Veränderung ökonomischer Rahmenbedingungen, bspw. durch Auftreten neuer Konkurrenz, die Entstehung neuer Märkte und Innovationen; (3) Veränderung politischer Rahmenbedingungen und Kriege, bzw. drohende Kriege; (4) Veränderung kultureller Werte und Erwartungen sowie neue politische Ideologien (Geels 2005, 31). Joerges (1988) sieht eine wichtige Voraussetzung des Pfadwechsels innerhalb eines GTS darin, dass die Politik für eine neue Technologie, die ohne Unterstützung nicht lebensfähig wäre, einen geschützten Raum herstellt. In einer solchen

\footnotetext{
${ }^{407}$ Baedecker führt das Beispiel des Übergangs vom Gleich- zum Wechselstromsystem an. Infolge der Zentralisierung der Stromproduktion und -verteilung muss der Strom über immer größere Distanzen transportiert werden. Diese Entwicklung war jedoch mit einem Gleichstromnetz nicht möglich, weil mit steigenden Distanzen, die Übertragungsverluste zu hoch geworden sind (ebd.).
} 
Nische bestehen für sie Entwicklungschancen, ohne dass sie in direkte Konkurrenz mit etablierten Technologien treten müsste. Markard/ Truffer $(2006,611 \mathrm{f}$.) zufolge können solche Nischen auch durch finanzkräftige Unternehmen und spezielle Konsumenten geschaffen werden, oder sind durch das Vorliegen spezifischer Rahmenbedingungen von Haus gegeben. ${ }^{408}$ Mautz (2008) zufolge sind radikale Transformationen am ehesten dann $\mathrm{zu}$ erwarten, wenn ein System nicht mehr anpassungsfähig genug ist, um auf externen Veränderungsdruck flexibel $\mathrm{zu}$ reagieren. Andererseits kann ein interner, inkrementeller Umbau des Systems insgesamt zu ähnlichen Veränderungen führen, wie man es ansonsten von ,externen Schocks' erwartete (vg. auch Dolata 2008).

Inkrementelle und radikale Innovationen in großtechnischen Systemen

Im vorherigen Abschnitt sind einige Argumente dargelegt worden, weshalb es $\mathrm{zu}$ Pfadwechseln in großtechnischen Systemen kommt, oder der Status quo erhalten bleibt. Wie reagieren große technische Systeme üblicherweise, wenn sie durch neue Technologien herausgefordert werden, die denselben Zweck erfüllen? Wehren sie sich ,mit Händen und Fußen', halten sie bis zuletzt am Status quo fest? Versuchen sie, die neue Technik in irgendeiner Weise für sich handhabbar zu machen? Ergeben sich Pfadwechsel ausschließlich durch Impulse von außen, oder lassen sie sich möglicherweise aus dem System heraus steuern? Geht der Eintritt radikaler Innovationen notwendig mit einem Pfadwechsel einher? Natürlich können hier nicht all diese Fragen ausführlich behandelt werden - und schon gar nicht anhand eines Einzelfalls. Es geht im folgenden lediglich darum, einige Positionen darzulegen, welche auf diese Fragen bezogen werden können.

Hughes zufolge kann es innerhalb eines GTS keine radikale Innovation geben. Tritt ein kritisches Problem auf, so wird eine Lösung angestrebt, welche auf einer konservativen (inkrementellen) Modifikation basiert. Wird keine Lösung gefunden, so treten Akteure von außen (,inventor-entrepreneurs', ,independent professional inventors', ,system builders') hinzu. Sie bieten möglicherweise Lösungen, d.h. neue Produkte und Verfahren an, die mit den bisherigen Systembestandteilen nicht mehr kompatibel sind, so dass ein Pfadwechsel unausweichlich wird (Hughes/Mayntz 1988, 13f.).

Dolata $(2008,54)$ geht davon aus, dass sich die realen Verläufe technischen Wandels nicht durch eine dichotome Unterscheidung langer Phasen der Stabilität, welche durch ,exogene Schocks...und ebenso radikale wie abrupte Umbrüche' unterbrochen würden, angemessen untersuchen lassen. Auf diese Weise werde das ,interessante Zwischenfeld zwischen struktureller und institutioneller Stabilität und radikalen Systemumbrüchen' ausgeblendet (ebd.). Typische Transformationsprozesse vollziehen sich Dolata zufolge als ,sektoraler Wandel'. Letzterer zeichnet sich sowohl durch ,längere Phasen der Diskontinuität', als auch ,eine Vielzahl gradueller Transformationen' aus (ebd.). Technologische ,lock-ins' und Pfadabhängigkeiten seien keineswegs 'dauerhaft und irreversibel' (ebd., 55). Die Ausbildung neuer Entwicklungspfade setzt häufig ,soziotechnische Readjustierungsprozesse' voraus, welche Jahrzehnte andauern können (ebd., 56).

\footnotetext{
${ }^{408}$ Man denke bspw. an Wind-Diesel Systeme zur Stromproduktion auf Inseln und in abgelegenen Regionen.
} 
Zur Bedeutung der Windenergie für die Dynamik des Elektrizitätssystems insgesamt, liegen bereits einige Interpretationsansätze vor. Hervorzuheben ist dabei der Aspekt, ob und unter welchen Bedingungen die Windenergie als radikale Innovation einzustufen ist. Markard/Truffer (2006) haben ein Konzept radikaler Innovation entworfen, dass speziell auf neue Energietechniken zugeschnitten ist und daher im folgenden ausgeführt wird.

Dem zufolge (ebd. 2006, 612) liegt eine radikale Innovation vor, wenn neue Produkte und Technologien eingeführt werden, welche neue Standards, Regimes und Paradigmen erforderlich machen. Dabei müssen die neuen Produkte nicht nur in der Konkurrenz mit den alten bestehen. Zusätzlich muss das vorherige Regime, bzw. die bisher geltenden Paradigmen überwunden werden. Dennoch finden radikale Innovationen in manchen Fällen auch in großen technischen Systemen statt (ebd. 2006, 9). Häufigste Ursachen sind Anstöße von außen wie veränderte politische Rahmenbedingungen und neue Präferenzen, sowie technische Durchbrüche in anderen Bereichen. Zusätzlich gehen Markard/ Truffer (ebd.), ebenso wie Dolata von der Möglichkeit aus, dass sich radikale Innovationen auch als Folge sukzessiver Veränderungen einstellen können. Jedoch räumen die Autoren dieser zweiten Möglichkeit keine so zentrale Rolle ein. Dieses mag darin begründet sein, dass sie offenbar von einem schwächeren Begriff radikaler Innovation ausgehen. So bewerten Markard/ Truffer die Entgegensetzung inkrementeller und radikaler Innovationen als zu vereinfachend. Erstens sei eine Innovation aus unterschiedlichen Blickwinkeln $\mathrm{zu}$ betrachten: Preissenkungen, verbesserte Funktionseigenschaften, Verringerung der zur Nutzung und Herstellung erforderlichen Kompetenzen seitens Käufer und Hersteller sowie das Potenzial, vorhandene Technologien zu ersetzen. Zweitens sei in der Praxis eher ein Kontinuum zu beobachten, als ein klarer Bruch zwischen alt und neu. Drittens hänge es von der Perspektive ab, ob ein Produkt eine radikale Innovation darstelle. So sei es durchaus möglich, dass der Einsatz einer Technologie auf Seiten des Produzenten zu radikalen Veränderungen führt, während auf der Seite des Konsumenten alles beim alten bleibe (bspw. Stromproduktion durch dezentrale Energietechnologien). Markard/Truffer (2006, 612f.) schlagen daher vor, die Radikalität einer Innovation anhand zweier Dimensionen bewerten. Wie stark ist der Wandel in der gesamten Wertschöpfungskette ${ }^{409}$ einzuschätzen (vertikale Dimension) und wie stark unterscheidet sich die neue Technologie von der vorherigen (horizontale Dimension)?

Als zentralen Anwendungsfall haben die Autoren das Energiesystem vor Augen. Mittels ihres Verfahrens bewerten sie vier (relativ) neue Energietechnologien: Atomenergie, Kraft-WärmeKopplung, Windenergie und Brennstoffzelle. Radikale Innovationen erzielen einen hohen Neuerungsgrad auf der horizontalen, vertikalen, oder beiden Skalen. Die folgende Tabelle 4a fasst zusammen inwiefern es sich bei jeder der neuen Technologien um eine radikale Innovation handelt.

Tab. 4a Radikale Innovationen im Energiesektor

\begin{tabular}{|l|l|l|l|}
\hline Technologie & $\begin{array}{l}\text { Grad der Innovation } \\
\text { vertikal } \\
\text { (Wertschöpfungskette) }\end{array}$ & $\begin{array}{l}\text { Grad der Innovation } \\
\text { horizontal } \\
\text { technischer Neuerung) }\end{array}$ & radikale Innovation? \\
\hline Atomenergie & mittel & hoch & ja \\
\hline Kraft-Wärme-Kopplung & hoch & mittel & ja \\
\hline Windenergie & hoch & hoch & ja \\
\hline Brennstoffzelle & hoch & hoch & ja \\
\hline
\end{tabular}

Quelle: Markard/ Truffer 2006

\footnotetext{
${ }^{409}$ Die Wertschöpfungskette besteht aus fünf Grundfunktionen: Zugriff auf Primärenergieträger (1), deren Transport (2), deren Umwandlung in Strom (3), Stromübertragung und -verteilung (4), Handel und Vertrieb (5).
} 
Für diesen Anwendungsfall ist die Frage, wie begründet wird, weshalb Windkraft eine radikale Innovation darstellt, von herausragendem Interesse. Markard/ Truffer $(2006,613)$ zufolge erfüllt die Windtechnologie schon deshalb die Bedingungen, weil es sich bei ihr um eine technische Neuerung gegenüber fossil-nuklearen Kraftwerken handelt (vertikale Dimension). Ebenso bedeutsam ist die Frage der veränderten Wertschöpfungskette. Anstatt Primärenergien auszubeuten, trägt Windenergie dazu bei, die Abhängigkeit von endlichen Rohstoffen wie Kohle, Öl, Gas und Uran zu mindern (Zugriff auf Primärenergieträger). Anders als bei den Primärenergien, bedarf es für die Windkraftnutzung keinerlei Infrastruktur, um den Rohstoff zum Kraftwerk zu transportieren (Transport). Die Stromproduktion in thermischen Kraftwerken basiert auf der Umwandlung von Wärme in Strom. Bei der Windenergie wird mechanische Energie unmittelbar in Strom verwandelt (Umwandlung in Strom). Der auf konventionelle Art hergestellte Strom wird zunächst über große Distanzen übertragen und anschließend in kleinere Verteilernetze gespeist. Windenergie wird (zumindest bis vor wenigen Jahren) dezentral hergestellt und muss daher nur über kurze Strecken transportiert (Stromübertragung und -verteilung) werden. Während die EVU als Eigentümer der Großkraftwerke den dort produzierten Strom selbst verkaufen, gründet der Vertrieb des Windstroms häufig auf der Basis neuer Vertragsstrukturen zwischen EVU und Windparkbetreibern, sofern es sich bei den letzteren tatsächlich um netzunabhängige Akteure handelt (Handel und Vertrieb).

Mautz (2006 u.a.) hat die Bedeutung erneuerbarer Energien im deutschen Elektrizitätssystem untersucht. Ebenso wie Markard/ Truffer beurteilt Mautz die Windenergie sowie die übrigen erneuerbaren Energien, insbesondere auch Photovoltaik und Strom aus Biomasse, als radikale Innovationen. Allerdings begründet Mautz den radikal innovativen Charakter erneuerbarer Energien gänzlich anders als Markard/ Truffer. Als Vergleichsmaßstab dienen drei grundlegende Paradigmen des konventionellen Stromsystems: Zentralistische Stromproduktion und -verteilung durch Großkraftwerke und entsprechende Netzstruktur (1), Stromproduktion durch wenige Akteure/ oligarchische Struktur des Sektors (2) und Wirtschaftlichkeit als wesentliches Auswahlkriterium der verwendeten Energierohstoffe (3). Mautz zufolge gelten erneuerbare Energien als radikale Innovationen, weil diese drei Grundsätze durch das Hinzutreten erneuerbarer Energien erschüttert werden. Erstens findet eine technische Dezentralisierung der Stromversorgung statt. Neben die Großkraftwerke sind zahlreiche kleine Windparks, Biogas- und Solaranlagen getreten. Zweitens kommt es zu einer deutlichen Erweiterung des Akteursfeldes auf dem Stromsektor. Denn die kleinen Kraftwerke werden nur in wenigen Fällen von Stromversorgern betrieben. In den meisten Fällen handelt es sich um Hausbesitzer, Landwirte und Kleinanleger. Drittens wird das Prinzip ,Wirtschaftlichkeit' infrage gestellt. Als wichtigste Legitimationsgrundlage und Leitnorm gilt die Orientierung an der Ökologie (vg. Mautz 2006, 29f.). Zur Beurteilung der Frage, ob von der Windenergie als radikaler Innovation gesprochen werden sollte, haben sich die Mautz'schen Kriterien als sehr hilfreich erwiesen. Daher werden sie im folgenden einen wichtigen Stellenwert einnehmen.

Im Unterschied zu Markard/ Truffer und Mautz begreifen Hirsh/ Serchuk (1999) Windenergie im Stromsystem nicht als radikale Innovation. Die Entwicklung großer Windanlagen und der Aufbau von Windparks durch EVU werden als konservative Innovationen angesehen, weil auf diese Weise das bestehende System geschützt und ausgeweitet würde. Nachdem in den 80er Jahren in Kalifornien große Windparks von Privatakteuren aufgebaut wurden, nutzten die EVU in den 90er Jahren die Möglichkeit der Installation eigener Windanlagen, um auf diese Weise die Kontrolle wieder zu erlangen. Zudem begreifen Hirsh/Serchuk die großen Windparks nicht als radikale Innovationen, weil sie sich gut in das System zentraler Stromproduktion einfügen. Ein kultureller Wandel, der infolge grundlegender Transformationen anzunehmen gewesen wäre, ist ausgeblieben. So hat die Existenz der 
Windparks auf Seiten der Konsumenten zu keinerlei Änderungen der Lebensweise geführt (vg. Heymann 1999, 114). ${ }^{410}$

Heymann hat sich gegenüber Hirsh/ Serchuk kritisch positioniert. Prinzipiell sieht Heymann $(1999,114)$ die Windtechnologie als inkompatibel mit dem Stromsystem an (dezentrale Energiequelle, Unregelmäßigkeit, Strom minderer Qualität). Er geht von einigen grundlegenden Veränderungen aus, zu deren Etablierung die Windenergie beigetragen hat. Diese Neuerungen sind gegen zentrale Eigenschaften des traditionellen Stromsystems gerichtet: starkes Wachstum, Zentralisierung und Marktkontrolle. Windenergie wird als wichtigste Triebkraft zu einer partiellen Veränderung des Systems betrachtet (ebd.). Heymann zufolge hat man nicht die Windanlagen an das Stromsystem angepasst. Vielmehr zwangen die in Dänemark, Kalifornien und der Bundesrepublik erlassenen Einspeisegesetze die Energieversorger dazu, ihre Netze so $\mathrm{zu}$ gestalten, dass größere Mengen Windstrom aufgenommen werden können (ebd., 130). Heymann räumt ein, dass der von ihm beschriebene Wandel bislang nur in einem begrenzten Umfang stattgefunden habe. Es bestehe die Tendenz zur Systemveränderung im Sinne einer Hybridisierung:

,Recent developments of electric power systems showed a tendency we might call ,hybridization'. Hybridization stands for an integration or combination of different, even contradictory structural elements into power supply, such as a combination of big and small, central and decentralized technologies, a combination of utility-owned and private-owned power plant capacities, and a combination of production-side oriented and demand-side oriented policies. While the real effect of hybridization hitherto remains limited, its tendency, nevertheless, is notable and likely to continue' (ebd., 131).

Heymann (ebd., 132) kritisiert Hughes Konzept der Entgegensetzung von radikaler und konservativer Innovation. Systemwandel setzte nicht notwendig das Auftreten radikaler Innovationen voraus, sondern könne sich auch allmählich, als Produkt vieler inkrementeller Schritte ergeben. ${ }^{411}$

Wendet man Dolatas Interpretation der Pfadabhängigkeitsthese auf die Bedeutung erneuerbarer Energien im Stromsystem an, so gelangt man zu der Vorhersage, dass die Präsenz erneuerbarer Energien, nicht kurzfristig zu einem Pfadwechsel führen kann. Diese Vorhersage wird durch die Ergebnisse von Mautz (2006 u.a.) über die Pfadstabilität des deutschen Stromsystems grundsätzlich bestätigt. ,Die Kontinuität des...Pfades im Elektrizitätssektor (bzw. in der Energiewirtschaft insgesamt) blieb trotz etlicher ,Störungen' seit den 1970er Jahren erhalten. Weder die Ölpreiskrisen sowie die dadurch ausgelösten wachstumskritischen Debatten der 70er Jahre noch die AntiAtomkraft-Bewegung und sonstige Umweltschutzdebatten führten zu tiefgreifenden Brüchen oder gar zu einer Abkehr von der zentralisierten Großproduktion auf der Basis fossil-atomarer Energieträger' (Mautz 2006, 29).

Neben diesem vorherrschenden Energiepfad führt der neue regenerative Energiepfad ein Nischendasein. In der Konkurrenz zu den etablierten Energietechnologien können erneuerbare Energien bis heute nicht bestehen. Anknüpfend an Markard/Truffer (2006) hebt Mautz (2006, 31) die Bedeutung des ,strategischen Nischenmanagements' seitens staatlicher Akteure hervor. Die politische Förderung erneuerbarer Energien stellt dabei eine notwendige, jedoch keine hinreichende Bedingung für die erfolgreiche Etablierung eines ,Nebenpfades' dar. Mautz (ebd.) verweist auf einen ,umfassenderen institutionellen Wandel', in den die politische Regulierung von Anfang an eingebettet gewesen war. $\mathrm{Zu}$ dessen Komponenten zählen der Wandel gesellschaftlicher Technikleitbilder, öffentliche Umweltdiskurse und die Institutionalisierung neuer sozialer Bewegungen.

\footnotetext{
410 Ähnlich wie Hirsh/ Serchuk haben sich auch Street/ Miles $(1996,424)$ zu der Rolle der Windkraft (und erneuerbarer Energie allgemein) positioniert: ,WP is a case study of the integration of renewables into the energy mix. Current developments indicate that in the foreseeable future, such a process is unlikely to change the system itself. Renewables are providing energy which contributes to the existing structure of electricity distribution, and users are still applying electricity in familiar ways. Thus a change in technical regime - if one is occuring - is more a process happening within power generation, than within the whole energy system.'

${ }^{411}$ Mit dieser Sichtweise befindet sich Heymann offenbar im Einklang mit Summerton (1994), Dolata (s.o.) und Mautz (2008 u.a.).
} 


\subsection{Internationale Windenergienutzung: \\ Auf dem Weg zu einer Empirie hybridisierter Stromsysteme?}

In welcher Beziehung stehen die Ergebnisse des internationalen Vergleichs über die Entwicklung der Windtechnologie zu unterschiedlichen Positionierungen innerhalb der Debatte um die Dynamik großer technischer Systeme ${ }^{\text {412 }}$ Beim Eintreten der Windkraft in das Stromnetz sind unterschiedliche Konstellation zu betrachten. Zum einen ist zu unterscheiden, ob Windanlagen und Windparks von Anfang möglichst groß geplant werden, oder ob eine dezentrale Nutzung angestrebt ist. Zum anderen macht es, nicht nur aus technischer Sicht, sondern auch aus der Perspektive innovationssoziologischer Analyse einen Unterschied, ob die Windanlagen von den Stromkonzernen oder Akteuren, von außerhalb' betrieben werden.

LSP-Windkraft - das Scheitern einer konservativen Innovation

Der erste Ansatz zur Etablierung der Windkraft ist das LSP. Windparks sollten die Kapazität üblicher Großkraftwerke erreichen und diese allmählich ersetzen. Die staatliche Förderpolitik war eine Reaktion auf Anstöße von außen (Ölkrise, Rohstoffknappheit, Anti-AKWBewegung, Umweltdiskussionen). Solche äußeren Impulse können oft die Ausgangspunkte radikaler Systemtransformationen sein (s.o.). Das LSP wollte gerade das Gegenteil dessen erreichen. LSP-Windkraft ist daher als konservative Innovation innerhalb der Stromsysteme zu interpretieren. Für sie gilt keines der Mautz'schen Kriterien. Durch den Erfolg des LSP hätte das geltende Regime auf eine sicherere Basis gestellt werden können. Die Akzeptanz der LSP-Windkraft durch die EVU bestätigt damit eine der wichtigsten Thesen Hughes: Großtechnische Systeme versuchen, kritische Probleme (reverse salients), in diesem Fall (Rohstoffknappheit, öffentliche Kritik, später zusätzlich: Diskussionen um klimaschädliche CO2-Emissionen) mittels konservativer Verbesserungen zu überwinden.

\section{EVU und dezentrale Windenergienutzung}

Aus dem Blickwinkel der EVU stellt sich die kleine Windkraft vollkommen anders dar. Deren Einsatz hätte unweigerlich zur Relativierung zweier Paradigmen des Stromsystems (Zentralismus, Orientierung an Wirtschaftlichkeit) geführt. An ihrer statt wären zwei der Mautz'schen Paradigmen getreten (Dezentralisierung, Orientierung an Ökologie ${ }^{413}$ ). Großtechnische Systeme bilden ein Momentum (Trägheitskraft) aus und setzen sich gegen radikale Innovationen konsequent zur Wehr, so Hughes. Insofern, als die EVU kein Interesse an der kleinen Windkraft zeigen, wird die These bestätigt. Die restriktive Haltung der EVU ist einer der Gründe, weshalb es der Gesetzgeber anfangs nur in wenigen Ländern ermöglichte, dass unabhängige Akteure Windanlagen betreiben durften und der produzierte Strom von den Netzbetreibern aufgenommen werden musste. Diese Form des Eintritts der Windenergie in das Elektrizitätssystem - ,von außen' - war für die Stromkonzerne nicht besser: Nicht nur mussten sie eine partielle Dezentralisierung hinnehmen - und den Windmüllern aus ihrer Sicht überhöhte Abnahmepreise zahlen. Nun wurden zusätzlich ihre Gebietsmonopole ausgehebelt (,Pluralisierung der Akteure'). Hughes These des System-Momentums und die Ergebnisse von Mautz über den deutschen Windenergiemarkt (Widerständigkeit der EVU

\footnotetext{
${ }^{412}$ Ein grundsätzliches Problem des Konzeptes großtechnischer Systeme besteht in der mangelnden Präzision des System-Begriffs. Gehören die Windmüller nicht seit dem Moment zum System, in welchem ihre Windanlagen an das Netz geschlossen werden? Gehören nicht politisch-staatliche Akteure zum System, weil sie darauf Einfluss nehmen können, welche Technologien verwendet werden (bspw. Atomausstiegsbeschluss, Erneuerbare Energien Gesetz)? Je nachdem wie der Systembegriff definiert wird, gelangt man ev. zu unterschiedlichen Schlussfolgerungen.

${ }^{413}$ Während man sich von den Großwindanlagen anfangs noch erhoffte, gegenüber den fossil-nuklearen Technologien Kostenvorteile zu erreichen, wurde diese Möglichkeit für die kleine Windkraft zu keiner Zeit erwogen. Aus Sicht der Stromkonzerne ließe sich das Paradigma 'Orientierung an Ökologie' vielleicht treffender übersetzen als 'Orientierung an öffentlicher Meinung/politischen Vorgaben'.
} 
gegen private Windanlagen) werden durch die Situation in den übrigen Pioniermärkten bestätigt. In den USA haben verschiedene Netzbetreiber gegen das PURPA geklagt. Einspeisevergütungen wurden oft unterhalb der festgelegten Höhe an die Produzenten ausgezahlt. Auch dänische EVU weigerten sich anfangs, die Windturbinen an ihre Netze zu schließen, geschweige denn Gegenleistungen für die abgenommene Energie zu erbringen. Man denke zudem an den erbitterten Widerstand des VDEW gegen das Stromeinspeisungsgesetz. Etwas anders ist der Fall in den Niederlanden gelagert. Abgesehen von einer Startphase, sind die EVU seit der zweiten Hälfte der 80er Jahre zum Hauptakteur des Sektors avanciert. Sie bemühten sich darum, ein ,abgemildertes LSP' frühzeitig wieder einzuführen, indem sie von den Herstellern forderten, immer größere WEA anzubieten. Als die neuen Anlagen nicht den Vorstellungen der EVU entsprachen, sich die Windenergie ein weiteres Mal nicht als konservative Innovation $\mathrm{zu}$ eignen schien, reduzierten sie ihr Windenergie-Engagement auf ein Minimum.

Transformationen des Elektrizitätssystems: Dänemark, Spanien und Deutschland

Auf den ersten Blick scheint die Windkraft-Empirie Hughes Modell vergleichsweise starrer und nach außen abgeschlossener großtechnischer Systeme zu bestätigen: LSP-Windkraft: ja, unter Umständen. Dezentrale Windkraft: nein - und schon gar nicht von außerhalb. Anhand der folgenden Beispiele ist zu zeigen, inwieweit keines der Stromsysteme, die Einführung der Windenergie überstanden hat, ohne das sich bestimmte Neuerungen eingestellt hätten. ${ }^{414}$

\section{Pfadentwicklungen im dänischen Stromsystem}

Infolge der Ölkrise haben sich im dänischen Stromsystem einige Veränderungen eingestellt. Drastisch gesunken ist der Ölanteil an der Stromproduktion. Lag dieser 1973 noch bei 64,1\%, so ist er 1979 bereits auf 36,8\% abgesunken. 1990 erreicht der Anteil mit vier Prozent seinen Tiefpunkt und pendelte sich in den nachfolgenden Jahren um zehn Prozent ein. (Hadjilambrinos 2000, 1122). 1973 wurde fast der gesamte Strom durch acht thermische Kraftwerke gewonnen. Noch 1980 lag der Anteil dezentraler Stromproduktion bei nur etwa einem Prozent. Infolge des Energiplan 81 entstand ein neuer Energiepfad im dänischen Elektrizitätssystem. Bezieht man auch größere KWK-Anlagen mit ein, so liegt der Anteil der KWK heute bei etwa 50\%. Windenergie trägt zu circa $20 \%$ zur Stromversorgung bei (www.sonnenseite.com, Abruf vom 23.2.09). Hadjilambrinos führt einige Gründe an, weshalb diese Transformationen gerade in Dänemark möglich waren. Zunächst verweist sie auf demokratische und kooperative Strukturen in der dänischen Stromwirtschaft. Alle Großkraftwerke befanden sich in gemeinschaftlichem Besitz (ebd., 118ff.). Gewinne sollten mit der Stromproduktion nicht angestrebt werden. Das gleiche gilt für die Windmüller: Den meisten von ihnen wird man so etwas wie ,Gewinnstreben' kaum attestieren können.

Die kooperative Tradition Dänemarks ist dem Ausbau der Kraft-Wärme-Kopplung ebenso dienlich wie der Windkraft. Bereits 1990 verfügten mehr als 100.000 dänische Haushalte (über fünf Prozent der Bevölkerung) über Windmühlenanteile. Zahlreiche kleine KWKAnlagen werden von landwirtschaftlichen Kooperativen betrieben und versorgen die anliegende Gemeinde mit Wärme. Seitens der Regierung wird eine weitere Dezentralisierung bspw. dadurch unterstützt, dass sie den Bau von Gas-Pipelines in Gebiete untersagt, wo KWK-Anlagen geplant sind (ebd., 1120ff.).

Man kann sagen: Im dänischen Stromsystem existieren drei Entwicklungspfade.

Der erste beruht auf der Stromproduktion durch fossil-nukleare Großkraftwerke. Infolge der Ölkrise hat die Bedeutung des Öls stark abgenommen. Die Atomkraft wurde bereits 1981 von der energiepolitischen Agenda genommen und 1985 entgültig als Option verworfen. Zudem

\footnotetext{
${ }^{414}$ In den folgenden Darstellungen wird neben der Windkraft auch die Bedeutung anderer Energietechnologien wie der Kraft-Wärme-Kopplung berücksichtigt, sofern sie eine Rolle für etwaige Pfadänderungen einnehmen.
} 
wurde der Neubau von Kohlekraftwerken seit den 90er Jahren durch ein Moratorium verhindert. Es lässt sich zusammenfassen, dass der großtechnische Pfad in Dänemark seit Jahrzehnten stagniert und seine wichtigsten Optionen verloren hat.

Der zweite Pfad beruht auf mittelgroßen Kraftwerken, die von unterschiedlichen Akteuren der Energiewirtschaft, den großen EVU, Regionalversorgern und Stadtwerken betrieben werden: Dabei handelt es sich insbesondere um KWK-Anlagen und Offshore-Windparks. Die Nutzung der Abwärme von Kraftwerken hat seit den 90er Jahren stark zugenommen. Obgleich der Ausbau großer EVU-Windparks nur relativ langsam vonstatten geht, ist dennoch mit weiterer Zunahme zu rechnen: Industrie- und klimapolitische Gründe sprechen dafür. Als weiterer Grund für die Kontinuität des ,mittleren' Strompfades kann die Konkurrenz unabhängiger Akteure angesehen werden. Letztere sind die Protagonisten des dezentralen (dritten) Energiepfades. Sie betreiben Blockheizkraftwerke und kleine Windparks und andere Kleinanlagen wie Photovoltaik und Biogas.

Pfadentwicklungen im spanischen Stromsystem

Zwischen der Windenergienutzung in Spanien, Dänemark und der Bundesrepublik bestehen grundlegende Unterschiede. Als in Spanien zu Beginn der 90er Jahre die ersten Windparks errichtet wurden, standen für viele Probleme, mit denen die Pioniermärkte konfrontiert waren, mittlerweile adäquate Lösungen zur Verfügung. ${ }^{415} \mathrm{Zum}$ anderen wurde die Windenergie in Dänemark und der Bundesrepublik von außen in das System eingeführt. In Spanien dagegen ist sie von innen heraus entwickelt worden (System Endesa). Endesa und spätere andere Großakteure haben sich stets für Windparks entschieden. Auf diese Weise ist die Windenergie neben der Wasserkraft und mittlerweile auch der Kraft-Wärme-Kopplung zu einer sehr wichtigen Komponente des Pfades mittelgroßer Kraftwerke geworden. Ein Pfad 3 konnte sich in Spanien nicht herausbilden, da zivilgesellschaftliche Akteure zu keiner Zeit beteiligt waren. Trotz wachsender Bedeutung neuer dezentraler Energieträger wird der größte Anteil des Energiebedarfs noch immer in thermischen Großkraftwerken gewonnen.

Pfadentwicklungen im deutschen Stromsystem

Das deutsche Stromsystem und die Kraftwerkspolitik der wichtigsten Energiekonzerne, Vattenfall, RWE, E.ON und ENBW zeichnet sich durch eine enorme Stabilität des großtechnischen Pfades aus. Trotz des Klimawandels, trotz der Gefahr, die geplante Minderung der CO2-Emissionen zu verfehlen und trotz vielfältiger Kritik aus Öffentlichkeit und Politik, planen diese Konzerne, bis zum Jahr 2015 insgesamt 17 neue Kohlekraftwerke in Betrieb zu nehmen. ${ }^{416}$

Der insbesondere mit der Windenergie, Kraft-Wärme-Kopplung und Wasserkraft verbundene Systempfad 2, der sich in Dänemark und Spanien, sowie anderen EU-Ländern in den vergangenen Jahren entwickelt hat, befindet sich hierzulande eher in der Anfangsphase, vor allem was die erneuerbaren Energien betrifft. Windenergie wurde in den vergangenen Jahren konsequent gemieden. Eine große Unsicherheit besteht darin, ob und wann die großen Offshore-Windparks, deren Realisierung von den EVU seit Jahren vollmundig angekündigt wird, tatsächlich gebaut werden. Auch die Bedeutung der Kraft-Wärme-Kopplung ist

\footnotetext{
415 Sowohl technisch und ökonomisch, als auch psychologisch war die traditionsreiche dänische Windanlagenindustrie der wichtigste Akteur auf der Produzentenseite (Kontinuitätsfrage). Ihre Regeneration infolge der Krise auf dem kalifornischen Markt ist daher für die internationale Kontinuität von kaum zu überschätzender Bedeutung. Zertifikationsverfahren sind entwickelt worden, so dass Pannen wie in Kalifornien (s.o.) mit hoher Wahrscheinlichkeit ausgeschlossen werden konnten (proven technology). Zudem wurden immer größere WEA hergestellt. Die 500kW-Anlage hatte Anfang der 90er Jahre den Prototyp-Status deutlich überschritten und war zu diesem Zeitpunkt von deutschen, niederländischen und dänischen EVU getestet worden (Verfügbarkeit mittelgroßer WEA).

${ }^{416}$ Darunter befinden sich nur zwei Anlagen, bei denen die CO2-Emissionen gespeichert werden sollen (Stand November 2009, nach einer Aufstellung des BUND).
} 
nachrangig, insbesondere wenn man ihren Anteil von zwölf Prozent an der Stromproduktion mit anderen EU-Ländern vergleicht. Dieser liegt in Finnland, Österreich, den Niederlanden und Dänemark zwischen 35 und $45 \%{ }^{417}$

Ähnlich wie in Dänemark hat die Windenergie auch hierzulande ihren Eingang in das Stromsystem über Pfad 3 gefunden. Raven/ Vleuten (2006) zufolge kommt der dezentralen Elektrizitätsproduktion Dänemarks im Jahr 2001 ein Anteil von 35\% zu (24\% dezentrale KWK, 11\% Windenergie). In Deutschland ist der dritte Pfad durch Windenergie dominiert. Angesichts eines Anteils von über fünf Prozent an der Produktion, beginnt diese Technologie ihrem Nischenstatus allmählich zu entwachsen. Ein etwas anderer Eindruck entsteht, wenn man berücksichtigt, wie sehr die Windenergie noch immer von legislativer Förderung abhängig ist. So hat der Wegfall des Mindestpreissystems in Dänemark zu einem vollständigen Niedergang des Marktes geführt.

Hinsichtlich der Ausbildung und Verstetigung solcher dezentraler Energiepfade, handelt es sich bei den beiden Pioniermärkten um internationale Sonderfälle. In allen übrigen Ländern, in denen die Windenergie später nennenswerte Marktanteile erlangt hat, dominieren heute große Windparks, seien diese von EVU oder Privatgesellschaften betrieben (bspw. USA, Spanien und Großbritannien).

Windenergie als Komponente des Stromsektors - eine radikale Innovation?

Im Sinne der Mautz'schen Kriterien stellt Pfad 3 insgesamt eine radikale Innovation des Elektrizitätssystems dar (Pluralisierung der Akteure, Dezentralisierung, Ökologie als Leitnorm). ${ }^{418}$ Der Ausbau mittelgroßer, ressourcen- und umweltschonender Pfad-2Kraftwerke geschieht aus dem System heraus und stellt eine logische Antwort auf die Probleme mit den Großkraftwerken dar. Von einem radikalen Paradigmenwechsel kann keine Rede sein, weil die Produktion in der Hand der Konzerne verbleibt. Eine Dezentralisierung findet nur teilweise statt. Auch das Paradigma der Wirtschaftlichkeit wird eher auf eine erweiterte Basis gestellt: In dicht besiedelten Gebieten ist KWK ohnehin seit Jahrzehnten eine wirtschaftliche Option. Der Aufbau der Windparks spart offensichtlich Kosten an anderer Stelle (CO2-Zertifikate, Imageverluste). Bei der Adaption der Windkraft gemäß Pfad 2 handelt es sich daher nicht um eine radikale Innovation, sondern um die Erweiterung eines neuen Energiepfades, der innerhalb des Systems zu dessen Stabilisierung etabliert wurde.

Markard/ Truffer haben Windenergie als radikale Innovation definiert, weil sie sowohl technologisch, als auch die Wertsschöpfungskette betreffend, starke Neuerungen aufweist. Zwischen Dänemark und der Bundesrepublik einerseits, sowie Spanien andererseits bestehen hier geringfügige Unterschiede, was die Neuerungen innerhalb der Wertschöpfungskette betrifft. Die Vertriebsstrukturen auf dem spanischen Strommarkt bleiben auch im Windenergiesektor weitestgehend erhalten (Funktion 5, s.o.). Die Schlussfolgerung, Windenergie stellte im spanischen System eine Innovation ähnlicher Radikalität dar, wie in den beiden erfolgreichen Pioniermärkten, erscheint nur bedingt einleuchtend. Mehr Klarheit verschafft offenbar die Anwendung des Mautz'schen Innovationskonzeptes. Danach ist die Windenergie in Spanien keine radikale Innovation. In der Anfangszeit ging die Windkraftnutzung nicht mit einer Pluralisierung der Akteure des spanischen Stromsektors einher, weil die meisten Windparks direkt oder indirekt von Endesa betrieben wurden. Äußere

\footnotetext{
${ }^{417} \mathrm{http}$ //www.gruenebundestag.de/cms/bundestagsreden/dok/237/237285.foerderung_der_kraftwaermekopplung. html

${ }^{418}$ Dieses dritte Kriterium als Motivation der einzelnen Betreiber nachzuweisen, setzte umfangreiche empirische Arbeit voraus, die hier nicht geleistet werden kann. Zumindest für die Pioniere der deutschen Bürgerwindbewegung ist eben dieses durch Byzio et al. (2002) geschehen. Zum Nachweis eines Paradigmenwechsels ist es letztendlich weniger entscheidend, ob die Anlagen von den Besitzern vor allem als Geldanlagen betrachtet werden. Dieses ist einzig deshalb möglich, weil die Regierung entsprechende Bedingungen geschaffen hat. Entscheidend ist vielmehr die Tatsache der Etablierung von Energietechnologien, die nicht in erster Linie dem Primat der Wirtschaftlichkeit unterliegen.
} 
Impulse erhielt der Staatskonzern durch bestehende Importabhängigkeit ebenso wie durch internationale klimapolitische Prozesse wie die im Kyoto-Protokoll festgelegte Reduktion der CO2 Emissionen. Zivilgesellschaftliche Kritik am fossil-nuklearen Energiepfad hat in Spanien keine so große Bedeutung wie in den Pioniermärkten. Von einem Paradigmenwechsel zur Ökologie kann daher nicht die Rede sein. Vielmehr galt es, Strafzahlungen aufgrund überhöhter Emissionen $\mathrm{zu}$ vermeiden und nach neuen Energietechnologien $\mathrm{zu}$ suchen, um sich frühzeitig gegen Verluste durch wachsende Rohstoffpreise abzusichern. Das Beispiel ,Windenergie im Stromsystem' zeigt die geographische Relativität einer Innovation. Die Anwendung derselben Technologie, in demselben technischen Kontext, ${ }^{419}$ kann in einem Land eine radikale Innovation bedeuten, im anderen nicht. In Dänemark ist diese Relativität noch stärker ausgeprägt. Je nach dem, ob es sich um Pfad-2- oder Pfad-3-Windanlagen handelt, ist der Innovationsstatus zweier baugleicher benachbarter Windanlagen unterschiedlich zu bewerten.

Pfadwechsel, Pfadentstehung und institutioneller Wandel

Wie in Dänemark hat sich innerhalb des spanischen Stromsystems ein zweiter Pfad, ,mittelgroßer Kraftwerke' etabliert. ${ }^{420}$ Ein radikal innovativer Pfad 3 hat sich ausschließlich in der Bundesrepublik und Dänemark herausgebildet. Pfad 2 kommt hierzulande nur eine geringe Bedeutung zu. EVU-Windanlagen sind bislang die Ausnahme (Tab. 4b). ${ }^{421}$

Tab. 4b Entwicklungspfade im dänischen, deutschen und spanischen Elektrizitätssystem

\begin{tabular}{|l|l|l|l|}
\hline & $\begin{array}{l}\text { System-Pfad 2 } \\
\text { (Großkraftwerke, zentrale } \\
\text { Versorgung, wenige } \\
\text { Akteure) }\end{array}$ & $\begin{array}{l}\text { System-Pfad } \\
\text { (mittelgroße Kraftwerke, } \\
\text { wenige Akteure) }\end{array}$ & $\begin{array}{l}\text { Kraftwerke, Pluralisierung } \\
\text { der Akteure) }\end{array}$ \\
\hline Dänemark & ja & ja & ja \\
\hline Deutschland & ja & schwach ausgeprägt & ja \\
\hline Spanien & ja & ja & nein \\
\hline
\end{tabular}

Quellen: vg. Kap. 2 und 3

Tab. 4c Windenergie: Anteil und Bedeutungszunahme für die Stromproduktion

\begin{tabular}{|l|l|l|l|}
\hline & $\begin{array}{l}\text { Einführung der } \\
\text { Windkraft (Jahr) }\end{array}$ & $\begin{array}{l}\text { Windenergie-Anteil an } \\
\text { der Stromproduktion } \\
\mathbf{2 0 0 8}(\mathbf{\%})\end{array}$ & $\begin{array}{l}\text { Jährlicher Zuwachs an } \\
\text { der Stromproduktion } \\
(\mathbf{\%})\end{array}$ \\
\hline Dänemark & $1979(30 \%$ Förderung) & ca. 20 & 0,7 \\
\hline Deutschland & $1988(100 \mathrm{MW}-$ Progr.) & 6,5 & 0,3 \\
\hline Spanien große & ca. 10 & 0,6 \\
\hline
\end{tabular}

Quellen: vg. Kap. 2 und 3

\footnotetext{
${ }^{419}$ Gemeint ist Windenergie zur Einspeisung in ein allgemeines Stromnetz, in Abgrenzung gegenüber Windenergie zur Strom- und Wärmeproduktion in kleinen Stromnetzen (Inseln etc.), etwa in Kombination mit Dieselgeneratoren oder auch Windenergie zur Selbstversorgung.

${ }^{420}$ Seit Mitte der 90er Jahre spielen zwar auch netzfremde Akteure (u.a. Baukonzerne) eine wichtige Rolle im spanischen Windenergiesektor. Ebenso wie Endesa und die Stromkonzerne Iberdrola und EHN, setzen auch diese praktisch ausschließlich auf große Windparks. Zwar geht mit der Präsenz unabhängiger WindenergieAkteure eine ,Pluralisierung der Akteure' des spanischen Stromsektors einher. Allerdings fügen sich diese, mit ihren großen Windparks, exakt in Pfad 2 ein.

${ }^{421}$ Trotz aller Kritik und anderer Einflüsse haben die deutschen Stromkonzerne es bislang nicht für nötig gehalten, - und dieses gilt für den deutschen Markt ganz besonders -, von ihrem großtechnischen Kurs um mehr als einen Millimeter abzuweichen.
} 
Aus Tab. 4c wird ersichtlich, dass der Anteil der Windenergie in Dänemark knapp dreimal so hoch ist wie in der Bundesrepublik. Zudem hatte diese weitergehende Restrukturierung, beim größten Teil handelt es sich um Pfad-3-Windenergie, insgesamt eine deutlich höhere Geschwindigkeit. Zwischen beiden Ländern nimmt Spanien eine mittlere Position ein. Dieses Ergebnis spricht möglicherweise für die Wichtigkeit der Ausbildung eines Mittelpfades für die Geschwindigkeit der Transformationen. Andere Einflussgrößen können zur Erklärung der relativen Langsamkeit des Energiewechsels in Deutschland ebenso zur Erklärung herangeführt werden: Standortmangel, bürokratische Strukturen, Barrieren auf regionaler Ebene (vg. etwa Hessen, Bayern), Einfluss der EVU auf das politisch-administrative System. Unabhängig davon, ob langsam oder schnell: Überall dort, wo große Windparks zur Komponente eines neu etablierten Energiepfades geworden sind, lassen sich die daraus resultierenden technischen, ökonomischen und rechtlichen Entwicklungen durch das Konzept ,technikinduzierten sektoralen Wandels' (Dolata, 2008) adäquat beschreiben. Als Komponente im zentralen Stromnetz zählt die Windkraft offenbar zu jenen neuen Technologien, die gegenüber dem traditionellen Stromsystem eine niedrige Adaptionsfähigkeit aufweisen. Wichtigste Triebkraft ist der sektorale Anpassungs- und Veränderungsdruck (öffentliche Kritik, Umwelt- und Klimaschäden, Rohstoffmangel). Bis zur tatsächlichen Etablierung des neuen Pfades hat es zwar nicht unbedingt ,jahrzehntewährender Readjustierungsprozesse' bedurft. Dennoch lässt sich die gesamte Entwicklung der Integration der Windkraft als vielschrittiger Prozess charakterisieren, der bis heute nicht abgeschlossen ist. Nichtsdestoweniger hat dieser - zumindest in Dänemark bereits heute $\mathrm{zu}$ grundlegenden Transformationen geführt hat. Ausgehend von den Erfahrungen der letzten Jahre scheint die Annahme nicht unplausibel, dass der großtechnische Systempfad in Dänemark weiter an Bedeutung verlieren wird. Ob mittelgroße Kraftwerke (also insbesondere auch KWK) in Spanien eine vergleichbare Relevanz erlangen werden, ist bislang offen. ${ }^{422}$

Andere Aspekte dieser Pfadentwicklungen und -entstehungen lassen sich mit Dolatas Konzept des sektoralen Wandels weniger gut interpretieren. Allgemein lässt sich über dieses Konzept sagen, dass die Möglichkeit abrupter Veränderungen als eher gering eingeschätzt werden. Man betrachte etwa Pfad-3-Windenergie: Wie anders sollte man den Schritt Riisagers und anderer, ihre Windanlagen an das Netz zu schließen, bezeichnen, denn als radikalen Bruch mit dem bestehenden System? Die Windenergiepioniere haben in Dänemark den Grundstein eines neuen Energiepfades gelegt, der in jeder Hinsicht einen Bruch mit dem Systempfad bedeutete. Bevor sich von der Existenz eines neuen Energiepfades überhaupt sprechen lässt, mussten zahlreiche Probleme, die rund um die Windenergienutzung existiert hatten, gelöst werden. Dazu erforderliche Regimes haben sich bspw. in Dänemark und der Bundesrepublik während der Pionierphase herausgebildet. Der Mangel an Erklärungsfähigkeit des "sektoralen Wandels", bezogen auf die Pfadentstehung dezentraler Windkraft besteht darin, dass der Fokus zu sehr auf Prozesse innerhalb eines Systems gerichtet wird. ,Exogene Schocks' werden dagegen kaum in Rechnung gestellt. Dolatas Konzept scheitert daran, die Pfadentstehung der System-Windenergie in Dänemark zu erklären: ,Sektoraler Wandel erfolgt nicht als späte und krisenbehaftete Reaktion auf einen exogenen Schock, sondern als aufgeschlossene Nutzung und Weiterentwicklung neuer technologischer Möglichkeiten, die begleitet wird von einer ebenso aufgeschlossenen Suche nach dazu passenden strukturellen und institutionellen Arrangements.' (Dolata 2008, 54).

Der Startpunkt der dänischen EVU-Windkraft ist das Jahr 1985 (100MW-Programm). Die Bereitschaft der EVU, eigene Windparks zu installieren, war mit Nichten einer

\footnotetext{
${ }^{422}$ Wasserkraft und KWK als weitere Pfad-2-Säulen tragen in Spanien jeweils gut zehn Prozent zur Stromversorgung bei. Ähnlich wie in den meisten europäischen Ländern sind die Wasserkraftpotenziale Spaniens weitgehend ausgeschöpft. Neben der Windkraft hängt die Entwicklung von Pfad 2, aus heutiger Sicht, wesentlich vom Ausbau der KWK ab. Aufgrund des geringeren Wärmebedarfs sind die Potenziale für KWK in südeuropäischen Ländern vergleichsweise niedrig. Der größte der Teil der in Spanien verwendeten Abwärme wird von der Industrie genutzt.
} 
,aufgeschlossenen Haltung' des DEF geschuldet. Tatsächlich ist das exakte Gegenteil der Fall. Nichts anderes als ein exogener Schock bedeuteten die Aktivitäten der Windmüller - und um nichts anderes, als um eine krisenhafte Reaktion handelte es sich bei den Windenergieplänen des DEF (vg. Kap. 2.3). ${ }^{423}$

Mit dem Begriff des ,sektoralen Wandels' hat Dolata die Analyse schrittweiser Innovationsprozesse vor Augen. Insofern verweist das Konzept stets auf ein ,schon da gewesenes'. Daher lassen sich Verstetigungsprozesse und Neuentwicklungen, innerhalb der alten und neuen Energiepfade gut erklären. Das gilt insbesondere auch für die institutionellen Anpassungsprozesse, die zur Etablierung der Windkraft erforderlich waren, sei es entlang des Pfades 2 oder 3. Für die Entstehung neuer Pfade scheint Dolatas Konzept nicht geeignet. Eine Ausnahme bildet der Entstehungsvorgang von Pfad 2 in Spanien. Dieser ist als Produkt jahrelanger Planungen Endesas und insbesondere auch ohne unmittelbaren Druck von außen entstanden. Demgegenüber weist der dänische Pfad 2 einen gänzlich anderen Entstehungskontext auf. Pfadneuerungen, die als Reaktion auf exogene Schocks entstanden sind, passen nicht in das Analysekonzepts Dolatas. Die Tatsache dezentraler Windenergienutzung durch systemunabhängige Akteure sowie die erzwungene Pfad-2Windenergie in Dänemark sind Beispiele für die von Beyer $(2005,13)$ behauptete Anfälligkeit der Pfadabhängigkeiten für grundlegenden Wandel.

Der Einschätzung von Markard/Truffer (2006), Windenergie führe zu einer Konkurrenz der unterschiedlichen Regime im Stromsystem, weil sie mit dem zentralen Energiepfad nicht sei kompatibel sei, kann nicht in allen Fällen zugestimmt werden. ${ }^{424}$ Es besteht die Möglichkeit, dass Markard/Truffer von der deutschen Situation extrapoliert haben, wo sich bislang keine Pfad-2-Windenergie etablieren konnte. Die Windparks der spanischen und dänischen Energiekonzerne stehen nicht unbedingt in Konkurrenz zu den Großkraftwerken. Vertreter der Stromwirtschaft sprechen gern von der Notwendigkeit eines ,Energiemixes', wenn sie einerseits ihrer Offenheit gegenüber regenerativen Energien Ausdruck verleihen möchten und zum anderen für die Akzeptanz fossil-nuklearer Kraftwerke werben wollen.

\section{Ergebnisse}

Heutige Stromversorgungsnetze als große Infrastruktursysteme

An den Beispielen Dänemark, der Bundesrepublik und Spanien ist gezeigt worden, dass sich die Stromversorgung nicht mehr ohne weiteres in die Konzeption Hughes' über große technische Systeme einfügen lässt. Nach dem recht statischen Modell ${ }^{425}$ ist als Alternative zu einer Pfaderhaltung mit geringfügigen Korrekturen nur ein Pfadwechsel denkbar, der immer vollständig erfolgen muss. Dieses würde heißen, sämtliche große Kraftwerke abzubauen und durch mittlere oder kleine Einheiten $\mathrm{zu}$ ersetzen sowie entsprechende erforderliche Umbaumaßnahmen am Netz vorzunehmen. Beim Aufeinandertreffen von Windenergie und

\footnotetext{
${ }^{423}$ Beyer $(2005,5 \mathrm{ff}$.) hat einen impliziten Konservativismus der Sozialwissenschaften beklagt, die sich zunehmend auf das Pfadabhängigkeitstheorem berufe. ,Die Gefahr ist gegeben, dass vieles als zu kohärent und in sich stabil wahrgenommen wird, weil grundlegende Veränderungen schon vorab nicht als Regel, sondern als reine Ausnahmefälle konzipiert werden, die von nicht erwartbaren schockartigen Verursachungen abhängen.' (Beyer 2005, 6). Die Theorie ,institutionellen Wandels' (North, 1990; Dolata 2008 u.a.) betrachtet Beyer (ebd., 9) als Verallgemeinerung des Pfadabhängigkeitskonzeptes (inkrementeller Wandel ist Normalfall der Entwicklung großer Systeme).

${ }^{424}$,Wind power...leads to a competition of regimes in the field of power generation and on the level of the sector because, like other distributed energy sources, wind power is largely incompatible with the dominant regime of centralize generation.' (Markard/ Truffer 2006)

${ }^{425}$ Bei seiner Konzeption hatte Hughes möglicherweise die, bis in die 60er Jahre hinein sehr starren Systeme zur Elektrizitätsversorgung vor Augen, in denen Strom zumeist ausschließlich durch Pfad-1-Kraftwerke produziert wurde.
} 
Stromsystem kann weder der Fall gänzlicher Pfadstabilität, noch ein Pfadwechsel beobachtet werden. Eher lässt sich von einer Zerfaserung, einer Hybridisierung, im Sinne einer geplanten und nicht geplanten Pfadneuentstehung sprechen. Dabei kann der Pfad 1 in eine Stagnation geraten (Dänemark), oder das Hinzutreten der Windenergie weitgehend unbeschadet überstehen (Deutschland). Würde man Hughes Modell als ein Ideal verstehen, an welchem die Empirie zu messen ist, so käme man zu folgenden Ergebnissen. Am ehesten entspricht diesem Ideal das spanische System (Kontinuität von Pfad 1, zentral gesteuerte Einführung von Pfad-2-Windenergie). Es folgen die Bundesrepublik (Kontinuität von Pfad 1, erzwungene Entstehung von Pfad 3) und schließlich Dänemark (Stagnation von Pfad 1, erzwungene Entstehung der Pfade 2 und 3).

Das Aufeinandertreffen von Windenergie und dem konventionellen Elektrizitätssystem hat in den verschiedenen Ländern nicht zur Ausbildung einheitlicher Muster geführt. Für eine techniksoziologische Interpretation jüngerer Dynamiken in Stromversorgungssystemen ist das Modell großer technischer Systeme offenbar nicht mehr geeignet. ${ }^{426}$

Radikale und inkrementelle Innovationen

Das Beispiel hat gezeigt, dass die häufig verwendete Unterscheidung inkrementeller und radikaler Innovationen sehr kontextspezifisch vorgenommen werden muss.

Die eher technisch orientierte Definition Markard/Truffers (s.o.) ist im Rahmen dieser Untersuchung an ihre Grenzen gestoßen, weil in ihr die sozial-ökonomischen Besonderheiten der jeweiligen Entwicklungen nicht berücksichtigt werden.

So gelten die einzelnen Windanlagen der Kooperativen und Bürgerwindgesellschaften als radikale Innovationen (Pfad 3), die Windparks der Stromkonzerne hingegen nicht (Pfad 2). Zudem kann, unter Verweis auf eine immer bessere Adaptionsfähigkeit der Windenergie (verbesserte Sicherheit, präzisere Vorhersagbarkeit des Windes, Energiespeichermöglichkeiten und Größenwachstum der Anlagen, (Mit-)Verantwortung der Windanlagenbetreiber für die Netzstabilität) davon gesprochen werden, dass sogar zwischen System und Pfad 3 Annäherungstendenzen existieren. Es besteht also, aufgrund technischer und institutioneller Entwicklungen, die Tendenz zu einer Verringerung der Radikalität der Windkraft als Innovation. Im Zuge einer Liberalisierung der Elektrizitätsmärkte und dem allgemeinen Wachstumstrend von Windparks liegt eine zunehmend Konvergenz von der Pfade 2 und $3 \mathrm{im}$ Bereich des möglichen. Um darüber zu befinden, ob und inwiefern eine Innovation als radikal bezeichnet werden kann, muss damit nicht nur ein bestimmter nationaler und pfadspezifischer Kontext berücksichtigt werden, sondern es sollte auch in Betracht gezogen werden, dass sich der Status auch innerhalb solcher Kontexte mit der Zeit ändern kann. Darüber hinaus spielt die quantitative Dimension eine Rolle. So lange die Stromeinspeisung ein Randphänomen darstellt, erscheint es kontraintuitiv, diesbezüglich von einer radikalen Innovation des Gesamtsystems zu sprechen. Radikal innovativ ist Pfad-3Windenergie eigentlich erst dort, wo sie beginnt, für die etablierten Technologien eine reale Konkurrenz darzustellen, was bisher erst selten der Fall gewesen ist. ${ }^{427}$

Pfadabhängigkeit vs. Pfadwechsel

Für keines der Elektrizitätssysteme lässt sich entweder eine vollkommene Pfadstabilität oder ein vollständiger Pfadwechsel diagnostizieren. Die Windkraftempirie ist ein Beispiel dafür, dass in der Praxis weder das eine, noch das andere Extrem häufig beobachtbar ist. Selbst bei denjenigen Entwicklungen, die von Geels als Systemtransformation bezeichnet werden (s.o.),

\footnotetext{
${ }^{426}$ Wollte man dennoch an dem Konzept festhalten, so müsste präzise formuliert werden, für welche Zeiträume angenommen wird, dass sich die fragliche Struktur als GTS verhält.

${ }^{427}$ Die Systemkonkurrenz manifestiert sich dort, wo die Betreiber großer Kraftwerke bei Starkwind und geringer Nachfrage ihre Energie zu negativen Preisen anbieten müssen, also Geld für den Verkauf des Strom zahlen. Sie manifestiert sich ebenfalls, wenn die Netzbetreiber Windanlagen bei Starkwind vom Netz nehmen, um Überlastungen zu vermeiden.
} 
erscheinen noch weitere Präzisierungen erforderlich. Sind mit der Einführung der Dampfschifffahrt oder des Wechselstroms Pfadwechsel einhergegangen? Ja - und zwar bzgl. der Technologie und des zugehörigen Infrastruktursystems. Wenn man allerdings danach fragt, ob die Segelschiffe anderen Unternehmen, Personen und Institutionen gehören als die Dampfschiffe und ob, beim Übergang von Gleich- zum Wechselstromsystemen, die Eigentümer gewechselt haben und diese Frage verneint wird, so gelangt man vielleicht zu der Auffassung, dass in ökonomischer Hinsicht kein Pfadwechsel stattgefunden habe. Das Konzept institutionellen Wandels, dass scheinbar einen Kompromiss anbietet, stellt keine befriedigende Lösung dar, weil es in seiner Tendenz zur Negation abrupter Veränderungen und Entwicklungen, über das Ziel hinausschießt.

Möglicherweise leidet die Theorie-Debatte darunter, dass sie zu sehr darauf gerichtet ist, komplexe Gegebenheiten in dichotome Kategorien zu fassen. Große technische Systeme werden von Hughes als vollintegrierte Strukturen konzipiert, deren Komponenten sehr eng aufeinander bezogen sind. Was ist mit Strukturen, die ebenso in großem Umfang Funktionszwecke erfüllen, zwischen deren Komponenten jedoch zahlreiche Freiheitsgrade bestehen? Wie sehr muss eine bestimmte Struktur integriert sein, um als großtechnisches System zu gelten? Wie aussagekräftig sind die Zuschreibungen ,radikale Innovation' und ,Pfadwechsel', wenn sie jeweils nur für eine Dimension gelten? Noch einmal zurück zur Windenergie im Elektrizitätssystem: In einigen Ländern hat die Windenergie zur Entstehung oder Stabilisierung neuer Entwicklungspfade wesentlich beigetragen. Dort, wo zuvor nur ein Pfad existierte, bestehen heute zwei oder drei Pfade nebeneinander, in mehr oder weniger friedlicher Koexistenz. Angesichts dieser Tatsache ,hybridisierter Stromsysteme' ist die Frage nach Pfadstabilität oder Pfadwechsel obsolet geworden. Wichtiger erscheint es zu fragen, wie viel Heterogenität unter dem einen System, das ursprünglich für den Betrieb thermischer Großkraftwerke geschaffen wurde, realisiert werden kann.

Es bleibt damit festzuhalten, dass keines der hier verwendeten Konzepte die Empirie angemessen $\mathrm{zu}$ interpretieren vermag. Als Bezugspunkte waren sie dennoch sehr hilfreich. Erst der Imperativ, sich stets für diese oder jene Alternative zu entscheiden, hat weitere Differenzierungen ermöglicht.

Für die Diskussion um Pfadwechsel oder -Stabilität gilt ähnliches wie bei der Unterscheidung zwischen radikaler und inkrementeller Innovation: Es sollte genau erwogen werden, in welcher Hinsicht sich fundamentale Transformation vollziehen und welche Aspekte hingegen unverändert bleiben. Die Feststellung, dass wir es heute mit Energieversorgungssystemen zu tun haben, in denen mehrere Pfade nebeneinander bestehen können, bedeutet nicht, dass die Bezugnahme auf ihre klassischen, hoch integrierten Vorgänger bedeutungslos wäre. Gerade die Feststellung dieser Transformation macht die heutige Versorgungsstruktur für techniksoziologische Fragestellungen interessant. Die meisten Übergänge lassen sich adäquat als mehrjährige Aufsummierung von Einzelereignissen begreifen. Besonders interessant sind allerdings jene Transformationen, in denen sich der Umschlag des quantitativen ins qualitative in einem Einzelereignis manifestiert. Man kann eine Entwicklung kritisch als sektoralen Wandel insofern konzeptionieren, als man danach fragt, ob nicht doch eine größere Abbruchkante existiert. 


\section{Ausblick}

Die Entwicklung der Windenergie zu einer proven technology ist nur im Kontext ihrer frühen internationalen Diffusion während der Pionierphase $\mathrm{zu}$ verstehen. Ausschließlich für Dänemark ist die Windenergienutzung, bereits vor der Export-Welle nach Kalifornien, im Verlauf der Stabilisierungsperiode (1979-1982), zu einem Erfolgsmodell geworden. Die Studie hat gezeigt, dass

a) die wichtigsten Innovationen zur Windenergienutzung in einem Land hervorgebracht wurden

b) dänische Technologie über mehrere Jahre praktisch ausschließlich in Dänemark verwendet wurde. Die geografische Diffusion verlief in den ersten Jahren schleppend und war in hohem Maße von historischen Zufällen abhängig

c) sich die Adaption der Technologie in den neuen Märkten auf sehr heterogene Art vollzogen hat.

Inwieweit lassen sich diese Ergebnisse auf andere neue Energietechniken wie Photovoltaik und Biogas übertragen? Ist es üblich, dass Entwicklungen so sehr auf ein Land bezogen sind wie im Fall der Windkraft? Gibt es i.a. nur einen Königsweg? Wie stark sind die hier analysierten Diffusionshemmnisse, verglichen mit anderen Energietechniken zu bewerten?

Unabhängig davon, ob das Pionierwissen von einem Ursprungsland ,ausstrahlt', oder wichtige Erkenntnisse in mehreren Ländern parallel gewonnen werden, bzw. neue Erfahrungen an das Ursprungsland zurückfließen: Für eine technikhistorische und soziologische Interpretation dieses Entwicklungsprozesses bietet sich die hier verwendete Methode ebenfalls an.

Mit einer wechselseitigen internationalen Beeinflussung der Märkte ist in jedem Fall zu rechnen. Erst dadurch, dass die Pioniermärkte in einem zeitlichen Nacheinander betrachtet werden, tritt die Möglichkeit in das Blickfeld, ein- und wechselseitige Lernprozesse als solche zu erkennen und einzuordnen.

Einen weiteren Anknüpfungspunkt bietet die Diskussion um Pfadabhängigkeiten innerhalb nationaler Energieversorgungssysteme. In Dänemark ist die Windkraft neben dezentraler Kraft-Wärme-Kopplung (häufig Erdgas) zur wichtigsten Komponente eines ökologischen Energiewechsels avanciert. Beide Technologien wirken gut zusammen. Anders als Kohleund Atomkraftwerke lassen sich mit Erdgas betriebene Anlagen leicht regulieren und eignen sich daher zur Kombination mit Windanlagen. In einem inflexiblen, vorwiegend auf thermischen Großkraftwerken basierenden Elektrizitätssystem wie dem deutschen, wäre eine Netzintegration von 20\% Strom aus Wind- und Solarenergie, zumindest aus heutiger Sicht, technisch ausgeschlossen. Es lässt sich zusammenfassen, dass die Umsetzbarkeit einer ökologischen Energiewende nicht allein von den genutzten Energieträgern abhängt, sondern auch davon, dass diese miteinander harmonieren.

Dänemark ist sowohl das Ursprungsland der Windenergie, als auch Pionier einer allgemeinen, gleichwohl nicht abgeschlossenen, ökologischen Energiewende. Unter welchen Bedingungen und nach welchen Mustern hat sich diese vollzogen? Welches sind die wichtigsten Bedingungen ihrer Umsetzung? Wie reagieren andere Länder auf alte und neue Herausforderungen des traditionellen Energiepfades? Inwieweit ist das ,dänische Modell' nachhaltiger Energieversorgung diffusionsfähig? 


\section{Literatur- und Quellenverzeichnis}

Arocena, Pablo; Kühn, Kai-Uwe; Regibeau, Pierre: Regulatory reform in the Spanish electricity industry: a missed opportunity for competition. In: Energy Policy 27 (1999), 387399

Arthur, W.B.: Competing Technologies: an Overview. In: Dosi et al. (Hrsg.): Technical Change and Economic Theory, S. 590-608. London

Baedeker, Harald: Leitbild und Netzwerk. Techniksoziologische Überlegungen zur Entwicklung des Stromverbundsystems. Dissertation, Nürnberg 2002

Baumgärtner, S.; Dyckhoff, H.; Faber, M.; Proops, J.L.R.; Schiller, J.: The Concept of Joint Production and ecological Economics Bd. 36, S. 365-372

Bechberger, Mischa; Meyer, Niels I.; Mez, Lutz; Sohre, Annika: Die Entwicklung der Windenergie in Dänemark, Spanien und Großbritannien im Vergleich. In: Zeitschrift für Energiewirtschaft. Jg. 31 H. 3. S. 201-208 (2007)

Beuse, Ejvin; Boldt, Joergen; Maegaard, Preben; Meyer, Niels I.; Windeleff, Jens; Oestergaard, Iben: Vedvarende energi i Danmark. En kroenike om 25 opvaekstar 1975-2000. Johnson Offset, Dänemark, 2000 (Übersetzung: Dänisch Kurs von Mette Mygind am Skandinavischen Seminar der Universität Göttingen, 2007)

Blättel-Mink, Birgit; Renn, Ortwin (Hrsg.): Ökologische Innovationssysteme im Vergleich. Nationale und regionale Fallstudien. Nomos Verlagsgesellschaft, Baden-Baden 2003

BMFT: Statusreport 1988 Windenergie. Vorgelegt von dem Projektträger Biologie, Energie, Ökologie, Forschungszentrum Jülich GmbH. Heide: Boyens, 1988

BMFT: Statusreport 1990 Windenergie. Vorgelegt von dem Projektträger Biologie, Energie, Ökologie, Forschungszentrum Jülich GmbH. Heide: Boyens, 1988

Böckem, Alexandra: Umsetzungsprobleme in der deutschen Klimapolitik: Eine empirische Überprüfung politisch-ökonomischer Erklärungsansätze. HWWA-Institut für Wirtschaftsforschung Hamburg, Hamburg, 1999

Bolinger, Mark: Community Wind Power Ownership Schemes in Europe and their Relevance to the United States. Ernest Orlando Lawrence/ Berkeley National Laboratory, Mai 2001

Borish, Steven M.: The Land of the Living: The Danish Folk High Schools and Denmark's Non-Violent Path to Modernization. Nevada City, Ca. Buue Dolphin, 1991.

Brand, Karl-Werner: Neue soziale Bewegungen: Entstehung, Funktion und Perspektive neuer Protestpotenziale; Eine Zwischenbilanz. Opladen, Westdt. Verlag 1982

Bruns, Elke; Köppel, Johann; Ohlhorst, Dörte; Schön, Susanne: Die Innovationsbiographie der Windenergie. Absichten und Auswirkungen von Steuerungsimpulsen. Lit Verlag Dr. W. Hopf Berlin 2008

Buckley, Brian: Canada's early nuclear policy: fate, chance, and character. Montreal (u.a.): McGill-Queen's University Press, 2000

Byer, Jürgen: Pfadabhängigkeit ist nicht gleich Pfadabhängigkeit! Wider den impliziten Konservativismus eines gängigen Konzepts. Zeitschrift für Soziologie, Jg. 34, Heft 1, Februar 2005, S. 5-21

Byzio, Andreas; Heine, Hartwig; Mautz, Rüdiger, unter Mitarbeit von Wolf Rosenbaum: Zwischen Solidarhandeln und Marktorientierung. Ökologische Innovationen in selbstorganisierten Projekten - autofreies Wohnen, Car-Sharing und Windenergienutzung. Soziologisches Forschungsinstitut, Göttingen, 2002

Byzio, Andreas; Mautz, Rüdiger; Schumann, Michael (Leitung); unter Mitarbeit von Wolf Rosenbaum: Konflikte um die Offshore-Windkraftnutzung: Eine neue Konstellation der gesellschaftlichen Auseinandersetzung um Ökologie. Abschlussbericht eines Projektes vom Soziologisches Forschungsinstitut, Göttingen, 2004. 
Byzio, Andreas; Mautz, Rüdiger; Rosenbaum, Wolf: Auf dem Weg zur Energiewende: Die Entwicklung der Stromproduktion aus erneuerbaren Energien in Deutschland. Universitätsverlag Göttingen: Göttingen 2008

Callon, Michael: Techno-economic networks and irreversibility. In: A sociology of monsters. London u.a., Routledge 1991, 132-161

Carlman, Inga: Blasingen. Svensk Vindkraft 1973-1990. Uppsala, Sweden, 1990.

David, P.A.: Clio and the economics of QWERTY; American economic Review Vol. 75, 332337

Dede, Ioanna: Ökologiebewegung in Griechenland und der Bundesrepublik Deutschland. Unter Berücksichtigung historischer, gesellschaftspolitischer und theoretischer Aspekte. Peter Lang: Frankfurt/M. (u.a.), 1993

Degele, Nina: Einführung in die Techniksoziologie. Fink: München, 2002

Dolata, Ulrich: Technologische Innovation und sektoraler Wandel. Eingriffstiefe, Adaptionsfähigkeit, Transformationsmuster: Ein analytischer Ansatz. Zeitschrift für Soziologie, Jg. 37, Februar 2008, S. 42-59

Dolata, Ulrich; Werle, Raymund (Hrsg.): Gesellschaft und die Macht der Technik. Sozioökonomischer und institutioneller Wandel durch Technisierung. Frankfurt a. M./ New York: Campus 2007

Dosi, Giovanni: Technological paradigms and technological trajectories: a suggested interpretation of the determinants and directions of technical change. In: Research Policy Bd. 11 (1982), 3, S.147-162

Dryzek, John S.; Downes, David u.a.: Green States and Social Movements. Environmentalism in the United States, United Kingdom, Germany and Norway. Oxford University Press, New Yord, 2003

Ek, Kristina: Public and private attitudes towards ,green' electricity: the case of Swedish wind power. In: Energy Policy 33 (2005), 1677-1689

Elliot, David: Renewables and the privatization of the UK Electricity supply industry. A case study. In: Energy Policy 1992, 3, S.257-268

Elliot, David: Energy, Society and Environment. Technology for a sustainable future. Routledge: New York, 1997

Est, Rinie van: Winds of Change. A comparative Study of the Politics of Wind Energy Innovation in California and Denmark. International Books, Utrecht, 1999

European Wind Energy Association/ Greenpeace: Wind Force 12. A Blueprint to achieve $12 \%$ of the World's Electricity from Wind Power by 2020. Brüssel/ Amsterdam, 2001/2002

Faulin, Javier; García, Justo; Lera, Fernando; Pintor, Jesús M.: The outlook for renewable energy in Navarre: An economic profile. In: Energy Policy 34 (2006) 2201-2216

Fleckenstein, Kurt (Hg.): Aktuelle Probleme der Windkraft in Deutschland. Raumordnung, Naturschutz, Genehmigungsverfahren, Förderung, Perspektiven. Energiewirtschaft und Technik Verlag: Essen, 1996

Foereningen af Danske Vindmoellefabrikanter/ FDV: Windkraft in den 90er - reine Energie. Herning/ Dänemark, 1992

Garud, Raghu (Hrsg.): Path dependence and creation. Mawah, NJ u.a.. Erlbaum 2001

Garud, Raghu; Karnoe, Peter: Bricolage versus Breakthrough: distributed and embedded agency in technology entrepreneurship. In: Research Policy 32 (2003), 277-300

Geels, Frank W.: Technological Transitions and System Innovations. A Co-Evolutionary and Socio-technical Analysis. Edward Elgar Publishing Limited, Cheltenham u.a. 2005

Gipe, Paul: Windenergy comes of age. John Wiley \& Sons, INC., New York u.a. 1995

Hantsch, Peter: Wege zum Wind. Das Zustandekommen der politischen Rahmenbedingungen für die Windenergienutzung in Dänemark, mit vergleichenden Perspektiven für Deutschland und Österreich. Diplomarbeit. St. Pölten/ Österreich, 1998 
Hadjilambrinos, Constantine: Development of renewable energy resources in Greece. Policy initiatives and systematic constraints. In: Energy Policy, Vol. 24, (6), 1996, S. 563-573

Hadjilambrinos, Constantine: Understanding technology choice in electricity industries: A comparative study of France and Denmark. In: Energy Policy, Vol. 28, (15), S. 1111-1126

Heymann, Matthias: Die Geschichte der Windenergienutzung 1890-1990. Campus Verlag, Frankfurt/ New York, 1995

Heymann, Matthias: Signs of Hubris: The Shaping of Wind Technology Styles in Germany, Denmark, and the United States, 1940-1990. In: Technology and Culture 39.4 (1998)

Heymann, Matthias: A Fight of Systems? Wind Power and Electric Systems in Denmark, Germany, and the USA. In: Centaurus - International Magazin of the History of Mathematics, Science, and Technology. Bd.41, 1999, S. 112-136. Munksgaard, Dänemark, 1999

Hills, Richard L.: Power from Wind. A History of Windmill Technology. Cambridge University Press: New York, 1994

Hirsh, Richard F./ Serchuk, Adam H.: Power Switch: Will the Restructured Electric Utility System Help the Environment? In: Environment, Vol. 41, Number 7 (9/1999): 4-9; 32-39

Hohensee, Jens: Der erste Ölpreisschock 1973/74: die politischen und gesellschaftlichen Auswirkungen der arabischen Erdölpolitik auf die Bundesrepublik Deutschland und Westeuropa. Stuttgart: Steiner, 1996

Hughes, Thomas P.: Networks of power: electrification in western society, 1880-1930. Baltimore Md. (u.a.): John Hopkins Univ. Pr., 1983

Hughes, Thomas P. (Hrsg.); Mayntz, Renate: The development of large technical systems. Frankfurt a. M., Campus 1988

International Energy Agency: Large Scale WECS. Annual Report 1988. OECD/ IEA, Paris 1989

International Energy Agency: Renewable Energy Policy in IEA Countries. Volume I: Overview. OECD/ IEA, Paris 1997

International Energy Agency: Renewable Energy Policy in IEA Countries. Volume II: Country Reports. OECD/ IEA, Paris 1998

International Energy Agency: Dealing with Climate Change. Policies and Measures in IEA Member Countries. 3 Bände von 2000-2002. OECD/ IEA, Paris 2000, 2001, 2002

International Energy Agency: Large Scale Wind Energy. OECD/ IEA, Paris 1989

Jägeler, Franz Jürgen: Die Rohstoffabhängigkeit der Bundesrepublik Deutschland. Verlag Weltarchiv: Hamburg, 1975

Jänicke, Martin; Jörgens, Helge (Hg.): Umweltplanung im internationalen Vergleich: Strategien der Nachhaltigkeit. Unter Mitarbeit von Kristina Hahn und Claudia Koll. Springer: Berlin (u.a.), 2000

Jasper, James M.: Nuclear Politics. Energy and the state in the US, Sweden, and France. Princeton University Press, Oxford 1990

Jensen, Hans Siggaard et al.: Til samfundets tarv - Forskningscenter Risoes historie

Jacobsson, Staffan; Lauber, Volkmar: The politics and policy of energy system transformation - explaining German diffusion of renewable energy technology. In: Energy Policy 34 (2006) 256-276

Jacobsson, Staffan; Johnson, Anna: The emergence of a growth industry: A comparative analysis of the German, Dutch and Swedish Wind Turbine Industries. Göteborg/ Schweden, 2006

Jännicke, Martin et al.: Umweltplanung im internationalen Vergleich. Dietz: Springer: Berlin, 2000

Joerges, Bernward: Große technische Systeme. Zum Problem technischer Größenordnung und Maßstäblichkeit. In: Technik und Gesellschaft, Jahrbuch 6, S. 41-73. Frankfurt/ a. M., Campus: 1992 
Kahn, Edward; Wiser, Ryan: Alternative Windpower Ownership Structures: Financing Terms and Project Costs. Berkeley, 1996

Kamp, Linda Manon: Learning in wind turbine development. A comparison between the Netherlands and Denmark. Utrecht, 2002

Kapitler af Vindkraftens Historie i Danmark. 2. Jahrgang (Dezember 2005), (Übersetzung: Dänisch Kurs von Mette Mygind am Skandinavischen Seminar der Universität Göttingen, 2007)

Karnoe, Peter: Dansk Vindmoelleindustri - en overraskende international succes. Samfunslitteratur, Frederiksberg

Keiser, Günther: Die Energiekrise und Strategien der Energiesicherung. Verlag Franz Vahlen, München 1979

Kempf, Udo; Michelmann, Hans J.; Schiller, Theo (Hg.): Politik und Politikstile im kanadischen Bundesstaat: gesundheits- und energiepolitische Entscheidungsprozesse im Provinzenvergleich. Leske + Budrich: Opladen 1991

Klein, Martina; Schubert, Klaus: Das Politiklexikon, 4. aktual. Auflage. Bonn: Dietz 2006

Kowol, Uli; Krohn, Wolfgang: Innovationsnetzwerke. Ein Modell der Technikgenese. In: Technik und Gesellschaft, Jahrbuch 8, S. 77-107. Frankfurt a. M., Campus: 1995

König, Felix von: Großkraft Wind: weltweit nachgewiesen. Verlag C. F. Müller GmbH Karlsruhe: Karlsruhe, 1988

Löfstedt, Ragnar: Dilemma of swedish energy policy. Ashgate Publishing Company. Aldershot/ Vermont, 1993

Lagaaij, J. A. C.; Verbong, G. P. J.: Different visions of power - the introduction of nuclear power in the Netherlands 1955-1970. In: Centaurus 1999 Vol. 41, 37-63

Leach, Michael D.; Manczyk, Henry: Combined Heat and Power Generation and District Heating in Denmark: History, Goals and Technology

Markard, Jochen; Truffer, Bernharf: Innovation processes in large technical systems: Market liberalization as driver for radical change? In: Research Policy Bd. 35 (2006), 5, S. 609-625

Maurer, Andrea/ Schmid, Michael: Ökonomischer und soziologischer Institutionalismus: interdisziplinäre Beiträge und Perspektiven der Institutionentheorie und Analyse. MetropolisVerlag: Marburg, 2003

Mautz, Rüdiger: Der Ausbau der regenerativen Energien - Chancen und Barrieren. In: SOFIMitteilungen Nr. 34 Dezember 2006, 29-41

Mautz, Rüdiger: The Expansion of Renewable Energies in Germany between Niche Dynamics and System Integration - Opportunities and Restraints; Erschien in: Science, Technology \& Innovation Studies Vol 3, No.2 December, 2007

Mautz, Rüdiger: Soziale Dynamik der Energiewende in der Stromversorgung: Weder Bruch noch Pfadabhängigkeit. Vortrag beim 34. Kongress der Deutschen Gesellschaft für Soziologie. Jena, 8. Oktober 2008

Meyer-Abich, Klaus Michael: Die Grenzen der Atomwirtschaft: die Zukunft von Energie, Wirtschaft und Gesellschaft. Beck: München, 1986

Mez, Lutz (Hg.): Umweltpolitik und Staatsversagen: Perspektiven und Grenzen der Umweltpolitikanalyse; Festschrift für Martin Jänicke zum 60. Geburtstag. Ed. Sigma: Berlin, 1997

Miebach, Bernd: Soziologische Handlungstheorie. Eine Einführung. VS Verlag für Sozialwissenschaften/ GWV Fachverlage GmbH, Wiesbaden 2006

Miles, Ian; Street, Penny: Transition to alternative energy supply technologies. In: Energy Policy Bd. 24 (1996), 5, S. 413-425

Mol, Arthur P.J.; Sonnenfeld, David A.: Ecologigical Modernization around the World. Frank Casi Publishers: London, 2000

Mortensen, H. C.; Overgaard, B.: CHP development in Denmark: Role and results. In: Energy Policy 1992 (12), S. 1198-1206 
Morthorst, Poul Erik: Wind Power development - status and perspectives. Risoe National Laboratory, Roskilde, Dänemark: September 1998

Mourelatou, Aphrodite: Renewable Energies: Success Stories. Copenhagen, 2001

Müller-Brandeck, Gisela: Technologiefolgenabschätzung am Beispiel der friedlichen Nutzung der Kernenergie in der Bundesrepublik Deutschland. Verlag Peter Lang GmbH: Frankfurt/ M. (u.a.), 1986

Müller-.Rommel, Ferdinand: Grüne Parteien in Westeuropa. Entwicklungsphasen und Erfolgsbedingungen. Westdeutscher Verlag GmbH: Opladen 1993

Meyer, Niels I.: Distributed generation and the problematic deregulation of energy markets in Europe. In: International Journal of Sustainable Energy. Vol. 23, No.4, Dezember 2003, $217-$ 221

Nelson, R. R.; Winter, S. G.: An evolutionary theory of economic change. Cambridge, London 1982

Neukirch, Mario: Energiewirtschaft und Windkraft: Eine Länder vergleichende Politikanalyse zur deutschen Offshore-Windenergie. In: Ökologisches Wirtschaften 2/2008, 43-46

Nielsen, Kristian H.: Interpreting Wind Power vs. the electric power system: a Danish casestudy. In: Centaurus 1999, Vol. 41, 161-177

Nielsen, Henry; Nielsen, Keld; Petersen, Flemming; Siggaard, Hans: Risoe and the attempts to introduce nuclear power into Denmark. In: Centaurus 1999: Vol. 41, 64-92

Oelker, Jan (Hg.): Windgesichter: Aufbruch der Windenergie in Deutschland. Sonnenbuch Verlag: Dresden, 2005

Parker, Mike J.: Thatcherism and the fall of coal. Oxford University Press: Oxford, 2000

Pulczynski, Jörn: Interorganisationales Innovationsmanagement. Eine kritische Analyse des Forschungsprojektes GROWIAN. Wissenschaftsverlag Vauk Kiel KG 1991

Radkau, Joachim: Aufstieg und Krise der deutschen Atomwirtschaft 1945-1975. Verdrängte Alternativen in der Kerntechnik und der Ursprung der nuklearen Kontroverse. rororo, Reinbek 1983

Rammert, Werner: Regeln der technikgenetischen Methode. Die soziale Konstruktion der Technik und ihre evolutionäre Dynamik. In: Technik und Gesellschaft, Jahrbuch 8, 13-29. Frankfurt/ a. M., Campus: 1995, 13-29

Raven, Rob; van der Vleuten, Eric: Lock-in and change: Distributed generation in Denmark in a long-term perspective. Energy Policy Bd. 34 (2006), 18, S. 3739-3748

Räuber, Armin: Erneuerbare Energien: Stand - Aussichten - Forschungsziele. Bonn: Bundesminister für Forschung und Technologie, 1992

Reiche, Danyel: Erneuerbare Energien in den Niederlanden. Pfadabhängigkeiten, Belief Systems und Restriktionen. Peter Lang GmbH. Europäischer Verlag der Wissenschaften, Frankfurt/ M. 2002 (zitiert als: Reiche 2002a)

Reiche, Danyel (Hrsg.): Handbook of renewable Energies in the European Union. Peter Lang GmbH. Europäischer Verlag der Wissenschaften: Frankfurt/ M. 2002. (zitiert als: Reiche 2002b)

Reiche, Danyel: Rahmenbedingungen für erneuerbare Energien in Deutschland. Möglichkeiten und Grenzen einer Vorreiterpolitik. Peter Lang GmbH. Europäischer Verlag der Wissenschaften, Frankfurt/ M. 2004

Reichel, Markus: Markteinführung von erneuerbaren Energien. Lock-Out-Effekte und innovationspolitische Konsequenzen für die elektrische Wind- und Solarenergienutzung. Deutscher Universitätsverlag: Wiesbaden, 1998

Righter, Robert W.: Wind Energy in America - a history. University of Oklahoma Press: Norman and London, 1996

Rothgang, Heinz: Die Friedens- und Umweltbewegung in Großbritannien: eine empirische Untersuchung im Hinblick auf das Konzept der ,Neuen sozialen Bewegungen'. Deutsche Universitätsverlag: Wiesbaden 1990 
Schneider, Volker: Die Transformation der Telekommunikation. Vom Staatsmonopol zum globalen Markt (1800-2000). Campus Verlag GmbH, Frankfurt/Main 2001

Smith, Adrian: Alternative technology niches and sustainable development. Thesen-Papier, vorgelegt: ASEAT Konferenz/ Manchester, 7.-9. April 2003

Soerentsen, Bent: Progress in Wind Energy Utilization. Roskilde University: Roskilde, 1995

Soerentsen, Bent: The status of wind generators in Europe. Roskilde, 1986

Strohschneider, Renate (Schriftleitung); Alfred Toepfer Akademie für Naturschutz (NNA):

Offshore-Windparks - Konzepte und Entwicklungen. Schneverdingen 2003

Suck, André: Erneuerbare Energien und Wettbewerb in der Elektrizitätswirtschaft. Staatlicher Regulieren im Vergleich zwischen Deutschland und Großbritannien. VS Verlag für Sozialwissenschaften/ GWV Fachverlage GmbH: Wiesbaden, 2008; (zitiert noch nach wurde nach einer älteren Version: Suck, André: Die Politik erneuerbarer Energien in Großbritannien und Deutschland - ein strukturalistischer Erklärungsversuch. MPP RdG Bonn (9. September 2002)

Summerton, Jane (Hrsg.): Changing large technical systems. Boulder u.a.: Westview Press, 1994

Tacke, Franz: Windenergie - Die Herausforderung: gestern, heute, morgen. VDMA Verlag GmbH: Frankfurt/M., 2004

Toke, David: Community ownership - The only way ahead for UK wind power? Birmingham, 1999

Toke, David: Wind Power in the UK: How Planning conditions and financial arrangements affect outcomes. In: International Journal of Sustainable Energy. Vol. 23, No. 4, Dezember 2003, 207-216

Traenes, Flemming: Danish Wind Energy. Dänemark, 1997

Unruh, Gregory C.: Understanding carbon lock-in. In: Energy Policy Bd. 28 (2000), 12, S. 817-830

Verbong, G.P.J.: Wind Power in the Netherlands, 1970-1990. In: Centaurus - International Magazine of the History of Mathematics, Science and Technology. Bd.41, 1999, S. 137-160. Munksgaard, Dänemark, 1999

Verstergaard, Jens et.al.: Industry: Industry Formation and State Intervention - The Case of Windmill Industry in Denmark and the United States. Aarhus, 2004

Vleuten, Erik v.d.: Constructing Centralized electricity supply in Denmark and the Netherlands: An actor group perspective. Centaurus 1999 Vol. 41, 3-36

Vogt, Helmut: Nutzung der Windenergie in den Ländern Dänemark, den Niederlanden und Schweden. Schleswig-Holstein, September 1983

Walker, Stuart: The attraction of opposites: Reconciling Fashion with sustainable Product Design Innovation. The Journal of the Industrial Designers Society of America, Sommer 2000

Weingart, Sabine: Politik der Ideen. VS Verlag für Sozialwissenschaften; GWV Fachverlage GmbH, Wiesbaden 2007

Wolsink, Maarten: Dutch wind power policy. Stagnating implementation of renewables. In: Energy Policy. Vol. 24, Nr. 12, 1079-1088, 1996

Weyer, Johannes: Technik, die Gesellschaft schafft. Soziale Netzwerke als Ort der Technikgenese. Berlin: Ed. Sigma, 1997

\section{Zeitschriften:}

American economic Review

Centaurus

Energy Policy

Erneuerbare Energie

Energiewirtschaftliche Tagesfragen 
Naturlig Energi

Neue Energie

Renewable Energy World

Research Policy

Sonne, Wind \& Wärme

Wind Directions

Windenergie

Windpower Monthly

Zeitschrift für Soziologie

\section{$\underline{\text { Interviews }}$}

Interview mit Helge Petersen vom 26.6. 2007 (per Telefon)

Interview mit Erik Grove-Nielsen vom 27.6.2007 (per Telefon)

Interview mit Helge Petersen (Brief vom 2.7. 2007)

Interview mit Preben Maegaard vom 2.7.2007 (Göttingen)

Interview mit Erik Grove-Nielsen vom 20./21.8. 2007 (per E-Mail)

Interview mit Joergen Krogsgaard vom 19.9. 2007 (Husum)

$\underline{\text { Film }}$

Vestergaard, Joergen: Wind Power - A danish Story (Dänemark 2003), Original mit englischen Untertiteln

$\underline{\text { Websites: }}$

www.auswea.com

www.butendiek.de

www.bwea.com

www.canwea.de

www.eere.energy.de

www.global2000.at/pages/tatomspanien.htm

www.global2000.at/pages/tatomgrossbritannien.htm

www.gses.it/pub/1939-PirazziSilvi.pdf

www.hans-josef-fell.de

www.infogaspesie.de

www.icanw.org/italy

www.iwea.com

www.iwr.de

www.kowi.wiso.uni-erlangen.de

www.offshore-wind.de/page/index.php?id=4761

www.sonnenseite.com

www.udo-leuschner.de/energie-chronik/021215.htm

www.umwelt-online.de/recht/energie/einspei.htm

www.wind-energy.de

www.wind-energie.de

www.windkraft.de

www.windsofchange. $\mathrm{dk}$

www.wind-tschechien.de/site/portal/default.aspx?pid=45

www.world-energy.org

www.wxs.html 


\section{Glossar}

100MW-Übereinkommen

100MW-Programm

92er Märkte

Asynchrongenerator

Aufwind-Orientierung

bottom-up

Brown, Edward G., Brown-Administration
100MW-aftalen. Dänischer EVU-Dachverband DEF verpflichtet sich zum Aufbau von Windparks mit 100MW Kapazität. Als Gegenleistung werden die Rahmenbedingungen für die Installation von Windanlagen durch gewinnorientierte Privatakteure verschlechtert (vg. Kap. 2.3.2.1)

\section{vg. Förderregelungen (Übersicht)}

Spanien, Großbritannien und Griechenland. Diese Länder werden als 92er Märkte bezeichnet, weil die Windenergie dort im Jahr 1992 erstmals einen international wahrnehmbaren Aufschwung erfahren hat (vg. Kap. 3).

durch das Stromnetz magnetisierter und vom Netz geführter Generator, der mit einem Schlupf zwischen Anker und Polen läuft (Heymann 1995, 471).

Luvläufer. WEA mit einem in Luv des Turmes (vor dem Turm laufenden Rotor, Eigenschaft des danish design. Gegenteil: Abwind Orientierung, Leeläufer. WEA mit einem in Lee des Turms (hinter dem Turm) laufenden Rotor (Heymann 1995, 472).

Ist die Rede von einem ,bottom-up'-Prozess, so geht es i.a. darum $\mathrm{zu}$ betonen, dass eine Entwicklung von zivilgesellschaftlichen Akteuren ausgelöst und gesteuert wird. Später wird Einfluss auf das Handeln von Großakteuren aus Politik und Wirtschaft gewonnen, welche diesen Prozess auf einer breiteren Ebene stützen (Beispiele: Umweltinitiativen, deren Anliegen sich in der Gesetzgebung widerspiegelt; kleine Pionierunternehmen, die ihre Patente an Konzerne verkaufen, welche damit erfolgreich sind).

Brown (Demokratische Partei) war zwischen 1975 und 1983 Gouverneur Kaliforniens. Wichtigster Akteur des politischadministrativen Systems bei der Förderung der Windenergie (Einführung zusätzlicher tax credits in Höhe von 25\%). Charakteristisch für die Brown-Administration ist ein innovativer Politikstil, eine grundsätzliche Aufgeschlossenheit gegenüber neuen Ideen, Konzepten und Technologien wie regenativen Energieträgern. Die Brown-Administration richtete die, für die Energieversorgung Kaliforniens zuständigen Institutionen, California Public Utilities Commission und California Energy Commission, neu aus. Dort galt zuvor das grow-and-build-Paradigma. Nun wurden die Kommissionen mit Fürsprechern regenerativer Energien neu besetzt. 1976 gründete 
die Administration das ,Office for Appropriate Technology' (vg. Kap. 2.3.1.1).

Bürgerwindbewegung

Bürgerwindgesellschaften

danish design

Dänisches Modell

(des Windenergie-Sektors)

Danske

Vindmoellerfoerening

Darrieus Windanlagen

Diffusionsphase
Die B. ist aus Teilen der deutschen Anti-AKW-Bewegung entstanden, die infolge des GAUs von Tschernobyl, nicht mehr nur gegen Atomenergienutzung demonstrieren, sondern aktiv, die Möglichkeit einer alternativen Energieversorgung, aufzeigen wollte (vg. Kap. 2.4.3.3).

Bei einer B. handelt es sich um die wirtschaftliche und soziale Organisationsform zum gemeinschaftlichen Betrieb von Windanlagen, häufig GmbH. \& Co. KGs (vg. Kap. 2.4.3.3).

Dänisches Windanlagenkonzept, das in den 50er Jahren erstmals von Johannes Juul mit der Konstruktion der Gedser-Mühle realisiert wurde. Anfang der 80er Jahre hat sich das d.d. zuerst auf dem dänischen Markt bewährt. WEA werden bis heute auf dieser Grundlage produziert. $\mathrm{Zu}$ den wichtigsten Eigenschaften zählen: horizontale Achse, Rotor mit drei Flügeln, Aufwindorientierung, Asynchrongenerator, Stall-Regulierung, robuste Bauweise.

Während der Pionierphase ist ausschließlich das dänische Modell zur Etablierung der Windtechnologie erfolgreich. Charakteristika sind: Verwendung des danish design, Windanlagenbetrieb durch lokale Kooperativen, mittelständische Windanlagenindustrie, garantierte Mindesteinspeisepreise als zentrale Komponente des Fördersystems. Dieses Modell ist $\mathrm{zu}$ weiten Teilen vom deutschen Pioniermarkt übernommen worden.

Interessenorganisation dänischer Windmüller, gegründet 1978. In der Technikperiode bestand ihre Hauptaufgabe darin, gegenüber den Windanlagenherstellern durchzusetzen, dass bestimmte Sicherheitsstandards eingehalten werden. Spätere Kernaufgabe ist die Interessenwahrung gegenüber Politik und Energiewirtschaft (vg. Kap. 2.1 und 2.2).

Windanlagenkonzepte mit vertikaler Achse, benannt nach dem Franzosen George Darrieus: H-Rotor (Heidelberg-Rotor), Eggbeater (,Schneebesen'). Beide haben sich nicht bewährt.

Bei der Diffusionsphase handelt es sich um den Zeit- und Entwicklungsabschnitt, der an die 1991 endende Pionierphase anschließt. Der neue Abschnitt manifestiert sich am klarsten durch die Entstehung zahlreicher neuer Märkte. Erfahrungen werden aus den Pioniermärkten übernommen. Im Unterschied zu den Pioniermärkten, dominieren jetzt energiewirtschaftliche Akteure das Feld (vg. Kap. 3) 
Downscaling

Entwicklungspfade im Stromsystem

Energieoutput

(einer WEA)

Energia Hidroelélectrica de Navarra (EHN)

Erprobungsperiode

Energiplan 81

Energy Tax Act
Tendenz der LSP-Akteure, Prototyp-Windanlagen vorsichtiger zu dimensionieren. D. ist Ausdruck des seit Mitte der 90er Jahre in Erosion geratenden Large-Scale-Paradigma, LSP (Gegenteil: Upscaling).

In der Studie werden drei E. unterschieden.

Pfad 1: zentralisierte Elektrizitätsversorgung, basierend auf fossil-nuklearen Großkraftwerken. Wichtigste Akteure sind große Energiekonzerne, die teilweise über Gebietsmonopole verfügen.

Pfad 2: mittelgroße Kraftwerke (häufig Kraft-Wärme-Kopplung, große Windparks und Wasserkraftwerke), entsprechend weniger zentrale Versorgungsstruktur. Pfad 2 ist gegenüber Pfad 1 eine inkrementelle Innovation des Stromsystems. Am stärksten ausgeprägt ist Pfad 2 in Dänemark, in den meisten übrigen Industrieländern geht ein entsprechender Umbau nur langsam vonstatten.

Pfad 3: dezentrale Kleinkraftwerke: Windanlagen, Solardächer, Biogasanlagen, kleine Wasserwerke. Pfad-3-Kraftwerke sind mit den wirtschaftlichen Interessen der EVU i.a. nicht vereinbar, deshalb werden sie fast ausschließlich von zivilgesellschaftlichen Akteuren betrieben. Zudem besteht zwischen Pfad 3 und Pfad 1 eine deutlich geringere Kompatibilität als zwischen Pfad 1 und Pfad 2. Pfad-3Windanlagen etc. stellen daher (potenziell) eine radikale Innovation des Stromsystems dar (vg. Kap. 4)

Energie, die von einer WEA in einem bestimmten Zeitraum produziert wird.

Regionalversorger von Navarra. Für die Diffusion der Windtechnik in Spanien kommt EHN eine entscheidende Rolle zu (vg. Kap. 3.3.2).

siehe Pionierphase

Dänischer Energieplan, verabschiedet 1981. Erstmals wird erwogen, Atomenergie als künftige Energieoption aufzugeben. Die kontinuierliche Förderung kleiner WEA wird beschlossen, das Large-Scale-Paradigma verliert an Bedeutung (vg. Kap. 1; 2.2.1). Mit der verstärkten Förderung der Kraft-WärmeKopplung stellt der Energiplan 81 den Auftakt zur Schaffung eines neuen Entwicklungspfades mittelgroßer Kraftwerke im Stromsystem dar (vg. Kap. 4).

vg. Förderregelungen (Übersicht) 
Entrepreneur

EU-Förderung

Folkecenter

für erneuerbare Energie

Förderregelungen

(Übersicht)
Entrepreneurs sind Pionierunternehmen, die ein neues innovatives Geschäftsfeld betreten (bspw. Independent Power Producers auf dem Windsektor Kaliforniens)

Die EU hat die Windtechnologie durch unterschiedliche Programme gefördert. Sie hielt vergleichsweise lange am LargeScale-Paradigma fest. Erst 1990 auf der EU-WindenergieKonferenz von Madrid geriet die Förderung von Großwindanlagen in die Kritik (vg. Gipe 1995, 96ff.). Im Rahmen von EU-Demonstrationsprogrammen für regenerative Energien wie Hors Quota, Valoren und Thermie sind zunehmend auch mittelgroße WEA gefördert worden (vg. WPM 12/90, 13; WPM 11/91, 11f.; WPM 9/92, 26; WPM 10/92, 25ff.)

Gegründet wurde das ,Nordisk Folkecenter for Vedvarende Energi' im Jahr 1983 durch Pioniere der Organisation für erneuerbare Energie. Im Folkecenter werden Konzepte für die Nutzung dezentraler erneuerbarer Energietechnologien erprobt. Das Folkecenter hat versucht, die Kommerzialisierung des Windenergiesektors $\mathrm{zu}$ verhindern und stattdessen einen kooperativen Entwicklungspfad, wie er zu Zeiten der Technikperiode vorherrschte, aufrechtzuerhalten. Ende der 80er Jahre wurden die Arbeiten im Windenergiesektor aufgegeben, weil man nicht bereit war, ein vollständig kommerzialisiertes Feld zu unterstützen (vg. Kap. 2.2-2.4).

Dänemark

Seit 1979: Investitionsförderung von 30\%, die schrittweise reduziert und 1989 abgeschafft wurde. Seit 1984: Garantierte Mindesteinspeisetarife und Anschlusspflicht der WEA (ähnlich dem SEG). Gesetzliche Festschreibung: Windenergiegesetz von 1992 (vg. Kap. 2.2-2.4).

Deutschland

Seit 1988/89 wurde der Erwerb von WEA erstmals auf Bundesebene gefördert (100MW-Programm). Windanlagenbetreiber erhielten einen Zuschlag auf jede, in das Stromnetz gespeiste Kilowattstunde. Landwirte konnten sich alternativ für einen Investitionszuschuss von 50\% entscheiden. Mit dem Stromeinspeisungsgesetz von 1990 entschied sich die Bundesregierung für eine, dem dänischen Fördersystem ähnliche Regelung (Anschlusspflicht und garantierte Vergütung zu festen Tarifen, vg. Kap. 2.4.3.1).

Kalifornien

Durch den Public Utilities Regulatory Policies Act, ein Teil des National Energy Acts, sind US-amerikanische Netzbetreiber seit 1978 verpflichtet, kleine Regenerativkraftwerke und KWKAnlagen bis 30MW Kapazität an ihr Netz zu schließen und eingespeiste Energie zum Preis vermiedener Kosten zu vergüten. Zusätzlich gelten tax credits (Steuerabschreibungen). Von der 
ursprünglichen Investition dürfen pro Jahr 25\% steuerlich abgeschrieben werden. $\mathrm{Zu}$ diesem föderalen Steuerbonus addierten sich bundesstaatliche tax credits, die in Kalifornien seit 1980 ebenfalls $25 \%$ betrugen. 1985/86 wurden die tax credits abgeschafft (vg. Kap. 2.3.1).

Niederlande

Mit Einführung des ,Integraal Programma Windenergie' im Jahr 1986, wurde für den Kauf einer zertifizierten WEA, ein Investitionszuschuss von 40-50\% gewährt. Zusätzlich durften $40 \%$ der selbst getragenen Kosten steuerlich abgesetzt werden. Wesentliche Anteile der für Windenergie zur Verfügung gestellten Mittel reservierte die Regierung für EVU-Windparks (vg. Kap. 2.4).

\section{Spanien}

Vor 1994 existierte nur eine (sehr unverbindliche) Mindesteinspeiseregelung. Eine Anschlussverpflichtung der zuständigen Netzbetreiber galt nicht. Zudem konnte die Vergütungshöhe jährlich neu festgelegt werden. 1994, bzw. 1998 sind in Spanien ähnliche Regelungen wie in Dänemark und Deutschland eingeführt worden. Erst jetzt betreten nichtstaatliche Akteure den Sektor. Seitdem ermöglicht das Gesetz vergleichbare Erfolge nicht-staatlicher Akteure, wie zuvor bereits in den Windsektoren Dänemarks und Deutschlands (vg. Kap. 3.3).

\section{Großbritannien}

In Großbritannien wird 1989 die ,Non-fossil-fuel-Obligation' beschlossen. Diese basiert auf dem Auktionsprinzip. Potenzielle Betreiber von Regenerativkraftwerken bewerben sich um Anteile der ausgeschriebenen Kapazitäten. Dabei bieten sie die Energie zu bestimmten Preisen an, die allerdings ein Maximum nicht überschreiten dürfen. Zugelassen werden im allgemeinen diejenigen Projekte mit den niedrigsten Preisvorschlägen. Diese Kraftwerke müssen von den jeweils zuständigen Versorgern ans Netz geschlossen werden. Letztere sind ferner verpflichtet, die eingespeiste Energie zu den entsprechenden Tarifen zu vergüten (vg. Kap. 3.2).

Griechenland

Ein Mindesteinspeisemodell existierte in Griechenland nur formal. Das Energieministerium forderte vom staatlichen Netzbetreiber PPC, Einspeisetarife festzulegen, was dieser über Jahre verweigerte. Erst Mitte der 90er Jahre wurden Reglungen getroffen, durch welche die Situation für Privatakteure auf dem Windmarkt jedoch nur graduell verbessert wurde. Der PPC, der kein Interesse daran hatte, Marktanteile an die Windmüller zu verlieren, hatte an der Entscheidung, ob ein Projekt genehmigt würde, großen Anteil (vg. Kap. 3.1). 
Freiwillige Übereinkunft

Gedser-Mühle

Große technische Systeme

Großwindanlage

Growian
1984 hob der dänische Verband der EVU (DEF) die wichtigsten Investitionsschranken auf: Abstandskriterium und Eigenbedarfsgrenze. Von nun an durfte jeder, unabhängig von seinem Wohnort, so viele Windanlagen kaufen wie er wollte. Die Folge war der Aufbau von Investor-Windparks. Zahlreiche Akteure waren mit der neuen Entwicklung unzufrieden. Die Regierung wollte ein gemäßigtes Wachstum des Sektors, am liebsten unter Kontrolle der EVU. Letztere beklagten den Verlust von Marktanteilen. Kommunen verloren Einnahmen, weil Gewerbesteuereinnahmen nicht in der Region verblieben sind. Anrainer waren unzufrieden, da Beteiligungsmöglichkeiten stark eingeschränkt waren und eigene potenzielle Windanlagenpläne verunmöglicht wurden. Im Zuge des 100MW-Übereinkommens zwischen DEF und Regierung wurden Ende 1985 Regelungen geschaffen, die $\mathrm{zu}$ einem Ausschluss der Investoren vom Markt führten (vg. Kap. 2.3).

Nahe dem im Süden Lollands gelegenen Gedser wurde 1957 die damals größte Windanlage $(200 \mathrm{~kW})$ in Betrieb genommen. Konstrukteur der Maschine ist Johannes Juul. In der GedserMühle kam das dänische Anlagenkonzept erstmals zur Anwendung. Die robuste Turbine lief sehr zuverlässig. Über elf Jahre hinweg traten keine größeren Schäden auf. Die Konstruktionszeichnung war frei zugänglich ( $\mathrm{La}$ Cour Tradition). 1975 gelang es Christian Riisager erstmals, nach dem Vorbild der Gedser-Mühle, eine kleinere zuverlässig arbeitende Windanlage herzustellen. Später wurden die NibeZwillinge nach demselben Konzept konstruiert - und letztendlich alle heutigen Windanlagen (vg. Kap. 2.1).

auch: großtechnische Systeme. Große, räumlich ausgedehnte Infrastruktursysteme, die über lange Zeit fortbestehen und einem bestimmten Funktionszweck dienen. Große technische Systeme bestehen aus mehreren Komponenten, die wechselseitig aufeinander bezogen sind. Sie zeichnen sich durch eine hohe Resistenz gegen fundamentale Veränderungen aus (Beispiele: Netze für Schienen- und Straßenverkehr, Elektrizität und Telekommunikation, vg. Kap. 4).

Gemeint sind Windanlagen mit einer Generatorenkapazität von mindestens einem Megawatt. Der Terminus wird zumeist verwendet, wenn es um LSP-Projekte geht. Großwindanlagen sind vor allem relativ groß, verglichen mit der von kommerziellen Herstellern während der Pionierphase angebotenen Technologie. Heute sind praktisch alle WEA ,Großwindanlagen' und man müsste den Begriff neu definieren.

Großwindanlage. Größte Prototyp-Windanlage (3MWGenerator) des deutschen LSP-Programms und zugleich das kostenintensivste LSP-Projekt (ca. 90 Mio. DM). Growian war offenbar von Teilen der zentralen Administration und der 
Grove-Nielsen, Erik

Grow-and-build-Strategie

Grundvig, Nikolas F. S.

Hütter, Ulrich

Hybridisierung (eines Elektrizitätsversorgungssystems)

inkrementelle Innovation

institutioneller Wandel

Integraal Programma

Windenergie

Juul, Johannes
Energiewirtschaft geplant, um die Windenergie in Misskredit zu bringen. Die Versuchswindanlage erreichte eine Verfügbarkeit von einem Prozent, bei Stillstandzeiten von 99\% (vg. Kap. 1).

Erster unabhängiger Rotorenfabrikant Dänemarks, gründete 1977 das Unternehmen Oekaer Vind Energi. Grove-Nielsen kommerzialisierte den Rotor der Modellwindanlage der TvindMühle, Praktisk Teoretisk Grundkursus (vg. Kap. 2.1).

Tendenz (hier) der kalifornischen Kraftwerksbetreiber, immer neue und größere fossil-nukleare Kraftwerke zu installieren. Aufgrund niedriger Energiepreise war es den EVU möglich, ihre Gewinnspannen zu erhöhen und gleichzeitig Preisstabilität zu garantieren, oder die Preise sogar leicht zu senken (vg. Kap. 2.3).

Vordenker der kooperativen Bewegung Dänemarks (vg. Kap. 2.2.3)

Pionier der Windanlagenkonstruktion, tätig am DLR in Stuttgart. Hütter war maßgeblich an der Gestaltung des Growian-Projekt beteiligt (vg. Kap. 1).

Die Hybridisierung eines Stromsystems ist gegeben, wenn nicht länger nur ein einziger Entwicklungspfad - i.a. der zentralistische Pfad 1 - vorherrscht, sondern zwei, oder gar drei Pfade in Konkurrenz stehen, bzw. koexistieren.

Schrittweise Innovation, Gegenteil von radikaler Innovation. Bei einer i. I. handelt es sich um eine Verbesserung innerhalb geltender Systeme (bspw. Carbon Capture and Storage, Downscaling von Großwindanlagen, schrittweise Vergrößerung der WEA seit Einführung der Komponentenmühle von 1977/78 (vg. Kap. 4).

Schrittweiser Wandel innerhalb eines Systems. Modifikation der Pfadabhängigkeitsthese. Konzept großer technischer Systeme wird teilweise zurückgewiesen, weil deren Starrheit zu hoch eingeschätzt werde. Vielmehr können Jahrzehnte währende Anpassungsprozesse an veränderte Bedingungen, in ihrer Summe durchaus $\mathrm{zu}$ grundlegenden Veränderungen eines Systems führen (vg. Kap. 4).

vg. Förderregelungen (Übersicht)

Konstrukteur der 1957 in Betrieb gegangenen Gedser-Mühle. Hier wurde erstmals das dänische Konzept (danish Design) erprobt. Die Gedser-Mühle dient letztendlich als Vorbild 
Kapazitätsfaktor

Komponentenmühle

Kraft-Wärme-Kopplung (KWK)

La Cour, Paul; La Cour Tradition

Lagerwey sämtlicher moderner Windanlagen. Johannes Juul (1887-1969) war einer der ersten Schüler des Windenergiepioniers Paul La Cour (La Cour Tradition).

Der Kapazitätsfaktor ist ein Maß für die Effizienz und Zuverlässigkeit einer Windturbine. Läuft die Anlage, bspw. über ein Jahr gerechnet, durchschnittlich mit 30\% der Nennleistung, so beträgt der Kapazitätsfaktor 30\%.

Vor dem Hintergrund, dass die meisten Selbstbauer von Windmühlen mit der Herstellung sämtlicher Komponenten überfordert waren, wurde auf einem Windtreffen im Jahr 1975 der Plan gefasst, standardisierte Komponenten $\mathrm{zu}$ verwenden. Bei der ersten, 1976 fertiggestellten Komponentenmühle handelt es sich um ,Praktisk Teoretisk Grundkursus', eine kleine Version der Tvind-Mühle. Auf diese Entwicklungen geht die Entstehung einer großen und international erfolgreichen Zulieferindustrie für Windanlagenteile zurück. Bei den Hauptkomponenten handelt es sich um: Rotor, Getriebe, Bremssysteme, elektrische Kontrolle und Turm (vg. Kap. 2.1).

Effiziente Kraftwerke, bei denen die Abwärme zur lokalen Versorgung mit Heizwärme genutzt wird. Während herkömmliche Großkraftwerke einen Wirkungsgrad von maximal $40 \%$ erreichen, nutzten KWK-Anlagen mindestens $60 \%$. Letztere eignen sich insbesondere für dicht besiedelte Gebiete. Kleine KWK-Anlagen, sogenannte Blockheizkraftwerke, verwenden bis zu 90\% der Energie.

Benannt nach dem Metereologen Paul La Cour (1846-1908). La Cour unterrichtete Mathematik und Physik an der Volkshochschule von Askov. Der Erfinder setzte sich für die Elektrifizierung der ländlichen Gegenden Dänemarks ein. $\mathrm{Zu}$ diesem Zweck erforschte er die technischen Grundlagen der Windkraft. 1903 gründete er die Gesellschaft der WindElektriker. La Cour war kaum daran interessiert, aus seinen Erfindungen finanzielle Vorteile zu ziehen. Einige seiner Patente verkaufte er für wenig Geld an ausländische Unternehmen mit der Bedingung, dass sie in Dänemark frei produziert und verkauft werden durften. In den letzten Jahren seines Lebens wirkte La Cour beratend am Aufbau eines zentralisierten Stromsystems in Dänemark mit (vg. http://de.wikipedia.org/wiki/Poul_La_Cour, Abruf vom 4.6.09).

L. ist ein Kuriosum der niederländischen Windindustrie der Pionierphase. Als einziger erfolgreicher Hersteller richtete das Unternehmen sein Angebot auf zivilgesellschaftliche Betreiber aus. Anders als die Konkurrenz richtete Lagerwey die Produktion nicht an der EVU-Nachfrage aus, obwohl es sich 
dabei um einen gewinnträchtigen Sektor zu handeln schien. Von der Strategie her und seiner Zugehörigkeit zum Mittelstand betrachtet, ähnelt Lagerwey der erfolgreichen dänischen Windanlagenindustrie (vorsichtiges Upscaling, Kooperation mit dänischen Zulieferbetrieben, kooperative, nicht allein auf Profitmaximierung ausgerichtete Vorgehensweise, vg. Kap. 2.4.3).

Large-Scale-Ansatz

Übliche Vorgehensweise innerhalb des Large-Scale-Paradigma. Durch Konstruktion und Bau möglichst großer Windanlagendesigns und möglichst großer Windparks sollen Skaleneffekte erzielt werden. Protagonisten des Large-ScaleAnsatzes sind nicht nur die Akteure der LSPForschungsprogramme, sondern auch Planer und Betreiber großer Windparks (EVU, Investoren).

Problematisch an dem Ansatz sind nicht nur die technischen Fehlannahmen des LSP. Die Etablierung der Windenergie in den Pioniermärkten ist hauptsächlich von zivilgesellschaftlichen Akteuren getragen worden, von denen der neue Energieträger als ein Symbol gegen Atomenergienutzung und die Macht der Energiekonzerne betrachtet wurde. Die Akzeptanz der Windkraft beruhte $\mathrm{zu}$ großen Teilen darauf, dass die Windanlagen, tatsächlich, von diesen Akteuren auch betrieben wurden - und zwar lokal: nach dem Grundsatz, die Energie dort zu produzieren, wo sie genutzt wird. Dieser Zielgebung steht der Large-Scale-Ansatz entgegen (vg. Kap. 1 und 2).

Large-Scale-Paradigma (LSP)

Maegaard, Preben
Das LSP verweist auf die Geltung diverser Annahmen und Zielvorstellungen, welche die Grundlage der Forschungsprogramme zur Windkraft bildeten sowie auf eine bestimmte in den Pionierländern geltende Akteurskonstellation. $\mathrm{Zu}$ den wichtigsten Annahmen zählen: Hinreichende Verfügbarkeit des Know-hows zur Herstellung und Kommerzialisierung großer Windanlagen; Übertragbarkeit von Erfahrungen des Flugzeugbaus auf den Windenergiesektor.

Das Ziel der Aktivitäten bestand i.a. darin, große PrototypWindanlagen zur Serienreife zu bringen, die anschließend in großer Stückzahl von den EVU erworben und in Windparks betrieben werden sollten. Windenergie sollte in bestehende Versorgungssysteme integriert werden, ohne deren zentrale Strukturen $\mathrm{zu}$ ändern. An den LSP-Programmen waren im Idealfall ausschließlich Großakteure wie Ministerien, große Forschungsinstitute, Hightech-Konzerne und Energieversorger beteiligt (vg. Kap. 1.2).

Vorsitzender der OVE zwischen 1979 und 1984. M. gründete 1983 das Folkecenter und ist ein Pionier der Bewegung für erneuerbare Energien. Dabei verfolgte er einen dezentralen Ansatz und versuchte vergeblich, bis zum Ende der 80er Jahre, 
Mautz'sche Kriterien

Moderne

Windenergienutzung

Non-fossil-fuel-obligation

Nordwestjütländisches

Institut für erneuerbare

Energie (NIVE) einen kooperativen Entwicklungspfad innerhalb des Windenergiesektors aufrechtzuerhalten (vg. Kap. 2)

Mautz (2006, 2007) zufolge ist die Nutzung erneuerbarer Energien und besonders der Windenergie in Deutschland mit einem dreifachen Pfadwechsel im Stromsystem einhergegangen: Von zentraler, auf Großkraftwerken beruhender Stromproduktion, zu dezentralen Kleinanlagen (1), von einem durch wenige EVU dominierten Strommarkt $\mathrm{zu}$ einer ,Pluralisierung der Akteure' (2) und der Wandel der Entscheidungsgründe für die Auswahl einer bestimmten Technologie: von ökonomisch zu umweltpolitisch, ethisch (3). Windenergie und andere erneuerbare Energien gelten als radikale Innovation, weil sie diese Kriterien erfüllen.

Eigentlich müsste eher von ,Göttinger Kriterien' gesprochen werden. Denn bereits in einer früheren Studie des Göttinger SOFI (Soziologisches Forschungsinstitut) von Byzio, A.; Heine, H.; Mautz, R. und Rosenbaum, W. (2002, 268), ist die Rede von einem dreifachen Pfadwechsel (sozial, technisch, ökonomisch), bzgl. der Bedeutung erneuerbarer Energien. In späteren Arbeiten von Mautz $(2006,2007)$ werden diese Kriterien präzisiert (vg. Kap. 4).

Windkraft als Energiequelle wird seit Jahrhunderten eingesetzt, bspw. in der Segelschifffahrt und den klassischen Windmühlen. Im ausgehenden 19. Jahrhundert produzierten Windanlagen, sogenannte Windmotoren erstmals Elektrizität (Heymann 1995). Seit den späten 1970er Jahren wird der erzeugte Strom darüber hinaus in die großen Netze geleitet. Das moderne an der modernen Windenergienutzung besteht damit nicht allein in drastischen Effizienzsteigerungen, verbunden mit der Entwicklung des danish design, sondern auch darin, dass die Windkraft heute prinzipiell in derselben Weise zur allgemeinen Stromversorgung beiträgt wie konventionelle Energieträger.

vg. Förderegelungen(Übersicht)

NIVE ist auf Basis der La Cour Tradition entstanden. Auf Initiative von $O V E$-Mitgliedern wurde dort im Jahr 1977 der zweite Prototyp einer Komponentenmühle konstruiert (vg. Kap. 2.1).

Organisation zur Aufklärung über die Atomkraft (OOA) Organisationen til Oplysning om Atomkraft. Gegründet wurde die OOA im Jahr 1974, als im Zuge der Energiekrise, Atomenergie in Dänemark eingeführt werden sollte. Ihre Aktivitäten trugen zu einem großen Teil dazu bei, dass die Atomkraft 1985, als als energiepolitische Option Dänemarks, 
Organisation für

erneuerbare Energie (OVE) Organisationen for vadvarende Energi. Die OVE gründet sich

OVE-Netzwerk

Pfadabhängigkeiten

(Pfadwechsel, Pfad-...)

Pionierländer 1975 als Abspaltung der OOA. Ziel der neuen Organisation ist es, regenerative Energietechniken selbst zu entwickeln und auf diese Art die Praktikabilität der Energiewende zu beweisen (Ökologische Praktiker). Die OVE richtete die ersten Windtreffen der 70er Jahre aus. Für den Windsektor leistete sie wichtige Pionierarbeit (OVE-Netzwerk) (vg. Kap. 2.1).

endgültig aufgegeben wurde. Von der OOA stammt der international bekannte Slogan ,Atomkraft - Nein danke!' (http:// de.wikipedia.org/wiki/Organisationen_til_Oplysning_om_Atom kraft, Abruf vom 4.6.09), vg. auch: Kap. 2.1

Das OVE-Netzwerk besteht aus drei Hauptkomponenten: Vestjusk Energikontor, Windtreffen und Tvind-Projekt (TvindMühle). Trotz gewisser ideologischer Differenzen zwischen den Tvind-Leuten und Teilen der OVE, bestehen wichtige personale und organisatorische Überschneidungen. Der Einfluss der OVE auf die Entwicklungen des Sektors verstärkte sich zudem, weil einige der erfolgreichen Pioniere auf Herstellerseite (bspw. Erik Grove-Nielsen und Karl-Erik Joergensen) entweder selbst Mitglieder der OVE waren, oder mit dem OVE-Netzwerk in engem Kontakt standen (vg. Kap. 2.1).

Grundsätzlich versucht die Pfadabhängigkeitsthese zu erklären, weshalb bestimmte Technologien, Anwendungsverfahren und Organisationsstrukturen, trotz des Vorhandenseins besserer Alternativen, weiterhin verwendet werden. Der aus der Ökonomie stammende Ansatz steht der Meinung entgegen, dass die entsprechenden Korrekturen durch die ,unsichtbare Hand' des Marktes vorgenommen würden (klassischer Wirtschaftsliberalismus). Arthur (1988) und David (1985) konzentrieren sich darauf, die weitere Verwendung eigentlich überkommener Technologien zu erklären. Arthur (1988) geht von fünf Quellen sogenannter, increasing returns to adaption' aus: Optimierung der Technologie durch langjährige Erfahrung (learning by using), Herstellung ähnlicher Produkte und solcher, die mit der fraglichen Technologie kompatibel sind (network externalities), Preissenkung durch große Produktionszahlen (scale economies in production), größerer internationaler Bekanntheitsgrad unter den Nutzern (informational increasing returns) und Entwicklung ergänzender Technologien (technological interrrelatedness, Geels 2005, 54f.), vg. auch: Kap. 4.

Neben den Pioniermärkten werden auch alle weiteren Länder als Pionierländer bezeichnet, deren forschungspolitische Aktivitäten betrachtet werden, also: Großbritannien, Kanada, Schweden, Spanien und Italien. Dabei spielt es keine Rolle, dass in diesen Ländern selbst keine Innovationen hervorgebracht werden. Entscheidend ist, dass die Finanzierung von LSP-Programmen 
Pioniermärkte

Pionierphase

Pitch-Regulierung $\mathrm{zu}$ einer Zeit begonnen wurde, als das Large-Scale-Paradigma noch nicht als technologiepolitischer Irrweg erkannt worden ist.

Die Pioniermärkte bilden eine Untergruppe der Pionierländer. Hierbei handelt es sich um alle Länder, in denen Märkte für Windenergie während der Pionierphase entstanden sind. (Dänemark, Kalifornien, Niederlande und BRD).

Die Pionierphase umfasst den Zeitraum 1975-1991. Innerhalb dieses Zeitraums wird die neue Technologie, in den Pioniermärkten, zu einem international anerkannten Produkt entwickelt. Die Nutzung dieser Technologie setzt voraus, dass geeignete institutionelle Rahmenbedingungen vorhanden sind. Von Seiten des politisch-administrativen Systems (PAS) ist dieser Zeitraum durch die Schaffung von Maßnahmen zur Förderung des kommerziellen Windenergiesektors gekennzeichnet. Neben diesem Ansatz hat das PAS, insbesondere in der ersten Hälfte der Pionierphase, einen zweiten Weg zur Etablierung der neuen Technologie verfolgt: Forschungsförderung auf Basis des Large-Scale-Paradigma (vg. Kap. 1). Für den Reifungsprozess der Technologie ist ausschließlich der erste Ansatz, der sich aus der PASPerspektive zusammenfassend als Marktförderung bezeichnen lässt, interessant (vg. Kap. 2). Dieser Prozess wird in vier zeitlich aufeinander folgenden Perioden betrachtet. In der jeweiligen Periode werden immer jene Pionierländer betrachtet, in denen zur fraglichen Zeit wichtige Umbrüche und Neuentwicklungen beobachtet werden können. Bei den Perioden handelt es sich um:

Periode 1 (1975-1978): Technische Innovation und Entstehung des Ursprungsmarktes (Dänemark)

Periode 2 (1979-1982): Erste Industrialisierung und Stabilisierung des Ursprungsmarktes (Dänemark)

Periode 3 (1983-1987): Beschleunigtes Wachstum und Erprobung in Kalifornien (Dänemark, Kalifornien)

Periode 4 (1988-1991): Verstetigung internationaler Diffusion in der Pionierphase (Dänemark, Niederlande, Deutschland).

Die Pitch-Regulierung funktioniert, indem die Flügel bei Sturm aus dem Wind gedreht und dadurch gebremst werden. Bei hohen Windgeschwindigkeiten werden die Rotoren in eine parallele Position zum Wind gebracht. Liegt die Windgeschwindigkeit unterhalb der Anlaufschwelle werden die Rotorblätter ebenfalls aus dem Wind gedreht. Auf diese Weise werden Vibrationsbelastungen verringert und die Lebensdauer wird erhöht (Kamp 2002, 169). Nachteile: höhere Kosten, hohe dynamische Belastungen, falls Pitch-System nicht schnell genug auf zunehmende Windstärke reagiert. (Kamp 2002, 9) 
Politisch-administratives System (PAS)

Verstetigungsperiode proven technology

radikale Innovation

Riisager, Christian
Begriffliche Zusammenfassung der Führungs-, Entscheidungsund Verantwortungsfunktionen der gewählten politischen Handlungsträger (der Regierung im engeren Sinne) und der Umsetzungs- und Durchführungsfunktionen der Verwaltung, Behörden etc. (Klein/ Schubert, 2006).

siehe Pionierphase

$=$ erprobt, international als zuverlässige Technologie geltend. Grundsätzlich muss davon ausgegangen werden, dass unterschiedliche Akteure, jeweils eigene Maßstäbe anlegen, nach denen sie beurteilen, ob etwas als proven technology bezeichnet werden kann.

Für diejenigen, die ihre Windanlage in erster Linie als Symbol gegen Atomenergienutzung betrachten und von vorn herein keine kommerziellen Ziele verfolgen, ist es weniger entscheidend, ob die Lebenserwartung einer WEA zehn oder zwanzig Jahre beträgt, ob der Kapazitätsfaktor zehn oder fünfzehn Prozent beträgt etc. Ähnliches gilt für diejenigen, die in kalifornische Windparks investierten (vg. Kap. 2.3).

Als objektiverer Indikator gilt die Sichtweise derjenigen, die dem neuen Energieträger seit jeher mit der größten Skepsis entgegen getreten sind: die großen Energieversorger. Wenn zahlreiche EVU, seit den 90er Jahren auch in jenen Ländern bereit sind, Mittel für Windanlagen aufzuwenden, ohne, dass man äußeren Druck als Ursache dafür annehmen müsste (vg. 92er Märkte), ist davon auszugehen, dass wichtige technische und institutionelle Durchbrüche erreicht worden sind. In ihrer Summe erheben letztere den neuen Energieträger in den Status einer proven technology (vg. Kap. 2.4; 2.5; 3).

Prinzipielle Neuerung. Dieser Terminus wird in der Literatur sehr unterschiedlich definiert. Für diese Studie sehr wichtig ist der Gedanke, dass die Radikalität einer Innovation kontextspezifisch zu bewerten ist. (vg. Kap. 4).

Dänischer Pionier der Windtechnik. R. gelingt es, eine verkleinerte Version der Gedser-Mühle nachzubauen und $\mathrm{zu}$ kommerzialisieren. Auch als Windmüller ist R. Pionier. Er ist der erste Däne, der einen Energieversorger nötigt, den Netzanschluss seiner Windanlage zu dulden. Unter den ersten Herstellern ist R. ein Sonderfall. Anders als die meisten technisch erfolgreichen Akteure der ersten Periode kooperierte R. nicht mit dem OVE-Netzwerk und bediente sich nicht der neuen Zulieferindustrie, sondern konstruierte seine Anlagen vollständig selbst (vg. Kap. 2.1).

Teststation für kleine Windanlagen, die sich auf dem Gelände des großen, beim Ort Risoe gelegenen, Forschungsinstitutes befindet. Seit 1978 erhalten die Pionierhersteller technische 
Unterstützung seitens der Ingenieure der Teststation. Seitdem 1979 die Investitionsförderung eingeführt wurde, müssen die Herstellen ihre Produkte einem Testverfahren unterziehen, um ein qualifizierendes Zertifikat zu erlangen. Für die Erfolge der Windindustrie kommt Risoe eine Schlüsselrolle zu (vg. Kap. 2).

Spanisches Modell

(des Windenergie-Sektors) Ein zentrales Ergebnis dieser Studie besteht darin, dass während der Pionierphase im wesentlichen nur eine einzige Akteursstruktur zum Erfolg geführt hat: das dänische Modell. Dieses ändert sich im Verlauf der Diffusionsphase: Mit Spanien tritt ein neuer erfolgreicher Markt, dessen Charakteristika stark vom dänischen Modell abweichen. $\mathrm{Zu}$ den wichtigen Eigenschaften des spanischen Modells zählen: Verwendung des danish Design; Kooperation mit internationaler Windindustrie bei gleichzeitiger weitest möglicher Abschottung des Marktes; anfänglich konstruierter, durch das System Endesa geschützter Markt; Stromeinspeisungsgesetz; hohe Abgaben an benachbarte Gemeinden; große Windparks, vorwiegend betrieben durch Energiekonzerne (vg. Kap. 2.5 und Kap. 3).

Stabilisierungsperiode

Stall-Regulierung

System Endesa

System

,kleine Windkraft'

\section{siehe Pionierphase}

Bewährte Methode, ein Überdrehen des Rotors zu verhindern. Bei zu hohen Windgeschwindigkeiten wird eine Sicherungskomponente an den Flügelspitzen (bspw. Spoiler) aktiviert, wodurch das Abreißen des Luftstroms bewirkt wird. Aufgrund hoher mechanischer Belastungen ist diese Regulierungsweise für große Rotoren zunehmend ungeeignet (Kamp 2002, 9).

Bei dem Staatskonzern Endesa handelt es sich um den größten spanischen Energieversorger unter dessen Ägide der Windenergiesektor Anfang der 90er Jahre eröffnet wurde. Die meisten Windparks wurden, direkt oder indirekt, von Endesa in Auftrag gegeben. Die Windanlagen produzierte i.a. eine Tochterfirma Endesas (Made). Einige Windparks wurden von regionalen Versorgern gekauft, die ebenfalls in Teilen, oder vollständig zu dem Staatskonzern gehörten. Ziele des S. E. bestehen darin, den maximalen Teil der Wertschöpfung im Land $\mathrm{zu}$ halten und der inländischen Industrie einen geschützten Entwicklungsraum zu bieten. Endesa akzeptierte, Windanlagen $\mathrm{zu}$ installieren, deren Qualität nicht dem internationalen Standard entsprach (vg. Kap. 3.3).

Grundsätzlich bezieht sich der Begriff auf die Interaktion kleiner und mittelgroßer Akteure im Windenergiesektor. Auch zwischen Akteuren des Systems ,kleiner Windkraft' bestehen mit unter große Unterschiede. Man denke bspw. an die Stadtwerke Norden und einige Landwirte: Sie beide erwarben gegen Ende der 80er Jahre dasselbe Windanlagen-Modell von Enercon. 
Technikperiode

Tvind-Mühle

top-down

Verfügbarkeit

Vermiedene Kosten

Vestjusk Energikontor
Beide Akteure agieren im selben Feld eines von der Zentralregierung geförderten Marktes, der eine sukzessive Verbesserung der neuen Technologie ermöglichte. Das System ,kleine Windkraft' steht in einem kontradiktorischen Verhältnis zur LSP-orientierten Technologiepolitik.

siehe Pionierphase

An der Volkshochschule von Tvind entsteht zwischen 1975 und 1978 die einzige Großwindanlage (2MW-Generator), die von Amateuren konstruiert und praktisch ohne staatliche Förderung errichtet wurde. Im Gegensatz $\mathrm{zu}$ den meisten übrigen LSPGroßwindanlagen ist sie noch heute in Betrieb. Zahlreiche Selbstbauer erhielten auf der Baustelle von Tvind Gelegenheit, ihr Know-how zu erweitern. Für die Anti-AKW-Bewegung bildeten die Arbeiten in Tvind und schließlich die Realisierung des Projekts wichtige Bezugspunkte (vg. Kap. 2.1).

Gegenteil von bottom-up. Prozesse werden von höchster Ebene in Gang gesetzt. Um Einfluss auf die Peripherie zu nehmen werden Entscheidungen zentral getroffen. Beispiele für topdown: LSP-Programme, in abgeschwächter Form: System Endesa. In der Pionierphase waren sämtliche top-down-Ansätze gescheitert.

Zeitanteil, währenddessen eine Windanlage potenziell Strom produzieren kann. Ist eine Anlage, über ein Jahr gerechnet, 10\% der Zeit nicht betriebsbereit, etwa aufgrund technischer Defekte und Wartungsarbeiten, so beträgt die Verfügbarkeit während dieses Zeitraums 90\%.

Bei den vermiedenen Kosten handelt es sich um den Gegenwert, der von Kraftwerksbetreibern infolge der Stromeinspeisung (bspw. durch WEA) eingesparten konventionellen Rohstoffe. V. K. ist ein Kampfbegriff der Energiewirtschaft. Von dieser Seite wird argumentiert, dass Windenergie nicht zur kontinuierlichen Stromproduktion geeignet sei und es sich daher um Strom geringerer Qualität handele. Aufgrund dieser Unkalkulierbarkeit könne die Windenergie nur zur Rohstoffeinsparung dienen und sei entsprechend zu bewerten. Der Aspekt geringerer externer Kosten erneuerbarer Energien (vermiedene Umwelt-, Klimaund Gesundheitsschäden) bleibt unberücksichtigt.

Vestjusk Energikontor ist ein kleines Netzwerk sogenannter Energiebüros, die an den Volkshochschulen von Tvind und Kolding von der $O V E$ eingerichtet wurden. Energikontor war an der Realisierung der Komponentenmühle entscheidend beteiligt. Selbstbauer, Interessierte und Hersteller kamen zu den Energiebüros und erhielten Unterstützung (vg. Kap. 2.1). 
Windanlagenkooperative

Windmühle

Windmüller

Windtreffen

Zivilgesellschaft, zivilgesellschaftliche Akteure
Vindmoellelaugen. In Dänemark sind Windanlagenkooperativen (Konsumgenossenschaften) seit 1980 vorherrschender Betreibertyp von Windanlagen. Je nach Größe der Anlage umfasst eine Kooperative entsprechend mehr oder weniger Haushalte. Sämtliche Mitglieder stammen aus der Umgebung des Windmühlenstandortes. Diese lokale Verankerung der neuen Technologie begründet zu guten Teilen die hohe Akzeptanz, welche der Windenergie in den ersten Jahren der Pionierphase entgegengebracht wurde. In Form der Bürgerwindgesellschaft, verfasst als $\mathrm{GmbH} \& \mathrm{Co}$. KG., ist die W. in der zweiten Hälfte der 80er Jahre erfolgreich nach Deutschland importiert worden (vg. Kap. 2).

Gemeint sind aus heutiger Sicht sehr kleine Windanlagen bis zu einer Nennleistung von $100 \mathrm{~kW}$. Mitunter wird der Begriff auch zur Abgrenzung gegenüber $L S P$-Prototypen verwendet.

Betreiber kleinerer Windanlagen. Der Begriff wird häufig verwendet, um diese von den EVU abzugrenzen, in deren Netze sie Strom einspeisen. Betreiber großer Windparks, seien es Investoren oder EVU, zählen nicht zu den Windmüllern.

Vindtraefs. Bei den Windtreffen handelte es sich um die, seit Mitte der 70er Jahre an dänischen Volkshochschulen stattfindenden, halbjährlichen Zusammenkünfte der Akteure des Systems, kleiner Windkraft': Anfangs fand auf den Treffen ein Austausch von Know-how statt. Bis Ende der 70er Jahre organisierte die $O V E$ die Windtreffen. Später werden sie vom $D V$ ausgerichtet. Mit dem Wechsel der Organisatoren geht ein Bedeutungswandel der Treffen einher. Von nun an, seit Anfang der 80er Jahre, stehen nicht länger technische Aspekte im Vordergrund, sondern die Interessenvertretung gegenüber Politik und Energiewirtschaft.

Der Begriff Zivilgesellschaft bezeichnet i.a. einen Bereich der Gesellschaft, der zwischen staatlicher, wirtschaftlicher und privater Sphäre entstanden ist. Die Begriffe ,NichtRegierungsorganisationen', ,Non-profit-Organisationen' und ,Dritter Sektor' werden oft gleichbedeutend mit Zivilgesellschaft verwendet. Die Rede von der Zivilgesellschaft verweist auf Tendenzen der Demokratisierung und Zivilisierung einer Gesellschaft (http://de.wikipedia.org/wiki/Zivilgesellschaft, Abruf vom 4.6.09).

Im untersuchten Feld der Pionierphase lassen sich die Motivationen der Akteure nicht immer so klar erkennen, wie es im Fall der Anti-AKW-Bewegung und den ersten Windkooperativen und Bürgerwindgesellschaften der Fall gewesen ist. Politiker einer Gemeinde mögen an der Windenergie interessiert sein und befürworten daher die 
Ansiedelung von Windanlagen nahe der Ortsgrenze. Andererseits haben sie das Interesse, wiedergewählt zu werden und sind in ein System eingebunden, dass vielfältige Aspekte zu berücksichtigen hat (Industriepolitik, Beschäftigungsförderung, Interessen anderer Akteure wie Tourismus-Unternehmen, Naturschützer etc.). Man denke auch an den kleinen Handwerksbetrieb, dessen Inhaber, möglicherweise aus altruistischen Gründen, großes Interesse am Windmühlenbau hat. Trotz aller Überzeugung diktiert ihm die ökonomische Vernunft, sich für kein Geschäftsfeld zu entscheiden, dass den Bankrott des Unternehmens nach sich ziehen könnte. Bei den Windenergieakteuren der Pioniermärkte handelt es sich also um eine Kombination aus Personen und Institutionen, die mit ihrer Aktivität ausschließlich idealistische Ziele verfolgen und solche, bei denen anderen Motiven zumindest auch eine Rolle zukommt. Der Versuch einer Trennung in diese und jene Akteure hat sich nicht als sinnvoll erwiesen. Vielmehr hat sich der Versuch bewährt, beide Akteursgruppen als eine Gruppe kleiner Akteure zusammenzufassen, die aufgrund ihres Interesses an der Windkraft, bzgl. positiver Wirkungen für die Gesamtgesellschaft, verbunden sind.

An der Windkraft interessierte Bürgermeister kleinerer Ortschaften, Journalisten regionaler Zeitungen und kleine Windanlagenhersteller werden hier in derselben Weise als zivilgesellschaftliche Akteure begriffen wie Mitglieder der AntiAKW-Bewegung. 


\section{Abkürzungsverzeichnis}

AEC

AKW

AWEA

BEOP

BMFT

CCOO

CEC

CEGB

CPUC

DANIDA

DEEFOND

DEF

DEWI

DGW

DIFKO

DOE

DtA

DV

DWP

DWR

DWT

ECN

EEG

EHN

EIB

EMR

ENEA

ETA

EVU

FANE

F\&E

FGW

FWEP

GAU

GKSS

GROWIAN

GTS

GW

HAT

HAI

HEW

HSW

IEP

IPW

ISET

IWB
Atomic Energy Commission (USA)

Atomkraftwerk

American Wind Energy Association

Bureau Energie Onderzoeks Projecten (NL)

Bundesministerium für Forschung und Technologie

Comisiones Obreras

California Energy Commission

Central Electricity Generating Board (GB)

California Public Utilities Commission

Danish international development agency

Danish Energy Export Fund

Danske Elvarkers Forening (DK)

Deutsches Windenergie-Institut

Deutsche Gesellschaft für Windenergie

Danish Investment Fund

Department of Energy (USA)

Deutsche Ausgleichsbank

Danske Vindkraftvaerker (DK)

Danish Windpower Program

Department of Water Ressources

Danish Wind Technology

Energy Centre of the Netherlands

Erneuerbare Energien Gesetz

Energia Hidroelélectrica de Navarra (SP)

European Investment Bank

Department of Energy, Mines and Ressources (KAN)

Ente per le Nuove tecnologie, l'Energia e l'Ambiente

Energy Tax Act

Energieversorgungsunternehmen

Förderprogramms zur forcierten Anwendung und Nutzung neuer und erneuerbarer Energieträger

Forschung \& Entwicklung

Fördergesellschaft Windenergie

Federal Wind Energy Program

Größter angenommener Unfall

Gesellschaft für Kernenergieverwertung in Schifffahrt und Schiffbau

Große Windenergieanlage

Großes technisches System

Gigawatt

Horizontal Axis Turbine

Hellenic Aerospace Industry

Hamburger Elektrizitätswerke

Husumer Schiffswerft

Independent Energy Producers (USA)

Integraal Programma Windenergie (NL)

Institut für solare Energietechnologien

Interessengemeinschaft Windpark

Nordwestdeutsches

Binnenland/Interessenverband Windkraft Binnenland 


\begin{tabular}{|c|c|}
\hline IWSH & Interessenverband Windkraft Schleswig-Holstein \\
\hline KfW & Kreditanstalt für Wiederaufbau \\
\hline KWK & Kraft-Wärme-Kopplung \\
\hline $\mathrm{kWh}$ & Kilowattstunde \\
\hline LSEO & Landelijke Stuurgroep Energie Onderzoek (NL) \\
\hline LSP & Largescale-Paradigma \\
\hline MAN & Maschinenfabrik Augsburg-Nürnberg \\
\hline MAP & Environmental Action Plan \\
\hline MBB & Messerschmidt-Bölkow-Blohm \\
\hline MWh & Megawattstunde \\
\hline NEA & National Energy Act (USA) \\
\hline NEA & National Energy Administration (S) \\
\hline NEOM & Nederlandse Energie Ontwikkelings Maatschappij \\
\hline NEP & National Energy Program (KAN) \\
\hline NEP & National Energy Plan (SP) \\
\hline NFFO & Non-Fossil-Fuel-Obligation (GB) \\
\hline NIMBY & Not-in-my-backyard \\
\hline NIVE & Nordwestjütländisches Institut für erneuerbare Energie (DK) \\
\hline NMP & National Environment Policy Plan \\
\hline NOVEM & Nederlandse Onderneming voor Energie en Milieu \\
\hline NOW & National Research Program on Wind Energy \\
\hline NRC & National Research Council (KAN) \\
\hline NREL & National Research Energy Laboratory (USA) \\
\hline NSF & National Science Foundation (USA) \\
\hline NSHEB & North Scottish Hydro Electric Board \\
\hline NWP & National Wind Power (GB) \\
\hline OAT & Office for Appropriate Technology (USA) \\
\hline OOA & Organizationen til Oplysning om Atomkraft (DK) \\
\hline OPEC & Organization of Petrol exporting Countries \\
\hline OAPEC & Organization of Arab Petrol exporting Countries \\
\hline OVE & Organizationen for Vedvarende Energi (DK) \\
\hline PAWEX & De Vereniging van Particuliere Windenergie Exploitarien (NL) \\
\hline PESUR & Parque Eolico del Sur \\
\hline PG \& E & Pacific Gas \& Electric (USA) \\
\hline PPC & Public Power Corporation (GR) \\
\hline PTG & Praktisk Teoretisk Grundkursus (DK) \\
\hline PURPA & Public Utility Regulatory Policies Act (USA) \\
\hline QF & Qualified Facility (USA) \\
\hline $\mathrm{RCN}$ & Reactor Centre of the Netherlands (NL) \\
\hline $\mathrm{R} \& \mathrm{D}$ & Research \& Development \\
\hline REN & $\begin{array}{l}\text { Rationale Energieverwendung und Nutzung unerschöpflicher } \\
\text { Energiequellen (D) }\end{array}$ \\
\hline RV & Radikale Venstre (DK) \\
\hline RWE & Rheinisch-Westfälische Energiewerke (D) \\
\hline SCE & Souther California Edison (USA) \\
\hline SEG & Stromeinspeisegesetz (D) \\
\hline STF & Socio-technological Science \\
\hline TNO & Netherlands Organisation for Applied Scientific Research (NL) \\
\hline TWIN & Toiepassing Windenergie in Nederland (NL) \\
\hline TWT & Tacke Windtechnik GmbH \\
\hline UGT & Unión General de Trabajadores \\
\hline
\end{tabular}




$\begin{array}{ll}\text { ÜHN } & \text { Überlandwerke Hannover Nord } \\ \text { UWA } & \text { Unabhängige Windkraftakteure } \\ \text { VAT } & \text { Vertical Axis Turbine } \\ \text { VCBW } & \text { Association for Collective Wind Turbine Management (NL) } \\ \text { VDMA } & \text { Verband Deutscher Maschinen- und Anlagenbau } \\ \text { VEEN } & \text { Association for electricity company owners (NL) } \\ \text { VIK } & \text { Verein der Industriekraftwerke } \\ \text { VWFA } & \text { Verein für Windenergieforschung und -anwendung } \\ \text { WEA } & \text { Windenergieanlage } \\ \text { WEG } & \text { Wind Energy Group (GB) } \\ \text { WFL } & \text { Windfarms Limited } \\ \text { WP } & \text { Windpark } \\ \text { WPM } & \text { Windpower Monthly }\end{array}$

